\title{
Final Report, Survey and Removal of Radioactive Surface Contamination at Environmental Restoration Sites Sandia National Laboratories/New Mexico Volume 1
}

Kevin A. Lambert, Michael M. Mitchell, Deborah Jean, Craig Brown, Caroline S. Byrd

\section{Prepared by}

Sandia National Laboratories

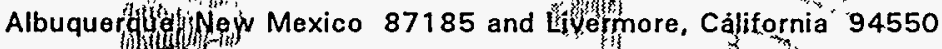

Sandia is a multiprogram laboratory operated by Sandia

Corporation, a Lockheed Martin Companyiffor the Unitedistates

Department of Energy under Contract DE-AC04-94AE 85000.

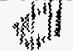

Approved for public release; distribution is unlimited.

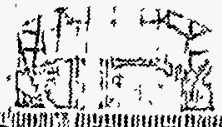

in Sandian National Laboratories

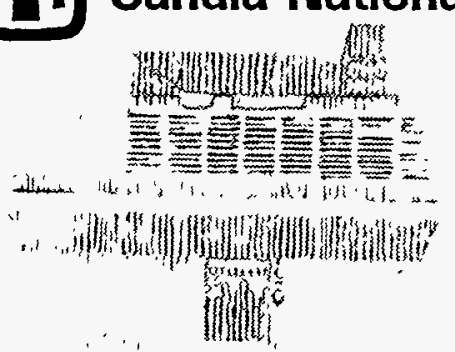

SF $29000(8.81)$

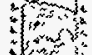

ories

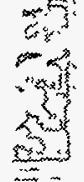

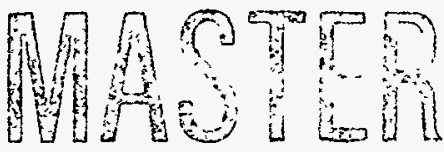

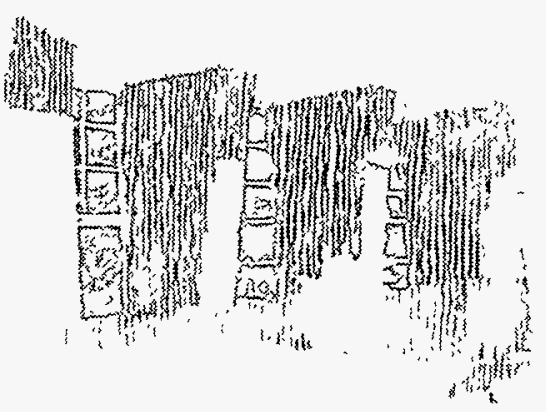

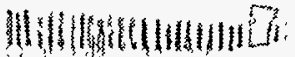
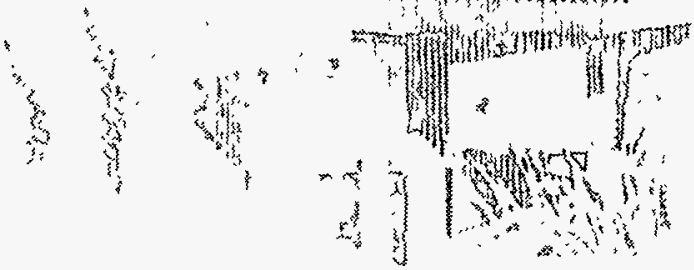
Issued by Sandia National Laboratories, operated for the United States Department of Energy by Sandia Corporation.

NOTICE: This report was prepared as an account of work sponsored by an agency of the United States Government. Neither the United States Government nor any agency thereof, nor any of their employees, nor any of their contractors, subcontractors, or their employees, makes any warranty, express or implied, or assumes any legal liability or responsibility for the accuracy, completeness, or usefulness of any information, apparatus, product, or process disclosed, or represents that its use would not infringe privately owned rights. Reference herein to any specific commercial product, process, or service by trade name, trademark, manufacturer, or otherwise, does not necessarily constitute or imply its endorsement, recommendation, or favoring by the United States Government, any agency thereof, or any of their contractors or subcontractors. The views and opinions expressed herein do not necessarily state or reflect those of the United States Government, any agency thereof, or any of their contractors.

Printed in the United States of America. This report has been reproduced directly from the best available copy.

Available to DOE and DOE contractors from

Office of Scientific and Technical Information

P.O. Box 62

Oak Ridge, TN 37831

Prices available from (615) 576-8401, FTS 626-8401

Available to the public from

National Technical Information Service

U.S. Department of Commerce

5285 Port Royal Rd

Springfield, VA 22161

NTIS price codes

Printed copy: A13

Microfiche copy: A01 
SAND97-2320/1

Unlimited Release

Printed September 1997
Distribution

Category UC-902

\title{
Final Report, Survey and Removal of Radioactive Surface Contamination at Environmental Restoration Sites, Sandia National Laboratories/New Mexico
}

\author{
Kevin A. Lambert and Michael M. Mitchell \\ Brown \& Root Environmental \\ Albuquerque, NM 87106 \\ Deborah Jean \\ MDM/Lamb, Inc. \\ Albuquerque, NM 87110 \\ Craig Brown \\ Environmental Dimensions, Inc. \\ Albuquerque, NM 87109 \\ Caroline S. Byrd \\ Environmental Restoration Project \\ P.O. Box 5800 \\ Sandia National Laboratories \\ Albuquerque, NM 87185-1148
}

\begin{abstract}
This report describes the survey and removal of radioactive surface contamination at Sandia's Environmental Restoration (ER) Sites. Radiological characterization was performed as a prerequisite to beginning the Resource Conservation and Recovery Act (RCRA) corrective action process. The removal of radioactive surface contamination was performed in order to reduce potential impacts to human health and the environment. The predominant radiological contaminant of concern was depleted uranium (DU). Between October 1993 and November 1996 scanning surface radiation surveys, using gamma scintillometers, were conducted at 65 sites covering approximately 908 acres. A total of 9,518 radiation anomalies were detected at 38 sites. Cleanup activities were conducted between October 1994 and November 1996. A total of 9,122 anomalies were removed and 2,072 waste drums were generated. The majority of anomalies not removed were associated with a site that has subsurface contamination beyond the scope of this project. Verification soil samples (1,008 total samples) were collected from anomalies during cleanup activities and confirm that the soil concentrations achieved in the field were far below the target cleanup level of $230 \mathrm{pCi} / \mathrm{g}$ of U-238 (the primary constituent of $\mathrm{DU}$ ) in the soil. Cleanup was completed at 21 sites and no further radiological action is required. Seventeen sites were not completed since cleanup activities were precluded by ongoing site activity or were beyond the original project scope.
\end{abstract}

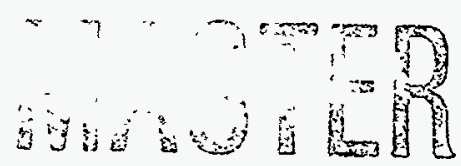


Intentionally Left Blank 


\section{DISCLAMIER}

Portions of this document may be illegible in electronic image products. Images are produced from the best available original docoment. 


\section{DISCLAIMER}

This report was prepared as an account of work sponsored by an agency of the United States Government. Neither the United States Government nor any agency thereof, nor any of their employees, make any warranty, express or implied, or assumes any legal liability or responsibility for the accuracy, completeness, or usefulness of any information, apparatus, product, or process disclosed, or represents that its use would not infringe privately owned rights. Reference herein to any specific commercial product, process, or service by trade name, trademark, manufacturer, or otherwise does not necessarily constitute or imply its endorsement, recommendation, or favoring by the United States Government or any agency thereof. The views and opinions of authors expressed herein do not necessarily state or reflect those of the United States Government or any agency thereof. 


\section{CONTENTS}

Section

Page

EXECUTIVE SUMMARY ..................................................................................................... $\mathrm{x}$ vii

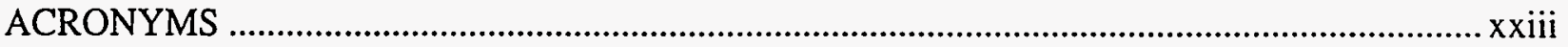

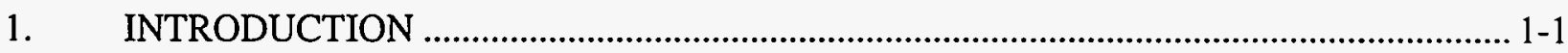

1.1. Report Organization ............................................................................................... 1-1

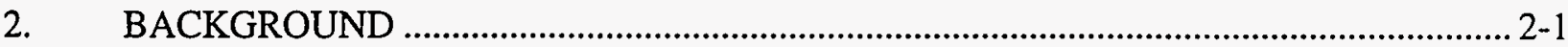

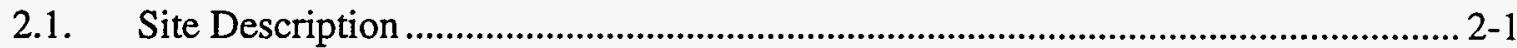

2.2. Surface Radiological Survey and Cleanup History .................................................. 2-1

2.2.1. Basis for Surface Radiological Survey (Phase I)......................................... 2-3

2.2.2. Basis for Surface Radiological Cleanup (Voluntary Corrective Measures).......................................................................................... 2-8

2.3. Waste Management Overview ........................................................................ 2-11

2.3.1. Phase I Radiological Survey Waste Management ................................... 2-11

2.3.2. VCM Waste Management ...................................................................... 2-11

2.4. Health and Safety Overview............................................................................... 2-13

2.4.1. Phase I Radiological Survey Health and Safety Plan ............................... 2-13

2.4.2. VCM Health and Safety Plan .................................................................. 2-13

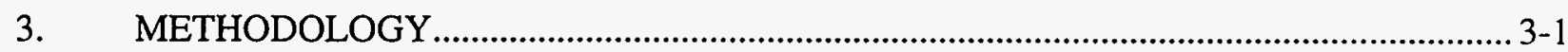

3.1. Field Procedures ................................................................................................. 3-1

3.1.1. Phase I Radiological Survey Procedures ................................................. 3-1

3.1.2. VCM Removal Action Procedures ............................................................. 3-1

3.1.3. Soil Sampling Procedures............................................................... 3-11

3.1.4. Waste Management ........................................................................... 3-17

3.1.5. Health and Safety......................................................................... 3-25

3.2. Laboratory Procedures...................................................................................... 3-32

3.2.1. Gamma Spectroscopy Principles and Instrumentation........................... 3-32

3.2.2. Gamma Spectroscopy Procedures and Limitations .................................... 3-33

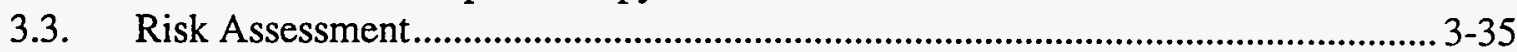

3.3.1. Internal Data Review Procedures ………........................................... 3-35

3.3.2. RESRAD and Radiological Pathway Analysis Description ....................... 3-36

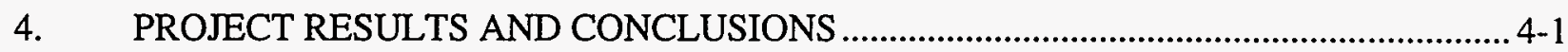

4.1. Phase I Radiological Survey ........................................................................... 4-1

4.1.1. Adequacy of Survey....................................................................... 4-1

4.1.2. Survey Results ................................................................................... 4-2

4.1.3. Conclusions and Recommendations ................................................... 4-8

4.2. VCM Cleanup............................................................................................. 4-16

4.2.1. Adequacy of Cleanup ...................................................................... 4-16

4.2.2. Additional Studies Supporting Adequacy of Cleanup.............................. 4-17 


\section{CONTENTS (Continued)}

Section

Page

4.2.3. Cleanup Results ................................................................................... 4-19

4.2.4. Conclusions and Recommendations.................................................... 4-24

5. GAMMA SURVEY/RADIOACTIVE SURFACE CONTAMINATION REMOVAL .........5-1

5.1. Health and Safety Monitoring ………………….................................................... 5-1

5.1.1. Bioassay Sampling.................................................................................. 5-1

5.1.2. Dosimetry ……................................................................................ 5-1

5.1.3. Air Sampling.......................................................................................... 5-2

5.1.4. Radioparticulate Sampling ................................................................... 5-2

5.1.5. Heat Stress Monitoring ................................................................................ 5-2

5.1.6. Heavy Metals Sampling............................................................................ 5-2

5.2. Technical Area II Operable Unit Sites (Activity Data Sheet [ADS] 1303) ............... 5-2

5.2.1. Decontamination Area and Uranium Calibration Pits (ER Site 44)......... 5-2

5.3. Technical Areas III/V OU Sites (ADS 1306) ......................................................... 5-6

5.3.1. Concrete Pad (ER Site 18).................................................................. 5-6

5.3.2. Long Sled Track (ER Site 83) ................................................................ 5-11

5.3.3. Gun Facilities (ER Site 84).................................................................... 5-16

5.3.4. Short Sled Track (ER Site 240) ............................................................. 5-22

5.3.5. Storage Yard (ER Site 241) .............................................................. 5-28

5.4. Tijeras Arroyo Operable Unit Sites (ADS 1309) ...................................................... 5-33

5.4.1. Open Dumps (ER Site 16) ................................................................. 5-33

5.4.2. Centrifuge Dump Site (ER Site 228) .................................................... 5-39

5.5. Foothills Test Area Operable Unit Sites (ADS 1332) .............................................. 5-44

5.5.1. Coyote Canyon Blast (ER Sites 8 and 58).............................................. 5-44

5.5.2. TRUPAK Boneyard Storage Area (ER Site 19)..................................... 5-52

5.5.3. Building 9820 - Animal Disposal Pit (ER Site 27) ................................. 5-58

5.5.4. Old Aerial Cable Site (ER Site 82)..................................................... 5-63

5.5.5. Building 9990 - Firing Site (ER Site 87) ................................................. 5-66

5.6. Canyons Test Area Operable Unit Sites (ADS 1333) ............................................... 5-74

5.6.1. Burial Mounds and Bunker Area (ER Sites 10 and 60) ........................... 5-74

5.6.2. Burn Site Area (ER Sites 12, 13, 65 and 94) ........................................ 5-82

5.6.3. New Aerial Cable Site, Burial Site, Dump, Test Area (ER Site 81) ...... 5-90

5.7. Central Coyote Test Area Operable Unit Sites (ADS 1334)................................... 5-93

5.7.1. Workman Sites (ER Sites 57A and 57B) ............................................... 5-93

5.7.2. Schoolhouse Mesa Test Sites (ER Sites 61A and 9) .............................. 5-101

5.7.3. Old Burnsite and Moonlight Shot Areas (ER Sites 68 and 71) ............. 5-107

5.7.4. Firing Site and Instrumentation Pole (ER Site 88) ............................... 5-116

5.8. Southwest Test Area Operable Unit Sites (ADS 1335) …………........................... 5-119

5.8.1. Building 9920 - Burial Site and Firing Site (ER Sites 14 and 85)........ 5-119

5.8.2. Scrap Yards/Open Dump (ER Sites 17A, 17B, and 17D) ..................... 5-125

5.8.3. Red Tower Site (ER Site 55) ............................................................... 5-131

5.8.4. Lead Firing Site (ER Site 91) ............................................................... 5-137

5.8.5. Building 9939 - Scrap Yard and Trenches (ER Sites 103 and 117)..... 5-143 


\section{CONTENTS (Continued)}

Section

Page

5.8.6. Building 9940 - Firing Site (ER Site 108) ........................................... 5-149

5.8.7. Building 9930 - Firing Site (ER Site 115) .......................................... 5-158

5.8.8. Equus Red (ER Site 191) .................................................................... 5-161

5.8.9. Sabotage Test Area (ER Site 193) ....................................................... 5-166

6. GAMMA SURVEY/NO RADIOACTIVE SURFACE CONTAMINATION ....................... 6-1

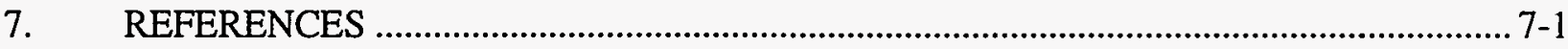

\section{APPENDICES}

A Voluntary Corrective Measure Plans

B Waste Management Plans

C Task-Specific Health and Safety Plan, "Bobcat HASP"

D Analytical Laboratory Procedures

E Gamma Spectroscopy Soil Sample Results

F In-Situ Gamma Spectroscopy Results for ER Sites 10/60 and 68/71

G Radionuclide Activity Summary of VCM Waste

H TCLP Soil Sample Results for ER Site 228

I Waste Characterization Memoranda

J Waste Drum Inventory Data

K Radiological Risk Assessment - RESRAD Computer Runs

L Summary of Site-Specific Recommendations for ER Sites 


\section{FIGURES}

Figure

2.1 Location of Kirtland Air Force Base and Sandia National Laboratories,

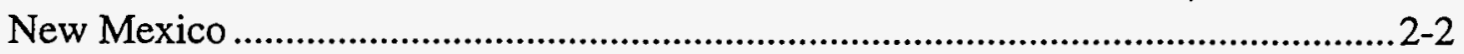

2.2 ER Sites Potentially Contaminated with Surface Radioactive Materials...................2-4

2.3 Project Timeline, Survey and Removal of Radioactive Surface Contamination ........2-5

3.1.1 Gamma Scintillometer (NaI Detector) ................................................................. 3-2

3.1.2 Surface Radiation Survey Using Gamma Scintillometer (NaI Detector).................... 3-3

3.1.3 Pinflagged and Painted Radiation Anomaly...........................................................3-3

3.1.4 Relocation of an Anomaly Originally Located During the Phase I Survey.................3-5

3.1.5 Point Source Removal and Gamma Scintillometer (NaI Detector) Scanning.............3-7

3.1.6 Point Source Removal and GM Pancake Probe Scanning ........................................3-7

3.1.7 Metal Fragments From Remediation of a Point Source ...............................................3-9

3.1.8 Area Source Removal and Gamma Scintillometer (NaI Detector) Scanning .............3-9

3.1.9 Soil Aggregates Coated by Schoepite (Uranium Oxide) From Remediation of an Area Source ........................................................................................... 3-10

3.1.10 Backhoe Used to Remediate an Area Source ......................................................... 3-10

3.1.11 Scanning of Trench in a Soil Mound .................................................................. 3-12

3.1.12 Soil Mound Dismantling Using a Backhoe ........................................................... 3-12

3.1.13 Scanning Soil on the "Lay Down" Pad Using NaI Detector and

GM Pancake Probe .................................................................................................

3.1.14 Post-Cleanup Soil Sampies Collected During the VCM..........................................3-15

3.1.15 Decision Process for Evaluating Gamma Spectroscopy Results...............................3-16

3.1.16 Waste Generation Log.............................................................................................

3.1.17 Lined 30 and 55 Gallon Steel Open-Top Drums Used for

3.1.18 Waste Drum with a Radioactive Waste Label and

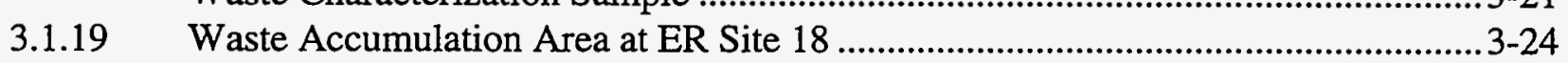

3.1.20 Site Access Control Station............................................................................

3.2.1 Gamma Spectrum Including Depleted Uranium .................................................3-34

4.1.1 Crutch Gamma Scintillometer..........................................................................

4.1.2 Pressurized Ionization Chamber..............................................................................4-4

4.1.3 Schoepite, Yellow Oxidized Form of DU Occurring as a Fine Powdery Mineral on a Soil Particle ...................................................................................................4-6

4.1.4 Schoepite, Yellow Oxidized Form of DU Occurring as Thin Bedded Layers of Clay-Sized Particles on Soil Sample ..........................................................................4-6

4.1.5 Microphotograph of a 1-cm-Diameter Soil Particle Coated by Schoepite.................... 4-7

4.1.6 A 253.6-Gram Metallic Fragment of DU ..................................................................4-7

4.2.1 Status of ER Sites After Completion of the Survey and Removal of
Radioactive Surface Contamination....................................................................4-31 


\section{FIGURES (Continued)}

Figure

Page

5.2.1 Phase I Survey Radiation Anomalies and VCM Surface Soil Sampling Locations at ER Site 44B $.5-4$

5.3.1 Phase I Survey Radiation Anomalies and VCM Surface Soil Sampling Locations at ER Site 18

5.3.2 Phase I Survey Radiation Anomalies at ER Site 83

5.3.3 VCM Radiation Anomalies and Surface Soil Sampling Locations at ER Site 83

5.3.4 Radiation Anomalies Remaining After Completion of the VCM at ER Site 83.

5.3.7 Phase I Survey Radiation Anomalies at ER Site 240

5.3.8 VCM Radiation Anomalies and Surface Soil Sampling Locations at ER Site 240

5.3.9 Radiation Anomalies Remaining After Completion of the VCM at ER Site 240.

5.3.10 Phase I Survey Radiation Anomalies and VCM Surface Soil Sampling Locations at ER Site 241

5.4.1 Phase I Survey Radiation Anomalies at ER Site 16

5.4.2 VCM Radiation Anomalies and Surface Soil Sampling Locations at ER Site 16

5.4.3 Radiation Anomalies Remaining After Completion of the VCM at ER Site 16.

5.4.4 Phase I Survey Radiation Anomalies and VCM Surface Soil Sampling Locations at ER Site 228

5.4.5 Radiation Anomalies Remaining After Completion of the VCM at ER Site 228

5.5.1 Phase I Survey Radiation Anomalies at ER Sites 8 \& 58

5.5.2 VCM Radiation Anomalies and Surface Soil Sampling Locations at ER Sites 8 \& 58

5.5.3 Radiation Anomalies Remaining After Completion of the VCM at ER Sites 8 \& 58

5.5.4 Phase I Survey Radiation Anomalies and VCM Surface Soil Sampling

Locations at ER Site 19

5.5.5 Radiation Anomalies Remaining After Completion of the VCM at ER Site 19.

5.5.6 Phase I Survey Radiation Anomalies and VCM Surface Soil Sampling Locations at ER Sites 27 \& 49

5.5.7 Phase I Survey Radiation Anomalies and VCM Surface Soil Sampling Locations at ER Site 82

5.5.8 Phase I Survey Radiation Anomalies at ER Site 87 


\section{FIGURES (Continued)}

Figure

5.5.9 VCM Surface Soil Sampling Locations for Area Source (87E499)

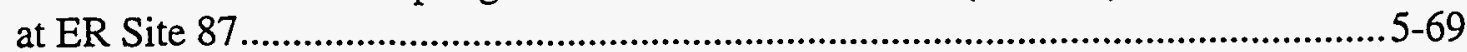

5.5.10 VCM Surface Soil Sampling Locations at ER Site 87 .............................................5-71

5.6.1 Phase I Survey Radiation Anomalies at ER Sites 10, 60, \& 59 ................................5-75

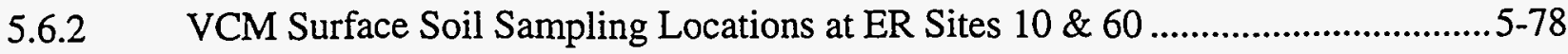

5.6.3 Radiation Anomalies Remaining After Completion of the VCM at ER Sites 10, 60, \& 59................................................................................. 5-81

5.6.4 Phase I Survey Radiation Anomalies at ER Sites 12, 13, 65, \& 94 .......................... 5-83

5.6.5 VCM Surface Soil Sampling Locations at ER Sites 12, 13, 65, \& 94 ..................... 5-85

5.6.6 VCM Surface Soil Sampling Locations in the Graded Area at ER Sites 12, $13,65, \& 94$

5.6.7 Radiation Anomalies Remaining After Completion of the VCM at ER Sites 12,

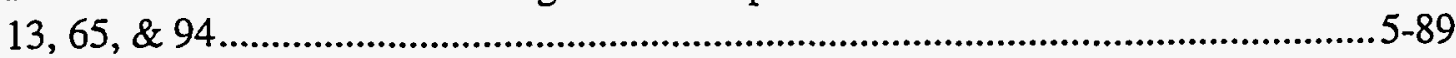

5.6.8 Phase I Survey Radiation Anomalies and VCM Surface Soil Sampling Locations at ER Site 81

5.7.1 Phase I Survey Radiation Anomalies and VCM Surface Soil Sampling Locations at ER Site 57A $5-94$

5.7.2 Phase I Survey Radiation Anomalies and VCM Surface Soil Sampling Locations at ER Site 57B

5.7.3 Radiation Anomalies Remaining After Completion of the VCM at ER Site 57A.

5.7.4 Radiation Anomalies Remaining After Completion of the VCM at ER Site 57B $5-100$

5.7.5 Phase I Survey Radiation Anomalies at ER Sites 61A \& 9 5-102

5.7.6 VCM Radiation Anomalies and Surface Soil Sampling Locations at ER Sites $61 \mathrm{~A} \& 9$

5.7.7 Radiation Anomalies Remaining After Completion of the VCM at ER Sites $61 \mathrm{~A} \& 9$

5.7.8 Phase I Survey Radiation Anomalies at ER Sites 68 \& 71 .....................................5-109

5.7.9 VCM Radiation Anomalies and Surface Soil Sampling Locations at ER Sites 68 \& 71

5.7.10 Radiation Anomalies Remaining After Completion of the VCM at ER Sites 68 \& 71

5.7.11 Phase I Survey Radiation Anomalies at ER Site 88 5-117 Phase I Survey Radiation Anomalies at ER Sites 14 \& 85

5.8.2 VCM Radiation Anomalies and Surface Soil Sampling Locations at ER Sites $14 \& 85$

5.8.3 Phase I Survey Radiation Anomalies at ER Site 17B $5-126$

5.8.4 VCM Radiation Anomalies and Surface Soil Sampling Locations at ER Site 17B 


\section{FIGURES (Continued)}

Figure Page

5.8.5 Phase I Survey Radiation Anomalies at ER Site 55

5-132

5.8.6 VCM Radiation Anomalies and Surface Soil Sampling Locations at ER Site 55.

5.8.7 Radiation Anomalies Remaining After Completion of the VCM

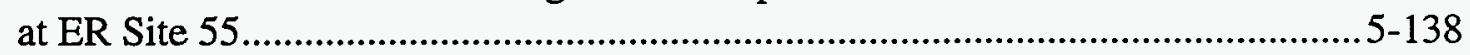

5.8.8 VCM Radiation Anomalies and Surface Soil Sampling Locations

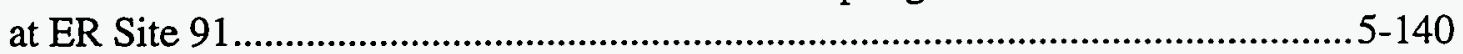

5.8.9 Phase I Survey Radiation Anomalies at ER Sites 103 \& 117 ..............................5-144

5.8.10 VCM Radiation Anomalies and Surface Soil Sampling Locations at ER Sites 103 \& 117

5.8.11 Radiation Anomalies Remaining After Completion of the VCM

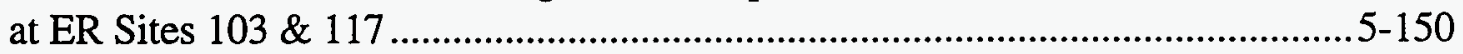

5.8.12 Phase I Survey Radiation Anomalies at ER Site 108 .......................................... 5-151

5.8.13 VCM Surface Soil Sampling Locations at ER Site 108 ..........................................5-153

5.8.14 Radiation Anomalies Remaining After Completion of the VCM at ER Site 108....................................................................................................... 5-157

5.8.15 Phase I Survey Radiation Anomalies and VCM Surface Soil Sampling Locations at ER Site 115 .

5.8.16 Phase I Survey Radiation Anomalies and VCM Surface Soil Sampling Locations at ER Site 191.

5.8.17 Phase I Survey Radiation Anomalies at ER Site 193 ............................................5-167

5.8.18 VCM Surface Soil Sampling Locations at ER Site 193 .........................................5-169 


\section{TABLES}

Table

Page

3.2.1 Ra-226 Comparison For Daughter Ingrowth and U-235 Correction Method ...........3-35

3.3.1 RESRAD Input Parameters For Industrial Land-Use Scenario.................................3-39

3.3.2 RESRAD Input Parameters For Residential Land-Use Scenario...............................3-42

3.3.3 RESRAD Input Parameters For Recreational Land-Use Scenario............................ 3-46

4.1.1 ER Project Sites Where Phase I Surface Radiological Surveys Were Conducted ..... 4-9

4.1.2 Summary of Phase I Survey ...............................................................................4-13

4.2.1 ER Project Sites Where VCM Field Activities Were Conducted .............................. 4-20

4.2.2 Summary of Point and Area Anomalies at ER Project Sites..................................... 4-25

4.2.3 Summary of Waste Drums Generated During the VCM........................................... 4-29

5.2.1 Summary of Field Activities at ER Site 44B ............................................................5-3

5.2.2 Post-Cleanup (Verification) Samples Collected at ER Site 44B................................5-5

5.2.3 Maximum Residual Radionuclide Levels in ER Site 44B Soils ...............................5-5

5.2.4 Summary of Waste Drums for ER Site 44B...........................................................5-5

5.2.5 Summary of Point and Area Source Removal at ER Site 44B................................5-6

5.3.1 Summary of Field Activities at ER Site 18 ..........................................................5-8

5.3.2 Post-Cleanup (Verification) Samples Collected at ER Site 18 .................................5-9

5.3.3 Maximum Residual Radionuclide Levels in ER Site 18 Soils..................................5-9

5.3.4 Summary of Waste Drums for ER Site 18 ……….................................................5-10

5.3.5 Summary of Point and Area Source Removal at ER Site 18 ................................5-11

5.3.6 Summary of Field Activities at ER Site 83 ............................................................5-11

5.3.7 Radiation Anomalies 30 Percent or Greater Than Natural Background Identified During the VCM at ER Site 83 ............................................................5-13

5.3.8 Summary of Post-Cleanup (Verification) Samples Collected at ER Site 83 ............5-15

5.3.9 Maximum Residual Radionuclide Levels in ER Site 83 Soils.................................5-15

5.3.10 Summary of Waste Drums for ER Site 83 ..............................................................5-15

5.3.11 Summary of Point and Area Source Removal at ER Site 83 ...................................5-16

5.3.12 Summary of Field Activities at ER Site 84 .........................................................5-19

5.3.13 Post-Cleanup (Verification) Samples Collected at ER Site 84 ................................5-21

5.3.14 Maximum Residual Radionuclide Levels in ER Site 84 Soils.................................5-21

5.3.15 Summary of Waste Drums for ER Site 84 …….................................................5-21

5.3.16 Summary of Point and Area Source Removal at ER Site 84 ...................................5-22

5.3.17 Summary of Field Activities at ER Site 240 ………................................................5-24

5.3.18 Radiation Anomalies 30 Percent or Greater Than Natural Background Identified During the VCM at ER Site 240 ...........................................................5-26

5.3.19 Post-Cleanup (Verification) Samples Collected at ER Site 240 ….............................5-26

5.3.20 Maximum Residual Radionuclide Levels in ER Site 240 Soils................................5-27

5.3.21 Summary of Waste Drums for ER Site 240 ….................................................5-27

5.3.22 Summary of Point and Area Source Removal at ER Site 240 ...............................5-28

5.3.23 Summary of Field Activities at ER Site 241 .........................................................5-30

5.3.24 Pre-Cleanup (Final Determination) Samples Collected at ER Site 241 ....................5-32 


\section{TABLES (Continued)}

5.3.25 Maximum Residual Radionuclide Levels in ER Site 241 Soils..............................5-32

5.3.26 Summary of Area Source Removal at ER Site 241 .................................................5-32

5.4.1 Summary of Field Activities at ER Site 16 .......................................................5-33

5.4.2 Pre-Cleanup (Final Determination) Samples Collected at ER Site 16 ......................5-35

5.4.3 Radiation Anomalies 30 Percent or Greater Than Natural Background Identified During the VCM at ER Site 16 ...........................................................5-37

5.4.4 Post-Cleanup (Verification) Samples Collected at ER Site 16 ................................5-37

5.4.5 Maximum Residual Radionuclide Levels in ER Site 16 Soils.................................5-37

5.4.6 Summary of Waste Drums for ER Site 16 ...........................................................5-38

5.4.7 Summary of Point and Area Source Removal at ER Site 16 ...................................5-39

5.4.8 Summary of Field Activities at ER Site 228 ….....................................................5-42

5.4.9 Post-Cleanup (Verification) Samples Collected at ER Site 228 ..............................5-42

5.4.10 Maximum Residual Radionuclide Levels in ER Site 228 Soils...............................5-43

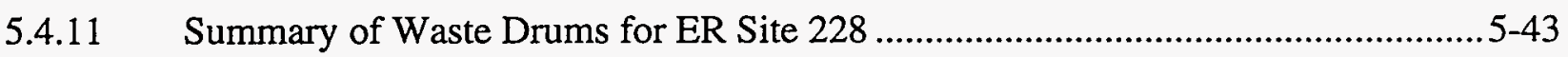

5.4.12 Summary of Point Source Removal at ER Site 228 ……..........................................5-44

5.5.1 Summary of Field Activities at ER Sites 8 and 58 ..................................................5-46

5.5.2 Pre-Cleanup (Final Determination) Samples Collected at ER Site 58 ......................5-48

5.5.3 Radiation Anomalies 30 Percent or Greater Than Natural Background Identified During the VCM at ER Site 8 ...........................................................5-48

5.5.4 Radiation Anomalies 30 Percent or Greater Than Natural Background Identified During the VCM at ER Site 58 .............................................................5-48

5.5.5 Post-Cleanup (Verification) Samples Collected at ER Sites 8 and 58.....................5-50

5.5.6 Maximum Residual Radionuclide Levels in ER Site 8 Soils................................5-50

5.5.7 Maximum Residual Radionuclide Levels in ER Site 58 Soils..............................5-50

5.5.8 Summary of Waste Drums for ER Sites 8 and 58 …..........................................5-51

5.5.9 Summary of Point and Area Source Removal at ER Sites 8 and 58 ……................5-52

5.5.10 Summary of Field Activities at ER Site 19 …….............................................5-55

5.5.11 Pre-Cleanup (Final Determination) Samples Collected at ER Site 19 ……...............5-55

5.5.12 Post-Cleanup (Verification) Samples Collected at ER Site 19 .................................5-56

5.5.13 Maximum Residual Radionuclide Levels in ER Site 19 Soils..................................5-56

5.5.14 Summary of Waste Drums for ER Site 19 ..........................................................5-57

5.5.15 Summary of Area Source Removal at ER Site 19................................................5-58

5.5.16 Summary of Field Activities at ER Site 27 ……........................................................5-61

5.5.17 Post-Cleanup (Verification) Samples Collected at ER Site 27 .................................5-61

5.5.18 Maximum Residual Radionuclide Levels in ER Site 27 Soils...............................5-62

5.5.19 Summary of Waste Drums for ER Site 27 ......................................................5-62

5.5.20 Summary of Point Source Removal at ER Site 27 ………………………….............5-63

5.5.21 Summary of Field Activities at ER Site 82 …………………………….................5-65

5.5.22 Pre-Cleanup (Final Determination) Samples Collected at ER Site 82 .....................5-65

5.5.23 Maximum Residual Radionuclide Levels in ER Site 82 Soils.................................5-65

5.5.24 Summary of Area Source Removal at ER Site 82................................................5-66

5.5.25 Summary of Field Activities at ER Site 87 ....................................................... $5-68$ 


\section{TABLES (Continued)}

Table

Page

5.5.26 Radiation Anomalies 30 Percent or Greater Than Natural Background Identified During the VCM at ER Site 87. $5-70$

5.5 .27

5.5 .28

5.5 .29

5.5 .30

5.5 .31

5.6 .1

5.6 .2

5.6 .3

5.6 .4

5.6 .5

5.6 .6

5.6 .7

5.6 .8

5.6 .9

5.6.10

5.6 .11

5.6 .12

5.6 .13

5.6 .14

5.6 .15

5.6 .16

5.6 .17

5.6 .18

5.7.1

5.7.2

Pre-Cleanup (Final Determination) Samples Collected at ER Site 87

$5-70$

Summary of Post-Cleanup (Verification) Samples Collected at ER Site 87 ............5-72

Maximum Residual Radionuclide Levels in ER Site 87 Soils..................................5-72

Summary of Waste Drums for ER Site 87

$5-73$

Summary of Point and Area Source Removal at ER Site 87 ....................................5-73

Summary of Field Activities at ER Sites 10 and 60.

$5-76$

In-situ Gamma Spectroscopy Locations at ER Sites 10 and $60 \ldots \ldots \ldots \ldots \ldots \ldots \ldots \ldots \ldots \ldots . . . . .5-76$

Pre-Cleanup (Final Determination) Samples Collected at ER Sites 10 and 60........5-77

Radiation Anomalies 30 Percent or Greater Than Natural Background

Identified During the VCM at ER Sites 10 and 60. $5-77$

Post-Cleanup (Verification) Samples Collected at ER Sites 10 and 60 ...................5-79

Maximum Residual Radionuclide Levels in ER Sites 10 and 60 Soils

$5-79$

Summary of Waste Drums for ER Sites 10 and 60 .

$5-80$

Summary of Point and Area Source Removal at ER Sites 10 and 60

5-82

Summary of Field Activities at ER Sites 12, 13, 65, and 94

5-84

Radiation Anomalies 30 Percent or Greater Than Natural Background

Identified During the VCM at ER Sites 12, 13, 65, and 94

Post-Cleanup (Verification) Samples Collected at ER Sites 12, 13, 65, and 94 ......5-87

Maximum Residual Radionuclide Levels in ER Sites 12, 13, 65, and 94 Soils ......5-87

Summary of Waste Drums for ER Sites 12, 13, 65, and 94

Summary of Point and Area Source Removal at ER Sites 12, 13, 65, and 94 .........5-90

Summary of Field Activities at ER Site 81

Pre-Cleanup (Final Determination) Samples Collected at ER Site 81 .....................5-92

Maximum Residual Radionuclide Levels in ER Site 81 Soils.

$5-92$

Summary of Area Source Removal at ER Site 81.

.5-93

Summary of Field Activities at ER Sites 57A and 57B

$5-96$

Pre-Cleanup (Final Determination) Samples Collected

at ER Sites 57A and 57B

5.7.3 Post-Cleanup (Verification) Samples Collected at ER Sites 57A and 57B .............5-97

5.7.4 Maximum Residual Radionuclide Levels in ER Site 57A Soils...............................5-97

5.7.5 Summary of Waste Drums for ER Sites 57A and 57B .........................................5-97

5.7.6 Summary of Point and Area Source Removal at ER Sites 57A and 57B................5-98

5.7.7 Summary of Field Activities at ER Sites 61A and 9 .............................................5-103

5.7.8 Radiation Anomalies 30 Percent or Greater Than Natural Background Identified During the VCM at ER Sites 61A and 9.............................................5-103

5.7.9 Pre-Cleanup (Final Determination) Samples Collected at ER Sites 61A and 9.....5-105

5.7.10 Post-Cleanup (Verification) Samples Collected at ER Sites 61A and 9................ 5-105

5.7.11 Maximum Residual Radionuclide Levels in ER Sites 61A and 9 Soils..................5-105

5.7.12 Summary of Waste Drums for ER Sites 61A and 9 ...........................................5-106

5.7.13 Summary of Point and Area Source Removal at ER Site 61A ...............................5-107 


\section{TABLES (Continued)}

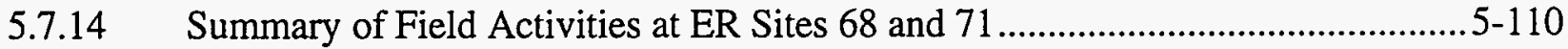

5.7.15 Pre-Cleanup (Final Determination) Samples Collected at ER Sites 68 and 71......5-111

5.7.16 Radiation Anomalies 30 Percent or Greater Than Natural Background

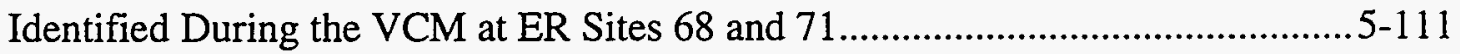

5.7.17 In-situ Gamma Spectroscopy Locations at ER Sites 68 and 71 ............................5-111

5.7.18 Summary of Post-Cleanup (Verification) Samples Collected

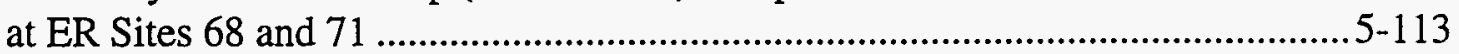

5.7.19 Maximum Residual Radionuclide Levels in ER Sites 68 and 71 Soils ..................5-113

5.7.20 Summary of Waste Drums for ER Sites 68 and 71 ..............................................5-114

5.7.21 Summary of Point and Area Source Removal at ER Sites 68 and 71 .....................5-116

5.7.22 Summary of Field Activities at ER Site 88 ..........................................................5-116

5.7.23 Summary of Point and Area Source Removal at ER Site 88 ……………..............5-118

5.8.1 Summary of Field Activities at ER Sites 14 and 85 ............................................5-119

5.8.2 Radiation Anomalies 30 Percent or Greater Than Natural Background Identified During the VCM at ER Site 85 ............................................................5-121

5.8.3 Post-Cleanup (Verification) Samples Collected at ER Sites 14 and 85 .................5-121

5.8.4 Maximum Residual Radionuclide Levels in ER Site 14 Soils.............................5-123

5.8.5 Maximum Residual Radionuclide Levels in ER Site 85 Soils................................ 5-123

5.8.6 Summary of Waste Drums for ER Sites 14 and 85 ............................................ 5-124

5.8.7 Summary of Point and Area Source Removal at ER Sites 14 and 85 ....................5-124

5.8.8 Summary of Field Activities at ER Sites 17A, 17B, and 17D ..............................5-125

5.8.9 Radiation Anomalies 30 Percent or Greater Than Natural Background Identified During the VCM at ER Site 17B .........................................................5-127

5.8.10 Post-Cleanup (Verification) Samples Collected at ER Site 17B ............................5-127

5.8.11 Maximum Residual Radionuclide Levels in ER Site 17B Soils .............................5-129

5.8.12 Summary of Waste Drums for ER Site 17B........................................................5-130

5.8.13 Summary of Point and Area Source Removal at ER Site 17B ............................... 5-131

5.8.14 Summary of Field Activities at ER Site 55 ….................................................5-133

5.8.15 Radiation Anomalies 30 Percent or Greater Than Natural Background Identified During the VCM at ER Site 55 ………............................................5-134

5.8.16 Post-Cleanup (Verification) Samples Collected at ER Site 55 ..............................5-136

5.8.17 Maximum Residual Radionuclide Levels in ER Site 55 Soils..............................5-136

5.8.18 Summary of Waste Drums for ER Site 55 .........................................................5-136

5.8.19 Summary of Point and Area Source Removal at ER Site 55 …………….............5-137

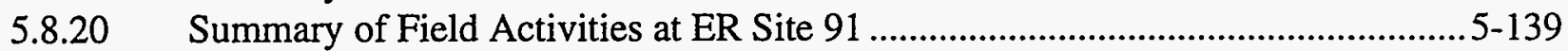

5.8.21 Post-Cleanup (Verification) Samples Collected at ER Site 91 ...............................5-141

5.8.22 Maximum Residual Radionuclide Levels in ER Site 91 Soils................................5-141

5.8.23 Summary of Waste Drums for ER Site 91 ........................................................5-142

5.8.24 Summary of Point and Area Source Removal at ER Site 91 ................................5-143

5.8.25 Summary of Field Activities at ER Sites 103 and 117 ...........................................5-145

5.8.26-Cleanup (Final Determination) Samples Collected
at ER Sites 103 and 117 ................................................................................ 5-145 


\section{TABLES (Continued)}

Table

Page

5.8.27 Radiation Anomalies 30 Percent or Greater Than Natural Background Identified During the VCM at ER Sites 103 and 117............................................5-146

5.8.28 Post-Cleanup (Verification) Samples Collected at ER Sites 103 and 117 ..............5-146

5.8.29 Maximum Residual Radionuclide Levels in ER Sites 103 and 117 Soils ..............5-146

5.8.30 Summary of Waste Drums for ER Sites 103 and 117 ..........................................5-148

5.8.31 Summary of Point and Area Source Removal at ER Sites 103 and 117 ...............5-149

5.8.32 Summary of Field Activities at ER Site 108 .....................................................5-152

5.8.33 Pre-Cleanup (Final Determination) Samples Collected at ER Site 108 ...................5-154

5.8.34 Post-Cleanup (Verification) Samples Collected at ER Site 108 ............................5-154

5.8.35 Maximum Residual Radionuclide Levels in ER Site 108 Soils...............................5-154

5.5.36 Summary of Waste Drums for ER Site 108 ……................................................5-156

5.8.37 Summary of Point and Area Source Removal at ER Site 108 ................................5-156

5.8.38 Summary of Field Activities at ER Site 115 ........................................................5-158

5.8.39 Pre-Cleanup (Final Determination) Samples Collected at ER Site 115 ..................5-160

5.8.40 Maximum Residual Radionuclide Levels in ER Site 115 Soils.............................5-160

5.8.41 Summary of Area Source Removal at ER Site 115................................................5-161

5.8.42 Summary of Field Activities at ER Site 191 ........................................................5-161

5.8.43 Post-Cleanup (Verification) Samples Collected at ER Site 191 .............................5-163

5.8.44 Maximum Residual Radionuclide Levels in ER Site 191 Soils..............................5-163

5.8.45 Summary of Waste Drums for ER Site 191 ...........................................................5-165

5.8.46 Summary of Point Source Removal at ER Site 191 ................................................5-166

5.8.47 Summary of Field Activities at ER Site 193 ……..................................................5-166

5.8.48 Post-Cleanup (Verification) Samples Collected at ER Site 193 ..............................5-168

5.8.49 Maximum Residual Radionuclide Levels in ER Site 193 Soils................................5-168

5.8.50 Summary of Waste Drums for ER Site 193 .......................................................5-171

5.8.51 Summary of Point and Area Source Removal at ER Site 193 .............................. 5-172

6.1 ER Project Sites Where Gamma Survey Was Conducted And No Radioactive Surface Contamination Was Identified 


\section{EXECUTIVE SUMMARY}

Sandia National Laboratories/New Mexico (SNL/NM) Environmental Restoration (ER) Project conducted surface radiological characterization and Voluntary Corrective Measure (VCM) cleanup of ER Project sites located at Kirtland Air Force Base (KAFB) between October 1993 and November 1996. The radiological characterization was performed as a prerequisite to beginning the Resource Conservation and Recovery Act (RCRA) corrective action process. The VCM was performed in order to reduce potential impacts to human health and the environment by removing point and area surface radiation sources that had been identified in the radiological assessment. Based on extensive background investigations, depleted uranium (DU) was determined to be the most likely, widespread surface contaminant of concern and was the primary target radionuclide.

Scanning surface radiation surveys were conducted between October 1993 and May 1994 at 64 SNL/NM ER sites covering approximately 830 acres on KAFB near Albuquerque, New Mexico (See Figure 2.2). These "Phase I" surveys defined the extent of surface radiological contamination at the SNL/NM ER sites.

Regulatory guidance pertaining to the conduct of radiological surveys was closely followed during the SNL/NM radiation surveys. A "Trial Survey" was first conducted at a typical SNL/NM ER site, known to be contaminated with DU, to demonstrate the effectiveness of the instruments' responses for the site-specific conditions. The Trial Survey was conducted during July 1993 and established the crutch gamma scintillometer as the instrument of choice for the Phase I surveys. The scintillometer was effective in identifying small anomalies of DU contamination. Three forms of DU were identified: finely divided oxide layers, oxide coatings on soil, and metal fragments. The Trial Survey was used to build a supporting foundation for the results of the Phase I survey, and ensured that the results of the Phase I survey would be consistent with (or exceed) regulatory guidance and any stated or implied data quality requirements.

The natural radiological background was first characterized so that changes in the gamma radiation field detected by the survey instruments could be attributed to either local variations in natural background or to potential environmental contamination. The variability in natural background radiation is a function of the geologic rock type encountered. Background values measured at the ER sites during the Phase I surveys ranged from 8 to 20 microroentgens per hour $(\mu \mathrm{R} / \mathrm{hr})$, with background at the majority of sites ranging from 10 to $13 \mu \mathrm{R} / \mathrm{hr}$. Many of the ER sites are located in geologically complex areas with many different rock types. Instrument threshold values were established based on site-specific background ranges for each ER site surveyed, rather than using a single value for all the sites. A threshold value of 1.3 times the ambient background determined at each site was used for the Phase I surveys, which is consistent with the Nuclear Regulatory Commission (NRC) NUREG/CR-5849 recommendations.

Therefore, gamma radiation delineated on the basis of scintillometer readings (counts per second) greater than 1.3 times the ambient background was considered anomalous and possibly indicative of contamination. 
The methods used in performing the Phase I surveys were limited to nonintrusive scanning techniques. The intention of these scanning surveys was to detect the gamma radiation anomalies at or near the ground surface (less than 0.5 foot deep). Areas within sites that may have subsurface radioactive materials require a different characterization strategy.

A total of 3,749 anomalous areas were detected during the Phase I surveys. Among these anomalies detected, 3,550 were attributed to "point sources," and 199 were considered "area sources." Point sources were typically associated with metallic fragments from past testing activities or characterized by measurements that decreased uniformly away from a discrete point. The types of anomalous gamma radiation detected during the Phase I surveys included area sources and point sources within the soil, area sources and point sources associated with metallic fragments, gamma radiation fields associated with radioactive materials storage areas, and gamma radiation associated with natural geologic outcrops.

Detailed results of the surface radiological assessments performed at the sites are presented in the Surface Gamma Radiation Surveys Final Report (RUST Geotech Inc. 1994b) and are summarized in Table 4.1.1.

Of the 64 total sites surveyed,

- 27 sites (42 percent) had no anomalies

- 37 sites (58 percent) had one or more anomalies

- 21 sites ( 33 percent) had 10 or more anomalies

- 6 sites (10 percent) had 100 or more anomalies.

These numbers have been revised from the Surface Gamma Radiation Surveys Final Report due to changes in site boundary interpretation and subsite designations.

The majority of the point source anomalies ranged from approximately 15 to $100 \mu \mathrm{R} / \mathrm{hr}$ on contact (background not subtracted), as converted directly from the scintillometer reading. These exposure rates are less than or equal to 20 percent of the posting criteria for Radiation Areas (greater than 5 millirems per hour at 1 foot from the source), per the SNL Radiological Protection Procedures Manual (SNL/NM 1997), which implements Title 10, Code of Federal Regulations, Part 835 (10 CFR 835), Occupational Radiation Protection (DOE 1995). Elevated gamma radiation values measured by the crutch scintillometer ranged from 11 to $1,103 \mu \mathrm{R} / \mathrm{hr}$, which is the upper range of the scintillometer. If the range of the scintillometer was exceeded, measurements were made with a portable ion chamber. No anomalies exceeded the Radiation Area posting criteria. In no instance was material found that had radiation readings that exceeded worker exposure limits for health and safety.

Results from the surveys were used to focus the radionuclide characterization process, cleanup, and final classification of the ER sites. The use of scanning surveys to narrow the focus of follow-up activities, such as voluntary cleanups and soil sampling, follows applicable regulatory guidance. 
Of the sites surveyed,

- 27 sites were recommended for no further action (NFA) because surface radiological anomalies were not detected. The NFA recommendation is only for radiological contamination at these sites.

- 11 sites where surface anomalies were believed to be related to natural geologic outcrops or "shine" from adjacent sources were recommended for additional field investigations, such as in situ gamma-ray spectroscopy, geologic mapping, and/or soil sampling.

- 10 sites where anomalies were detected at or near the Phase I survey boundaries were recommended for additional surface radiological surveys to adequately define the horizontal extent of contamination.

- 23 sites were recommended for VCM to remove surface anomalies associated with metallic DU fragments (point sources) and radiologically contaminated soils in order to eliminate the associated health and safety concerns related to surface contamination.

The recommendations are presented in greater detail in the Surface Gamma Radiation Surveys Final Report (RUST Geotech Inc. 1994b).

For some sites, corrective action objectives at SNL/NM ER sites include reducing contamination to levels that may allow unrestricted use of the formerly contaminated sites. The VCM based on the Phase I radiological surveys was consistent with this general objective and with the corresponding permit requirements, as well as the requirements of proposed Subpart $\mathrm{S}$ of Title 40, Part 264 of the Code of Federal Regulations (EPA 1990), in that the removal action did not preclude any other corrective action that may be deemed necessary in the future. U.S. Environmental Protection Agency (EPA) and U.S. Department of Energy (DOE) allowable exposure limits (given as total effective dose equivalent [TEDE] limits) drove the cleanup. The most restrictive of the EPA and DOE limits was used as the maximum allowable exposure in a generic risk assessment scenario, which was used to back-calculate the related maximum allowable soil concentration. The target cleanup level, as determined by this generic risk assessment and discussed in Section 2.2.2, is 230 picoCuries per gram (pCi/g) of uranium (U)-238 in the soil.

For this cleanup, a value of 1.3 times ambient background using a sodium iodide (NaI) gamma scintillometer was chosen as static count cleanup criteria when surface radioactive anomalies were remediated. Review of verification soil samples as cleanup progressed showed that this 1.3 times background static count provided for residual soil concentrations (in $\mathrm{pCi} / \mathrm{g}$ ) that were a small fraction of the target cleanup level.

Verification soil sampling was conducted on 10 percent of all point source anomalies and all area source anomalies (1,008 total samples) to confirm if acceptable soil concentrations were achieved under each anomaly cleaned up. The verification soil sampling data were used in sitespecific risk assessments to show that the residual radioactivity levels of the soils left on site did 
not exceed the more conservative EPA allowable dose limit and that cleanup was complete. Choosing to clean up to a near-background value gave a considerable margin of safety at each individual site, and was done by design since it would not be cost effective to revisit any site. In addition, at the time the decision was made to clean up to 1.3 times background, the future land use had not been established.

It was assumed that since all anomalies were remediated to 1.3 times background, and the anomaly subset sampled all met risk-based cleanup levels for residual radionuclides, then all of the remediated anomalies met these risk-based cleanup levels. To ensure adequate representation, a 100 percent quality assurance check was performed on the $\mathrm{NaI}$ detector field readings and the gamma spectroscopy data at the sampled areas. Thus, the soil concentrations achieved in the field were far below the target cleanup level ( $230 \mathrm{pCi} / \mathrm{g}$ of U-238 in the soil) indicated by the generic risk assessment.

Cleanup activities were conducted, using hand tools and heavy equipment, between October 1994 and November 1996 at 38 ER sites covering approximately 908 acres on KAFB. Additional surface gamma radiation surveys were conducted at 13 ER sites where anomalies were detected at or near the Phase I survey radiological boundaries and where the original coverage was only 70 percent (technicians walking on 10 -foot centers). In addition, pre-cleanup soil sampling was conducted at 15 ER sites during the VCM to assess the need to remediate area sources. Table 4.2.1 summarizes the field activities conducted at ER sites during the VCM.

A total of 9,518 anomalies were detected during the Phase I surveys $(3,749)$ and during the additional surface gamma radiation surveys of the VCM $(5,769)$. Among these anomalies detected, 9,199 were attributed to "point sources," and 319 were considered "area sources."

A total of 38 sites had surface radiological anomalies removed-37 sites identified during the Phase I survey and one new site identified during the VCM. A total of 9,122 anomalies were removed $-8,884$ point sources and 238 area sources. The types of anomalous gamma radiation remediated included area sources and point sources within the soil and area sources and point sources associated with metallic fragments. The majority of the anomalies not removed ( 266 of 396) were associated with a site that has subsurface contamination beyond the scope of this project (greater than 18 inches in depth). Table 4.2.2 summarizes the anomalous areas detected and removed for $38 \mathrm{ER}$ sites, and detailed cleanup results are presented in Section 5.

Verification soil sampling data show the maximum residual soil concentration for U-238, the primary constituent of DU, ranged from a high of $116 \mathrm{pCi} / \mathrm{g}$ at ER Site 87 to a low of $0.49 \mathrm{pCi} / \mathrm{g}$ at ER Site 57A. The average maximum residual soil concentration from all sites for U-238 was $19.43 \mathrm{pCi} / \mathrm{g}$. Other radionuclides, such as cesium, cobalt, radium, and thorium, have been found in small quantities in verification soil samples. The maximum residual soil concentrations for DU and the other radionuclides are discussed for the 38 ER sites in Section 5, and detailed results are presented in Appendix E.

The cleanup activities produced soil, metal fragment, and personal protective equipment wastes. All waste was containerized in either 30-gallon or 55-gallon drums. A total of 2,072 waste 
drums were generated during cleanup activities: 15 30-gallon drums and 2,057 55-gallon drums. Waste consolidation was performed to minimize the number of drums produced for each waste stream. The waste was shipped to a licensed disposal facility in Utah.

The VCM was effective at removing surface radiological anomalies at most SNL/NM ER Project sites. The potential effects on human health due to exposure to the remaining radionuclides at the sites are well within EPA and DOE proposed standards. Comprehensive characterization data obtained during the VCM will be used to guide future remediation at complex sites where further cleanup may be necessary.

Of the 38 ER sites where surface radiological anomalies were removed,

- 21 sites had the VCM completed and no further radiological action is required

- 17 sites require further radiological action.

Of the 21 sites where the VCM was completed, 7 sites had a radiological risk assessment performed, and results indicate the potential effects on human health due to exposure to radionuclides are well within EPA and DOE proposed standards. At another seven sites, the radiological risk assessment is pending due to other nonradiological issues. For these sites, the preliminary radiological risk assessment results indicate the potential effects on human health due to exposure to radionuclides are well within EPA and DOE proposed standards. No further radiological cleanup action was required at two sites where cleanup resulted in residual surface soil concentrations less than site-specific background levels, at three sites where elevated surface radiation was due to natural conditions (geologic outcrops), at one site where elevated surface radiation was due to "shine" (gamma interference) from adjacent material, and at one site where the nondegradable source of elevated surface radiation was removed.

At 17 sites, cleanup was not completed since further radiological characterization is necessary to assess remediation requirements, cleanup activities were beyond the original project scope, health and safety concerns required additional planning, or ongoing site activity precludes cleanup.

Figure 4.2.1 depicts the status of the ER sites after completion of the survey and removal of radioactive surface contamination. Appendix L summarizes the site-specific recommendations for ER sites. 
Intentionally Left Blank 


\section{LIST OF ACRONYMS}

\begin{tabular}{|c|c|}
\hline ADS & Activity Data Sheet \\
\hline ALARA & as low as reasonably achievable \\
\hline cpm & counts per minute \\
\hline DAC & derived air concentration \\
\hline DOE & U.S. Department of Energy \\
\hline DR & Disposal Requisitions \\
\hline DU & depleted uranium \\
\hline CEDE & committed effective dose equivalent \\
\hline CFR & Code of Federal Regulations \\
\hline Co & cobalt \\
\hline $\mathrm{COC}$ & contaminant of concern \\
\hline $\mathrm{Cs}$ & cesium \\
\hline EDD & Electronic Data Deliverable \\
\hline EOD & Explosive Ordnance Disposal \\
\hline EPA & U.S. Environmental Protection Agency \\
\hline ER & Environmental Restoration \\
\hline ERCTS & Environmental Restoration Container Tracking System \\
\hline ERDMS & Environmental Restoration Data Management System \\
\hline ERFO & Environmental Restoration Field Office \\
\hline $\mathrm{g} / \mathrm{cm}^{3}$ & gram(s) per cubic centimeter \\
\hline GJPO & Grand Junction Projects Office \\
\hline GM & Geiger Müieller \\
\hline GPS & Global Positioning System \\
\hline Geotech & RUST Geotech Inc. \\
\hline HASP & Health and Safety Plan \\
\hline HSWA & Hazardous and Solid Waste Amendments \\
\hline KAFB & Kirtland Air Force Base \\
\hline $\mathrm{keV}$ & kilo electronvolts \\
\hline MCA & multichannel analyzer \\
\hline MDA & minimum detectable activity \\
\hline $\mathrm{mg} / \mathrm{cm}^{3}$ & milligram(s) per cubic centimeter \\
\hline $\mathrm{ml}$ & milliliter(s) \\
\hline $\mathrm{mm}$ & millimeter(s) \\
\hline $\mathrm{mrem} / \mathrm{yr}$ & millirem per year \\
\hline $\mathrm{NaI}$ & sodium iodide \\
\hline NEPA & National Environmental Policy Act \\
\hline NFA & No Further Action \\
\hline NRC & U.S. Nuclear Regulatory Commission \\
\hline OSHA & Occupational Safety and Health Administration \\
\hline OH\&S & occupational health and safety \\
\hline OU & Operable Unit \\
\hline PCB & polychlorinated biphenyls \\
\hline $\mathrm{pCi} / \mathrm{g}$ & picoCuries per gram \\
\hline
\end{tabular}




\section{LIST OF ACRONYMS (Continued)}

PIC

PPE

$\mathrm{Ra}$

RCRA

RCT

RME

RPM

RPPM

RPO

SMO

SNL/NM

TA

TEDE

TCLP

$\mathrm{Th}$

TLD

TRA

$\mathrm{U}$

UXO

VCM

WMP

XRF

$\mu \mathrm{m}$

$\mu \mathrm{R} / \mathrm{hr}$ pressurized ionization chamber

personal protective equipment

radium

Resource Conservation and Recovery Act

Radiological Control Technician

reasonably maximally exposed

Radiation Protection Measurements

Radiological Protection Procedures Manual

Radiation Protection Operations

Sample Management Office

Sandia National Laboratories/New Mexico

Temporary Authorization

total effective dose equivalent

Toxicity Characteristic Leachate Procedure

thorium

thermoluminescent dosimeters

Trial Removal Action

uranium

unexploded ordnance

Voluntary Corrective Measure

Waste Management Plan

$\mathrm{x}$-ray fluorescence

micrometer(s)

microroentgens per hour 


\section{INTRODUCTION}

Sandia National Laboratories/New Mexico (SNL/NM) Environmental Restoration (ER) Project has conducted a surface radiological characterization and Voluntary Corrective Measure (VCM) cleanup of ER Project sites located at Kirtland Air Force Base (KAFB), with support from the U.S. Department of Energy (DOE) Grand Junction Projects Office (GJPO), through its prime contractor, RUST Geotech Inc. (Geotech). The radiological characterization was performed as a prerequisite to beginning the Resource Conservation and Recovery Act (RCRA) corrective action process. The VCM was performed in order to reduce potential impacts to human health and the environment by removing point and area surface radiation sources that had been identified in the radiological assessment.

This document describes the cleanup strategy (Trial Removal Action [TRA] and VCM), postcleanup (verification) sampling, and results on a site-by-site basis. The radiological characterization of ER sites is described in the Final Report, Surface Gamma Radiation Surveys for SNL/NM Environmental Restoration Project (Geotech 1994b). The purpose of this report is to serve as a reference for further cleanup plans and/or no further action (NFA) proposals for ER sites at SNL/NM.

\subsection{Report Organization}

This report presents the results of the VCM performed at SNL/NM. It is organized into eight major sections.

1. Introduction

Provides the purpose of the VCM and gives a brief description of the sections within the report.

2. Background

Gives a description of the facility and discusses the project history, including a timeline of the surface gamma radiation surveys (Phase I Survey) and subsequent VCM activities. Discusses the applicable regulatory guidance used, and the activities undertaken to obtain approval and public support for the VCM. Summarizes waste management and health and safety activities related to the survey and VCM.

3. Methodology

Provides a general overview of the methods and procedures used in the VCM. Presents descriptions of the field procedures, laboratory procedures, and risk assessment used in the project.

4. Project Results and Conclusions

Discusses the adequacy of survey and cleanup, summarizes the status of all sites involved in the VCM, and gives conclusions and general recommendations for further activities. 
5. Gamma Survey/Radioactive Surface Contamination Removal

Presents results of the survey and VCM for each site, grouped by the Operable Unit (OU). Gives a general overview of the activities conducted at the site, followed by specific findings and observations, verification soil sampling data, waste management data, and specific conclusions and recommendations.

6. Gamma Survey/No Radioactive Surface Contamination Summarizes Phase I survey sites not included in the VCM because no radioactive contamination was detected.

7. References

Lists references cited in the Final Report.

8. Appendices

Presents plans, procedures, analytical data, calculations, and other supporting documents. 


\section{BACKGROUND}

\subsection{Site Description}

SNL/NM is located near Albuquerque, New Mexico, just east of the Albuquerque International Airport and south of Gibson Boulevard. The SNL/NM ER Project sites are located at KAFB (Figure 2.1). KAFB is located on two broad mesas bisected by the Tijeras Arroyo, an east-west canyon. These mesas are bounded by the Manzanita Mountains (Cibola National Forest) to the east and the Rio Grande to the west. Elevations range from 4,920 feet at the Rio Grande to 10,676 feet at Sandia Crest, which is in the Sandia Mountains adjacent to Albuquerque. KAFB is at a mean elevation of 5,346 feet. The majority of the ER Project sites are located in open desert areas, but some are located in rough canyon terrain including steep, rocky hillsides and arroyos in the Manzanita Mountains.

Several of the ER Project sites were historically used as testing areas for weapons components and involve large areas with unknown boundaries and undocumented radiological hazards. Additionally, some of the ER Project sites were used for disposal and discharge of several types of waste. The most common radioactive contaminant known at these sites is depleted uranium (DU), which has been used for weapons testing and development; however, other radionuclides have been found in small quantities. Various hazardous substances such as solvents, fuels, acids, polychlorinated biphenyls (PCBs), heavy metals, mixed wastes, and trace amounts of high explosives and/or unexploded ordnance (UXO) may also be present.

\subsection{Surface Radiological Survey and Cleanup History}

The ER sites listed on the SNL/NM Hazardous and Solid Waste Amendments (HSWA) permit were required to be characterized and assessed on a timetable negotiated with the U.S. Environmental Protection Agency (EPA). Assessment fieldwork could not be undertaken until information regarding site hazards was obtained. Several initial site visits indicated the presence of UXO and ordnance debris. Thorough surface surveys to detect and remove any UXO were conducted by KAFB Explosive Ordnance Disposal (EOD) personnel. These surveys were conducted at all sites, with the exception of the Technical Area III sites (UXO clearance was not deemed necessary) between September 1993 and July 1994 (SNL/NM 1994c).

Many of the ER sites were identified as being potentially contaminated with radioactive materials, based only on site history information. SNL/ER decided to conduct a single survey project that would cover all sites with known or suspected surface radiological contamination. This project was determined to be the most effective and efficient way to ensure that a uniform technical approach was applied at all the sites. Geotech developed a work plan for the initial surface radiological assessment (Geotech 1993a). A "Trial Survey" was first conducted at a typical SNL/NM ER site to demonstrate the effectiveness of instrument response to DU for the site-specific conditions. The Phase I Survey was then conducted to delineate the nature and extent of surface radioactive contamination at all sites that were known or suspected to be contaminated. Scanning surface surveys were conducted between October 1993 and May 1994 at 64 SNL/NM ER sites covering approximately 830 acres on KAFB. The surface-based radiological assessment of these sites (Phase I Survey) helped ensure worker safety by identifying 


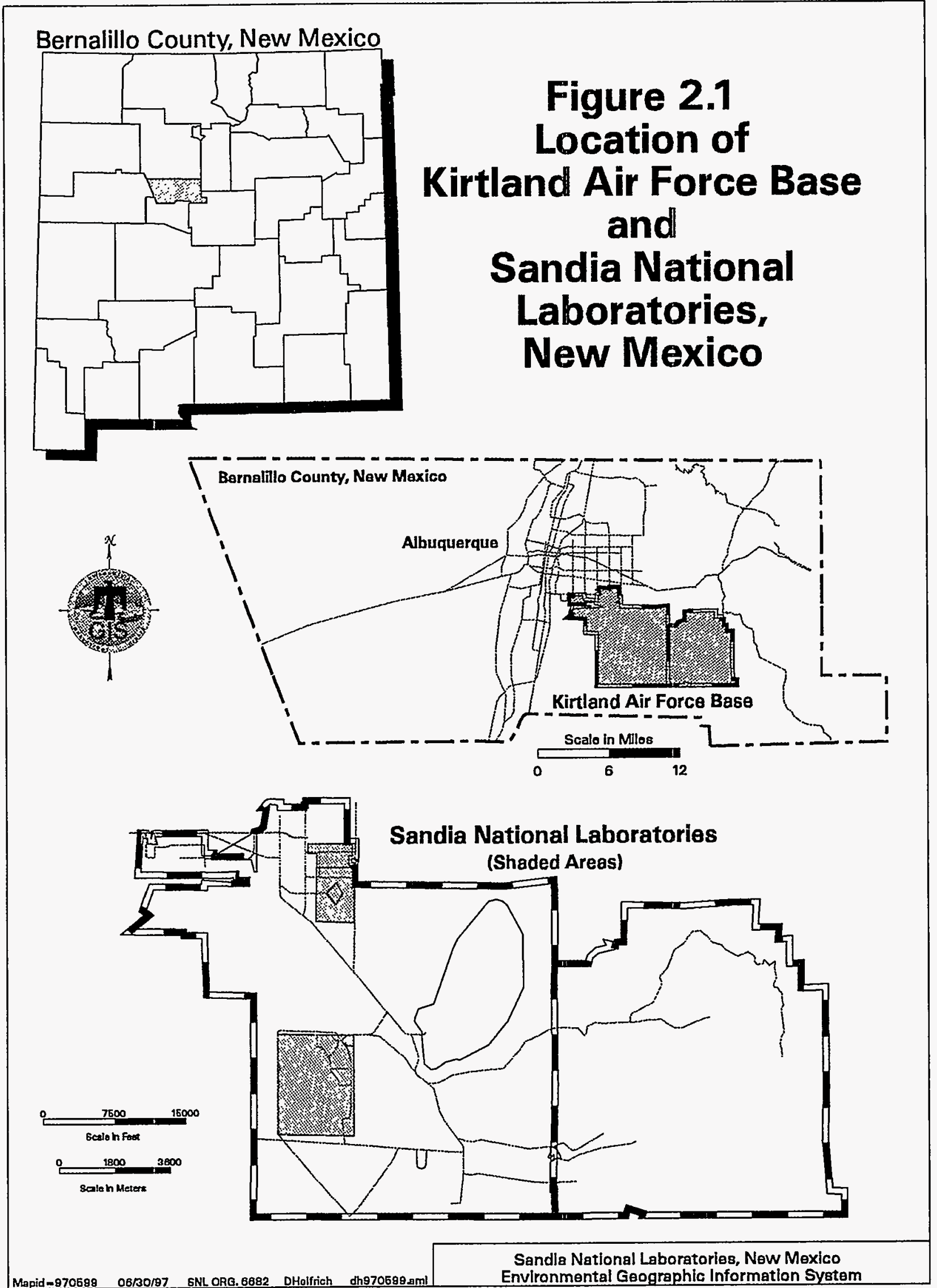


gamma exposure rates and the appropriate health and safety controls for access, as well as providing information that would assist in the site characterization process and cleanup strategy development. Figure 2.2 shows ER sites potentially contaminated with radioactive materials.

Once an understanding of the scope of the surface contamination was gained, a cleanup strategy (VCM) was created to address only the surface point sources (mainly radioactive metal fragments) and small area sources that had been identified by the Phase I Survey. In July 1994, a Temporary Authorization (TA) to conduct the VCM was obtained from the EPA, after the appropriate public notification. Stakeholder participation occurred during the course of the survey and cleanup and involved numerous public meetings and site tours. A TRA was conducted to ensure that cleanup procedures could be implemented in the field, then the fullscale VCM was implemented in October 1994. Using information and field experience gained from this cleanup activity, a second VCM Plan was outlined, approved, and implemented to clean up the larger radioactive areas at the sites. The resurvey of several sites was also included in this VCM as a result of new historical information. This second VCM activity began in June 1995. A Class II permit modification (EPA 1994a) was obtained from the New Mexico Environment Department to allow work of this type to continue once the second 6-month TA from the EPA expired. All field work was completed by November 1996. The overall project timeline is shown in Figure 2.3.

\subsubsection{Basis for Surface Radiological Survey (Phase I)}

The surface-based radiological assessment of SNL/NM ER sites represents a preliminary site characterization effort limited to surface radiological contaminants. This study was the initial step at these sites and was performed as a prerequisite to beginning the RCRA corrective action process. The results of the surface radiological survey are summarized in Section 4.1 of this report and are described in greater detail in the Surface Gamma Radiation Surveys Final Report (Geotech 1994b).

Surface-based gamma surveys have been used since the 1960s to measure environmental exposure rates and gamma-emitting radionuclides occurring in the near-surface soil (Adams and Lowder 1964). Similar radiological assessment techniques were used at the ER sites to identify gamma exposure rates and the appropriate health and safety controls for access. The procedures and methods used in the Trial and Phase I surveys were prepared consistent with the guidelines found in the following:

- Draft Environmental Implementation Guide for Radiological Survey Procedures, U.S. Department of Energy, Assistant Secretary for Environment, Safety, and Health, Washington, DC 20585, November 1994 (DOE 1994). This manual contains a set of guidelines for DOE and DOE contractors to use in planning, conducting, and/or evaluating a radiological survey. 


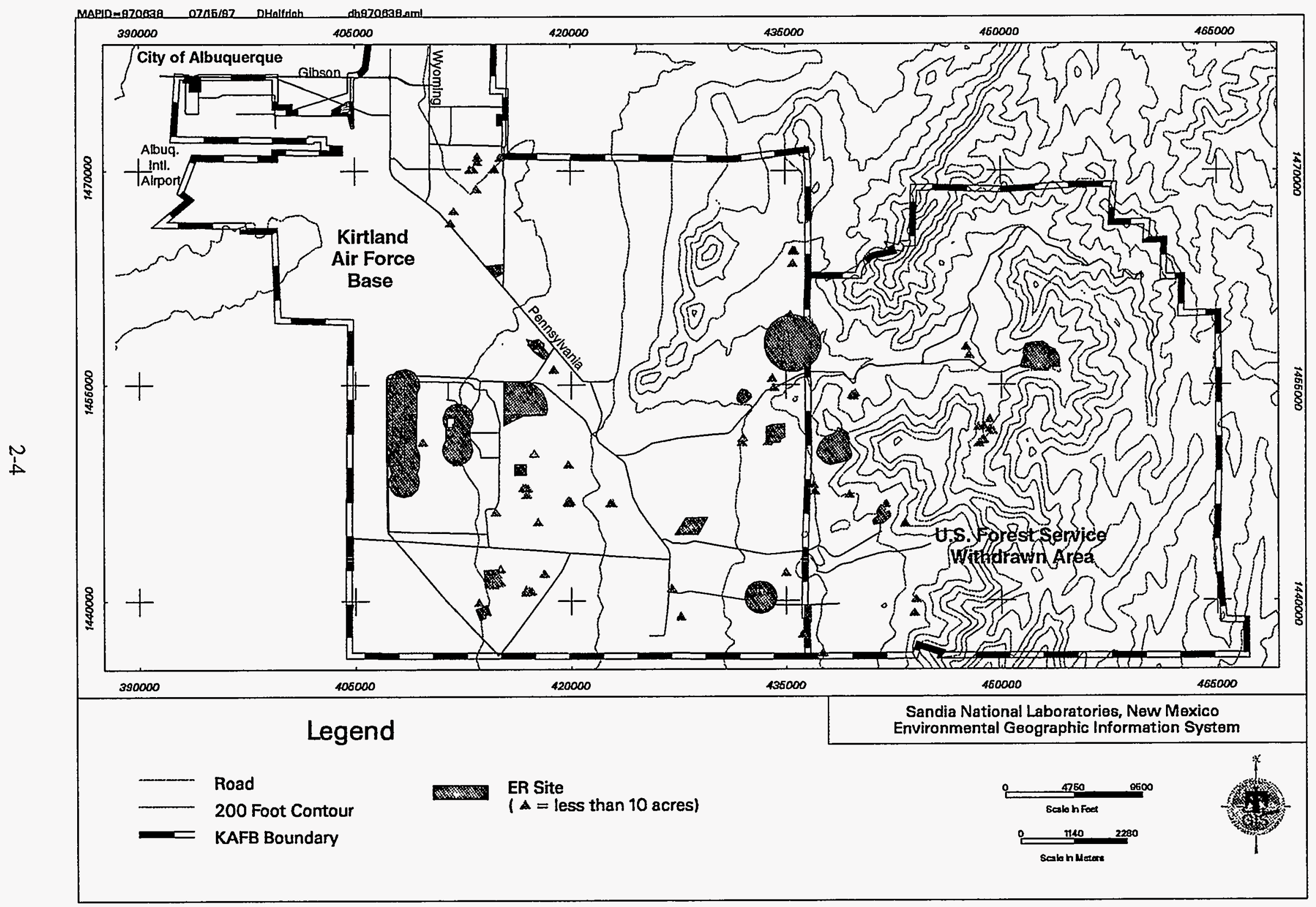

Figure 2.2 ER Sites Potentially Contaminated with Surface Radioactive Materials 
YEAR

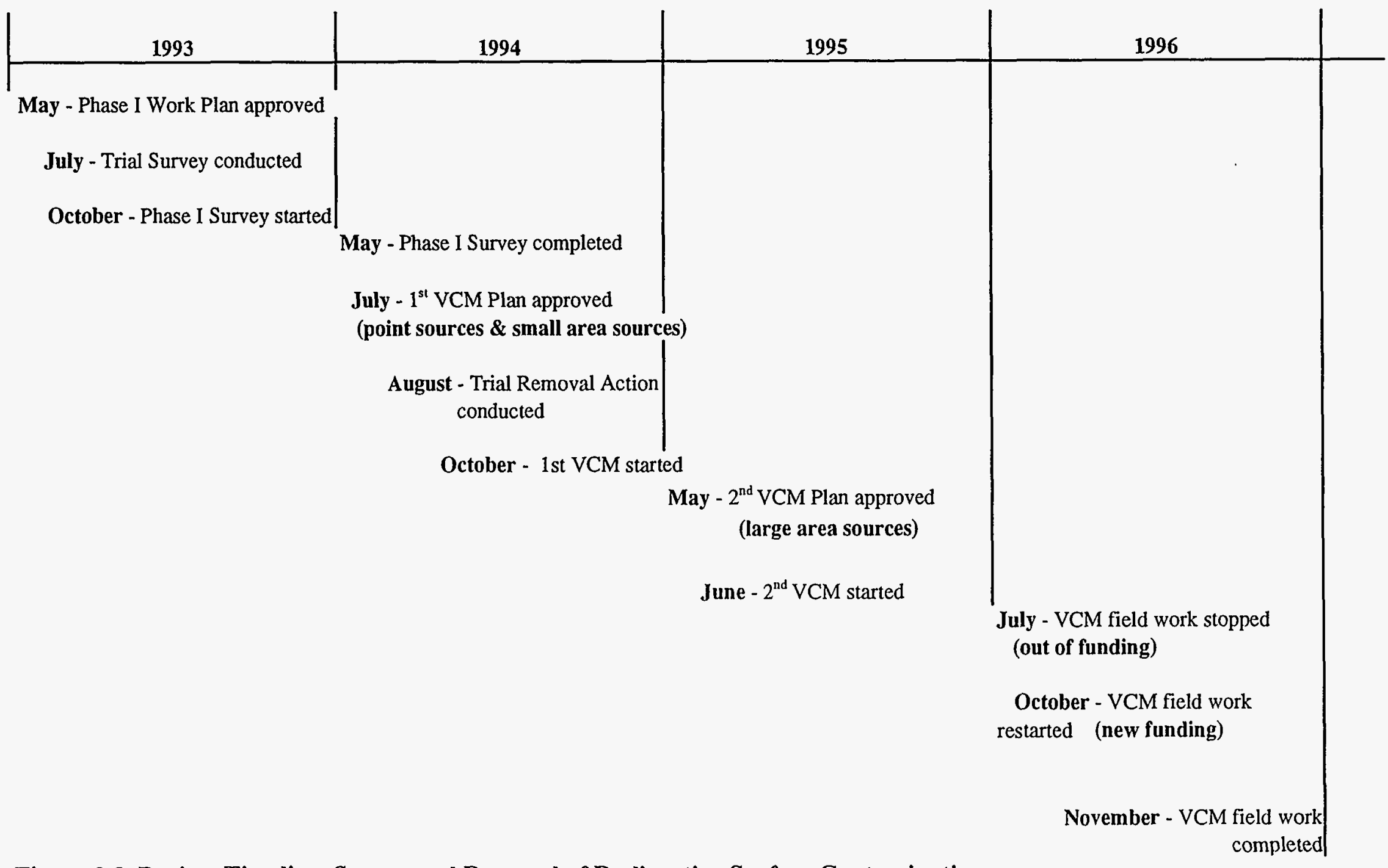

Figure 2.3 Project Timeline, Survey and Removal of Radioactive Surface Contamination 
- Manual for Conducting Radiological Surveys in Support of License Termination, Draft Report for Comment, NUREG/CR5849, U.S. Nuclear Regulatory Commission, June 1992 (NRC 1992). This manual contains procedures for conducting radiological surveys during decommissioning to demonstrate that any residual radioactive materials pass release criteria.

\section{Trial Survey}

In addition to closely following the regulatory guidance pertaining to the conduct of radiological surveys, before beginning the extensive and costly Phase I Surveys, a "Trial Survey" was first conducted at a typical SNL/NM ER site known to be contaminated with DU to demonstrate the effectiveness of instrument response for the site-specific conditions. The Trial Survey was used to build a supporting foundation for the results of the Phase I survey and to ensure that the results of the Phase I survey would be consistent with (or exceed) regulatory guidance and any stated or implied data quality requirements. The Trial Survey was conducted during July 1993 and established the crutch gamma-scintillometer as the instrument of choice for the Phase I surveys.

As recommended in the above guidance documents, cross-correlation of the sodium iodide ( $\mathrm{NaI}$ ) gamma scintillometer was performed with a pressurized ion chamber (PIC) to determine radiation exposure values (in microroentgens per hour $[\mu \mathrm{R} / \mathrm{hr}]$ ) and also with estimated soil concentrations of DU. This information later helped in determining the static count cleanup criteria set for the VCM.

Surface radiological measurements were also collected during the Trial Survey from selected natural background locations to determine the range of natural background. The natural radiological background was characterized so that changes in the gamma radiation field detected by the survey instruments could be attributed to either local variations in natural background or to potential environmental contamination. During the actual Phase I Survey, site-specific background measurements were taken at each site before the surveying began.

The results of the Trial Survey are summarized in the Section 4.1 of this report and are described in greater detail in the Surface Gamma Radiation Surveys Final Report (Geotech 1994b).

\section{Site Classification and Survey Coverage}

Guidelines in the DOE and U.S. Nuclear Regulatory Commission (NRC) documents include classification of sites into those that are either radiologically affected or unaffected by site operations. These classifications are defined as follows:

Affected Areas: Areas that have potential radioactive contamination (based on plant operating history) or known radioactive contamination (based on past or preliminary radiological surveillance). This would normally include areas where radioactive materials were used and stored, where records indicate spills or other unusual occurrences that could have resulted in spread of contamination, and where 
radioactive materials were buried. Areas immediately surrounding or adjacent to locations where radioactive materials were used, stored, spilled, or buried are included in this classification because of the potential for inadvertent spread of contamination.

Unaffected Areas: All areas not classified as affected. Based on a knowledge of site history and previous survey information, these areas are not expected to contain residual radioactivity.

The guidelines in the DOE and NRC documents for scanning surveys include 100 percent coverage for scanning of affected areas and a minimum of 10 percent coverage for scanning of unaffected areas.

\section{Instrument Selection, Sensitivity, and Use}

In the selection of instruments for the field detection of radionuclides of concern, there are a number of situations and conditions that must be taken into account. For example, the instrument must be reliable for the environmental and physical conditions under which it will be used, and its size and weight must be compatible with the application of interest. Instruments must also be capable of detecting the type and energy of the radiation of interest and must be able to detect this radiation at levels of interest in relation to final cleanup of the site.

Initial estimates provided in NUREG/CR-5849 (NRC 1992) indicated that the detection sensitivity for a gamma field scan survey with a NaI scintillation detector should be on the order of $2-5 \mu \mathrm{R} / \mathrm{hr}$ (converted from NaI counts per unit of time) using an audible output response. With an average background exposure rate on the order of $10 \mu \mathrm{R} / \mathrm{hr}$, it was determined that the NaI gamma scintillometer would most likely provide the necessary portability and resilience to harsh field conditions as well as the necessary detection sensitivities. This was confirmed during the Trial Survey.

In optimizing the scan survey with the goal of matching the operator's ability to discern elevated radiation readings from background fluctuations and detecting radioactive anomalies at the lowest levels possible, guidance provided in the DOE and NRC documents recommends detection levels of 1.25 to 2.0 (1.25 to 1.5 for the NRC and 1.5 to 2.0 for DOE) times the ambient background level when background is on the order of several thousand counts per minute. As noted above, NaI counts were converted to and reported in $\mu \mathrm{R} / \mathrm{hr}$. For the Phase I surveys, a value of 1.3 times ambient background using a NaI gamma scintillometer was chosen, which is within the range recommended by the NRC and below that recommended by DOE.

The DOE and NRC documents recommend that when a gamma scintillometer is used to conduct scanning surveys, the scanning speed be approximately 1 mile per hour, with the detector held as close to the ground as practical, generally less than 2 inches from the surface. The Trail Survey verified the detection sensitivity as a function of scanning speed and provided an opportunity to "calibrate" operator walking speeds to provide as consistent a scan speed as possible. Further 
discussion is provided in the Trial Survey section of the Surface Gamma Radiation Surveys Final Report (Geotech 1994b).

Guidance provided in NUREC/CR-5849 suggests that the instrument chosen for the scan survey be capable of detecting the contaminant of concern at 25 to 75 percent of the target cleanup level. (The target cleanup level, as determined by a generic risk assessment and discussed in Section 2.2.2, was approximately $230 \mathrm{pCi} / \mathrm{g}$ of U-238 in the soil, thus the instrument must be capable of detecting U-238 at a level between 57.5 to $172.5 \mathrm{pCi} / \mathrm{g}$.) It was necessary to attempt to correlate field survey measurements using a $\mathrm{NaI}$ (in counts per unit of time) to $\mathrm{pCi} / \mathrm{g}$ of U-238 in soil since the determination of risk to an onsite individual from residual radionuclides in soil is based upon $\mathrm{pCi} / \mathrm{g}$ of these radionuclides.

As discussed in the Trial Survey section in the Surface Gamma Radiation Surveys Final Report (RUST Geotech 1994b), correlation of scan surveys using a NaI gamma scintillometer with actual laboratory-analyzed soil samples of the detected DU anomalies provided the following estimated lower limits of detection (in $\mathrm{pCi} / \mathrm{g}$ ) corresponding to approximately 1.3 times ambient background (in counts per unit of time) using a NaI scan survey:

- For area sources of DU, it was estimated that soil concentrations as low as $13 \mathrm{pCi} / \mathrm{g}$ of $\mathrm{U}-238$ in soil may be detected.

- For point sources of DU, it was found that a concentration of $80 \mathrm{pCi} / \mathrm{g}$ of U-238 in soil was detected, but the area tested provided a NaI response on the order of 2 times ambient background. It is expected, therefore, that a 1.3 times ambient background response on a $\mathrm{NaI}$ scan survey would correspond to less than $80 \mathrm{pCi} / \mathrm{g}$ of U-238.

The estimated detection limit, using the NaI gamma scintillometer for a point source was approximately 35 percent of the target cleanup level. The estimated detection limit, using the NaI gamma scintillometer for an area source, was approximately 6 percent of the target cleanup level. These are both well within the NUREG/CR-5849 guidance provided, with the conclusion that the NaI gamma scintillometer with alarms set at 1.3 times ambient background would be sensitive enough to detect DU at or below the concentration of concern.

The procedures associated with development of detection limits are discussed in greater detail in the Surface Gamma Radiation Surveys Final Report (Geotech 1994b).

\subsubsection{Basis for Surface Radiological Cleanup (Voluntary Corrective Measures)}

Corrective action objectives for SNL/NM ER sites include reducing contamination to levels that allow uses of the formerly contaminated sites consistent with future land-use designations. This VCM was consistent with this general objective and with the corresponding permit requirements, as well as the requirements of proposed Subpart S of Title 40, Part 264 of the Code of Federal Regulations (EPA 1990), in that this removal action does not preclude any other corrective action that may be deemed necessary in the future. Statutes, regulations, and guidance that pertain to the establishment of cleanup criteria for this project are discussed below. EPA and DOE 
allowable exposure limits, given as total effective dose equivalent (TEDE) limits, drove the cleanup and are discussed first. The most restrictive of the EPA and DOE limits was then used as the maximum allowable TEDE in a generic risk assessment scenario, which was used to backcalculate the related maximum allowable soil concentration.

\section{TEDE Limit Used In Generic Risk Assessment}

Guidance relating to the development of standards for residual radioactivity in soil at DOE sites is provided through three sources:

- DOE Order 5400.5, Radiation Protection of the Public and the Environment, U.S. Department of Energy, 1990 (DOE 1990).

- (Draft) Title 10, Code of Federal Regulations (CFR), Part 834 (10 CFR 834), Radiation Protection of the Public and the Environment, U.S. Department of Energy, 1993 (DOE 1993).

- (Preliminary Draft) 40 CFR 196, Radiation Site Cleanup Regulation, U.S. Environmental Protection Agency, 1994 (EPA 1994b).

Standards presented in these EPA and DOE regulations generally assign a TEDE limit, above background radiation dose, to the reasonably maximally exposed (RME) individual based on the most probable use scenario for the land area in question (e.g., industrial land use) and the radioactive contaminants of concern. In addition to the standards that are assigned based on the most probable land use, a second tier of evaluation is required in which it is assumed that a least likely, more conservative land use is utilized on site (e.g., residential land use).

The EPA and the DOE regulations approach the TEDE determination in the same manner but assign different limits, as follows:

EPA: 15 millirem per year (mrem/yr) TEDE for the most probable land use (with active control measures), not to exceed $4 \mathrm{mrem} / \mathrm{yr}$ through the drinking water pathway, and a maximum of $75 \mathrm{mrem} / \mathrm{yr}$ TEDE in the event that all of the active control measures fail. If active control measures are not instituted and the $15 \mathrm{mrem} / \mathrm{yr}$ limit can be met, the site may be unconditionally released.

DOE: $30 \mathrm{mrem} / \mathrm{yr}$ TEDE for the most probable land use (with active control measures) with a maximum of $100 \mathrm{mrem} / \mathrm{yr}$ TEDE in the event that all active control measures fail.

The risk assessments conducted for this project used the more conservative EPA standard of $15 \mathrm{mrem} / \mathrm{yr}$. 


\section{Generic Risk Assessment Used To Generate A Target Cleanup Level}

The most restrictive of the TEDE limits from EPA and DOE regulations was used as the maximum allowable exposure in a generic risk assessment scenario. A TEDE limit of $15 \mathrm{mrem} / \mathrm{yr}$ was used to back-calculate the related maximum allowable soil concentration of DU. Due to the location of the ER sites within KAFB, it was assumed that the RME individual was an on-site worker in an industrial land use scenario. Parameters typical of SNL/NM ER sites were input into the RESRAD code (Yu et al. 1993a). It was assumed that DU contamination would occur in typical isotopic activity ratios:

- $\mathrm{U}-238 / \mathrm{U}-234=11$

- $\mathrm{U}-238 / \mathrm{U}-235=62$.

The U-238 value was used as a primary indicator since the portable instruments to be used for the VCM cleanup detect the presence of DU by detecting the 1,001 kiloelectron volts (keV) gamma of the U-238 short-lived daughter protactinium $(\mathrm{Pa})-234 \mathrm{~m}$. Given these assumptions, the generic risk assessment resulted in a target cleanup level of $230 \mathrm{pCi} / \mathrm{g}$ of U-238 in the soil (see Appendix K).

The portable instruments used during the cleanup activity measured surface radiation levels in counts per minute (cpm), not soil concentrations. Therefore, for this cleanup, a value of 1.3 times ambient background using a NaI gamma scintillometer was chosen as a static count cleanup criteria when surface radioactive anomalies were remediated. Experience gained through review of verification soil samples as cleanup progressed showed, as discussed below, that this 1.3 times background static count provided for residual soil concentrations (in $\mathrm{pCi} / \mathrm{g}$ ) that were a small fraction of the target cleanup level.

Tests made during the Trial Survey tried to relate $\mathrm{cpm}$ to minimum detectable soil concentrations. However, a low correlation was achieved due to the fact that many different subsurface source configurations could result in the identical reading at the ground surface. For example, a weak source on the surface may give a reading identical to a stronger source a few inches below the surface. The residual soil concentration following cleanup was far less than the maximum allowable soil concentration calculated by the generic risk assessment, and indicated that the portable radiation detection instruments ( $\mathrm{NaI}$ gamma scintillometer) were adequately sensitive for cleanup. This is confirmed by the maximum residual soil concentrations presented on a site-specific basis in Section 5 of this report.

Verification sampling confirmed that acceptable soil concentrations were achieved under each anomaly cleaned up. These soil sampling data were then used in site-specific risk assessments to show that the residual radioactivity levels of the soils left on site did not exceed the EPA allowable exposure limit, and that cleanup was complete. The soil concentrations achieved in the field were far below the target cleanup level indicated by the generic risk assessment. Choosing to clean up to a near-background value gave a considerable margin of safety at each individual site, is consistent with the DOE viewpoint that radiation exposure be maintained as low as reasonably achievable (ALARA), and was done by design since it would not be cost effective to 
revisit any site. In addition, at the time the decision was made to clean up to 1.3 times background, the land-use scenarios for each site had not been established, and also may be subject to change in the future.

Resurvey work necessary during the VCM followed the most recent NRC guidance document:

Measurement Methods for Radiological Surveys in Support of New Decommissioning Criteria, Draft Report for Comment, NUREG-1506, U.S. Nuclear Regulatory Commission, July 1995.

\subsection{Waste Management Overview}

\subsubsection{Phase I Radiological Survey Waste Management}

The work plan for the Phase I surveys specified how to control various waste products that may be generated during the field activities. Before the fieldwork began, this plan was superseded by an SNL/NM Waste Management Plan, which was adhered to during the Phase I surveys. No radiological, hazardous, or mixed waste was generated during the Phase I surface radiological surveys. No decontamination was necessary as determined by the site release surveys performed prior to the field crew leaving each ER site. The Waste Management Plan is explained in greater detail in the Surface Gamma Radiation Surveys Final Report (Geotech 1994b).

\subsubsection{VCM Waste Management}

In July 1994, the ER Project Waste Management and Characterization Plan (FOP 94-78) was issued by ER Logistics and Integration Department (Department 6684) to standardize waste characterization and management procedures used by ER personnel associated with ER Project waste-producing activities. These procedures were used to supplement the TRA Waste Management Plan (SNL/NM 1994b) and the Waste Management Plan, Removal of Surface Radiation Voluntary Corrective Measure (SNL/NM 1994d).

\section{Trial Removal Action}

The TRA was conducted at the SNL/NM ER Project Sites $18,83,240$, and 87 by Geotech in August 1994. The primary goals of the TRA were to: (1) gather waste management and characterization data from several representative VCM sites for determining whether or not there was a potential to generate mixed waste, (2) generate better waste stream information and volume estimates for the VCM, and (3) to determine the effectiveness of the proposed cleanup methods. The TRA waste management strategy allowed for the collection of necessary waste characterization data, but minimized the generation of radioactive waste volumes and potential mixed waste volumes. Procedures are explained in greater detail in the TRA Waste Management Plan (SNL/NM 1994b).

The three waste streams involved were radioactive fragments, radioactive soils, and personal protective equipment (PPE). The waste streams mentioned were containerized separately and by site to streamline characterization sampling and handling. A total of approximately 
50 representative radioactive fragments were analyzed in the Technical Area III Field Laboratory using $\mathrm{x}$-ray fluorescence (XRF). The XRF analyses were used to determine if the fragments contained characteristic hazardous metals, as defined by the EPA Toxicity Characteristic Leachate Procedure (TCLP) analyte list. Further analysis would be performed if any target metals (RCRA/TCLP listed metals) were identified. In addition, gamma spectroscopy was performed on the same fragments to characterize the radionuclides present in the fragments.

Representative composite soil samples were collected and analyzed for metals only (using the EPA TCLP method) to determine if characteristic hazardous metals were present at concentrations high enough to indicate that the soil contained hazardous waste, and therefore mixed waste. The number of soil samples collected was based on the volume of soil generated during the TRA. Also, gamma spectroscopy was performed on the same soil samples to characterize the radionuclides present in the soil.

As directed by Department 7572 (Generator Interface), PPE was managed as radioactive waste.

\section{VCM}

The procedures for the VCM Waste Management Plan are based on the protocols developed during the TRA. The plan was developed, with the assistance of Department 7572 (Generator Interface) and ER Departments 6682 and 6685, to be consistent with existing SNL/NM, DOE, EPA, and New Mexico Environment Department guidelines. The plan discusses types of waste streams expected to be generated, waste characterization, waste handling and containerization, waste storage and disposal, and waste minimization. Procedures are explained in greater detail in the VCM Waste Management Plan (SNL/NM 1994d).

Representative composite soil samples were collected and analyzed for metals only (using the EPA TCLP method) to determine if characteristic hazardous metals were present at concentrations high enough to indicate that the soil contained hazardous waste, and therefore mixed waste. Also, gamma spectroscopy analysis was performed for each composite soil sample to characterize the radionuclides present in the soil.

It was determined for each site that one composite soil sample would be collected for every five soil drums and tested using TCLP analytical methods (typically RCRA metals only, based on site information) per EPA guidance (EPA 1980). This waste characterization analysis requirement was determined based on 12 TCLP surface soil samples that were taken during the TRA. All 12 samples passed the TCLP tests.

The requirement to collect one composite sample for every five drums did not apply to radioactive fragments. Fragments were sampled based on quantity available and size of the fragments. If the fragments could fill a 500 milliliter $(\mathrm{ml})$ marinelli jar, a sample was collected. Therefore, only 13 fragment samples were collected from 12 sites and analyzed using TCLP analytical methods during the VCM. The PPE was managed in the same manner as the PPE that was generated during the TRA. The three waste streams were containerized separately and by site to streamline both waste characterization sampling and handling. 
The waste characterization sampling strategy evolved as the VCM project continued. Sample size calculations (EPA 1986) were performed by Generator Interface in August 1995, and showed that the soil samples that were collected by site up to this point were more than adequate to characterize the waste stream. Based on these sample size calculations, Department 7572 (Generator Interface) concluded that the VCM sampling strategy of 1 composite soil sample for every 5 drums by site could be changed to 1 composite soil sample for every 50 drums by site.

\subsection{Health and Safety Overview}

\subsubsection{Phase I Radiological Survey Health and Safety Plan}

During the Trial and Phase I surveys, all activities were conducted under the provisions of the Geotech Technical Support Program for SNL/NM, Health and Safety Plan (HASP) for Phase I (Geotech 1993b). All reasonable precautions were taken to protect the safety and health of the employees and members of the public and to comply with all applicable safety and health regulations and requirements of DOE.

The health and safety program included site-specific training and daily safety meetings, which were attended by all field personnel and site visitors. Access onto and egress from the ER sites were logged daily by use of the Radiological Access and Frisking Log and by use of the Hazardous Materials Access Log. No decontamination was necessary as determined by the site release surveys performed by SNL/NM Radiological Control Technicians (RCTs) prior to the field crew leaving each ER site.

Health and safety monitoring activities included bioassay sampling, external dosimetry measurements, air sampling, sampling for radioparticulates, and heat stress monitoring. All results were below (in most cases, several orders of magnitude below) the reporting limits. These activities are discussed further, and results of sampling are presented, in Appendix A of the Surface Gamma Radiation Surveys Final Report (Geotech 1994b).

\subsubsection{VCM Health and Safety Plan}

All activities were conducted under the provisions of the Geotech Technical Support Program for SNL/NM, HASP for Phase I and II (Geotech 1994a). The plan is based on the HASP for Phase I (Geotech 1993b), and the protocols developed during the Trial and Phase I surveys. The HASP for Phase I and II was developed by Geotech and covers Geotech personnel who conducted the VCM field work. All reasonable precautions were taken to protect the safety and health of the employees and members of the public and to comply with all applicable safety and health regulations and requirements of DOE.

The health and safety program included site-specific training and daily safety meetings, which were attended by all field personnel and site visitors. Health and safety monitoring activities included bioassay sampling, external dosimetry measurements, air sampling, sampling for radioparticulates, heat stress monitoring, and heavy metals sampling. All sampling results were 
below the reporting limits. The program is explained in greater detail in Section 5.1 of this report and the HASP for Phase I and II (Geotech 1994a). 


\section{METHODOLOGY}

\subsection{Field Procedures}

\subsubsection{Phase I Radiological Survey Procedures}

Techniques, instrumentation, and procedures used for the Phase I surveys were based on protocols developed by the DOE Environmental Management Technical Measurement Center. Parameters and methodologies specific to the SNL/NM ER Project sites, such as optimum scanning speed, grid spacing, detection limits, determination of natural background, and instrument configurations, were established during the Trial Survey conducted at the SNL/NM sled track site by Geotech in July 1993. The procedures and methods used in the surveys were developed to be consistent with and comply with NUREG/CR-5849 and DOE guidance.

The Phase I surveys of elevated radioactivity (anomalies) on ER sites used a NaI gamma scintillometer ( $\mathrm{NaI}$ detector) to scan the ground surface to detect any gamma readings that were 30 percent above background ( 1.3 times site-specific background radiation levels). Locations of these readings were recorded, pinflagged, and painted with the location number and high gamma measurement. The scan spacing was determined prior to the start based on results of the Trial Survey and historical data. Scan spacing was on a 6-foot center (100 percent coverage) or 10-foot center (70 percent coverage). Figure 3.1.1 shows a NaI detector, Figure 3.1.2 shows field personnel performing a surface radiation survey using gamma scintillometer, and Figure 3.1.3 shows pinflagged and painted radiation anomaly.

The Phase I surveys identified area sources, point sources, and outcrop sources. Area sources were usually larger than 3 feet in diameter and were suspected of having finely dispersed DU near or at the surface, or consisted of multiple point sources within the area. Point sources were small areas that displayed a sudden change in gamma readings or a point source characteristic (fragment). The size of the point source was typically less than three feet in diameter. Outcrop sources consisted of elevated gamma readings that appeared to be caused by visible rock outcrops. The most common outcrop was granite. These outcrops usually exhibited slightly elevated gamma readings over an area and did not display the characteristics of DU contamination.

All anomalies, along with physical features such as roads and buildings, were located by land surveying. This information was used to produce a base map for each site. These base maps contained all the radiological data for the site. The procedure used in conducting the Phase I surveys is explained in greater detail in the Surface Gamma Radiation Surveys Final Report (Geotech 1994b).

\subsubsection{VCM Removal Action Procedures}

Procedures used to remove anomalous gamma readings were based on the protocols developed during the Trial Survey and Phase I surveys. Methodologies such as relocating areas of elevated radioactivity, radioactive fragments and soil removal, sample collection and handling, and waste management process were established during the TRA conducted at SNL/NM Project 


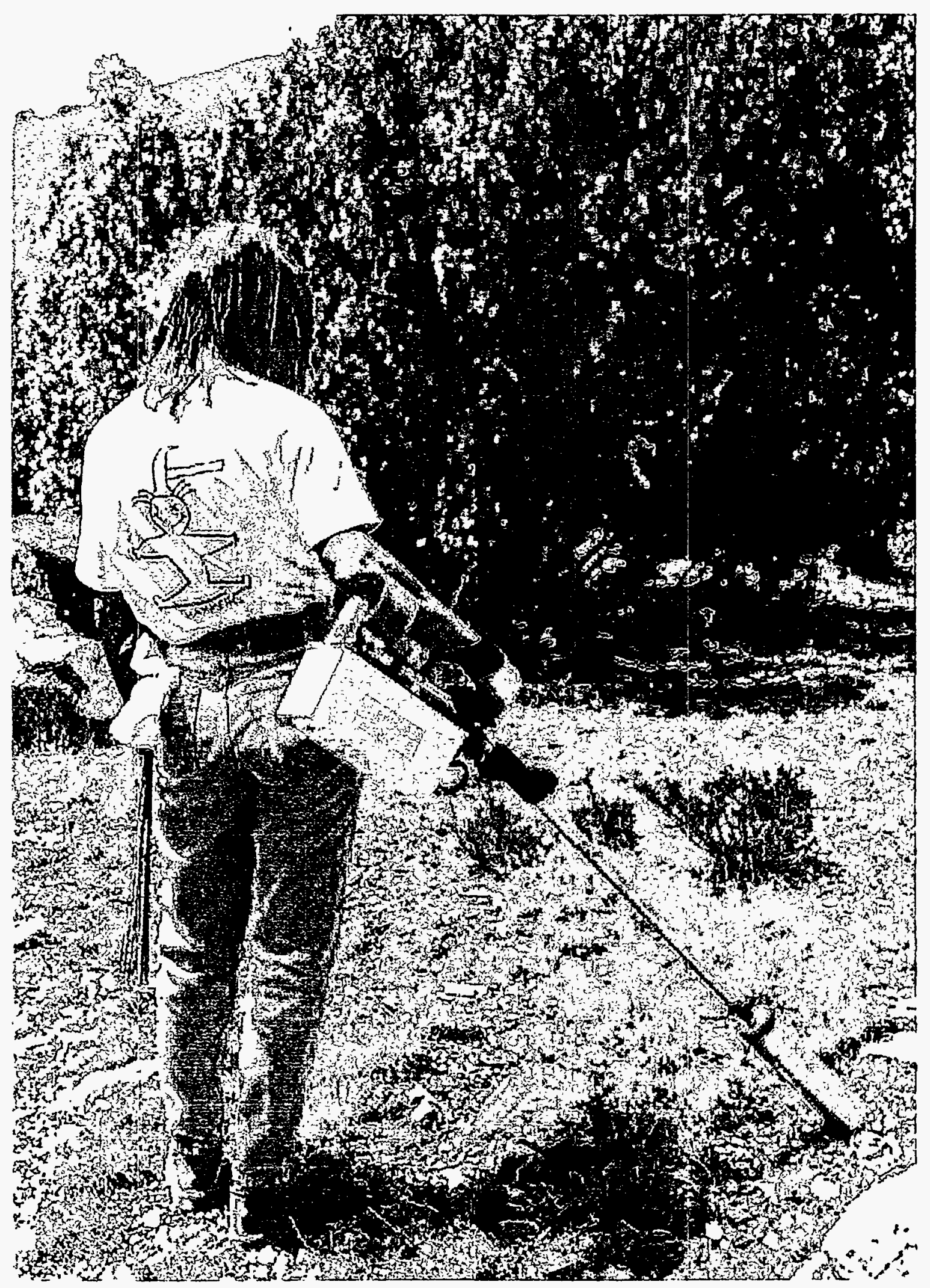

Figure 3.1.1 Gramma Scintillometer (NaI Detector) 


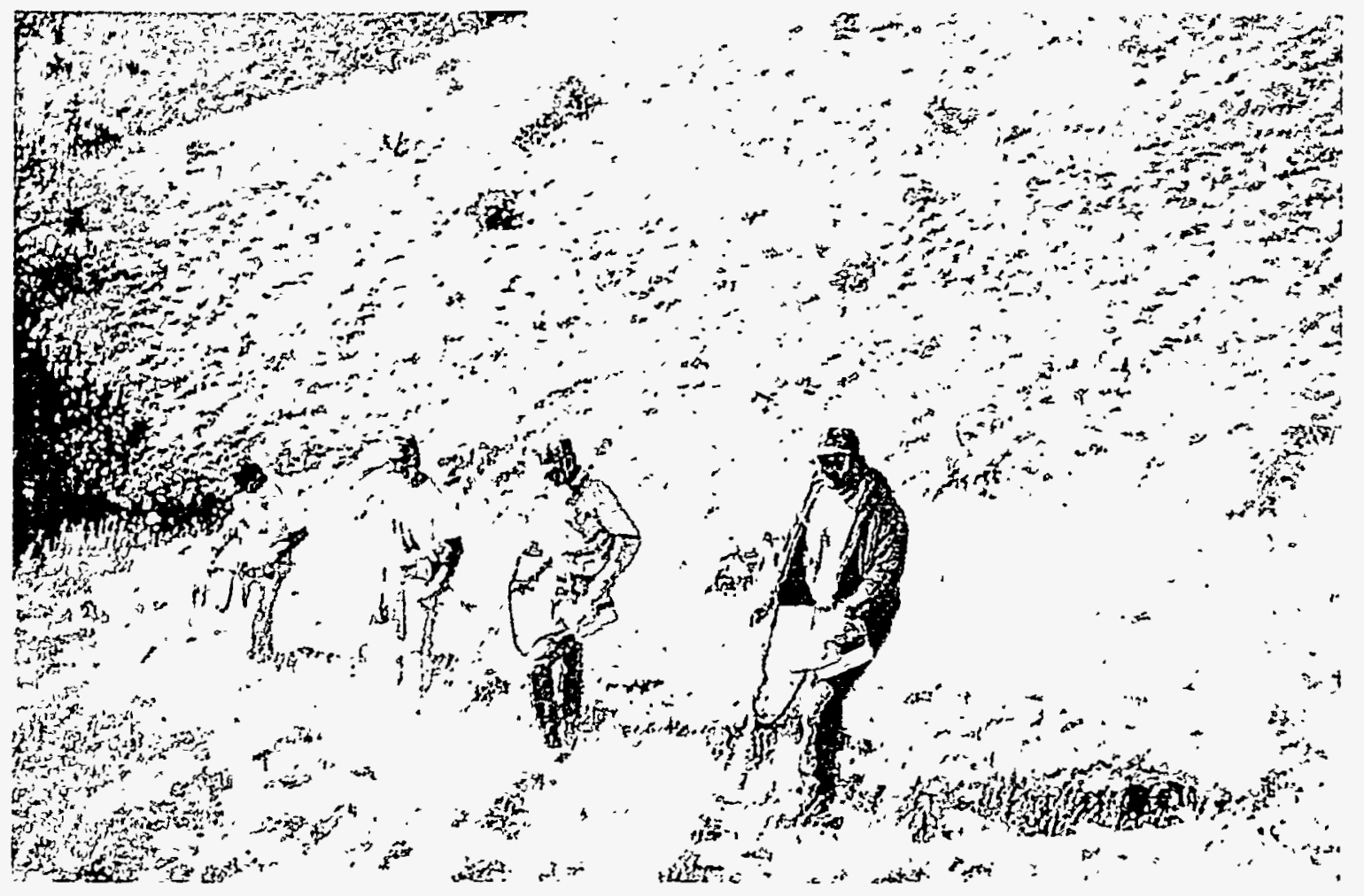

Figure 3.1.2 Surface Radiation Survey Using Gam ma Scintillom eter (NaI Detector)

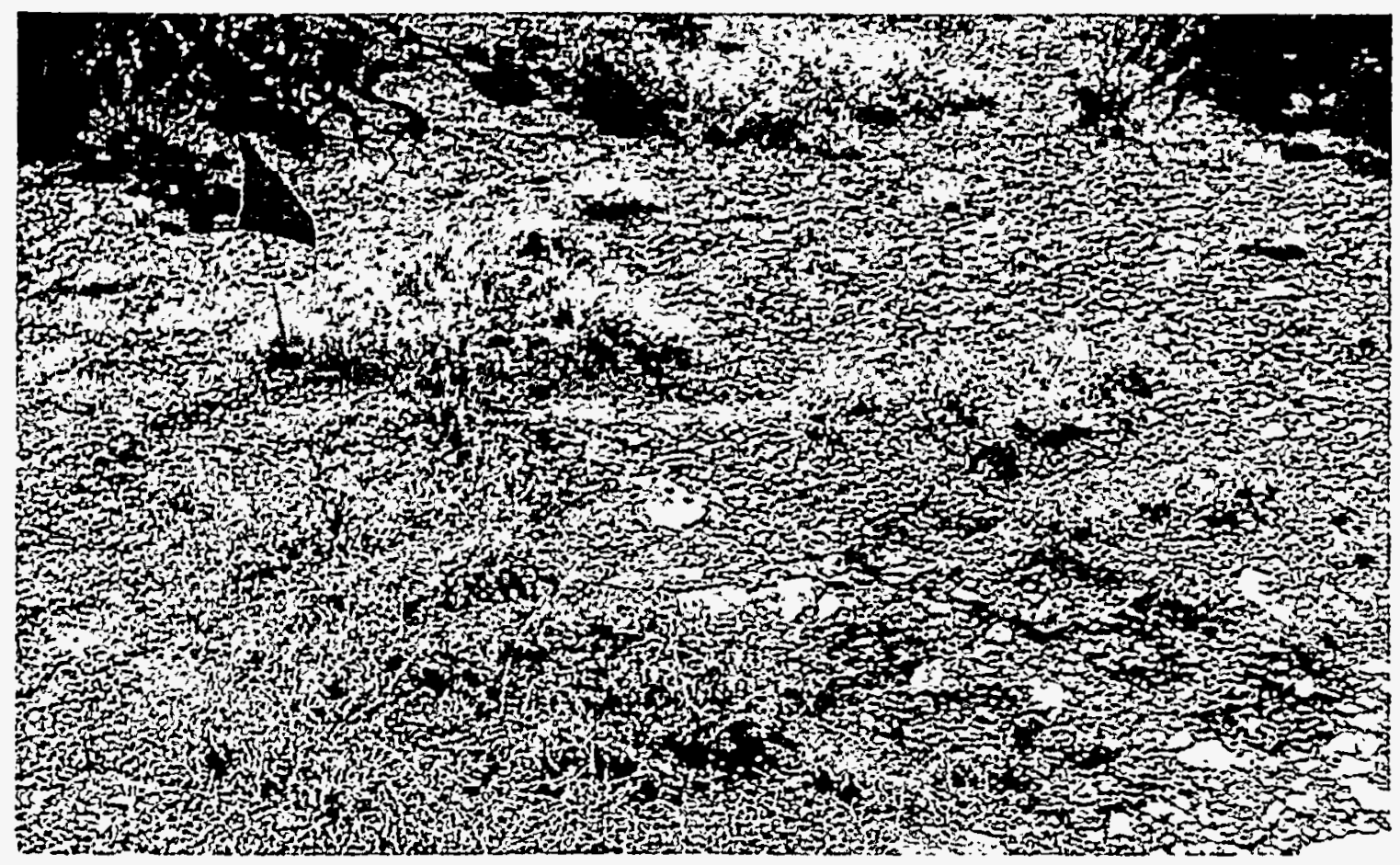

Figure 3.1.3 Pinflagged and Painted Radiation Anomaly 
Sites $18,83,240$, and 87 by Geotech in August 1994. The procedures used in conducting the removal action are explained in greater detail in the VCM Plans (SNL/NM 1994a and 1995a). Field work was performed on 10-day rotations with 4 days off.

\section{Anomaly Relocation}

The time between the original Phase I surveys and anomaly identification to the relocation of anomalies for remediation during the VCM was a year or longer in some cases. During this time, pinflags blew away and paint weathered, making it difficult to relocate anomalies.

The anomalies located during the Phase I surveys were relocated for remediation using several methods. Anomalies near physical features were easily located by scaling off the base map and then taping to the anomaly in the field. Once known anomalies were located, other anomalies were located using the same scaling and taping method. Other anomalies were identified using the wires and sometimes the original identifier flag from the pinflags used during the Phase I surveys. Fragment locations were confirmed by re-scanning the area with the gamma scintillometer or by visually identifying the fragment on the ground surface. For anomalies that were not easily identified by the above methods, a Global Positioning System (GPS) was used. The GPS was useful in establishing boundaries of large area sources. When an anomaly was identified, a new pinflag, with the anomaly location number, was placed at the location to be remediated. Figure 3.1.4 shows relocation of an anomaly originally located during the Phase I survey.

\section{DU Contaminated Soil Remediation}

The objective of the VCM was to remove sources that resulted in anomalous gamma readings (point and area sources) identified during the Phase I surveys. Reasonable attempts were be made to screen both point and area sources for elevated radioactivity and to remediate the sources to site-specific background levels. Approximately 1.3 times the site-specific background radiation levels ( 30 percent above background) was used for the cleanup criterion. If any instrument measurements were above the cleanup criterion, further remediation was conducted until readings fell below the criteria. In most cases, removal of the DU contamination resulted in background readings.

Point sources and small area sources were addressed first in the VCM, with the large area sources being addressed in the second VCM. Soil mounds of known or suspected DU contaminated soil were dismantled layer by layer, scanned, and cleaned up. Actions were taken on a site-by-site basis, and site-specific changes to procedures were documented on field logs and data tracking forms.

\section{Point Sources}

The remediation of point sources followed the general procedures described below. 


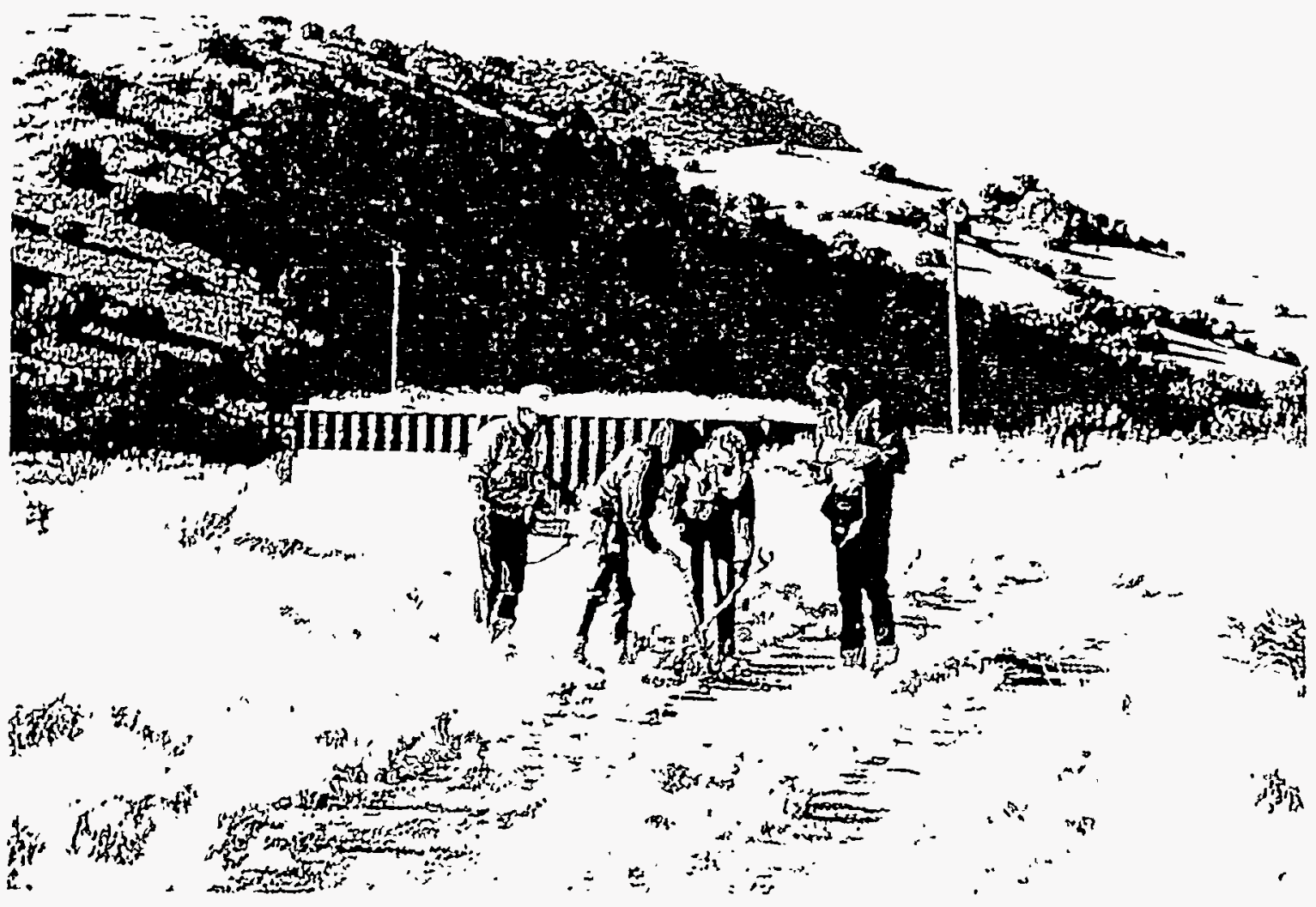

Figure 3.1.4 Relocation of an Anomaly Originally Located During the Phase I Survey 
1. A detailed gamma scintillometer scan was performed to pinpoint the suspected point source location.

2. The initial high gamma measurement (NaI detector), high beta/gamma measurement (Geiger Müeller [GM] pancake probe), and the site-specific background level were recorded. The instrument measurements at the point source were compared to the background level.

3. If the point source reading did not exceed the cleanup criterion (1.3 times site-specific background radiation level), it was considered solid waste and left on site.

4. If the point source reading exceeded 1.3 times the site-specific background radiation level, it was considered radioactive waste.

5. A piece of plastic sheeting was laid down beside the location, and a hand trowel was used to remove the point source. The soil was placed on the plastic sheet and was searched with the scintillometer for the point source.

6. Gamma and beta/gamma measurements were obtained on the point source, and the point source was placed in an appropriate container (30- or 55-gallon open-top steel drum).

7. The soil was scanned with both instruments to determine if all the contamination had been removed. If measurements exceeded the cleanup criterion (1.3 times the sitespecific background radiation level), additional soil was removed until the measurements fell below this criterion.

8. The soil and any additional metal fragments were placed in an appropriate container (30or 55-gallon open-top steel drum).

9. The soil remaining in the immediate vicinity from which the point source was removed was scanned with both instruments and visually inspected to determine if oxidized DU was present.

10. If the soil displayed any readings above the cleanup criterion or if oxidized DU was seen, it was placed in an appropriate container for disposal.

11. If no evidence of contamination was seen, a post-cleanup soil sample was collected at one in every ten locations to provide verification that cleanup was achieved.

Figure 3.1.5 and Figure 3.1.6 show the general procedures for removing a point source.

All work was performed by hand at the immediate location of the point source to minimize waste generated. Tools used to perform the actual removal included hand trowels, shovels, and buckets 


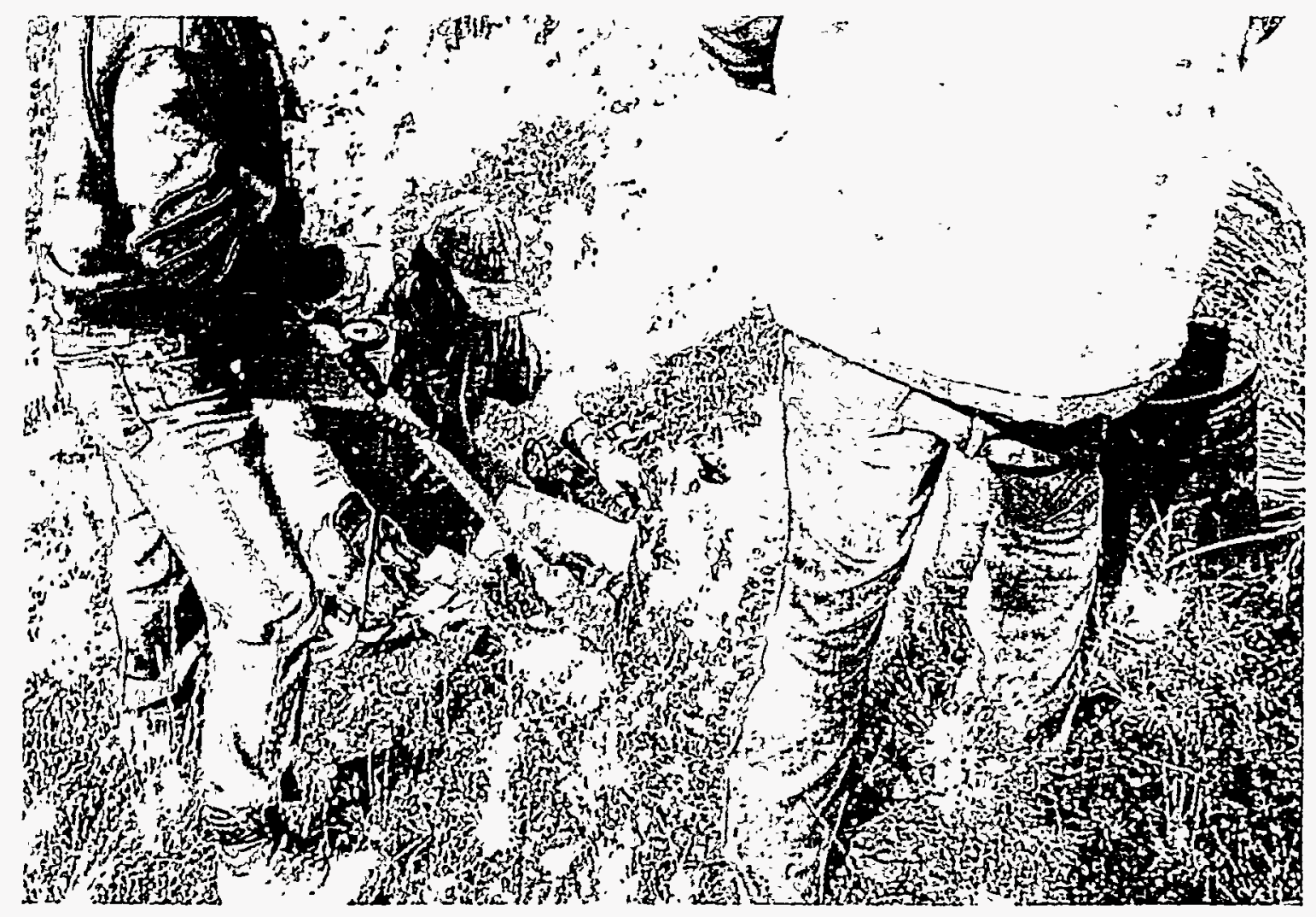

Figure 3.1.5 Point Source Removal And Gamma Scintillometer (NaI Detector) Scanning

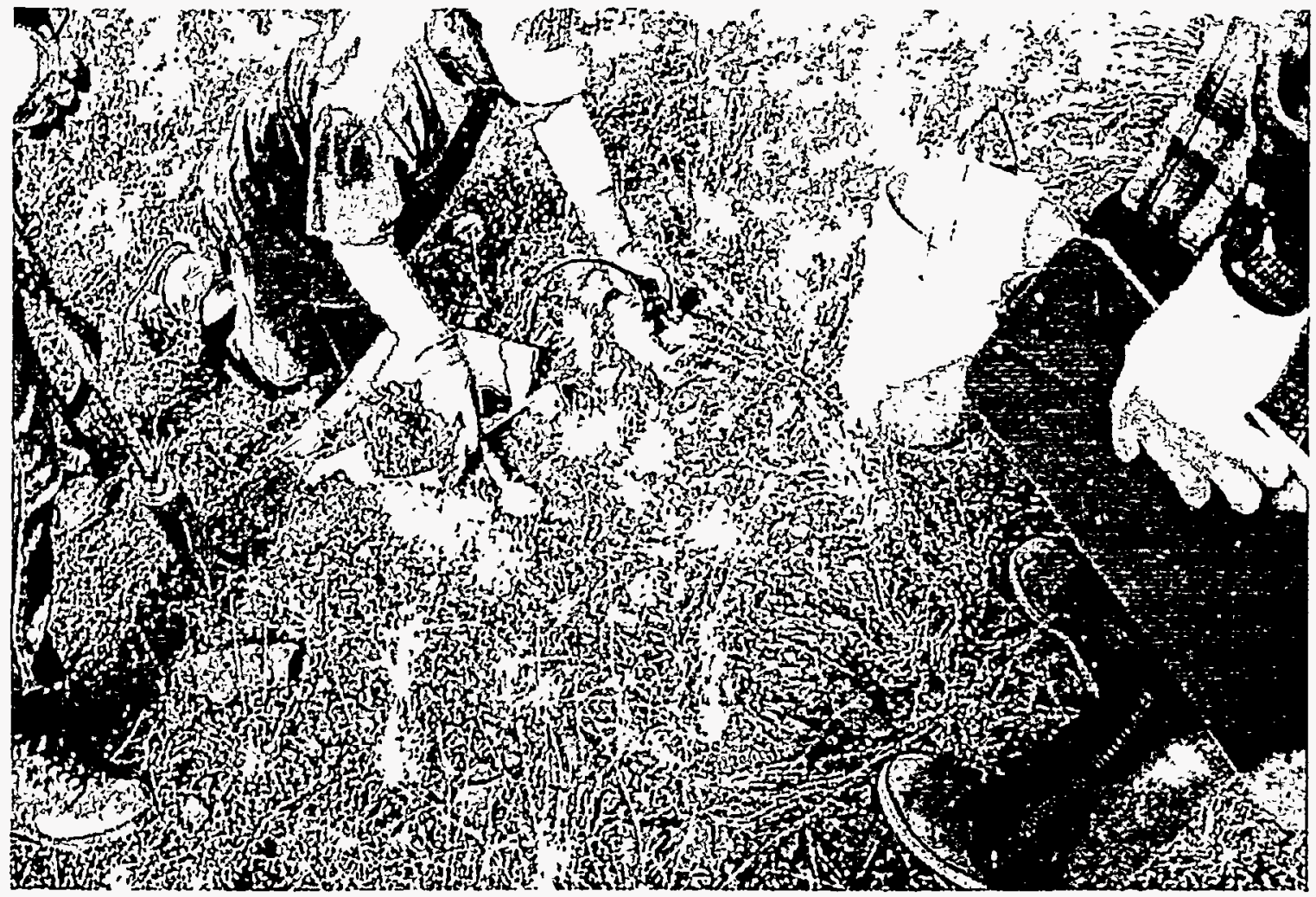

Figure 3.1.6 Point Source Removal And GM Pancake Scanning 
(5 gallon). Disturbance to surface soil occurred only in the immediate vicinity of the anomaly and no deeper than 12 to 18 inches (unless unusual circumstances were encountered). At many locations the only action was to remove a metal fragment from the surface. If the remediation at a given anomaly required digging deeper than 12 to 18 inches, work was halted at that anomaly until further consultation with appropriate SNL/NM personnel occurred (ER Project Leader, and ER Task Leader, Radiation Protection Operations [RPO] and Radiation Protection Engineering personnel, at a minimum). Once approval was granted to proceed with remediation greater than 12 to 18 inches deep, cleanup proceeded with hand tools. Figure 3.1.7 shows metal fragments from remediation of a point source.

\section{Area Sources}

Figure 3.1.8 shows the general procedures for removing an area source. Area sources typically had DU dispersed in the soils. Figure 3.1.9 shows soil aggregates coated by schoepite (uranium oxide) from remediation of an area source. The remediation process for area sources was similar to the general procedures described above for point sources. The area sources were scanned with a $\mathrm{NaI}$ detector to pinpoint their locations. If the soil readings exceeded 1.3 times the site-specific background radiation level, it was considered radioactive waste. The NaI detector was used to initially guide the depth and lateral extent of soil removal, and the GM pancake probe was then used to guide the final cleanup. The entire area was scanned to detect any area exceeding the cleanup criterion (1.3 times the site- specific background radiation level). Any soil exceeding the criterion was removed. Gamma and beta/gamma measurements were obtained, and the soil was placed in an appropriate container (30- or 55-gallon open-top steel drum). A post-cleanup soil sample was collected to provide verification that cleanup was achieved.

All work was performed by hand at the immediate location of the area source. Tools used to perform the actual removal included hand trowels, shovels, and buckets (5 gallon). If the remediation at a given area source required digging deeper than 12 to 18 inches, work was halted at that anomaly until further consultation with appropriate SNL personnel occurred (ER Project Leader, ER Task Leader, and RPO and Radiation Protection Engineering personnel, at a minimum). Once approval was granted to proceed with remediation greater than 12 to 18 inches deep, cleanup proceeded with hand tools.

Under some circumstances, it was more feasible to use large equipment (e.g., backhoe, skidster, front-end loader, forklift) for remediation greater than 12 to 18 inches in depth. Hand tools were not feasible and/or not cost effective on some large area sources due to the depth and lateral extent of contamination. The use of large equipment reduced the time and effort required to address large area sources. The large equipment and operators were provided by the SNL/NM ER Field Office (ERFO). The procedure used by ERFO for operating large equipment during the VCM is explained in greater detail in the task-specific Health and Safety Project Plan supplement (SNL/NM 1995b and 1996). Figure 3.1 .10 shows a backhoe being used to remediate an area source. 


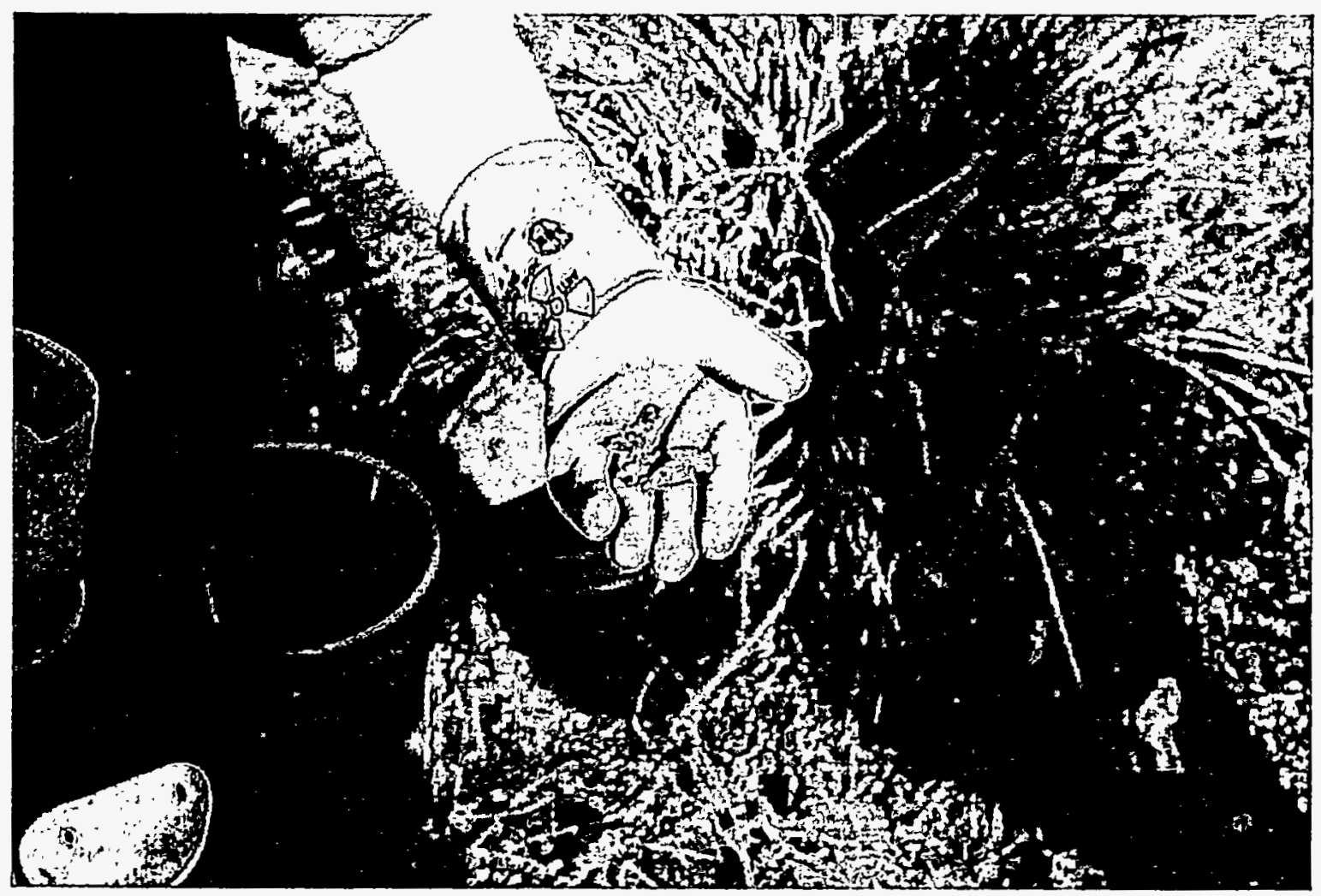

Figure 3.1.7 Metal Fragments From Remediation of a Point Source

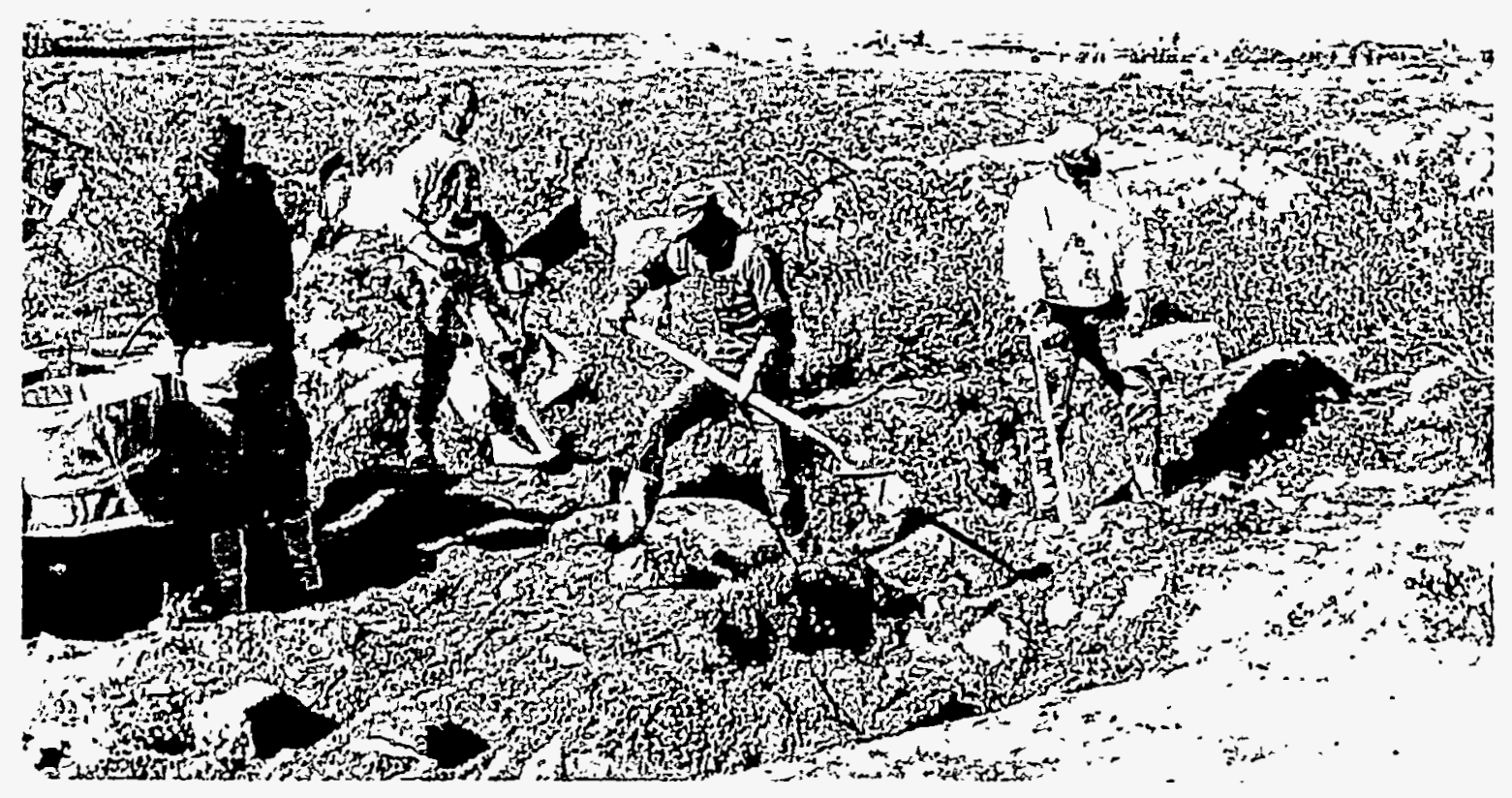

Figure 3.1.8 Area Source Rem oval and Gamma Scintillom eter (NaI Detector) Scanning 


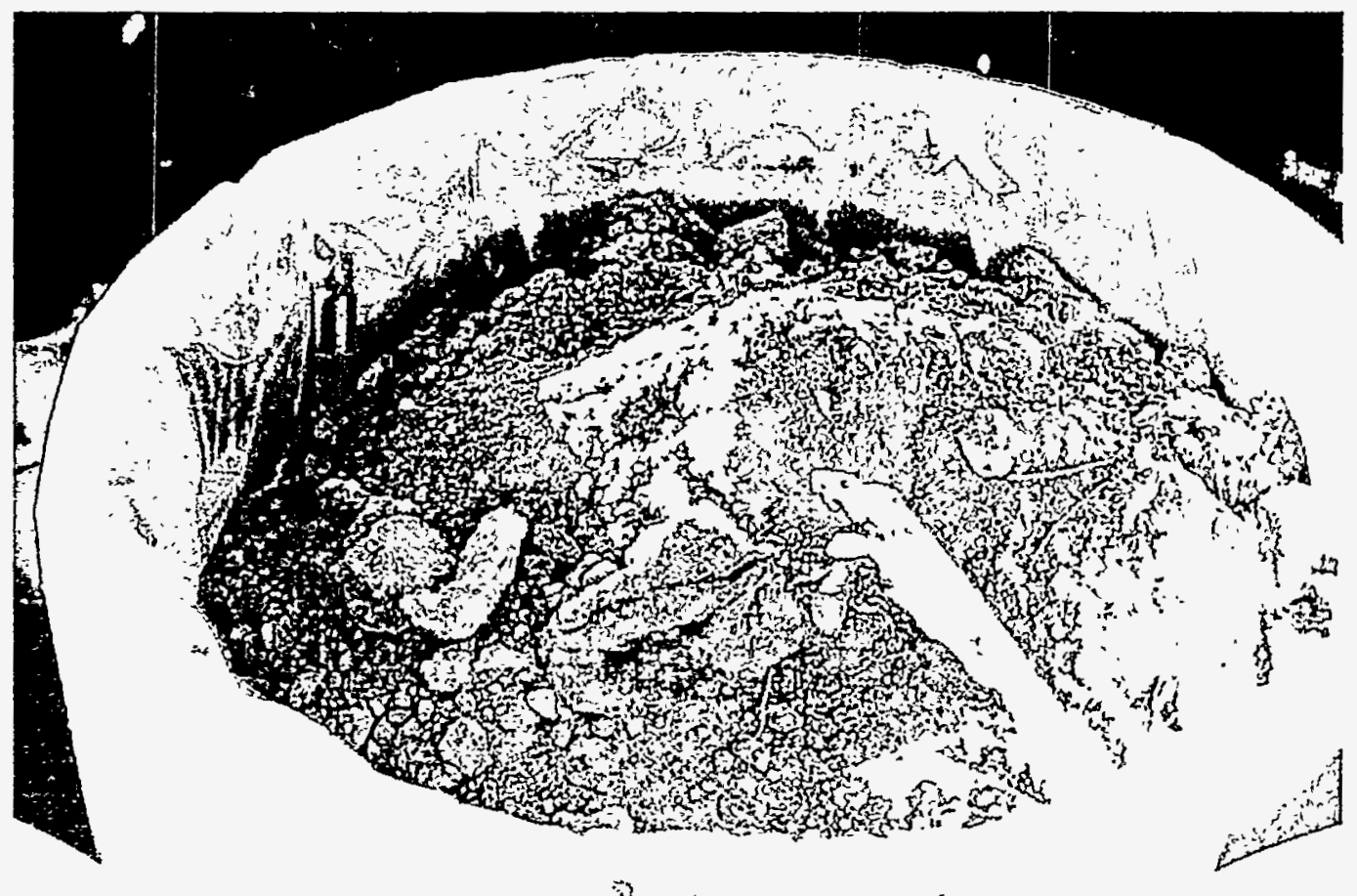

Figure 3.1.9 Soil Aggregates Coated by Schoepite (Uranium Oxide) From Rem ediation of an Area Source

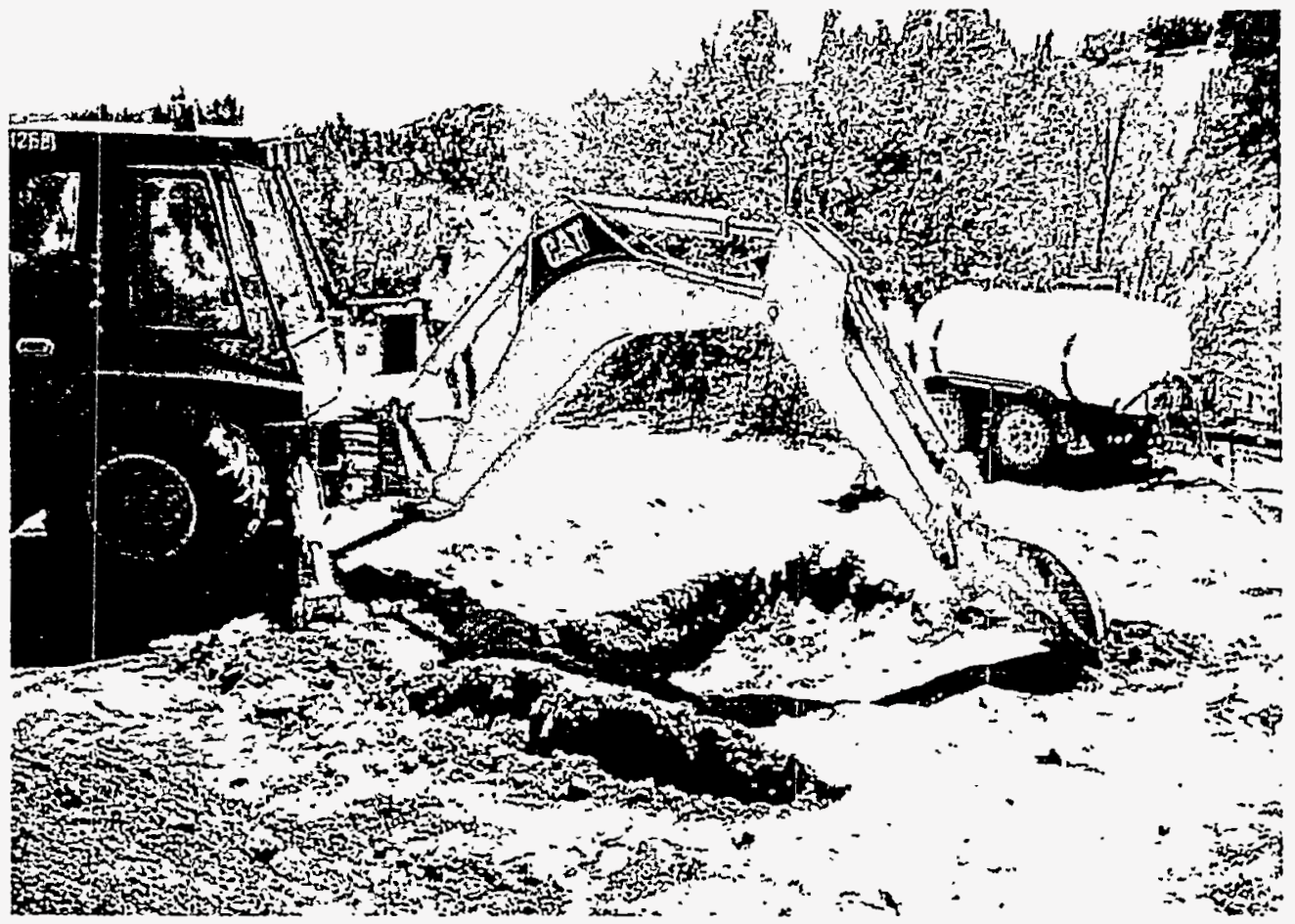

Figure 3.1.10 Backhoe Used to Remediate an Area Source 


\section{Soil-Mound Dismantling}

The remediation process for soil mounds that contained DU-contaminated soils was similar to the general procedures described above for area sources except that large equipment was used to "dismantle" the mounds. Prior to conducting any remediation on soil mounds, background information was reviewed to assess chemical and explosive/ordinance hazards of the mounds. Appropriate PPE requirements and engineering controls were established based on the review.

Soil mounds were scanned with a $\mathrm{NaI}$ detector to characterize DU-contaminated soils near the surface of the mounds and were trenched to facilitate scanning of the interior of the mounds. A backhoe was used to trench through the soil mound down to the estimated original ground surface. The trench faces and the spoils were scanned with the NaI detector and GM pancake probe, and were visually inspected to detect the possible presence of DU. If the soil readings exceeded 1.3 times the site-specific background radiation level, the soil was considered radioactive waste. Figure 3.1.11 shows the scanning of a trench in a soil mound.

Any soil on the surface exceeding the cleanup criterion was removed using shovels and placed in an appropriate container (30- or 55-gallon open-top steel drum). Soil mounds with disseminated DU fragments required dismantling for remediation. A flat area ("lay down" pad) adjacent to the soil mound was used to spread out a layer of soil from the mound. The soil layer was about 2 to 4 inches thick and was spread by a front-end loader. The soil was scanned with both instruments, and contaminated soil and fragments were scooped up with shovels and/or the backhoe bucket and placed in an appropriate container (30- or 55-gallon open-top steel drum). Gamma and beta/gamma measurements were obtained on the soil. Figure 3.1.12 shows the dismantling of a soil mound, and Figure 3.1.13 shows scanning of soil on the "lay down" pad using the $\mathrm{NaI}$ detector and GM pancake probe.

After the completion of the scanning and contamination removal, the scanned-clean soil was scooped up with the front-end loader and placed into clean spoils piles. This process was repeated until the soil mound was down to the original ground level, or no additional contamination was found. Once remediation was complete, a post-cleanup soil sample was collected from the soil mound "footprint" to provide verification that cleanup was achieved.

\subsubsection{Soil Sampling Procedures}

The methods used for soil sample collection were consistent with NRC and DOE guidelines. Soil samples were collected by Geotech per the following SNL/NM ER procedures:

- FOP 94-25: Documentation of Field Activities

- FOP 94-26: General Equipment Decontamination

- FOP 94-34: Field Sample Management and Custody

- FOP 94-39: Excavating Methods 


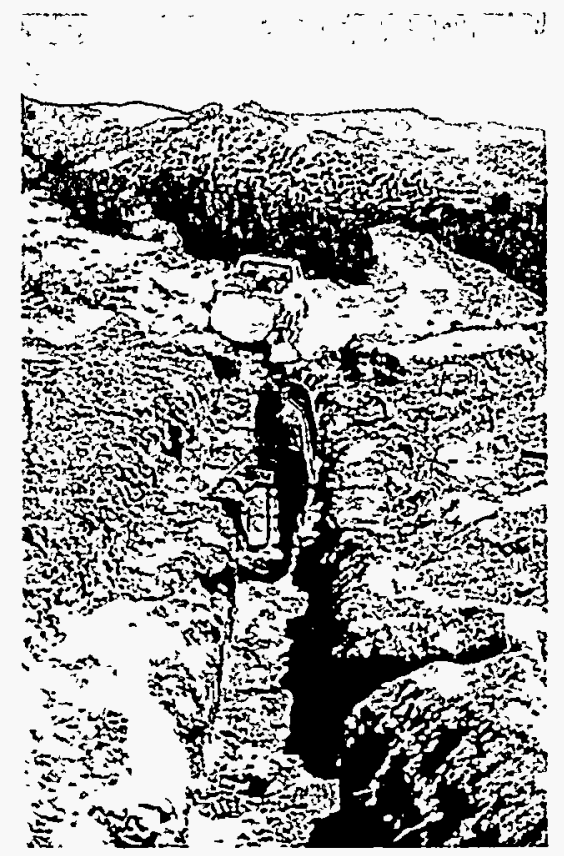

Figure 3.1.11 Scanning of Trench in a Soil Mound

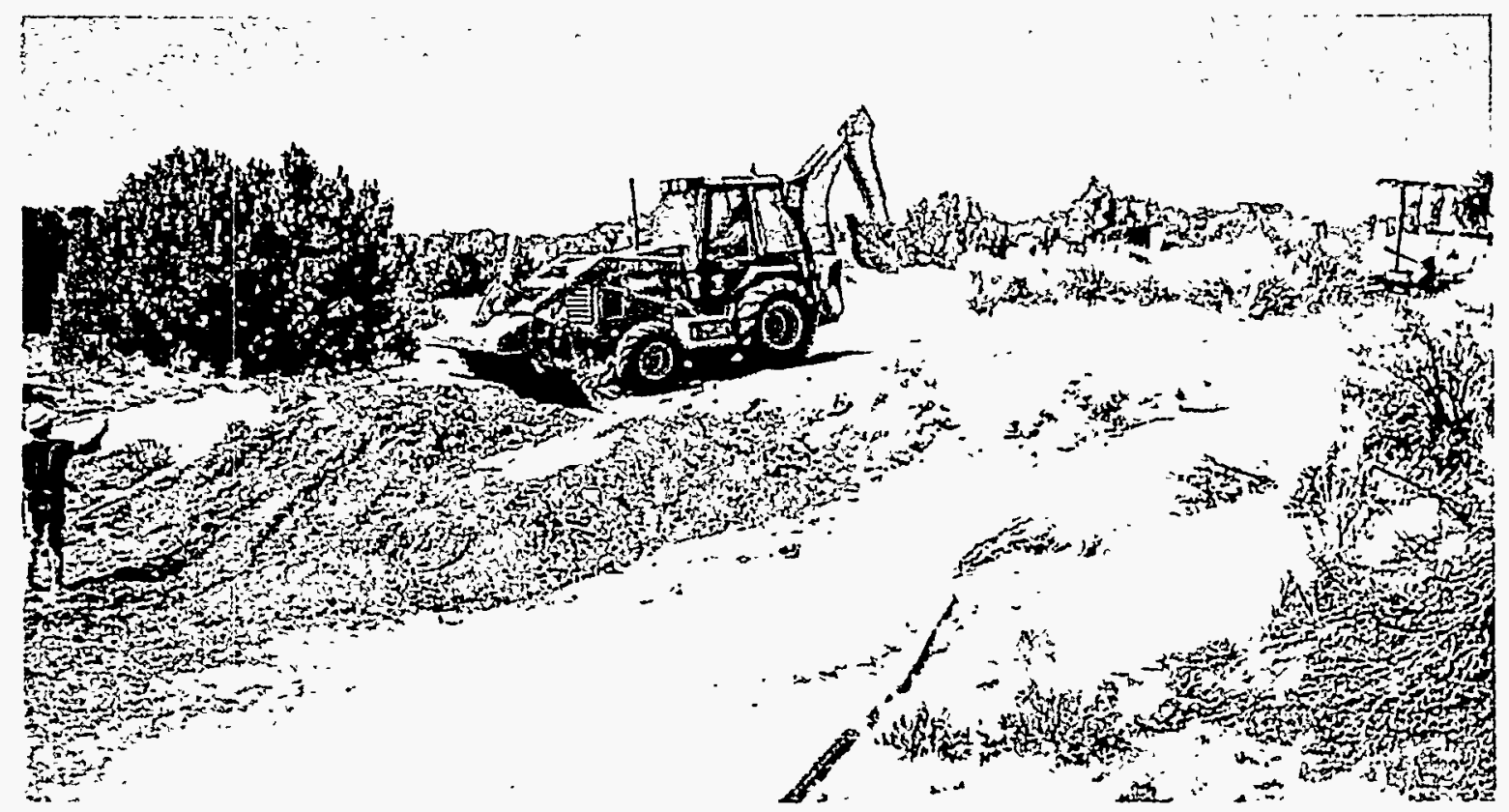

Figure 3.1.12 Soil Mound Dismantling Using A Backhoe 


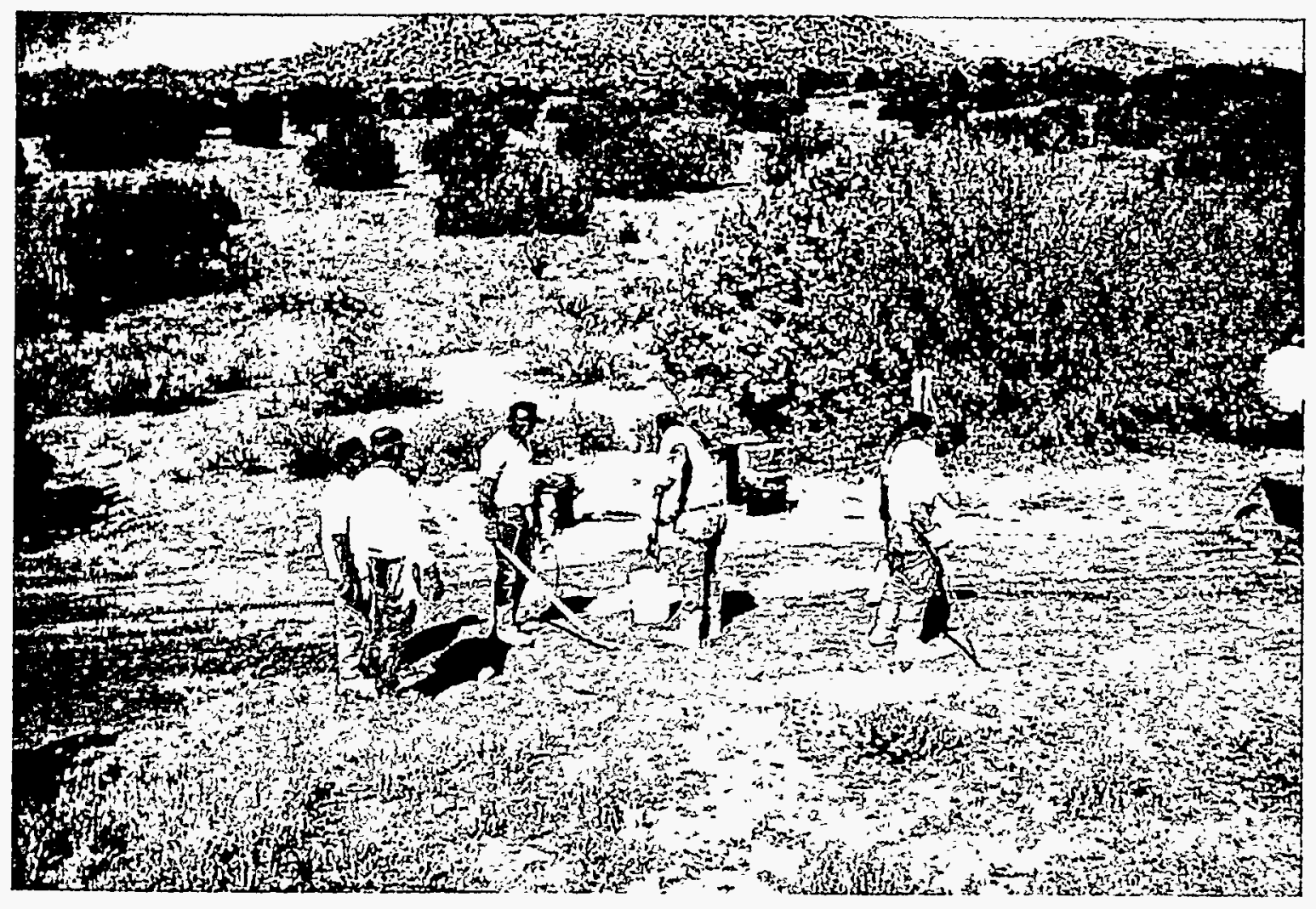

Figure 3.1.13 Scanning Soil on the "Lay Down" Pad Using NaI Detector and GM Pancake Probe 
- FOP 94-52: Spade and Scoop Method for Collection of Soil Samples

- FOP 94-54: Surface Sediment/Soil Sampling

- FOP 94-78: Environmental Restoration Project Waste Management and Characterization

- AOP 94-22: Sandia National Laboratories Environmental Operations Center Sample Management Office User's Guide

- AOP 95-16: Administrative Operating Procedure for Sample Management and Custody

In some cases, pre-cleanup soil samples were collected at area sources to assess the need for remediation. After remediation, post-cleanup (verification) soil samples were collected at point and area sources to verify the final cleanup concentration (or activity) of DU. Soil samples were submitted to the SNL/NM on-site Radiation Sample Laboratory (Department 7715) for gamma spectroscopy analysis to identify the gamma-emitting radionuclides present.

At point sources (fragments), a soil sample was collected at a minimum of 10 percent of the fragment locations remediated. A duplicate soil sample was collected for 10 percent of the soil samples collected. At area sources, a representative number of soil samples were collected to assess the need for remediation (pre-cleanup) and to show the average concentration in the soil after remediation (post-cleanup). The number of soil samples was dependent on the area source size. Typically the number of soil samples collected varied from one to six samples and was determined by the SNL/NM Task Leader or Assistant Task Leader. The locations of the precleanup and post-cleanup (verification) soil samples were chosen by scanning the area and finding the highest gamma measurement. A 3-inch soil sample was collected and placed in a $500 \mathrm{ml}$ plastic marinelli beaker. All soil samples were numbered and recorded on the sample label and chain-of-custody form. The samples, along with the chain-of-custody form, were delivered to the laboratory by RPO personnel. Sample custody was maintained at all times, and sample transfer was recorded on the chain-of-custody form. Figure 3.1.14 shows post-cleanup soil samples collected during the VCM.

\section{Analytical Data Review and Management}

Data packages for pre-cleanup and post-cleanup soil samples were reviewed for completeness as they were received from the Radiation Sample Laboratory (Department 7715). The analytical results were evaluated to determine remediation requirements or to verify final cleanup concentrations. Figure 3.1.15 presents the decision process for evaluating gamma spectroscopy results. 


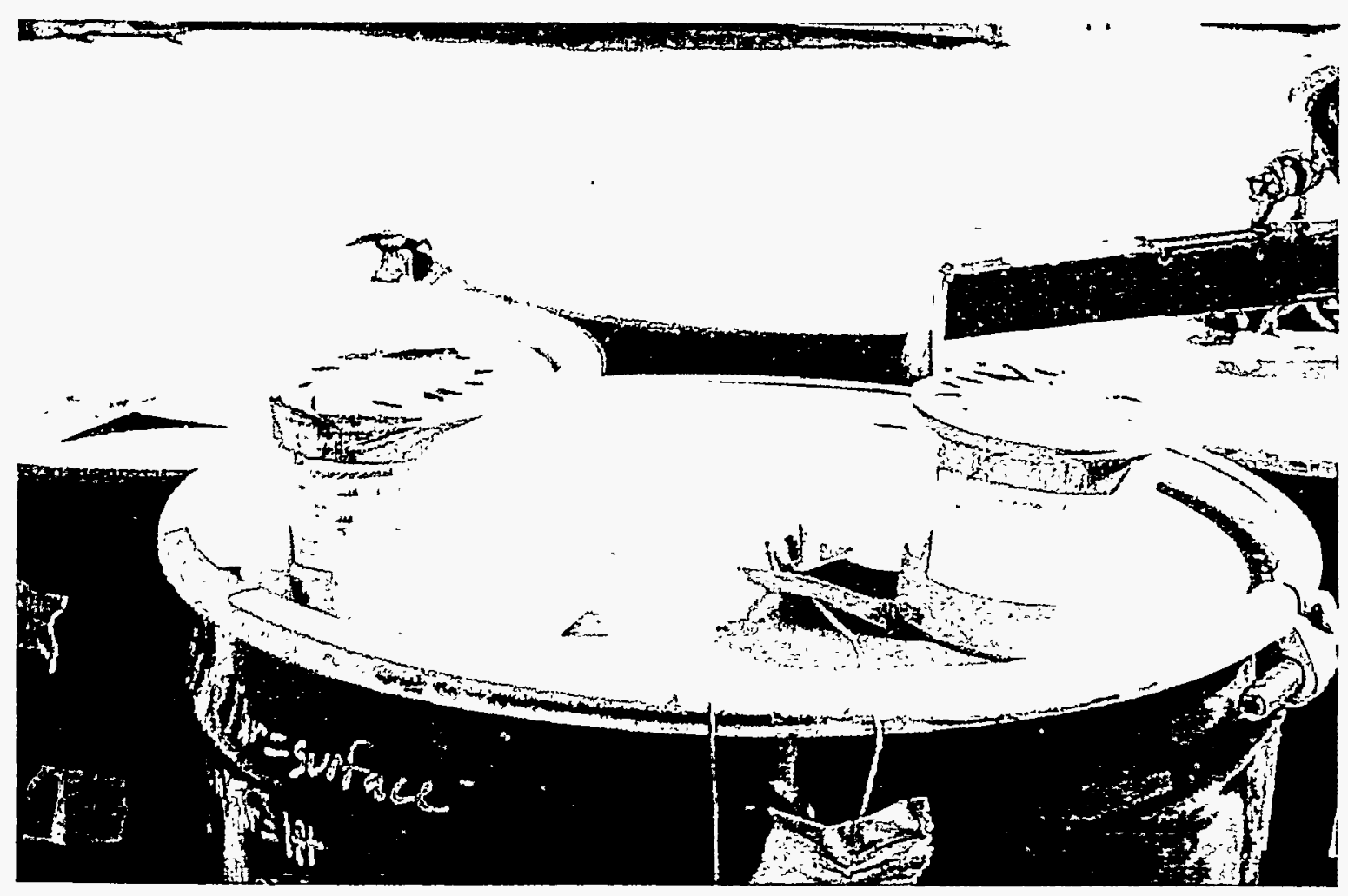

Figure 3.1.14 Post-Cleanup Soil Samples Collected During the VCMI 


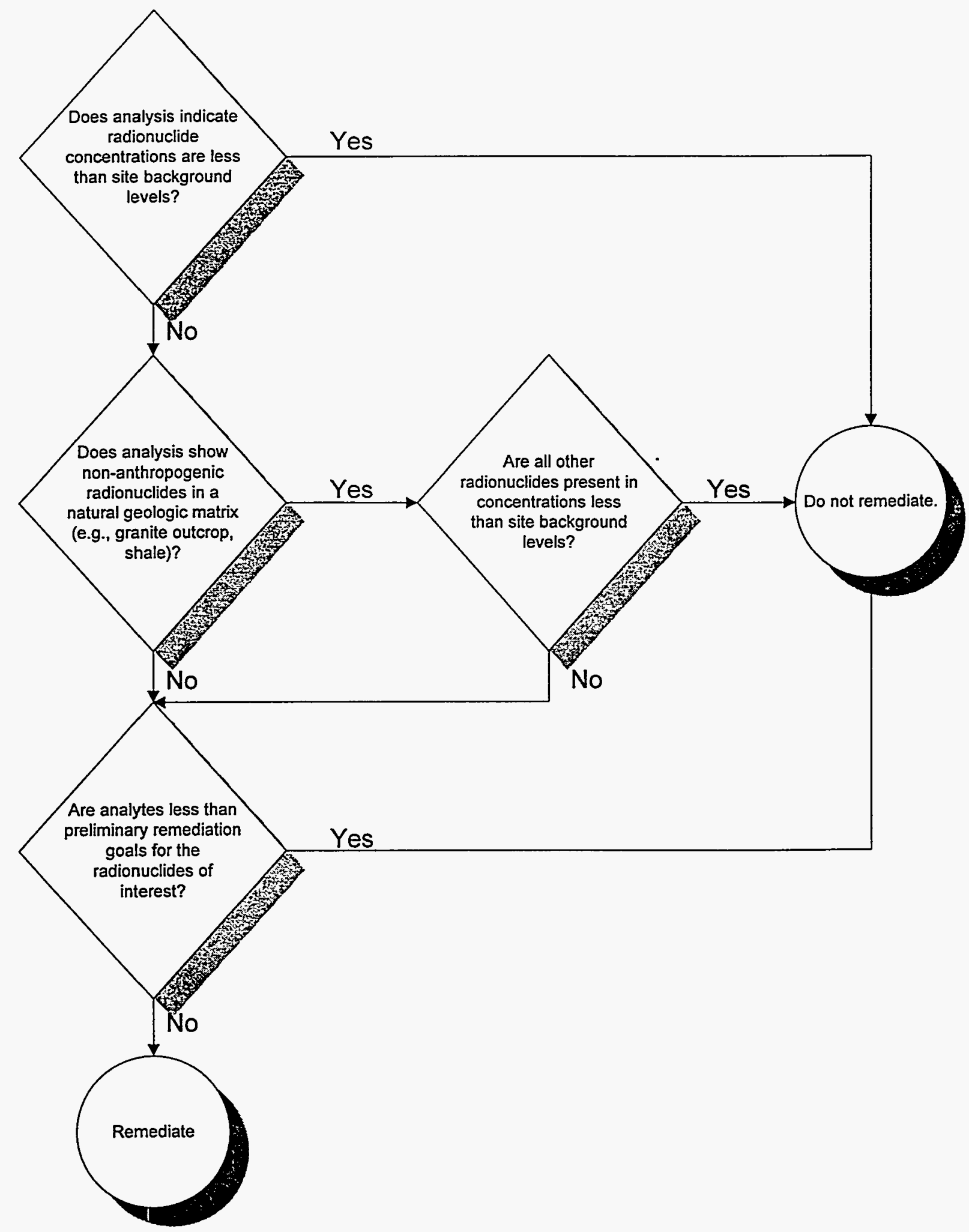

Figure 3.1.15 Decision Process for Evaluating Gamma Spectroscopy Results : 
The data packages were copied and submitted to the SNL/NM ER data management group. The data management group requested the electronic data deliverable (EDD) from Department 7715 for input into the ER Data Management System (ERDMS). A periodic review of the ERDMS was performed by project staff to verify that all data were in the database.

\subsubsection{Waste Management}

Techniques and procedures used for waste management during the VCM were developed with guidance from SNL/NM Pollution Prevention and Hazardous Waste Management Department (Department 7572) and were consistent with the ER procedures for waste management and characterization (FOP 94-78). Department 7572 required that waste be managed as follows:

- Wastes shall be stored in appropriate containers in good condition

- Containers shall be compatible with wastes

- Containers shall remain closed except when adding or removing wastes

- Containers shall be managed to prevent ruptures, leaks, etc.

- Containers shall be marked with "Caution Radioactive Waste" and "Radioactive" labels.

Methodologies for waste documentation, waste handling and containerization, waste sampling and characterization, waste storage and disposal, and waste minimization were established during the TRA conducted at ER Sites 18, 83, 240, and 87 by Geotech in August 1994. Waste management procedures are explained in greater detail in the TRA Waste Management Plan (SNL/NM 1994b) and the VCM Waste Management Plan (SNL/NM 1994d). The process proceeded according to the following steps:

1. Located previously identified areas of elevated (relative to background) surface gamma radiation.

2. Removed and separately containerized radioactive fragments and soil (if radioactively contaminated soil was present).

3. After work was completed at a given site, collected appropriate radioactive fragment and soil samples. For radioactive fragments, the number of representative samples was determined based on the quantity available and physical diversity of fragment types (e.g., if they all looked the same, very few were analyzed). For radioactive soil, a representative composite soil sample was taken for every 50 drums of soil waste. This was based on the TCLP soil samples from the TRA and sample size calculations by Department 7572 personnel. 
4. After sampling, waste drums were moved to an interim storage area in Technical Area III.

5. After analytical results were obtained, a Disposal Requisition (DR) was submitted to Radioactive and Mixed Waste Management Department (Department 7577).

6. Department 7577 was responsible for inspection, packaging, and shipment preparation of waste.

\section{Field Documentation}

Field work was performed on 10-day rotations with 4 days off. Prior to the start of a field rotation, the Geotech field crew was provided with waste generation logs, addition logs, sample labels, and various other field supplies. During remediation at each of the ER sites, Geotech recorded all soil and metal fragment wastes generated on a waste generation log. The log was used to maintain accountability of the waste generated and to track waste from generation to disposal. Information recorded on the log included ER Site number, container type and size, container(s) identification number, waste type and volume, and waste characterization sampling, chain-of custody number, and descriptive information as warranted. In addition, the Geotech field crew maintained a Field Log Book to document any site-specific changes and/or variations in the waste management procedures. Figure 3.1.16 shows a waste generation log.

Project staff periodically visited the sites during field work to take photos and ensure that the field crew had plenty of supplies needed to track and properly document the generated waste. When a field rotation was completed, waste generation logs were returned to project staff, who verified that all information was accurate and in conformance with the Waste Management Plan (SNL/NM 1994d). This review included checking the assignment of sample and chain-ofcustody numbers based on the 1 -in-50 drum sampling strategy.

All original waste generation logs were maintained in a three-ring binder. Copies of waste generation logs were made for the project file and for ER Department 6682, and the logs were returned to the field crew at the beginning of the next field rotation. The waste generation logs were used by project staff to maintain a drum inventory for tracking the number of waste drums, by waste stream generated, for each site. Department 6682 used the waste generation logs to input information into the ER Container Tracking System (ERCTS) and to develop DRs for Department 7577.

\section{Waste Handling and Containerization}

All soil and fragment wastes that screened positive for elevated radioactivity were removed from the surface or near surface of the sites. Soil and metal fragments were not removed from any areas of known organic contamination (spills or other potential areas where organic contaminants may have been released). Wastes were containerized in separate lined 30- and/or 55-gallon steel open-top drums by placement into the drums using shovels and/or a 12-inch backhoe bucket. Waste drums were filled below their maximum capacity to avoid exceeding weight limit 
Waste Generation Log

Complete to Gray Line \& Return to Ernest

Vinsant M/S 1147

Task Leader: Waste Owner:Ernest Vinsant Accum.

Area

Person filling out this form

Phone:

ADS\#:

\begin{tabular}{|c|c|c|c|}
\hline $\begin{array}{l}\text { Container I.D. \# } \\
\text { (a) }\end{array}$ & & & \\
\hline \multicolumn{4}{|l|}{ Project Name } \\
\hline \multicolumn{4}{|l|}{ Site Number } \\
\hline \multicolumn{4}{|l|}{ Initial Label Type(b) } \\
\hline Accumulation Date(c) & $\begin{array}{l}\text { Start } \\
\text { Full }\end{array}$ & $\begin{array}{l}\text { Start } \\
\text { Full }\end{array}$ & $\begin{array}{l}\text { Start } \\
\text { Full }\end{array}$ \\
\hline \multicolumn{4}{|l|}{ Waste Matrix (d) } \\
\hline \multicolumn{4}{|l|}{$\begin{array}{l}\text { Depth intervals if } \\
\text { Applic. }\end{array}$} \\
\hline \multicolumn{4}{|l|}{$\begin{array}{l}\text { Container Type / } \\
\text { Vol (e) }\end{array}$} \\
\hline \multicolumn{4}{|l|}{ Volume of Waste $(f)$} \\
\hline \multicolumn{4}{|l|}{ Total Drum Weight } \\
\hline $\begin{array}{l}\text { SMO COC \#'s } \\
\text { SMO Sample \# }\end{array}$ & $\begin{array}{l}\text { Rad [] } \\
\text { HAZ [] }\end{array}$ & \begin{tabular}{|l} 
Rad [] \\
HAZ []
\end{tabular} & \begin{tabular}{|l|} 
Rad [] \\
HAZ [] \\
\end{tabular} \\
\hline $\begin{array}{l}\text { ER Chem Lab COC } \\
\text { "'s } \\
\text { ER Chem Lab Sample } \\
\text { \# }\end{array}$ & $\begin{array}{l}\operatorname{Rad}[] \\
\operatorname{HAZ}[]\end{array}$ & $\begin{array}{l}\text { Rad [] } \\
\operatorname{HAZ}[]\end{array}$ & $\begin{array}{l}\text { Rad [] } \\
\mathrm{HAZ} \text { [] }\end{array}$ \\
\hline $\begin{array}{l}7713 \text { Rad Lab COC } \\
\text { \#'s } \\
7713 \text { Rad Lab Sample } \\
\#\end{array}$ & $\begin{array}{l}\text { Rad [] } \\
\text { HAZ [] }\end{array}$ & $\begin{array}{l}\text { Rad [] } \\
\text { HAZ [] }\end{array}$ & $\begin{array}{l}\text { Rad [] } \\
\operatorname{HAZ}[]\end{array}$ \\
\hline \multicolumn{4}{|l|}{ Date 2 Accum. Area } \\
\hline 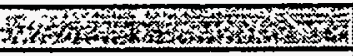 & 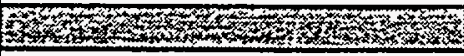 & K & 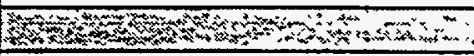 \\
\hline \multicolumn{4}{|l|}{ ERwm Memo \# } \\
\hline \multicolumn{4}{|l|}{ Date RCRA Revicw } \\
\hline \multicolumn{4}{|l|}{ Date Rad Review } \\
\hline \multicolumn{4}{|l|}{ Final Classification } \\
\hline \multicolumn{4}{|l|}{ ERFO WR" } \\
\hline \multicolumn{4}{|l|}{ CWDR or DR \# } \\
\hline \multicolumn{4}{|l|}{$\begin{array}{l}\text { Water Permit (Type } \\
\left({ }^{\prime \prime}\right)\end{array}$} \\
\hline $\begin{array}{l}\text { Date Data Base } \\
\text { Complete }\end{array}$ & & & \\
\hline
\end{tabular}

Generator: You own this waste Legally, Morally, and Financially until Erne accepts a completed Generation

$\log \&$ Coples of the COCs.

Figure 3.1.16 Waste Generation Log 
specifications of the drums. Figure 3.1.17 shows lined 30- and 55-gallon steel open-top drums used for waste containerization.

Waste drums were tagged with a Radioactive Waste Label, and a contamination survey and a dose rate measurement were performed on the outside of each drum by an SNL/NM RPO Technician (Department 7714). The waste label contained pertinent information to assist in waste container tracking. Proper labeling of the drums was performed under the guidance of the ER Department 6682. Figure 3.1.18 shows a waste drum with a Radioactive Waste Label.

\section{Waste Sampling}

Waste characterization sampling was conducted to determine if a hazardous component existed in the waste, making it mixed waste subject to RCRA time clocks and storage requirements. The waste sampling was performed on a site-specific basis and included both soil and metal fragments for TCLP analysis. The sampling procedures were designed to produce a representative sample of the waste streams. At each site, the radioactive soil was considered a homogeneous waste stream; however, the radioactive metal fragments were not assumed to be homogeneous.

The number of composite soil samples collected for TCLP analysis was originally determined based on the "one-in-five strategy" for each site. This "one-in-five strategy" was based on EPA waste sampling guidance (EPA 1980). In August 1995, the sampling strategy was modified to "one-in-fifty" based on sample size calculations (EPA 1986) performed by Department 7572 personnel. The sample size calculations showed that the waste characterization samples collected by site to this point were more than adequate to characterize the waste stream. Therefore, the sampling strategy was changed to one composite soil sample for every 50 drums by site.

Fragments were sampled based on quantity available and size of the fragments. If the fragments could fit into a $500 \mathrm{ml}$ marinelli jar, a sample was collected. Thirteen fragment samples were collected from 12 sites and analyzed using TCLP analytical methods.

An RCT was on site to monitor radiation levels during sampling activities. The technician also surveyed and swiped the sample containers ( $500 \mathrm{ml}$ marinelli jars) before the samples were taken to the SNL/NM Sample Management Office (SMO). Each waste characterization sample was analyzed for radionuclides by gamma spectroscopy at the SNL/NM Radiation Sample Laboratory (Department 7715) prior to being shipped to the Geotech Laboratory by the SMO.

Sampling procedures for both soil and metal fragment waste are detailed below.

1. The drums were opened along with the double plastic bags to allow access to the waste.

2. A sampling trowel or scoop was used to gently mix and remove the waste from the waste drum. Waste was removed from the surface to approximately 6 inches below the surface 


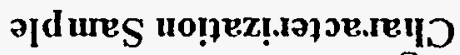

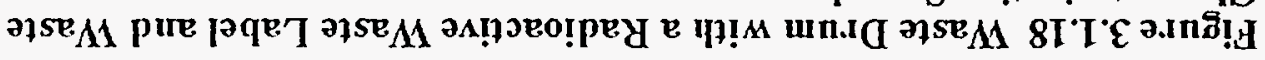

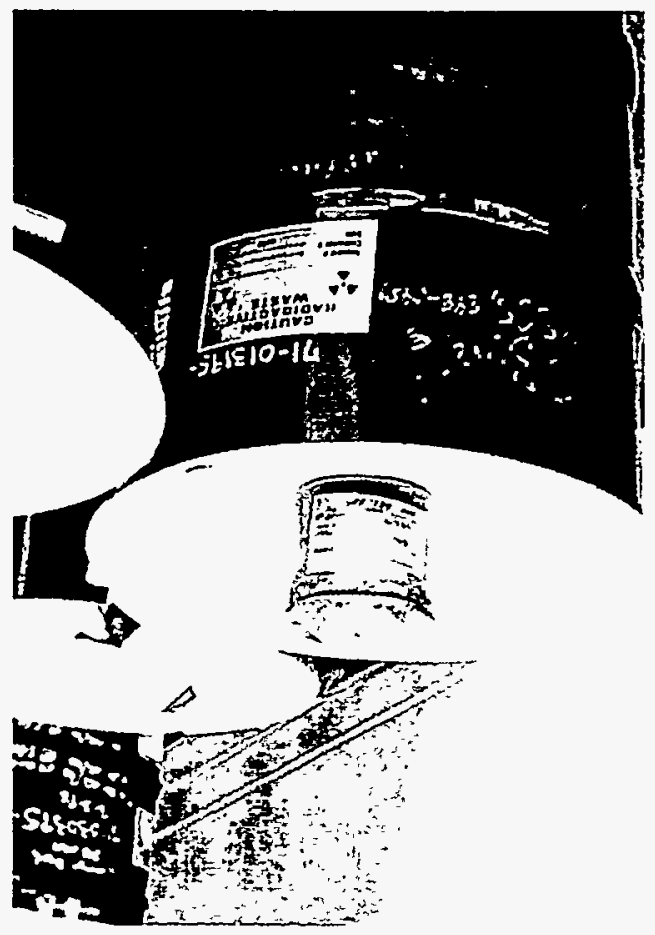

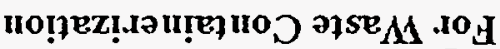

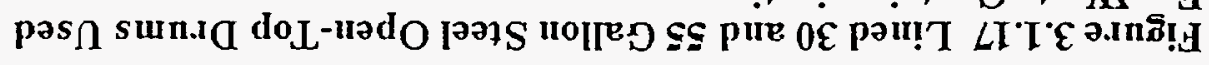

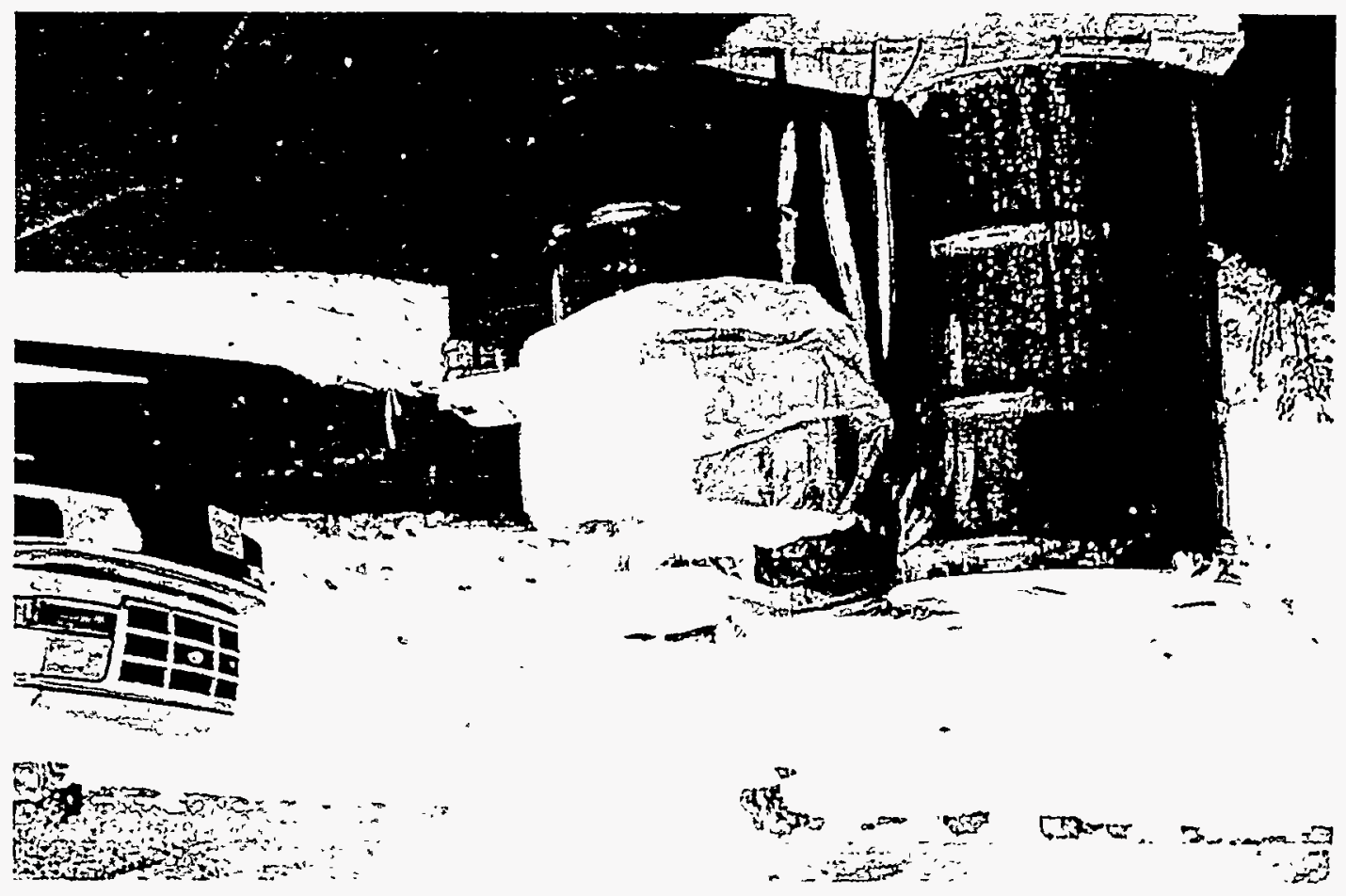


and placed directly into the sample containers. Care was taken to ensure no airborne particulates were generated outside the drum interior. Dedicated tools were used, and all decontamination was performed dry, with wipes or rags.

3. Plastic marinelli jars $(500 \mathrm{ml})$ were filled and sealed. The jars were sealed with electrical tape, then duct tape, then custody tape (see Figure 3.1.18). Each marinelli jar was used for both the gamma spectroscopy screen at the Department 7715 Radiation Sample Laboratory and the TCLP analysis at the Geotech Laboratory in Grand Junction, Colorado.

4. The marinelli jars were labeled with ER sample labels; the sample date, sample collector, sample ID number, sample type, analytical method, ER site number, and SMO number were recorded on each label.

5. Once the marinelli jars were labeled and sealed, an RCT surveyed and swiped the jars. The jars, chain-of-custody records, and radiological survey results were then delivered to the SMO shipping area.

\section{Waste Characterization}

All waste characterization samples were submitted to Geotech Laboratory for analysis of TCLP metals. The samples were analyzed for RCRA metals listed in the TCLP procedure. Based on review of site histories by the Task Leaders or Assistant Task Leaders, mercury (separate analysis) was excluded when it was not identified as a contaminant of concern. Sample preparation and analysis were performed in accordance with the following Geotech Laboratory procedures:

- SOP L-20: Toxicity Characteristics Leaching Procedure

- SOP AS-5: Inductively Coupled Plasma Atomic Emission Spectroscopy

Also, waste characterization samples were analyzed by gamma spectroscopy by the Radiation Sample Laboratory (Department 7715) in accordance with the laboratory and quality assurance procedures presented in Section 3.2.

All laboratory quality control requirements were met during the course of these analyses. Analytical laboratory procedures are presented in Appendix D.

\section{Waste Storage and Disposition}

Waste drums were stored at an interim storage area in Technical Area III by Department 6682 . The interim storage area was the concrete pad at the south end of the Shot Sled Track within ER Site 18. The waste drums were moved to the storage area by ERFO personnel. ERFO weighed each waste drum prior to it being moved to the storage area. The drum weight, site number, drum number, and date moved to the storage area were documented by ERFO and provided to project staff. The information was added to the waste generation logs, copied for the 
project files, and distributed to Department 6682 personnel to update ERCTS. Figure 3.1.19 shows the waste accumulation area at ER Site 18.

The wastes were stored at the storage area until waste characterization data were received and reviewed by Department 6682 . Department 6682 prepared DRs using the waste characterization data and submitted the DRs to Department 7577 . Department 7577 was responsible for inspection, packaging, and shipment preparation of waste upon receipt of the DRs.

\section{Waste Minimization}

Waste minimization was incorporated into the anomaly screening and removal procedure. If a piece of metal fragment was removed from an anomaly and the remaining soil had no residual radioactivity exceeding 1.3 times background, no soil removal was performed. Field screening of metal fragment and soils for radioactivity was performed at all anomalies, and nonradioactive materials/soil was carefully segregated to minimize the volume of radioactive waste generated (only the contaminated portion was removed and containerized). In addition, waste drums were consolidated to minimize the number of drums produced for each waste stream (metal, soil, and PPE). Appendix $\mathrm{J}$ summarizes the waste minimization/consolidation effort.

\section{Analytical Data Review and Management}

Analytical data packages were reviewed for completeness as they were received from the Geotech Laboratory and Radiation Sample Laboratory (Department 7715). The analytical results were evaluated to determine if a hazardous component existed in the waste, thereby making it mixed waste and subjecting it to RCRA requirements. Site-specific results are presented in Section 5.

All TCLP analytical data packages and the EDD were given to the ER database management group for input into the ERDMS. TCLP results were distributed to the ER waste management staff (Department 6682) to characterize the waste. Gamma spectroscopy analytical data packages were copied and submitted to the data management group. The data management group requested the EDD from Radiation Sample Laboratory (Department 7715) for input into the ERDMS. A periodic review of the ERDMS was performed by project staff to verify that all data was in the database.

All original analytical data packages were filed with the ER Records Center, and a copy was maintained in the project files. Project staff maintained a summary of the waste characterization gamma spectroscopy data. The summary contained the radionuclide activity $(\mathrm{pCi} / \mathrm{g})$, average and weight average by site for U-238, U-234, radium (Ra)-226, U-235, thorium (Th)-232, Th-228, cobalt (Co)-60, and cesium (Cs)-137. 


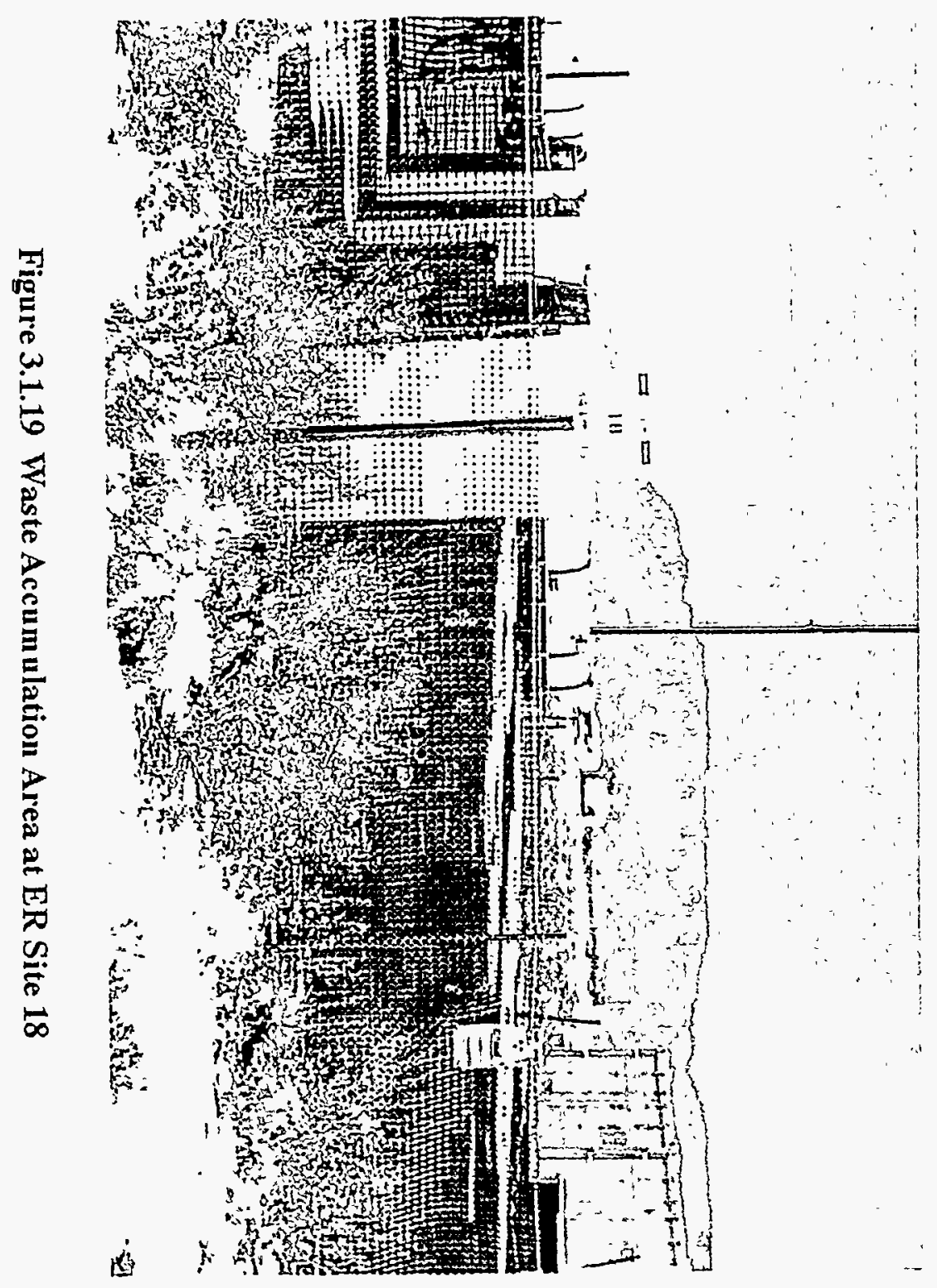




\subsubsection{Health and Safety}

The HASP (Geotech 1994a) for the VCM was developed by Geotech and covers ( ieotech personnel who conducted the VCM field work.

\section{Support and Field Personnel}

Support personnel located at GJPO were utilized on an as-needed basis to suppor the SNL/NM field operations. The Geotech Occupational Health and Safety (OH\&S) Supervi. or was directly responsible for the OH\&S personnel assigned to the field operations. The Geote $h$ Field Services Manager was directly responsible for the field services personnel assigı $2 d$ to the field operations.

Field personnel consisted of at a minimum a Site Supervisor, OH\&S Techniciar, and field technicians. The Site Supervisor was responsible for directing the field technic. ans in performing the tasks identified by SNL/NM. The OH\&S Technician was respo ssible for oversight of health and safety requirements and maintaining an employee recors s files at the SNL/NM ER sites.

\section{SNL/NM Health and Safety Program Support}

SNL/NM Health and Safety and Geotech Health and Safety combined forces $t$. ensure that the most efficient methods for providing a safe and healthy workplace were used. Program support from SNL/NM Health and Safety was provided for specific aspects of the Ger ech Health Safety Program. The SNL/NM support and/or shared responsibilities with Geotech : ıcluded:

Internal and External Dosimetry-SNL Radiation Protection Measurements RPM) Department (Department 7715) administered the external dosimetry thermoluminescent $d$ ssimeter (TLD) program for Geotech personnel and gathered urinalysis bioassays. Geotech $\mathrm{p}$;rsonnel requested a prior exposure record history from EG\&G Idaho and provided it to SNL/NM.

Radioanalytical Support-RPM provided all radioanalytical support to Geot: ch for samples obtained from personnel monitoring and surveillance programs. Geotech obt ained airborne radioparticulate samples, which were analyzed for gross alpha/beta activity $b$, SNL/NM RPO Department (Department 7714).

Radiological Release of Materials—Department 7714 provided RCT coverá se, supervisory oversight, and all radiological support services to demonstrate compliance w th the SNL/NM Radiation Protection Program. All radiological activities were conducted ur der the direction and with consent of SNL/NM RPO personnel. RPO support services included the following: 
- Emergency planning and response

- Occurrence reporting

- Analytical services

- Radiological release surveys.

A Geotech OH\&S Technician trained as an RCT was provided to support the VCM characterization and remediation work. Geotech provided field portable calibrated instruments for use in performing personnel contamination surveys. Radiological surveys were performed as directed by RPO personnel.

Training-Pers onnel were trained to the DOE Standardized Radiological Worker II Core Training Standard. SNL/NM provided "site-specific" Radiological Worker II Training. SNL/NM and KAFB EOD provided ordnance-familiarization training. Geotech performed and documented the daily "tailgate" training sessions. Other training requirements are outlined below in the Trauning Section.

\section{Hazard Analysis}

Geotech performed a hazard analysis in conformance with the Geotech Health and Safety Manual Volume i, Procedure 5.2, "Health and Safety Hazard Analysis." A hazard analysis was used as a preliminary evaluation, to identify hazards, to gather prerequisite information, to identify risks, and to communicate findings to the field workers. This analysis also identified tasks that were expected to be performed and the anticipated exposure. The following activities were usually performed in total or in part, at each of the ER sites.

Boundaries and Stte Access Control Station-Establishing boundaries of the site and the site access control station was the initial step prior to entering the ER site. The boundaries of the ER site were estab:ished by the SNL/NM Task Leader. Physical features were used to inform workers where the established boundaries were. The entrance to the site had the site access control station with. the personnel frisker and 'sign-in logs' for entrance and exit. Figure 3.1.20 shows a site access control station.

Initial Site Access-A Pre-Activity Inspection Checklist was used to analyze possible hazards that may be encountered. This was usually performed by the OH\&S Technician during the initial visit to the ER Site.

Surface Radiation Measurements-A gamma scan survey was one of the first steps in the investigation process. These surveys used a hand-held crutch-mounted scintillometer with a 1.5 inch by 1.5 inch $\mathrm{NaI}$ detector. The detector was swung from side to side while walking across the site. Any areas that displayed gamma anomalies (30 percent or greater than sitespecific background) were painted out and flagged. 


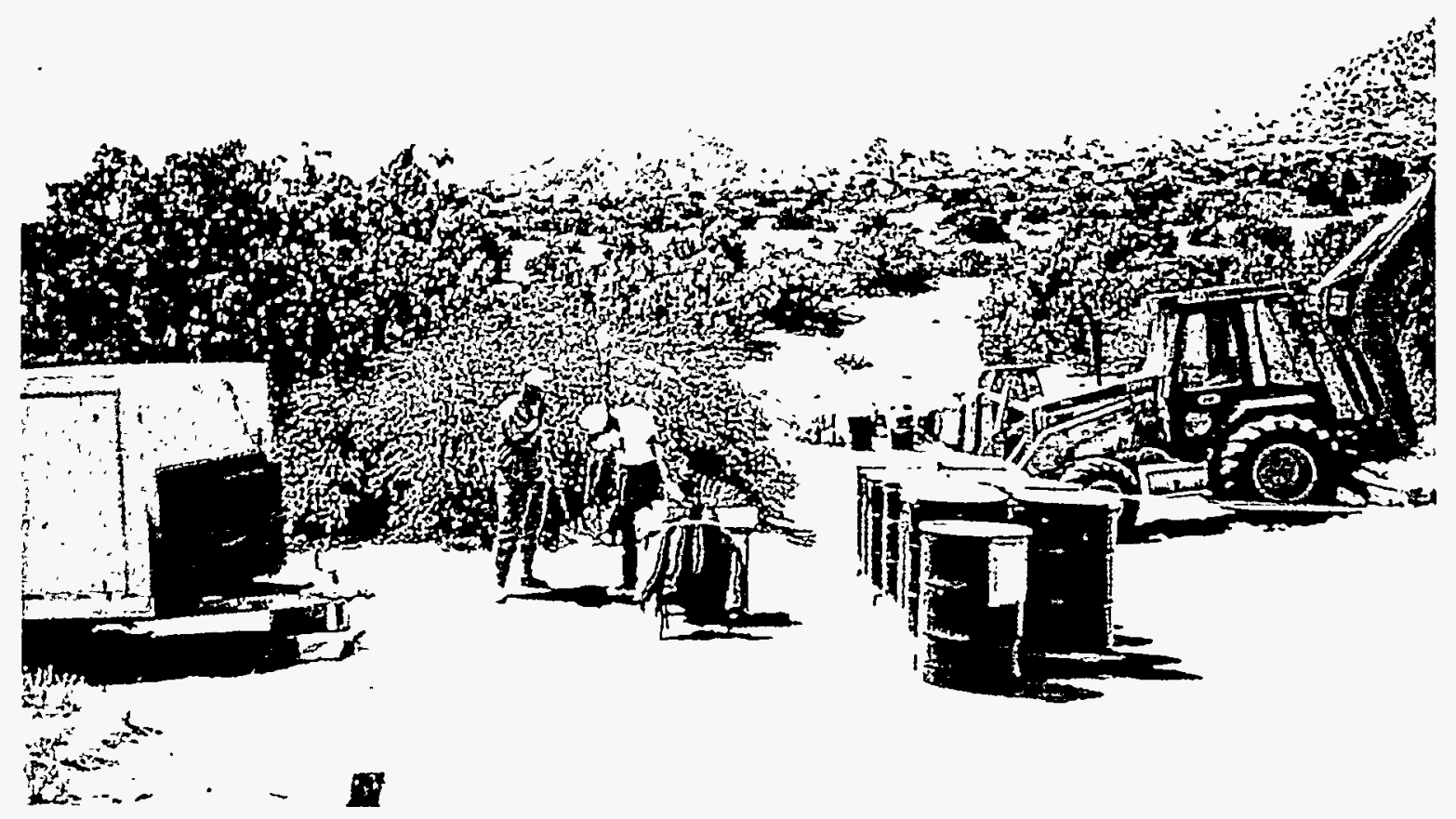

Figure 3.1.20 Site Access Control Station 
During remediation, a beta/gamma GM pancake probe was used to detect surface contamination. This instrument was used to detect the presence of DU in the surface soil, and to show that detected contamination had been removed.

Radiation Hazard Identification-Radioactive materials scattered as a result of the ordnance testing operations were potential contaminants. Surveys performed during the Phase I surveys showed no material that had radiation readings that exceeded worker exposure limits for health and safety.

Chemical Hazard Identification - The documentation provided by SNL/NM was utilized to identify sites that have possible metals contamination of the soils, volatile organic contaminants, asbestos insulation, and inorganic acids contamination. If any strange odors, discolored soil, unexplained nausea or dizziness or tastes were encountered, the work stopped, people evacuated from the area, and appropriate SNL/NM personnel would be informed to investigate the cause.

Biological Hazard Identification-Possible biological exposure that may have presented a hazard was from small desert mammals, flying insects (bees, mosquitoes, and gnats), snakes, and spiders. There was concern with the Hantavirus, which enters the body by inhalation of airborne particulates of saliva, urine, or droppings, so rodent droppings or nests were avoided during scanning or remediation.

UXO-An orientation and identification video was used to inform field workers of the potential for UXO. Each site was evaluated by EOD before the initial scan. If any additional ordnance or suspected ordnance was found during the scanning or remediation process, the area was flagged, other people in the area were informed of the ordnance presence, and SNL/NM personnel or the EOD personnel were contacted for investigation. Under no circumstances did Geotech investigate anomalies suspected of being ordnance.

\section{Personal Protective Equipment}

The basic work clothing ensemble used as the minimum level of PPE for remediation activities at any ER site was Modified Level D. This included worker-supplied sturdy work pants, sleeved shirt, safety glasses with UV protection, leather or sturdy cotton work gloves with nitrile gloves for soil handling, and sturdy sole, 8-inch high smooth-leather work-boots meeting ANSI Z41.1-75 with nonpermeable boot coverings. For skin protection, SPF 15 or greater sun screen was used on exposed skin. Additional PPE at some sites included hard hats or hearing protection.

With sites that had a potential exposure to hazardous chemicals, the PPE requirements increased to Level $\mathrm{C}$ based on the level of protection needed. This level PPE included the basic ensemble above with the addition of a full-face air-purifying respirator, nitrile gloves ( $>10 \mathrm{mil})$, and coveralls of Tyvek or similar material. 


\section{Training}

The training that all Geotech employees were required to have prior to entering an ER Site was as follows:

- Radiation Worker II Training

- Radiation Workers Refresher Training

- Hazardous Waste Site

- Hazardous Waste Site Refresher

- Pre-entry Briefing

- Ordnance Identification/Information Briefing

- Hazard Communications Training

- Portable Fire Extinguisher Training

- Respiratory Protection

- SNL Site-Specific Radiation Worker Training.

Additional training required for the OH\&S Safety Technician included radiological control training and First Aid/CPR, and the Site Supervisor was required to have Hazardous Waste Site Supervisor Training.

A daily "tailgate" safety meeting was held for field personnel to discuss schedules, health and safety concerns or considerations, and changes to the Health and Safety Manual. The meeting was conducted by the OH\&S Technician who maintained all documentation of this training.

\section{Medical Surveillance}

The medical examinations for field personnel included a medical and work history with special emphasis on symptoms related to the handling of hazardous substances and health hazards, and fitness for duty including the ability to wear any required PPE under the conditions expected at the SNL ER sites. A Worker/Supervisor Medical Checklist was completed by Geotech medical department, and a copy of this form was maintained in the records file at the project site during work activities to allow ready access of the information for the employees and any auditors. Geotech maintained the medical records for their field personnel as required by law.

\section{Exposure Monitoring}

Real-time air monitoring was conducted when necessary to identify "immediately dangerous to life or health" conditions, exposure over the permissible exposure limit or published exposure levels, cumulative exposure to radiation, or other dangerous conditions such as flammable or oxygen-deficient environments. The OH\&S Technician and Site Supervisor researched the possible hazards associated with the specific job tasks, and monitored for the exposures that were present. 
Action levels were used in conjunction with the monitoring data to ensure that the appropriate levels of worker protection were maintained. Action levels were defined in the HASP. The levels monitored involved the following:

- Radiation dose rate

- Radiological surface contamination

- Airborne radioactivity

- Metals

- Volatile organic carbon compounds

- Carbon monoxide

- Respirable silica

- Respirable dust

- Heat stress

- Noise.

Required actions for individual monitoring parameters were implemented whenever the action levels were exceeded. PPE provided a level of protection that guaranteed exposures did not exceed action limits from known or suspected site hazards until such time as monitoring indicated that a downgrade in PPE was warranted.

\section{Project Site Control}

The access point to the sites served as an information area for people accessing and exiting the site. The vehicles were usually parked in this area, and they contained the first aid box, map of the evacuation routes, fire extinguisher, and air horns and vehicle horns for emergency signals.

This area also contained the frisking station for personnel contamination frisking and a radiological survey point for the release of equipment for unrestricted use. Equipment and instruments used for intrusive remediation required a radiological survey by SNL/NM RPO.

Decontamination-Before leaving the site, all personnel frisked themselves for radioactive contamination.

Equipment Release-Initially, all equipment and instruments used on the ER sites were frisked by SNL RPO for unrestricted use. After several months of frisking determined that no equipment or instruments were radiologically contaminated, SNL RPO downgraded the requirement and required frisking only for equipment and instruments used in intrusive work. Intrusive work involved digging in soils that had a high potential for contaminating equipment.

PPE Disposal-All PPE frisked clean was disposed of in a drum kept near the access control point. If any PPE was scanned and found to have contamination, the OH\&S Technician monitored the removal of the PPE and bagged the contaminated PPE separately. The bag was labeled and placed in a drum designated to contain contaminated material. The personnel frisking was also monitored by the $O H \& S$ technician to assure no contamination was spread to personnel. 


\section{Safe Work Practices}

The work practices used by Geotech to promote a safe working environment were the following:

- The buddy system

- Training employees to recognize, avoid, and prevent unsafe conditions

- Head protection in areas of possible danger of head injury

- Eye and face protection when operations presented potential eye and face injury

- Protection against the effects of noise when $85 \mathrm{~dB}(\mathrm{~A})$ was exceeded

- Temperature extreme monitoring and heat-related illness monitoring

- Protection against electrical hazards

- Checklists for the use of motor vehicles and mechanized equipment

- Safe work permits for projects requiring additional safety attention

- Avoidance of asbestos and asbestos-containing products.

\section{Excavations and Excavation Machinery}

During remediation activities, excavations greater than 18 inches were sometimes required. Any excavations deeper than 18 inches increased the hazards of encountering underground utilities. The requirements of the National Environmental Policy Act (NEPA) sometimes pertained. For excavations deeper than 18 inches, the SNL/NM Task Leader was contacted for approval to proceed. This allowed the task leader to research the possibility of underground utility lines, to check on NEPA requirements for the area, and to gather an estimate of soil removal volume and time requirements.

For area source removals, the use of excavation machinery (backhoe, skidster, and front-end loader) was sometimes more efficient. If this equipment was used for the removal, the SNL/NMdeveloped HASP for mechanical digging was used as guidelines for safe operation. The guidelines and rules established by this plan were followed by both SNL/NM and Geotech.

For excavations greater than 4 feet in depth, a safe work permit was required from the Geotech OH\&S Department. This safe work permit was monitored and administered by the site OH\&S technician to assure that the Occupational Safety and Health Administration (OSHA) regulations for excavations were followed. The competent person for the excavation was usually the SNL/NM equipment operator, with safe-work suggestions relayed to the operator from the Site Supervisor and the OH\&S Technician.

\section{Emergency Response}

Emergency phone numbers were posted in a conspicuous location at the project site. The location was usually in the back of the vehicle parked near the site access point. The phone numbers posted included the following: 
- Emergency medical

- KAFB Fire Department

- KAFB EOD

- Sandia medical.

Also, emergency alarms and actions to be taken were posted in the back of the vehicle near the site access point. The alarms were posted for evacuation, take cover, and all clear.

A map to Sandia Medical and Lovelace Medical Center was posted in the same location as the emergency alarms and emergency phone numbers.

\subsection{Laboratory Procedures}

\subsubsection{Gamma Spectroscopy Principles and Instrumentation}

Many radionuclides emit gamma rays as part of the radioactive decay process. The fraction of a radionuclide's total disintegrations that produces gamma rays is called the gamma intensity. Each radionuclide that emits a gamma ray does so at specific energies. One radionuclide might emit only one gamma at one energy, while another might emit several gamma rays at several different energies. Each one of these different gamma rays, with different energies, has its own gamma intensity. For example, Co-60 emits two gamma rays, one with an energy of $1,173.2 \mathrm{keV}$ and one with an energy of $1,332.5 \mathrm{keV}$, every time (intensity of 1.0) that it undergoes a radioactive decay. U-235, on the other hand, emits a gamma ray of $185.7 \mathrm{keV}$ during 54 percent (intensity of 0.54 ) of its decays and a gamma ray of $143.8 \mathrm{keV}$ during 10 percent (intensity of 0.1 ) of its decays (as well as several other different energy gamma rays and intensities).

It is possible to identify the gamma-emitting radionuclides present in a sample by measuring the energy of gamma rays emitted from a sample. This is possible since the energy of a gamma ray is specific to the radionuclide that emitted it, like a fingerprint of that specific radionuclide. The gamma rays that are emitted by a sample are measured utilizing a gamma spectroscopy system. This system is made up of the following major components:

- The detector: Generally made up of a high purity germanium, lithium-drifted germanium, or NaI element that is coupled to a multichannel analyzer (MCA). The gamma rays interact with the detector material, and an electronic pulse is generated that is proportional to the energy of the gamma energy.

- The MCA: An electronic device that analyzes and processes the electronic pulses generated by the detector. These pulses can be related to the number of gamma rays being emitted from a sample and, eventually, to the number of radioactive disintegrations occurring in the sample. The MCA counts the number of pulses that are sent from the detector and measures the amplitude of the pulses it counts. Since the pulse amplitude is proportional to the energy of the gamma ray, the MCA can allocate the different pulses to their respective energy channels. The MCA also amplifies, reshapes, and converts signals from analog to digital. 
Once the pulses have been counted and allocated to energy channels, they may be linked to their associated radionuclides. The energy will determine the radionuclide of interest, and the number of pulses, along with known gamma intensities for the radionuclide, is used to determine the number of disintegrations of that specific radionuclide that took place in the sample during the processing time. Figure 3.2.1 shows a gamma spectrum including the characteristic $1,001.0 \mathrm{keV}$ $(\mathrm{Pa}-234 \mathrm{~m})$ peak associated with DU.

\subsubsection{Gamma Spectroscopy Procedures and Limitations}

Soil characterization samples (pre-cleanup and post-cleanup) were analyzed by gamma spectroscopy by the SNL/NM RPM Department (Department 7715) in accordance with the following laboratory and quality assurance procedures:

- RPSD-21-01: Set-up and Acceptance Testing of the Gamma Spectrometer

- RPSD-21-02: Calibration of the Gamma Spectrometer

- RPSD-21-03: Maintenance of the Gamma Spectrometer

- RPSD-21-04: Routine QC of the Gamma Spectrometer

- RPSD-09-01: Gamma Spectrometer Sample Analysis

- RPSD-06-01: Sample Receiving and Chain-of-Custody

- RPSD-02-11: Laboratory Data Review Guidelines

- RPSD-02-08: Intercomparison Studies

- RPSD-02-09: Quality Control Samples

- RPSD-03-01: Records Management Life Cycle.

Uncontrolled copies of the above procedures are provided in Appendix D.

Use of gamma spectroscopy for characterization of radiologically contaminated soils sometimes required manual corrections to the data output. These corrections are necessary based on limitations associated with gamma spectroscopy systems. The corrections are covered in the above procedures, with the following two exceptions.

During the first part of the project, the Department 7715 on-site laboratory attempted to quantify U-234 activity concentrations through measurement and analysis of the low-abundance $53 \mathrm{keV}$ gamma emitted by U-234. This often resulted in a measurement that erroneously indicated the U-234 activity concentrations exceeded those of U-238. Typically for DU, U-238 exists in activities (in pCi/g) approximately 11 times that of U-234. For example, if there were $11 \mathrm{pCi} / \mathrm{g}$ of U-238 in a given soil sample, it would be expected to be approximately $1 \mathrm{pCi} / \mathrm{g}$ of U-234. Therefore, for the purpose of performing site-specific characterization and risk assessment, it was assumed that the ratio of U-238 to U-234 was $8 \mathrm{pCi} / \mathrm{g}$. This assumed ratio was consistent with results of the inductively coupled plasma-mass spectrometry analyses performed during the Trial Survey. To avoid incorrect interpretation of the data, the Department 7715 on-site laboratory chose to discontinue reporting analytical results for U-234 by gamma spectroscopy during the VCM. 


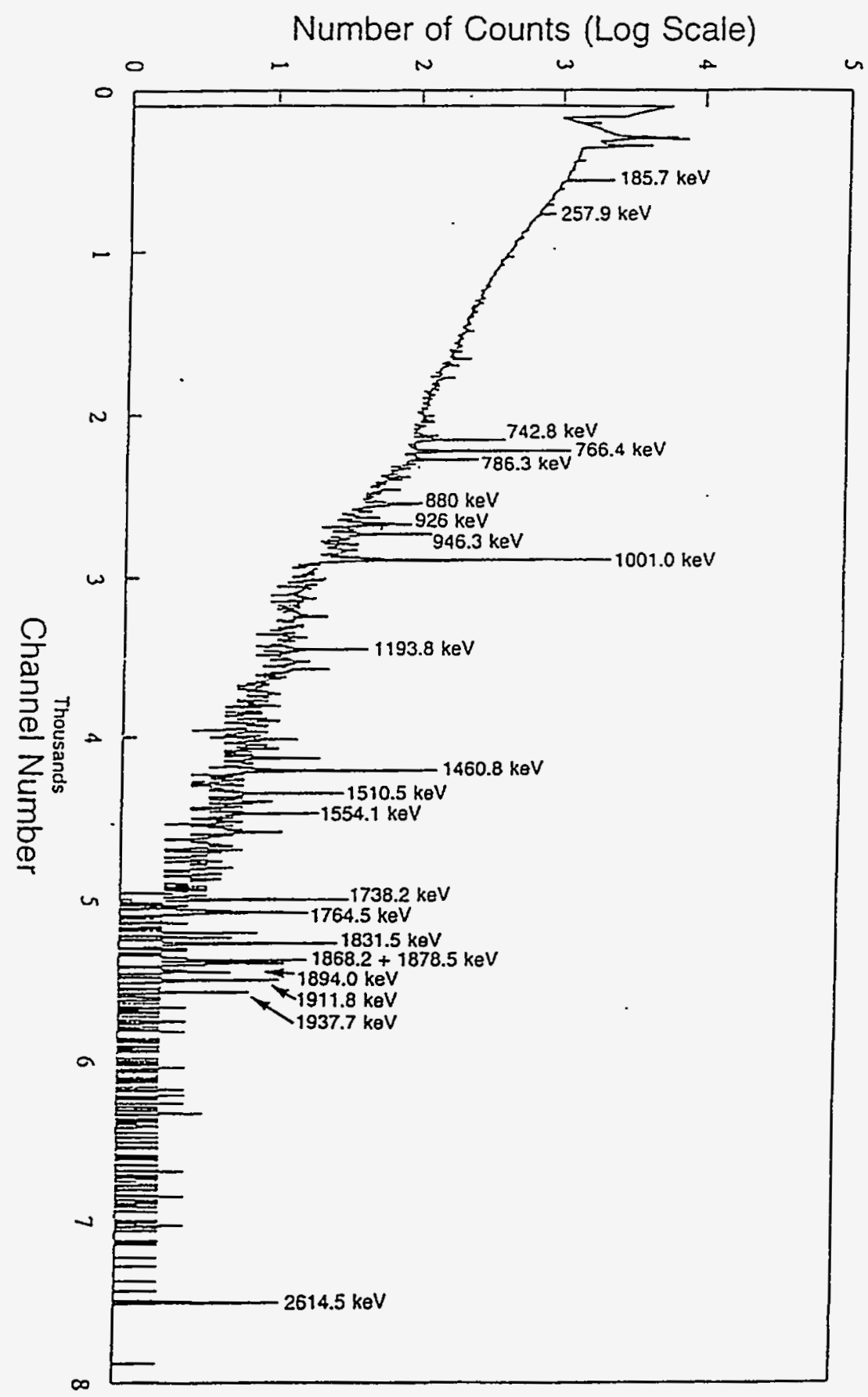

Figure 3.2.1 Gamma Spectrum Including Depleted Uranium (1001.0 keV), (Rust Geotech 1994b) 
A second problem that was found was related to the quantification of Ra-226 based on the $186 \mathrm{keV}$ gamma energy region. Ra-226 emits a $186.2 \mathrm{keV}$ gamma ray approximately 3.3 out of every 100 disintegrations. U-235 emits a $185.7 \mathrm{keV}$ gamma ray approximately 54 out of every 100 disintegrations. The use of the $186 \mathrm{keV}$ gamma ray region to quantify the Ra- 226 activity concentration requires other less abundant gamma rays emitted by U-235 be used to quantify the U-235 concentration. This U-235 concentration developed, based on the less abundant gamma energy, is then used to correct for the U-235 gamma contribution to the $186 \mathrm{keV}$ net counts attributed to Ra-226. It was discovered early in the project that this correction did not provide for an accurate quantification of Ra-226. Although the short-lived daughters of Ra-226 (lead-214 and bismuth-214) could not be assumed to be in complete equilibrium with Ra-226 due to radon-222 off-gas, it was obvious that their relatively low concentrations, combined with the Ra-226 half-life of 1600 years, would not be consistent with the reported concentrations of Ra-226. Since the production of uranium, and therefore DU, attempts to minimize radium inclusion in the final product, it was assumed that initial $\mathrm{Ra}-226$ concentrations at production time (i.e., 30+ years ago in most cases) would be negligible, and its long half-life would not allow ingrowth of Ra-226, by decay of U-234, to the levels being reported.

The final approach developed to facilitate data review was based on the assumption that if Ra-226 daughter concentrations were indicative of background concentrations (generally less than $1 \mathrm{pCi} / \mathrm{g}$ ), then Ra-226 (determined by the U-235 correction method) would be assumed to be at background concentrations. To verify this assumption, three samples were analyzed by daughter ingrowth analysis at the GJPO analytical laboratory, and the reported concentrations were compared with concentrations reported when using the U-235 correction method. In all cases, the Ra-226 daughter-product concentrations reported on the Department 7715 on-site laboratory analysis report were indicative of background. Review of Table 3.2.1 confirms that the assumption discussed above provides for an accurate assessment of Ra-226 at background levels. Consequently, Ra-226 was not determined to be a contaminant in any analysis performed over the course of the project.

Table 3.2.1 Ra-226 Comparison For Daughter Ingrowth and U-235 Correction Method

\begin{tabular}{|l|c|c|}
\hline \multicolumn{1}{|c|}{ Sample Number } & $\begin{array}{c}\text { Daughter Ingrowth } \\
\text { Ra-226 Activity (pCi/g) }\end{array}$ & $\begin{array}{c}\text { U-235 Correction Method } \\
\text { Ra-226 Activity (pCi/g) }\end{array}$ \\
\hline CCTA-61A-DR-04 & $<0.59$ & 46.5 \\
\hline SWTA-108-COM-05 & $<0.62$ & 6.17 \\
\hline SWTA-14-COM-01 & $<0.43$ & 21.6 \\
\hline
\end{tabular}

\subsection{Risk Assessment}

\subsubsection{Internal Data Review Procedures}

Gamma spectroscopy analytical results for verification soil samples (post-cleanup) were reviewed to determine the maximum levels of radiological contaminants of concern (COC) remaining at each of the surface cleanup sites. Analytical results found to be greater than the 
minimum detectable activity and greater than background concentrations were deemed residual radionuclides in soil and were retained for risk assessment. Background concentrations are reported in Background Concentrations of Constituents of Concern to the Sandia National Laboratories/New Mexico Environmental Restoration Project and the Kirtland Air Force Base Installation Restoration Program (IT Corporation 1996). For conservatism, the maximum values of residual radioactivity in soil were used in the risk assessment rather than average values.

The field readings obtained with the $\mathrm{NaI}$ gamma scintillometer at the sampled areas were entered into a spreadsheet along with the corresponding gamma spectroscopy results to perform a sideby-side comparison of field readings to laboratory data. This comparison was performed to ensure that remediated areas where soil samples were not collected contained levels of residual radioactivity in soil similar to those areas that had been sampled. Given that the predominant radiological contaminant of concern was DU, it was assumed that if all anomalies were remediated to 1.3 times background, and if the subset of these anomalies that were sampled all met risk-based cleanup levels for residual radionuclides, then all of the remediated anomalies would meet these risk-based cleanup levels. To ensure adequate representation, a 100 percent quality assurance check was performed on the field and laboratory data entered into the abovementioned spreadsheets.

\subsubsection{RESRAD and Radiological Pathway Analysis Description}

DOE developed the first version of the RESRAD computer code in 1989 at Argonne National Laboratory. The code has been used widely by DOE, the NRC, and various state programs. The following exposure pathways are currently available in RESRAD (Yu et al. 1993a):

1. Direct exposure to external radiation from the contaminated soil

2. Internal dose from inhalation of airborne radionuclides, including radon progeny

3. Internal dose from ingestion of:

a) Plant foods grown in contaminated soil and irrigated with contaminated water

b) Meat and milk from livestock fed with contaminated fodder and water

c) Drinking water from a contaminated well or pond

d) Fish from a contaminated pond

e) Contaminated soil.

The pathway analysis for determining the acceptable levels of radionuclides remaining in soil, while meeting regulatory guidelines, is made up of the exposure pathways and the following four parts:

1. Source analysis

2. Environmental transport

3. Exposure and dose analysis

4. Scenario analysis. 


\section{Source Term Analysis}

Analysis of the source term consists of determining the rate at which the residual radioactivity is released to the environment and, therefore, to a human receptor. The rate at which the radioactivity is released to a receptor is dependent on:

1. The source geometry

2. The concentrations of the radionuclides present on site

3. Ingrowth of the decay products of the initial radionuclides

4. The removal rate of the radionuclides by erosion and leaching.

\section{Environmental Transport}

Environmental transport of contaminants on the site requires determinations of:

1. Pathways by which the radionuclides can migrate from the source to a human receptor

2. A determination as to the rate at which these contaminants migrate along the pathways of concern.

This may be as simple as determining an assumed soil ingestion rate per year and, based on the radionuclide concentrations in the soil, the resultant committed effective dose equivalent (CEDE) due to this ingestion.

It may also be as complicated as determining the plant uptake rate of specific radionuclides, how much of this plant livestock may eat, how much of the ingested radionuclide is retained by the livestock, how much of this livestock, and therefore how much of the specific radionuclide, is ingested by a human receptor, and, finally, the resultant CEDE to the human receptor.

\section{Exposure and Dose Analysis}

Dose and exposure analysis relies on determining the resultant dose due to external exposure, inhalation, and ingestion of radionuclides of concern. This dose is calculated by using the transport and source mechanisms mentioned above to determine how much of a specific radionuclide a receptor has been exposed to. This amount is then used, along with dose conversion factors (conversion factors that relate radionuclide intake into the body to an absorbed dose), to determine the TEDE to the on-site receptor.

\section{Scenario analysis}

The final part of the pathway analysis is dependent on the expected land use of the site. The land-use scenario is defined by the patterns of activity undertaken by a human receptor on site. These activity patterns are defined by several factors including, but not limited to, some of the following: 
1. Time spent outdoors or indoors on site

2. Amount of soil incidentally ingested from on site

3. Volume of air breathed while on site

4. Amount of liquid ingested from a well or pond on site

5. Any food materials grown or raised on site that are ingested.

An example of how these may affect the dose to an on-site receptor may be seen by comparing inhalation dose in an industrial and a recreation land-use scenario. In the case of an industrial land use scenario, a receptor may spend approximately 25 percent of his/her year on site but, at the same time, may have a low inhalation rate due to limited physical activity. On the other hand, the recreational user may only spend 2 weeks per year on site, but would have a much higher average inhalation rate due to the increased physical activity associated with recreational land-use. Therefore, the land-use scenario is more a combination of the other three parts of the pathway analysis integrated together to define the activity patterns of a human receptor.

Meetings between SNL/NM, regulators, and stakeholders have identified three land-use scenarios: industrial, recreational, and residential. These meetings have resulted in future landuse designations as industrial and recreational. Table 3.3.1 shows the generic RESRAD input parameters for industrial land-use scenario, Table 3.3.2 shows the generic RESRAD input parameters for residential land-use scenario, and Table 3.3.3 shows the generic RESRAD input parameter for recreational land-use scenario. 
Table 3.3.1 RESRAD Input Parameters For Industrial Land-Use Scenario

\begin{tabular}{|c|c|c|}
\hline Parameter & Input & Comment \\
\hline Area of Contaminated Zone $\left(\mathrm{m}^{2}\right)$ & Site-Specific & \\
\hline Thickness of Contaminated Zone (m) & Site-Specific & Assumes survey covered upper 6 inches of soil \\
\hline Length Parallel to Aquifer Flow (m) & Site-Specific & \\
\hline Basic Radiation Dose Limit (mrem/yr) & 15 & Dose limit per 40 CFR 196. \\
\hline Time Since Material Placement (yr) & 0 & $\begin{array}{l}\text { Samples taken represent current radionuclide levels (long half- } \\
\text { lives), no groundwater contamination. }\end{array}$ \\
\hline Times for Calculations (yr) & 1000 & Requirement per 40 CFR 196. \\
\hline Initial Principal Radionuclide (pCi/g) & Site-Specific & \\
\hline Concentration in Groundwater $(\mathrm{pCi} / \mathrm{L})$ & 0 & $\begin{array}{l}\text { No radioactive contamination has been found in SNL } \\
\text { groundwater. }\end{array}$ \\
\hline Cover Depth (m) & 0 & Conservatively assumes contamination is not shielded \\
\hline Density of Cover Material $\left(\mathrm{g} / \mathrm{cm}^{3}\right)$ & 0 & No cover material. \\
\hline Cover Depth Erosion Rate (m/yr) & 0 & No cover material. \\
\hline Density of Contaminated Zone $\left(\mathrm{g} / \mathrm{cm}^{3}\right)$ & Site-Specific & \\
\hline Contaminated Zone Erosion Rate (m/yr) & 0 & Conservatively assumes that no contamination is eroded away. \\
\hline Contaminated Zone Total Porosity & Site-Specific & \\
\hline Contaminated Zone Effective Porosity & Site-Specific & \\
\hline $\begin{array}{l}\text { Contaminated Zone Hydraulic Conductivity } \\
(\mathrm{m} / \mathrm{yr})\end{array}$ & Site-Specific & \\
\hline Contaminated Zone b Parameter & Site-Specific & \\
\hline Humidity in Air $\left(\mathrm{g} / \mathrm{cm}^{3}\right)$ & 6.6 & Appendix L of Reference 1. \\
\hline Evapotranspiration Coefficient & 0.999 & Reference 2. \\
\hline Precipitation $(\mathrm{m} / \mathrm{yr})$ & .206 & Reference 2. \\
\hline Irrigation (m/yr) & 0 & Industrial Scenario, no irrigation. \\
\hline Irrigation Mode & $\mathrm{n} / \mathrm{a}$ & \\
\hline Runoff Coefficient & Site-Specific & \\
\hline Watershed Area for Nearby Stream or Pond $\left(\mathrm{m}^{2}\right)$ & $2.0 \times 10^{8}$ & Reference 2. \\
\hline
\end{tabular}


Table 3.3.1 RESRAD Input Parameters For Industrial Land-Use Scenario

\begin{tabular}{|c|c|c|}
\hline Parameter & Input & Comment \\
\hline Accuracy for water/soil computations & 0.001 & RESRAD Default \\
\hline Saturated Zone Parameters & Not Used & \\
\hline Unsaturated Zone Parameters & Not Used & \\
\hline Distribution Coefficients & $\begin{array}{l}\text { Nuclide- } \\
\text { specific }\end{array}$ & Use RESRAD defaults. \\
\hline Inhalation Rate $\left(\mathrm{m}^{3} / \mathrm{yr}\right)$ & 20,000 & $\begin{array}{l}\text { When adjusted with the } 25 \% \text { occupancy factor this inhalation } \\
\text { rate equates to } 20 \mathrm{~m}^{3} / \text { day, } 250 \text { days per year. }\end{array}$ \\
\hline Mass Loading for Inhalation $\left(\mathrm{g} / \mathrm{m}^{3}\right)$ & $1.36 \times 10^{-5}$ & $\begin{array}{l}\text { Reference 4. Maximum average PM-10 dust loading for SNL- } \\
\text { measured sites (Reference } 3 \text { ). }\end{array}$ \\
\hline Dilution Length for Airborne Dust (m) & 3 & RESRAD default. \\
\hline Exposure Duration (yr) & 30 & Assumes receptor is on site for 30 years \\
\hline Shielding Factor, Inhalation & 0.4 & Assumes indoor dust levels are $40 \%$ of outdoor levels. \\
\hline Shielding Factor, External Gamma & 0.7 & $\begin{array}{l}\text { Assumes that indoor gamma exposure levels are } 70 \% \text { of outdoor } \\
\text { gamma exposure levels. }\end{array}$ \\
\hline Fraction of Time Spent Indoors (on site) & 0.125 & $\begin{array}{l}\text { Assumes that approximately } 4 \text { hours per day, } 250 \text { days per year } \\
\text { are spent indoors on site. }\end{array}$ \\
\hline Fraction of Time Spent Outdoors (on site) & 0.125 & $\begin{array}{l}\text { Assumes that approximately } 4 \text { hours per day, } 250 \text { days per year } \\
\text { are spent outdoors on site. }\end{array}$ \\
\hline Shape Factor & 1 & $\begin{array}{l}\text { Conservatively assumes that all sites are circular for maximum } \\
\text { gamma exposure. }\end{array}$ \\
\hline Food and Water Ingestion Parameters & Not Used & \\
\hline Soil Ingestion Rate (g/yr) & 36.5 & $\begin{array}{l}\text { Assumes adult ingests } 100 \mathrm{mg} / \text { day. Adjusted by } 25 \% \text { occupancy } \\
\text { factor. }\end{array}$ \\
\hline Livestock Intake Parameters & Not Used & \\
\hline Depth of Soil Mixing Layer (m) & 0.15 & Assumes upper 6 inches of soil is routinely mixed. \\
\hline Water-use Fractions & Not Used & \\
\hline C-12/C-14 Parameter & Not Used & \\
\hline
\end{tabular}


Table 3.3.1 RESRAD Input Parameters For Industrial Land-Use Scenario

\begin{tabular}{|c|c|c|}
\hline Parameter & Input & Comment \\
\hline Storage Time for Foodstuffs (days) & Not Used & \\
\hline Thickness of Building Foundation (m) & 0.15 & RESRAD default. \\
\hline Bulk Density of Building Foundation $\left(\mathrm{g} / \mathrm{cm}^{3}\right)$ & 2.4 & RESRAD default. \\
\hline Total Porosity of Cover Material & Not Used & \\
\hline Total Porosity of Building Foundation & 0.1 & RESRAD default. \\
\hline Volumetric Water Content of Cover Material & Not Used & \\
\hline Volumetric Water Content of Foundation & 0.03 & RESRAD default. \\
\hline \multicolumn{3}{|l|}{ Diffusion Coefficient for Radon Gas (m/sec) } \\
\hline - in cover material & Not Used & \\
\hline - in foundation material & $3.0 \times 10^{-7}$ & RESRAD default. \\
\hline - in contaminated zone soil & $2.0 \times 10^{-6}$ & RESRAD default. \\
\hline Radon Vertical Dimension of Mixing (m) & 2.0 & RESRAD default. \\
\hline Average Annual Wind Speed $(\mathrm{m} / \mathrm{sec})$ & 2.7 & Reference 3. Average annual wind speed. \\
\hline Average Building Air Exchange Rate (1/hr) & 0.5 & RESRAD default. \\
\hline Height of Building (room) (m) & 2.5 & RESRAD default. \\
\hline Building Interior Area Factor & Site-Specific & Computed by RESRAD based on site dimensions. \\
\hline Building Depth Below Ground Surface (m) & Site-Specific & Time dependent, computed by RESRAD. \\
\hline Emanating Power of Rn-222 Gas & 0.25 & RESRAD default. \\
\hline Emanating Power of Rn-220 Gas & 0.15 & RESRAD default. \\
\hline
\end{tabular}

Reference 1: Yu, C., et al, 1993a, "Manual for Implementing Residual Radioactive Material Guidelines Using RESRAD, Version 5.0," Argonne National Laboratory, Argonne, IL.

Reference 2: Wolford, R., et al, 1996, “1995 Site-Wide Hydrogeologic Characterization Project," Sandia National Laboratories, Albuquerque, NM.

Reference 3: Culp, T., et al, 1993, "1992 Environmental Monitoring Report," Sandia National Laboratories, Albuquerque, NM.

Reference 4: US EPA Office of Emergency and Remedial Response, 1991, "Risk Assessment Guidance for Superfund: Volume I - Human Health Evaluation Manual (Part B, Development of Risk-based Preliminary Remediation Goals)," US EPA, Washington, DC. 
Table 3.3.2 RESRAD Input Parameters For Residential Land-Use Scenario

\begin{tabular}{|c|c|c|}
\hline Parameter & Input & Comment \\
\hline Area of Contaminated Zone $\left(\mathrm{m}^{2}\right)$ & Site-Specific & \\
\hline Thickness of Contaminated Zone (m) & Site-Specific & Assumes survey covered upper 6 inches of soil \\
\hline Length Parallel to Aquifer Flow (m) & Site-Specific & \\
\hline Basic Radiation Dose Limit (mrem/yr) & 75 & Dose limit per 40 CFR 196. \\
\hline Time Since Material Placement (yr) & 0 & $\begin{array}{l}\text { Samples taken represent current radionuclide levels (long half- } \\
\text { lives), no groundwater contamination. }\end{array}$ \\
\hline Times for Calculations (yr) & 1000 & Requirement per 40 CFR 196. \\
\hline Initial Principal Radionuclide (pCi/g) & Site-Specific & \\
\hline Concentration in Groundwater $(\mathrm{pCi} / \mathrm{L})$ & 0 & $\begin{array}{l}\text { No radioactive contamination has been found in SNL } \\
\text { groundwater. }\end{array}$ \\
\hline Cover Depth (m) & 0 & Conservatively assumes contamination is not shielded \\
\hline Density of Cover Material $\left(\mathrm{g} / \mathrm{cm}^{3}\right)$ & 0 & No cover material. \\
\hline Cover Depth Erosion Rate (m/yr) & 0 & No cover material. \\
\hline Density of Contaminated Zone $\left(\mathrm{g} / \mathrm{cm}^{3}\right)$ & Site-Specific & \\
\hline Contaminated Zone Erosion Rate (m/yr) & 0 & Conservatively assumes that no contamination is eroded away. \\
\hline Contaminated Zone Total Porosity & Site-Specific & \\
\hline Contaminated Zone Effective Porosity & Site-Specific & \\
\hline $\begin{array}{l}\text { Contaminated Zone Hydraulic Conductivity } \\
(\mathrm{m} / \mathrm{yr})\end{array}$ & Site-Specific & \\
\hline Contaminated Zone b Parameter & Site-Specific & \\
\hline Humidity in Air $\left(\mathrm{g} / \mathrm{cm}^{3}\right)$ & 6.6 & Reference 1, Appendix L. \\
\hline Evapotranspiration Coefficient & 0.999 & Reference 2. \\
\hline Precipitation (m/yr) & .206 & Reference 2. \\
\hline Irrigation (m/yr) & 0 & $\begin{array}{l}\text { Irrigation for plants from local water supply. Depth to } \\
\text { groundwater precludes contaminant transport to groundwater. }\end{array}$ \\
\hline Irrigation Mode & $\mathrm{n} / \mathrm{a}$ & \\
\hline Runoff Coefficient & Site-Specific & \\
\hline
\end{tabular}


Table 3.3.2 RESRAD Input Parameters For Residential Land-Use Scenario

\begin{tabular}{|c|c|c|}
\hline Parameter & Input & Comment \\
\hline Watershed Area for Nearby Stream or Pond $\left(\mathrm{m}^{2}\right)$ & $2.1 \times 10^{8}$ & Reference 2. \\
\hline Accuracy for water/soil computations & 0.001 & RESRAD Default \\
\hline Saturated Zone Parameters & Not Used & \\
\hline Unsaturated Zone Parameters & Not Used & \\
\hline Distribution Coefficients & $\begin{array}{l}\text { Nuclide- } \\
\text { specific }\end{array}$ & Use RESRAD defaults. \\
\hline Inhalation Rate $\left(\mathrm{m}^{3} / \mathrm{yr}\right)$ & 7300 & $\begin{array}{l}\text { Reference } 4 . \text { When adjusted for occupancy factor results in } 15 \\
\mathrm{~m}^{3} / \text { day, } 365 \text { days per year, inhaled. }\end{array}$ \\
\hline Mass Loading for Inhalation $\left(\mathrm{g} / \mathrm{m}^{3}\right)$ & $1.36 \times 10^{-5}$ & $\begin{array}{l}\text { Reference 3. Maximum average PM-10 dust loading for SNL- } \\
\text { measured sites. }\end{array}$ \\
\hline Dilution Length for Airborne Dust (m) & 3 & RESRAD default. \\
\hline Exposure Duration (yr) & 30 & Assumes receptor is on site for 30 years \\
\hline Shielding Factor, Inhalation & 0.4 & Assumes indoor dust levels are $40 \%$ of outdoor levels. \\
\hline Shielding Factor, External Gamma & 0.7 & $\begin{array}{l}\text { Assumes that indoor gamma exposure levels are } 70 \% \text { of outdoor } \\
\text { gamma exposure levels. }\end{array}$ \\
\hline Fraction of Time Spent Indoors (on site) & .5 & $\begin{array}{l}\text { Assumes that } 12 \text { hours per day, } 365 \text { days per year are spent } \\
\text { indoors on site. }\end{array}$ \\
\hline Fraction of Time Spent Outdoors (on site) & .25 & $\begin{array}{l}\text { Assumes that } 4 \text { hours per day, } 365 \text { days per year are spent } \\
\text { outdoors on site. }\end{array}$ \\
\hline Shape Factor & 1 & $\begin{array}{l}\text { Conservatively assumes that all sites are circular for maximum } \\
\text { gamma exposure. }\end{array}$ \\
\hline Drinking Water Ingestion Parameters & Not Used & \\
\hline Dairy, Meat, Poultry, and Fish Parameters & Not Used & \\
\hline Fruits and Vegetable Consumption (kg/yr) & 124 & $\begin{array}{l}\text { Reference } 5 . \text { This is total fruits and vegetables consumed, } \\
\text { including contaminated and non-contaminated. }\end{array}$ \\
\hline Leafy Vegetable Consumption (kg/yr) & 14 & $\begin{array}{l}\text { Reference } 5 . \text { This is total leafy vegetables consumed, including } \\
\text { contaminated and non-contaminated }\end{array}$ \\
\hline
\end{tabular}


Table 3.3.2 RESRAD Input Parameters For Residential Land-Use Scenario

\begin{tabular}{|c|c|c|}
\hline Parameter & Input & Comment \\
\hline Soil Ingestion Rate (g/yr) & 43.8 & $\begin{array}{l}\text { Weighted average assuming } 100 \mathrm{mg} / \text { day for an adult for } 24 \text { years } \\
\text { and } 200 \mathrm{mg} / \text { day for a child for } 6 \text { years. }\end{array}$ \\
\hline Livestock Intake Parameters & Not Used & \\
\hline $\begin{array}{l}\text { Contamination Fraction of Water, Fish, Meat, and } \\
\text { Milk }\end{array}$ & 0 & Pathways are not included. \\
\hline Contamination Fraction of Plant Food & 0.25 & $\begin{array}{l}\text { Reference } 5 . \text { Assumes that } 25 \% \text { of fruits and vegatables eaten } \\
\text { during the year are taken from on site. }\end{array}$ \\
\hline Mass Loading for Foliar Deposition $\left(\mathrm{g} / \mathrm{m}^{3}\right)$ & $1 \times 10^{-4}$ & RESRAD default. \\
\hline Depth of Soil Mixing Layer (m) & 0.15 & Assumes upper 6 inches of soil is routinely mixed. \\
\hline Depth of Roots (m) & 0.9 & RESRAD default. \\
\hline Water-use Fractions & Not Used & \\
\hline C-12/C-14 Parameters & Not Used & \\
\hline \multicolumn{3}{|l|}{ Storage Time for Foodstuffs (days) } \\
\hline - fruits, non-leafy vegatables & 14 & RESRAD default. \\
\hline - leafy vegetables & 14 & RESRAD default \\
\hline Thickness of Building Foundation (m) & 0.15 & RESRAD default. \\
\hline Bulk Density of Building Foundation $\left(\mathrm{g} / \mathrm{cm}^{3}\right)$ & 2.4 & RESRAD default. \\
\hline Total Porosity of Cover Material & Not Used & \\
\hline Total Porosity of Building Foundation & 0.1 & RESRAD default. \\
\hline Volumetric Water Content of Cover Material & Not Used & \\
\hline Volumetric Water Content of Foundation & 0.03 & RESRAD default. \\
\hline \multicolumn{3}{|l|}{ Diffusion Coefficient for Radon Gas (m/sec) } \\
\hline - in cover material & Not Used & \\
\hline - in foundation material & $3.0 \times 10^{-7}$ & RESRAD default. \\
\hline - in contaminated zone soil & $2.0 \times 10^{\cdot 6}$ & RESRAD default. \\
\hline Radon Vertical Dimension of Mixing (m) & 2.0 & RESRAD default. \\
\hline
\end{tabular}


Table 3.3.2 RESRAD Input Parameters For Residential Land-Use Scenario

\begin{tabular}{|l|c|l|}
\hline \multicolumn{1}{|c|}{ Parameter } & Input & \multicolumn{1}{c|}{ Comment } \\
\hline Average Annual Wind Speed (m/sec) & 2.7 & Reference 3. Average annual wind speed. \\
\hline Average Building Air Exchange Rate (1/hr) & 0.5 & RESRAD default. \\
\hline Height of Building (room) $(\mathrm{m})$ & 2.5 & RESRAD default. \\
\hline Building Interior Area Factor & Site-Specific & Computed by RESRAD based on site dimensions. \\
\hline Building Depth Below Ground Surface (m) & Site-Specific & Time dependent, computed by RESRAD. \\
\hline Emanating Power of Rn-222 Gas & 0.25 & RESRAD default. \\
\hline Emanating Power of Rn-220 Gas & 0.15 & RESRAD default. \\
\hline
\end{tabular}

Reference 1: Yu, C., et al, 1993a, "Manual for Implementing Residual Radioactive Material Guidelines Using RESRAD, Version 5.0," Argonne National Laboratory, Argonne, IL.

Reference 2: Wolford, R., et al, 1996, "1995 Site-Wide Hydrogeologic Characterization Project," Sandia National Laboratories, Albuquerque, NM.

Reference 3: Culp, T., et al, 1993, “1992 Environmental Monitoring Report," Sandia National Laboratories, Albuquerque, NM.

Reference 4: US EPA Office of Emergency and Remedial Response, 1991, "Risk Assessment Guidance for Superfund: Volume I - Human Health Evaluation Manual (Part B, Development of Risk-based Preliminary Remediation Goals)," US EPA, Washington, DC.

Reference 5: Yu, C., et al, 1993b, "Data Collection Handbook to Support Modeling the Impacts of Radioactive Material in Soil," Argonne National Laboratory, Argonne, IL. 
Table 3.3.3 RESRAD Input Parameters For Recreational Land-Use Scenario

\begin{tabular}{|c|c|c|}
\hline Parameter & Input & Comment \\
\hline Area of Contaminated Zone $\left(\mathrm{m}^{2}\right)$ & Site-Specific & \\
\hline Thickness of Contaminated Zone (m) & Site-Specific & \\
\hline Length Parallel to Aquifer Flow (m) & Sile Sperific & \\
\hline Basic Radiation Dose Limit (mrem/yr) & 15 & Dose limit per 40 CFR 106. \\
\hline Time Since Material Placement (yr) & 0 & $\begin{array}{l}\text { Samples taken represent current radionuclide levels (long } i_{i}^{-1} \text { f } \\
\text { lives), no groundwater contamination. }\end{array}$ \\
\hline Times for Calculations (yr) & 1000 & Requirement per 40 CFR 196. \\
\hline Initial Principal Radionuclide (pCi/g) & Site-Specific & \\
\hline Concentration in Groundwater $(\mathrm{pCi} / \mathrm{L})$ & 0 & $\begin{array}{l}\text { No radioactive contamination has been found in SNL } \\
\text { groundwater. }\end{array}$ \\
\hline Cover Depth (m) & 0 & Conservatively assumes contamination is not shielded \\
\hline Density of Cover Material $\left(\mathrm{g} / \mathrm{cm}^{3}\right)$ & 0 & No cover material. \\
\hline Cover Depth Erosion Rate (m/yr) & 0 & No cover material. \\
\hline Density of Contaminated Zone $\left(\mathrm{g} / \mathrm{cm}^{3}\right)$ & Site-Specific & \\
\hline Contaminated Zone Erosion Rate $(\mathrm{m} / \mathrm{yr})$ & 0 & Conservatively assumes that no contamination is eroded away. \\
\hline Contaminated Zone Total Porosity & Site-Specific & \\
\hline Contaminated Zone Effective Porosity & Site-Specific & \\
\hline $\begin{array}{l}\text { Contaminated Zone Hydraulic Conductivity } \\
(\mathrm{m} / \mathrm{yr})\end{array}$ & Site-Specific & \\
\hline Contaminated Zone b Parameter & Site-Specific & \\
\hline Humidity in Air $\left(\mathrm{g} / \mathrm{cm}^{3}\right)$ & 6.6 & Reference 1, Appendix L. \\
\hline Evapotranspiration Coefficient & 0.999 & Reference 2. \\
\hline Precipitation $(\mathrm{m} / \mathrm{yr})$ & .206 & Reference 2. \\
\hline Irrigation (m/yr) & 0 & No plant ingestion pathway used \\
\hline Irrigation Mode & $\mathrm{n} / \mathrm{a}$ & \\
\hline Runoff Coefficient & Site-Specific & \\
\hline Watershed Area for Nearby Stream or Pond $\left(\mathrm{m}^{2}\right)$ & $2.1 \times 10^{8}$ & Reference 2. \\
\hline
\end{tabular}


Table 3.3.3 RESRAD Input Parameters For Recreational Land-Use Scenario

\begin{tabular}{|c|c|c|}
\hline Parameter & Input & Comment \\
\hline Accuracy for water/soil computations & 0.001 & RESRAD Default \\
\hline Saturated Zone Parameters & Not Used & \\
\hline Unsaturated Zone Parameters & Not Used & \\
\hline Distribution Coefficients & $\begin{array}{l}\text { Nuclide- } \\
\text { specific }\end{array}$ & Use RESRAD defaults. \\
\hline Inhalation Rate $\left(\mathrm{m}^{3} / \mathrm{yr}\right)$ & 12,300 & $\begin{array}{l}\text { Reference } 5 \text {. Outdoor activity scenario where an individual has } \\
\text { an activity mix of } 37 \% \text { moderate activity, } 28 \% \text { resting, } 28 \% \text { light } \\
\text { activity, and } 7 \% \text { heavy activity. Results in } 1.4 \mathrm{~m}^{3} / \mathrm{hr} \text { inhalation } \\
\text { rate. This yearly rate is adjusted by time spent on site, below. }\end{array}$ \\
\hline Mass Loading for Inhalation $\left(\mathrm{g} / \mathrm{m}^{3}\right)$ & $1.36 \times 10^{-5}$ & $\begin{array}{l}\text { Reference 3. Maximum average PM-10 dust loading for SNL- } \\
\text { measured sites. }\end{array}$ \\
\hline Dilution Length for Airborne Dust (m) & 3 & RESRAD default. \\
\hline Exposure Duration (yr) & 30 & Assumes receptor is on site for 30 years \\
\hline Shielding Factor, Inhalation & 0 & Not used, all time is spent outside \\
\hline Shielding Factor, External Gamma & 0 & Not used, all time is spent outside \\
\hline Fraction of Time Spent Indoors (on site) & 0 & No time is spent outside \\
\hline Fraction of Time Spent Outdoors (on site) & 0.012 & $\begin{array}{l}\text { Assumes } 4 \text { hours is spent on site every } 2 \text { weeks for a total of } 104 \\
\text { hours spent on site per year. }\end{array}$ \\
\hline Shape Factor & 1 & $\begin{array}{l}\text { Conservatively assumes that all sites are circular for maximum } \\
\text { gamma exposure. }\end{array}$ \\
\hline Drinking Water Ingestion Parameters & Not Used & \\
\hline Dairy, Meat, Poultry, and Fish Parameters & Not Used & \\
\hline Fruits and Vegetable Consumption (kg/yr) & Not Used & \\
\hline Leafy Vegetable Consumption (kg/yr) & Not Used & \\
\hline Livestock Intake Parameters & Not Used & \\
\hline $\begin{array}{l}\text { Contamination Fraction of Water, Fish, Meat, and } \\
\text { Milk }\end{array}$ & 0 & Pathways are not included. \\
\hline
\end{tabular}


Table 3.3.3 RESRAD Input Parameters For Recreational Land-Use Scenario

\begin{tabular}{|c|c|c|}
\hline Parameter & Input & Comment \\
\hline Soil Ingestion Rate (g/yr) & 520 & $\begin{array}{l}\text { Reference 5: Assumes that for outdoor activities (reference was } \\
\text { May through October) ingestion rate is approximately } 60 \mathrm{mg} \text { of } \\
\text { soil per hour of activity. This value is adjusted by the amount of } \\
\text { time spent outdoors on site to yeild } 6.24 \mathrm{~g} / \mathrm{yr} \text { actual ingestion. }\end{array}$ \\
\hline Contamination Fraction of Plant Food & 0 & Pathways are not included. \\
\hline Mass Loading for Foliar Deposition $\left(\mathrm{g} / \mathrm{m}^{3}\right)$ & Not Used & \\
\hline Depth of Soil Mixing Layer (m) & 0.15 & Assumes upper 6 inches of soil is routinely mixed. \\
\hline Depth of Roots (m) & Not Used & \\
\hline Water-use Fractions & Not Used & \\
\hline C-12/C-14 Parameters & Not Used & \\
\hline Storage Time for Foodstuffs (days) & Not Used & \\
\hline Thickness of Building Foundation (m) & Not Used & \\
\hline Bulk Density of Building Foundation $\left(\mathrm{g} / \mathrm{cm}^{3}\right)$ & Not Used & \\
\hline Total Porosity of Cover Material & Not Used & \\
\hline Total Porosity of Building Foundation & Not used & \\
\hline Volumetric Water Content of Cover Material & Not Used & \\
\hline Volumetric Water Content of Foundation & Not Used & \\
\hline \multicolumn{3}{|l|}{ Diffusion Coefficient for Radon Gas (m/sec) } \\
\hline - in cover material & Not Used & \\
\hline - in foundation material & Not Used & \\
\hline - in contaminated zone soil & $2.0 \times 10^{-6}$ & $\begin{array}{l}\text { RESRAD default. Also may be calculated based on soil } \\
\text { moisture and porosity by inserting a " }-1 \text { " flag. }\end{array}$ \\
\hline Radon Vertical Dimension of Mixing (m) & 2.0 & RESRAD default. \\
\hline Average Annual Wind Speed $(\mathrm{m} / \mathrm{sec})$ & 2.7 & Reference 3. Average annual wind speed. \\
\hline Average Building Air Exchange Rate (1/hr) & Not Used & \\
\hline Height of Building (room) (m) & Not Used & \\
\hline Building Interior Area Factor & Not Used & \\
\hline
\end{tabular}


Table 3.3.3 RESRAD Input Parameters For Recreational Land-Use Scenario

\begin{tabular}{|l|c|l|}
\hline \multicolumn{1}{|c|}{ Parameter } & Input & Comment \\
\hline Building Depth Below Ground Surface $(\mathrm{m})$ & Not Used & \\
\hline Emanating Power of Rn-222 Gas & 0.25 & RESRAD default. \\
\hline Emanating Power of Rn-220 Gas & 0.15 & RESRAD default. \\
\hline
\end{tabular}

Reference 1: Yu, C., et al, 1993a, "Manual for Implementing Residual Radioactive Material Guidelines Using RESRAD, Version 5.0," Argonne National Laboratory, Argonne, IL.

Reference 2: Wolford, R., et al, 1996, "1995 Site-Wide Hydrogeologic Characterization Project," Sandia National Laboratories, Albuquerque, NM.

- Reference 3: Culp, T., et al, 1993, “1992 Environmental Monitoring Report," Sandia National Laboratories, Albuquerque, NM.

Reference 4: US EPA Office of Emergency and Remedial Response, 1991, "Risk Assessment Guidance for Superfund: Volume I - Human Health Evaluation Manual (Part B, Development of Risk-based Preliminary Remediation Goals)," US EPA, Washington, DC.

Reference 5: Yu, C., et al, 1993b, "Data Collection Handbook to Support Modeling the Impacts of Radioactive Material in Soil," Argonne National Laboratory, Argonne, IL. 
Intentionally Left Blank 


\section{PROJECT RESULTS AND CONCLUSIONS}

\subsection{Phase I Radiological Survey}

\subsubsection{Adequacy of Survey}

The Phase I surveys provide a preliminary assessment of site conditions relative to guidance values and provide additional data for classifying sites (and areas within sites) into "affected" and "unaffected" areas. Sites with affected areas that had potential radioactive contamination (based on previous operating history) or known radioactive contamination (based on past or preliminary radiological surveillance) were given 100 percent survey coverage. Unaffected areas that were not expected to contain residual radioactivity were scanned with 10 -foot spacing, or approximately 70 percent coverage. The NRC and DOE guidelines for scanning surveys recommend 100 percent coverage for affected areas and a minimum of 10 percent coverage for unaffected areas (see Section 2.2.1), thus the actual survey exceeded this coverage.

In addition to closely following the regulatory guidance pertaining to the conduct of radiological surveys, before beginning the extensive and costly Phase I Surveys, a "Trial Survey" was first conducted at a typical SNL/NM ER site known to be contaminated with DU to demonstrate the effectiveness of the instruments' responses for the site-specific conditions. The Trial Survey was used to build a supporting foundation for the results of the Phase I survey, and ensured that the results of the Phase I survey would be consistent with (or exceed) regulatory guidance and any stated or implied data quality requirements. Further details of the Trial Survey are summarized in the Surface Gamma Radiation Surveys Final Report (Geotech 1994b).

Guidance provided in NUREG/CR-5849 suggested that the instrument chosen for the scan survey be capable of detecting the contaminant of concern at 25 percent to 75 percent of the target cleanup level. The target cleanup level, as determined by a generic risk assessment and discussed in Section 2.2.2, was $230 \mathrm{pCi} / \mathrm{g}$ of U-238 in the soil. Therefore, it was determined that the instrument must be capable of detecting U-238 at a level between 57.5 to $172.5 \mathrm{pCi} / \mathrm{g}$.

As discussed in the Trial Survey section of the Surface Gamma Radiation Surveys Final Report (Geotech 1994b), correlation of scan surveys using a NaI gamma scintillometer with actual laboratory-analyzed soil samples of the detected DU anomalies provided the following estimated lower limits of detection (in $\mathrm{pCi} / \mathrm{g}$ ) corresponding to approximately 1.3 times ambient background (in counts per unit of time) using a NaI scan survey:

- For area sources of DU, it was estimated that soil concentrations as low as $13 \mathrm{pCi} / \mathrm{g}$ of U-238 may be detected.

- For point sources of DU, it was found that a concentration of $80 \mathrm{pCi} / \mathrm{g}$ of U-238 in soil was detected, but the area tested provided a $\mathrm{NaI}$ response on the order of 2 times ambient background. It is expected, therefore, that a 1.3 times ambient background response on a $\mathrm{NaI}$ scan survey would correspond to less than $80 \mathrm{pCi} / \mathrm{g}$ of U-238. 
The estimated detection limit, using the $\mathrm{NaI}$ gamma scintillometer for a point source, was thus approximately 35 percent of the target cleanup level. The estimated detection limit, using the NaI gamma scintillometer for an area source, was approximately 6 percent of the target cleanup level. These are both well within the NUREG/CR-5849 guidance provided, with the conclusion that the NaI gamma scintillometer with alarms set at 1.3 times ambient background would be sensitive enough to detect DU at or below the concentration of concern.

NRC and DOE guidance, discussed in greater detail in Section 2.2.1, recommended detection levels of 1.25 to 2.0 (1.25 to 1.5 for the NRC and 1.5 to 2.0 for DOE) times the ambient background level when background is on the order of several thousand cpm. For all surveys, a value of 1.3 times ambient background using a NaI gamma scintillometer was used to map radiation anomalies, well within the range recommended by the NRC and well below that recommended by DOE. The guidance also recommended a gamma scintillometer scanning speed of approximately 1 mile per hour, with the detector held as close to the ground as practical, generally less than 2 inches from the ground surface. Actual surveys were conducted at a somewhat slower pace, approximately 0.5 mile per hour, due in part to the rugged terrain. The Trial Survey also verified the detection sensitivity as a function of scanning speed and provided an opportunity to "calibrate" operator walking speeds to provide as consistent a scan speed as possible. Further discussion is provided in the Trial Survey section of the Surface Gamma Radiation Surveys Final Report (Geotech 1994b).

Results from the surveys were used to focus the radionuclide characterization process, cleanup, and final classification of the ER Project sites. The use of scanning surveys to narrow the focus of follow-up activities, such as voluntary cleanups and soil sampling, was consistent with applicable regulatory guidance.

The methods used in performing the Phase I surveys were limited to nonintrusive scanning techniques. The intention of these scanning surveys was to detect the gamma radiation anomalies at or near the ground surface (less than 0.5 foot deep). Areas within sites that may have subsurface radioactive materials required a different characterization strategy.

The procedures associated with development of detection limits are discussed in greater detail in the Surface Gamma Radiation Surveys Final Report (Geotech 1994b).

\subsubsection{Survey Results}

\section{Trial Survey}

A "Trial Survey" was first conducted at a typical SNL/NM ER site, known to be contaminated with DU, to demonstrate the effectiveness of instrument response to DU for the site-specific conditions.

$\mathrm{NaI}$ gamma scintillometers that were cross-correlated with a PIC for more accurate measurements of exposure rate were the primary instruments used (see Figures 4.1.1 and 4.1.2). These instruments and survey techniques required field calibration and evaluation for 


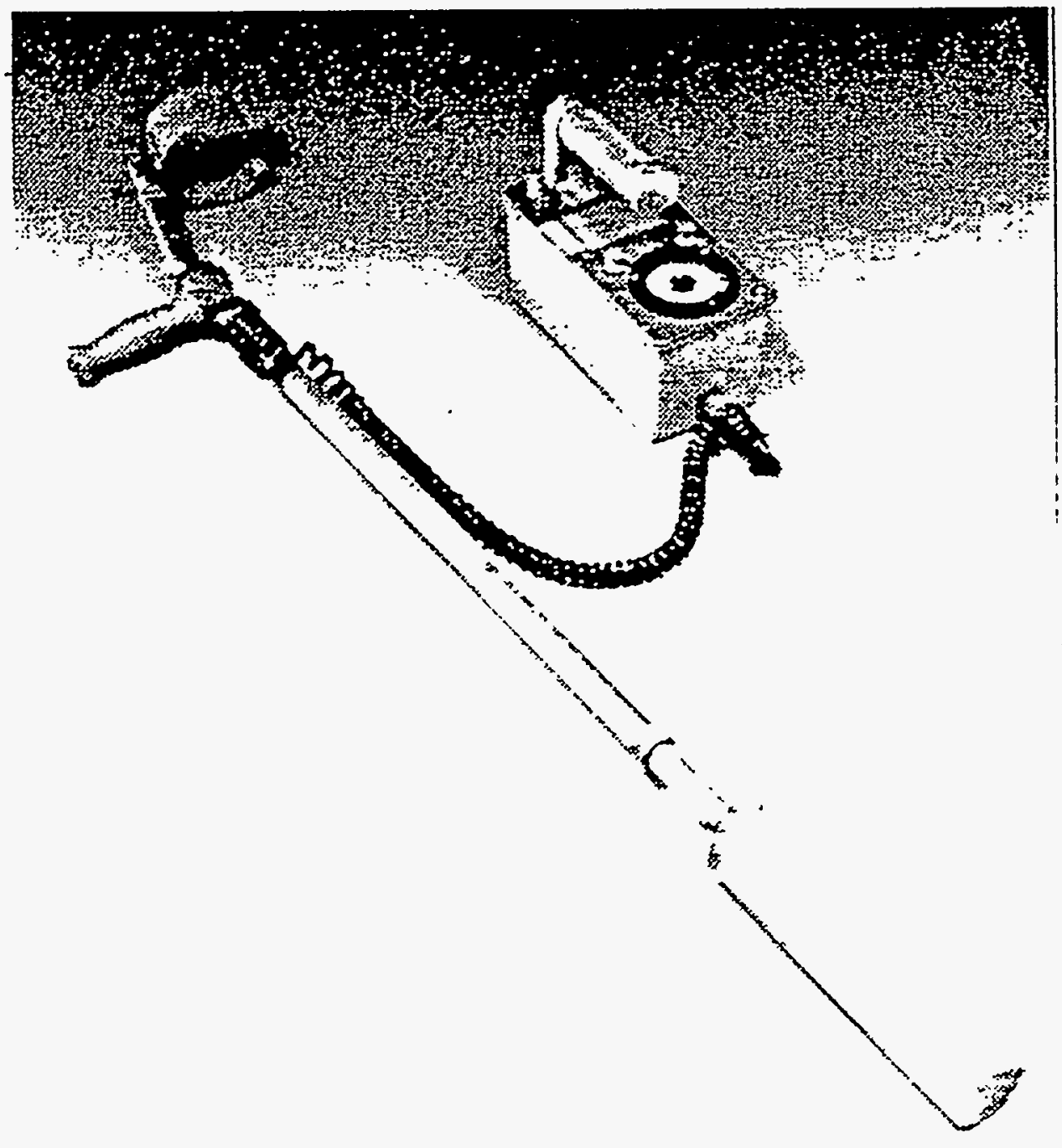

Figure 4.1.1 Crutch Gamma Scintillometer (Mount Sporis EL-0047A), RUST Greotech 1994b) 


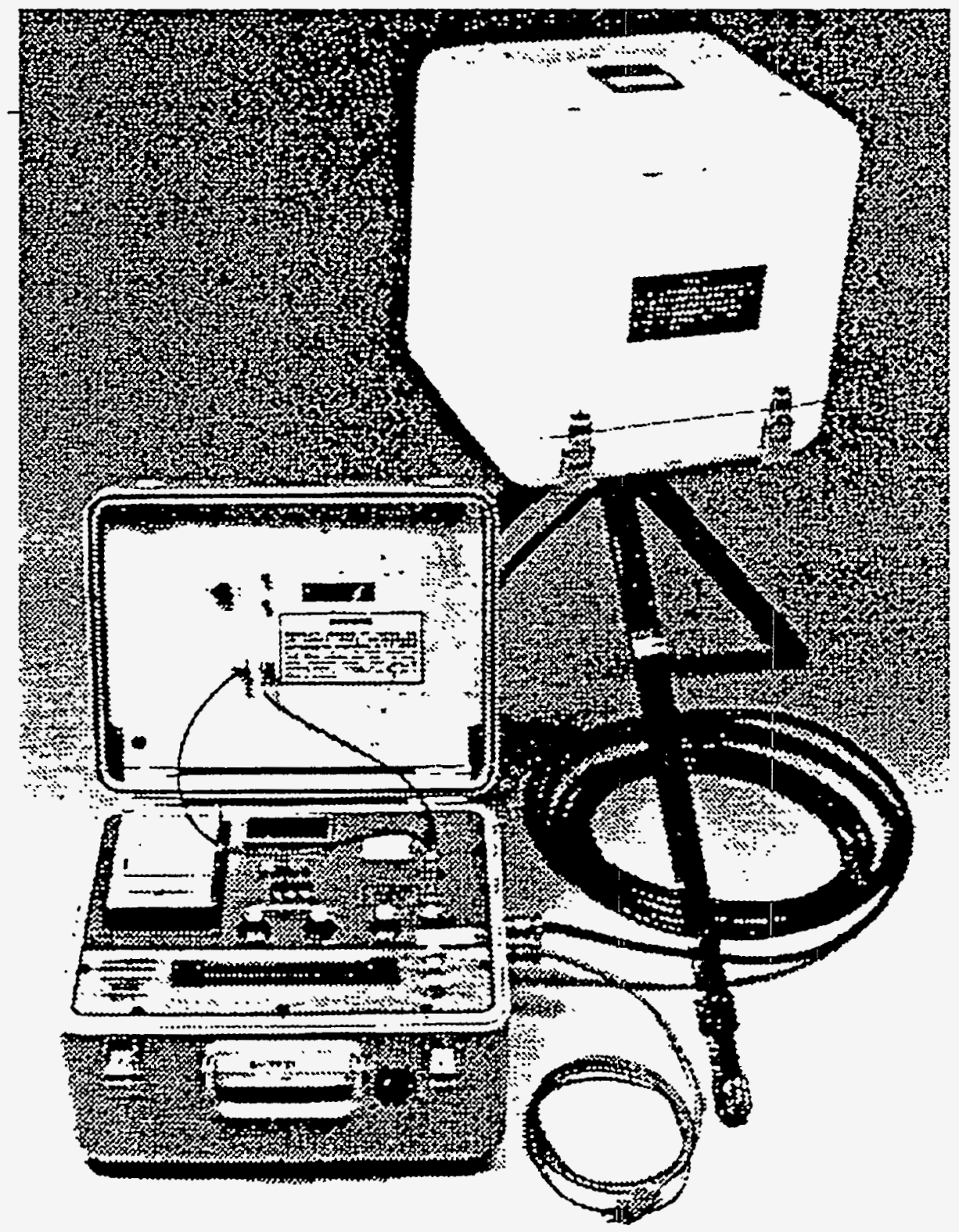

Figure 4.1.2 Pressurized Ionization Chamber (Reuter-Stokes Model RSS-111), (RUST Geotech 1994b) 
environmental conditions and contaminants specific to the ER Project sites. Field measurements were taken to qualitatively evaluate the instruments' detection limits and to substantiate optimum gamma survey parameters such as scanning speed and grid spacing.

The Trial Survey was conducted during July 1993 and established the NaI detector mounted in a crutch as the instrument of choice for the Phase I surveys. The scintillometer was effective in identifying small anomalies of DU contamination. Three forms of DU were identified: finely divided oxide layers, oxide coatings on soil, and metal fragments (see Figures 4.1.3 to 4.1.6). The scintillometer readings (counts per second) were converted to an exposure reading in $\mu \mathrm{R} / \mathrm{hr}$ by a conversion factor derived specifically for DU from cross-correlation data collected with a PIC during the Trial Survey. The calculated MDA was verified during the Trial Survey, as demonstrated by the detection of a $1.8 \mu \mathrm{R} / \mathrm{hr}$ above background, 1-inch diameter point source. The calculated MDA for the crutch scintillometer was $1.8 \mu \mathrm{R} / \mathrm{hr}$ above background, which is consistent with NUREG/CR-5849 guidance. The scintillometers were able to detect DU fragments and oxides in soil at depths as great as 6 inches. The optimum survey speed was found to be 0.5 mile per hour, and the only parameter that was changed from site to site was the instrument grid spacing.

Surface radiological measurements were also collected from selected natural background locations to determine the range of natural background. The natural radiological background was characterized so that changes in the gamma radiation field detected by the survey instruments could be attributed to either local variations in natural background or to potential environmental contamination. The variability in natural background radiation is a function of the geologic rock type encountered. Results of the measurements demonstrate that the values decrease as a function of distance away from the natural background locations. Relatively high exposure-rate readings ( 16.1 to $16.7 \mu \mathrm{R} / \mathrm{hr}$ ) were obtained for crystalline terrain, while much lower readings (12.1 to $14.7 \mu \mathrm{R} / \mathrm{hr}$ ) were measured for alluvial material during the Trial Survey.

\section{Phase I Surveys}

Scanning surface radiation surveys were conducted between October 1993 and May 1994 at 64 SNL/NM ER sites covering approximately 830 acres on KAFB. The Phase I surveys were effective at defining the extent of surface radiological contamination at the SNL/NM ER Project sites.

Background values measured at the ER sites during the Phase I surveys ranged from 8 to $20 \mu \mathrm{R} / \mathrm{hr}$, with background at the majority of sites ranging from 10 to $13 \mu \mathrm{R} / \mathrm{hr}$. Many of the ER sites are located in structurally complex areas with many different rock types. Instrument threshold values were established based on site-specific background ranges for each ER site surveyed, rather than using a single value for all the sites. A threshold value of 1.3 times the ambient background determined at each site was used for the Phase I surveys, which is consistent with NUREG/CR-5849 recommendations. Therefore, anomalies delineated on the basis of scintillometer readings (counts per second) greater than 1.3 times the ambient background were considered anomalous and possibly indicative of contamination. 


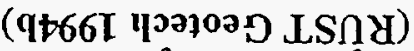

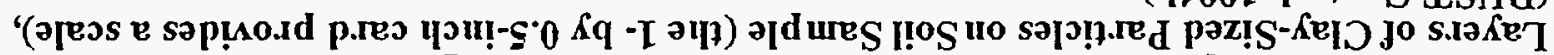

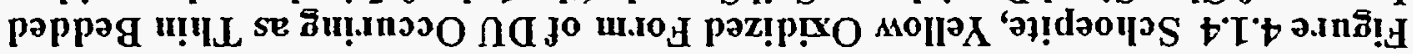

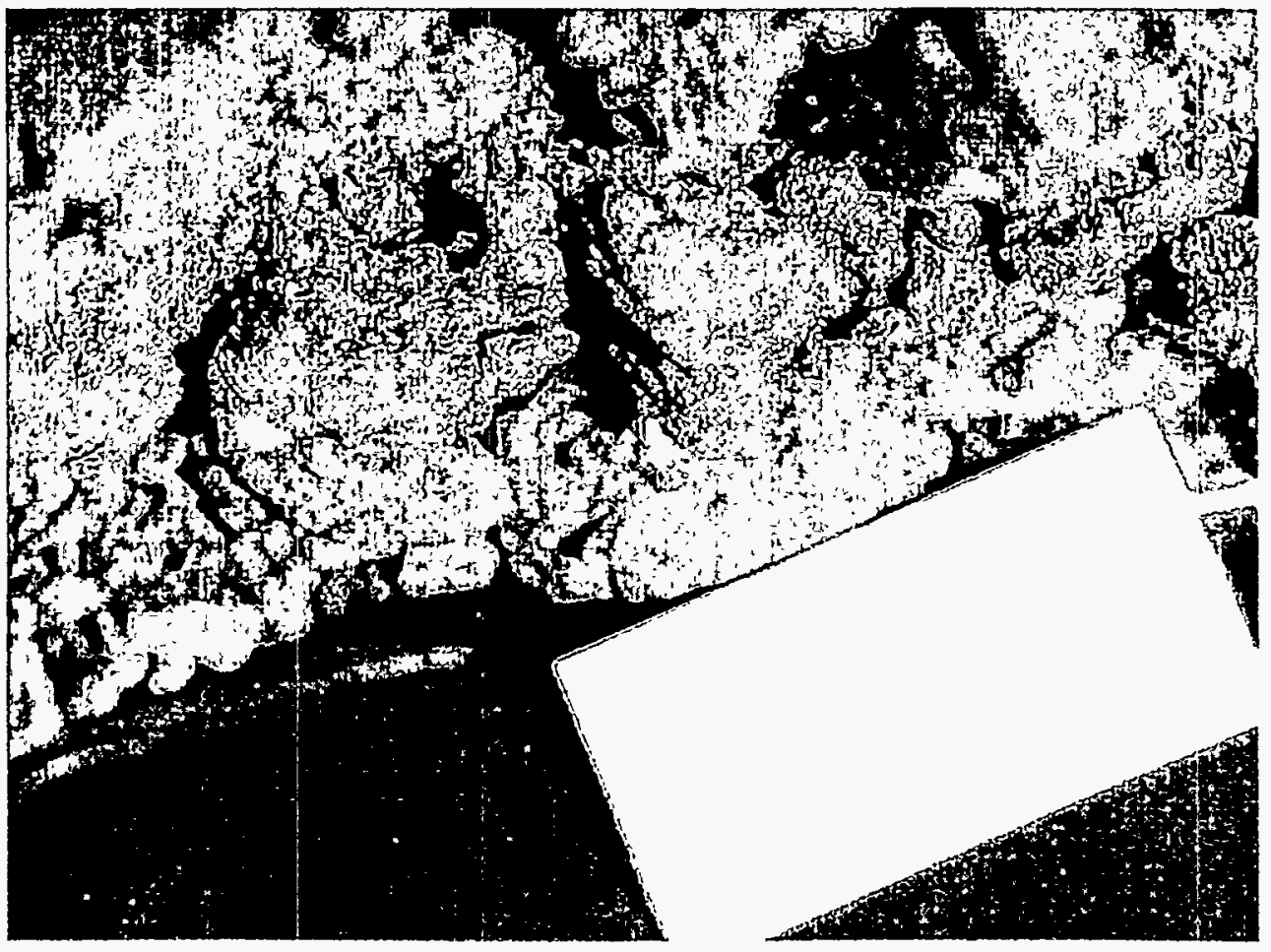

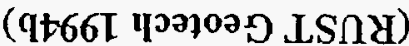

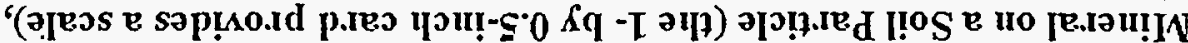

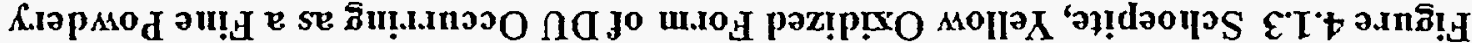

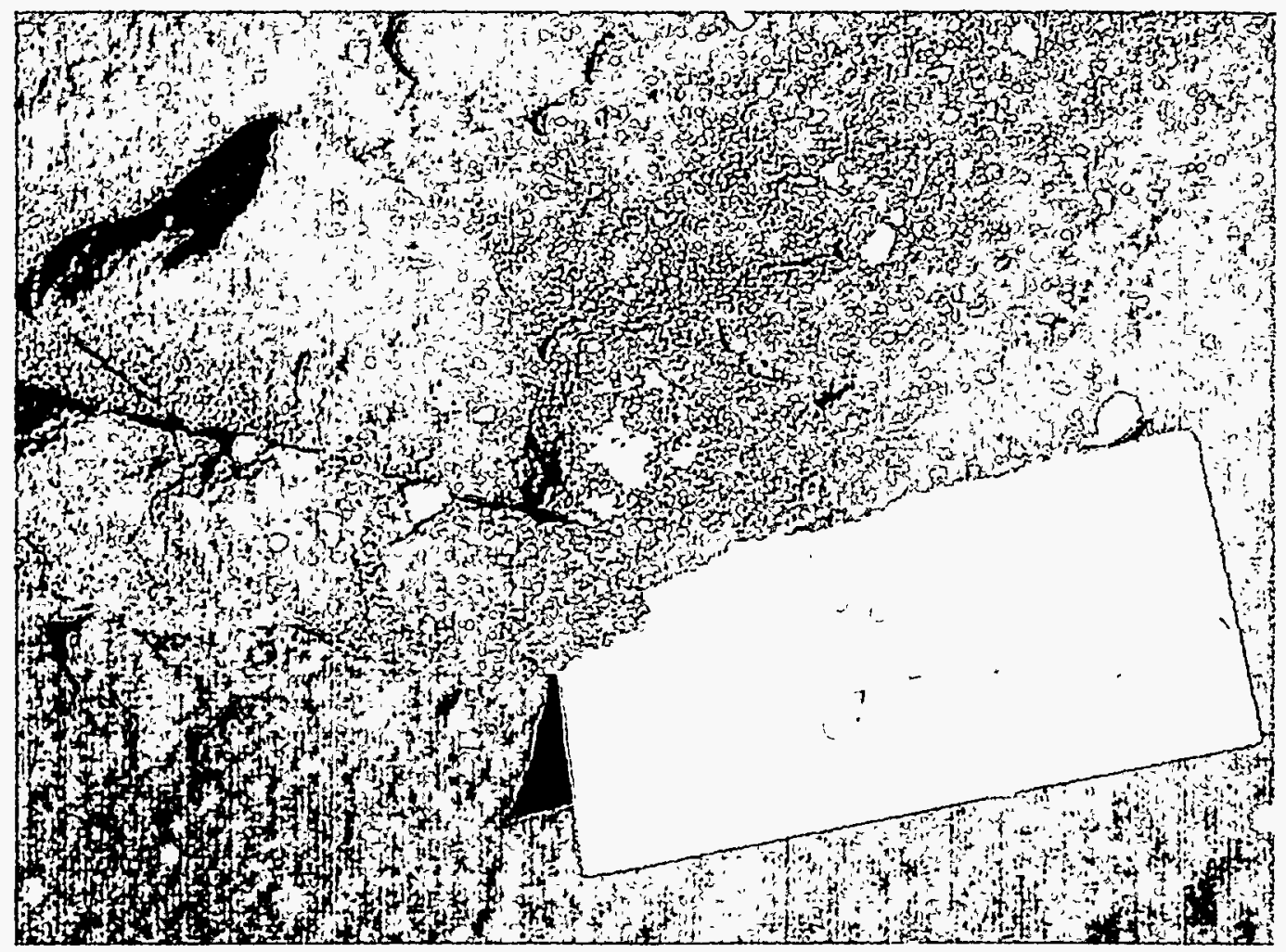




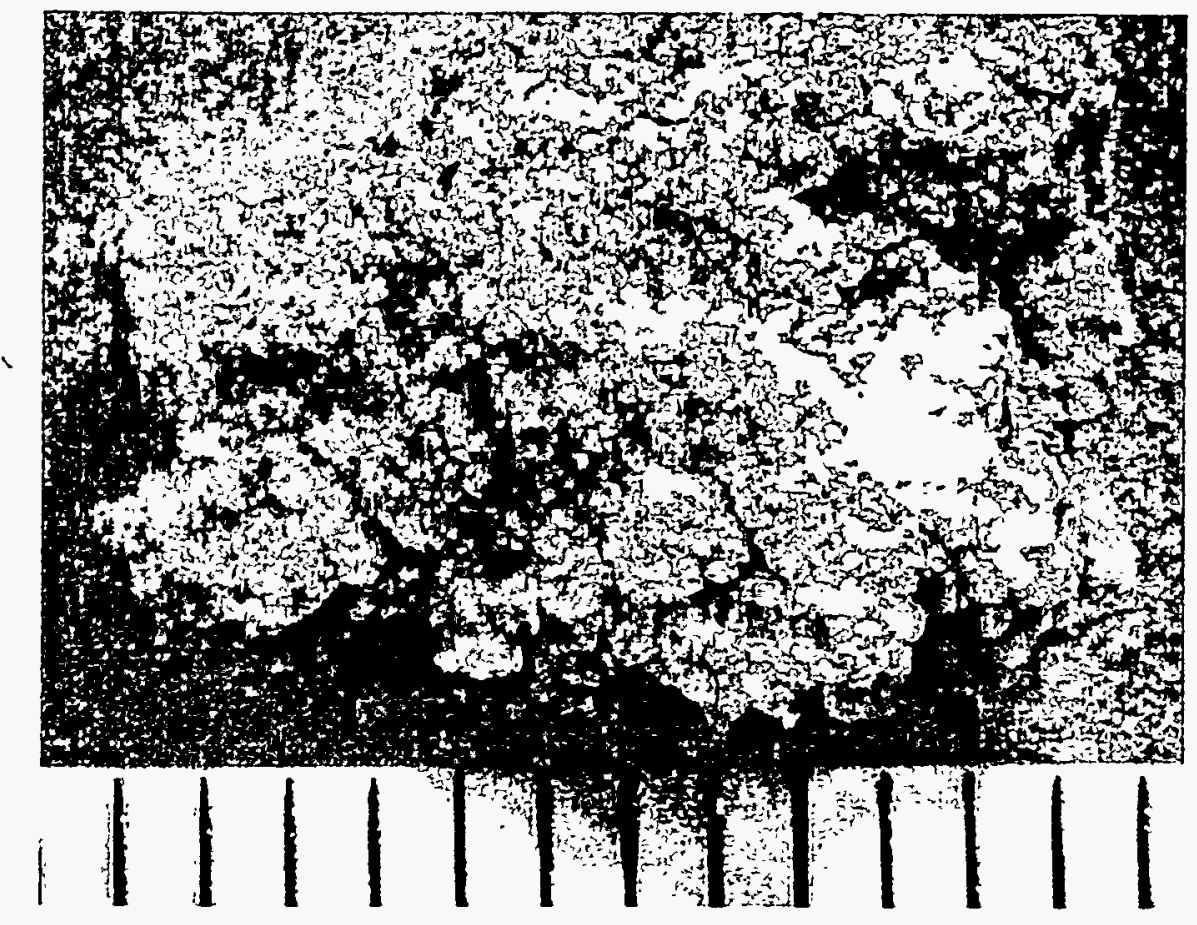

Figure 4.1.5 Microphotograph of a 1-cm-Diameter Soil Particle Coated by Schoepite (the scale at the bottom is in millimeters), (RUST Geotech 1994b)

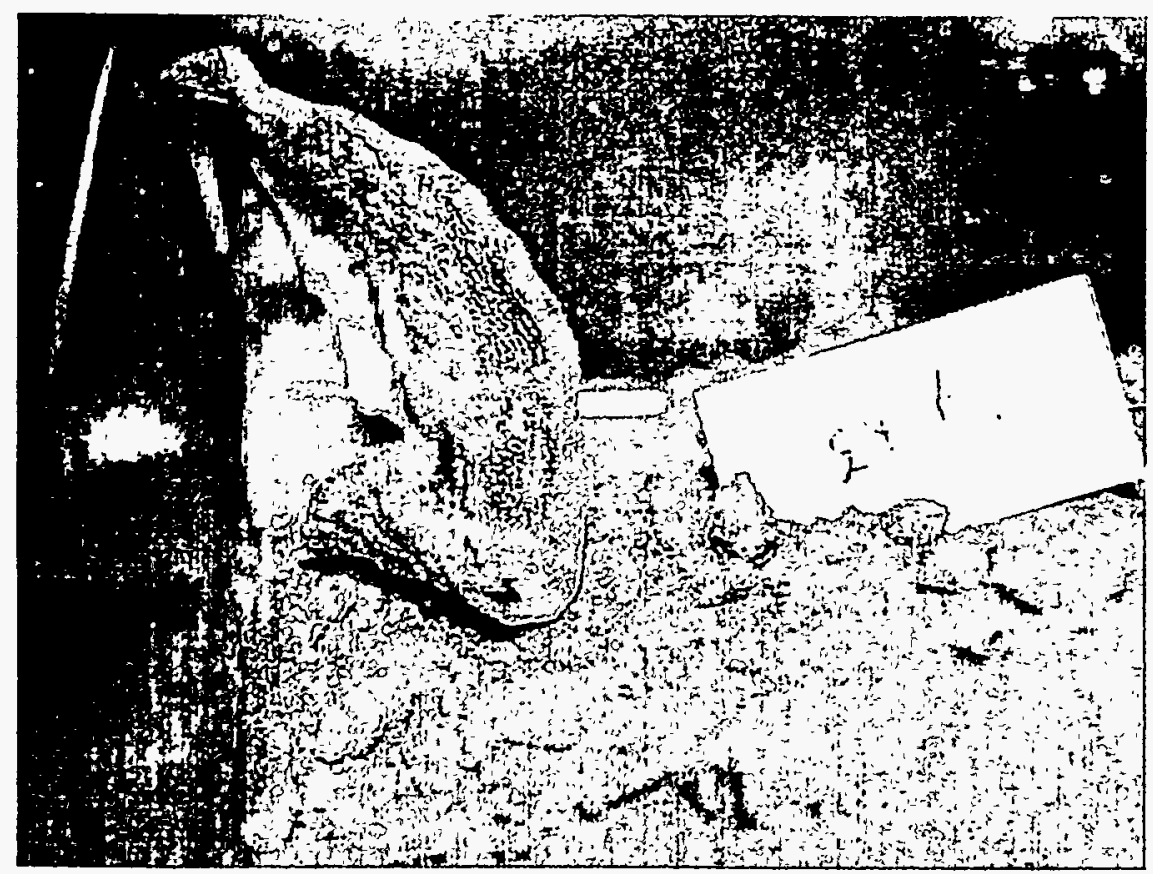

Figure 4.1.6 A 253.6-Gram Metallic Fragment of DU (note light coating of schoepite along upper part of sample; the 1 - by 0.5 -inch card provides a scale), (RUST Geotech 1994b) 
A total of 3,749 anomalous areas were detected during the Phase I surveys. Among these anomalies detected, 3,550 were attributed to "point sources," and 199 were considered "area sources." Point sources were typically associated with metallic fragments from testing activities or characterized by measurements that decreased uniformly away from a discrete point. The types of anomalous gamma radiation detected during the Phase I surveys included area sources and point sources within the soil, area sources and point sources associated with metallic fragments, gamma radiation fields associated with radioactive materials storage areas, and gamma radiation associated with natural geologic outcrops.

Table 4.1.1 summarizes the overall results of the Phase I surface radiological surveys for all 64 ER sites. Detailed results of the surface radiological assessments performed at the sites are presented in the Surface Gamma Radiation Surveys Final Report (Geotech 1994b).

Of the 64 total sites surveyed,

- 27 sites (42 percent) had no anomalies

- 37 sites (58 percent) had 1 or more anomalies

- 21 sites (33 percent) had 10 or more anomalies

- 6 sites (10 percent) had 100 or more anomalies.

These numbers have been revised from the Surface Gamma Radiation Surveys Final Report due to changes in site boundary interpretation and subsite designation.

The majority of the point source anomalies ranged from approximately 15 to $100 \mu \mathrm{R} / \mathrm{hr}$ on contact (background not subtracted), as converted directly from the scintillometer reading. These exposure rates are less than or equal to 20 percent of the posting criteria for Radiation Areas (greater than 5 millirems per hour at 1 foot from the source), per the SNL/NM Radiological Protection Procedures Manual (SNL/NM 1997), which implements 10 CFR 835, Occupational Radiation Protection (DOE 1995). Elevated gamma radiation values measured by the crutch scintillometer ranged from 11 to $1,103 \mu \mathrm{R} / \mathrm{hr}$, which is the upper range of the scintillometer. If the range of the scintillometer was exceeded, measurements were made with a portable ion chamber (Eberline RO 3C). No anomalies exceeded the Radiation Area posting criteria.

\subsubsection{Conclusions and Recommendations}

The Phase I surveys were effective at defining the extent of surface radiological contamination at the SNL/NM ER Project sites. Table 4.1.2 summarizes the overall recommendations for follow-up work on the Phase I surface radiological surveys. The recommendations are presented in greater detail in the Surface Gamma Radiation Surveys Final Report (Geotech 1994b). 
Table 4.1.1. ER Project Sites Where Phase I Surface Radiological Surveys Were Conducted

\begin{tabular}{|c|c|c|c|c|c|c|c|}
\hline \multirow[b]{2}{*}{ ADS } & \multirow[b]{2}{*}{$\begin{array}{c}\text { ER Site } \\
\text { Number } \\
\text { (SWMU \#) }\end{array}$} & \multirow[b]{2}{*}{ Site Name } & \multirow[b]{2}{*}{ Actual Coverage } & \multicolumn{2}{|c|}{ No. of Anomalies } & \multirow[b]{2}{*}{$\begin{array}{c}\text { Site-Specific } \\
\text { Background } \\
\text { Range } \\
(\mu \mathrm{R} / \mathrm{hr})\end{array}$} & \multirow[b]{2}{*}{$\begin{array}{l}\text { Highest } \\
\text { Value } \\
(\mu \mathrm{R} / \mathrm{hr})\end{array}$} \\
\hline & & & & $\begin{array}{l}\text { Point } \\
\text { Source }\end{array}$ & $\begin{array}{c}\text { Area } \\
\text { Source } \\
\end{array}$ & & \\
\hline 1303 & 44 & $\begin{array}{l}\text { Decontamination } \\
\text { Area and Uranium } \\
\text { Calibration Pits }\end{array}$ & $\begin{array}{c}6-\mathrm{ft} \text { centers; } \\
0.3 \text { acre; logged } \\
8 \text { calibration pits }\end{array}$ & 1 & 2 & $11-13$ & 36 \\
\hline 1303 & 113 & Area II Firing Sites & $\begin{array}{l}\text { 6-ft centers; } \\
0.3 \text { acre }\end{array}$ & 0 & 0 & $11-13$ & Background \\
\hline 1306 & 18 & Concrete Pad & $\begin{array}{l}\text { 6-ft centers; } \\
1.9 \text { acres }\end{array}$ & 1 & 0 & $10-12$ & 17 \\
\hline 1306 & 83 & Long Sled Track & $\begin{array}{l}10-\mathrm{ft} \text { centers; } \\
176.3 \text { acres }\end{array}$ & 1361 & 33 & $10-13$ & $>1103$ \\
\hline 1306 & 84 & Gun Facilities & $\begin{array}{l}\text { 6-ft centers; } \\
7.4 \text { acres }\end{array}$ & 50 & 9 & $10-12$ & $>1103$ \\
\hline 1306 & 241 & Storage Yard & $\begin{array}{l}\text { 6-ft centers; } \\
1.8 \text { acres }\end{array}$ & 0 & 4 & $11-12$ & $>1103$ \\
\hline 1306 & 102 & Radioactive Disposal & $\begin{array}{l}\text { 10-ft centers; } \\
4.4 \text { acres }\end{array}$ & 0 & 0 & $10-13$ & Background \\
\hline 1306 & 240 & Short Sled Track & $\begin{array}{l}\text { 10-ft centers; } \\
82.6 \text { acres }\end{array}$ & 251 & 9 & $10-12$ & 308 \\
\hline 1309 & 7,16 & $\begin{array}{c}\text { Gas Cylinder } \\
\text { Disposal and Open } \\
\text { Dumps }\end{array}$ & $\begin{array}{c}7.3 \text { acres, } 6-\mathrm{ft} \\
\text { centers; } 26.4 \text { acres, } \\
10-\mathrm{ft} \text { centers }\end{array}$ & 3 & 18 & $10-12$ & 555 \\
\hline 1309 & $\begin{array}{c}23 \mathrm{~A}, 23 \mathrm{~B} \\
23 \mathrm{C}\end{array}$ & Disposal Trenches & $\begin{array}{l}\text { 6-ft centers; } \\
0.7 \text { acre }\end{array}$ & 0 & 0 & $11-14$ & Background \\
\hline 1309 & 45 & Liquid Discharge & $\begin{array}{l}10-\mathrm{ft} \text { centers; } \\
1.2 \text { acres }\end{array}$ & 0 & 0 & $10-12$ & Background \\
\hline 1309 & 46 & $\begin{array}{l}\text { Old Acid Waste Line } \\
\text { Outfall }\end{array}$ & $\begin{array}{l}\text { 6-ft centers; } \\
0.9 \text { acre }\end{array}$ & 0 & 0 & $10-13$ & Background \\
\hline 1309 & 228 & $\begin{array}{l}\text { Centrifuge Dump } \\
\text { Site }\end{array}$ & $\begin{array}{l}\text { 10-ft centers; } \\
9.2 \text { acres }\end{array}$ & 3 & 0 & $11-12$ & 308 \\
\hline 1309 & 235 & $\begin{array}{c}\text { Storm Drain Systems } \\
\text { Outfall }\end{array}$ & $\begin{array}{l}\text { 6-ft centers; } \\
1.5 \text { acres }\end{array}$ & 0 & 0 & $10-14$ & Background \\
\hline
\end{tabular}


Table 4.1.1. ER Project Sites Where Phase I Surface Radiological Surveys Were Conducted

\begin{tabular}{|c|c|c|c|c|c|c|c|}
\hline \multirow[b]{2}{*}{ ADS } & \multirow[b]{2}{*}{$\begin{array}{c}\text { ER Site } \\
\text { Number } \\
\text { (SWMU \#) }\end{array}$} & \multirow[b]{2}{*}{ Site Name } & \multirow[b]{2}{*}{ Actual Coverage } & \multicolumn{2}{|c|}{ No. of Anomalies } & \multirow{2}{*}{$\begin{array}{c}\text { Site-Specific } \\
\text { Background } \\
\text { Range } \\
(\mu \mathrm{R} / \mathrm{hr}) \\
\end{array}$} & \multirow[b]{2}{*}{$\begin{array}{c}\text { Highest } \\
\text { Value } \\
(\mu \mathrm{R} / \mathrm{hr})\end{array}$} \\
\hline & & & & $\begin{array}{l}\text { Point } \\
\text { Source }\end{array}$ & $\begin{array}{l}\text { Area } \\
\text { Source }\end{array}$ & & \\
\hline 1332 & $\begin{array}{c}8,58,58 \mathrm{~A} \\
58 \mathrm{~B}, 58 \mathrm{C}\end{array}$ & $\begin{array}{c}\text { Open Dump and } \\
\text { Coyote Canyon Blast } \\
\text { Area } \\
\end{array}$ & $\begin{array}{l}\text { 6-ft centers; } \\
49.6 \text { acres }\end{array}$ & 82 & 2 & $10-13$ & 994 \\
\hline 1332 & 15,67 & $\begin{array}{c}\text { Trash Pits } \\
\text { (Frustration Site), } \\
\text { Frustration Site }\end{array}$ & $\begin{array}{l}\text { 6-ft centers; } \\
0.6 \text { acre }\end{array}$ & 0 & 0 & $13-20$ & Background \\
\hline 1332 & 19 & $\begin{array}{l}\text { TRUPAK Boneyard } \\
\text { Storage Area } \\
\end{array}$ & $\begin{array}{l}6-\mathrm{ft} \text { centers; } \\
1.9 \text { acres }\end{array}$ & 0 & 5 & $11-15$ & 105 \\
\hline 1332 & 27,49 & $\begin{array}{l}\text { Building } 9820- \\
\text { Animal Disposal Pit } \\
\text { and Drains }\end{array}$ & $\begin{array}{l}\text { 6-ft centers; } \\
1.4 \text { acres }\end{array}$ & 1 & 0 & $12-14$ & 42 \\
\hline 1332 & $\begin{array}{c}66,66 \mathrm{~A} \\
66 \mathrm{~B}\end{array}$ & Boxcar Site & $\begin{array}{c}1.8 \text { acres, } 6-\mathrm{ft} \\
\text { centers; } 2.9 \text { acres, } \\
10-\mathrm{ft} \text { centers }\end{array}$ & 0 & 0 & $12-17$ & Background \\
\hline 1332 & 82 & $\begin{array}{l}\text { Old Aerial Cable Site } \\
\text { Scrap }\end{array}$ & $\begin{array}{l}\text { 6-ft centers; } \\
19.4 \text { acres }\end{array}$ & 0 & $4^{a}$ & $11-17$ & 18 \\
\hline 1332 & 87 & $\begin{array}{l}\text { Building } 9990- \\
\quad \text { Firing Site }\end{array}$ & $\begin{array}{l}\text { 10-ft centers; } \\
44.6 \text { acres }\end{array}$ & 1241 & $9^{\mathrm{a}, \mathrm{b}}$ & $10-20$ & 719 \\
\hline 1333 & $10,60,59$ & $\begin{array}{l}\text { Burial Mounds, } \\
\text { Bunker Area, } \\
\text { Pendulum Site }\end{array}$ & $\begin{array}{l}\text { 6-ft centers; } \\
30.5 \text { acres }\end{array}$ & 31 & $21^{2}$ & $10-16$ & 39 \\
\hline 1333 & $\begin{array}{l}12,13,65 \\
\text { and } 94\end{array}$ & $\begin{array}{l}\text { Burial Site/Open } \\
\text { Dump, Oil Surface } \\
\text { Impoundment, } \\
\text { Lurance Canyon } \\
\text { Explosive Test Site, } \\
\text { Lurance Canyon } \\
\text { Burn Site }\end{array}$ & $\begin{array}{c}15.9 \text { acres, } 6-\mathrm{ft} \\
\text { centers; } 87.7 \text { acres, } \\
10-\mathrm{ft} \text { centers }\end{array}$ & 67 & 13 & $10-13$ & 664 \\
\hline 1333 & 63 & Balloon Test Area & $\begin{array}{l}\text { 6-ft centers; } \\
19.8 \text { acres }\end{array}$ & 0 & 0 & $9-12$ & Background \\
\hline 1333 & $\begin{array}{l}239 \mathrm{~A} \\
239 \mathrm{~B}^{\mathrm{c}}\end{array}$ & $\begin{array}{c}\text { Impact Area } 155 \mathrm{~mm} \\
\text { and Rockets }\end{array}$ & $\begin{array}{l}\text { 6-ft centers; } \\
1.2 \text { acres }\end{array}$ & 0 & 0 & $11-16$ & Background \\
\hline
\end{tabular}


Table 4.1.1. ER Project Sites Where Phase I Surface Radiological Surveys Were Conducted

\begin{tabular}{|c|c|c|c|c|c|c|c|}
\hline \multirow[b]{2}{*}{ ADS } & \multirow[b]{2}{*}{$\begin{array}{c}\text { ER Site } \\
\text { Number } \\
\text { (SWMU \#) }\end{array}$} & \multirow[b]{2}{*}{ Site Name } & \multirow[b]{2}{*}{ Actual Coverage } & \multicolumn{2}{|c|}{ No. of Anomalies } & \multirow[b]{2}{*}{$\begin{array}{c}\text { Site-Specific } \\
\text { Background } \\
\text { Range } \\
(\mu \mathrm{R} / \mathrm{hr})\end{array}$} & \multirow[b]{2}{*}{$\begin{array}{l}\text { Highest } \\
\text { Value } \\
(\mu \mathrm{R} / \mathrm{hr})\end{array}$} \\
\hline & & & & $\begin{array}{l}\text { Point } \\
\text { Source }\end{array}$ & $\begin{array}{l}\text { Area } \\
\text { Source }\end{array}$ & & \\
\hline 1333 & 81 & $\begin{array}{c}\text { New Aerial Cable } \\
\text { Site/Burial } \\
\text { Site/Dump/Test Area }\end{array}$ & $\begin{array}{l}\text { 6-ft centers; } \\
31.2 \text { acres }\end{array}$ & 0 & $4^{a}$ & $9-13$ & 17 \\
\hline 1333 & 92 & $\begin{array}{c}\text { Pressure Vessel Test } \\
\text { Site }\end{array}$ & $\begin{array}{l}\text { 6-ft centers; } \\
2.1 \text { acres }\end{array}$ & 0 & 0 & $10-13$ & Background \\
\hline 1333 & $236^{c}$ & $\begin{array}{c}\text { Pit East of Balloon } \\
\text { Test Site }\end{array}$ & $\begin{array}{c}3.0 \text { acres, } 6-\mathrm{ft} \\
\text { centers; } 3.7 \text { acres, } \\
10-\mathrm{ft} \text { centers }\end{array}$ & 0 & 0 & $11-14$ & Background \\
\hline 1334 & $\begin{array}{c}61 \mathrm{~A}, 61 \mathrm{C} \\
9 \text { and } 20\end{array}$ & $\begin{array}{c}\text { Schoolhouse Mesa } \\
\text { Test Site }\end{array}$ & $\begin{array}{c}1.8 \text { acres, } 6-\mathrm{ft} \\
\text { centers; } 37.7 \text { acres, } \\
10-\mathrm{ft} \text { centers }\end{array}$ & 63 & 11 & $10-13$ & 116 \\
\hline 1334 & 21,62 & $\begin{array}{l}\text { Metal Scrap and } \\
\text { Greystone Manor }\end{array}$ & $\begin{array}{l}\text { 6-ft centers; } \\
1.4 \text { acres }\end{array}$ & 0 & 0 & $10-13$ & Background \\
\hline 1334 & 22 & Storage/Burn & $\begin{array}{l}\text { 6-ft centers; } \\
0.1 \text { acre }\end{array}$ & 0 & 0 & $11-13$ & Background \\
\hline 1334 & 47 & Doomed Bunker & $\begin{array}{l}\text { 6-ft centers; } \\
1.1 \text { acres }\end{array}$ & 0 & 0 & $10-13$ & Background \\
\hline 1334 & $57 \mathrm{~A}, 57 \mathrm{~B}$ & Workman Site & $\begin{array}{c}10 \text {-ft centers; } \\
15.6 \text { acres }\end{array}$ & 1 & 6 & $11-13$ & 83 \\
\hline 1334 & 88 & Firing Site & $\begin{array}{c}10-\mathrm{ft} \text { centers; } \\
16.6 \text { acres }\end{array}$ & 0 & 1 & $11-14$ & 17 \\
\hline 1334 & 68,71 & $\begin{array}{l}\text { Old Burn Site and } \\
\text { Moonlight Shot Area }\end{array}$ & $\begin{array}{c}14.7 \text { acres, } 6-\mathrm{ft} \\
\text { centers; } 64.2 \text { acres, } \\
10-\mathrm{ft} \text { centers }\end{array}$ & 242 & 16 & $9-13$ & 610 \\
\hline 1334 & 69 & Firing Pits & $\begin{array}{c}6-\mathrm{ft} \text { centers; } \\
1.0 \text { acre }\end{array}$ & 0 & 0 & $10-12$ & Background \\
\hline 1334 & $\begin{array}{c}70 \mathrm{~A}, 70 \mathrm{~B} \\
70 \mathrm{C}\end{array}$ & Explosives Test Pit & $\begin{array}{l}\text { 6-ft centers; } \\
0.5 \text { acre }\end{array}$ & 0 & 0 & $8-12$ & Background \\
\hline 1335 & 14,85 & $\begin{array}{c}\text { Building } 9920- \\
\text { Burial Site and Firing } \\
\text { Site }\end{array}$ & $\begin{array}{l}\text { 6-ft centers; } \\
1.4 \text { acres }\end{array}$ & 0 & 1 & $10-12$ & 50 \\
\hline
\end{tabular}


Table 4.1.1. ER Project Sites Where Phase I Surface Radiological Surveys Were Conducted

\begin{tabular}{|c|c|c|c|c|c|c|c|}
\hline \multirow[b]{2}{*}{ ADS } & \multirow[b]{2}{*}{$\begin{array}{c}\text { ER Site } \\
\text { Number } \\
\text { (SWMU \#) }\end{array}$} & \multirow[b]{2}{*}{ Site Name } & \multirow[b]{2}{*}{ Actual Coverage } & \multicolumn{2}{|c|}{ No. of Anomalies } & \multirow{2}{*}{$\begin{array}{c}\text { Site-Specific } \\
\text { Background } \\
\text { Range } \\
(\mu \mathrm{R} / \mathrm{hr})\end{array}$} & \multirow[b]{2}{*}{$\begin{array}{c}\text { Highest } \\
\text { Value } \\
(\mu \mathrm{R} / \mathrm{hr})\end{array}$} \\
\hline & & & & $\begin{array}{c}\text { Point } \\
\text { Source }\end{array}$ & $\begin{array}{c}\text { Area } \\
\text { Source }\end{array}$ & & \\
\hline 1335 & $\begin{array}{c}17 \mathrm{~A}, 17 \mathrm{~B} \\
17 \mathrm{D}\end{array}$ & $\begin{array}{c}\text { Scrap Yards/Open } \\
\text { Dump }\end{array}$ & $\begin{array}{l}\text { 10-ft centers; } \\
2.8 \text { acres }\end{array}$ & 5 & 2 & $10-13$ & 39 \\
\hline 1335 & 55 & Red Towers Site & $\begin{array}{l}\text { 6-ft centers; } \\
14.6 \text { acres }\end{array}$ & 123 & 1 & $11-12$ & 116 \\
\hline 1335 & 86 & $\begin{array}{c}\text { Building } 9927- \\
\text { Firing Site } \\
\end{array}$ & $\begin{array}{l}\text { 6-ft centers; } \\
2.8 \text { acres }\end{array}$ & 0 & 0 & $10-12$ & Background \\
\hline 1335 & 90 & Beryllium Firing Site & $\begin{array}{l}\text { 6-ft centers; } \\
0.2 \text { acre }\end{array}$ & 0 & 0 & $10-11$ & Background \\
\hline 1335 & 103,117 & $\begin{array}{l}\text { Building } 9939- \\
\text { Scrap Yard and } \\
\text { Trenches }\end{array}$ & $\begin{array}{l}\text { 6-ft centers; } \\
6.3 \text { acres }\end{array}$ & 8 & 13 & $10-13$ & 198 \\
\hline 1335 & 108 & $\begin{array}{l}\text { Building } 9940- \\
\text { Firing Site } \\
\end{array}$ & $\begin{array}{l}\text { 6-ft centers; } \\
2.2 \text { acres }\end{array}$ & 4 & 11 & 11 & 39 \\
\hline 1335 & $\begin{array}{l}109 \mathrm{~A} \\
109 \mathrm{~B}\end{array}$ & $\begin{array}{c}\text { Building } 9956- \\
\text { Firing Site }\end{array}$ & $\begin{array}{l}\text { 6-ft centers; } \\
0.5 \text { acre }\end{array}$ & 0 & 0 & $10-12$ & 0 \\
\hline 1335 & 115 & $\begin{array}{c}\text { Building } 9930- \\
\text { Firing Site }\end{array}$ & $\begin{array}{l}\text { 6-ft centers; } \\
1.0 \text { acre }\end{array}$ & 0 & $1^{2}$ & $10-12$ & 15 \\
\hline 1335 & 191 & Equus Red & $\begin{array}{l}\text { 6-ft centers; } \\
4.2 \text { acres }\end{array}$ & 5 & 0 & $11-12$ & 24 \\
\hline 1335 & 193 & Sabotage Test Area & $\begin{array}{l}\text { 6-ft centers; } \\
0.5 \text { acre }\end{array}$ & 7 & 3 & $11-12$ & 28 \\
\hline 1335 & 194 & $\begin{array}{c}\text { General Purpose } \\
\text { Heat Source Test } \\
\text { Area }\end{array}$ & $\begin{array}{l}\text { 6-ft centers; } \\
0.2 \text { acre }\end{array}$ & 0 & 0 & $11-13$ & Background \\
\hline & & & TOTAL & 3,550 & 199 & & \\
\hline
\end{tabular}

${ }^{2}$ Includes anomalies that appear to be natural geologic outcrops.

${ }^{b}$ One area source includes approximately 175 point sources.

c This site is a potential SWMU.

Source: Geotech 1994b 
Table 4.1.2. Summary of Phase I Survey

\begin{tabular}{|c|c|c|c|c|c|c|}
\hline \multirow[b]{2}{*}{ SWMU } & \multirow[b]{2}{*}{$\begin{array}{c}\text { No } \\
\text { Further } \\
\text { Action }\end{array}$} & \multicolumn{3}{|c|}{ Verify Anomaly } & \multirow[b]{2}{*}{$\begin{array}{c}\text { Expand } \\
\text { Radiological } \\
\text { Boundaries } \\
\end{array}$} & \multirow[b]{2}{*}{$\begin{array}{l}\text { Establish } \\
\text { Cleanup } \\
\text { Criteria }\end{array}$} \\
\hline & & Geologic & "Shine" & Cultural & & \\
\hline \multicolumn{7}{|c|}{ Technical Area II Operable Unit Sites (ADS 1303) } \\
\hline 44 & & & & & & $\mathbf{x}$ \\
\hline 113 & $\mathbf{x}$ & & & & & \\
\hline \multicolumn{7}{|c|}{ Technical Area III/V Operable Unit Sites (ADS 1306) } \\
\hline 18 & & & & & & $\mathbf{x}$ \\
\hline 83 & & & & & $\mathbf{x}$ & $\mathbf{x}$ \\
\hline 84 & & & & & $\mathbf{x}$ & $\mathrm{x}$ \\
\hline 241 & & & $\mathbf{x}$ & & & \\
\hline 102 & $\mathbf{x}$ & & & & & \\
\hline 240 & & & $\mathbf{x}$ & & $\mathbf{x}$ & $\mathbf{x}$ \\
\hline \multicolumn{7}{|c|}{ Tijeras Arroyo Operable Unit Sites (ADS 1309) } \\
\hline 7 & $\mathbf{x}$ & & & & & \\
\hline 16 & & & & & & $\mathbf{x}$ \\
\hline $\begin{array}{c}23 \mathrm{~A}, 23 \mathrm{~B} \\
23 \mathrm{C}\end{array}$ & $\mathbf{x}$ & & & & & \\
\hline 45 & $\mathbf{x}$ & & & & & \\
\hline 46 & $\mathbf{x}$ & & & & & \\
\hline 228 & & & & & & $\mathbf{x}$ \\
\hline 235 & $\mathbf{x}$ & & & & & \\
\hline \multicolumn{7}{|c|}{ Foothills Test Area Operable Unit Sites (ADS 1332) } \\
\hline $58 \mathrm{~A}, 58 \mathrm{~B}$ & $\mathbf{x}$ & & & & & \\
\hline $8,58,58 \mathrm{C}$ & & & & & & $\mathbf{x}$ \\
\hline 15,67 & $\mathbf{x}$ & & & & & \\
\hline 19 & & & & & $\mathbf{x}$ & $\mathbf{x}$ \\
\hline 27,49 & & & & & & $\mathbf{x}$ \\
\hline
\end{tabular}


Table 4.1.2. Summary of Phase I Survey

\begin{tabular}{|c|c|c|c|c|c|c|}
\hline \multirow[b]{2}{*}{ SWMU } & \multirow[b]{2}{*}{$\begin{array}{c}\text { No } \\
\text { Further } \\
\text { Action }\end{array}$} & \multicolumn{3}{|c|}{ Verify Anomaly } & \multirow[b]{2}{*}{$\begin{array}{c}\text { Expand } \\
\text { Radiological } \\
\text { Boundaries }\end{array}$} & \multirow[b]{2}{*}{$\begin{array}{l}\text { Establish } \\
\text { Cleanup } \\
\text { Criteria }\end{array}$} \\
\hline & & Geologic & "Shine" & Cultural & & \\
\hline $\begin{array}{c}66,66 \mathrm{~A} \\
66 \mathrm{~B}\end{array}$ & $\mathbf{x}$ & & & & & \\
\hline 82 & & $\mathbf{X}$ & & & & \\
\hline 87 & & $\mathbf{x}$ & & & $\mathbf{X}$ & $\mathbf{x}$ \\
\hline \multicolumn{7}{|c|}{ Canyons Test Area Operable Unit Sites (ADS 1333) } \\
\hline 10,60 & & $\mathbf{X}$ & & & & $\mathbf{x}$ \\
\hline 59 & $\mathbf{X}$ & & & & & \\
\hline $\begin{array}{c}12,13,65 \\
94\end{array}$ & & & & & & $\mathbf{x}$ \\
\hline 63 & $\mathbf{x}$ & & & & & \\
\hline 239 & $\mathbf{X}$ & & & & & \\
\hline 81 & & $\mathbf{X}$ & & & & \\
\hline 92 & $\mathbf{X}$ & & & & & \\
\hline 236 & $\mathbf{X}$ & & & & & \\
\hline \multicolumn{7}{|c|}{ Central Coyote Test Area Operable Unit Sites (ADS 1334) } \\
\hline $61 \mathrm{~A}, 9$ & & & & & $\mathbf{X}$ & $\mathbf{X}$ \\
\hline $61 \mathrm{C}, 20$ & $\mathbf{X}$ & & & & & \\
\hline 21 & $\mathbf{x}$ & & & & & \\
\hline 62 & $\mathbf{X}$ & & & & & \\
\hline 22 & $\mathbf{X}$ & & & & & \\
\hline 47 & $\mathbf{X}$ & & & & & \\
\hline $57 \mathrm{~A}, 57 \mathrm{~B}$ & & & & $\mathbf{X}$ & & $\mathbf{X}$ \\
\hline 88 & & & & $\mathbf{X}$ & & \\
\hline 68,71 & & & & & $\mathbf{X}$ & $\mathbf{X}$ \\
\hline 69 & $\mathbf{X}$ & & & & & \\
\hline $\begin{array}{c}70 \mathrm{~A}, 70 \mathrm{~B} \\
70 \mathrm{C}\end{array}$ & $\mathbf{x}$ & & & & & \\
\hline
\end{tabular}


Table 4.1.2. Summary of Phase I Survey

\begin{tabular}{|c|c|c|c|c|c|c|}
\hline \multirow[b]{2}{*}{ SWMU } & \multirow[b]{2}{*}{$\begin{array}{c}\text { No } \\
\text { Further } \\
\text { Action }\end{array}$} & \multicolumn{3}{|c|}{ Verify Anomaly } & \multirow[b]{2}{*}{$\begin{array}{c}\text { Expand } \\
\text { Radiological } \\
\text { Boundaries }\end{array}$} & \multirow[b]{2}{*}{$\begin{array}{l}\text { Establish } \\
\text { Cleanup } \\
\text { Criteria }\end{array}$} \\
\hline & & Geologic & "Shine" & Cultural & & \\
\hline \multicolumn{7}{|c|}{ Southwest Test Area Operable Unit Sites (ADS 1335) } \\
\hline 14,85 & & & $\mathbf{x}$ & & & \\
\hline $17 \mathrm{~B}$ & & & & & & $\mathbf{x}$ \\
\hline 17A,17D & $\mathbf{x}$ & & & & & $\mathbf{x}$ \\
\hline 55 & & & & & $\mathbf{x}$ & $\mathbf{x}$ \\
\hline 86 & $\mathbf{x}$ & & & & & \\
\hline 90 & $\mathbf{x}$ & & & & & \\
\hline 103,117 & & & $\mathbf{x}$ & & & $\mathbf{x}$ \\
\hline 108 & & & & & & $\mathbf{x}$ \\
\hline 109A,109B & $\mathbf{x}$ & & & & & \\
\hline 115 & & $\mathbf{x}$ & & & & \\
\hline 191 & & & & & $\mathbf{x}$ & $\mathbf{x}$ \\
\hline 193 & & & & & $\mathbf{x}$ & $\mathbf{x}$ \\
\hline 194 & $\mathbf{x}$ & & & & & \\
\hline
\end{tabular}

Source: Geotech 1994b 
Of the sites surveyed,

- 27 sites were recommended for NFA because surface radiological anomalies were not detected within the radiological survey boundaries. The NFA recommendation was only for radiological contamination at these sites.

- 11 sites were recommended for additional field investigations, such as in situ gamma-ray spectroscopy, geologic mapping, and/or soil sampling where surface anomalies were believed to be related to natural geologic outcrops, "shine" from adjacent sources, or the result of cultural objects.

- 10 sites were recommended for additional surface radiological surveys where anomalies were detected at or near the Phase I radiological boundaries. Additional surveys were required to adequately define the horizontal extent of contamination.

- 23 sites were recommended for VCM to remove surface anomalies associated with metallic DU fragments (point sources) and soils. This will eliminate the associated health and safety and site access concerns related to residual radionuclides in soil.

\subsection{VCM Cleanup}

\subsubsection{Adequacy of Cleanup}

Corrective action objectives at SNL/NM ER sites include reducing contamination to levels that allow uses of the formerly contaminated sites consistent with future land-use designations and the ALARA principle. This VCM was consistent with this general objective and with the corresponding permit requirements, as well as the requirements of proposed Subpart $S$ of Title 40 of the Code of Federal Regulations (EPA 1990), in that this removal action does not preclude any other corrective action deemed necessary in the future. EPA and DOE allowable dose limits (given as TEDE limits) drove the cleanup. The most restrictive of the EPA and DOE limits was used as the maximum allowable TEDE in a generic risk assessment scenario, which was used to back-calculate the related maximum allowable soil concentration. The target cleanup level, as determined by this generic risk assessment and discussed in Section 2.2.2, was $230 \mathrm{pCi} / \mathrm{g}$ of $\mathrm{U}-238$ in the soil.

Guidance provided in NUREG/CR-5849 suggested that the instrument chosen for the scan survey be capable of detecting the contaminant of concern at 25 percent to 75 percent of the target cleanup level. Therefore, it was determined that the instrument must be capable of detecting U-238 at a level between 57.5 to $172.5 \mathrm{pCi} / \mathrm{g}$.

The estimated detection limit, using the NaI gamma scintillometer for a point source, was approximately 35 percent of the target cleanup level. The estimated detection limit, using the $\mathrm{NaI}$ gamma scintillometer for an area source was approximately 6 percent of the target cleanup level. These are both well within the NUREG/CR-5849 guidance provided, with the conclusion 
that the NaI gamma scintillometer with alarms set at 1.3 times ambient background was sensitive enough to detect DU at or below the concentration of concern.

For this cleanup, a value of 1.3 times ambient background using a NaI gamma scintillometer and a GM pancake probe was chosen as a static count cleanup criteria when surface radioactive anomalies were remediated. During cleanup, the soils were spread on a plastic sheet so that the handheld instruments were essentially always giving a contact, or surface, measurement.

Verification soil sampling of 10 percent of all point source anomalies and all area source anomalies (1,008 total samples) confirmed that acceptable soil concentrations were achieved under each anomaly cleaned up. The predominant radiological contaminant of concern was DU. The maximum residual soil concentration for U-238, the primary constituent of DU, ranged from a high of $116 \mathrm{pCi} / \mathrm{g}$ at ER Site 87 to a low of $0.49 \mathrm{pCi} / \mathrm{g}$ at ER Site 57A. The average maximum residual soil concentration from all sites for U-238 was $19.43 \mathrm{pCi} / \mathrm{g}$. It was assumed that since all anomalies were remediated to 1.3 times background, and the anomaly subset sampled all met risk-based cleanup levels for residual radionuclides, then all of the remediated anomalies met these risk-based cleanup levels. To ensure adequate representation, a 100 percent quality assurance check was performed on the NaI detector field readings and the gamma spectroscopy data at the sampled areas. Thus, the soil concentrations achieved in the field were far below the target cleanup level ( $230 \mathrm{pCi} / \mathrm{g}$ of U-238 in the soil) indicated by the generic risk assessment.

The verification soil sampling data were used in site-specific risk assessments to show that the residual radioactivity levels of the soils left on site did not exceed the more conservative EPA allowable dose limit and that cleanup was complete. Choosing to clean up to a near-background value gave a considerable margin of safety at each individual site, was consistent with the ALARA principle, and was done by design since it would not be cost-effective to revisit any site. In addition, at the time the decision was made to clean up to 1.3 times background, the land use had not been established.

\subsubsection{Additional Studies Supporting Adequacy of Cleanup}

\section{Munk Report}

In November of 1995 , a study was commissioned by the SNL/NM Environmental Monitoring Program. The objectives of the study included:

1. To compile information about the nature and extent of DU contamination at SNL/NM

2. To review the environmental chemistry and toxicology of uranium

3. To identify the principal exposure pathways and target populations associated with exposure to DU.

In addition, data were presented relating to the concentration of uranium in a respirable fraction from soil samples taken at several ER sites. Findings and conclusions from this study may be 
seen in the Preliminary Risk Analysis for Depleted Uranium in Outdoor Environments Sandia National Laboratory, New Mexico (Munk 1995).

The study was undertaken to address concerns relating to the possibility that the surface gamma radiation surveys and VCM may have overlooked areas of DU contamination that could present a contribution to the inhalation dose to members of the public in the vicinity of SNL/NM-owned technical areas. In support of this study, the SNL/NM Environmental Monitoring Program subcontracted an independent party to collect and analyze 9 composite samples and 90 subsamples from three separate ER sites. These sites, the Long Sled Track (ER Site 83), Moonlight Shot (ER Site 71), and the Old Aerial Cable site (ER Site 82), were chosen based on their having impact and explosives tests performed with DU and were selected for sampling due to the likelihood of their containing finely-divided anthropogenic (man-made) sources of DU at the soil surface (Munk 1995).

In addition to analyzing the 90 subsamples by gamma spectroscopy, the 9 composite samples were analyzed for total isotopic uranium by alpha spectroscopy on the $<2$ millimeters ( $\mathrm{mm}$ ) and $<10$ micrometers $(\mu \mathrm{m})$ particle size fractions. The particle size analysis was performed in order to determine the respirable fraction of DU in the soil. The sample locations at these sites were chosen to represent typical surface conditions and to provide a range of distances from impact and detonation zones. Samples were drawn in the upper 1 inch of soil, and sample locations were chosen to lie outside of areas identified by the surface gamma radiation surveys as being contaminated or in areas that had been identified as being cleaned up during the VCM.

Through research and analysis of the samples taken, the following conclusions were made:

1. No evidence of elevated U-238 levels were found in the composite samples taken from the three sites in both the $<2 \mathrm{~mm}$ and $<10 \mu \mathrm{m}$ fractions

2. The gamma spectroscopy analysis of the 90 subsamples showed no elevated U-238 concentrations

3. DU that does occur on ER sites has a low mobility in the environment, both in the subsurface and as airborne contamination

4. Extensive air contamination by DU, and therefore exposure through the inhalation pathway to off-site individuals, is not expected due to the DU contamination occurring in localized areas.

\section{Background Study}

Establishing background concentrations of naturally occurring constituents of concern is an extremely important aspect when determining the existence and extent of chemical and radiological contamination at a site. The report Background Concentrations of Constituents of Concern to the Sandia National Laboratories/New Mexico Environmental Restoration Project 
and the Kirtland Air Force Base Installation Restoration Program, (IT Corporation 1996) discusses the SNL/NM approach in making this determination.

The naturally occurring constituents included ten long-lived radionuclides. For the chemical and radiological constituents combined, approximately 75,000 data points were initially considered as part of the analysis (IT Corporation 1996). These data points were taken from an extensive list of sources and span over a 20-year period. It was assumed that some of these data points could be representative of possible contamination since not all of the samples were taken specifically for the determination of background constituents of concern. To mitigate the effects that contaminated samples could have on the final background determination, several statistical tests were performed using both parametric and nonparametric methods to determine possible contaminated samples and exclude them from the background population.

A primary goal of the report was to express background concentrations on as large a spatial (aerial as well as depth) scale as was technically defensible (IT Corporation 1996). If background values could not be represented on a base-wide scale, then values representing subsets of the base were developed. This was the case for both surface and subsurface, when applicable.

The final conclusion of the report, based on statistical and professional interpretation of the results, was that the data points used in the final analysis were sufficient to determine accurate background concentrations. It was determined that defining background on as large a scale as possible provided the most consistent, efficient, credible, and cost-effective approach to establishing background concentrations (IT Corporation 1996).

For reasons stated above, these background values were used in determining the presence and extent of radioactive contamination on the ER sites of interest in this report. Following comparison to background, pre- and post-cleanup samples were analyzed to determine the need for further remediation and, in some cases, if contaminants other than DU were present. In cases where a final radiological risk assessment was performed, the background values were subtracted from site residual radioactivity values in order to determine the incremental TEDE in excess of background.

\subsubsection{Cleanup Results}

Cleanup activities were conducted between October 1994 and November 1996 at 38 ER sites covering approximately 908 acres on KAFB. Additional expanded surface gamma radiation surveys were conducted at 13 ER sites where anomalies were detected at or near the Phase I survey radiological boundaries and where the original coverage was only 70 percent ( 10 -foot centers). In addition, pre-cleanup soil sampling was conducted at $15 \mathrm{ER}$ sites during the VCM to assess the need to remediate area sources. Table 4.2.1 summarizes the field activities conducted at ER sites during the VCM. 
Table 4.2.1 ER Project Sites Where VCM Field Activities Were Conducted

\begin{tabular}{|c|c|c|c|c|c|c|c|c|c|c|}
\hline \multicolumn{11}{|c|}{ Removal Action Procedures } \\
\hline ADS \# & ER Site\# & $\begin{array}{c}\text { Actual } \\
\text { Acreage } \\
\text { Surveyed }\end{array}$ & $\begin{array}{c}\text { Duration of } \\
\text { RAD VCM } \\
\text { Cleanup } \\
\text { (days) }\end{array}$ & 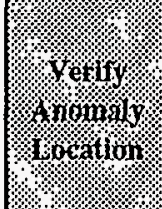 & : & 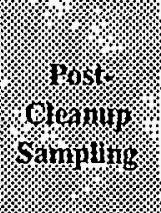 & $\begin{array}{l}\text { New Areal } \\
\text { Resurveyed } \\
(100 \%)\end{array}$ & $\begin{array}{c}\text { Pre-Cleanup } \\
\text { Sampling } \\
\text { (area sources) }\end{array}$ & $\begin{array}{c}\text { Heavy } \\
\text { Equipment } \\
\text { Support }\end{array}$ & Comments \\
\hline 1303 & 44 & 0.30 & 1.50 & $\mathrm{x}$ & $\mathbf{x}$ & $\mathrm{x}$ & & $\mathbf{x}$ & & $\begin{array}{l}\text { Pre-cleanup sampling performed } \\
\text { by SNL RPO personnel }\end{array}$ \\
\hline \multicolumn{2}{|c|}{ Tech Area II } & D.30: & 1.50 & & & $\because$ & 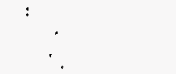 & $\therefore$ & .. & $\cdots$ \\
\hline 1306 & 18 & 1.90 & 0.25 & $\mathbf{x}$ & $\mathbf{x}$ & $\mathrm{x}$ & & & & \\
\hline 1306 & 83 & 176.30 & 24.50 & $\mathbf{x}$ & $\mathbf{x}$ & $\mathrm{x}$ & & & & \\
\hline 1306 & 84 & 7.40 & 18.00 & $\mathbf{x}$ & $\mathbf{x}$ & $\mathbf{x}$ & & & $\mathbf{x}$ & $\begin{array}{l}\text { Skidloader used on large area } \\
\text { sources }\end{array}$ \\
\hline 1306 & 240 & 82.60 & 8.00 & $\mathbf{x}$ & $\mathbf{x}$ & $\mathbf{x}$ & & & & \\
\hline 1306 & 241 & 1.80 & $0.00^{*}$ & $\mathbf{x}$ & & & & $\mathbf{x}$ & & Area sources result of "shine" \\
\hline \multicolumn{2}{|c|}{ Téch Area $1 / / v$} & 270.00 & 50.75 & : & & $\because \because$ & 品: & $\therefore$ & . & . \\
\hline 1309 & 16 & 26.40 & 33.25 & $\mathbf{x}$ & $\mathbf{x}$ & $\mathrm{x}$ & $\mathrm{x}$ & $\mathbf{x}$ & $\mathrm{x}$ & $\begin{array}{l}\text { Resurveyed site on 6-ft centers } \\
(100 \%) \text {. Backhoe used on large } \\
\text { area sources. }\end{array}$ \\
\hline 1309 & 228 & 9.20 & 1.00 & $\mathbf{x}$ & $\mathbf{x}$ & $\mathbf{x}$ & & & & \\
\hline \multicolumn{2}{|c|}{ Tijeras Arroyo } & 35.60 & 34.25 & & & & & & & \\
\hline
\end{tabular}




\begin{tabular}{|c|c|c|c|c|c|c|c|c|c|c|}
\hline & & & & Remov & al Action Pr & cedures & & & & \\
\hline ADS \# & ER Site \# & $\begin{array}{c}\text { Actual } \\
\text { Acreage } \\
\text { Surveyed }\end{array}$ & $\begin{array}{l}\text { Duration of } \\
\text { RAD VCM } \\
\text { Cleanup } \\
\text { (days) }\end{array}$ & 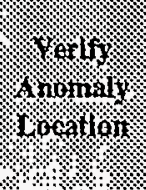 & 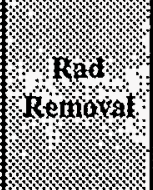 & 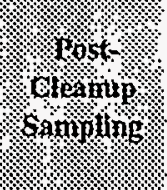 & $\begin{array}{l}\text { New Areal } \\
\text { Resurveyed } \\
(100 \%)\end{array}$ & $\begin{array}{c}\text { Pre-Cleanup } \\
\text { Sampling } \\
\text { (area sources) }\end{array}$ & $\begin{array}{c}\text { Heavy } \\
\text { Equipment } \\
\text { Support }\end{array}$ & Comments \\
\hline 1332 & $\begin{array}{l}8,58,58 \mathrm{~A} \\
58 \mathrm{~B}, 58 \mathrm{C}\end{array}$ & 50.60 & 15.25 & $\mathrm{x}$ & $\mathrm{x}$ & $\mathrm{x}$ & $\mathbf{x}$ & $\mathrm{x}$ & $\mathbf{x}$ & $\begin{array}{l}\text { At Site } 58 \text { expanded boundary (1 } \\
\text { acre) and surveyed on } 6-\mathrm{ft} \\
\text { centers }(100 \%) \text {. Pre-cleanup } \\
\text { sampling of natural outcrops. } \\
\text { Backhoe used on large area } \\
\text { source at Site } 8 \text {. }\end{array}$ \\
\hline 1332 & 15,67 & 0.60 & 1.00 & & & & $\mathrm{x}$ & & & $\begin{array}{l}\text { Original survey conducted on 6-ft } \\
\text { centers }(100 \%) \text { at start of VCM. } \\
\text { No anomalies were identified. }\end{array}$ \\
\hline 1332 & 19 & 1.90 & 2.00 & $\mathrm{x}$ & $\mathrm{x}$ & $\mathrm{x}$ & $\mathrm{x}$ & $\mathrm{x}$ & & $\begin{array}{l}\text { Surveyed area beneath truck } \\
\text { trailers on } 6 \text {-ft centers }(100 \%)\end{array}$ \\
\hline 1332 & 27,49 & 1.40 & $0.00^{*}$ & $\mathrm{x}$ & $\mathrm{x}$ & $\mathrm{x}$ & & & & $\begin{array}{l}\text { One source removed during Phase } \\
\text { I survey. No VCM performed. }\end{array}$ \\
\hline 1332 & 82 & 19.40 & $0.00^{*}$ & $\mathbf{x}$ & & & & $\mathrm{x}$ & & $\begin{array}{l}\text { Pre-cleanup sampling of natural } \\
\text { outcrops. }\end{array}$ \\
\hline 1332 & 87 & 56.50 & 105.00 & $\mathrm{x}$ & $\mathrm{x}$ & $\mathrm{x}$ & $\mathrm{x}$ & $\mathrm{x}$ & & $\begin{array}{l}\text { Resurveyed site and expanded } \\
\text { area }(11.9 \text { acres) on 6-ft centers } \\
(100 \%) \text {. }\end{array}$ \\
\hline \multicolumn{2}{|c|}{ Foothills Test Area } & 130.40 & 123.25 & & & & & & & \\
\hline 1333 & $10,60,59$ & 30.50 & 24.25 & $\mathrm{x}$ & $\mathrm{x}$ & $\mathbf{X}$ & & $\mathrm{x}$ & $\mathrm{x}$ & $\begin{array}{l}\text { Pre-cleanup sampling and insitu } \\
\text { gamma spec of natural outcrops. } \\
\text { Backhoe and skidloader used on } \\
\text { large area sources. }\end{array}$ \\
\hline 1333 & $\begin{array}{c}12,13,65 \text {, and } \\
94\end{array}$ & 103.60 & 14.00 & $\mathrm{x}$ & $\mathrm{x}$ & $\mathrm{x}$ & & & $\mathrm{x}$ & $\begin{array}{l}\text { Backhoe used on large area } \\
\text { sources. }\end{array}$ \\
\hline
\end{tabular}


Table 4.2.1 ER Project Sites Where VCM Field Activities Were Conducted

Removal Action Procedures

\begin{tabular}{|c|c|c|c|c|c|c|c|c|c|c|}
\hline ADS \# & ER Site\# & $\begin{array}{c}\text { Actual } \\
\text { Acreage } \\
\text { Surveyed }\end{array}$ & $\begin{array}{l}\text { Duration of } \\
\text { RAD VCM } \\
\text { Clcanup } \\
\text { (days) }\end{array}$ & W & 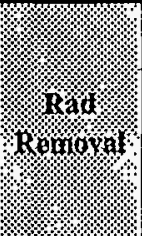 & 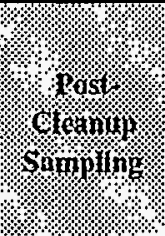 & $\begin{array}{l}\text { New Area/ } \\
\text { Resurveyed } \\
(100 \%)\end{array}$ & $\begin{array}{c}\text { Pre-Cleanup } \\
\text { Sampling } \\
\text { (area sources) }\end{array}$ & $\begin{array}{l}\text { Heavy } \\
\text { Equipment } \\
\text { Support }\end{array}$ & Comments \\
\hline 1333 & 63 & 19.80 & 1.50 & & & & $X$ & & & $\begin{array}{l}\text { Completed original survey on 6-ft } \\
\text { centers }(100 \%) \text { at start of VCM. } \\
\text { No anomalies identified. }\end{array}$ \\
\hline 1333 & 81 & 31.20 & $0.00^{a}$ & $\mathbf{X}$ & & & & $\mathbf{x}$ & & $\begin{array}{l}\text { Pre-cleanup sampling of natural } \\
\text { outcrops. }\end{array}$ \\
\hline \multicolumn{2}{|c|}{$\begin{array}{l}\text { Canyons Test Area } \\
0\end{array}$} & 185.10 & 39.75 & & & & & & & \\
\hline 1334 & $57 \mathrm{~A}, 57 \mathrm{~B}$ & 15.60 & 0.25 & $\mathbf{X}$ & $\mathbf{X}$ & $\mathrm{X}$ & & $\mathbf{X}$ & & $\begin{array}{l}\text { Pre-cleanup sampling of natural } \\
\text { outcrops. }\end{array}$ \\
\hline 1334 & $\begin{array}{c}61 \mathrm{~A}, 61 \mathrm{C}, 9 \\
\text { and } 20\end{array}$ & 39.50 & 29.25 & $\mathbf{X}$ & $\mathbf{X}$ & $X$ & $\mathbf{X}$ & $\mathbf{X}$ & $\mathbf{X}$ & $\begin{array}{l}\text { Resurveyed site on 6-ft centers } \\
(100 \%) \text {. Pre-cleanup sampling of } \\
\text { natural outcrops. Backhoe used } \\
\text { on large area sources. }\end{array}$ \\
\hline 1334 & 68,71 & 137.90 & 31.00 & $\mathbf{X}$ & $\mathbf{X}$ & $\mathbf{X}$ & $\mathbf{X}$ & $\mathrm{X}$ & & $\begin{array}{l}\text { Resurveyed site and expanded } \\
\text { area (59 acres) on 6-ft centers } \\
(100 \%) \text {. Pre-cleanup sampling } \\
\text { and insitu gamma spec of natural } \\
\text { outcrops. }\end{array}$ \\
\hline 1334 & 88 & 16.60 & 0.25 & $\mathbf{X}$ & $\mathbf{X}$ & & & & & $\begin{array}{l}\text { One point source (fiesta ware) } \\
\text { removed during Phase I survey. } \\
\text { No VCM performed. }\end{array}$ \\
\hline \multicolumn{2}{|c|}{$\begin{array}{c}\text { Central Coyote Test" } \\
\vdots \text { Area }\end{array}$} & 209.60 & 60.75 & & & & & & & \\
\hline 1335 & 14,85 & 21.00 & 6.00 & $\mathbf{X}$ & $\mathbf{X}$ & $\mathbf{X}$ & $\mathrm{X}$ & $\mathbf{x}$ & & $\begin{array}{l}\text { At Site } 85 \text { surveyed new area } \\
(19.6 \text { acres }) \text { on } 6 \text {-ft centers } \\
(100 \%) \text {. }\end{array}$ \\
\hline
\end{tabular}


Table 4.2.1 ER Project Sites Where VCM Field Activities Were Conducted

\begin{tabular}{|c|c|c|c|c|c|c|c|c|c|c|}
\hline \multicolumn{11}{|c|}{ Removal Action Procedures } \\
\hline ADS \# & ER Site\# & $\begin{array}{l}\text { Actual } \\
\text { Acreage } \\
\text { Surveyed }\end{array}$ & $\begin{array}{c}\text { Duration of } \\
\text { RAD VCM } \\
\text { Cleanup } \\
\text { (days) }\end{array}$ & $\begin{array}{l}\text { yeriy } \\
\text { Anonily } \\
\text { Howion }\end{array}$ & : $:$ ? & ${ }^{6}{ }^{6}$ & $\begin{array}{l}\text { New Areal } \\
\text { Resurveyed } \\
(100 \%)\end{array}$ & $\begin{array}{l}\text { Pre-Cleanup } \\
\text { Sampling } \\
\text { (area sources) }\end{array}$ & $\begin{array}{c}\text { Heavy } \\
\text { Equipment } \\
\text { Support }\end{array}$ & Comments \\
\hline 1335 & 55 & 14.60 & 18.75 & $\mathrm{x}$ & $\mathrm{x}$ & $\mathrm{x}$ & $\mathrm{x}$ & $\mathbf{x}$ & & $\begin{array}{l}\text { Resurveyed large area source (1.8 } \\
\text { acres) on 6-ft centers (100\%). }\end{array}$ \\
\hline 1335 & 86 & 2.80 & 0.50 & & & & $\mathrm{x}$ & & & $\begin{array}{l}\text { Original survey conducted at start } \\
\text { of VCM on 6-ft centers ( } 100 \%) \text {. } \\
\text { No anomalies were identified. }\end{array}$ \\
\hline 1335 & 91 & 21.20 & 3.00 & $\mathbf{x}$ & $\mathbf{x}$ & $\mathbf{x}$ & $\mathbf{x}$ & & & $\begin{array}{l}\text { New area }(21.2 \text { acres) surveyed } \\
\text { during VCM on 6-ft centers } \\
(100 \%) \text {. }\end{array}$ \\
\hline 1335 & 103,117 & 6.30 & 7.50 & $\mathbf{x}$ & $\mathrm{x}$ & $\mathbf{x}$ & & $\mathbf{x}$ & $\mathbf{x}$ & \\
\hline 1335 & 108 & 2.20 & 18.50 & $\mathbf{x}$ & $\mathbf{x}$ & $\mathbf{x}$ & & $\mathbf{x}$ & & \\
\hline 1335 & $115^{\mathrm{a}}$ & 1.00 & $0.00^{\star}$ & $\mathrm{x}$ & & & & $\mathbf{x}$ & & $\begin{array}{l}\text { Pre-cleanup sampling of natural } \\
\text { outcrops. }\end{array}$ \\
\hline 1335 & 191 & 4.20 & 0.25 & $\mathrm{x}$ & $\mathbf{x}$ & $\mathrm{x}$ & & & & \\
\hline 1335 & 193 & 0.50 & 1.75 & $\mathrm{x}$ & $\mathrm{x}$ & $\mathbf{x}$ & & & & \\
\hline \multicolumn{2}{|c|}{ sW Test Area } & 76.60 & 59.75 & & & & & & & \\
\hline & TOTAL & 908 & 370 & & & & & & & \\
\hline
\end{tabular}

a Less than 0.25 day required to complete field activities. 
A total of 9,518 anomalies were detected during the Phase I surveys $(3,749)$ and during the additional surface gamma radiation surveys of the VCM $(5,769)$. Among these anomalies detected, 9,199 were attributed to "point sources," and 319 were considered "area sources." The types of anomalous gamma radiation detected during the Phase I surveys and the VCM included area sources and point sources within the soil, area sources and point sources associated with metallic fragments, gamma radiation fields associated with radioactive materials storage areas, and gamma radiation associated with natural geologic outcrops.

A total of 38 sites had surface radiological anomalies removed: 37 sites identified during the Phase I survey and one new site identified during the VCM. A total of 9,122 anomalies were removed: 8,884 point sources and 238 area sources. The types of anomalous gamma radiation remediated included area sources and point sources within the soil and area sources and point sources associated with metallic fragments. The majority of the anomalies not removed (266 of 396) coincide with the original large area source at ER Site 55, which has extensive subsurface contamination (greater than 18 inches in depth). Table 4.2.2 summarizes the anomalous areas detected and removed for 38 ER sites. Detailed cleanup results are presented in Section 5.

To ensure acceptable soil concentrations were achieved under each anomaly remediated, a total of 1,008 verification soil samples were collected during cleanup activities. The predominant radiological contaminant of concern was DU. Verification soil sampling data show the maximum residual soil concentration for $U-238$, the primary constituent of DU, ranged from a high of $116 \mathrm{pCi} / \mathrm{g}$ at ER Site 87 to a low of $0.49 \mathrm{pCi} / \mathrm{g}$ at ER Site $57 \mathrm{~A}$. The average maximum residual soil concentration from all sites for U-238 was $19.43 \mathrm{pCi} / \mathrm{g}$. Other radionuclides have been found in small quantities in verification soil samples, such as cesium, cobalt, and thorium. The maximum residual soil concentration for DU and the other radionuclides discussed for the 38 ER sites in Section 5 and detailed results are presented in Appendix E.

The cleanup activities produced soil, metal fragment, and PPE wastes. All waste was containerized in either 30-gallon or 55-gallon drums. A total of 2,072 waste drums were generated during cleanup activities: 15 30-gallon drums and 2,057 55-gallon drums. Waste consolidation was performed to minimize the number of drums produced for each waste stream. Table 4.2.3 summarizes the number of waste drums after waste minimization/consolidation was performed, and Appendix J contains waste drum inventory data.

\subsubsection{Conclusions and Recommendations}

The VCM was effective at removing surface radiological anomalies at SNL/NM ER Project sites. The potential effects on human health due to exposure to the remaining radionuclides at the sites are well within EPA and DOE proposed standards.

Of the 38 ER sites where surface radiological anomalies were removed ( 37 Phase I survey sites and 1 VCM site),

- 21 sites had the VCM completed, and no further radiological action is required

- 17 sites require further radiological action. 


\begin{tabular}{|c|c|c|c|c|c|c|c|c|c|c|}
\hline & & Phiss & 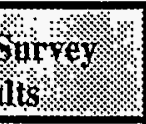 & $3 / 4$ ycM & results? & Traten & omalies & 9.8 & Hediries: & \\
\hline ADS \# & ER Site \# & $\begin{array}{l}\text { No. of } \\
\text { Point } \\
\text { Sources }\end{array}$ & $\begin{array}{c}\text { No. of } \\
\text { Area } \\
\text { Sources }\end{array}$ & $\begin{array}{l}\text { No. of } \\
\text { Point } \\
\text { Sources }\end{array}$ & $\begin{array}{c}\text { No. of } \\
\text { Area } \\
\text { Sources }\end{array}$ & $\begin{array}{l}\text { No. of } \\
\text { Point } \\
\text { Sources }\end{array}$ & $\begin{array}{c}\text { No. of } \\
\text { Area } \\
\text { Sources }\end{array}$ & $\begin{array}{l}\text { No. of } \\
\text { Point } \\
\text { Sources }\end{array}$ & $\begin{array}{l}\text { No. of } \\
\text { Area } \\
\text { Sources } \\
\end{array}$ & Comments \\
\hline 1303 & 44 & 1 & 2 & 0 & 0 & 1 & 2 & 1 & 2 & Cleanup complete and no further action is required. \\
\hline TOTAL & & 1 & 2 & 0 & 0 & 1 & 2 & 1 & 2 & \\
\hline 1306 & 18 & 1 & 0 & 0 & 0 & 1 & 0 & 1 & 0 & $\begin{array}{l}\text { Radiological risk assessment performed and no } \\
\text { further action is required }\end{array}$ \\
\hline 1306 & 83 & 1361 & 33 & 19 & 0 & 1380 & 33 & 1372 & 27 & $\begin{array}{l}\text { Four point sources and one area source could not be } \\
\text { relocated. Cleanup was not completed on four } \\
\text { point sources and five area sources. Active site, no } \\
\text { further action planned. }\end{array}$ \\
\hline 1306 & 84 & 50 & 9 & 0 & 0 & 50 & 9 & 50 & 9 & Active site, no further action planned. \\
\hline 1306 & 240 & 251 & 9 & 6 & 0 & 257 & 9 & 254 & 6 & $\begin{array}{l}\text { Three point and two area sources were not } \\
\text { remediated because they are associated with a } \\
\text { concrete pad. One area source is associated with } \\
\text { "shinc." Active site, no further action planned. }\end{array}$ \\
\hline 1306 & 241 & 0 & 4 & 0 & 0 & 0 & 4 & 0 & 0 & $\begin{array}{l}\text { The sources are related to "shine" from materials } \\
\text { stored within the site boundaries. No further action } \\
\text { required. }\end{array}$ \\
\hline TOTAL & & 1663 & 55 & 25 & $\mathbf{0}$ & 1688 & 55 & 1677 & 42 & \\
\hline 1309 & 16 & 3 & 18 & 1 & 1 & 4 & 19 & 2 & 11 & $\begin{array}{l}\text { Two point sources are large concrete blocks and } \\
\text { further action is required. Two area sources are } \\
\text { related to underlying, naturally-occurring geologic } \\
\text { material. Additional characterization and source } \\
\text { removal will be required for six area sources. }\end{array}$ \\
\hline
\end{tabular}




\begin{tabular}{|c|c|c|c|c|c|c|c|c|c|c|}
\hline & & 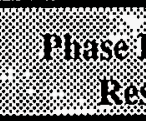 & 5 ins & : & iesuits' & 1rialy & (nimalles: & 8 rala & redralles: & \\
\hline ADS \# & ER Site \# & $\begin{array}{l}\text { No. of } \\
\text { Point } \\
\text { Sources }\end{array}$ & $\begin{array}{c}\text { No. of } \\
\text { Area } \\
\text { Sources }\end{array}$ & $\begin{array}{c}\text { No. of } \\
\text { Point } \\
\text { Sources } \\
\end{array}$ & $\begin{array}{l}\text { No. of } \\
\text { Area } \\
\text { Sources } \\
\end{array}$ & $\begin{array}{l}\text { No. of } \\
\text { Point } \\
\text { Sources } \\
\end{array}$ & $\begin{array}{c}\text { No. of } \\
\text { Area } \\
\text { Sources } \\
\end{array}$ & $\begin{array}{l}\text { No. of } \\
\text { Point } \\
\text { Sources }\end{array}$ & $\begin{array}{l}\text { No. of } \\
\text { Area } \\
\text { Sources } \\
\end{array}$ & Comments \\
\hline 1309 & 228 & 3 & 0 & 0 & 0 & 3 & 0 & 1 & 0 & $\begin{array}{l}\text { Remediation of two point sources (i.e. one large } \\
\text { area) was not completed. Additional } \\
\text { characterization and source removal will be }\end{array}$ \\
\hline TOTAL & & 6 & 18 & 1 & 1 & 7 & 19 & 3 & 11 & \\
\hline 1332 & 8,58 & 82 & 2 & 3 & 8 & 85 & 10 & 85 & 9 & $\begin{array}{l}\text { One area source is related to underlying, naturally- } \\
\text { occurring geologic material and no further action is } \\
\text { required. }\end{array}$ \\
\hline 1332 & 19 & 0 & 5 & 0 & 0 & 0 & 5 & 0 & 3 & $\begin{array}{l}\text { One source is related to "shine" and one source } \\
\text { does not exceed risk-based action levels. No further } \\
\text { action is required. }\end{array}$ \\
\hline 1332 & 27 & 1 & 0 & 0 & 0 & 1 & 0 & 1 & 0 & $\begin{array}{l}\text { Additional nonradiological characterization is } \\
\text { required. }\end{array}$ \\
\hline 1332 & 82 & 0 & 4 & 0 & 0 & 0 & 4 & 0 & 4 & $\begin{array}{l}\text { Sources are related to underlying, naturally- } \\
\text { occurring geologic material. }\end{array}$ \\
\hline 1332 & 87 & 1241 & 9 & 5000 & $100^{\circ}$ & 6241 & 109 & 6241 & 104 & $\begin{array}{l}\text { Area sources are related to underlying, naturally- } \\
\text { occurring geologic material. Cleanup complete and } \\
\text { no further action is planned. }\end{array}$ \\
\hline TOTAL & 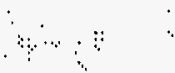 & 1324 & 20 & .5003 & 108 & 6327 & 128 & 6327 & 120 & \\
\hline 1333 & 10,60 & 31 & 21 & 8 & 0 & 39 & 21 & 25 & 6 & $\begin{array}{l}\text { Four sources could not be relocated. Five point } \\
\text { sources are associated with a telephone pole, metal } \\
\text { debris pile, and bunker. Five point sources and } 15 \\
\text { area sourcesare related to underlying, naturally- } \\
\text { occurring geologic material. }\end{array}$ \\
\hline
\end{tabular}




\begin{tabular}{|c|c|c|c|c|c|c|c|c|c|c|}
\hline & & Phase & Siltrey & $1+19$ & (4) & rofalis & irina & Total & oyed anlies & \\
\hline ADS \# & ER Site \# & $\begin{array}{l}\text { No. of } \\
\text { Point } \\
\text { Sources } \\
\end{array}$ & $\begin{array}{l}\text { No. of } \\
\text { Area } \\
\text { Sources }\end{array}$ & $\begin{array}{l}\text { No. of } \\
\text { Point } \\
\text { Sources }\end{array}$ & $\begin{array}{l}\text { No. of } \\
\text { Area } \\
\text { Sources }\end{array}$ & $\begin{array}{l}\text { No. of } \\
\text { Point } \\
\text { Sources }\end{array}$ & $\begin{array}{c}\text { No. of } \\
\text { Area } \\
\text { Sources }\end{array}$ & $\begin{array}{l}\text { No. of } \\
\text { Point } \\
\text { Sources }\end{array}$ & $\begin{array}{l}\text { No. of } \\
\text { Area } \\
\text { Sources }\end{array}$ & Comments \\
\hline 1333 & $\begin{array}{l}12,13,65 \\
\text { and } 94\end{array}$ & 67 & 13 & 2 & 0 & 69 & 13 & 69 & 12 & $\begin{array}{l}\text { One area source is associated with concrete in the } \\
\text { large open burn pool. Cleanup complete and no } \\
\text { further action is planned. }\end{array}$ \\
\hline 1333 & 81 & 0 & 4 & 0 & 0 & 0 & 4 & 0 & 0 & $\begin{array}{l}\text { Area sources are related to underlying, naturally- } \\
\text { occurring geologic material. }\end{array}$ \\
\hline TOTAL & & 98 & 38 & 10 & 0 & 108 & 38 & 94 & 18 & \\
\hline 1334 & $57 \mathrm{~A}, 57 \mathrm{~B}$ & 1 & 6 & 0 & 0 & 1 & 6 & 1 & 0 & $\begin{array}{l}\text { Area sources are related to underlying, naturally- } \\
\text { occurring geologic material. Cleanup complete and } \\
\text { no further action is planned. }\end{array}$ \\
\hline 1334 & $61 \mathrm{~A}, 9$ & 63 & 11 & 21 & 1 & 84 & 12 & 83 & 11 & $\begin{array}{l}\text { One point source and one area source are related to } \\
\text { underlying, naturally-occurring geologic material. }\end{array}$ \\
\hline 1334 & 68,71 & 242 & 16 & 275 & 9 & 517 & 25 & 500 & 8 & $\begin{array}{l}\text { Two point sources could not be relocated. Fifteen } \\
\text { point sources and fourteen area sources are related } \\
\text { to underlying, naturally-occurring geologic } \\
\text { material. Three area sources have high thorium } \\
\text { and will require further cleanup. }\end{array}$ \\
\hline 1334 & 88 & 0 & 1 & 0 & 0 & 0 & 1 & 0 & 1 & $\begin{array}{l}\text { One source (fiesta ware) removed during Phase I } \\
\text { survey. }\end{array}$ \\
\hline TOTAL & & 306 & 34 & 296 & 10 & 602 & 44 & 584 & 20 & \\
\hline 1335 & 14,85 & 0 & 1 & 2 & 0 & 2 & 1 & 2 & 1 & Cleanup complete and no further action is required. \\
\hline
\end{tabular}




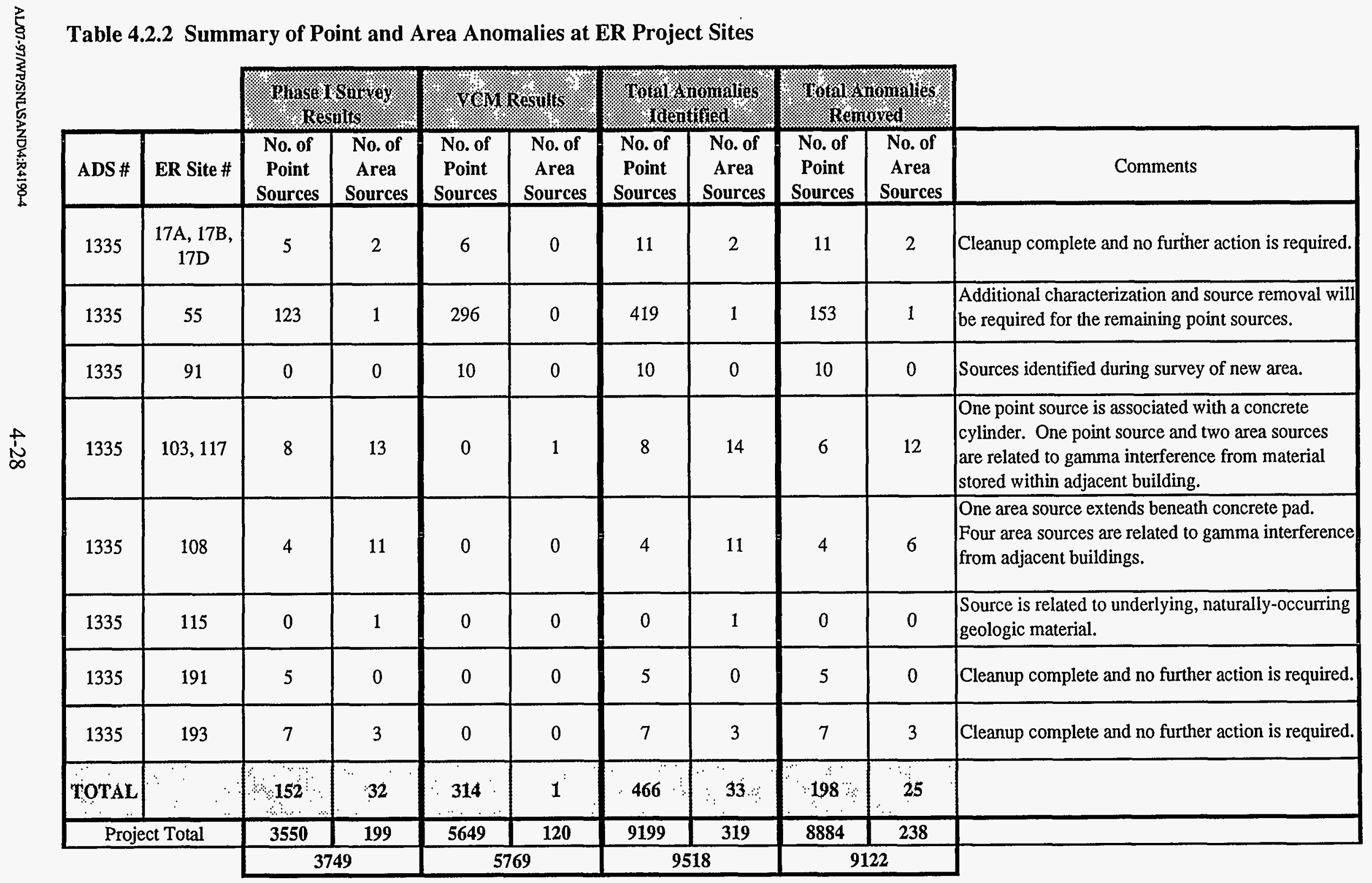


Table 4.2.3. Summary of Waste Drums Generated During the VCM

\begin{tabular}{|c|c|c|c|c|c|c|c|}
\hline \multicolumn{2}{|c|}{ Soil Waste } & \multicolumn{2}{|c|}{$\begin{array}{l}\text { Metal Frag } \\
\text { Waste }\end{array}$} & \multicolumn{2}{|c|}{ PPE } & \multirow[b]{2}{*}{$\begin{array}{c}\text { TCLP/ } \\
\text { Gamma } \\
\text { Spec } \\
\text { Samples }\end{array}$} & \multirow[b]{2}{*}{ Comments } \\
\hline $\begin{array}{c}30 \\
\text { Gallon } \\
\text { Drums }\end{array}$ & $\begin{array}{l}55 \\
\text { Gallon } \\
\text { Drums }\end{array}$ & \begin{tabular}{|c}
30 \\
Gallon \\
Drums
\end{tabular} & $\begin{array}{l}55 \\
\text { Gallon } \\
\text { Drums }\end{array}$ & $\begin{array}{c}30 \\
\text { Gallon } \\
\text { Drums }\end{array}$ & $\begin{array}{l}55 \\
\text { Gallon } \\
\text { Drums }\end{array}$ & & \\
\hline 7 & 2018 & 5 & 8 & 3 & 31 & $\begin{array}{l}80 \text { Soil } \\
13 \text { Frag }\end{array}$ & $\begin{array}{l}\text { Total }=2072+3 \text { wooden } \\
\text { crates }+1 \text { drum of parachute } \\
\text { material. }\end{array}$ \\
\hline
\end{tabular}

Of the 21 sites where the VCM was completed, 7 sites had a radiological risk assessment performed, and results indicate the potential effects on human health due to exposure to residual radionuclides are well within EPA and DOE proposed standards. At another seven sites, the radiological risk assessment is pending due to other nonradiological issues. For these sites, the preliminary radiological risk assessment results indicate the potential effects on human health due to exposure to radionuclides are well within EPA and DOE proposed standards. At two sites, no further radiological action is required because cleanup resulted in residual surface soil concentrations less than site-specific background levels. No further radiological action is required at three sites where elevated surface radiation was due to natural conditions (geologic outcrops). Finally, no further radiological action is required at one site where elevated surface radiation is due to "shine" (gamma interference) from adjacent material and at one site where the nondegradable source of elevated surface radiation was removed (a piece of fiesta-ware pottery).

At 17 sites, cleanup was not completed since further radiological characterization is necessary to assess remediation requirements, cleanup activities are beyond the original project scope, health and safety concerns require additional planning, and ongoing site activity precludes cleanup. These sites were grouped as high, moderate, and low based on the potential success for remediating the remaining radiological anomalies.

For eight sites where further radiological action is required, the potential success for remediating the remaining radiological anomalies is high. Five of these sites require additional radiological characterization to define small areas of elevated surface and potential subsurface radiation, one site requires decontamination and demolition of concrete walls, and two sites require additional health and safety planning (UXO hazards and respirator requirements) in order to complete surface radiation cleanup.

For two sites where further radiological action is required, the potential success for remediating the remaining radiological anomalies is moderate. One site has large areas of elevated surface and potential subsurface radiation interspersed with construction debris (concrete rubble, wood trash, metal scraps, and piping) that will require the use of specialized heavy machinery designed for tremendous weight (i.e., a crane). The other site has a large area of elevated surface and potential subsurface radiation that will require expanded waste handling and 
containerization requirements to address the immense volume of waste expected to be generated.

For seven sites where further radiological action is required, the potential cleanup success for remediating the remaining radiological anomalies is low. Three sites are part of facilities currently in use ("active" sites), and no further remedial action is planned until their site designation changes. One site has the potential to generate large volumes of mixed waste and is located on a steep slope where specialized heavy machinery (all-terrain vehicle) will be required. Three sites have the potential for large areas of elevated subsurface radiation where extensive radiological characterization and cleanup will be required and have complex terrain that may complicate cleanup activities.

Figure 4.2.1 depicts the status of the ER sites after completion of the survey and removal of radioactive surface contamination. See Appendix $L$ for a summary of the site-specific recommendations for ER sites. 


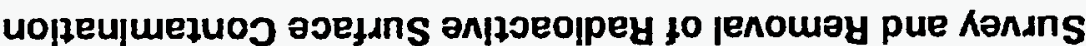

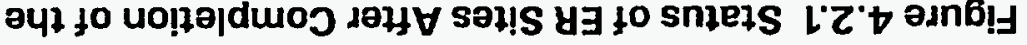

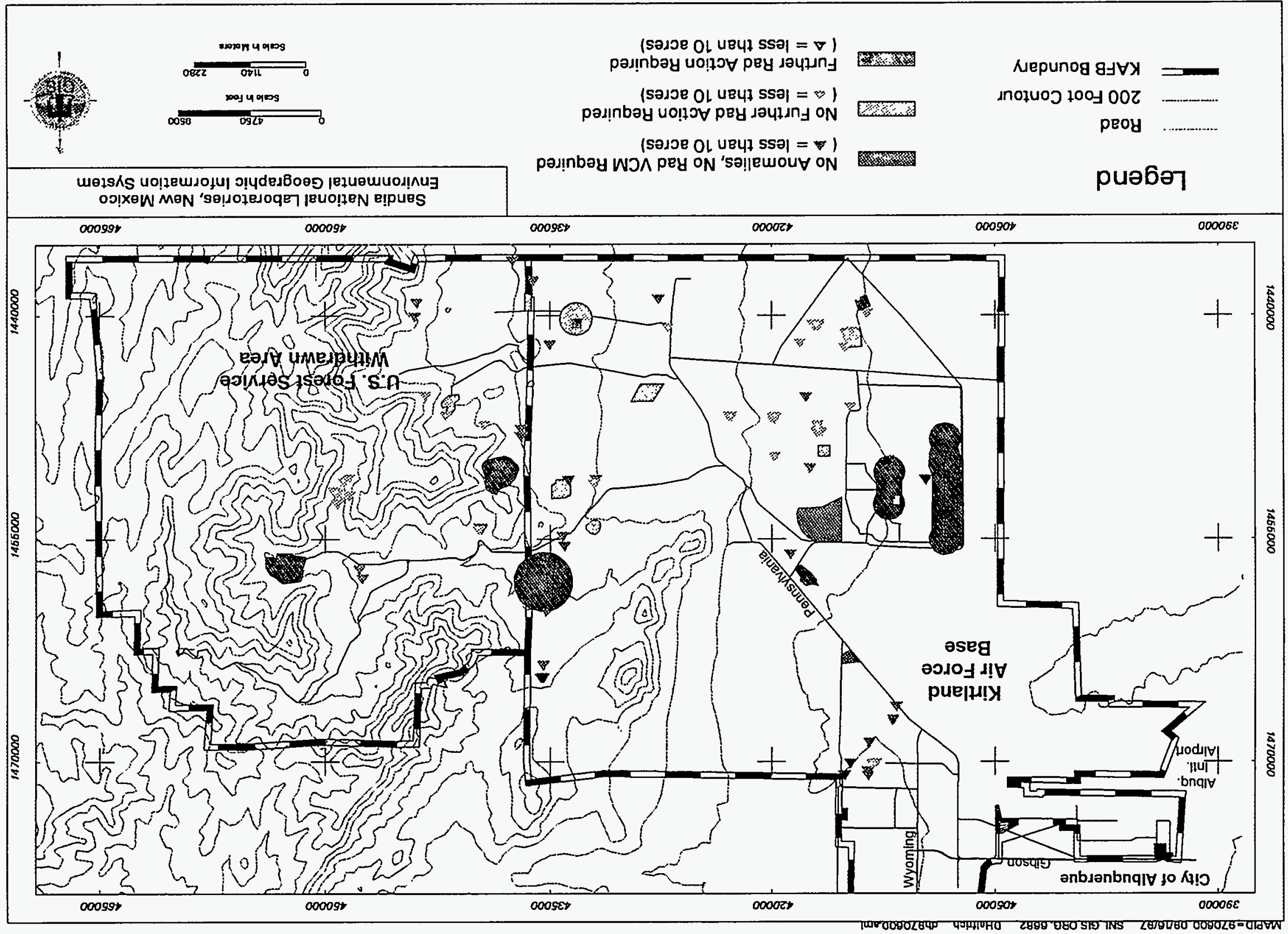


Intentionally Left Blank 


\section{GAMMA SURVEY/RADIOACTIVE SURFACE CONTAMINATION REMOVAL}

\subsection{Health and Safety Monitoring}

Activities performed on the SNL/NM ER Project sites by the Geotech field team were recorded on a Hazardous Material Access Log. The log was used to record time of site entrance and exit, work performed, PPE used, and air monitoring samplers. The Radiological Access and Frisking Logs were also filled out by personnel entering and exiting the site to record the results of personnel surveys performed with a beta-gamma detector.

\subsubsection{Bioassay Sampling}

All members of the Geotech field team participated in the SNL/NM bioassay program as described in Appendix E of the Surface Gamma Radiation Surveys Final Report (Geotech 1994b). A total of 448 baseline and termination samples were provided by 35 individuals during VCM field activities. These samples were analyzed as follows:

- 207 were analyzed for tritium, isotopic plutonium, isotopic thorium, and total strontium.

- 4 were analyzed for isotopic plutonium, isotopic thorium, isotopic uranium, and total strontium.

- 175 were analyzed for americium-241 and isotopic uranium.

- 2 were analyzed for isotopic thorium and isotopic uranium.

- 2 were analyzed for isotopic uranium.

- 32 were analyzed for total uranium.

Analysis showed doses to be below the Radiation Protection Internal Dosimetry reporting limit of 10 mrem. Results of the bioassay samples collected from Geotech personnel were forwarded by SNL/NM to the Geotech Dosimetry Health Physicist. The results are considered personal and confidential and will be available only to the individual upon written request to the Geotech Dosimetry Health Physicist.

\subsubsection{Dosimetry}

SNL/NM issued TLDs to all personnel on the Geotech field team as described in Appendix E of the Surface Gamma Radiation Surveys Final Report (Geotech 1994b). TLDs were worn by all Geotech field team members while on the ER Project sites. Results obtained from the personal dosimeters worn by the Geotech personnel were forwarded by SNL/NM to the Geotech Dosimetry Health Physicist. The results are considered personal and confidential and will be available only to the individual upon written request to the Geotech Dosimetry Health Physicist. 


\subsubsection{Air Sampling}

A MiniRam ${ }^{\mathrm{TM}}$ instrument was used to measure dust levels when dust from digging and remediation activities appeared to come close to the nuisance dust levels. A dust level of 5 milligrams per cubic meter $\left(\mathrm{mg} / \mathrm{m}^{3}\right)$ was used for the limit of nuisance dust. A total of eight days of monitoring was performed for average dust concentrations, and all measurements were below the nuisance dust level.

\subsubsection{Radioparticulate Sampling}

Geotech personnel wore radioparticulate samplers. Area samples were also collected while working at some of the ER Project sites. A total of 46 radioparticulate samples were collected by Geotech Health and Safety Personnel and analyzed by the SNL/NM RPO personnel. The calculated results were compared with the derived air concentration (DAC) limits. All the airborne radioparticulate concentrations calculated from Phase II survey data were less than 10 percent of their associated DAC Level.

\subsubsection{Heat Stress Monitoring}

A Quest heat stress monitor was used to determine possible adverse heat stress effects that would require a work rest/regime. During hot days, frequent water breaks were taken to lessen the possible danger of heat stress on the body. A total of five days of heat stress monitoring was performed to confirm the work/rest regime was adequate.

\subsubsection{Heavy Metals Sampling}

Heavy metals cassettes were used to gather personnel samples when heavy metals were a concern. A total of six samples were collected. The metals of concern that were analyzed for were beryllium and lead. No elevated metals air samples were found during the monitoring of metals samples.

\subsection{Technical Area II Operable Unit Sites (Activity Data Sheet [ADS] 1303)}

\subsubsection{Decontamination Area and Uranium Calibration Pits (ER Site 44)}

\section{Overview}

The Phase I survey in Technical Area II at ER Site 44 was conducted in January 1994 and covered a total of 0.3 acre of gravel-covered graded terrain encompassing the Decontamination Area (Buildings 906 and 906A) and the Uranium Calibration Pits. A gamma scan survey was performed at 6-foot centers (100 percent coverage) over the surface of the site. One point source and two area sources of gamma activity 30 percent or greater than the natural background were identified during this survey at the Decontamination Area. Additionally, a downhole gamma survey was performed for four of the Uranium Calibration Pits. A detailed summary of the surface radiological survey and anomalies found at the site and the results of the downhole 
gamma surveys are presented in Section 5.2.1 of the Surface Gamma Radiation Surveys Final Report (Geotech 1994b).

Figure 5.2.1 shows the site, surface radiological survey boundaries, and anomalies found during the Phase I survey and VCM verification sampling locations (post-cleanup).

VCM activities were conducted at the Decontamination Area during November 1996. Precleanup soil sampling for gamma spectroscopy analysis was conducted by SNL/NM RPO personnel to assess the need for remediation.

Cleanup activities included radiation scanning to verify anomaly location, removal of fragment and/or soil until readings were less than 1.3 times site-specific background levels, and postcleanup (verification) soil sampling for gamma spectroscopy analysis (see Section 3.1).

Table 5.2.1 summarizes field activities during the VCM.

Table 5.2.1 Summary of Field Activities at ER Site 44B

Removal Action Procedures

\begin{tabular}{|c|c|c|c|c|c|c|}
\hline $\begin{array}{c}\text { Actual } \\
\text { Acreage } \\
\text { Surveyed }\end{array}$ & $\begin{array}{c}\text { Duration of } \\
\text { Cleanup } \\
\text { (days) }\end{array}$ & $\begin{array}{c}\text { Verify } \\
\text { Anomaly } \\
\text { Location }\end{array}$ & $\begin{array}{c}\text { Rad } \\
\text { Removal }^{2}\end{array}$ & $\begin{array}{c}\text { Post- } \\
\text { Cleanup } \\
\text { Sampling }\end{array}$ & $\begin{array}{c}\text { Pre-Cleanup } \\
\text { Sampling } \\
\text { (area sources) }\end{array}$ & Comments \\
\hline 0.30 & 1.50 & $\mathbf{X}$ & $\mathbf{X}$ & $\mathbf{X}$ & $\mathbf{X}$ & $\begin{array}{l}\text { Pre-cleanup sampling } \\
\text { performed by SNL/NM } \\
\text { RPO personnel }\end{array}$ \\
\hline
\end{tabular}

${ }^{a}$ Removal of fragment and/or soil until readings are less than 1.3 times site-specific background

\section{Findings and Observations}

\section{Point and Area Source Status}

Gamma spectroscopy results from pre-cleanup samples collected by RPO personnel indicated the elevated radiation was related to anthropogenic (man-made) material. Geotech completed cleanup on one point source (44E3) and two area sources (44E1 and 44E2). No additional point or area sources were identified during this VCM.

\section{Post-Cleanup (Verification) Sample Results}

After the removal of radiologically contaminated soils, three post-cleanup (verification) samples were collected from areas exhibiting the highest residual gamma radiation readings. Gamma spectroscopy were performed on these samples to characterize the residual radioactivity remaining in the soil. The radiological COCs were Cs-134 and Cs-137. Table 5.2.2 shows the post-cleanup (verification) samples collected, and the maximum level of residual radiological COCs in soil is presented in Table 5.2.3. 


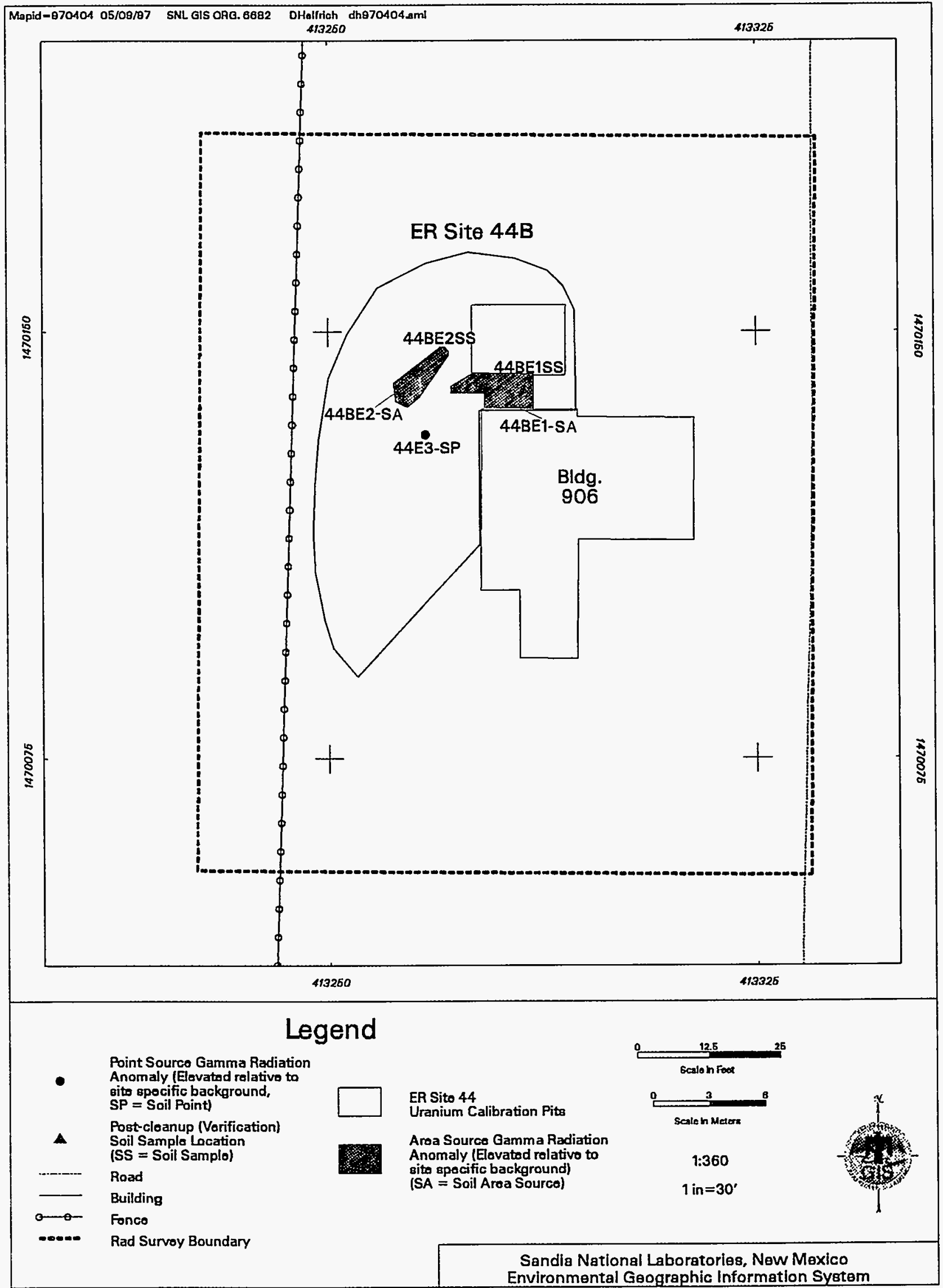

Figure 5.2.1 Phase I Survey Radiation Anomalies and VCM Surface Soil Sampling Locations at ER Site 44B 
Table 5.2.2 Post-Cleanup (Verification) Samples Collected at ER Site 44B

\begin{tabular}{|lc|}
\multicolumn{3}{|c|}{ Area Source Sample Number } \\
\hline \hline 44BE1SS & $44 \mathrm{BE} 1 \mathrm{Sd}^{\mathrm{a}}$ \\
\hline
\end{tabular}

${ }^{a}$ Sample duplicate

Table 5.2.3 Maximum Residual Radionuclide Levels in ER Site 44B Soils

\begin{tabular}{|c|c|c|}
\hline Radionuclide & Maximum Activity (pCi/g) & Background Activity (pCi/g) \\
\hline $\mathrm{Cs}-134$ & $\mathrm{ND}$ & $\mathrm{n} / \mathrm{a}^{\mathrm{a}}$ \\
\hline $\mathrm{Cs}-137$ & 0.77 & 0.84 \\
\hline
\end{tabular}

${ }^{\mathrm{a}}$ Does not occur naturally, or due to fallout, in the environment

ND: Not detected above the minimum detectable activity

\section{Risk Assessment Results}

Post-cleanup (verification) sample results from remediated areas showed nondetectable values or values less than area-specific background concentrations and, therefore, a risk assessment was not performed.

\section{Waste Management}

The cleanup activities produced soil and PPE wastes. No metal fragment waste was generated. All waste was containerized in 55-gallon drums. A total of seven waste drums were generated during cleanup activities: six soil drums and one PPE drum. Table 5.2.4 shows the number of waste drums produced at the site.

Table 5.2.4 Summary of Waste Drums for ER Site 44B

\begin{tabular}{|c|c|c|c|c|c|c|c|}
\hline \multicolumn{2}{|c|}{ Soil Waste } & \multicolumn{2}{|c|}{$\begin{array}{l}\text { Metal Fragment } \\
\text { Waste }\end{array}$} & \multicolumn{2}{|c|}{ PPE Waste } & \multirow[b]{2}{*}{$\begin{array}{c}\text { TCLP/ } \\
\text { Gamma } \\
\text { Spec } \\
\text { Samples }\end{array}$} & \multirow[b]{2}{*}{ Comments } \\
\hline \begin{tabular}{|c|}
30 Gallon \\
Drums
\end{tabular} & \begin{tabular}{|c|}
55 Gallon \\
Drums
\end{tabular} & $\begin{array}{c}30 \text { Gallon } \\
\text { Drums }\end{array}$ & \begin{tabular}{|c|}
55 Gallon \\
Drums
\end{tabular} & $\begin{array}{c}30 \text { Gallon } \\
\text { Drums }\end{array}$ & \begin{tabular}{|c|}
55 Gallon \\
Drums
\end{tabular} & & \\
\hline 0 & 6 & 0 & 0 & 0 & 1 & 1 Soil & \\
\hline
\end{tabular}

One composite soil sample was collected from the waste drums and analyzed for gamma emitters using standard laboratory gamma spectroscopy methods and for leachable RCRA metals using TCLP analytical procedures. All samples passed the TCLP tests, and all waste was characterized as "Radioactive-Low Level Only." A summary of radiological activity for the waste is presented in Appendix G. 
Disposal of regulated VCM waste was handled by SNL/NM Department 7577 (Waste Operations), which packaged and secured waste drums for transfer to Envirocare of Utah.

Nonregulated waste was disposed of using standard SNL/NM-approved waste disposal methods.

\section{Conclusions}

All point and area sources of gamma activity 30 percent or greater than the natural background were removed from the site. Further radiological characterization is planned to determine whether or not plutonium isotopes are present in the remaining soil. Risk assessment will be conducted once the additional radiological characterization and, if necessary, source removal is performed. Source removal is summarized in Table 5.2.5.

Table 5.2.5 Summary of Point and Area Source Removal at ER Site 44B

\begin{tabular}{|c|c|c|c|}
\hline Anomaly Type & Total Identified & Total Removed & Comments \\
\hline Point Source & 1 & 1 & \multirow{2}{*}{$\begin{array}{l}\text { Additional characterization is } \\
\text { required to determine whether or } \\
\text { not plutonium isotopes are present } \\
\text { in remaining soils }\end{array}$} \\
\hline Area Sources & 2 & 2 & \\
\hline
\end{tabular}

No additional cleanup activities were performed during this VCM. The status of other possible COCs is not addressed in this report.

All waste was characterized as "Radioactive-Low Level Only" and managed in accordance with SNL/NM Department 7572 (Waste Management) procedures.

\subsection{Technical Areas III/N OU Sites (ADS 1306)}

\subsubsection{Concrete Pad (ER Site 18)}

\section{Overview}

The Phase I survey at ER Site 18 was conducted in March 1994 and covered a total of 1.9 acres of flat alluvial terrain. A concrete pad approximately 120 by 400 feet is located on the area covered by the survey. A gamma scan survey was performed at 6 -foot centers (100 percent coverage) over approximately one-half of the site. One soil point source of gamma activity 30 percent or greater than the natural background was identified during this survey on the east edge of the pad. A detailed summary of the surface radiological survey and the anomaly found at the site is presented in Section 5.3.1 of the Surface Gamma Radiation Surveys Final Report (Geotech 1994b).

Figure 5.3.1 shows the site, surface radiological survey boundaries, and anomaly found during the Phase I survey and VCM verification sampling locations (post-cleanup). 


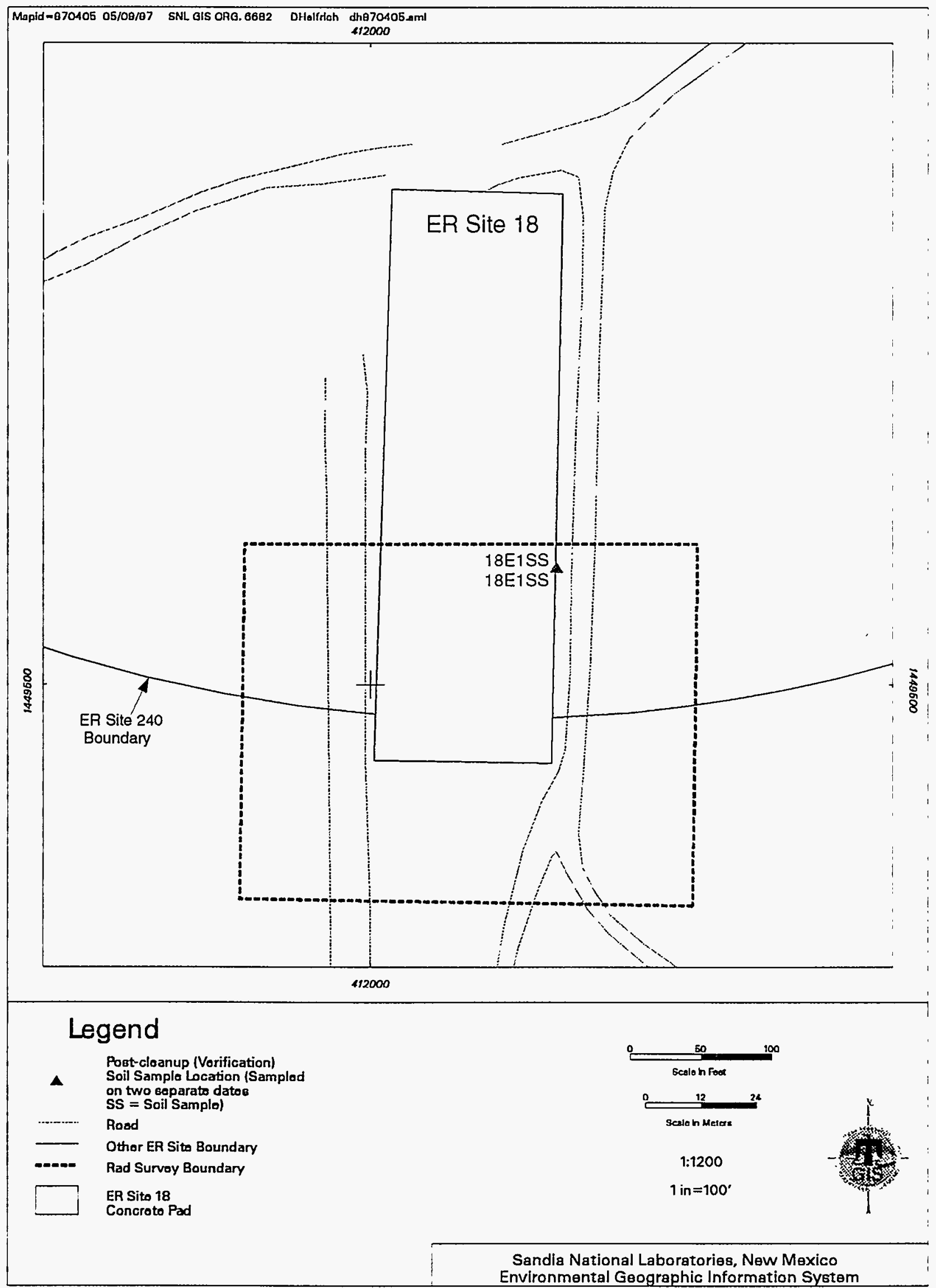

Figure 5.3.1 Phase I Survey Radiation Anomalies and

VCM Surface Soil Sampling Locations at ER Site 18 
VCM activities were conducted during August 1994. Resurveying (scanning) was not performed at the site. In May 1996, at the request of SNL/NM personnel, an additional gamma survey was conducted, and a soil sample was collected at the point source location identified during the Phase I survey.

Cleanup activities included radiation scanning to verify the anomaly location, removal of soil until readings were less than 1.3 times site-specific background levels, and post-cleanup (verification) soil sampling for gamma spectroscopy analysis (see Section 3.1). Table 5.3.1 summarizes field activities during the VCM.

\section{Table 5.3.1 Summary of Field Activities at ER Site 18}

Removal Action Procedures

\begin{tabular}{|c|c|c|c|c|}
\hline $\begin{array}{l}\text { Actual Acreage } \\
\text { Surveyed }\end{array}$ & $\begin{array}{c}\text { Duration of Cleanup } \\
\text { (days) }\end{array}$ & $\begin{array}{l}\text { Verify Anomaly } \\
\text { Location }\end{array}$ & Rad Removal $^{\mathrm{a}}$ & Post-Cleanup Sampling \\
\hline 1.90 & 0.25 & $\mathbf{X}$ & $\mathbf{X}$ & $\mathbf{X}$ \\
\hline
\end{tabular}

a Removal of fragment and/or soil until readings are less than 1.3 times site-specific background

\section{Findings and Observations}

\section{Point and Area Source Status}

Cleanup was completed on one point source during the TRA. No visible evidence of DU was observed, and no additional anomalies were detected. After cleanup of this point source, a gamma scan was performed, and readings were slightly elevated, but less than 30 percent above background levels. To determine if these elevated gamma readings were the result of geometry within the point source excavation, a test hole approximately the same size as this excavation was completed in a clean background area. Gamma readings from this test hole indicated gamma activity at natural background levels.

The results of gamma spectroscopy analysis on post-cleanup soil samples collected from the point source in August 1994 indicated elevated levels of Co-60. In May 1996, an additional gamma scan and soil sampling for gamma spectroscopy analysis were performed on the point source location. Gamma readings at this location were slightly greater than 30 percent above natural background levels. The soil sample was collected from the place with the highest gamma reading within the point source location. Gamma spectroscopy results of this additional sample indicated elevated levels of $\mathrm{Co}-60$.

\section{Post-Cleanup (Verification) Sample Results}

After the removal of radiologically contaminated soils, three post-cleanup (verification) samples (two in August 1994 and one in May 1996) were collected from areas exhibiting the highest residual gamma radiation readings. Gamma spectroscopy analysis was performed on the samples to verify that the residual radionuclide concentrations met risk-based action levels. The radiological COC was Co-60. Table 5.3.2 shows the post-cleanup (verification) samples collected at the site, and the maximum level of residual radiological COCs in soil is presented in Table 5.3.3. 
Table 5.3.2 Post-Cleanup (Verification) Samples Collected at ER Site 18

\begin{tabular}{|c|c|c|}
\hline \multicolumn{3}{|c|}{$\begin{array}{c}\text { Point Source } \\
\text { Sample Number } \\
\end{array}$} \\
\hline $18 \mathrm{E} 1 \mathrm{SS}^{\mathrm{b}}$ & $\overline{~ 18 \mathrm{E} 1 \mathrm{SD}^{\mathrm{a}}}$ & 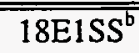 \\
\hline
\end{tabular}

${ }^{\text {a }}$ Sample duplicate

${ }^{b}$ Anomaly location sampled on two separate dates (see Appendix E for dates).

Table 5.3.3 Maximum Residual Radionuclide Levels in ER Site 18 Soils

\begin{tabular}{|c|c|c|}
\hline Radionuclide & Maximum Activity (pCi/g) & Background Activity (pCi/g) \\
\hline Co-60 & 4.91 & $\mathrm{n} / \mathrm{a}^{\mathrm{a}}$ \\
\hline
\end{tabular}

${ }^{a}$ Does not occur naturally, or due to fallout, in the environment.

\section{Risk Assessment Results}

A risk assessment, using the DOE computer code RESRAD, was performed on ER Site 18 assuming both an industrial and a residential (loss of active control measures) land-use scenario, consistent with Section 3.3.2. The RESRAD input parameters that were not site specific are provided for both land-use scenarios in Section 3.3.2. Site-specific input parameters were developed based on information provided by the Task Leader responsible for the site and were as follows:

- Area of Contaminated Zone: 4,645 square meters $\left(\mathrm{m}^{2}\right)$

- Thickness of contaminated zone: 0.15 meters $(\mathrm{m})$

- Length Parallel to Aquifer Flow: not applicable

- Density of Contaminated Zone: 1.6 grams per cubic centimeters $\left(\mathrm{g} / \mathrm{cm}^{3}\right)$

- Contaminated Zone Total Porosity: 0.4

- Contaminated Zone Effective Porosity: 0.3

- Contaminated Zone Hydraulic Conductivity: 315 meters per year (m/yr)

- Contaminated Zone b Parameter: 4.9 (Silty Sand)

- Runoff Coefficient: 0.4

Site-specific risk assessment resulted in the following TEDEs to the RME individual:

- Industrial Land-Use: $10 \mathrm{mrem} / \mathrm{yr}$

- Residential Land-Use: $29 \mathrm{mrem} / \mathrm{yr}$

The calculated TEDEs for both scenarios are below the proposed EPA guidance discussed in Section 2.2.2 of $15 \mathrm{mrem} / \mathrm{yr}$ maximum TEDE for industrial land-use and $75 \mathrm{mrem} / \mathrm{yr}$ for residential land-use. The average radiation exposure due to natural sources (radon, internal radiation, cosmic radiation, and terrestrial radiation) in the U.S. is approximately $295 \mathrm{mrem} / \mathrm{yr}$ TEDE (NCRP 1987). Given the above, the potential effects on human health due to exposure to radionuclides at the site are within proposed standards when considering both an industrial land-use scenario and a residential land-use scenario. 
The uncertainties associated with this assessment are considered small because of the location and history of the site. There is low uncertainty in the future land-use and the potentially affected populations considered in making the risk assessment analysis. An RME approach was used to calculate the risk assessment values. As a result, the parameter values used in the calculations were conservative, and the calculated intakes are likely overestimates. An example of this conservatism lies in the area assumed to be contaminated. Although only one small area of Co-60 was detected, the entire pad and perimeter soils were assumed to be impacted. Maximum measured, decay corrected concentrations of the COCs were used to provide conservative results. Because the COCs were found in the surface soils and because of the location and physical characteristics of the site, there is little uncertainty in the exposure pathways relevant to the analysis.

The cleanup activities produced soil and PPE wastes. No metal fragment waste was generated. All waste was containerized in either 30-gallon or 55-gallon drums. A total of two waste drums were generated during cleanup activities: one soil drum and one PPE drum. Table 5.3.4 shows the number of waste drums produced at the site.

Table 5.3.4 Summary of Waste Drums for ER Site 18

\begin{tabular}{|c|c|c|c|c|c|c|c|}
\hline \multicolumn{2}{|c|}{ Soil Waste } & \multicolumn{2}{|c|}{ Metal Fragment Waste } & \multicolumn{2}{|c|}{ PPE Waste } & \multirow[b]{2}{*}{$\begin{array}{c}\text { TCLP/ } \\
\text { Gamma } \\
\text { Spec } \\
\text { Samples }\end{array}$} & \multirow[b]{2}{*}{ Comments } \\
\hline $\begin{array}{l}0 \text { Gallon } \\
\text { Drums }\end{array}$ & $\begin{array}{c}55 \text { Gallon } \\
\text { Drums }\end{array}$ & $\begin{array}{c}30 \text { Gallon } \\
\text { Drums }\end{array}$ & $\begin{array}{c}55 \text { Gallon } \\
\text { Drums }\end{array}$ & $\begin{array}{l}30 \text { Gallon } \\
\text { Drums }\end{array}$ & $\begin{array}{c}\mathbf{5 5} \text { Gallon } \\
\text { Drums }\end{array}$ & & \\
\hline 0 & $\overline{11}$ & $\overline{0}$ & 0 & 1 & 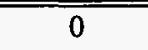 & 1 Soil & \\
\hline
\end{tabular}

One soil sample was collected from the soil waste drum and analyzed for gamma emitters using standard laboratory gamma spectroscopy methods and for leachable RCRA metals using TCLP analytical procedures. Mercury was identified as a COC and was included in the TCLP analysis. All samples passed the TCLP tests, and all waste was characterized as "Radioactive-Low Level Only." A summary of radiological activity for the waste is presented in Appendix G.

Disposal of regulated VCM waste was handled by SNL/NM Department 7577 (Waste Operations), which packaged and secured waste drums for transfer to Envirocare of Utah. Nonregulated waste was disposed of using standard SNL/NM-approved waste disposal methods.

\section{Conclusions}

The point source of gamma activity 30 percent or greater than the natural background was removed from the site. A radiological risk assessment was performed assuming both an industrial and a residential (loss of active control measures) land-use scenario, and using site-specific input parameters. The risk assessment shows the potential effects on human health due to exposure to radionuclides at the site are within proposed standards when considering both land-use scenarios. Source removal is summarized in Table 5.3.5. 
Table 5.3.5 Summary of Point and Area Source Removal at ER Site 18

\begin{tabular}{|c|c|c|l|}
\hline Anomaly Type & Total Identified & Total Removed & \multicolumn{1}{c|}{ Comments } \\
\hline Point Source & 1 & 1 & $\begin{array}{l}\text { Radiological risk assessment } \\
\text { performed and no further action is } \\
\text { required }\end{array}$ \\
\hline
\end{tabular}

No additional cleanup activities were performed during this VCM. The status of other possible COCs is not addressed in this report.

All waste was characterized as "Radioactive-Low Level Only" and managed in accordance with SNL/NM Department 7572 (Waste Management) procedures.

\subsubsection{Long Sled Track (ER Site 83)}

\section{Overview}

The Phase I survey at ER Site 83 was conducted during March, April, and May 1994 and covered a total of 176.3 acres of flat alluvial terrain centered around the sled track and Building 6742. A gamma scan survey was performed at 10 -foot centers ( 70 percent coverage) over the surface of the site. Thirty-three area sources and 1,361 point sources of gamma activity 30 percent or greater than the natural background were identified during this survey. A detailed summary of the surface radiological survey and anomalies found at the site is presented in Section 5.3.2 of the Surface Gamma Radiation Surveys Final Report (Geotech 1994b).

Figure 5.3.2 shows the site, surface radiological survey boundaries, and anomalies found during the Phase I survey.

VCM activities conducted during August 1994 and October to December 1994 included the remediation of point sources and small area sources. The site is currently classified as "active"; therefore, large area sources were not remediated, and resurveying (scanning) was not performed.

Cleanup activities included radiation scanning to verify anomaly location, removal of fragment and/or soil until readings were less than 1.3 times site-specific background levels, and post-cleanup (verification) soil sampling for gamma spectroscopy analysis (see Section 3.1). Table 5.3.6 summarizes field activities during the VCM.

\section{Table 5.3.6 Summary of Field Activities at ER Site 83}

Removal Action Procedures

\begin{tabular}{|c|c|c|c|c|}
\hline $\begin{array}{c}\text { Actual Acreage } \\
\text { Surveyed }\end{array}$ & $\begin{array}{c}\text { Duration of Cleanup } \\
\text { (days) }\end{array}$ & $\begin{array}{c}\text { Verify Anomaly } \\
\text { Location }\end{array}$ & Rad Removal $^{\mathrm{a}}$ & Post-Cleanup Sampling $^{\text {(dad }}$ \\
\hline 176.30 & 24.50 & $\mathbf{X}$ & $\mathbf{X}$ & $\mathbf{X}$ \\
\hline
\end{tabular}

Removal of fragment and/or soil until readings are less than 1.3 times site-specific background 


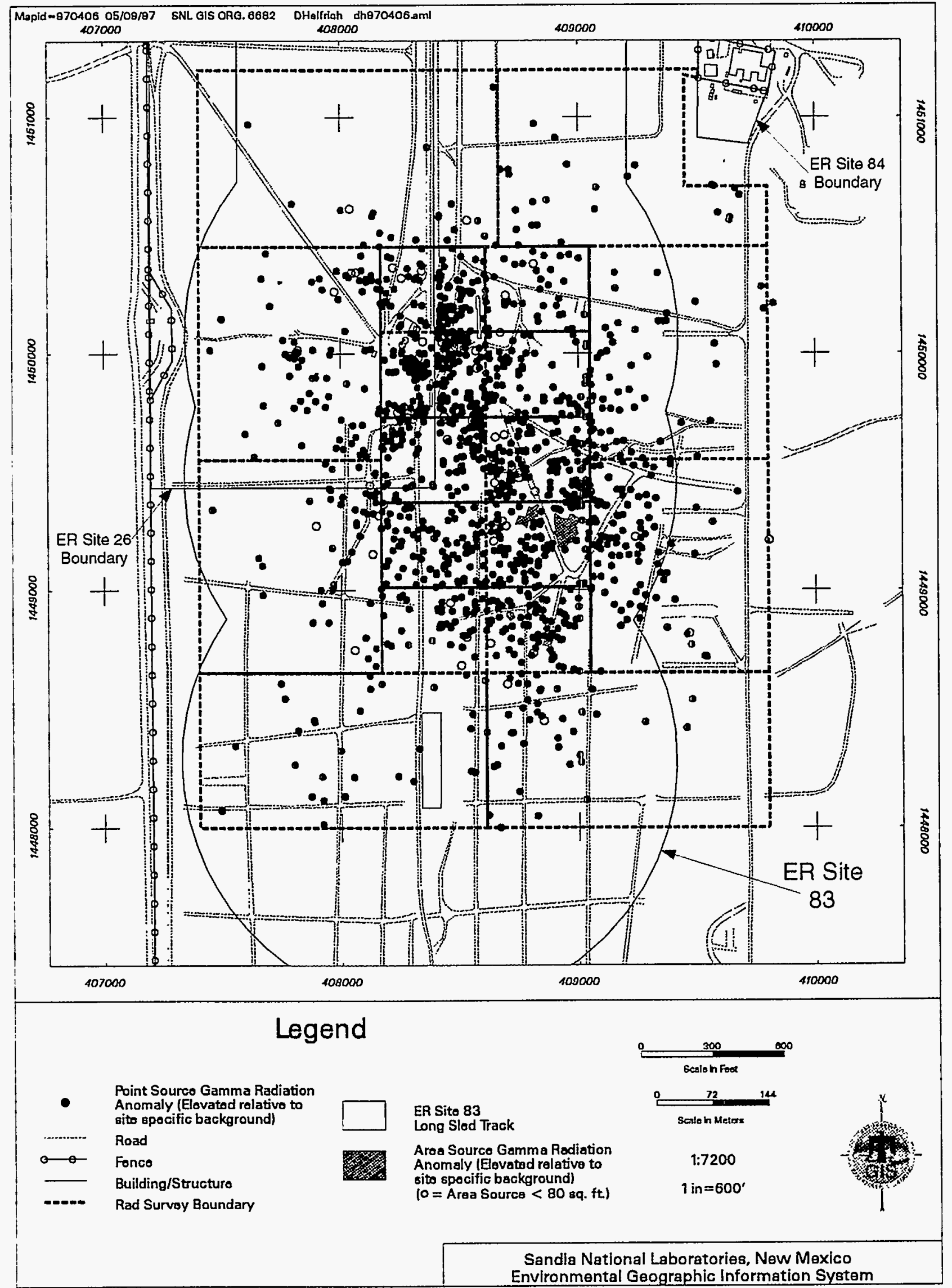

Figure 5.3.2 Phase I Survey Radiation Anomalies at ER Site 


\section{Findings and Observations}

\section{Point and Area Source Status}

Of the sources identified during the Phase I survey, 1,353 point sources and 27 area sources were remediated during the initial cleanup activities. Four point sources $(83 \mathrm{E} 307,83 \mathrm{E} 1343,83 \mathrm{E} 253$, and $83 E 90)$ and one area source (83E1230) could not be relocated. Field screening of these five locations indicated no elevated gamma radiation levels. Remediation on one point source (83E1256) and two area sources (83E714 and 83E224) was stopped before cleanup was completed when contamination extended deeper than 18 inches in depth. Excavation of three closely-spaced point sources $(83 \mathrm{E} 335,83 \mathrm{E} 336$, and $83 \mathrm{E} 319)$ showed them to be linked to one large area source that was fenced off by SNL/NM RPO personnel. This area source and three other large area sources (83E708, 83E957, and 83E921) were not cleaned up.

During the initial cleanup, 19 new point sources were detected and remediated. Cleanup was completed on these sources, and no additional point or area sources were identified during this VCM. The new sources identified during the VCM are summarized in Table 5.3.7, and Figure 5.3.3 shows VCM radiation anomalies and verification sampling locations (post-cleanup).

Table 5.3.7 Radiation Anomalies 30 Percent or Greater Than Natural Background Identified During the VCM at ER Site 83

\begin{tabular}{|c|c|l|}
\hline Anomaly Type & Total & \multicolumn{1}{c|}{ Comments } \\
\hline Point Sources & 19 & $\begin{array}{l}\text { Gray, black fragments with yellow } \\
\text { uranium oxide (DU) in soil }\end{array}$ \\
\hline
\end{tabular}

Resurveying (scanning) and additional source removal will be required under future cleanup activities. A gamma survey at 100 percent coverage may result in additional anomalies being identified. Cleanup will be required on original large area sources not completely remediated during the initial cleanup and on new point and area sources identified during resurveying.

\section{Post-Cleanup (Verification) Sample Results}

After the removal of radiologically contaminated soils, 149 post-cleanup (verification) samples were collected from areas exhibiting the highest residual gamma radiation readings. Gamma spectroscopy analysis was performed on these samples to characterize the residual radioactivity remaining in the soil. The radiological COC was DU (U-238, U-235, and U-234). Table 5.3.8 summarizes the number of post-cleanup (verification) samples collected, and the maximum level of residual radiological COCs in soil is presented in Table 5.3.9.

\section{Risk Assessment Results}

Further work is planned at ER Site 83 and, therefore, risk assessment has been postponed pending additional characterization. It is anticipated that the potential effects on human health due to exposure to radionuclides at the sites will be within proposed standards. This is based on 


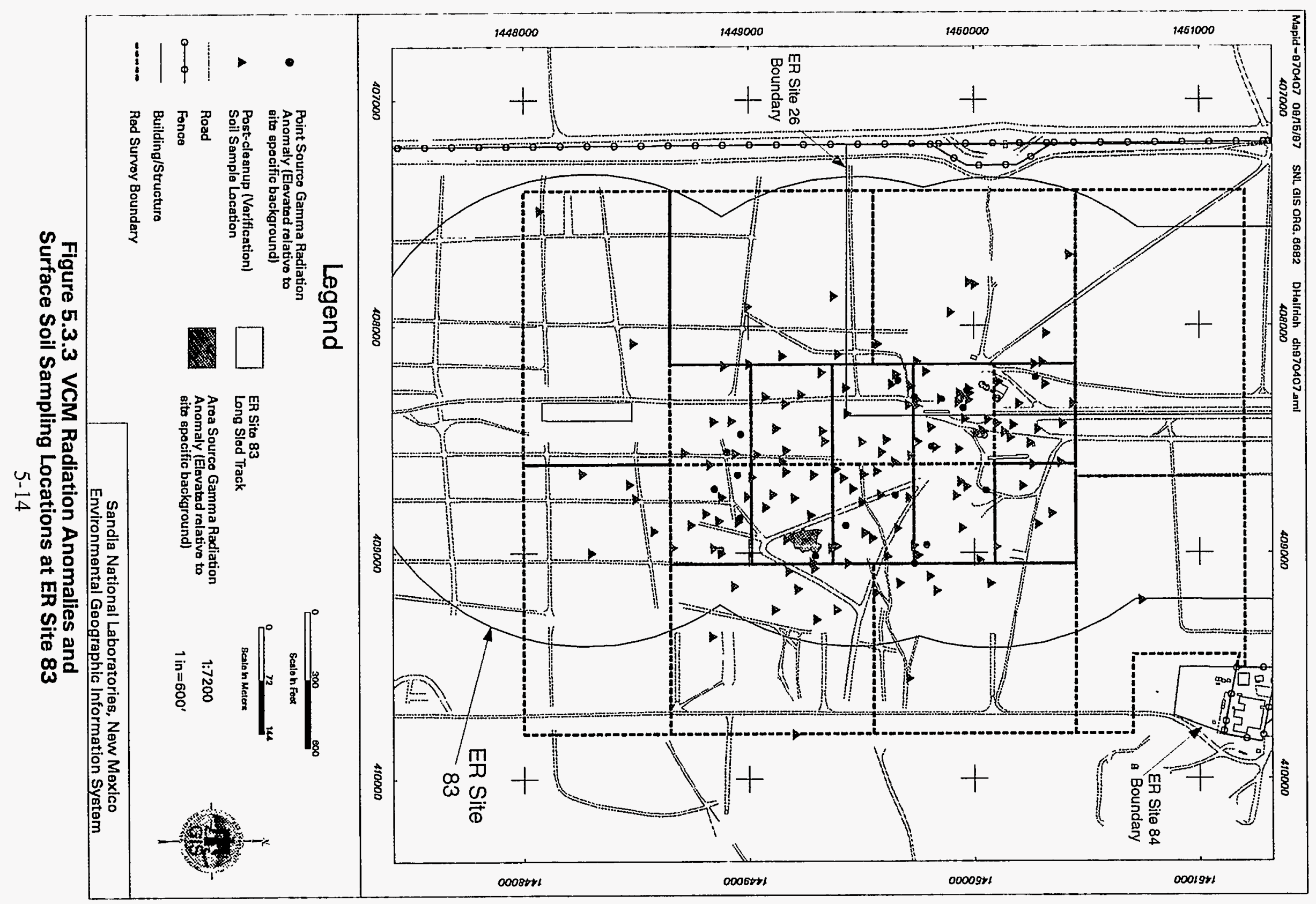


Table 5.3.8 Summary of Post-Cleanup (Verification) Samples Collected at ER Site 83

\begin{tabular}{|c|c|}
\hline $\begin{array}{c}\text { Point Source } \\
\text { Totals }\end{array}$ & $\begin{array}{c}\text { Area Source } \\
\text { Totals }\end{array}$ \\
\hline 145 & 4 \\
\hline
\end{tabular}

Table 5.3.9. Maximum Residual Radionuclide Levels in ER Site 83 Soils

\begin{tabular}{|c|c|c|}
\hline Radionuclide & Maximum Activity (pCi/g) & Background Activity (pCi/g) \\
\hline $\mathrm{U}-238$ & 28.3 & 1.4 \\
\hline $\mathrm{U}-235$ & 0.57 & 0.16 \\
\hline $\mathrm{U}-234$ & 3.5 & 1.6 \\
\hline
\end{tabular}

preliminary review of site-specific input parameters and land-use scenarios for the risk assessments to be performed using the RESRAD code.

\section{Waste Management}

The cleanup activities produced soil, metal fragment, and PPE wastes. All waste was containerized in 55-gallon drums. A total of 54 waste drums were generated during cleanup activities: 49 soil drums, 3 metal fragment drums, and 2 PPE drums. Table 5.3.10 shows the number of waste drums produced at the site.

Table 5.3.10 Summary of Waste Drums for ER Site 83

\begin{tabular}{|c|c|c|c|c|c|c|c|}
\hline \multicolumn{2}{|c|}{ Soil Waste } & \multicolumn{2}{|c|}{ Metal Fragment Waste } & \multicolumn{2}{|c|}{ PPE Waste } & \multirow[b]{2}{*}{$\begin{array}{l}\text { TCLP/ } \\
\text { Gamma } \\
\text { Spec } \\
\text { Samples }\end{array}$} & \multirow[b]{2}{*}{ Comments } \\
\hline $\begin{array}{c}\text { 30 Gallon } \\
\text { Drums }\end{array}$ & $\begin{array}{c}55 \text { Gallon } \\
\text { Drums }\end{array}$ & $\begin{array}{c}30 \text { Gallon } \\
\text { Drums }\end{array}$ & $\begin{array}{l}55 \text { Gallon } \\
\text { Drums }\end{array}$ & $\begin{array}{c}\text { 30 Gallon } \\
\text { Drums }\end{array}$ & $\begin{array}{c}55 \text { Gallon } \\
\text { Drums }\end{array}$ & & \\
\hline 0 & 49 & 0 & 3 & 0 & 2 & $\begin{array}{l}2 \text { Soil } \\
2 \text { Frag }\end{array}$ & \\
\hline
\end{tabular}

Two composite soil samples and two composite metal fragment samples were collected from the waste drums and analyzed for gamma emitters using standard laboratory gamma spectroscopy methods and for leachable RCRA metals using TCLP analytical procedures. Mercury was identified as a COC and was included in the TCLP analysis. All samples passed the TCLP tests, and all waste was characterized as "Radioactive-Low Level Only." A summary of radiological activity for the waste is presented in Appendix G.

Disposal of regulated VCM waste was handled by SNL/NM Department 7577 (Waste Operations), which packaged and secured waste drums for transfer to Envirocare of Utah. Nonregulated waste was disposed of using standard SNL/NM-approved waste disposal methods. 


\section{Conclusions}

Remediation was completed on all point and area sources of gamma activity 30 percent or greater than the natural background, with the exception of four point and six area sources. Source removal is summarized in Table 5.3.11, and sources remaining after completion of the VCM are shown in Figure 5.3.4.

Table 5.3.11 Summary of Point and Area Source Removal at ER Site 83

\begin{tabular}{|c|c|c|l|}
\hline Anomaly Type & Total Identified & Total Removed & \multicolumn{1}{|c|}{ Comments } \\
\hline Point Sources & 1,380 & 1,372 & $\begin{array}{l}\text { Four sources could not be relocated } \\
\text { and cleanup was not completed on } \\
\text { four other sources. Active site. }\end{array}$ \\
\hline Area Sources & 33 & 27 & $\begin{array}{l}\text { One source could not be relocated } \\
\text { and cleanup was not completed on } \\
\text { five sources. Active site. }\end{array}$ \\
\hline
\end{tabular}

Further radiological characterization and source removal will be required for those sources not completely remediated during the initial cleanup. The site is currently classified as "active," and no further cleanup activities are planned until the site designation changes. When the site designation changes, resurveying (scanning) and additional source removal will be addressed, and a radiological risk assessment will be performed.

No additional cleanup activities were performed during this VCM. The status of other possible COCs is not addressed in this report.

All waste was characterized as "Radioactive-Low Level Only" and managed in accordance with SNL/NM Department 7572 (Waste Management) procedures.

\subsubsection{Gun Facilities (ER Site 84)}

\section{Overview}

The Phase I survey at ER Site 84 was conducted February 1994 and covered a total of 7.4 acres of flat alluvial terrain. A gamma scan survey was performed at 6-foot centers (100 percent coverage) over the surface of the site. Fifty point sources and nine area sources of gamma activity 30 percent or greater than the natural background were identified during this survey. A detailed summary of the surface radiological survey and anomalies found at the site is presented in Section 5.3.3 of the Surface Gamma Radiation Surveys Final Report (Geotech 1994b). Figure 5.3.5 shows the site, surface radiological survey boundaries, and anomalies found during the Phase I survey.

VCM activities were conducted during October and November 1994 and May and June 1996. Point sources and small area sources were removed in October and November 1994. Large area sources were remediated in May and June 1996. Heavy equipment (skidloader) was used on two area 


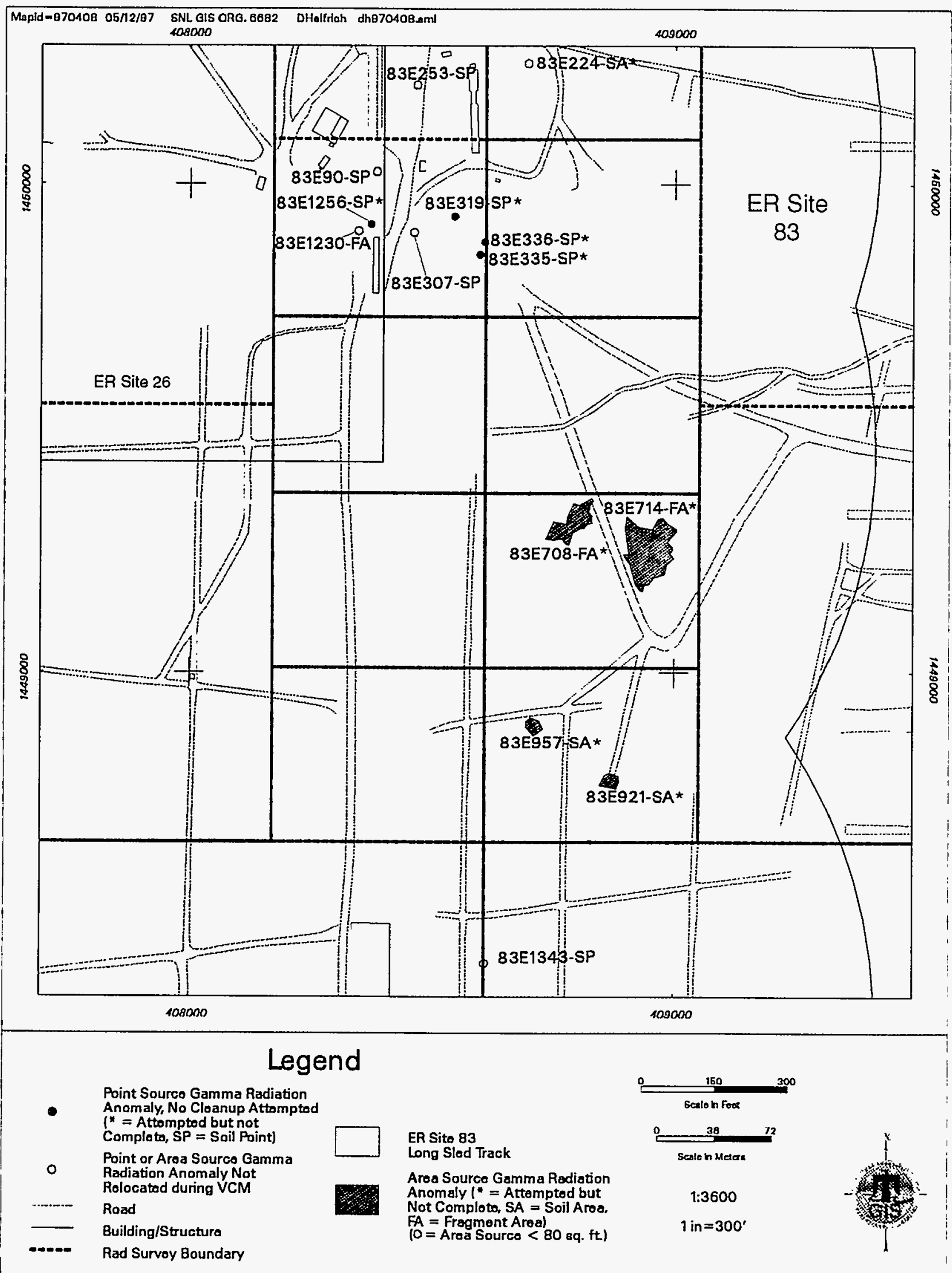

Sandla National Laboratories, New Mexico Environmental Goographic Information System

Figure 5.3.4 Radiation Anomalies Remaining After Completion of the VCM at ER Site $\mathbf{8 3}$ 


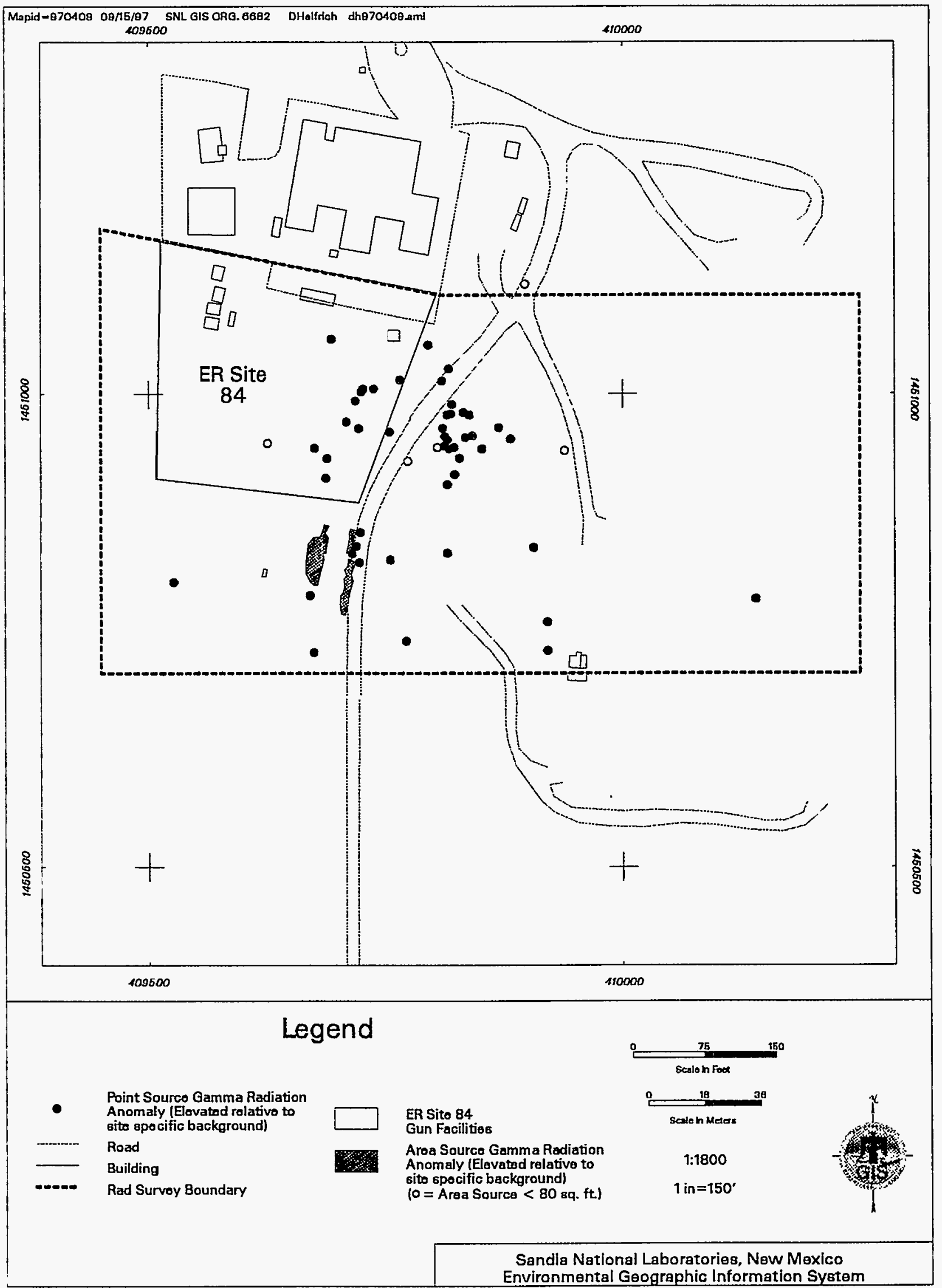

Figure 5.3.5 Phase I Survey Radiation Anomalies at ER Site 84 
sources since the lateral and vertical extent of elevated radiation exceeded the capabilities of manual cleanup procedures.

Cleanup activities included radiation scanning to verify anomaly location, removal of fragment and/or soil until readings were less than 1.3 times site-specific background levels, and post-cleanup (verification) soil sampling for gamma spectroscopy analysis (see Section 3.1). Table 5.3.12 summarizes field activities during the VCM.

Table 5.3.12 Summary of Field Activities at ER Site 84

Removal Action Procedures

\begin{tabular}{|c|c|c|c|c|c|c|}
\hline $\begin{array}{c}\text { Actual } \\
\text { Acreage } \\
\text { Surveyed }\end{array}$ & $\begin{array}{c}\text { Duration of } \\
\text { Cleanup } \\
\text { (days) }\end{array}$ & $\begin{array}{c}\text { Verify } \\
\text { Anomaly } \\
\text { Location }\end{array}$ & $\begin{array}{c}\text { Rad } \\
\text { Removal }^{\mathrm{a}}\end{array}$ & $\begin{array}{c}\text { Post-Cleanup } \\
\text { Sampling }\end{array}$ & $\begin{array}{c}\text { Heavy } \\
\text { Equipment } \\
\text { Support }\end{array}$ & Comments \\
\hline 7.40 & 18.00 & $\mathrm{X}$ & $\mathrm{X}$ & $\mathrm{X}$ & $\mathrm{X}$ & $\begin{array}{l}\text { Skidloader used on } \\
\text { large area sources }\end{array}$ \\
\hline
\end{tabular}

${ }^{a}$ Removal of fragment and/or soil until readings are less than 1.3 times site-specific background

\section{Findings and Observations}

\section{Point and Area Source Status}

Of the sources identified during the Phase I survey, 50 point sources and 6 small area sources were remediated during the initial cleanup. On two of the point sources (84E1 and 84E56), RPO personnel performed cleanup and post-cleanup (verification) sampling. Excavation of two closelyspaced area sources (84E34 and 84E35) showed them to be linked to one large area source. This area source and one other area source (84E47) required a skidloader to complete cleanup. No additional point or area sources were identified during cleanup activities. Figure 5.3.6 shows VCM verification sampling (post-cleanup) locations.

\section{Post-Cleanup (Verification) Sample Results}

After the removal of radiologically contaminated soils, 11 post-cleanup (verification) samples were collected from areas exhibiting the highest residual gamma radiation readings. Gamma spectroscopy analysis was performed on these samples to characterize the residual radioactivity remaining in the soil. The radiological COC was DU (U-238, U-235, and U-234). Table 5.3.13 shows the postcleanup (verification) samples collected, and the maximum level of residual radiological COCs in soil is presented in Table 5.3.14.

\section{Risk Assessment Results}

Further work is planned at ER Site 84 and, therefore, risk assessment has been postponed pending additional characterization. It is anticipated that the potential effects on human health due to 


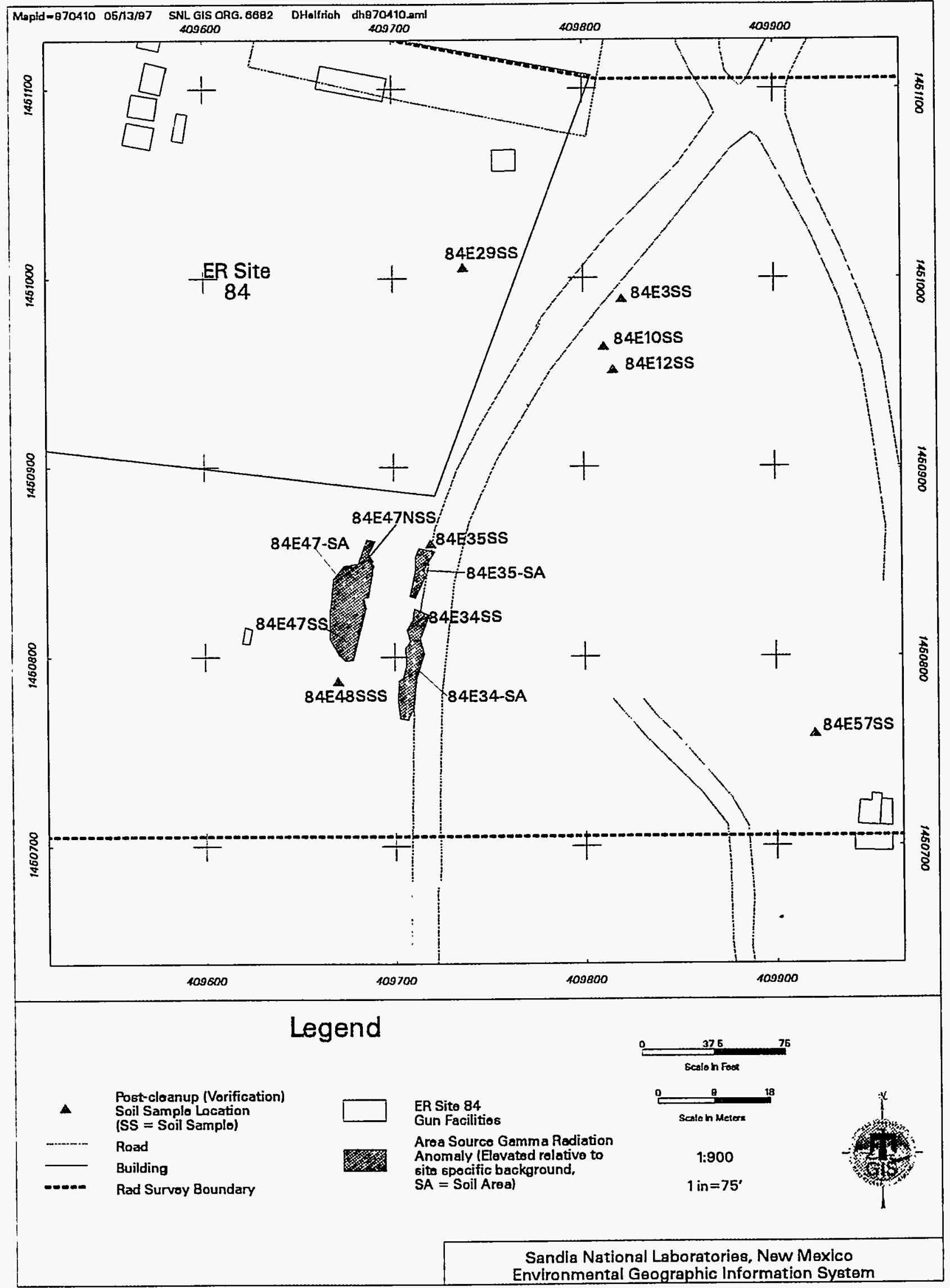

Figure 5.3.6 VCM Surface Soil Sampling Locations at ER Site 84 
Table 5.3.13 Post-Cleanup (Verification) Samples Collected at ER Site 84

\begin{tabular}{|c|c|c|c|c|c|}
\hline \multicolumn{3}{|c|}{$\begin{array}{c}\text { Point Source } \\
\text { Sample Number }\end{array}$} & \multicolumn{3}{|c|}{$\begin{array}{c}\text { Area Source } \\
\text { Sample Number }\end{array}$} \\
\hline 84E3SS & 84E10SS & 84E12SS & 84E34SS & 84E35SS & 84E47NSS \\
\hline $84 \mathrm{E} 12 \mathrm{SD}^{2}$ & 84E29SS & 84E48SS & 84E47SSS & & \\
\hline 84E57SS & & & & & \\
\hline
\end{tabular}

${ }^{a}$ Sample duplicate

Table 5.3.14 Maximum Residual Radionuclide Levels in ER Site 84 Soils

\begin{tabular}{|c|c|c|}
\hline Radionuclide & Maximum Activity (pCi/g) & Background Activity (pCi/g) \\
\hline U-238 & 31.1 & 1.4 \\
\hline U-235 & 0.55 & 0.16 \\
\hline U-234 & 3.9 & 1.6 \\
\hline
\end{tabular}

exposure to radionuclides at the sites will be within proposed standards. This is based on preliminary review of site-specific input parameters and land-use scenarios for the risk assessments to be performed using the RESRAD code.

\section{Waste Management}

The cleanup activities produced soil, metal fragment, and PPE wastes. All waste was containerized in 55-gallon drums. Oversized wood and metal trash was placed in a wooden crate ( 4 by 4 by 7 feet). A total of 230 waste drums (and 1 wooden crate) were generated during cleanup activities: 228 soil drums, 1 metal fragment drum, and $1 \mathrm{PPE}$ drum. Table 5.3.15 shows the number of waste drums produced at the site.

Table 5.3. 15 Summary of Waste Drums for ER Site 84

\begin{tabular}{|c|c|c|c|c|c|c|c|}
\hline \multicolumn{2}{|c|}{ Soil Waste } & \multicolumn{2}{|c|}{$\begin{array}{l}\text { Metal Fragment } \\
\text { Waste }\end{array}$} & \multicolumn{2}{|c|}{ PPE Waste } & \multirow[b]{2}{*}{$\begin{array}{c}\text { TCLP/ } \\
\text { Gamma } \\
\text { Spec } \\
\text { Samples }\end{array}$} & \multirow[b]{2}{*}{ Comments } \\
\hline $\begin{array}{c}30 \text { Gallon } \\
\text { Drums }\end{array}$ & $\begin{array}{c}55 \text { Gallon } \\
\text { Drums }\end{array}$ & $\begin{array}{c}30 \text { Gallon } \\
\text { Drums }\end{array}$ & $\begin{array}{c}55 \text { Gallon } \\
\text { Drums }\end{array}$ & $\begin{array}{l}30 \text { Gallon } \\
\text { Drums }\end{array}$ & $\begin{array}{c}55 \text { Gallon } \\
\text { Drums }\end{array}$ & & \\
\hline 0 & 228 & 0 & 1 & $\overline{0}$ & 1 & $\begin{array}{l}6 \text { Soil } \\
1 \text { Frag }\end{array}$ & $\begin{array}{l}1 \text { wooden crate ( } 4 \text { by } 4 \text { by } \\
7 \text { feet) that contains } \\
\text { contaminated wood, angle } \\
\text { iron, \& } 3 \text { large plates of } \\
\text { steel is being stored at } \\
\text { Bldg. } 897 X \text {. Container } \\
\# 84-061196-31 \text {. }\end{array}$ \\
\hline
\end{tabular}


Six composite soil samples and one metal fragment sample were collected from the waste drums and analyzed for gamma emitters using standard laboratory gamma spectroscopy methods and for leachable RCRA metals using TCLP analytical procedures. Mercury was identified as a COC and was included in the TCLP analysis in November 1994. The samples passed the TCLP test. As a result, mercury was not included in the TCLP analysis for samples collected in May and June 1996. These samples also passed the TCLP tests. All waste was characterized as "Radioactive-Low Level Only." A summary of radiological activity for the waste is presented in Appendix G.

Disposal of regulated VCM waste was handled by SNL/NM Department 7577 (Waste Operations), which packaged and secured waste drums for transfer to Envirocare of Utah. Nonregulated waste was disposed of using standard SNL/NM-approved waste disposal methods.

\section{Conclusions}

All surface point and area sources of gamma activity 30 percent or greater than the natural background were removed from the site. The site is currently classified as "active," and no further cleanup activities are planned until the site designation changes. When the site designation changes, further radiological characterization (resurveying) and source removal will be conducted, and risk assessment will be performed. Source removal is summarized in Table 5.3.16.

Table 5.3.16 Summary of Point and Area Source Removal at ER Site 84

\begin{tabular}{|c|c|c|c|}
\hline Anomaly Type & Total Identified & Total Removed & Comments \\
\hline Point Sources & 50 & 50 & Active site, no further action planned. \\
\hline Area Sources & 9 & 9 & Active site, no further action planned. \\
\hline
\end{tabular}

No additional cleanup activities were performed during this VCM. The status of other possible COCs is not addressed in this report.

All waste was characterized as "Radioactive-Low Level Only" and managed in accordance with SNL/NM Department 7572 (Waste Management) procedures.

\subsubsection{Short Sled Track (ER Site 240)}

\section{Overview}

The Phase I survey at ER Site 240 was conducted in February and March 1994 and covered a total of 82.6 acres of flat, bushy terrain surrounding the impact area of the small sled track in Technical Area III. A gamma scan survey was performed at 10 -foot centers ( 70 percent coverage) over the surface of the site. A total of 251 point sources and 9 area sources of gamma activity 30 percent or greater than the natural background were identified during this survey. A detailed summary of the surface radiological survey and anomalies found at the site is presented in Section 5.3.6 of the Surface Gamma Radiation Surveys Final Report (Geotech 1994b).

Figure 5.3.7 shows the site, surface radiological survey boundaries, and anomalies found during the Phase I survey. 


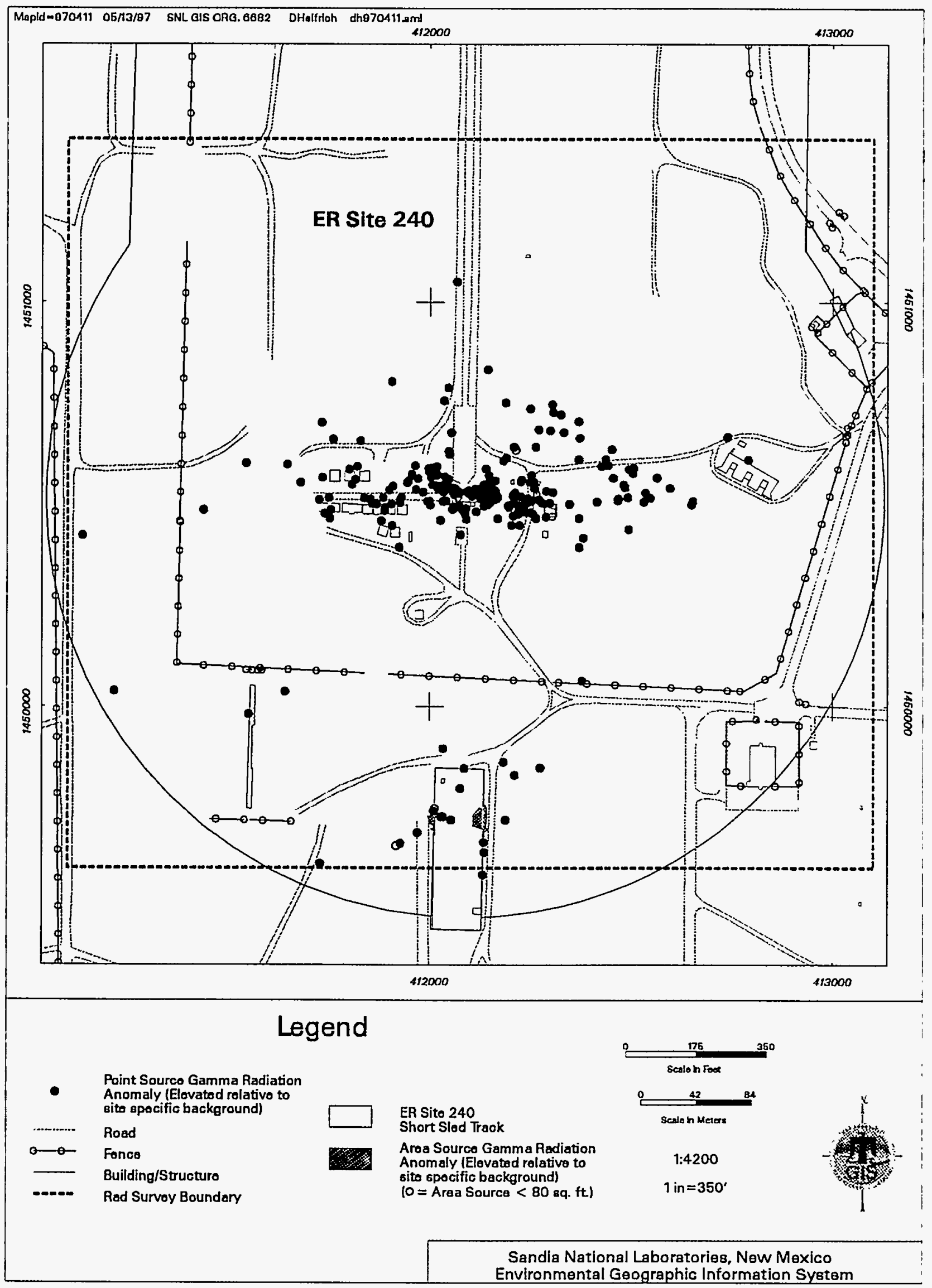

Figure 5.3.7 Phase I Survey Radiation Anomalies at ER Site 240 
VCM activities were conducted during August, October, and November 1994, and May and June 1996. Resurveying (scanning) was not performed at this site. Point sources and small area sources were removed in August and October 1994. Large area sources were remediated in November 1994. Sources that could not be relocated during the initial cleanup activities were relocated and remediated in May 1996. In June 1996, at the request of SNL/NM personnel, an additional gamma survey was conducted on a source previously remediated.

Cleanup activities included radiation scanning to verify anomaly location, removal of fragment and/or soil until readings were less than 1.3 times site-specific background levels, and post-cleanup (verification) soil sampling for gamma spectroscopy analysis (see Section 3.1). Table 5.3.17 summarizes field activities during the VCM.

Table 5.3.17 Summary of Field Activities at ER Site 240

Removal Action Procedures

\begin{tabular}{|c||c|c|c|c|}
\hline $\begin{array}{c}\text { Actual Acreage } \\
\text { Surveyed }\end{array}$ & $\begin{array}{c}\text { Duration of Cleanup } \\
\text { (days) }\end{array}$ & $\begin{array}{c}\text { Verify Anomaly } \\
\text { Location }\end{array}$ & Rad Removal $^{\mathrm{a}}$ & Post-Cleanup Sampling $^{\text {(days }}$ \\
\hline 82.60 & 8.00 & $\mathbf{X}$ & $\mathbf{X}$ & $\mathbf{X}$ \\
\hline
\end{tabular}

${ }^{3}$ Removal of fragment and/or soil until readings are less than 1.3 times site-specific background

\section{Findings and Observations}

\section{Point and Area Source Status}

Of the sources identified during the Phase I survey, 248 point sources and 6 area sources were remediated. Three point sources and three area sources could not be remediated. Three point sources (240E224, 240E225, and 240E227) and one area source (240E226) were located within cracks on the concrete pad. One area source (240E228) extended under the concrete pad and, at the other area source (240E216), the elevated gamma readings were related to "shine" (gamma interference) from material stored on the concrete pad. Four point sources (240E9, 204E11, 240E40, and 240E132) were relocated using GPS and were remediated with large area sources. Field screening performed at the request of SNL/NM personnel on one source previously remediated (240E235) indicated no elevated gamma readings at that location. Resurveying (scanning) on 6-foot centers (100 percent coverage) was not performed, and additional surface radiation cleanup may be required on the site.

During the initial cleanup, six new point sources were detected and remediated. Cleanup was completed on these sources, and no additional point or area sources were identified during this VCM. The new sources identified during the VCM are summarized in Table 5.3.18, and Figure 5.3.8 shows VCM radiation anomalies and verification sampling locations (post-cleanup). 


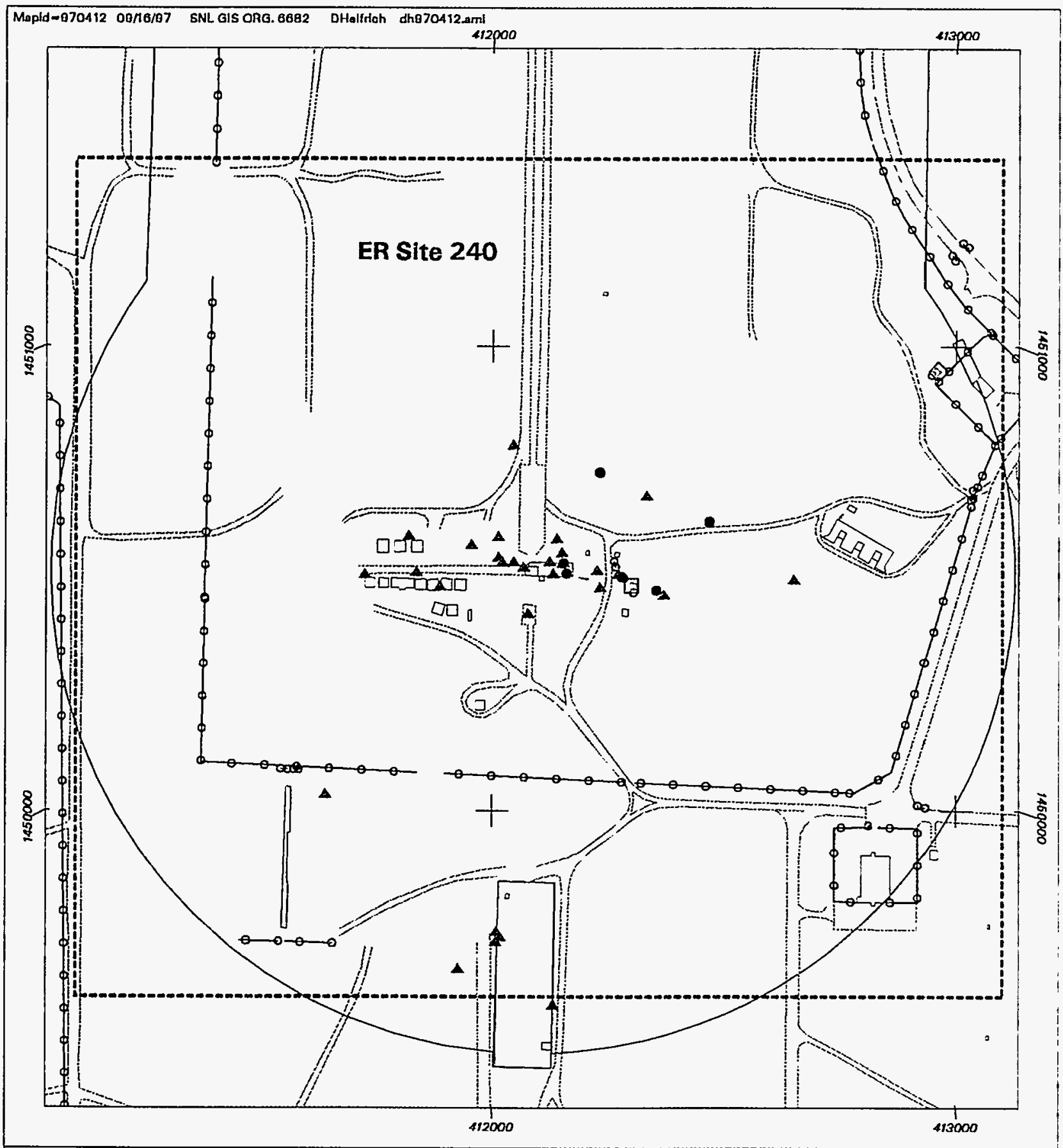

Legend

Point Sourco Gamma Radiation

Anomaly (Elovatad rolativo to

sito spocific background)

Post-cloanup (Vorification)

Soil Samplo Location

Road

o- 0 Fonce

Building/Structuro

-.no Rad Survoy Boundary

ER Sito 240

Short Slod Traok

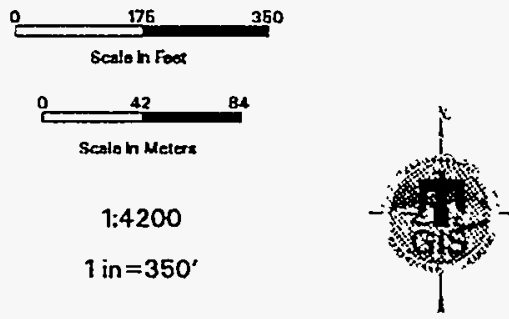

Sandia National Laboratories, New Mexico Environmental Geographic Information System 
Table 5.3.18 Radiation Anomalies 30 Percent or Greater Than Natural Background Identified During the VCM at ER Site 240

\begin{tabular}{|c|c|l|}
\hline Anomaly Type & Total & \multicolumn{1}{c|}{ Comments } \\
\hline Point Sources & 6 & $\begin{array}{l}\text { Gray, black fragments with yellow } \\
\text { uranium oxide (DU) in soil }\end{array}$ \\
\hline
\end{tabular}

Resurveying (scanning) and additional source removal may be required under future cleanup activities. A gamma survey at 100 percent coverage may result in additional anomalies being identified. Cleanup will be required on original large area sources not completely remediated during the initial cleanup and on new point and area sources identified during resurveying.

\section{Post-Cleanup (Verification) Sample Results}

After the removal of radiologically contaminated soils, 33 post-cleanup (verification) samples were collected from areas exhibiting the highest residual gamma radiation readings. Gamma spectroscopy analysis was performed on these samples to characterize the residual radioactivity remaining in the soil. The radiological COCs were DU (U-238, U-235, and U-234), Co-60, Cs-137, and thorium series radionuclides. Table 5.3.19 shows the post-cleanup (verification) samples collected at the site, and the maximum level of residual radiological COCs in soil is presented in Table 5.3.20.

Table 5.3.19 Post-Cleanup (Verification) Samples Collected at ER Site 240

\begin{tabular}{|c|c|c|c|}
\hline \multicolumn{3}{|c|}{$\begin{array}{c}\text { Point Source } \\
\text { Sample Number }\end{array}$} & $\begin{array}{c}\text { Area Source } \\
\text { Sample Number }\end{array}$ \\
\hline $240 E 13 S S$ & 240E29SS & $240 \mathrm{E} 40 \mathrm{SS}$ & 240E230ASS 240E230BSS 240E232SS \\
\hline $240 \mathrm{E} 46 \mathrm{SS}$ & 240E55SS & $240 \mathrm{E} 55 \mathrm{SD}^{\mathrm{a}}$ & $240 \mathrm{E} 232 \mathrm{SD}^{\mathrm{a}}$ \\
\hline 240E58SS & 240E59SS & 240E72SS & \\
\hline 240E90SS & 240E106SS & $240 \mathrm{E} 108 \mathrm{SS}$ & \\
\hline 240E112SS & 240E125SS & $240 \mathrm{E} 125 \mathrm{SD}^{\mathrm{a}}$ & \\
\hline 240E137SS & $240 \mathrm{E} 137 \mathrm{SD}^{\mathrm{a}}$ & $240 \mathrm{E} 142 \mathrm{SS}$ & \\
\hline $240 \mathrm{E} 142 \mathrm{SD}^{\mathrm{a}}$ & 240E153SS & 240E162SS & \\
\hline $240 \mathrm{E} 165 \mathrm{SS}$ & 240E174SS & $240 \mathrm{E} 188 \mathrm{SS}$ & \\
\hline 240E196SS & 240E229SS & $240 \mathrm{E} 235 \mathrm{SS}$ & \\
\hline 240E239SS & $240 \mathrm{E} 260 \mathrm{SS}$ & & \\
\hline
\end{tabular}

${ }^{a}$ Sample duplicate 
Table 5.3.20 Maximum Residual Radionuclide Levels in ER Site 240 Soils

\begin{tabular}{|c|c|c|}
\hline Radionuclide & Maximum Activity (pCi/g) & Background Activity (pCi/g) \\
\hline U-238 & 9.4 & 1.4 \\
\hline $\mathrm{U}-235$ & 0.12 & 0.16 \\
\hline $\mathrm{U}-234$ & 1.2 & 1.6 \\
\hline Th-232 & 1.4 & 1.03 \\
\hline Ra-228 & 1.4 & 1.08 \\
\hline Co-60 & 7.5 & $\mathrm{n} / \mathrm{a}^{\mathrm{a}}$ \\
\hline Cs-137 & 1.4 & 1.063 \\
\hline
\end{tabular}

${ }^{a}$ Does not occur naturally, or due to fallout, in the environment.

\section{Risk Assessment Results}

Further work is planned at ER Site 240 and, therefore, risk assessment has been postponed pending additional characterization. It is anticipated that the potential effects on human health due to exposure to radionuclides at the sites will be within proposed standards. This is based on preliminary review of site-specific input parameters and land-use scenarios for the risk assessments to be performed using the RESRAD code.

\section{Waste Management}

The cleanup activities produced soil, metal fragment, and PPE wastes. All waste was containerized in either 30-gallon or 55-gallon drums. A total of 31 waste drums were generated during cleanup activities: 28 soil drums, 2 metal fragment drums, and 1 PPE drum. Table 5.3.21 shows the number of waste drums produced at the site.

Table 5.3.21 Summary of Waste Drums for ER Site 240

\begin{tabular}{|c|c|c|c|c|c|c|c|}
\hline \multicolumn{2}{|c|}{ Soil Waste } & \multicolumn{2}{|c|}{$\begin{array}{c}\text { Metal Fragment } \\
\text { Waste }\end{array}$} & \multicolumn{2}{|c|}{ PPE Waste } & \multirow[b]{2}{*}{$\begin{array}{c}\text { TCLP/ } \\
\text { Gamma } \\
\text { Spec } \\
\text { Samples }\end{array}$} & \multirow[b]{2}{*}{ Comments } \\
\hline $\begin{array}{l}30 \text { Gallon } \\
\text { Drums }\end{array}$ & $\begin{array}{c}55 \text { Gallon } \\
\text { Drums }\end{array}$ & $\begin{array}{c}30 \text { Gallon } \\
\text { Drums }\end{array}$ & $\begin{array}{c}55 \text { Gallon } \\
\text { Drums }\end{array}$ & $\begin{array}{c}30 \text { Gallon } \\
\text { Drums }\end{array}$ & $\begin{array}{c}55 \text { Gallon } \\
\text { Drums }\end{array}$ & & \\
\hline 0 & 28 & $\overline{0}$ & 2 & 1 & 0 & $\begin{array}{l}1 \text { Soil } \\
1 \text { Frag }\end{array}$ & \\
\hline
\end{tabular}

One composite soil sample and one composite metal fragment were collected from the waste drums and analyzed for gamma emitters using standard laboratory gamma spectroscopy methods and for leachable RCRA metals using TCLP analytical procedures. Mercury was not identified as a COC and was not included in the TCLP analysis. All samples passed the TCLP tests, and all waste was characterized as "Radioactive-Low Level Only." A summary of radiological activity for the waste is presented in Appendix G. 
Disposal of regulated VCM waste was handled by SNL/NM Department 7577 (Waste Operations), which packaged and secured waste drums for transfer to Envirocare of Utah. Nonregulated waste was disposed of using standard SNL/NM-approved waste disposal methods.

\section{Conclusions}

All point and area sources of gamma activity 30 percent or greater than the natural background were removed from the site with the exception of five sources associated with the concrete pad and another source associated with "shine" from material stored on the concrete pad. Source removal is summarized in Table 5.3.22, and sources remaining after completion of the VCM are shown in Figure 5.3.9.

Table 5.3.22 Summary of Point and Area Source Removal at ER Site 240

\begin{tabular}{|c|c|c|l|}
\hline Anomaly Type & Total Identified & Total Removed & \multicolumn{1}{|c|}{ Comments } \\
\hline Point Sources & 257 & 254 & $\begin{array}{l}\text { Three sources were not remediated } \\
\text { because they are associated with a } \\
\text { concrete pad. Active site. }\end{array}$ \\
\hline Area Sources & 9 & 6 & $\begin{array}{l}\text { Three sources were not remediated } \\
\text { because two sources are associated } \\
\text { with a concrete pad and one source is } \\
\text { associated with "shine" (gamma } \\
\text { interference from nearby material. } \\
\text { Active site. }\end{array}$ \\
\hline
\end{tabular}

Further radiological characterization and source removal may be required for those sources not completely remediated during the initial cleanup. The site is currently classified as "active," and no further cleanup activities are planned until the site designation changes. When the site designation changes, resurveying (scanning) and additional source removal will be addressed, and a radiological risk assessment will be performed.

No additional cleanup activities were performed during this VCM. The status of other possible COCs is not addressed in this report.

All waste was characterized as "Radioactive-Low Level Only" and managed in accordance with SNL/NM Department 7572 (Waste Management) procedures.

\subsubsection{Storage Yard (ER Site 241)}

\section{Overview}

The Phase I survey at ER Site 241 was conducted in April 1994 and covered a total of 1.8 acres of flat terrain with little or no vegetation. A gamma scan survey was performed at 6 -foot centers (100 percent coverage) over the surface of the site. Four area sources of gamma activity 30 percent or greater than the natural background were identified during this survey. A detailed summary 


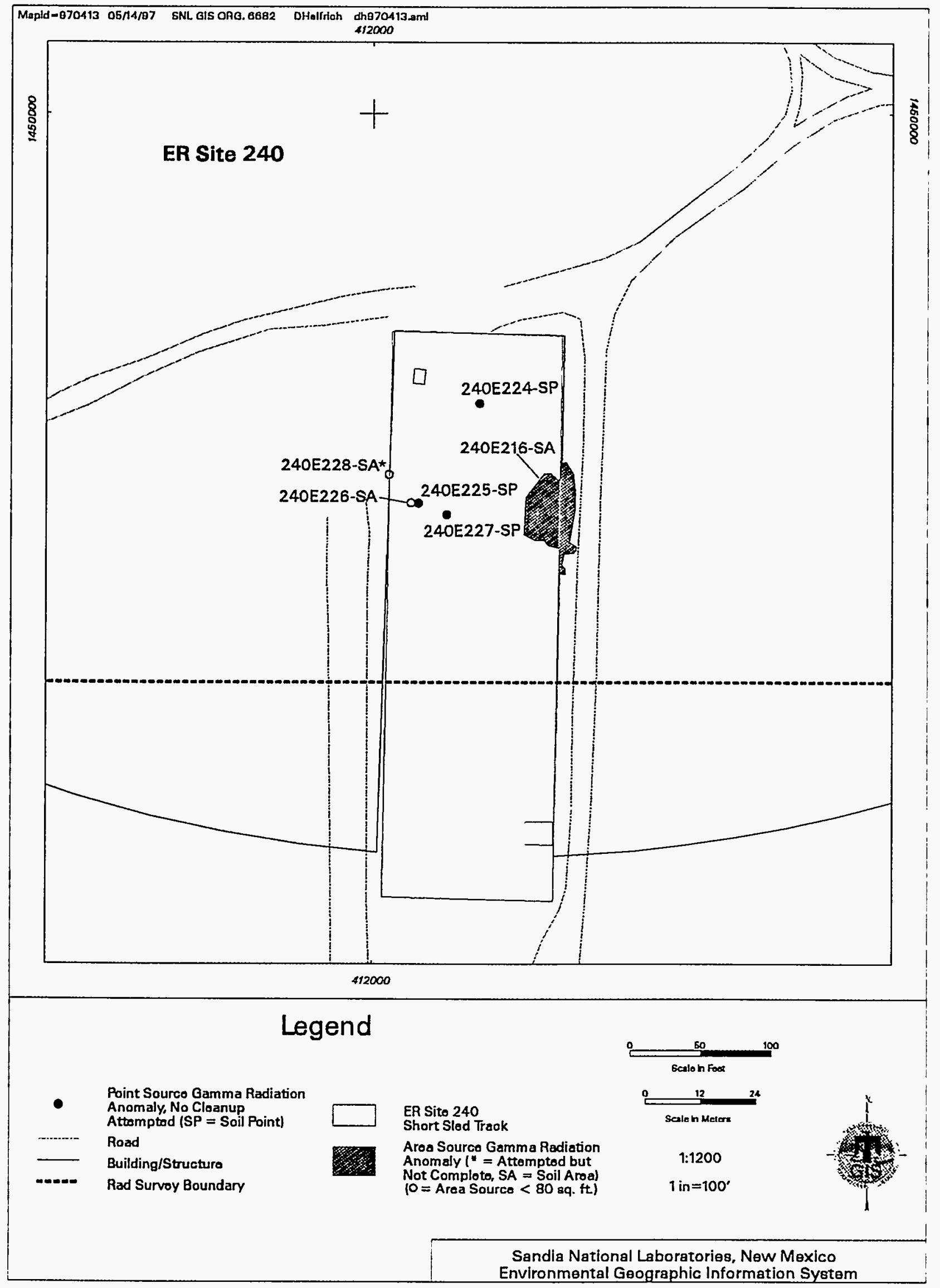

Figure 5.3.9 Radiation Anomalies Remaining After Completion of the VCM at ER Site $\mathbf{2 4 0}$ 
of the surface radiological survey and anomalies found at the site is presented in Section 5.3.4 of the Surface Gamma Radiation Surveys Final Report (Geotech 1994b).

Figure 5.3.10 shows the site, surface radiological survey boundaries, and anomaly found during the Phase I survey.

VCM activities were conducted during July 1995 . Radiation scanning to verify anomaly locations was performed, and pre-cleanup soil samples for gamma spectroscopy analysis were collected on area sources to assess the need for remediation. Table 5.3.23 summarizes field activities during the VCM.

Table 5.3.23 Summary of Field Activities at ER Site 241

\begin{tabular}{|c|c|c|c|c|}
\hline $\begin{array}{c}\text { Actual Acreage } \\
\text { Surveyed }\end{array}$ & $\begin{array}{c}\text { Duration of } \\
\text { Cleanup (days) }\end{array}$ & $\begin{array}{c}\text { Verify } \\
\text { Anomaly } \\
\text { Location }\end{array}$ & $\begin{array}{c}\text { Pre-Cleanup } \\
\text { Sampling } \\
\text { (area sources) }\end{array}$ & \multicolumn{1}{c|}{ Comments } \\
\hline 1.80 & $<0.25$ & $\mathbf{X}$ & $\mathbf{X}$ & $\begin{array}{l}\text { Area sources result of "shine" } \\
\text { (gamma interference) from } \\
\text { nearby material }\end{array}$ \\
\hline
\end{tabular}

\section{Findings and Observations}

\section{Point and Area Source Status}

The four area sources were not remediated. The gamma spectroscopy results on the pre-cleanup samples showed the elevated radiation was related to "shine" (gamma interference) from materials stored within the site boundaries. The materials were removed, and follow-up gamma survey detected no elevated radiation. No additional point or area sources were identified during this VCM.

\section{Pre-Cleanup Sample Results}

The four anomalies detected were due to "shine" associated with activated materials stored within the site boundaries. Four pre-cleanup soil samples were collected from areas exhibiting the highest residual gamma radiation readings. The maximum U-238 activity detected in soils was slightly greater than area-specific background values, but is within the range of natural background for SNL/NM as a whole. The DU (U-238, U-235, and U-234) activity for three pre-cleanup soil samples was less than area-specific background. Therefore, no radioactive soil contamination was indicated, and no post-cleanup soil samples were taken. Table 5.3.24 shows the post-cleanup (verification) samples collected at the site, and the maximum level of residual radiological COCs in soil is presented in Table 5.3.25.

\section{Risk Assessment Results}

Anomalies were characterized as "shine," and no risk assessment was performed. 


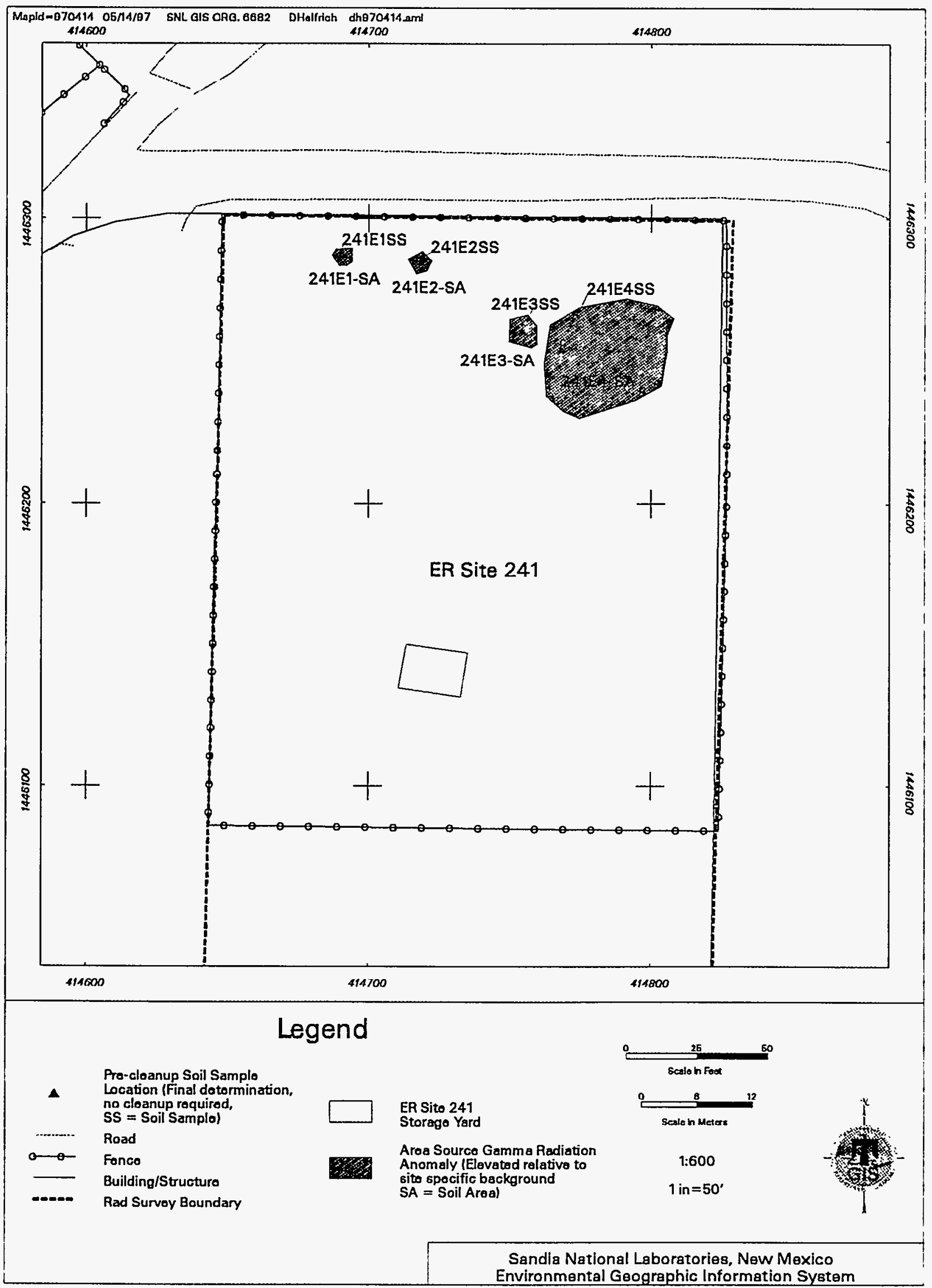

Figure 5.3.10 Phase I Survey Radiation Anomalies and VCM Surface Soil Sampling Locations at ER Site 241 
Table 5.3.24 Pre-Cleanup (Final Determination) Samples Collected at ER Site 241

\begin{tabular}{|c|c|c|c|}
\hline \multicolumn{4}{|c|}{$\begin{array}{c}\text { Area Source } \\
\text { Sample Number }\end{array}$} \\
\hline 241E1SS & 241E2SS & 241E3SS & 241E4SS \\
\hline
\end{tabular}

Table 5.3.25 Maximum Residual Radionuclide Levels in ER Site 241 Soils

\begin{tabular}{|c|c|c|}
\hline Radionuclide & Maximum Activity (pCi/g) & Background Activity (pCi/g) \\
\hline U-238 & 1.64 & 1.4 \\
\hline U-235 & ND & 0.16 \\
\hline U-234 & ND & 1.6 \\
\hline
\end{tabular}

\section{Waste Management}

No VCM was conducted at the site therefore, no waste was generated.

\section{Conclusions}

Four area sources of gamma activity 30 percent or greater than the natural background were not remediated since the elevated radiation is related to "shine" associated with activated materials stored within the site boundaries. No radioactive soil contamination was remediated, no waste was generated, and no risk assessment was performed. Source removal is summarized in Table 5.3.26.

Table 5.3.26 Summary of Area Source Removal at ER Site 241

\begin{tabular}{|c|c|c|l|}
\hline Anomaly Type & Total Identified & Total Removed & \multicolumn{1}{c|}{ Comments } \\
\hline Area Sources & 4 & 0 & $\begin{array}{l}\text { The sources are related to "shine" } \\
\text { from materials stored within the site } \\
\text { boundaries. No further action } \\
\text { required. }\end{array}$ \\
\hline
\end{tabular}

No additional cleanup activities were performed during this VCM. The status of other possible COCs is not addressed in this report. 


\subsection{Tijeras Arroyo Operable Unit Sites (ADS 1309)}

\subsubsection{Open Dumps (ER Site 16)}

\section{Overview}

The Phase I survey at ER Site 16 was conducted in January and February 1994 and covered a total of 26.4 acres of an approximately 2,200-foot-long section of the bottom and banks of Arroyo del Coyote wash northeast of Technical Areas III/V. A gamma scan survey was performed at 10-foot centers ( 70 percent coverage) over the surface of the site. Three point sources and eighteen area sources of gamma activity 30 percent or greater than the natural background were identified during this survey. A detailed summary of the surface radiological survey and anomalies found at the site is presented in Section 5.4.1 of the Surface Gamma Radiation Surveys Final Report (Geotech 1994b).

Figure 5.4.1 shows the site, surface radiological survey boundaries, and anomalies found during the Phase I survey.

VCM activities were conducted during March 1995 and June, October, and November 1996. Point sources were removed in March 1995. In June 1996, resurveying (scanning) of the entire site was performed on 6-foot centers (100 percent coverage), and pre-cleanup soil sampling for gamma spectroscopy analysis was conducted on eight area sources to assess the need for remediation. Area sources were cleaned up in June, October, and November 1996. These area sources were associated with large debris/soil mounds. Heavy equipment (backhoe and skidloader) was used on 14 area sources since the lateral and vertical extent of elevated radiation exceeded the capabilities of manual cleanup procedures.

Cleanup activities included radiation scanning to verify anomaly location, removal of fragment and/or soil until readings were less than 1.3 times site-specific background levels, and postcleanup (verification) soil sampling for gamma spectroscopy analysis (see Section 3.1). Table 5.4.1 summarizes field activities during the VCM.

Table 5.4.1 Summary of Field Activities at ER Site 16 Removal Action Procedures

\begin{tabular}{|c|c|c|c|c|c|c|c|c|}
\hline $\begin{array}{c}\text { Actual } \\
\text { Acreage } \\
\text { Surveyed }\end{array}$ & $\begin{array}{c}\text { Duration of } \\
\text { Cleanup } \\
\text { (days) }\end{array}$ & $\begin{array}{c}\text { Verify } \\
\text { Anomaly } \\
\text { Location }\end{array}$ & $\begin{array}{c}\text { Rad } \\
\text { Removal }\end{array}$ & $\begin{array}{c}\text { Post- } \\
\text { Cleanup } \\
\text { Sampling }\end{array}$ & $\begin{array}{c}\text { New Area/ } \\
\text { Resurveyed } \\
(\mathbf{1 0 0 \% )}\end{array}$ & $\begin{array}{c}\text { Pre-Cleanup } \\
\text { Sampling } \\
\text { (area sources) }\end{array}$ & $\begin{array}{c}\text { Heavy } \\
\text { Equipment } \\
\text { Support }\end{array}$ & Comments \\
\hline 26.40 & 33.25 & $\mathbf{X}$ & $\mathbf{X}$ & $\mathbf{X}$ & $\mathbf{X}$ & $\mathbf{X}$ & $\mathbf{X}$ & $\begin{array}{l}\text { Resurveyed original } \\
\text { area on 6-ft centers } \\
\text { (100\%). Backhoe } \\
\text { used on large area } \\
\text { sources. }\end{array}$ \\
\hline
\end{tabular}

\footnotetext{
${ }^{a}$ Removal of fragment and/or soil until readings are less than 1.3 times site-specific background
} 
$\downarrow \varepsilon-\varsigma$

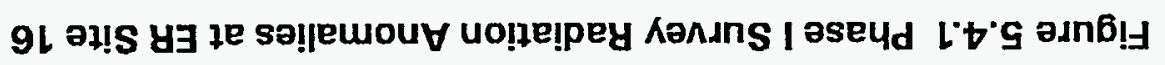

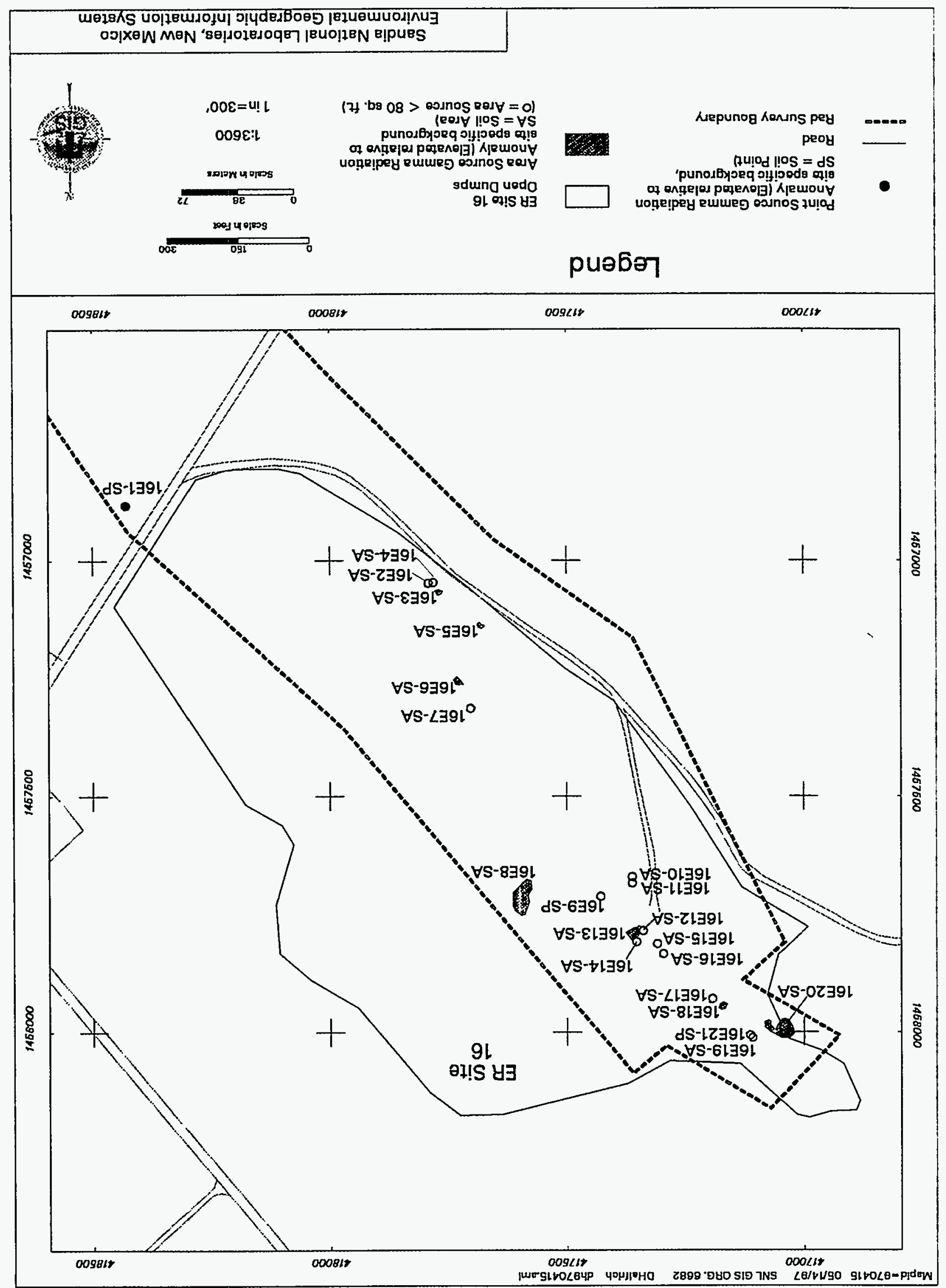




\section{Findings and Observations}

\section{Point and Area Source Status}

Of the sources identified during the Phase I survey, two point sources (16E1 and 16E21) were remediated during the initial cleanup in March 1995. One point source (16E9) was a large concrete block and was not removed. The results of gamma spectroscopy analysis on precleanup samples collected from five area sources indicate the elevated radiation is related to anthropogenic (man-made) material. Two of these sources (16E6 and 16E7) were not remediated due to the presence of fire bricks containing asbestos. Three of these sources $(16 \mathrm{E} 5,16 \mathrm{E} 11$, and $16 \mathrm{E} 15)$ and eight other area sources $(16 \mathrm{E} 2,16 \mathrm{E} 3,16 \mathrm{E} 4,16 \mathrm{E} 10,16 \mathrm{E} 16,16 \mathrm{E} 17,16 \mathrm{E} 18$, and $16 \mathrm{E} 19)$ were cleaned up. Excavation of three closely-spaced area sources $(16 \mathrm{E} 12,16 \mathrm{E} 13$, and $16 \mathrm{E} 14)$ showed them to be linked to one large area source. Remediation of this area source was not completed due to the large quantity of concrete rubble and debris present which exceeded the capabilities of the heavy equipment (backhoe and skidloader).

Gamma spectroscopy results on pre-cleanup samples collected from two area sources (16E8 and $16 \mathrm{E} 20$ ) indicate the elevated radiation is related to naturally-occurring geologic material, and no cleanup was required. Table 5.4.2 shows the pre-cleanup samples collected from these two sources.

Table 5.4.2 Pre-Cleanup (Final Determination) Samples Collected at ER Site 16

\begin{tabular}{|lll|}
\hline \multicolumn{3}{|c|}{$\begin{array}{c}\text { Area Source } \\
\text { Sample Number }\end{array}$} \\
\hline \hline 16E8SS & 16E8BSS & $16 \mathrm{E} 8 \mathrm{CSS}$ \\
16E20SS & 16E20ASS & $16 \mathrm{E} 20 \mathrm{BSS}$ \\
\hline
\end{tabular}

During gamma resurveying (100 percent coverage) in June 1996, a new point and a new area source were identified. The new point source (16E23) was a large concrete block ( 4 by 4 by 2.5 feet) and was not remediated. The results of gamma spectroscopy analysis on the pre-cleanup sample collected from the new area source (16E22) indicated the elevated radiation is related to naturally-occurring geologic material and radiological remediation is not required. However, the new area source may require hazardous material remediation due to the possible presence of RCRA-metal contaminated soil. Both new sources identified during the VCM are summarized in Table 5.4.3. Figure 5.4.2 shows VCM radiation anomalies and verification sampling (precleanup and post-cleanup) locations. 


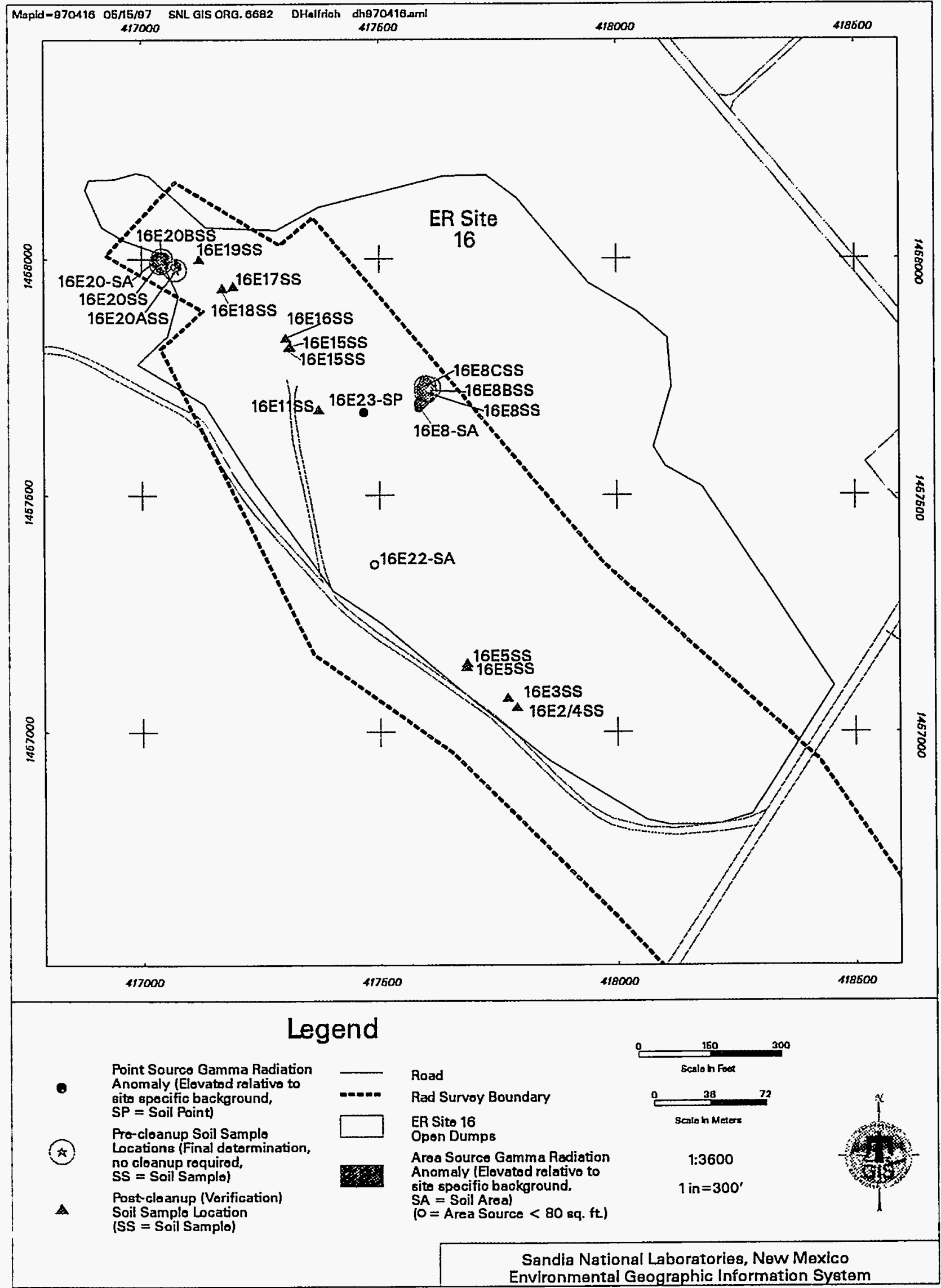

Figure 5.4.2 VCM Radiation Anomalies and Surface Soil Sampling Locations at ER Site 16 
Table 5.4.3 Radiation Anomalies 30 Percent or Greater Than Natural Background Identified During the VCM at ER Site 16

\begin{tabular}{|c|c|l|}
\hline Anomaly Type & Total & \multicolumn{1}{c|}{ Comments } \\
\hline Point Source & 1 & $\begin{array}{l}\text { Large concrete block (16E23) in } \\
\text { bottom of arroyo (4 by 4 by } \\
2.5 \text { feet) }\end{array}$ \\
\hline Area Source & 1 & $\begin{array}{l}\text { Concrete rubble, "baked shale" } \\
\text { and soil (16E22) }\end{array}$ \\
\hline
\end{tabular}

\section{Post-Cleanup (Verification) Sample Results}

After the removal of radiologically contaminated soils, 12 post-cleanup (verification) samples were collected from areas exhibiting the highest residual gamma radiation readings. Gamma spectroscopy analysis was performed on these samples to characterize the residual radioactivity remaining in the soil. The radiological COC was DU (U-238, U-235, and U-234). Table 5.4.4 shows the post-cleanup (verification) samples collected at the site, and the maximum level of residual radiological COCs in soil is presented in Table 5.4.5.

\section{Table 5.4.4 Post-Cleanup (Verification) Samples Collected at ER Site 16}

\begin{tabular}{|lll|}
\hline \multicolumn{3}{|c|}{$\begin{array}{c}\text { Area Source } \\
\text { Sample Number }\end{array}$} \\
\hline $16 \mathrm{E} 2 / 4 \mathrm{SS}$ & $16 \mathrm{E} 3 \mathrm{SS}$ & $16 \mathrm{E} 3 \mathrm{SD}^{2}$ \\
$16 \mathrm{E} 5 \mathrm{SS}$ & $16 \mathrm{E} 5 \mathrm{ASS}$ & $16 \mathrm{E} 11 \mathrm{SS}$ \\
$16 \mathrm{E} 15 \mathrm{SS}$ & $16 \mathrm{E} 15 \mathrm{ASS}$ & $16 \mathrm{E} 16 \mathrm{SS}$ \\
$16 \mathrm{E} 17 \mathrm{SS}$ & $16 \mathrm{E} 18 \mathrm{SS}$ & $16 \mathrm{E} 19 \mathrm{SS}$ \\
\hline
\end{tabular}

${ }^{\mathrm{a}}$ Sample duplicate

Table 5.4.5 Maximum Residual Radionuclide Levels in ER Site 16 Soils

\begin{tabular}{|c|c|c|}
\hline Radionuclide & Maximum Activity $(\mathrm{pCi} / \mathrm{g})$ & Background Activity $(\mathrm{pCi} / \mathrm{g})$ \\
\hline $\mathrm{U}-238$ & 11.8 & 1.4 \\
\hline $\mathrm{U}-235$ & 0.16 & 0.16 \\
\hline $\mathrm{U}-234$ & 1.41 & 1.6 \\
\hline
\end{tabular}

\section{Risk Assessment Results}

Further work is planned at ER Site 16 and, therefore, risk assessment has been postponed pending additional characterization and remediation. After cleanup is complete, it is anticipated that the potential effects on human health due to exposure to radionuclides at the sites will be within proposed standards. This is based on preliminary review of site-specific input parameters and land-use scenarios for the risk assessments to be performed using the RESRAD code (see Section 3.3.2). 


\section{Waste Management}

Cleanup activities produced soil and PPE wastes with no metal fragment waste generated. All waste was containerized in either 30- or 55-gallon drums. A total of 423 waste drums were generated during cleanup activities. Waste consolidation was performed to minimize the number of drums produced for each waste stream. One soil drum was consolidated into another soil drum from ER Site 193. Table 5.4.6 shows the number of waste drums after waste minimization/consolidation was performed, and Appendix J summarizes the waste minimization/consolidation effort.

Table 5.4.6 Summary of Waste Drums for ER Site 16 (Post Minimization/Consolidation Effort)

\begin{tabular}{|c|c|c|c|c|c|c|c|}
\hline \multicolumn{2}{|c|}{ Soil Waste } & \multicolumn{2}{|c|}{$\begin{array}{c}\text { Metal Fragment } \\
\text { Waste }\end{array}$} & \multicolumn{2}{|c|}{ PPE Waste } & \multirow{2}{*}{$\begin{array}{l}\text { TCLP/ } \\
\text { Gamma } \\
\text { Spec } \\
\text { Samples } \\
\end{array}$} & \multirow[b]{2}{*}{ Comments } \\
\hline $\begin{array}{c}30 \text { Gallon } \\
\text { Drums }\end{array}$ & $\begin{array}{c}55 \text { Gallon } \\
\text { Drums }\end{array}$ & $\begin{array}{c}30 \text { Gallon } \\
\text { Drums }\end{array}$ & \begin{tabular}{|c|}
55 Gallon \\
Drums
\end{tabular} & $\begin{array}{c}30 \text { Gallon } \\
\text { Drums }\end{array}$ & $\begin{array}{c}55 \text { Gallon } \\
\text { Drums }\end{array}$ & & \\
\hline 0 & 419 & 0 & 0 & 0 & 3 & 10 Soil & $\begin{array}{l}\text { One additional } 55 \text { gallon } \\
\text { drum contains parachute } \\
\text { material. Waste } \\
\text { Minimization/Consolidation } \\
\text { was performed. }\end{array}$ \\
\hline
\end{tabular}

${ }^{\mathbf{a}}$ See Appendix J

Ten composite soil samples were collected from the waste drums and analyzed for gamma emitters using standard laboratory gamma spectroscopy methods and for leachable RCRA metals using TCLP analytical procedures. Mercury was not identified as a COC and was not included in the TCLP analysis. All samples passed the TCLP tests, and all waste was characterized as "Radioactive-Low Level Only." A summary of radiological activity for the waste is presented in Appendix G.

Disposal of regulated VCM waste was handled by SNL/NM Department 7577 (Waste Operations), which packaged and secured waste drums for transfer to Envirocare of Utah. Nonregulated waste was disposed of using standard SNL/NM-approved waste disposal methods.

\section{Conclusions}

Two point sources and eleven area sources of gamma activity 30 percent or greater than the natural background were removed from the site. Elevated radiation at two area sources was related to naturally occurring geologic material, and remediation is not required. Further radiological and nonradiological characterization and source removal will be required for two point sources and six area sources. These sources will require large, specialized heavy equipment to handle large quantities of concrete rubble and debris, as well as qualified personnel to remediate asbestos, RCRA-metal contaminated soil, and radioactively contaminated soil. Risk assessment will be conducted after additional characterization and source removal is performed. 
Source removal is summarized in Table 5.4.7, and sources remaining after completion of the VCM are shown in Figure 5.4.3.

Table 5.4.7 Summary of Point and Area Source Removal at ER Site 16

\begin{tabular}{|c|c|c|l|}
\hline Anomaly Type & Total Identified & Total Removed & \multicolumn{1}{|c|}{ Comments } \\
\hline Point Sources & 4 & 2 & $\begin{array}{l}\text { Two sources were not remediated } \\
\text { because they are associated with } \\
\text { large concrete blocks. Further } \\
\text { action is required. }\end{array}$ \\
\hline Area Sources & 19 & 11 & $\begin{array}{l}\text { Two sources are related to } \\
\text { underlying, naturally-occurring } \\
\text { geologic material and no further } \\
\text { action is required. Six sources will } \\
\text { require additional characterization } \\
\text { and specialized heavy equipment } \\
\text { for source removal. }\end{array}$ \\
\hline
\end{tabular}

No additional cleanup activities were performed during this VCM. The status of other possible COCs is not addressed in this report.

All waste was characterized as "Radioactive-Low Level Only" and managed in accordance with SNL/NM Department 7572 (Waste Management) procedures.

\subsubsection{Centrifuge Dump Site (ER Site 228)}

\section{Overview}

The Phase I survey at ER Site 228 was conducted during March 1994 and covered a total of 9.2 acres of uneven terrain on a southeast-facing hillside. A gamma scan survey was performed at 10 -foot centers ( 70 percent coverage) over the surface of the site. Three point sources of gamma activity 30 percent or greater than the natural background were identified during this survey. A detailed summary of the surface radiological survey and anomalies found at the site is presented in Section 5.4.5 of the Surface Gamma Radiation Surveys Final Report (Geotech 1994b).

Figure 5.4.4 shows the site, surface radiological survey boundaries, and anomalies found during the Phase I survey, and VCM verification sampling locations (post-cleanup).

VCM activities were conducted during March and April 1995. Resurveying (scanning) was not performed at this site. 


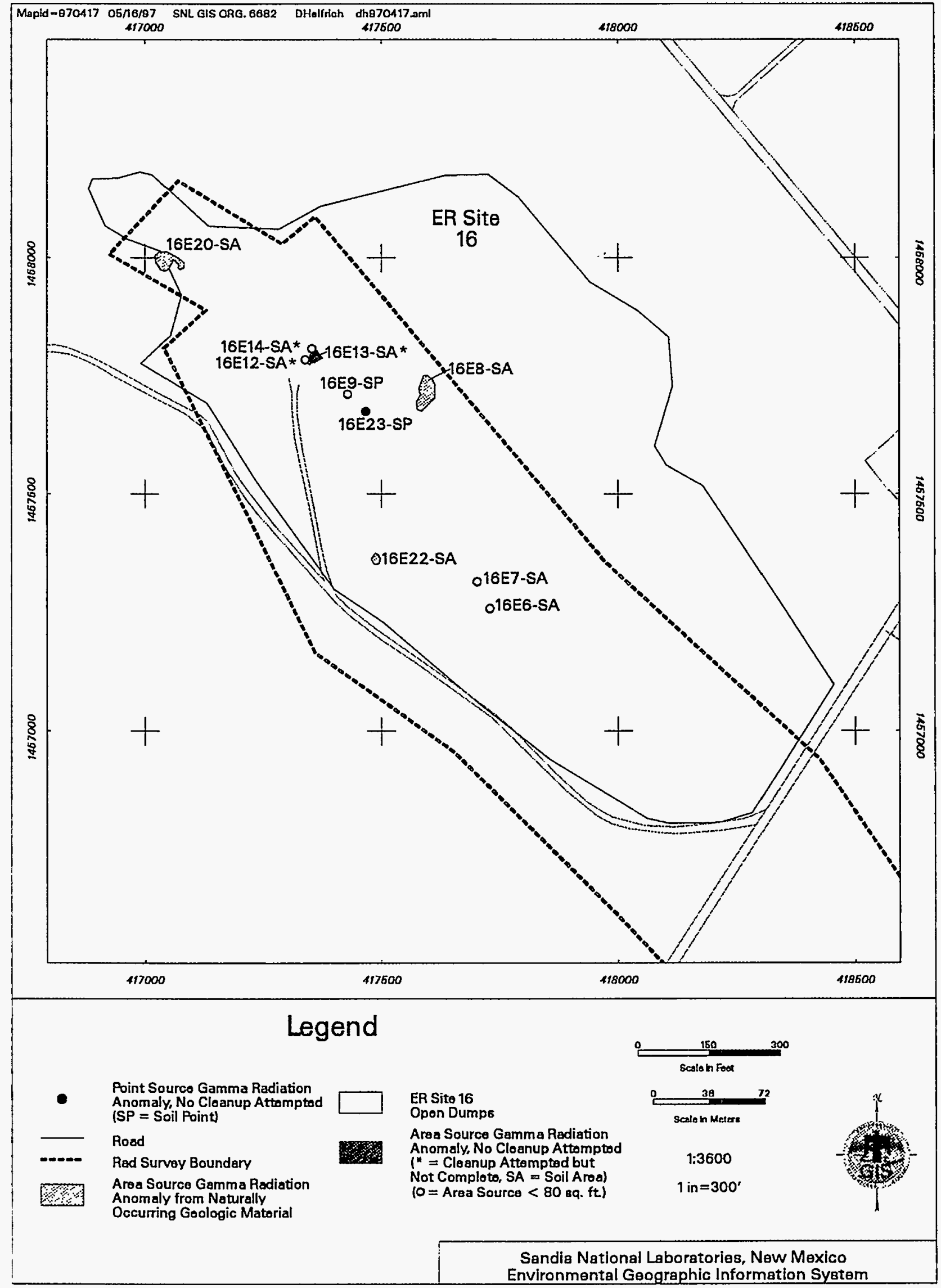

Figure 5.4.3 Radiation Anomalies Remaining After Completion of the VCM at ER Site 16 


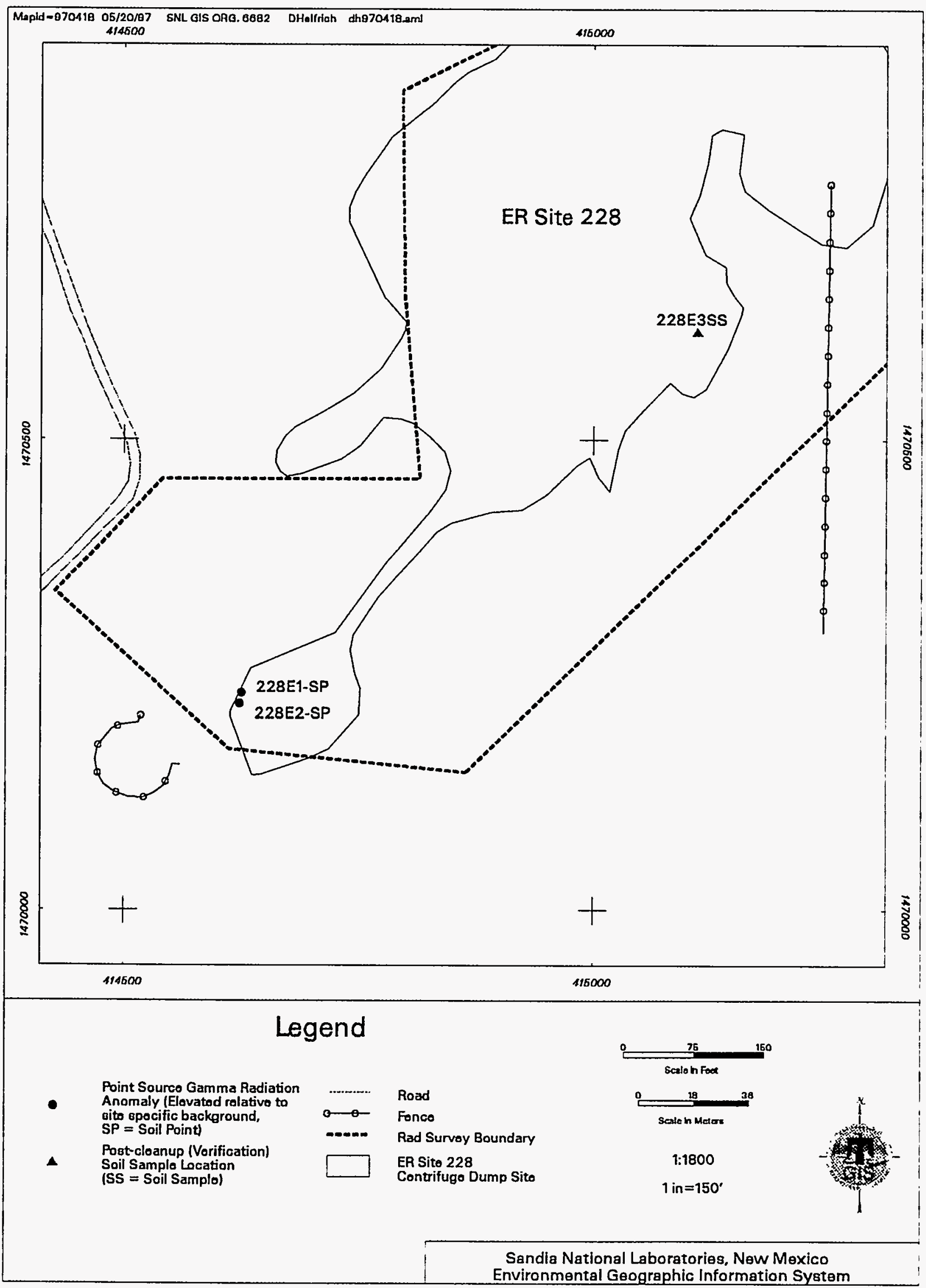

Figure 5.4.4 Phase I Survey Radiation Anomalies and VCM Surface Soil Sampling Locations at ER Site 228 
Cleanup activities included radiation scanning to verify anomaly location, removal of fragment and/or soil until readings were less than 1.3 times site-specific background levels, and postcleanup (verification) soil sampling for gamma spectroscopy analysis (see Section 3.1). Table 5.4.8 summarizes VCM field activities.

\section{Table 5.4.8 Summary of Field Activities at ER Site 228}

\begin{tabular}{|c|c|c|c|c|}
\hline $\begin{array}{c}\text { Actual Acreage } \\
\text { Surveyed }\end{array}$ & $\begin{array}{c}\text { Duration of Cleanup } \\
\text { (days) }\end{array}$ & $\begin{array}{c}\text { Verify Anomaly } \\
\text { Location }\end{array}$ & Rad Removal $^{\mathrm{a}}$ & $\begin{array}{c}\text { Post-Cleanup } \\
\text { Sampling }\end{array}$ \\
\hline 9.20 & 1.00 & $\mathrm{X}$ & $\mathrm{X}$ & $\mathrm{X}$ \\
\hline
\end{tabular}

Removal of fragment and/or soil until readings are less than 1.3 times site-specific background

\section{Findings and Observations}

\section{Point and Area Source Status}

Of the sources identified during the Phase I survey, one point source (228E3) was potentially remediated during the initial cleanup. Excavation of two closely-spaced point sources (228E1 and 228E2) showed them to be linked as one large area source. Remediation of this area source was not completed due to the steep hillslope, the large quantity of radioactive contaminated soil, the possible presence of RCRA-metal contaminated soil, and the potential for generating mixed waste. No additional point or area sources were identified during this VCM.

\section{Post-Cleanup (Verification) Sample Results}

After the removal of radiologically contaminated soils, two post-cleanup (verification) samples were collected from areas exhibiting the highest residual gamma radiation readings at anomaly 228E3. The radiological COC was DU (U-238, U-235, and U-234). It was found that this anomaly had been cleaned up to background levels. Post-cleanup (verification) samples collected are shown in Table 5.4.9, with maximum level of residual radiological COCs in soil presented in Table 5.4.10.

Table 5.4.9 Post-Cleanup (Verification) Samples Collected at ER Site 228

\begin{tabular}{|c|c|}
\hline \multicolumn{2}{|c|}{$\begin{array}{c}\text { Point Source } \\
\text { Sample Number }\end{array}$} \\
\hline 228E3SS & $228 \mathrm{E} 3 \mathrm{SD}^{\mathrm{a}}$ \\
\hline
\end{tabular}

${ }^{\text {a }}$ Sample duplicate 
Table 5.4.10 Maximum Residual Radionuclide Levels in ER Site 228 Soils

\begin{tabular}{|c|c|c|}
\hline Radionuclide & Maximum Activity (pCi/g) & Background Activity (pCi/g) \\
\hline U-238 & 1.19 & $1 . .3$ \\
\hline U-235 & ND & 0.18 \\
\hline U-234 & ND & 1.6 \\
\hline
\end{tabular}

\section{Risk Assessment Results}

Further field work is planned at ER Site 228, therefore, risk assessment has been postponed pending additional characterization and remediation. After cleanup is complete, it is anticipated that the potential effects on human health due to radionuclide exposure at the site will be within proposed standards. This is based on preliminary review of site-specific input parameters and land-use scenarios for the risk assessments to be performed using the RESRAD code.

\section{Waste Management}

Cleanup activities produced soil, metal fragment, and PPE wastes. All waste was containerized in either 30-gallon or 55-gallon drums. A total of 13 waste drums were generated during cleanup activities: 12 soil drums and 1 metal fragment drum. One bag of PPE waste was consolidated. Table 5.4.11 shows the number of waste drums after waste minimization/consolidation was performed, and Appendix J summarizes the waste minimization/consolidation effort.

Table 5.4.11 Summary of Waste Drums for ER Site 228

\begin{tabular}{|c|c|c|c|c|c|c|c|}
\hline \multicolumn{2}{|c|}{ Soil Waste } & \multicolumn{2}{|c|}{$\begin{array}{c}\text { Metal Fragment } \\
\text { Waste }\end{array}$} & \multicolumn{2}{|c|}{ PPE Waste } & \multirow[b]{2}{*}{$\begin{array}{c}\text { TCLP/ } \\
\text { Gamma } \\
\text { Spec } \\
\text { Samples }\end{array}$} & \multirow[b]{2}{*}{ Comments } \\
\hline $\begin{array}{c}30 \text { Gallon } \\
\text { Drums }\end{array}$ & \begin{tabular}{|c|}
55 Gallon \\
Drums
\end{tabular} & $\begin{array}{c}30 \text { Gallon } \\
\text { Drums }\end{array}$ & \begin{tabular}{|c|}
55 Gallon \\
Drums
\end{tabular} & \begin{tabular}{|c|}
30 Gallon \\
Drums
\end{tabular} & $\begin{array}{c}55 \text { Gallon } \\
\text { Drums }\end{array}$ & & \\
\hline 1 & 11 & 1 & 0 & 0 & 0 & $\begin{array}{l}3 \text { Soil } \\
1 \text { Frag }\end{array}$ & \\
\hline
\end{tabular}

Three composite soil samples and one metal fragment sample were collected from waste drums and analyzed for gamma emitters using standard laboratory gamma spectroscopy methods, and for leachable RCRA metals using TCLP analytical procedures. Mercury was not identified as a COC and was not included in the TCLP analysis. Only one soil sample passed the TCLP tests. The other two soil samples and one metal fragment sample did not pass the TCLP tests. As a result, all waste was characterized as "Mixed Waste," with all 13 waste drums labeled accordingly. A summary of radiological activity is presented in Appendix G, and TCLP results for the waste is presented in Appendix $\mathrm{H}$. 
Disposal of regulated VCM waste will be handled by SNL/NM Department 7577 (Waste Operations).

\section{Conclusions}

All point sources of gamma activity 30 percent or greater than the natural background were removed from the site with the exception of two point sources (228E1 and 228E2). These two point sources are possibly linked to one large area source. Further radiological and nonradiological characterization and source removal will be required for this large area source. Remediation of this source will require specialized heavy equipment to deal with the steep hillslope and expected large quantities of contaminated soil. Qualified personnel will be needed to manage the radioactive and possible RCRA-metal (cadmium) contaminated soil. Risk assessment will be conducted after additional characterization and source removal is performed.

Source removal is summarized in Table 5.4.12, and sources remaining after completion of the VCM are shown in Figure 5.4.5.

Table 5.4.12 Summary of Point Source Removal at ER Site 228

\begin{tabular}{|c|c|c|l|}
\hline Anomaly Type & Total Identified & Total Removed & \multicolumn{1}{|c|}{ Comments } \\
\hline Point Sources & 3 & 1 & $\begin{array}{l}\text { Remediation of two sources (one } \\
\text { large area source) was not } \\
\text { completed. Additional } \\
\text { characterization and source removal } \\
\text { will be required. }\end{array}$ \\
\hline
\end{tabular}

No additional cleanup activities were performed during this VCM. The status of other possible COCs is not addressed in this report.

All waste was characterized as "Mixed Waste" and managed in accordance with SNL/NM Department 7572 (Waste Management) procedures.

\subsection{Foothills Test Area Operable Unit Sites (ADS 1332)}

\subsubsection{Coyote Canyon Blast (ER Sites 8 and 58)}

\section{Overview}

The Phase I survey at ER Sites 8 and 58 was conducted during October and November 1993 and covered a total of 49.6 acres of mostly flat, sparsely vegetated terrain with numerous dirt mounds, buildings, bunkers, and piles of concrete and scrap metal scattered throughout the area. A gamma scan survey was performed at 6 -foot centers (100 percent coverage) over the surface 


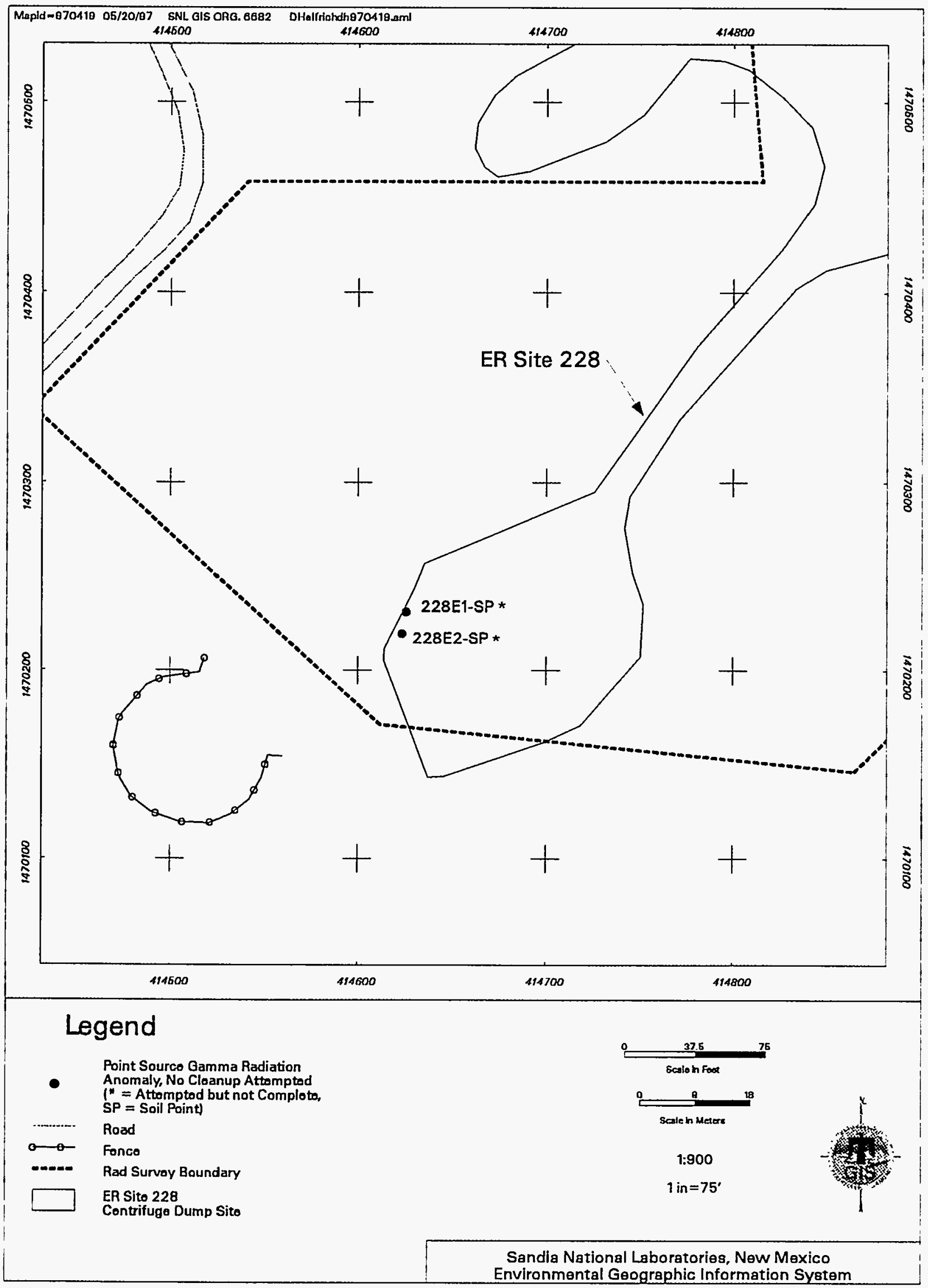

Figure 5.4.5 Radiation Anomalies Remaining After Completion of the VCM at ER Site 228 
of the site. Eighty-two point sources and two area sources of gamma activity 30 percent or greater than the natural background were identified during this survey. A detailed summary of the surface radiological survey and anomalies found at the site is presented in Section 5.5.1 of the Surface Gamma Radiation Surveys Final Report (Geotech 1994b).

Figure 5.5.1 shows the site, surface radiological survey boundaries, and anomalies found during the Phase I survey.

VCM activities were conducted during February and March 1995 and July and October 1996. Point sources and small area sources were removed in February and March 1995, and precleanup soil sampling for gamma spectroscopy analysis was conducted on one area source to assess the need for remediation. Larger area sources were remediated in July and October 1996. Resurveying (scanning) was performed during October 1996 at ER Site 58. The survey boundary was expanded on the south side, and an additional acre was surveyed on 6-foot centers (100 percent coverage). Heavy equipment (backhoe) was used on two new area sources since the lateral and vertical extent of elevated radiation exceeded the capabilities of manual cleanup procedures.

Cleanup activities included radiation scanning to verify anomaly location, removal of fragment and/or soil until readings were less than 1.3 times site-specific background levels, and postcleanup (verification) soil sampling for gamma spectroscopy analysis (see Section 3.1). Table 5.5.1 summarizes field activities during the VCM.

Table 5.5.1 Summary of Field Activities at ER Sites 8 and 58 Removal Action Procedures

\begin{tabular}{|c|c|c|c|c|c|c|c|c|}
\hline $\begin{array}{c}\text { Actual } \\
\text { Acreage } \\
\text { Surveyed }\end{array}$ & $\begin{array}{c}\text { Duration of } \\
\text { Cleanup } \\
\text { (days) }\end{array}$ & $\begin{array}{c}\text { Verify } \\
\text { Anomaly } \\
\text { Location }\end{array}$ & $\begin{array}{c}\text { Rad } \\
\text { Removal }\end{array}$ & $\begin{array}{c}\text { Post- } \\
\text { Cleanup } \\
\text { Sampling }\end{array}$ & $\begin{array}{c}\text { New Area/ } \\
\text { Resurveyed } \\
(\mathbf{1 0 0 \% )}\end{array}$ & $\begin{array}{c}\text { Pre-Cleanup } \\
\text { Sampling } \\
\text { (area sources) }\end{array}$ & $\begin{array}{c}\text { Heavy } \\
\text { Equipment } \\
\text { Support }\end{array}$ & Comments \\
\hline 50.60 & 15.25 & $\mathbf{X}$ & $\mathbf{X}$ & $\mathbf{X}$ & $\mathbf{X}$ & $\mathbf{X}$ & $\mathbf{X}$ & $\begin{array}{l}\text { At Site } 58 \text { expanded } \\
\text { boundary (1 acre) } \\
\text { and surveyed on 6-ft } \\
\text { centers(100\%). Pre- } \\
\text { cleanup sampling of } \\
\text { natural outcrops. } \\
\text { Backhoe used on } \\
\text { large area source at } \\
\text { Site 8. }\end{array}$ \\
\hline
\end{tabular}

${ }^{a}$ Removal of fragment and/or soil until readings are less than 1.3 times site-specific background

\section{Findings and Observations}

\section{Point and Area Source Status}

Of the sources identified during the Phase I survey, 82 point sources and 1 small area source were remediated during the initial cleanup. Two point sources ( $8 \mathrm{E} 1$ and $58 \mathrm{E} 76)$ were removed 


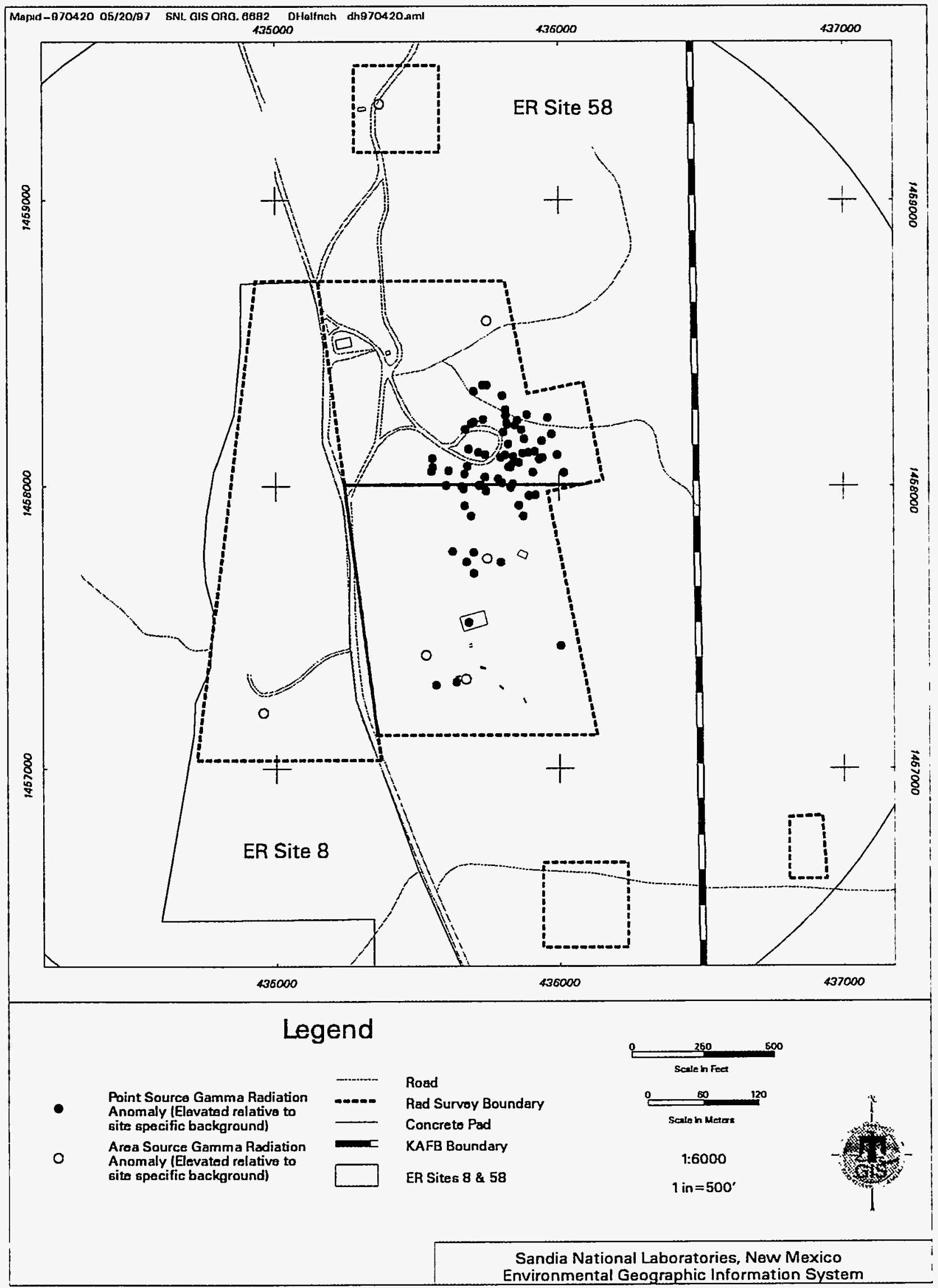

Figure 5.5.1 Phase I Survey Radiation Anomalies at ER Sites 8 \& 58 
by RPO personnel. The results of gamma spectroscopy analysis on the pre-cleanup sample collected from one area source (58E1) indicated the elevated radiation is related to the underlying, naturally-occurring geologic material, and remediation is not required. Table 5.5.2 shows the pre-cleanup sample collected from this source.

Table 5.5.2 Pre-Cleanup (Final Determination) Samples Collected at ER Site 58

\begin{tabular}{|c|}
\hline $\begin{array}{c}\text { Area Source } \\
\text { Sample Number }\end{array}$ \\
\hline \hline $58 \mathrm{E} 1 \mathrm{SS}$ \\
\hline
\end{tabular}

At ER Site 8, RPO personnel identified two new large area sources (trench area and wood pile) that were remediated using a backhoe. During resurveying (scanning) in the expanded area at ER Site 58, three new point and six new area sources were identified and remediated. Cleanup was completed on all point sources and area sources. The new sources identified during the VCM at ER Sites 8 and 58 are summarized in Table 5.5.3 and Table 5.5.4, respectively. Figure 5.5.2 shows VCM radiation anomalies and surface soil sampling locations.

Table 5.5.3 Radiation Anomalies 30 Percent or Greater Than Natural Background Identified During the VCM at ER Site 8

\begin{tabular}{|c|c|l|}
\hline Anomaly Type & Total & \multicolumn{1}{c|}{ Comments } \\
\hline Area Sources & 2 & $\begin{array}{l}\text { Trench area at Feature B and wood } \\
\text { pile at Feature Y }\end{array}$ \\
\hline
\end{tabular}

Table 5.5.4 Radiation Anomalies 30 Percent or Greater Than Natural Background Identified During the VCM at ER Site 58

\begin{tabular}{|c|c|l|}
\hline Anomaly Type & Total & \multicolumn{1}{c|}{ Comments } \\
\hline Point Sources . & 3 & $\begin{array}{l}\text { Gray, black fragments with yellow } \\
\text { uranium oxide (DU) in soil }\end{array}$ \\
\hline Area Source & 6 & Yellow uranium oxide (DU) in soil \\
\hline
\end{tabular}

\section{Post-Cleanup (Verification) Sample Results}

After the removal of radiologically contaminated soils, 10 post-cleanup (verification) samples were collected from the trench area and wood pile at ER Site 8. The samples were collected from areas exhibiting the highest residual gamma radiation readings. At ER Site 58, 10 postcleanup (verification) samples were collected from point sources. The samples were collected in the immediate vicinity of the point source (fragment) at one in every 10 locations to provide verification that cleanup was achieved. Gamma spectroscopy analysis was performed on these samples to characterize the residual radioactivity remaining in the soil. The radiological 


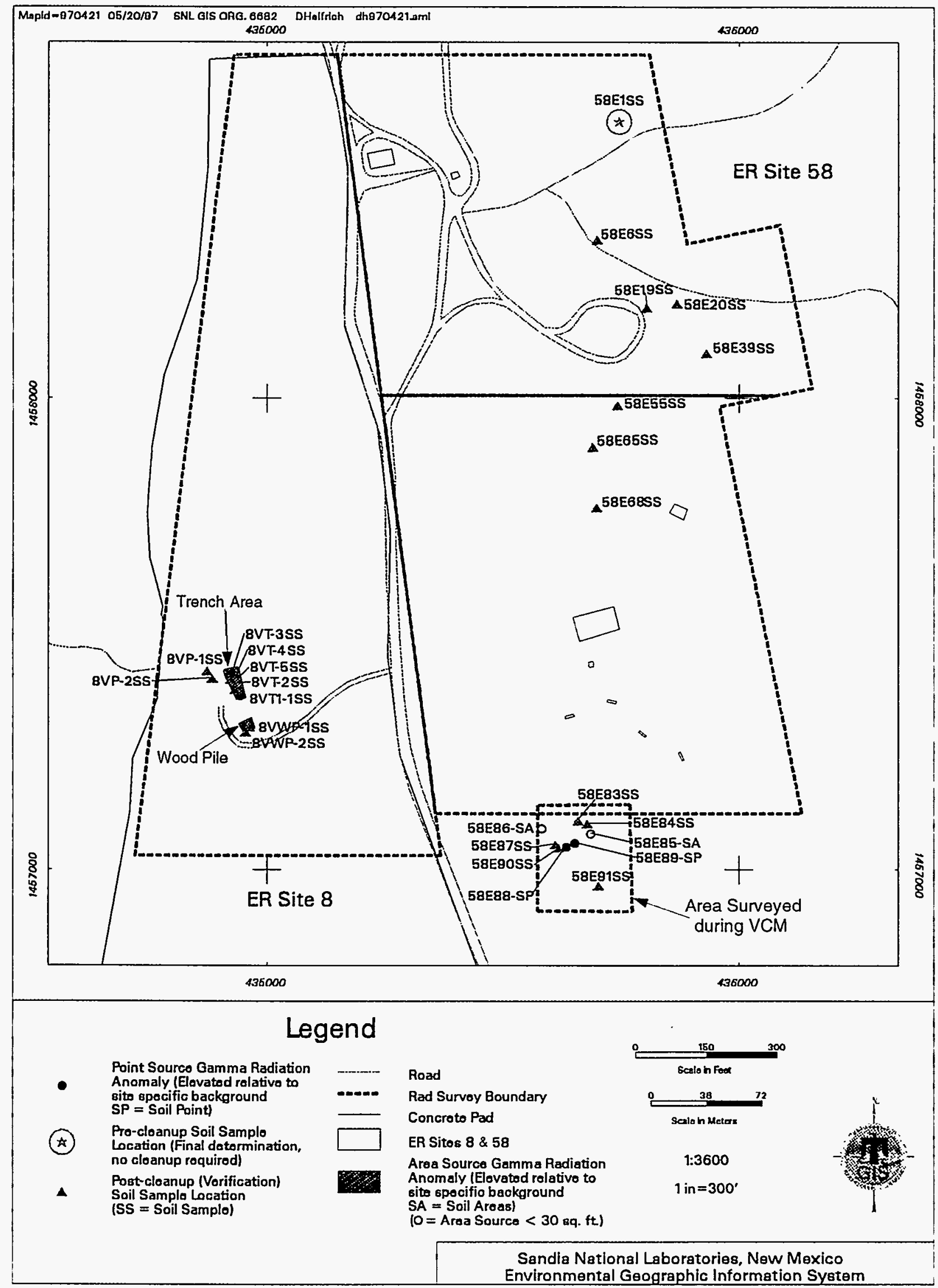

Figure 5.5.2 VCM Radiation Anomalies and Surface Soil Sampling Locations at ER Sites 8 \& 58 
COC was DU (U-238, U-235, and U-234). Table 5.5.5 summarizes the post-cleanup (verification) samples collected at the sites, and the maximum level of residual radiological COCs in soils is presented in Table 5.5.6 and Table 5.5.7.

Table 5.5.5 Post-Cleanup (Verification) Samples Collected at ER Sites 8 and 58

\begin{tabular}{|c|c|c|c|c|c|}
\hline \multicolumn{3}{|c|}{$\begin{array}{c}\text { Point Source } \\
\text { Sample Number }\end{array}$} & \multicolumn{3}{|c|}{$\begin{array}{c}\text { Area Source } \\
\text { Sample Number }\end{array}$} \\
\hline 58E6SS & "58E19SS & $\bar{~} 58 \mathrm{E} 19 \mathrm{SD}^{\mathrm{a}}$ & $8 V P-1 S S^{b}$ & 8VP-2SS & 8VT-1SS ${ }^{b}$ \\
\hline 58E20SS & 58E39SS & $58 \mathrm{E} 9 \mathrm{SD}^{\mathrm{a}}$ & 8VT-2SS & 8VT-3SS & $8 V T-3 S^{a}$ \\
\hline 58E55SS & 58E65SS & 58E68SS & 8VT-4SS & 8VT-5SS & $8 V W P-1 S S^{b}$ \\
\hline 58E83SS & 58E84SS & $58 \mathrm{E} 84 \mathrm{SD}^{\mathrm{a}}$ & 8VWP-2SS & & \\
\hline 58E87SS & 58E90SS & 58E91SS & & & \\
\hline
\end{tabular}

${ }^{2}$ Sample duplicate

'Samples with the "VP" designation are associated with the spoils pile area,

"VT" is associated with the trench area, and "VWP" is associated with the waste pile area.

Table 5.5.6 Maximum Residual Radionuclide Levels in ER Site 8 Soils

\begin{tabular}{|c|c|c|}
\hline Radionuclide & Maximum Activity (pCi/g) & Background Activity (pCi/g) \\
\hline U-238 & 7.21 & 2.3 \\
\hline U-235 & 0.1 & 0.16 \\
\hline U-234 & 0.9 & 2.3 \\
\hline
\end{tabular}

Table 5.5.7 Maximum Residual Radionuclide Levels in ER Site 58 Soils

\begin{tabular}{|c|c|c|}
\hline Radionuclide & Maximum Activity (pCi/g) & Background Activity (pCi/g) \\
\hline U-238 & 7.6 & 2.3 \\
\hline U-235 & 0.1 & 0.16 \\
\hline U-234 & 0.9 & 2.3 \\
\hline Th-232 & 12.9 & 1.03 \\
\hline Ra-228 & 8.96 & 1.08 \\
\hline
\end{tabular}

\section{Risk Assessment Results}

Further field work is planned at ER Sites 8 and 58, therefore, risk assessments have been postponed pending additional characterization and remediation. After cleanup is complete, it is anticipated that the potential effects on human health due to exposure to radionuclides at the sites will be within proposed standards. This is based on preliminary review of site-specific input parameters and land-use scenarios for the risk assessments to be performed using the RESRAD code. 


\section{Waste Management}

At ER Site 8, the cleanup activities produced soil waste, wood, and metal trash. Soil waste was containerized in 55-gallon drums. Oversized wood and metal trash was placed in wooden crates ( 4 by 4 by 7 feet). A total of 69 soil waste drums and 2 wooden crates were generated during cleanup activities. The number of waste drums produced at the site are shown in Table 5.5.8.

Table 5.5.8 Summary of Waste Drums for ER Sites 8 and 58 (Post Minimization/ Consolidation Effort)

\begin{tabular}{|c|c|c|c|c|c|c|c|c|}
\hline & \multicolumn{2}{|c|}{ Soil Waste } & \multicolumn{2}{|c|}{$\begin{array}{l}\text { Metal Fragment } \\
\text { Waste }\end{array}$} & \multicolumn{2}{|c|}{ PPE Waste } & \multirow[b]{2}{*}{$\begin{array}{c}\text { TCLP/ } \\
\text { Gamma } \\
\text { Spec } \\
\text { Samples }\end{array}$} & \multirow[b]{2}{*}{ Comments } \\
\hline & $\begin{array}{l}30 \\
\text { Gallon } \\
\text { Drums }\end{array}$ & $\begin{array}{l}55 \\
\text { Gallon } \\
\text { Drums }\end{array}$ & $\begin{array}{l}30 \\
\text { Gallon } \\
\text { Drums }\end{array}$ & $\begin{array}{l}55 \\
\text { Gallon } \\
\text { Drums }\end{array}$ & $\begin{array}{l}30 \\
\text { Gallon } \\
\text { Drums }\end{array}$ & $\begin{array}{l}55 \\
\text { Gallon } \\
\text { Drums }\end{array}$ & & \\
\hline Site 8 & 0 & 69 & 0 & 0 & 0 & $\overline{0}$ & 2 Soil & $\begin{array}{l}2 \text { wooden crates that contain } \\
\text { scrap wood and metal are } \\
\text { being stored at Bldg. } 897 X \text {. } \\
\text { Container \#'s 8-072296-1 } \\
\text { and 8-072396-6. }\end{array}$ \\
\hline $\begin{array}{l}\text { Site } \\
58\end{array}$ & 0 & 37 & 0 & 0 & 0 & $\overline{1}$ & $\begin{array}{l}7 \text { Soil } \\
1 \text { Frag }\end{array}$ & $\begin{array}{l}\text { Waste } \\
\text { Minimization/Consolidation } \\
\text { was performed. }\end{array}$ \\
\hline
\end{tabular}

${ }^{a}$ See Appendix J

At ER Site 58, the cleanup activities produced soil, metal fragment, and PPE wastes. All waste was containerized in either 30-gallon or 55-gallon drums. A total of 41 waste drums were generated during cleanup activities: 38 soil drums, 1 metal fragment drum (partially filled), and 2 PPE drums. Waste consolidation was performed to minimize the number of drums produced for each waste stream. A metal fragment drum was consolidated, a soil drum was consolidated, and a PPE drum was consolidated. Table 5.5.8 shows the number of waste drums after waste minimization/consolidation was performed, and Appendix $\mathrm{J}$ summarizes the waste minimization/consolidation effort.

Two composite soil samples were collected from the ER Site 8 waste drums, and seven composite soil samples and one metal fragment sample were collected from the ER Site 58 waste drums. The samples were analyzed for gamma emitters using standard laboratory gamma spectroscopy methods and for leachable RCRA metals using TCLP analytical procedures. Mercury was not identified as a COC and was not included in the TCLP analysis. All samples passed the TCLP tests, and all waste was characterized as "Radioactive-Low Level Only." A summary of radiological activity for the waste is presented in Appendix G.

Disposal of regulated VCM waste was handled by SNL/NM Department 7577 (Waste Operations), which packaged and secured waste drums for transfer to Envirocare of Utah. Nonregulated waste was disposed of using standard SNL/NM-approved waste disposal methods. 


\section{Conclusions}

All point and area sources of gamma activity 30 percent or greater than the natural background were removed from the site. However, recent investigations have identified surface radiological contamination outside the original surface radiation survey boundary at ER Site 8 and possible subsurface radiological contamination at ER Site 58. Therefore, additional radiological characterization is planned at ER Sites 8 and 58. Source removal will be performed at ER Site 8 and, if necessary, at ER Site 58. Risk assessments will be conducted after all characterization and source removal is performed.

Source removal is summarized in Table 5.5.9, and sources remaining after completion of the VCM are shown in Figure 5.5.3.

Table 5.5.9 Summary of Point and Area Source Removal at ER Sites 8 and 58

\begin{tabular}{|c|c|c|l|}
\hline Anomaly Type & Total Identified & Total Removed & \multicolumn{1}{|c|}{ Comments } \\
\hline Point Sources & 85 & 85 & $\begin{array}{l}\text { Cleanup complete and no further } \\
\text { action is required. }\end{array}$ \\
\hline Area Sources & 10 & 9 & $\begin{array}{l}\text { One source is related to underlying, } \\
\text { naturally-occurring geologic } \\
\text { material and no further action is } \\
\text { required. }\end{array}$ \\
\hline
\end{tabular}

No additional cleanup activities were performed during this VCM. The status of other possible COCs is not addressed in this report.

All waste was characterized as "Radioactive-Low Level Only" and managed in accordance with SNL/NM Department 7572 (Waste Management) procedures.

\subsubsection{TRUPAK Boneyard Storage Area (ER Site 19)}

\section{Overview}

The Phase I survey at ER Site 19 was conducted during January 1994 and covered a total of 1.9 acres of rocky terrain at the base of a hill. A gamma scan survey was performed at 6-foot centers (100 percent coverage) over the surface of the site. Five area sources of gamma activity 30 percent or greater than the natural background were identified during this survey. A detailed summary of the surface radiological survey and anomalies found at the site is presented in Section 5.5.2 of the Surface Gamma Radiation Surveys Final Report (Geotech 1994b). Figure 5.5.4 shows the site, surface radiological survey boundaries, and anomalies found during the Phase I survey and VCM verification sampling (pre-cleanup and post-cleanup) locations. 


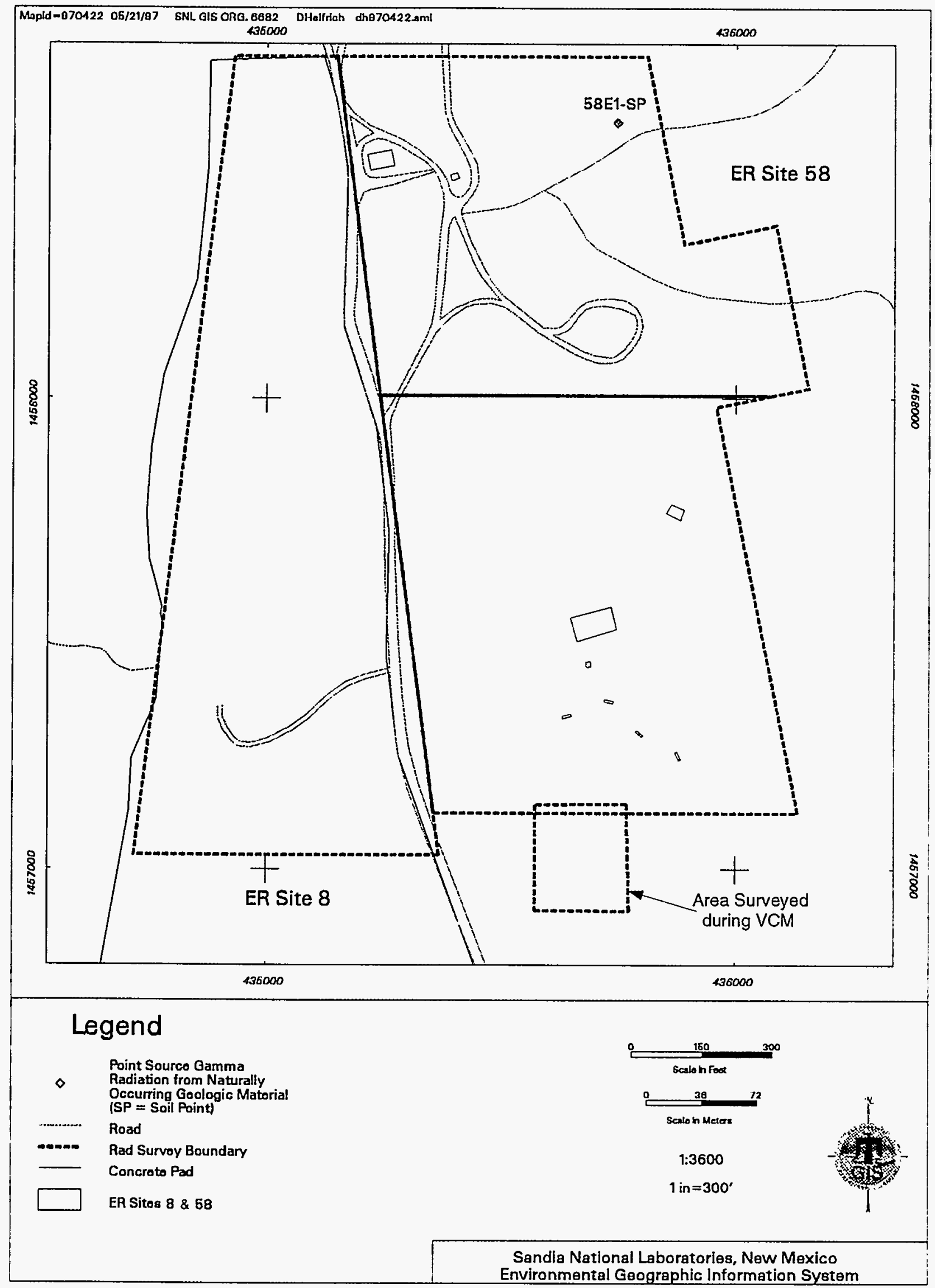

Figure 5.5.3 Radiation Anomalies Remaining After Completion of the VCM at ER Sites 8 \& 58 


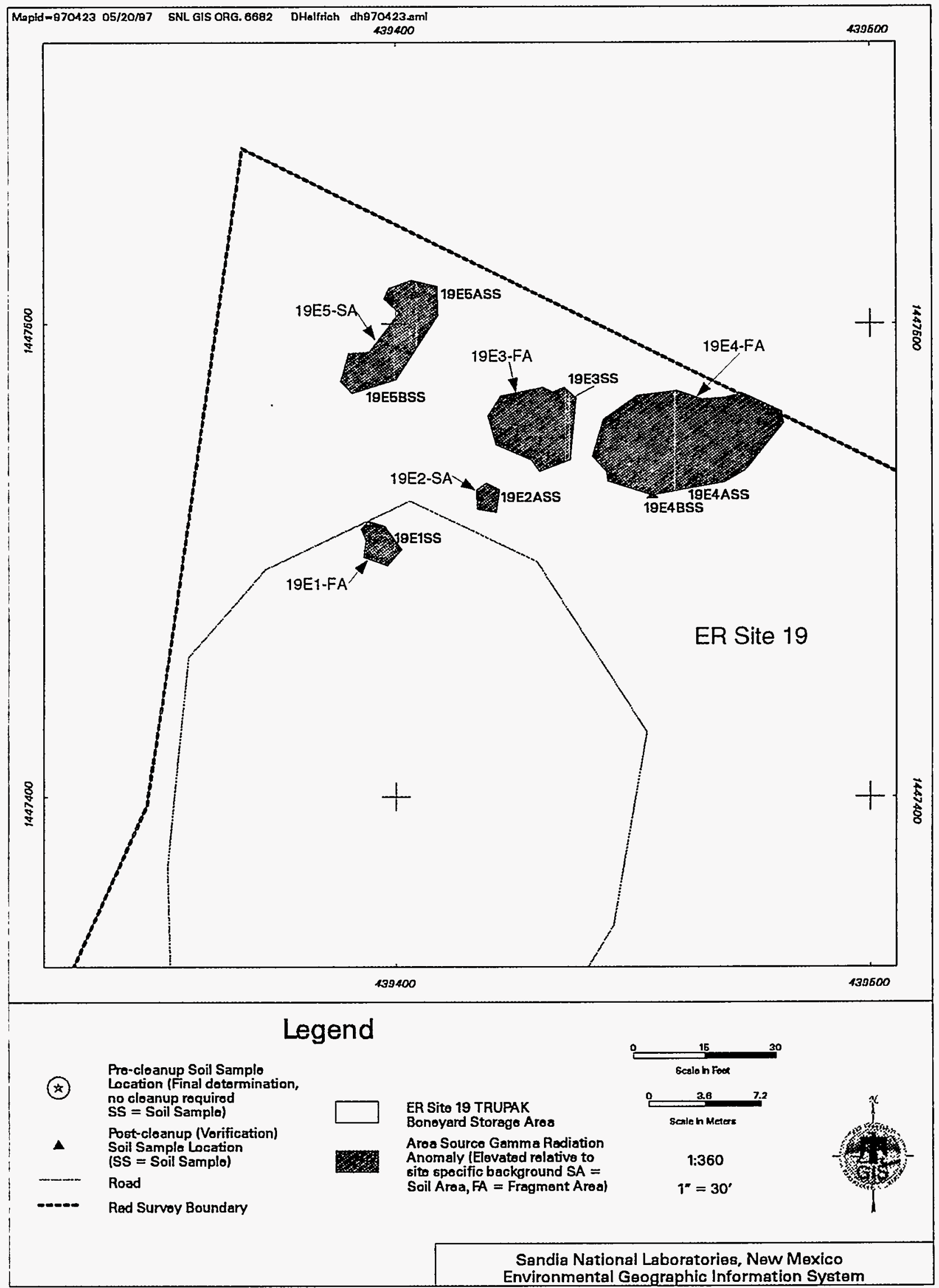

Figure 5.5.4 Phase I Survey Radiation Anomalies and VCM Surface Soil Sampling Locations at ER Site 19 
During February 1996, pre-cleanup soil sampling for gamma spectroscopy analysis was conducted on the five area sources to assess the need for remediation. In June 1996, three small area sources were remediated.

Cleanup activities included radiation scanning to verify anomaly location, removal of fragment and/or soil until readings were less than 1.3 times site-specific background levels, and postcleanup (verification) soil sampling for gamma spectroscopy analysis (see Section 3.1).

Table 5.5.10 summarizes field activities during the VCM

Table 5.5.10 Summary of Field Activities at ER Site 19

Removal Action Procedures

\begin{tabular}{|c|c|c|c|c|c|c|c|}
\hline $\begin{array}{c}\text { Actual } \\
\text { Acreage } \\
\text { Surveyed }\end{array}$ & $\begin{array}{c}\text { Duration of } \\
\text { Cleanup } \\
\text { (days) }\end{array}$ & $\begin{array}{c}\text { Verify } \\
\text { Anomaly } \\
\text { Location }\end{array}$ & $\begin{array}{c}\text { Rad } \\
\text { Removal }\end{array}$ & $\begin{array}{c}\text { Post- } \\
\text { Cleanup } \\
\text { Sampling }\end{array}$ & $\begin{array}{c}\text { New Area/ } \\
\text { Resurveyed } \\
(\mathbf{1 0 0 \% )}\end{array}$ & $\begin{array}{c}\text { Pre-Cleanup } \\
\text { Sampling } \\
\text { (area sources) }\end{array}$ & Comments \\
\hline 1.90 & 2.00 & $\mathbf{X}$ & $\mathbf{X}$ & $\mathbf{X}$ & $\mathbf{X}$ & $\mathbf{X}$ & $\begin{array}{l}\text { Surveyed area } \\
\text { beneath truck trailers } \\
\text { on 6-ft centers } \\
(100 \%) .\end{array}$ \\
\hline
\end{tabular}

Removal of fragment and/or soil until readings are less than 1.3 times site-specific background

\section{Findings and Observations}

\section{Point and Area Source Status}

Prior to remediation, pre-cleanup samples were collected from five area sources (19E1, 19E2, 19E3, 19E4, and 19E5) for gamma spectroscopy analysis. Cleanup was performed on three area sources (19E2, 19E4, and 19E5) where gamma spectroscopy results on pre-cleanup samples showed the elevated radiation was related to anthropogenic (man-made) material. These area sources were associated with two truck trailers and were remediated after the trailers were removed from the site. Gamma spectroscopy results from one area source (19E1) indicated the elevated radiation was related to "shine" (gamma interference) from adjacent material, and from the other area source (19E3) the elevated radiation does not exceed risk-based action levels. Therefore, remediation was not required for these two area sources. Table 5.5.11 shows the precleanup samples collected from these two sources.

Table 5.5.11 Pre-Cleanup (Final Determination) Samples Collected at ER Site 19

\begin{tabular}{|c|}
\hline Area Source \\
Sample Number
\end{tabular}




\section{Post-Cleanup (Verification) Sample Results}

After the removal of radiologically contaminated soils, five post-cleanup (verification) samples were collected from areas exhibiting the highest residual gamma readings. Gamma spectroscopy analysis were performed on the samples to verify that the residual concentration meet risk-based action levels. The radiological COCs were Cs-137 and Co-60. Table 5.5.12 shows the postcleanup (verification) samples collected at the site, and the maximum levels of residual radionuclides in soil are presented in Table 5.5.13.

Table 5.5.12 Post-Cleanup (Verification) Samples Collected at ER Site 19

\begin{tabular}{|lcl|}
\hline \multicolumn{3}{|c|}{$\begin{array}{c}\text { Area Source } \\
\text { Sample Number }\end{array}$} \\
\hline \hline 19E2ASS & 19E4ASS & 19E4BSS \\
19E5ASS & 19E5BSS & \\
\hline
\end{tabular}

Table 5.5.13. Maximum Residual Radionuclide Levels in ER Site 19 Soils

\begin{tabular}{|c|c|c|}
\hline Radionuclide & Maximum Activity (pCi/g) & Background Activity (pCi/g) \\
\hline Cs-137 & 1.06 & 1.063 \\
\hline Co-60 & 1.3 & $\mathrm{n} / \mathrm{a}^{\mathrm{a}}$ \\
\hline
\end{tabular}

${ }^{a}$ Does not occur naturally, or due to fallout, in the environment.

\section{Risk Assessment Results}

A risk assessment, using the DOE computer code RESRAD, was performed on ER Site 19 assuming both a recreational and a residential (loss of active control measures) land-use scenario, consistent with Section 3.3.2. The RESRAD input parameters that were not site specific are provided for both land-use scenarios in Section 3.3.2. Site-specific input parameters were developed based on information provided by the Task Leader responsible for the site and were as follows:

- Area of Contaminated Zone: $18.5 \mathrm{~m}^{2}$

- Thickness of contaminated zone: $0.15 \mathrm{~m}$

- Length Parallel to Aquifer Flow: $8 \mathrm{~m}$

- Density of Contaminated Zone: $1.27 \mathrm{~g} / \mathrm{m}^{3}$

- Contaminated Zone Total Porosity: 0.5

- Contaminated Zone Effective Porosity: 0.3

- Contaminated Zone Hydraulic Conductivity: $890 \mathrm{~m} / \mathrm{yr}$

- Contaminated Zone b Parameter: 4.9 (Sandy Loam)

- Runoff Coefficient: 0.4

Site-specific risk assessment, performed using the RESRAD code, resulted in the following maximum TEDEs to the RME individual: 
- Recreational Land-Use: $0.35 \mathrm{mrem} / \mathrm{yr}$

- Residential Land-Use: $8.7 \mathrm{mrem} / \mathrm{yr}$

The calculated TEDEs for both scenarios are well below the proposed EPA guidance discussed in Section 2.2.2. The maximum TEDE to the RME individual for recreational land-use is $15 \mathrm{mrem} / \mathrm{yr}$ and for residential land-use is $75 \mathrm{mrem} / \mathrm{yr}$. The average radiation exposure due to natural sources (radon, internal radiation, cosmic radiation, and terrestrial radiation) in the U.S. is approximately $295 \mathrm{mrem} / \mathrm{yr}$ TEDE (NCRP 1987). Therefore, the potential effects on human health due to exposure to radionuclides at the site are well within proposed standards when considering both a recreational land-use scenario and a residential land-use scenario.

The uncertainty in this assessment is considered to be small because of the location and history of the site. There is low uncertainty in the land-use scenario and the potentially affected populations considered in making the risk assessment analysis. An RME approach was used to calculate the risk assessment values. As a result, the parameter values used in the calculations were conservative, and the calculated intakes are likely overestimates. Maximum measured concentrations of the COCs were used to provide conservative results. Because the COCs were found in the surface soils and because of the location and physical characteristics of the site, there is little uncertainty in the exposure pathways relevant to the analysis.

\section{Waste Management}

The cleanup activities produced only soil waste. All waste was containerized in 55-gallon drums, and a total of 19 soil waste drums were generated. Table 5.5.14 shows the number of waste drums produced at the site.

Table 5.5.14 Summary of Waste Drums for ER Site 19

\begin{tabular}{|c|c|c|c|c|c|c|c|}
\hline \multicolumn{2}{|c|}{ Soil Waste } & \multicolumn{2}{|c|}{$\begin{array}{l}\text { Metal Fragment } \\
\text { Waste }\end{array}$} & \multicolumn{2}{|c|}{ PPE Waste } & \multirow[b]{2}{*}{$\begin{array}{c}\text { TCLP/ } \\
\text { Gamma } \\
\text { Spec } \\
\text { Samples }\end{array}$} & \multirow[b]{2}{*}{ Comments } \\
\hline $\begin{array}{c}30 \text { Gallon } \\
\text { Drums }\end{array}$ & $\begin{array}{c}\text { 55 Gallon } \\
\text { Drums }\end{array}$ & $\begin{array}{c}30 \text { Gallon } \\
\text { Drums }\end{array}$ & $\begin{array}{l}55 \text { Gallon } \\
\text { Drums }\end{array}$ & $\begin{array}{l}\text { 30 Gallon } \\
\text { Drums }\end{array}$ & $\begin{array}{c}55 \text { Gallon } \\
\text { Drums }\end{array}$ & & \\
\hline 0 & 19 & 0 & 0 & 0 & 0 & 2 Soil & \\
\hline
\end{tabular}

Two composite soil samples were collected from the waste drums and analyzed for gamma emitters using standard laboratory gamma spectroscopy methods and for leachable RCRA metals using TCLP analytical procedures. Mercury was not identified as a COC and was not included in the TCLP analysis. All samples passed the TCLP tests, and all waste was characterized as "Radioactive-Low Level Only." A summary of radiological activity for the waste is presented in Appendix G. 
Disposal of regulated VCM waste was handled by SNL/NM Department 7577 (Waste Operations), which packaged and secured waste drums for transfer to Envirocare of Utah. Nonregulated waste was disposed of using standard SNL/NM-approved waste disposal methods.

\section{Conclusions}

Three area sources of gamma activity 30 percent or greater than the natural background were removed from the site. At two area sources, elevated radiation was related to the "shine" or does not exceed risk-based action levels. A radiological risk assessment was performed assuming both a recreational and a residential (loss of active control measures) land-use scenario, and using site-specific input parameters. The risk assessment shows the potential effects on human health due to exposure to radionuclides at the site are within proposed standards when considering both land-use scenarios.

Source removal is summarized in Table 5.5.15, and sources remaining after completion of the VCM are shown in Figure 5.5.5.

Table 5.5.15 Summary of Area Source Removal at ER Site 19

\begin{tabular}{|c|c|c|l|}
\hline Anomaly Type & Total Identified & Total Removed & \multicolumn{1}{c|}{ Comments } \\
\hline Area Sources & 5 & 3 & $\begin{array}{l}\text { Two sources are related to shine (gamma } \\
\text { interference) from adjacent material, or the } \\
\text { elevated radiation does not exceed risk-based } \\
\text { action levels. Radiological risk assessment } \\
\text { performed and no further action is required. }\end{array}$ \\
\hline
\end{tabular}

No additional cleanup activities were performed during this VCM. The status of other possible COCs is not addressed in this report.

All waste was characterized as "Radioactive-Low Level Only" and managed in accordance with SNL/NM Department 7572 (Waste Management) procedures.

\subsubsection{Building 9820 - Animal Disposal Pit (ER Site 27)}

\section{Overview}

The Phase I survey at ER Site 27 was conducted during November 1993 and covered a total of 1.4 acres of gently sloping banks of an arroyo. A gamma scan survey was performed at 6-foot centers ( 100 percent coverage) over the surface of the site. One point source of gamma activity 30 percent or greater than the natural background was identified during this survey. A detailed summary of the surface radiological survey and anomaly found at the site is presented in Section 5.5.3 of the Surface Gamma Radiation Surveys Final Report (Geotech 1994b).

Figure 5.5.6 shows the site, surface radiological survey boundaries, and anomaly found during the Phase I survey, and VCM verification sampling locations (post-cleanup). 


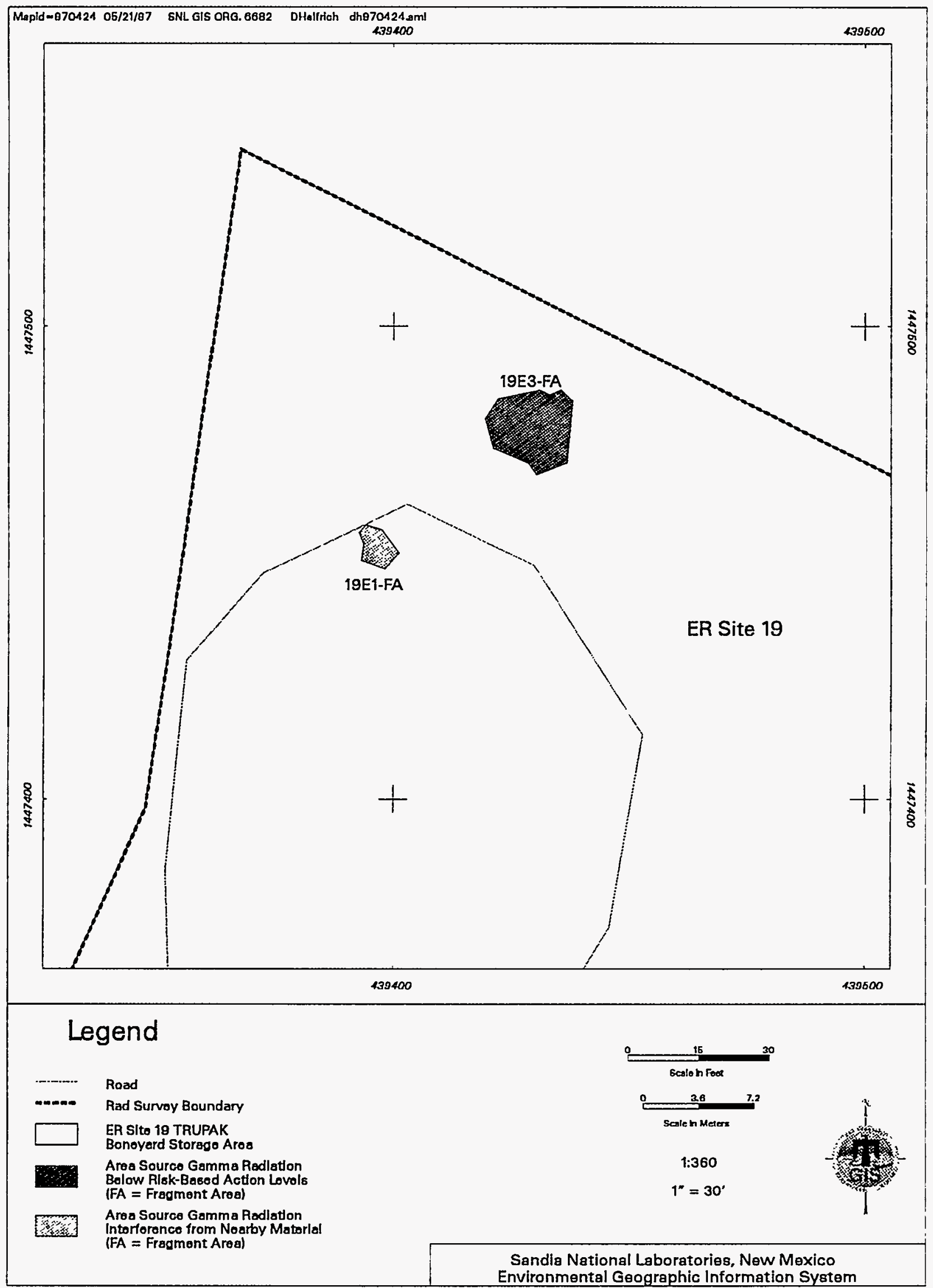

Figure 5.5.5 Radiation Anomalies Remaining After Completion of the VCM at ER Site 19 


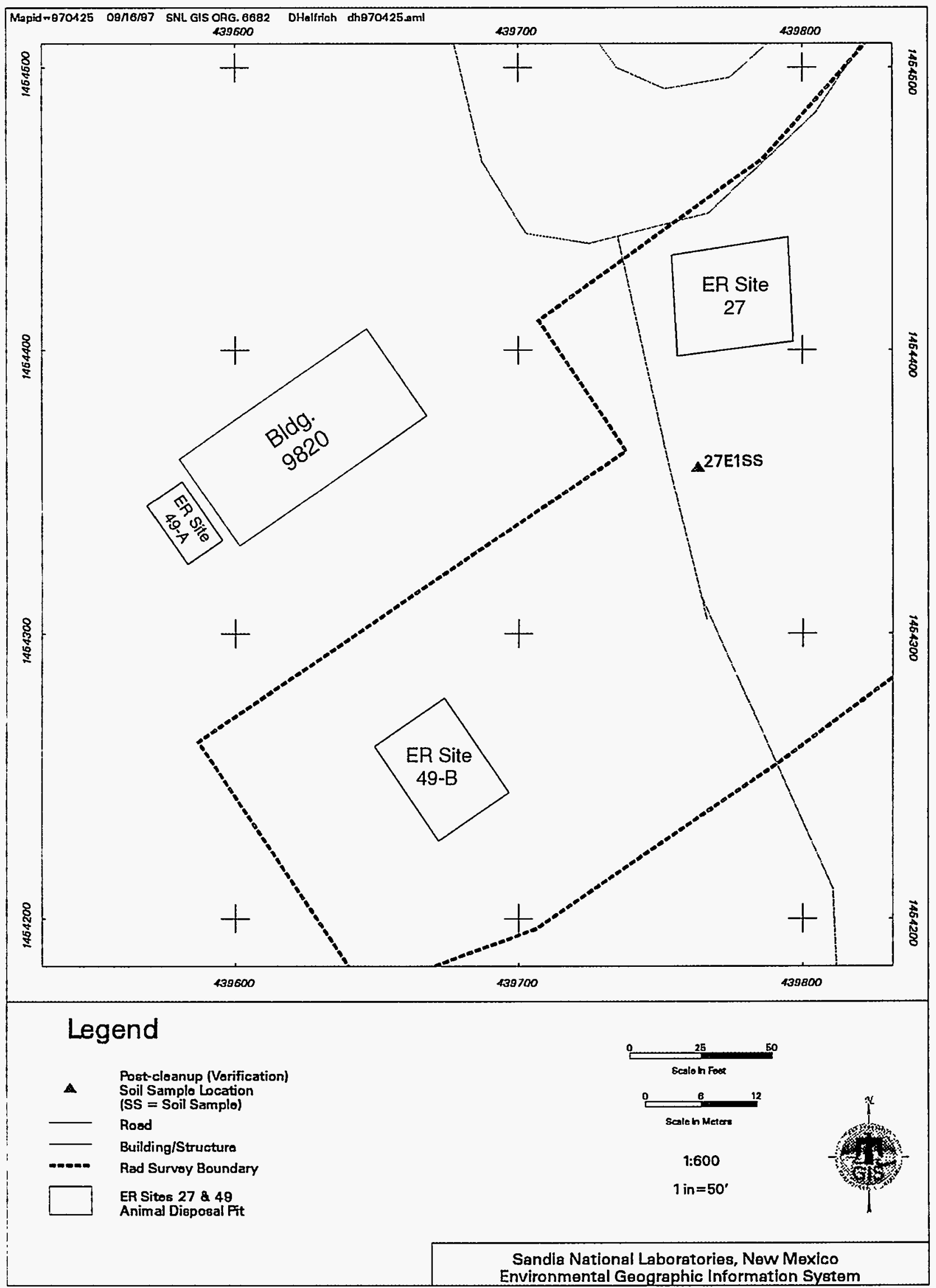

Figure 5.5.6 Phase I Survey Radiation Anomalies and VCM Surface Soil Sampling Locations at ER Sites $27 \& 49$ 
VCM activities were conducted during March 1995. Cleanup activities included radiation scanning to verify anomaly location, removal of fragment until readings were less than 1.3 times site-specific background levels, and post-cleanup (verification) soil sampling for gamma spectroscopy analysis (see Section 3.1). Table 5.5.16 summarizes field activities during the VCM.

\section{Table 5.5.16 Summary of Field Activities at ER Site 27}

Removal Action Procedures

\begin{tabular}{|c|c|c|c|c|}
\hline $\begin{array}{c}\text { Actual Acreage } \\
\text { Surveyed }\end{array}$ & $\begin{array}{c}\text { Duration of Cleanup } \\
\text { (days) }\end{array}$ & $\begin{array}{c}\text { Verify Anomaly } \\
\text { Location }\end{array}$ & Rad Removal $^{\mathrm{a}}$ & $\begin{array}{c}\text { Post-Cleanup } \\
\text { Sampling }\end{array}$ \\
\hline 1.40 & $<0.25$ & $\mathbf{X}$ & $\mathbf{X}$ & $\mathbf{X}$ \\
\hline
\end{tabular}

a Removal of fragment and/or soil until readings are less than 1.3 times site-specific background

\section{Findings and Observations}

\section{Point and Area Source Status}

Cleanup was completed on the one point source (27E1), and no additional point or area sources were identified during VCM cleanup activities.

\section{Post-Cleanup (Verification) Sample Results}

After the removal of radiologically contaminated soils, two post-cleanup (verification) samples were collected from areas exhibiting the highest residual gamma radiation readings. Gamma spectroscopy analysis was performed on these samples to characterize the residual radioactivity remaining in the soil. The radiological COC was DU (U-238, U-235, and U-234). Table 5.5.17 shows the post-cleanup (verification) samples collected, and the maximum level of residual radiological COCs in soil is presented in Table 5.5.18.

Table 5.5.17 Post-Cleanup (Verification) Samples Collected at ER Site 27

\begin{tabular}{|c|c|}
\hline \multicolumn{2}{|c|}{$\begin{array}{c}\text { Point Source } \\
\text { Sample Number }\end{array}$} \\
\hline 27E1SS & $27 \mathrm{E} 1 \mathrm{SD}^{2}$ \\
\hline
\end{tabular}

Sample duplicate 
Table 5.5.18. Maximum Residual Radionuclide Levels in ER Site 27 Soils

\begin{tabular}{|c|c|c|}
\hline Radionuclide & Maximum Activity (pCi/g) & Background Activity (pCi/g) \\
\hline U-238 & 3.19 & 2.3 \\
\hline U-235 & ND & 0.16 \\
\hline U-234 & ND & 2.3 \\
\hline
\end{tabular}

\section{Risk Assessment Results}

Further field work is planned at the site, and therefore, risk assessment has been postponed pending additional characterization and remediation. After cleanup is complete, it is anticipated that the potential effects on human health due to exposure to radionuclides at the site will be within proposed standards. This is based on preliminary review of site-specific input parameters and land-use scenarios for the risk assessment to be performed using the RESRAD code.

\section{Waste Management}

Cleanup activities produced metal fragment waste. Waste consolidation was performed to minimize the number of drums produced for each waste stream. One metal fragment drum was generated and was consolidated with metal fragment waste from 10 other sites into one metal fragment drum. Table 5.5.19 shows the number of waste drums after waste minimization/consolidation was performed, and Appendix J summarizes the waste minimization/consolidation effort.

Table 5.5.19 Summary of Waste Drums for ER Site 27

\begin{tabular}{|c|c|c|c|c|c|c|c|c|}
\hline \multicolumn{2}{|c|}{ Soil Waste } & & $\begin{array}{c}\text { Metal Fragment } \\
\text { Waste }\end{array}$ & & \multicolumn{2}{c|}{ PPE Waste } & Comments \\
\cline { 2 - 7 } $\begin{array}{c}\text { 30 Gallon } \\
\text { Drums }\end{array}$ & $\begin{array}{c}\text { 55 Gallon } \\
\text { Drums }\end{array}$ & $\begin{array}{c}\text { 30 Gallon } \\
\text { Drums }\end{array}$ & $\begin{array}{c}\text { 55 Gallon } \\
\text { Drums }\end{array}$ & $\begin{array}{c}\text { 30 Gallon } \\
\text { Drums }\end{array}$ & $\begin{array}{c}\text { 55 Gallon } \\
\text { Drums }\end{array}$ & $\begin{array}{c}\text { TCLP/ } \\
\text { Gamma } \\
\text { Spec } \\
\text { Samples }\end{array}$ & \\
\hline \hline 0 & 0 & 0 & 0 & 0 & 0 & 0 & $\begin{array}{l}\text { Only 1 metal fragment } \\
\text { was collected from this } \\
\text { site (container \#27- } \\
\text { 030795-1), so it was } \\
\text { combined with the Site 87 } \\
\text { metal fragment sample. }\end{array}$ \\
\hline
\end{tabular}

Only one metal fragment was collected from the site, so it was combined with the ER Site 87 TCLP metal fragment sample. The sample was analyzed for gamma emitters using standard laboratory gamma spectroscopy methods and for leachable RCRA metals using TCLP analytical procedures. Mercury was not identified as a COC and was not included in the TCLP analysis. 
The sample passed the TCLP tests, and the waste was characterized as "Radioactive-Low Level Only." A summary of radiological activity for the waste is presented in Appendix G.

Disposal of regulated VCM waste was handled by SNL/NM Department 7577 (Waste Operations), which packaged and secured waste drums for transfer to Envirocare of Utah.

Nonregulated waste was disposed of using standard SNL/NM-approved waste disposal methods.

\section{Conclusions}

One point source of gamma activity 30 percent or greater than the natural background was removed from the site. Further characterization is planned at the site. A risk assessment will be conducted after all characterization is performed. Source removal is summarized in Table 5.5.20.

Table 5.5.20 Summary of Point Source Removal at ER Site 27

\begin{tabular}{|c|c|c|c|}
\hline Anomaly Type & Total Identified & Total Removed & Comments \\
\hline Point Source & 1 & 1 & $\begin{array}{l}\text { Additional nonradiological } \\
\text { characterization is required. }\end{array}$ \\
\hline
\end{tabular}

No additional cleanup activities were performed during this VCM. The status of other possible COCs is not addressed in this report.

All waste was characterized as "Radioactive-Low Level Only" and managed in accordance with SNL/NM Department 7572 (Waste Management) procedures.

\subsubsection{Old Aerial Cable Site (ER Site 82)}

\section{Overview}

The Phase I survey at ER Site 82 was conducted during January 1994 and covered a total of 19.4 acres situated in a small, steep-walled canyon. A gamma scan survey was performed at 6-foot centers (100 percent coverage) over the surface of the site. Four area sources of gamma activity 30 percent or greater than the natural background were identified during this survey. The elevated radiation at these area sources is suspected to be related to the underlying, naturallyoccurring geological material. A detailed summary of the surface radiological survey and anomalies found at the site is presented in Section 5.5.5 of the Surface Gamma Radiation Surveys Final Report (Geotech 1994b).

Figure 5.5.7 shows the site, surface radiological survey boundaries, and anomaly found during the Phase I survey, and VCM verification sampling locations (pre-cleanup). 


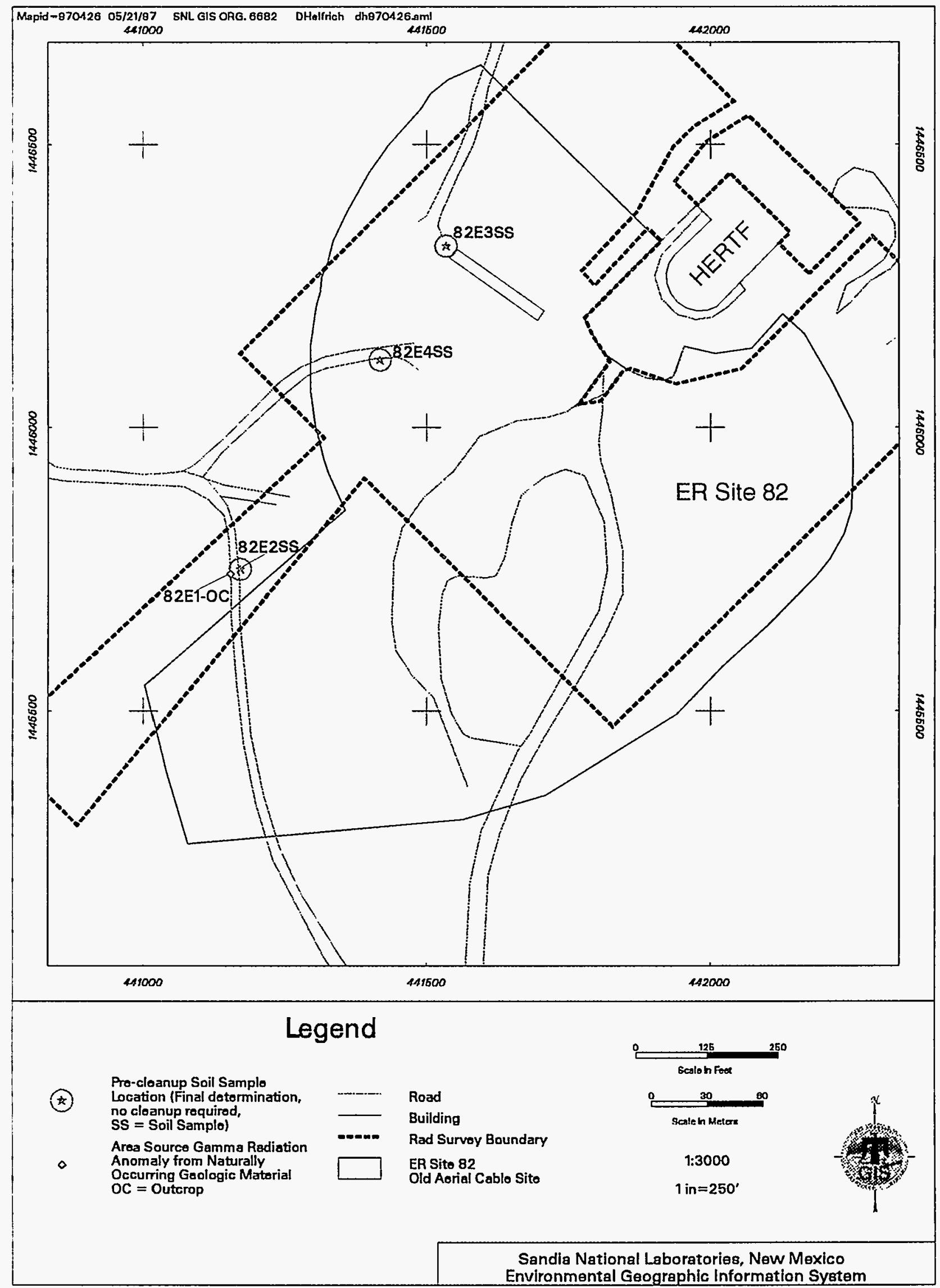

Figure 5.5.7 Phase I Survey Radiation Anomalies and VCM Surface Soil Sampling Locations at ER Site 82 
During June 1996, pre-cleanup soil sampling for gamma spectroscopy analysis was conducted on three area sources to assess the need for remediation. The pre-cleanup samples were collected on only three area sources since two of the four area sources were geologically identical.

Table 5.5.21 summarizes field activities during the VCM.

Table 5.5.21 Summary of Field Activities at ER Site 82

\begin{tabular}{|c|c|c|c|c|}
\hline $\begin{array}{c}\text { Actual Acreage } \\
\text { Surveyed }\end{array}$ & $\begin{array}{c}\text { Duration of } \\
\text { Cleanup (days) }\end{array}$ & $\begin{array}{c}\text { Verify } \\
\text { Anomaly } \\
\text { Location }\end{array}$ & $\begin{array}{c}\text { Pre-Cleanup } \\
\text { Sampling } \\
\text { (area sources) }\end{array}$ & Comments \\
\hline 19.40 & $<0.25$ & $\mathbf{X}$ & $\mathbf{X}$ & $\begin{array}{l}\text { Pre-cleanup sampling of } \\
\text { natural outcrops. }\end{array}$ \\
\hline
\end{tabular}

\section{Findings and Observations}

\section{Point and Area Source Status}

The four area sources were not remediated. The gamma spectroscopy results on the pre-cleanup samples show that the elevated radiation is related to the underlying, naturally-occurring geologic material.

\section{Pre-Cleanup (Confirmatory) Sample Results}

The four area sources consisted of natural rock outcroppings containing thorium series radionuclides. Three pre-cleanup (confirmatory) samples were collected from areas exhibiting the highest residual gamma radiation readings. Gamma spectroscopy analysis was performed on these samples to characterize, if present, the residual radioactivity in the soil. Review of these analyses showed the radiological COCs were thorium series isotopes that were representative of background distributions. Table 5.5.22 shows the pre-cleanup samples collected at the site, and the maximum level of residual radiological COCs in soil is presented in Table 5.5.23.

Table 5.5.22 Pre-Cleanup (Final Determination) Samples Collected at ER Site 82

\begin{tabular}{|ccc|}
\hline & $\begin{array}{c}\text { Natural Outcrop } \\
\text { Sample Number }\end{array}$ \\
\hline \hline 82E2SS & $82 E 3 S S$ & $82 E 4 S S$ \\
\hline
\end{tabular}

Table 5.5.23 Maximum Residual Radionuclide Levels in ER Site 82 Soils

\begin{tabular}{|c|c|c|}
\hline Radionuclide & Maximum Activity (pCi/g) & Background Activity (pCi/g) \\
\hline Th-232 & 2.39 & 1.03 \\
\hline Ra-228 & 2.86 & 1.08 \\
\hline
\end{tabular}




\section{Risk Assessment Results}

Elevated gamma readings are due to natural outcrops; therefore, a risk assessment was not performed.

\section{Waste Management}

No VCM was conducted at the site; therefore, no waste was generated.

\section{Conclusions}

No surface radiation cleanup activities was performed, and no waste was generated. Four area sources were not remediated since the elevated radiation is related to the underlying, naturallyoccurring geologic material. Further radiological and nonradiological characterization is planned at the site. If necessary, a risk assessment will be conducted after all characterization is performed. Source removal is summarized in Table 5.3.24.

Table 5.5.24 Summary of Area Source Removal at ER Site 82

\begin{tabular}{|c|c|c|l|}
\hline Anomaly Type & Total Identified & Total Removed & \multicolumn{1}{c|}{ Comments } \\
\hline Area Sources & 4 & 0 & $\begin{array}{l}\text { Sources are related to underlying, } \\
\text { naturally-occurring geologic } \\
\text { material. }\end{array}$ \\
\hline
\end{tabular}

No additional cleanup activities were performed during this VCM. The status of other possible COCs is not addressed in this report.

\subsubsection{Building 9990 - Firing Site (ER Site 87)}

\section{Overview}

The Phase I survey at ER Site 87 was conducted during February, April, and May 1994 and covered a total of 44.6 acres in a box canyon with steep hillsides. A gamma scan survey was performed at 10-foot centers (70 percent coverage) over the surface of the site. One thousand, two hundred and forty-one point sources and six area sources of gamma activity 30 percent or greater than the natural background were identified during this survey. A detailed summary of the surface radiological survey and anomalies found at the site is presented in Section 5.5 .6 of the Surface Gamma Radiation Surveys Final Report (Geotech 1994b).

Figure 5.5.8 shows the site, surface radiological survey boundaries, and anomalies found during the Phase I survey. 


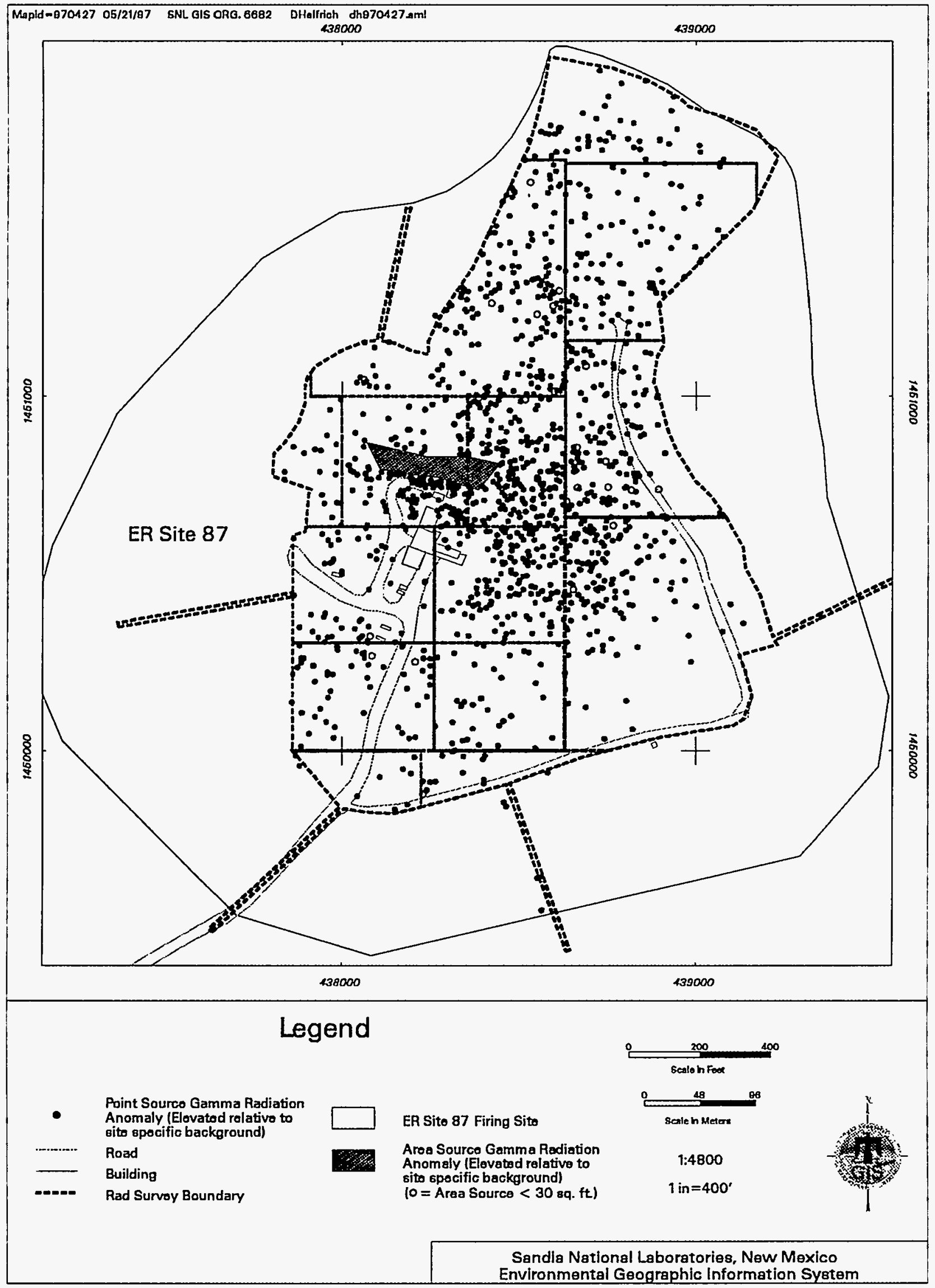

Figure 5.5.8 Phase I Survey Radiation Anomalies at ER Site 87 
The anomalies found during the Phase I survey were remediated in November 1994 through January 1995. The original site boundaries were resurveyed from March 1995 through June 1995 on 6-foot centers (100 percent coverage). From July 1995 through December 1995 survey boundaries were expanded on the north, east, south, and west sides of the site, and an additional 11.9 acres were surveyed on 6-foot centers (100 percent coverage). Pre-cleanup soil sampling for gamma spectroscopy analysis was conducted during July 1995 on five area sources that were suspected to be related to underlying, naturally-occurring geologic material. Remediation of new point and area sources identified during the resurveying was performed from March 1995 through December 1995.

Cleanup activities included radiation scanning to verify anomaly location, removal of fragment and/or soil until readings were less than 1.3 times site-specific background levels, and postcleanup (verification) soil sampling for gamma spectroscopy analysis (see Section 3.1). Table 5.5.25 summarizes field activities during the VCM.

Table 5.5.25 Summary of Field Activities at ER Site 87

Removal Action Procedures

\begin{tabular}{|c|c|c|c|c|c|c|c|}
\hline $\begin{array}{c}\text { Actual } \\
\text { Acreage } \\
\text { Surveyed }\end{array}$ & $\begin{array}{c}\text { Duration of } \\
\text { Cleanup } \\
\text { (days) }\end{array}$ & $\begin{array}{c}\text { Verify } \\
\text { Anomaly } \\
\text { Location }\end{array}$ & $\begin{array}{c}\text { Rad } \\
\text { Removal }\end{array}$ & $\begin{array}{c}\text { Post- } \\
\text { Cleanup } \\
\text { Sampling }\end{array}$ & $\begin{array}{c}\text { New Area/ } \\
\text { Resurveyed } \\
(\mathbf{1 0 0 \% )}\end{array}$ & $\begin{array}{c}\text { Pre-Cleanup } \\
\text { Sampling } \\
\text { (area sources) }\end{array}$ & Comments \\
\hline 56.50 & 105.00 & $\mathbf{X}$ & $\mathbf{X}$ & $\mathbf{X}$ & $\mathbf{X}$ & $\mathbf{X}$ & $\begin{array}{l}\text { Resurveyed original } \\
\text { area on 6-ft centers } \\
(100 \%) \text { and } \\
\text { surveyed new area } \\
(11.9 \text { acres) on 6-ft } \\
\text { centers (100\%). }\end{array}$ \\
\hline
\end{tabular}

${ }^{a}$ Removal of fragment and/or soil until readings are less than 1.3 times site-specific background

\section{Findings and Observations}

\section{Point and Area Source Status}

Of the sources identified during the Phase I surveys, 1,241 point sources and 6 area sources were remediated during the initial cleanup. A large area source (87E499) required extensive resurveying, cleanup, and verification sampling due to the association of elevated radiation from underlying, naturally-occurring geologic material and roughly 175 point sources (fragments). Cleanup of this area source was thorough but may never be complete because of the commingling of naturally-occurring geologic material with finely disseminated DU fragments. Figure 5.5.9 shows verification sampling locations (post-cleanup) for area source 87E499.

During resurveying (scanning) of the original site ( 44.6 acres) and the expanded area ( 11.9 acres), more than 5,000 new point and area sources were identified. Initially these sources were located on field maps; however, it was more efficient to stop locating these sources on field maps and remediate them as they were identified. Due to the vast number of new point and area 


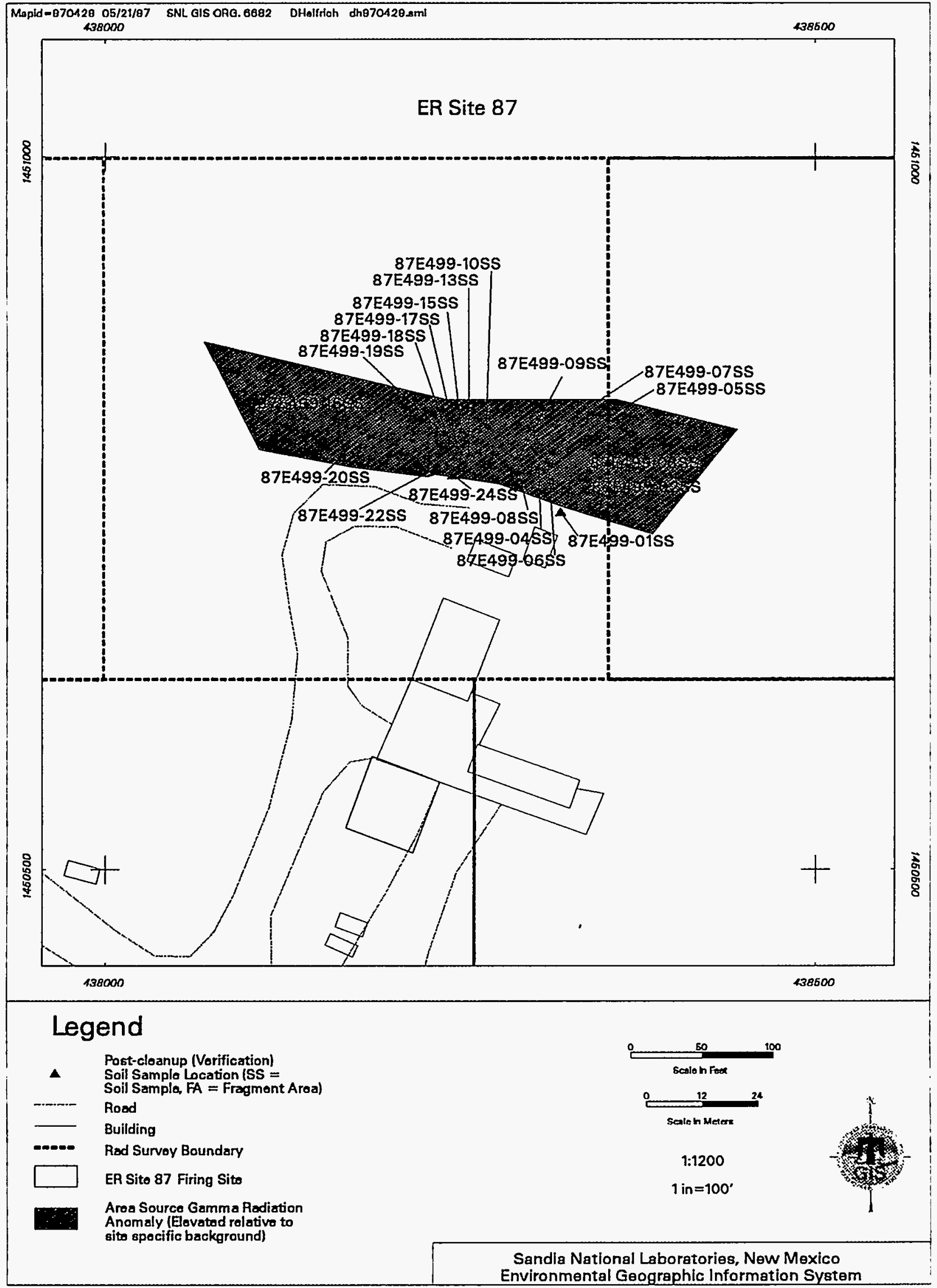

Figure 5.5.9 VCM Surface Soil Sampling Locations for Area Source (87E499) at ER Site 87 
sources identified, no locations were surveyed. Cleanup was not performed on new sources in the graded area north of Building 9990. This graded area has DU ground into the soil surface from normal road maintenance, and it is suspected that DU fragments may exist several feet below the graded surface. Figure 5.5.10 shows expanded surface radiological survey boundaries and VCM verification sampling locations (post-cleanup).

Gamma spectroscopy results on pre-cleanup samples collected from five area sources (crystalline rock formations) indicated the elevated radiation related to the underlying, naturally-occurring geologic material and remediation was not required. Visual inspection of several other area sources showed similar crystalline rock formations and are documented in the field notebook for the site. Consequently, no cleanup was performed on these area sources. Table 5.5.26 summarizes the new sources identified during the VCM, and Table 5.5.27 summarizes the precleanup samples collected at the site.

Table 5.5.26 Radiation Anomalies 30 Percent or Greater Than Natural Background Identified During the VCM at ER Site 87

\begin{tabular}{|c|c|l|}
\hline Anomaly Type & Total & \multicolumn{1}{c|}{ Comments } \\
\hline Point Sources & $>5,000$ & $\begin{array}{l}\text { Gray, black fragments with yellow } \\
\text { uranium oxide (DU) in soil }\end{array}$ \\
\hline Area Sources & 100 & $\begin{array}{l}\text { Yellow uranium oxide (DU) in soil } \\
\text { and crystalline rock formations }\end{array}$ \\
\hline
\end{tabular}

Table 5.5.27 Pre-Cleanup (Final Determination) Samples Collected at ER Site 87

\begin{tabular}{|c|c|}
\hline $\begin{array}{c}\text { Point Source } \\
\text { Sample Number }\end{array}$ & \multicolumn{1}{c|}{$\begin{array}{c}\text { Area Source } \\
\text { Sample Number }\end{array}$} \\
\hline \hline 87E3595-SS & $\begin{array}{l}\text { 87E3549-SS 87E3591-SS 87E3651-SS } \\
87 E 3657-S S\end{array}$ \\
\hline
\end{tabular}

\section{Post-Cleanup (Verification) Sample Results}

After the removal of radiologically contaminated soils, 534 post-cleanup (verification) samples were collected from point and area sources. Samples from point sources were collected in the immediate vicinity of the point source (fragment) and at one in every ten locations to provide verification that cleanup was achieved. At area sources, samples were collected from areas exhibiting the highest residual gamma radiation readings. Gamma spectroscopy analysis was performed on these samples to characterize the residual radioactivity remaining in the soil. The radiological COCs were DU (U-238, U-235, and U-234), Cs-137, and thorium series nuclides. Table 5.5.28 summarizes the post-cleanup (verification) samples collected at the site, and the maximum level of residual radiological COCs in soils is presented in Table 5.5.29. 


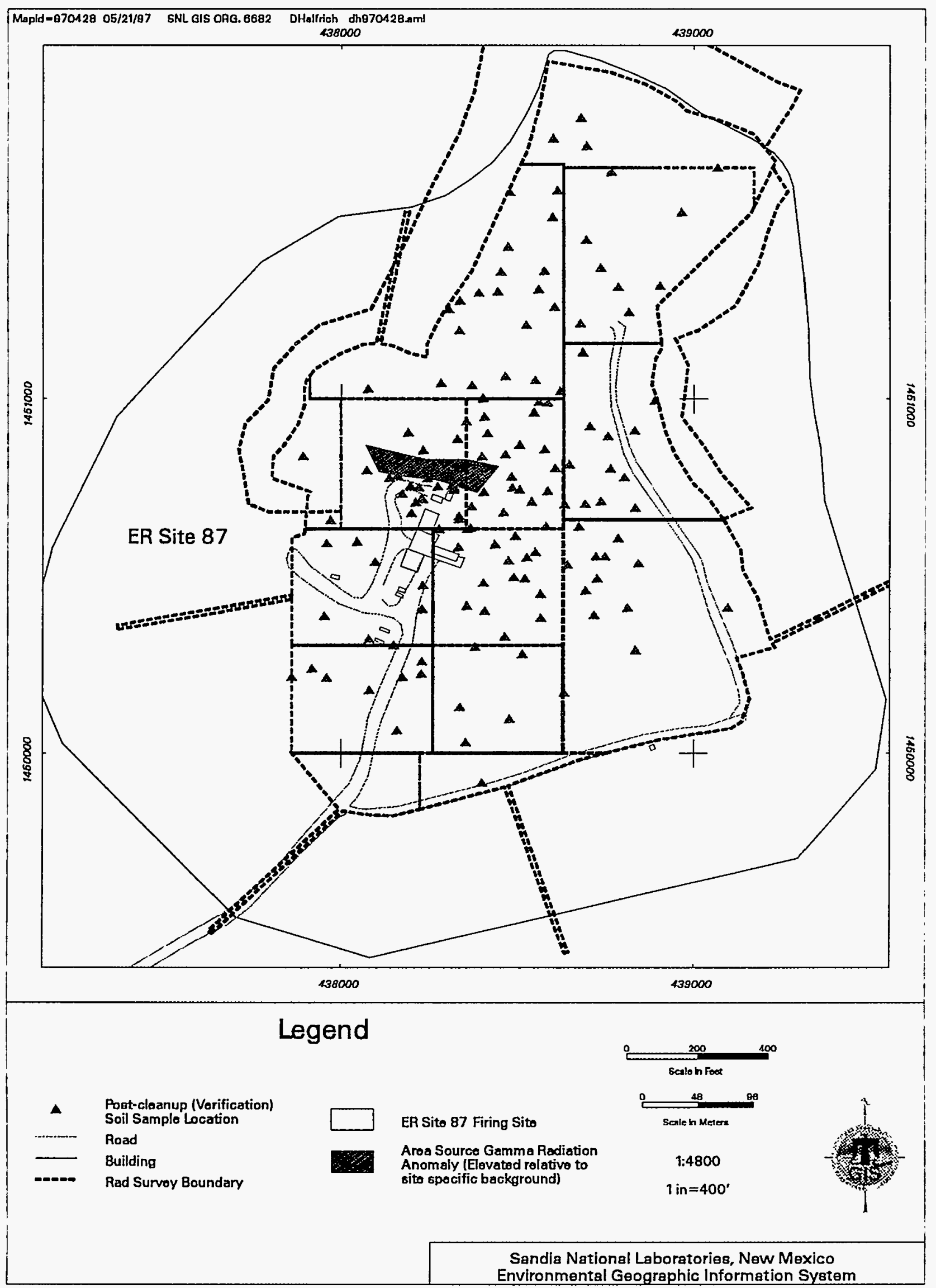

Figure 5.5.10 VCM Surface Soil Sampling Locations at ER Site 87 
Table 5.5.28 Summary of Post-Cleanup (Verification) Samples Collected at ER Site 87

\begin{tabular}{|c|c|}
\hline $\begin{array}{c}\text { Point Source } \\
\text { Totals }\end{array}$ & $\begin{array}{c}\text { Area Source } \\
\text { Totals }\end{array}$ \\
\hline \hline 495 & 39 \\
\hline
\end{tabular}

Table 5.5.29 Maximum Residual Radionuclide Levels in ER Site 87 Soils

\begin{tabular}{|c|c|c|}
\hline Radionuclide & Maximum Activity (pCi/g) & Background Activity (pCi/g) \\
\hline U-238 & 116 & 2.3 \\
\hline U-235 & 1.6 & 0.16 \\
\hline U-234 & 14.5 & 2.3 \\
\hline Th-232 & 25.3 & 1.03 \\
\hline Ra-228 & 25.3 & 1.08 \\
\hline Cs-137 & 3.7 & 1.06 \\
\hline
\end{tabular}

\section{Risk Assessment Results}

Further work is planned at ER Site 87 and, therefore, risk assessment has been postponed pending additional characterization and remediation. After cleanup is complete, it is anticipated that the potential effects on human health due to exposure to radionuclides at the site will be within proposed standards. This is based on preliminary review of site-specific input parameters and land-use scenarios for the risk assessment to be performed using the RESRAD code.

\section{Waste Management}

The cleanup activities produced soil, metal fragment, and PPE wastes. All waste was containerized in either 30 -gallon or 55-gallon drums. A total of 31 waste drums were generated during cleanup activities: 24 soil drums, 3 metal fragment drums, and 4 PPE drums. Waste consolidation was performed to minimize the number of drums produced for each waste stream. One soil drum was consolidated, two metal fragment drums were consolidated, and one PPE drum was consolidated. Table 5.5.30 shows the number of waste drums after waste minimization/consolidation was performed, and Appendix $\mathrm{J}$ summarizes the waste minimization/consolidation effort.

Four composite soil samples and one metal fragment sample were collected from the waste drums and analyzed for gamma emitters using standard laboratory gamma spectroscopy methods and for leachable RCRA metals using TCLP analytical procedures. Mercury was not identified as a COC and was not included in the TCLP analysis. All samples passed the TCLP tests, and all waste was characterized as "Radioactive-Low Level Only." A summary of radiological activity for the waste is presented in Appendix G. 
Table 5.5.30 Summary of Waste Drums for ER Site 87 (Post Minimization/Consolidation Effort)

\begin{tabular}{|c|c|c|c|c|c|c|c|}
\hline \multicolumn{2}{|c|}{ Soil Waste } & \multicolumn{2}{|c|}{ Metal Fragment Waste } & \multicolumn{2}{|c|}{ PPE Waste } & \multirow[b]{2}{*}{$\begin{array}{l}\text { TCLP/ } \\
\text { Gamma } \\
\text { Spec } \\
\text { Samples }\end{array}$} & \multirow[b]{2}{*}{ Comments } \\
\hline $\begin{array}{l}30 \text { Gallon } \\
\text { Drums }\end{array}$ & $\begin{array}{l}55 \text { Gallon } \\
\text { Drums }\end{array}$ & $\begin{array}{l}30 \text { Gallon } \\
\text { Drums }\end{array}$ & $\begin{array}{l}55 \text { Gallon } \\
\text { Drums }\end{array}$ & $\begin{array}{l}30 \text { Gallon } \\
\text { Drums }\end{array}$ & $\begin{array}{c}55 \text { Gallon } \\
\text { Drums }\end{array}$ & & \\
\hline 0 & 23 & 0 & 1 & 0 & 3 & $\begin{array}{l}4 \text { Soil } \\
1 \text { Frag }\end{array}$ & $\begin{array}{l}\text { Waste } \\
\text { Minimization/Consolidation } \\
\text { was performed. }\end{array}$ \\
\hline
\end{tabular}

See Appendix J

Disposal of regulated VCM waste was handled by SNL/NM Department 7577 (Waste Operations), which packaged and secured waste drums for transfer to Envirocare of Utah. Nonregulated waste was disposed of using standard SNL/NM-approved waste disposal methods.

\section{Conclusions}

All point and area sources of gamma activity 30 percent or greater than the natural background were removed from the site. Area sources related to underlying, naturally-occurring geologic materials and anomalies in the graded area north of Building 9990 were not remediated. Due to the vast number of new point and area sources identified, no locations were surveyed. Further radiological and nonradiological characterization is planned at the site and cleanup may be required in this graded area. A risk assessment will be conducted after all characterization and source removal is performed. Source removal is summarized in Table 5.5.31

Table 5.5.31 Summary of Point and Area Source Removal at ER Site 87

\begin{tabular}{|c|c|c|l|}
\hline Anomaly Type & Total Identified & Total Removed & \multicolumn{1}{|c|}{ Comments } \\
\hline Point Sources & $>6,241$ & $>6,241$ & $\begin{array}{l}\text { Cleanup complete and no further } \\
\text { action is planned. }\end{array}$ \\
\hline Area Sources & 109 & 104 & $\begin{array}{l}\text { Sources are related to underlying, } \\
\text { naturally-occurring geologic } \\
\text { material. }\end{array}$ \\
\hline
\end{tabular}

No additional cleanup activities were performed during this VCM. The status of other possible COCs is not addressed in this report.

All waste was characterized as "Radioactive-Low Level Only" and managed in accordance with SNL/NM Department 7572 (Waste Management) procedures. 


\subsection{Canyons Test Area Operable Unit Sites (ADS 1333)}

\subsubsection{Burial Mounds and Bunker Area (ER Sites 10 and 60)}

\section{Overview}

The Phase I survey at ER Sites 10 and 60 was conducted during October 1994 with the survey of ER Site 59 and covered a total of 30.5 acres of terrain of varying geology and topography including flat alluvial terrain, arroyos, hillsides, and outcrops of crystalline rock formations. A gamma scan survey was performed at 6-foot centers (100 percent coverage) over the surface of the site. Thirty-one point sources and twenty-one area sources of gamma activity 30 percent or greater than the natural background were identified during this survey at ER Sites 10 and 60 . The elevated radiation at 7 of the 14 area sources $(60 \mathrm{E} 36,60 \mathrm{E} 39,60 \mathrm{E} 41,60 \mathrm{E} 42,60 \mathrm{E} 43,60 \mathrm{E} 44$, and 60E45) was determined to related to the underlying, naturally-occurring geologic material. No anomalies were identified at ER Site 59. A detailed summary of the surface radiological survey and anomalies found at the site is presented in Section 5.6.1 of the Surface Gamma Radiation Surveys Final Report (Geotech 1994b).

Figure 5.6.1 shows the site, surface radiological survey boundaries, and anomalies found during the Phase I survey.

VCM activities were conducted during March 1995 and April and May 1996. Resurveying (scanning) was not performed at this site. Point sources and small area sources were removed in March 1995. Larger area sources were remediated in April and May 1996. In-situ gamma spectroscopy analysis was conducted by RPO personnel on several area sources where the elevated radiation appeared to be related to the underlying, naturally-occurring geologic material. Pre-cleanup soil sampling for gamma spectroscopy analysis was conducted on three area sources to assess the need for remediation.

At ER Site 10, nine large soil mounds, including those that were not identified as area sources, were investigated using heavy equipment (skidloader and backhoe). The soil mounds had been generated during past site activities. At soil mounds with anomalous gamma measurements (Mounds 3, 4, 5, and 6), soil was spread using a skidloader and scanned to identify elevated gamma readings. All fragments and soil with elevated gamma readings were segregated from the clean soil and containerized. At the soil mounds where no elevated gamma reading were detected on the surface (Mounds 1,2,7,8, and 10), trenches were excavated with a backhoe, and a gamma scan was performed on the sidewalls and floor of the excavated area to identify elevated gamma readings. If elevated gamma readings were identified, fragments and soil were segregated from the clean soil and containerized. If no elevated gamma readings were identified, trenches were backfilled with the previously excavated material.

At ER Site 10, Level C PPE was used because of the potential inhalation and dermal exposure from metals (beryllium) contamination. Based on the results of air lapel monitoring performed during the initial remediation of Mound 3, PPE requirements were downgraded to Modified Level D for subsequent soil mound cleanup activities at ER Site 10. 


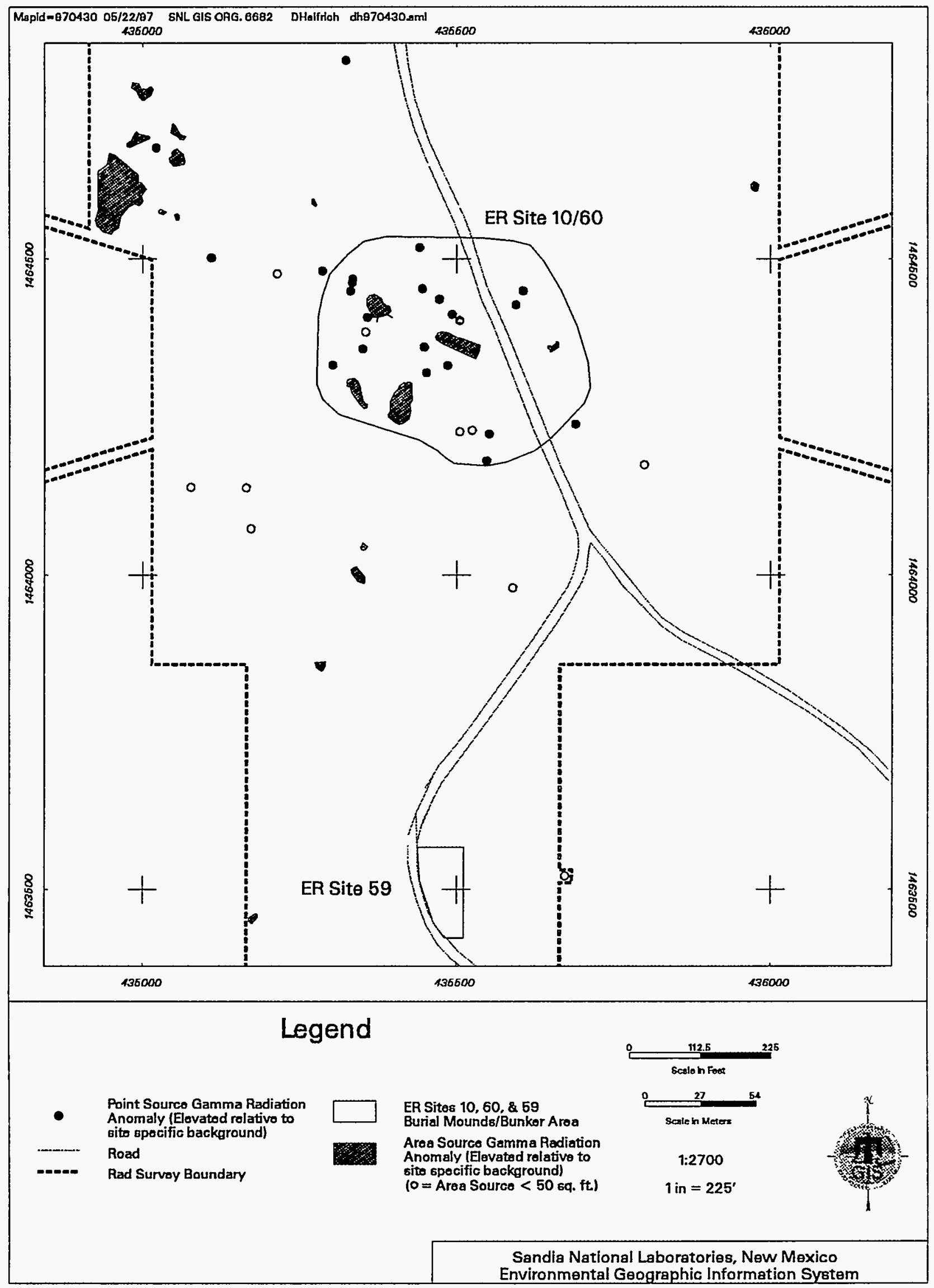

Figure 5.6.1 Phase I Survey Radiation Anomalies at ER Sites 10, 60, \& 59 
Cleanup activities included radiation scanning to verify anomaly location, removal of fragment and/or soil until readings were less than 1.3 times site-specific background levels, and postcleanup (verification) soil sampling for gamma spectroscopy analysis (see Section 3.1). Table 5.6.1 summarizes field activities during the VCM.

Table 5.6.1 Summary of Field Activities at ER Sites 10 and 60 Removal Action Procedures

\begin{tabular}{|c|c|c|c|c|c|c|c|}
\hline $\begin{array}{c}\text { Actual } \\
\text { Acreage } \\
\text { Surveyed }\end{array}$ & $\begin{array}{c}\text { Duration of } \\
\text { Cleanup } \\
\text { (days) }\end{array}$ & $\begin{array}{c}\text { Verify } \\
\text { Anomaly } \\
\text { Location }\end{array}$ & $\begin{array}{c}\text { Rad } \\
\text { Removal }\end{array}$ & $\begin{array}{c}\text { Post- } \\
\text { Cleanup } \\
\text { Sampling }\end{array}$ & $\begin{array}{c}\text { Pre-Cleanup } \\
\text { Sampling } \\
\text { (area sources) }\end{array}$ & $\begin{array}{c}\text { Heavy } \\
\text { Equipment } \\
\text { Support }\end{array}$ & Comments \\
\hline 30.50 & 24.25 & $\mathbf{X}$ & $\mathbf{X}$ & $\mathbf{X}$ & $\mathbf{X}$ & $\mathbf{X}$ & $\begin{array}{l}\text { Pre-cleanup sampling } \\
\text { and in-situ gamma } \\
\text { spec. of natural } \\
\text { outcrops. Backhoe } \\
\text { and skidloader used } \\
\text { on large mounds } \\
\text { (area sources). }\end{array}$ \\
\hline
\end{tabular}

${ }^{a}$ Removal of fragment and/or soil until readings are less than 1.3 times site-specific background

\section{Findings and Observations}

\section{Point and Area Source Status}

Of the sources identified during the Phase I survey, 18 point sources and 3 small area sources were remediated during the initial cleanup. Four of the original sources (60E15, 60E24, 60E29, and 60E37) could not be relocated. Field scanning of these four locations indicated no elevated gamma radiation levels. Two original point sources (60E21 and 60E 22) were not remediated. These two point sources are imbedded in a telephone pole and/or located beneath the telephone pole. Additional surface radiation cleanup will be required on the telephone pole since these areas were not remediated during the VCM.

In-situ gamma spectroscopy measurements collected by RPO personnel on original sources $(60 \mathrm{E} 1,60 \mathrm{E} 2,60 \mathrm{E} 3,60 \mathrm{E} 4,60 \mathrm{E} 5,60 \mathrm{E} 6,60 \mathrm{E} 7,60 \mathrm{E} 8,60 \mathrm{E} 9,60 \mathrm{E} 10,60 \mathrm{E} 11,60 \mathrm{E} 12$, and 60E35) show that the elevated radiation is related to the underlying, naturally-occurring geologic material. The close proximity of sources reduced the number of in-situ gamma spectroscopy measurement locations required. Table 5.6.2 summarizes the in-situ gamma spectroscopy locations.

Table 5.6.2 In-situ Gamma Spectroscopy Locations at ER Sites 10 and 60

Location Number

$\begin{array}{llllll}60 \mathrm{E} 1 & 60 \mathrm{E} 1 \mathrm{~A} & 60 \mathrm{E} 6 & 60 \mathrm{E} 8 & 60 \mathrm{E} 12 & 60 \mathrm{E} 35\end{array}$


Gamma spectroscopy results on pre-cleanup samples collected from two area sources (10E2 and $10 \mathrm{E} 3$ ) indicated that the elevated radiation is related to anthropogenic (man-made) material.

These two sources along with three area sources (10E1, 10E4, and 10E6) were remediated with the cleanup of four soil mounds. The results of gamma spectroscopy analysis on the pre-cleanup sample collected from one area source (10E5) indicated the elevated radiation is related to the underlying, naturally-occurring geologic material and remediation is not required. Table 5.6.3 summarizes the pre-cleanup sample collected at the sites.

Table 5.6.3 Pre-Cleanup (Final Determination) Samples Collected at ER Sites 10 and 60

Area Source

Sample Number

10E5SS

Eight new point sources were identified during the initial cleanup. These sources were located on field maps although their true locations were not surveyed. Five of these sources were remediated during the initial cleanup. Three new point sources were not remediated since they were imbedded in the concrete walls the bunker and in metal debris located in the debris pile near the bunker. Additional surface radiation cleanup will be required on the bunker and debris pile near the bunker since these areas were not remediated during the VCM. The new sources identified during the VCM are summarized in Table 5.6.4, and Figure 5.6.2 shows VCM verification sampling locations (pre-cleanup and post-cleanup).

Table 5.6.4 Radiation Anomalies 30 Percent or Greater Than Natural Background Identified During the VCM at ER Sites 10 and 60

\begin{tabular}{|c|c|l|}
\hline Anomaly Type & \multicolumn{1}{|c|}{ Total } & \multicolumn{1}{c|}{ Comments } \\
\hline Point Sources & 8 & $\begin{array}{l}\text { Five gray, black fragments with } \\
\text { yellow uranium oxide (DU) in soil. } \\
\text { Two fragments imbedded in } \\
\text { telephone pole and one fragment } \\
\text { imbedded in bunker wall. }\end{array}$ \\
\hline
\end{tabular}

Four soil mounds (Mounds 3, 4, 5, and 6) were scanned to identify elevated gamma readings, and all fragments and soil with elevated readings were segregated from the clean soil and containerized. At five other soil mounds (Mounds 1,2, 7, 8, and 10), trenches were excavated and scanned to identify elevated gamma readings. No elevated gamma readings were identified in these soil mounds.

\section{Post-Cleanup (Verification) Sample Results}

After the removal of radiologically contaminated soils, 15 post-cleanup (verification) samples were collected at ER Site 10, and 4 post-cleanup (verification) samples were collected at 


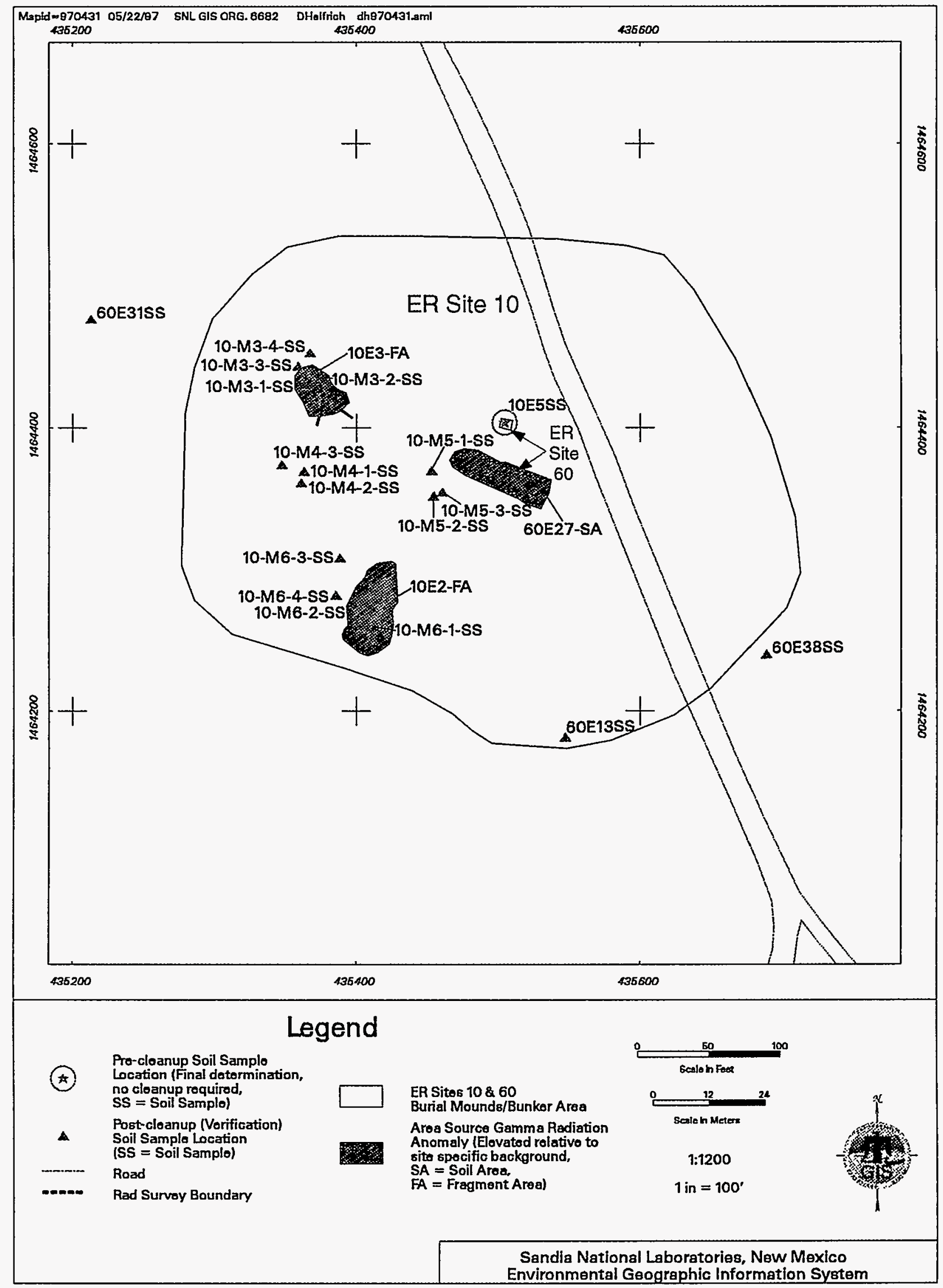

Figure 5.6.2 VCM Surface Soil Sampling Locations at ER Sites 10 \& 60 
ER Site 60. These samples were collected from areas exhibiting the highest residual gamma radiation readings. Gamma spectroscopy analysis was performed on these samples to characterize the residual radioactivity remaining in the soil. The radiological COCs were DU (U-238, U-235, and U-234) and thorium series nuclides. Table 5.6.5 summarizes the postcleanup (verification) samples collected at the sites, and the maximum level of residual radiological COCs in soils is presented in Table 5.6.6.

\section{Table 5.6.5 Post-Cleanup (Verification) Samples Collected at ER Sites 10 and 60}

\begin{tabular}{|c|c|c|c|c|c|}
\hline \multicolumn{3}{|c|}{$\begin{array}{c}\text { Point Source } \\
\text { Sample Number }\end{array}$} & \multicolumn{3}{|c|}{$\begin{array}{c}\text { Area Source } \\
\text { Sample Number }^{b}\end{array}$} \\
\hline 60E13SS & 60E31SS & 60E38SS & 10-M3-1SS & 10-M3-2SS & 10-M3-3SS \\
\hline \multirow[t]{4}{*}{$60 \mathrm{E} 38 \mathrm{SD}^{a}$} & & & 10-M3-3DS ${ }^{\mathrm{a}}$ & $10-M 3-4 S S$ & 10-M4-1SS \\
\hline & & & 10-M4-2SS & 10-M4-3SS & 10-M5-1SS \\
\hline & & & 10-M5-2SS & 10-M5-3SS & 10-M6-1SS \\
\hline & & & 10-M6-2SS & 10-M6-3SS & 10-M6-4SS \\
\hline
\end{tabular}

a Sample duplicate

bamples with "M" designation are associated with soil mounds

Table 5.6.6 Maximum Residual Radionuclide Levels in ER Sites 10 and 60 Soils

\begin{tabular}{|c|c|c|}
\hline Radionuclide & Maximum Activity (pCi/g) & Background Activity (pCi/g) \\
\hline U-238 & 6.81 & 2.3 \\
\hline U-235 & 0.09 & 0.16 \\
\hline U-234 & 0.9 & 2.3 \\
\hline Th-232 & 2.27 & 1.03 \\
\hline Ra-228 & 3.04 & 1.08 \\
\hline
\end{tabular}

\section{Risk Assessment Results}

Further work is planned at ER Sites 10 and 60 and, therefore, risk assessment has been postponed pending additional characterization and remediation. After cleanup is complete, it is anticipated that the potential effects on human health due to exposure to radionuclides at the site will be within proposed standards. This is based on preliminary review of site-specific input parameters and land-use scenarios for the risk assessment to be performed using the RESRAD code.

\section{Waste Management}

The cleanup activities produced soil, metal fragment, and PPE wastes. All waste was containerized in either 30-gallon or 55-gallon drums. A total of 114 waste drums were generated during cleanup activities: 101 soil drums, 3 metal fragment drums, and 10 PPE drums. Waste consolidation was performed to minimize the number of drums produced for each waste stream. One metal fragment drum was consolidated and two PPE drums were consolidated. 
Table 5.6.7 shows the number of waste drums after waste minimization/consolidation was performed, and Appendix J summarizes the waste minimization/consolidation effort.

Table 5.6.7 Summary of Waste Drums for ER Sites 10 and 60 (Post Minimization/ Consolidation Effort)

\begin{tabular}{|c|c|c|c|c|c|c|c|}
\hline \multicolumn{2}{|c|}{ Soil Waste } & \multicolumn{2}{|c|}{$\begin{array}{l}\text { Metal Fragment } \\
\text { Waste }\end{array}$} & \multicolumn{2}{|c|}{ PPE Waste } & \multirow[b]{2}{*}{$\begin{array}{c}\text { TCLP/ } \\
\text { Gamma } \\
\text { Spec } \\
\text { Samples }\end{array}$} & \multirow[b]{2}{*}{ Comments } \\
\hline $\begin{array}{l}30 \text { Gallon } \\
\text { Drums }\end{array}$ & $\begin{array}{c}55 \text { Gallon } \\
\text { Drums }\end{array}$ & $\begin{array}{l}30 \text { Gallon } \\
\text { Drums }\end{array}$ & $\begin{array}{c}55 \text { Gallon } \\
\text { Drums }\end{array}$ & $\begin{array}{l}30 \text { Gallon } \\
\text { Drums }\end{array}$ & $\begin{array}{c}55 \text { Gallon } \\
\text { Drums }\end{array}$ & & \\
\hline 1 & 100 & 2 & 0 & 0 & 8 & $\begin{array}{l}4 \text { Soil } \\
1 \text { Frag }\end{array}$ & $\begin{array}{l}\text { Waste Minimization/ } \\
\text { Consolidation was performed. }\end{array}$ \\
\hline
\end{tabular}

${ }^{a}$ See Appendix J

Four composite soil samples and one metal fragment sample were collected from the waste drums and analyzed for gamma emitters using standard laboratory gamma spectroscopy methods and for leachable RCRA metals using TCLP analytical procedures. Mercury was not identified as a COC at these sites and was not included in the TCLP analysis. All samples passed the TCLP tests, and all waste was characterized as "Radioactive-Low Level Only." A summary of radiological activity for the waste is presented in Appendix G.

Disposal of regulated VCM waste was handled by SNL/NM Department 7577 (Waste Operations), which packaged and secured waste drums for transfer to Envirocare of Utah. Nonregulated waste was disposed of using standard SNL/NM-approved waste disposal methods.

\section{Conclusions}

All point and area sources of gamma activity 30 percent or greater than the natural background were removed from ER Sites 10 and 60 with the exception of anomalies in the telephone pole, the bunker, and the debris pile, related to the underlying, naturally-occurring geologic materials, and those that could not be re-located. Further radiological characterization is planned for soil mounds that were not investigated during this VCM. Source removal will be required at the telephone pole, bunker, and debris pile. A risk assessment will be conducted after all characterization and source removal is performed. No radiological anomalies were identified at ER Site 59.

Source removal is summarized in Table 5.6.8, and sources remaining after completion of the VCM are shown in Figure 5.6.3. 


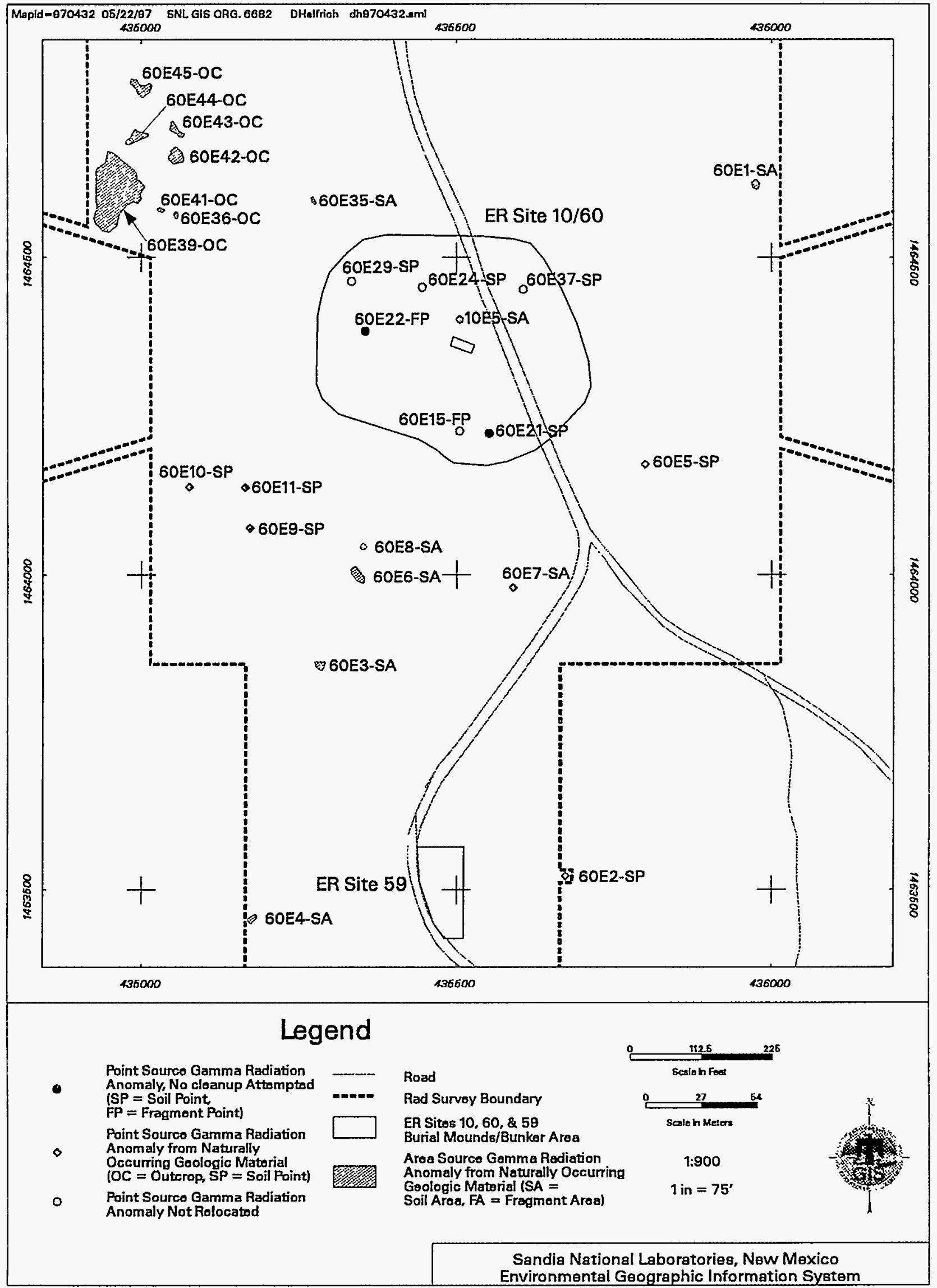

Figure 5.6.3 Radiation Anomalies Remaining After Completion of the VCM at ER Sites 10, 60, \& 59 
Table 5.6.8 Summary of Point and Area Source Removal at ER Sites 10 and 60

\begin{tabular}{|c|c|c|l|}
\hline Anomaly Type & Total Identified & Total Removed & \multicolumn{1}{|c|}{ Comments } \\
\hline Point Sources & 39 & 25 & $\begin{array}{l}\text { Four sources could not be relocated. } \\
\text { Five sources are related to } \\
\text { underlying, naturally-occurring } \\
\text { geologic material. Five sources are } \\
\text { associated with a telephone pole, } \\
\text { metal debris pile, and bunker. }\end{array}$ \\
\hline Area Sources & 21 & 6 & $\begin{array}{l}\text { Fifteen sources are related to } \\
\text { underlying, naturally-occurring } \\
\text { geologic material. }\end{array}$ \\
\hline
\end{tabular}

No additional cleanup activities were performed during this VCM. The status of other possible COCs is not addressed in this report.

All waste was characterized as "Radioactive-Low Level Only" and managed in accordance with SNL/NM Department 7572 (Waste Management) procedures.

\subsubsection{Burn Site Area (ER Sites 12, 13, 65 and 94)}

\section{Overview}

The Phase I survey at ER Sites 12,13, 65, and 94 was conducted during November and December 1993 and January 1994. This survey covered a total of 103.6 acres of brush-, cactus-, and grass-covered, flat and rolling areas adjacent to fairly steep canyon hills covered with piñon and juniper trees. ER Site 94 was surveyed with ER Sites 12, 13, and 65 and, since survey boundaries for these areas had not been defined, all anomalies were given a "94E" designation. A gamma scan survey was performed at 6-foot centers (100 percent coverage) over the surface of the graded portion of the site ( 15.9 acres); the remainder of the survey area ( 87.7 acres) was surveyed at 10 -foot centers ( 70 percent coverage). Sixty-seven point sources and thirteen area sources of gamma activity 30 percent or greater than the natural background were identified during this survey. At ER Site 13, only the exterior of the surface impoundment was surveyed; the interior was excluded. In June 1997, the surface impoundment interior was surveyed on 6-foot centers (100 percent coverage) by RPO, and no anomalies were identified. A detailed summary of the surface radiological survey and anomalies found at the site is presented in Section 5.6.2 of the Surface Gamma Radiation Surveys Final Report (Geotech 1994b).

Figure 5.6.4 shows the site, surface radiological survey boundaries, and anomalies found during the Phase I survey.

VCM activities were conducted during March 1995 and May, June, and October 1996. Resurveying (scanning) was not performed at these sites. Point sources and small area sources were removed in March 1995. Larger area sources were remediated in May, June, and October 1996. Heavy equipment (backhoe) was used on one area source (94E63) since the lateral and vertical extent of elevated radiation exceeded the capabilities of manual cleanup procedures. 


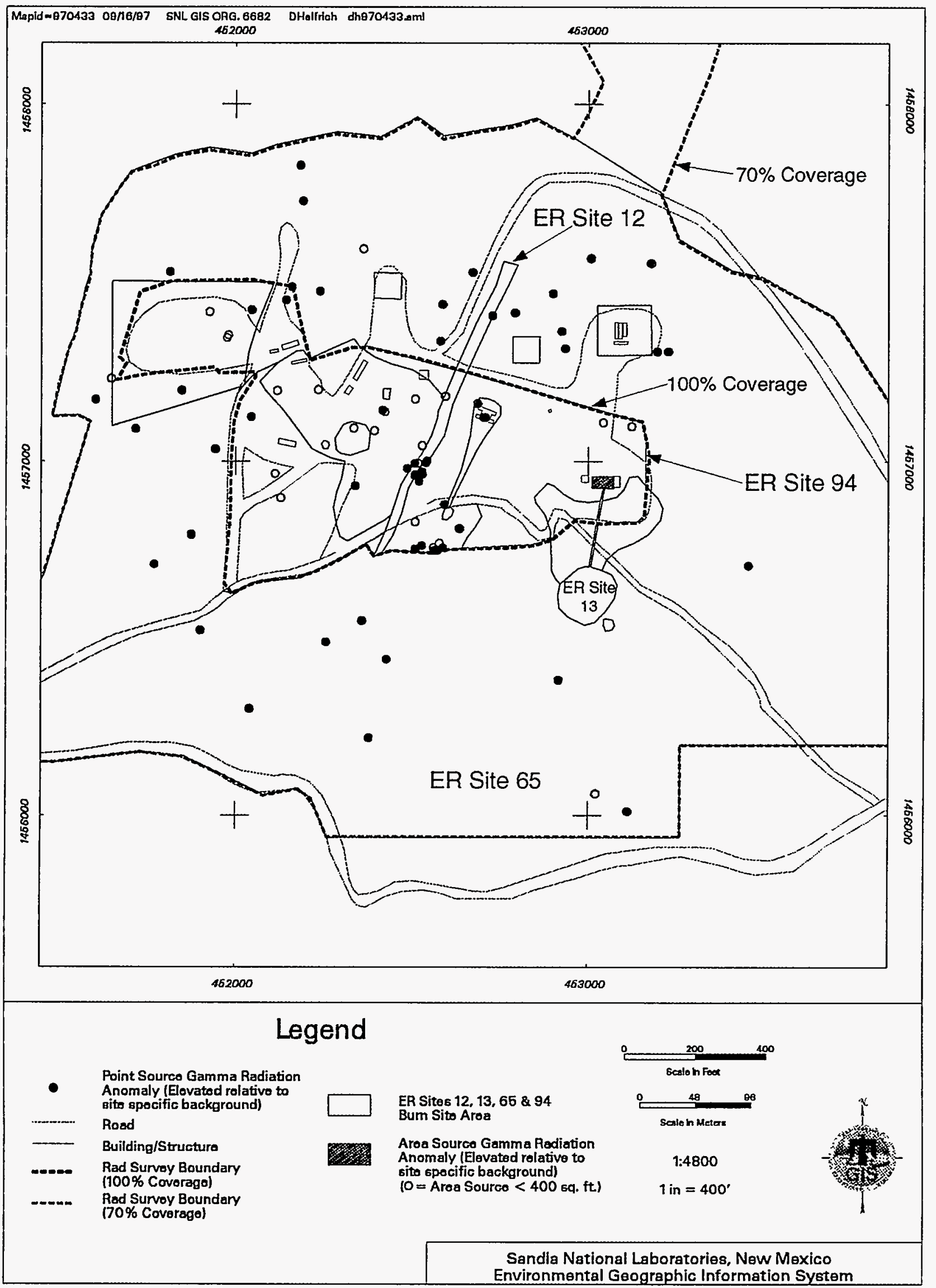

Figure 5.6.4 Phase I Survey Radiation Anomalies at ER Sites 12, 13, 65, \& 94 
Cleanup activities included radiation scanning to verify anomaly location, removal of fragment and/or soil until readings were less than 1.3 times site-specific background levels, and post-cleanup (verification) soil sampling for gamma spectroscopy analysis (see Section 3.1). Table 5.6.9 summarizes field activities during the VCM.

Table 5.6.9 Summary of Field Activities at ER Sites 12, 13, 65, and 94

Removal Action Procedures

\begin{tabular}{|c|c|c|c|c|c|c|}
\hline $\begin{array}{c}\text { Actual } \\
\text { Acreage } \\
\text { Surveyed }\end{array}$ & $\begin{array}{c}\text { Duration of } \\
\text { Cleanup } \\
\text { (days) }\end{array}$ & $\begin{array}{c}\text { Verify } \\
\text { Anomaly } \\
\text { Location }\end{array}$ & $\begin{array}{c}\text { Rad } \\
\text { Removal }\end{array}$ & $\begin{array}{c}\text { Post- } \\
\text { Cleanup } \\
\text { Sampling }\end{array}$ & $\begin{array}{c}\text { Heavy } \\
\text { Equipment } \\
\text { Support }\end{array}$ & Comments \\
\hline 103.60 & 14.00 & $\mathrm{X}$ & $\mathrm{X}$ & $\mathrm{X}$ & $\mathrm{X}$ & $\begin{array}{l}\text { Backhoe used on large } \\
\text { area sources. }\end{array}$ \\
\hline
\end{tabular}

${ }^{a}$ Removal of fragment and/or soil until readings are less than 1.3 times site-specific background

\section{Findings and Observations}

\section{Point and Area Source Status}

During the initial cleanup, 52 point sources and 4 small area sources were remediated.

Excavation of two closely-spaced sources (94E14 and 94E15) showed them to be linked to one large area source. This area source and nine other large area sources were remediated during subsequent cleanup activities. Cleanup was initiated on one area source (94E63) but was stopped since the lateral and vertical extent of elevated radiation exceeded the capabilities of manual cleanup procedures. Remediation on this area source was completed in October 1996 using a backhoe. Figure 5.6.5 shows VCM verification sampling locations (post-cleanup), and Figure 5.6.6 shows verification sampling locations (post-cleanup) for the graded portion of the site.

Two new sources were detected and remediated during the initial cleanup. The new sources were in the graded portion of the site. These gamma anomalies were at a depth beyond the detection capabilities of the gamma scintillometers during the initial survey and have become exposed over time by weathering events. Cleanup was completed on all sources and no additional point or area sources were identified during this VCM. However, the majority of ER Site 65 was surveyed at only 70 percent coverage, and additional anomalies may remain. New sources are summarized in Table 5.6.10.

Table 5.6.10 Radiation Anomalies 30 Percent or Greater Than Natural Background Identified During the VCM at ER Sites 12, 13, 65, and 94

\begin{tabular}{|c|c|l|}
\hline Anomaly Type & Total & \multicolumn{1}{c|}{ Comments } \\
\hline Point Sources & 2 & $\begin{array}{l}\text { Two gray, black fragments with } \\
\text { yellow uranium oxide (DU) in soil. }\end{array}$ \\
\hline
\end{tabular}




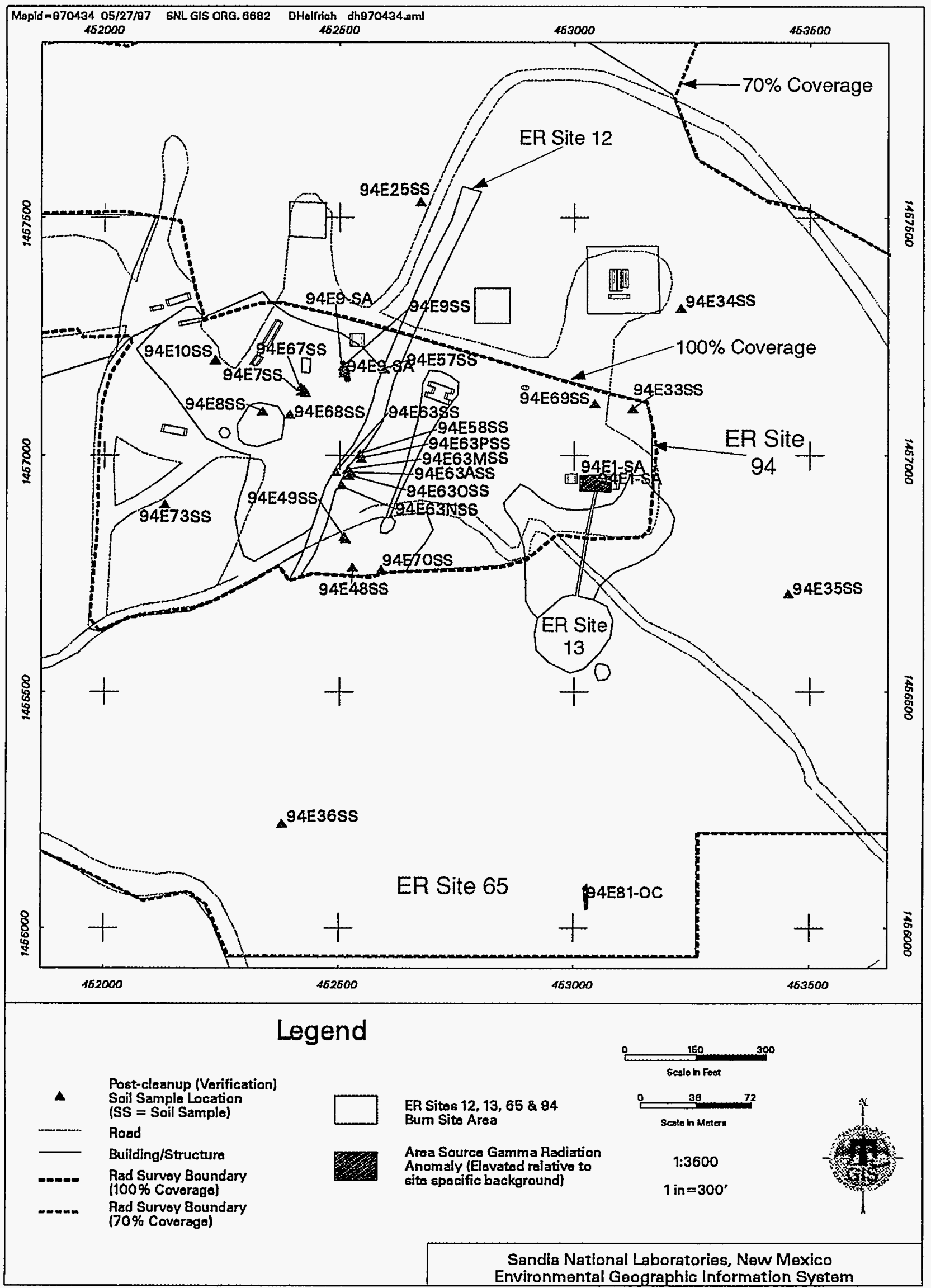

Figure 5.6.5 VCM Surface Soil Sampling Locations at ER Sites 12, 13, 65, \& 94 


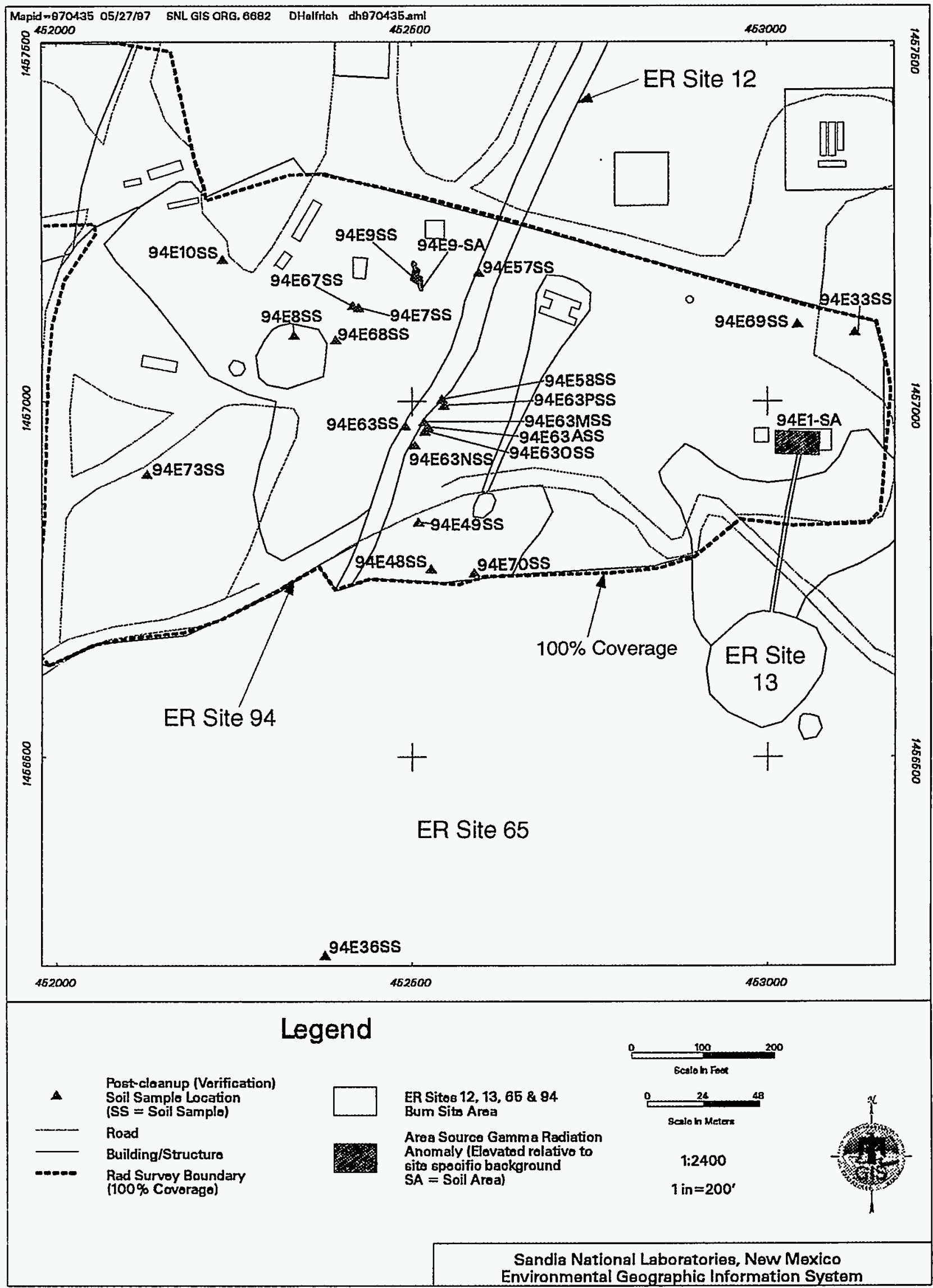

Figure 5.6.6 VCM Surface Soil Sampling Locations

in the Graded Area at ER Sites 12, 13, 65, \& 94 


\section{Post-Cleanup (Verification) Sample Results}

After the removal of radiologically contaminated soils, 21 post-cleanup (verification) samples were collected from areas exhibiting the highest residual gamma radiation readings. Gamma spectroscopy analysis was performed on these samples to characterize the residual radioactivity remaining in the soil. The radiological COC was DU (U-238, U-235, and U-234). Table 5.6.11 summarizes the post-cleanup (verification) samples collected at the site, and the maximum level of residual radiological COCs in soils is presented in Table 5.6.12.

Table 5.6.11 Post-Cleanup (Verification) Samples Collected at ER Sites 12, 13, 65, and 94

\begin{tabular}{|c|c|c|c|c|c|}
\hline \multicolumn{3}{|c|}{$\begin{array}{c}\text { Point Source } \\
\text { Sample Number }\end{array}$} & \multicolumn{3}{|c|}{$\begin{array}{c}\text { Area Source } \\
\text { Sample Number }\end{array}$} \\
\hline 94E25SS & 94E33SS & 94E34SS & 94E7SS & 94E8SS & 94E9SS \\
\hline 94E35SS & 94E36SS & 94E48SS & 94E10SS & 94E49SS & 94E57SS \\
\hline 94E58SS & $94 \mathrm{E} 63 S^{b}$ & 94E63SS ${ }^{b}$ & 94E67SS & 94E68SS & 94E69SS \\
\hline 94E63ASS & 94E63MSS & 94E63NSS & & & \\
\hline 94E63OSS & 94E63PSS & $94 \mathrm{E} 63 \mathrm{PSD}^{\mathrm{a}}$ & & & \\
\hline 94E70SS & 94E73SS & & & & \\
\hline
\end{tabular}

${ }^{\text {a }}$ Sample duplicate

${ }^{\mathrm{b}}$ Anomaly location sampled on two separate dates (see Appendix E for dates).

Table 5.6.12 Maximum Residual Radionuclide Levels in ER Sites 12, 13, 65, and 94 Soils

\begin{tabular}{|c|c|c|}
\hline Radionuclide & Maximum Activity (pCi/g) & Background Activity (pCi/g) \\
\hline U-238 & 35.8 & 2.3 \\
\hline $\mathrm{U}-235$ & 0.55 & 0.16 \\
\hline $\mathrm{U}-234$ & 4.5 & 2.3 \\
\hline
\end{tabular}

\section{Risk Assessment Results}

Further work is planned at these sites and, therefore, risk assessment has been postponed pending additional characterization and remediation. After future cleanup and characterization activities are complete, it is anticipated that the potential effects on human health due to exposure to radionuclides at the sites will be within proposed standards. This is based on preliminary review of site-specific input parameters and land-use scenarios for the risk assessment to be performed using the RESRAD code.

\section{Waste Management}

The cleanup activities produced soil, metal fragment, and PPE wastes. All waste was containerized in either 30- or 55-gallon drums. A total of 202 waste drums were generated during cleanup activities: 198 soil drums, 1 metal fragment drum, and 3 PPE drums. Waste 
consolidation was performed to minimize the number of drums produced for each waste stream. One metal fragment drum was consolidated, and one PPE drum was consolidated. Table 5.6.13 shows the number of waste drums after waste minimization/consolidation was performed, and Appendix J summarizes the waste minimization/consolidation effort.

Table 5.6.13 Summary of Waste Drums for ER Sites 12, 13, 65, and 94 (Post Minimization/Consolidation Effort)

\begin{tabular}{|c|c|c|c|c|c|c|c|}
\hline \multicolumn{2}{|c|}{ Soil Waste } & \multicolumn{2}{|c|}{$\begin{array}{l}\text { Metal Fragment } \\
\text { Waste }\end{array}$} & \multicolumn{2}{|c|}{ PPE Waste } & \multirow[b]{2}{*}{$\begin{array}{c}\text { TCLP/ } \\
\text { Gamma } \\
\text { Spec } \\
\text { Samples }\end{array}$} & \multirow[b]{2}{*}{ Comments } \\
\hline $\begin{array}{c}30 \text { Gallon } \\
\text { Drums }\end{array}$ & $\begin{array}{c}55 \text { Gallon } \\
\text { Drums }\end{array}$ & $\begin{array}{l}30 \text { Gallon } \\
\text { Drums }\end{array}$ & $\begin{array}{l}55 \text { Gallon } \\
\text { Drums }\end{array}$ & $\begin{array}{c}30 \text { Gallon } \\
\text { Drums }\end{array}$ & $\begin{array}{l}55 \text { Gallon } \\
\text { Drums }\end{array}$ & & \\
\hline 0 & 198 & 0 & 0 & 0 & 2 & $\begin{array}{l}5 \text { Soil } \\
1 \text { Frag }\end{array}$ & $\begin{array}{l}\text { Waste Minimization/ } \\
\text { Consolidation was performed. }\end{array}$ \\
\hline
\end{tabular}

${ }^{a}$ See Appendix J

Five composite soil samples and one metal fragment sample were collected from the waste drums and analyzed for gamma emitters using standard laboratory gamma spectroscopy methods and for leachable RCRA metals using TCLP analytical procedures. Mercury was not identified as a COC and was not included in the TCLP analysis. All samples passed the TCLP tests, and all waste was characterized as "Radioactive-Low Level Only." A summary of radiological activity for the waste is presented in Appendix G.

Disposal of regulated VCM waste was handled by SNL/NM Department 7577 (Waste Operations), which packaged and secured waste drums for transfer to Envirocare of Utah. Nonregulated waste was disposed of using standard SNL/NM-approved waste disposal methods.

\section{Conclusions}

All identified point and area sources of gamma activity 30 percent or greater than the natural background were removed from the site with the exception of one area source associated with the large open burn pool. This source was not cleaned up because it is embedded within concrete at an active test structure. Further radiological characterization is planned for the graded portion and oil surface impoundment area at the site. A risk assessment will be conducted after all characterization and source removal is performed. No radiological anomalies were identified at ER Site 13.

Source removal is summarized in Table 5.6.14, and sources remaining after completion of the VCM are shown in Figure 5.6.7.

No additional cleanup activities were performed during this VCM. The status of other possible COCs is not addressed in this report. 


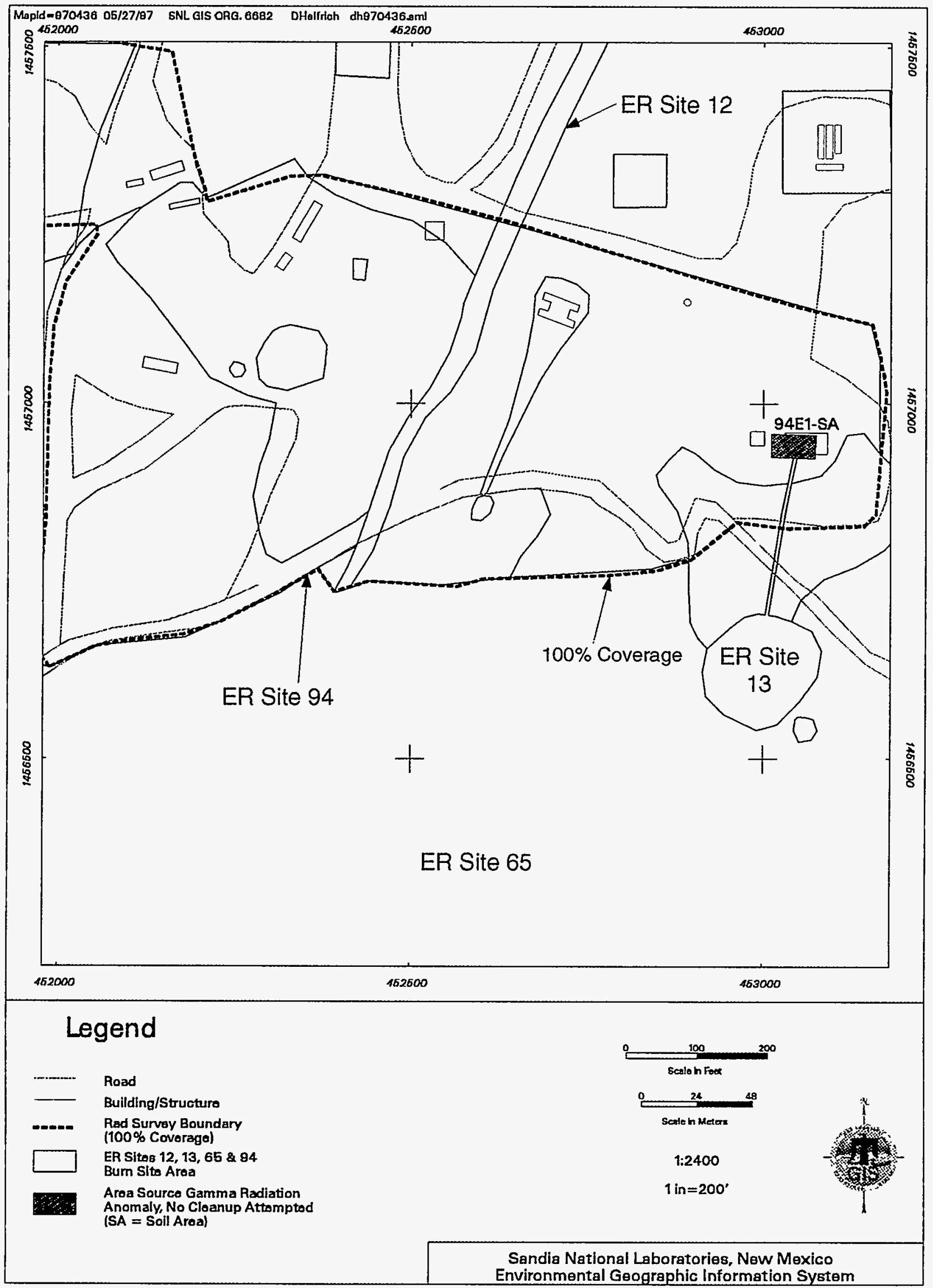

Figure 5.6.7 Radiation Anomalies Remaining After Completion of the VCM at ER Sites 12, 13, 65, \& 94 
Table 5.6.14 Summary of Point and Area Source Removal at ER Sites 12, 13, 65, and 94

\begin{tabular}{|c|c|c|l|}
\hline Anomaly Type & Total Identified & Total Removed & \multicolumn{1}{|c|}{ Comments } \\
\hline Point Sources & 69 & 69 & $\begin{array}{l}\text { Cleanup complete and no further } \\
\text { action is required. }\end{array}$ \\
\hline Area Sources & 13 & 12 & $\begin{array}{l}\text { One source is associated with } \\
\text { concrete in the large open burn } \\
\text { pool. }\end{array}$ \\
\hline
\end{tabular}

All waste was characterized as "Radioactive-Low Level Only" and managed in accordance with SNL/NM Department 7572 (Waste Management) procedures.

\subsubsection{New Aerial Cable Site, Burial Site, Dump, Test Area (ER Site 81) \\ Overview}

The Phase I survey at ER Site 81 was conducted during March 1994 and covered a total of 31.2 acres of uneven terrain nestled within a narrow valley. A gamma scan survey was performed at 6-foot centers (100 percent coverage) over the surface of the site. Four area sources of gamma activity 30 percent or greater than the natural background were identified during this survey. The elevated radiation at these area sources is suspected to be related to the underlying, naturally-occurring geological material. A detailed summary of the surface radiological survey and anomalies found at the site is presented in Section 5.6.5 of the Surface Gamma Radiation Surveys Final Report (Geotech 1994b).

Figure 5.6.8 shows the site, surface radiological survey boundaries, and anomalies found during the Phase I survey, and VCM pre-cleanup (confirmatory) sampling locations.

During July 1996, pre-cleanup (confirmatory) soil sampling for gamma spectroscopy analysis was conducted on the four area sources to assess the need for remediation. Table 5.6.15 summarizes field activities during the VCM.

Table 5.6.15 Summary of Field Activities at ER Site 81

\begin{tabular}{|c|c|c|c|c|}
\hline $\begin{array}{c}\text { Actual Acreage } \\
\text { Surveyed }\end{array}$ & $\begin{array}{c}\text { Duration of } \\
\text { Cleanup (days) }\end{array}$ & $\begin{array}{c}\text { Verify } \\
\text { Anomaly } \\
\text { Location }\end{array}$ & $\begin{array}{c}\text { Pre-Cleanup } \\
\text { Sampling } \\
\text { (area sources) }\end{array}$ & Comments \\
\hline 31.20 & $<0.25$ & $\mathbf{X}$ & $\mathbf{X}$ & $\begin{array}{l}\text { Pre-cleanup sampling of } \\
\text { natural outcrops. }\end{array}$ \\
\hline
\end{tabular}

a Removal of fragment and/or soil until readings are less than 1.3 times site-specific background 


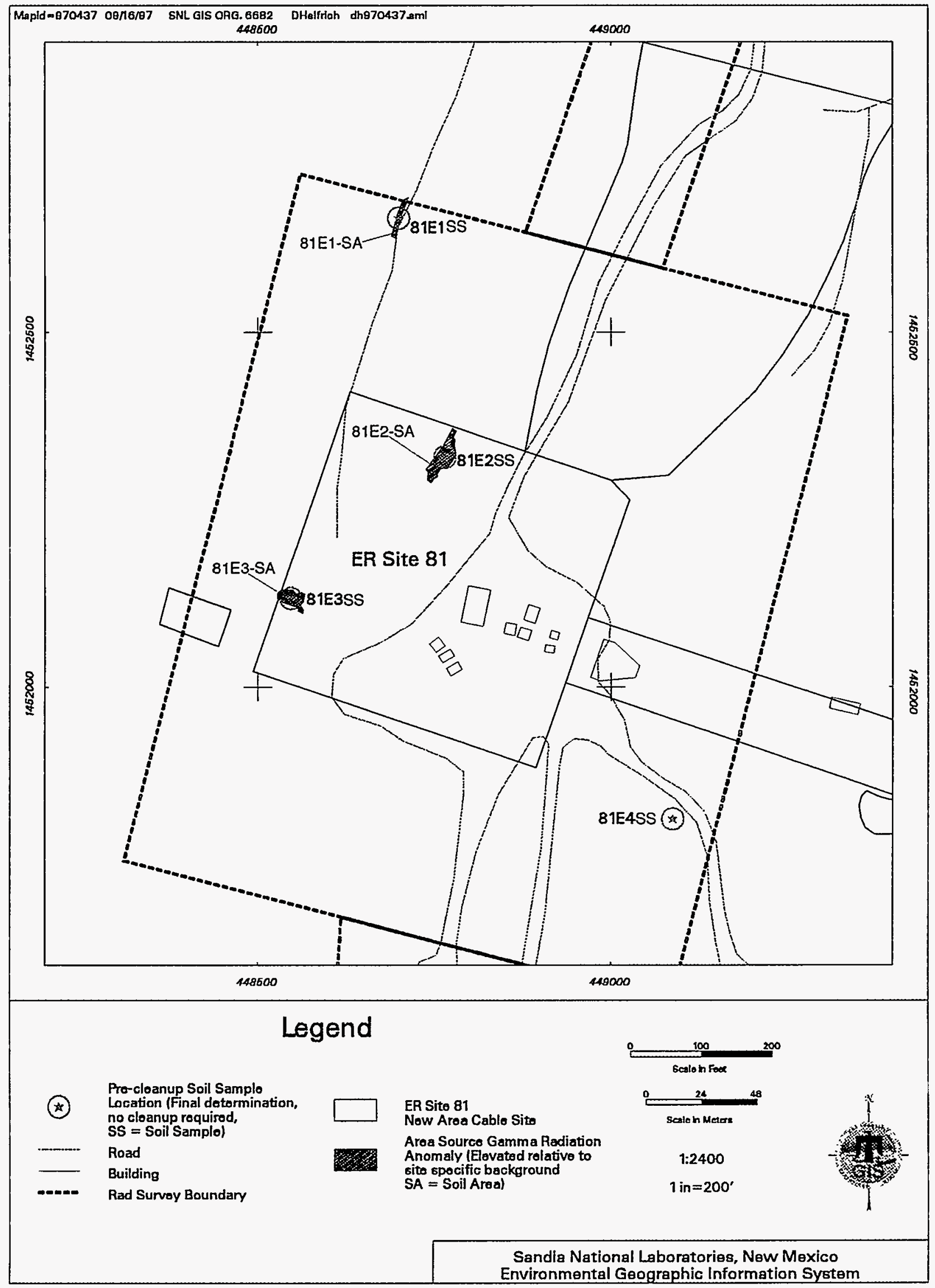

Figure 5.6.8 Phase I Survey Radiation Anomalies and VCM Surface Soil Sampling Locations at ER Site 81 


\section{Findings and Observations}

\section{Point and Area Source Status}

The four area sources $(81 \mathrm{E} 1,81 \mathrm{E} 2,81 \mathrm{E} 3$, and 81E4) were not remediated. The results of gamma spectroscopy analysis on pre-cleanup samples collected from these locations indicate the elevated radiation is related to the underlying, naturally-occurring geologic material. No additional point or area sources were identified during VCM sampling activities.

\section{Pre-Cleanup (Confirmatory) Sample Results}

The four area sources consisted of natural rock outcroppings containing elevated thorium and uranium series radionuclides. Four pre-cleanup (confirmatory) samples were collected from areas exhibiting the highest residual gamma radiation readings and in-situ gamma spectroscopy was performed on the largest anomaly. Gamma spectroscopy analysis was performed on the samples to characterize, if present, the residual radioactivity in the soil. Review of these analyses showed that, although the results were in excess of regional background values, the samples were representative of background distributions. The primary indicator for this determination was the existence of a state of equilibrium in the uranium series, which can only occur when the radionuclides have existed in the matrix for millions of years. Table 5.6.16 shows the precleanup samples collected at the site, and the maximum level of residual radiological COCs in soil is presented in Table 5.6.17.

Table 5.6.16 Pre-Cleanup (Final Determination) Samples Collected at ER Site 81

\begin{tabular}{|cc|}
\hline & $\begin{array}{c}\text { Natural Outcrop } \\
\text { Sample Number }\end{array}$ \\
\hline \hline 81E1SS & $81 \mathrm{E} 2 \mathrm{SS}$ \\
$81 \mathrm{E} 3 \mathrm{SS}$ & $81 \mathrm{E} 4 \mathrm{SS}$ \\
\hline
\end{tabular}

Table 5.6.17 Maximum Residual Radionuclide Levels in ER Site 81 Soils

\begin{tabular}{|c|c|c|}
\hline Radionuclide & Maximum Activity (pCi/g) & Background Activity (pCi/g) \\
\hline U-238 & 1.3 & 2.3 \\
\hline U-235 & 0.22 & 0.16 \\
\hline U-234 & ND & 2.3 \\
\hline Th-232 & 1.43 & 1.03 \\
\hline Ra-228 & 1.96 & 1.08 \\
\hline
\end{tabular}

\section{Risk Assessment Results}

Since anomalies were characterized as only being elevated background areas, no risk assessment was performed. 


\section{Waste Management}

No VCM was conducted; therefore, no waste was generated.

\section{Conclusions}

No surface radiation cleanup activities were performed, and no waste was generated. The four area sources of gamma activity 30 percent or greater than the natural background were not remediated since the elevated radiation is related to the underlying, naturally-occurring geologic material. No radiological risk assessment is planned. Source removal information is summarized in Table 5.6.18.

Table 5.6.18 Summary of Area Source Removal at ER Site 81

\begin{tabular}{|c|c|c|l|}
\hline Anomaly Type & Total Identified & Total Removed & \multicolumn{1}{c|}{ Comments } \\
\hline Area Sources & 4 & 0 & $\begin{array}{l}\text { Sources are related to underlying, } \\
\text { naturally-occurring geologic } \\
\text { material. }\end{array}$ \\
\hline
\end{tabular}

No additional cleanup activities were performed during this VCM. The status of other possible COCs is not addressed in this report.

\subsection{Central Coyote Test Area Operable Unit Sites (ADS 1334)}

\subsubsection{Workman Sites (ER Sites 57A and 57B)}

\section{Overview}

The Phase I survey at ER Sites 57A and 57B was conducted during March 1994 and covered a total of 15.6 acres of flat alluvial terrain. A gamma scan survey was performed at 10 -foot centers (70 percent coverage) over the surface of the sites. One point source and two area sources of gamma activity 30 percent or greater than the natural background were identified during this survey at ER Site 57A. Four area sources were identified at ER Site 57B. The elevated radiation of the area sources are suspected to be related to the underlying, naturally-occurring geologic material. A detailed summary of the surface radiological survey and anomalies found at these sites is presented in Section 5.7.5 of the Surface Gamma Radiation Surveys Final Report (Geotech 1994b).

Figures 5.7.1 and 5.7.2 show the site, surface radiological survey boundaries, and anomalies found during the Phase I survey, and VCM sampling (pre-cleanup and post-cleanup) locations at ER Site 57A and 57B, respectively.

VCM activities were conducted during March and July 1995. Pre-cleanup soil sampling for gamma spectroscopy analysis was conducted on area sources to assess the need for remediation. Resurveying (scanning) was not performed at these sites. 


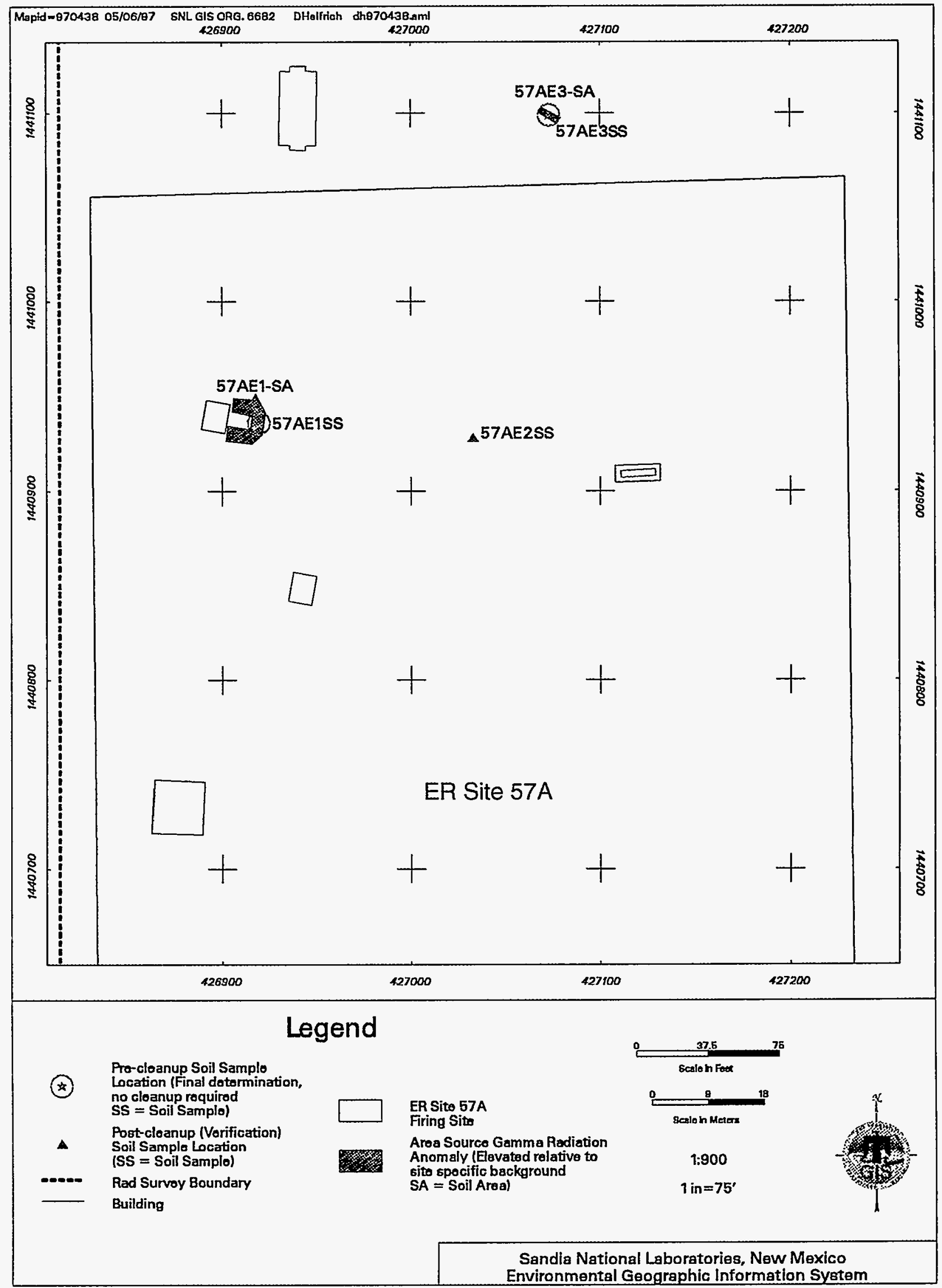

Figure 5.7.1 Phase I Survey Radiation Anomalies and VCM Surface Soil Sampling Locations at ER Site 57A 


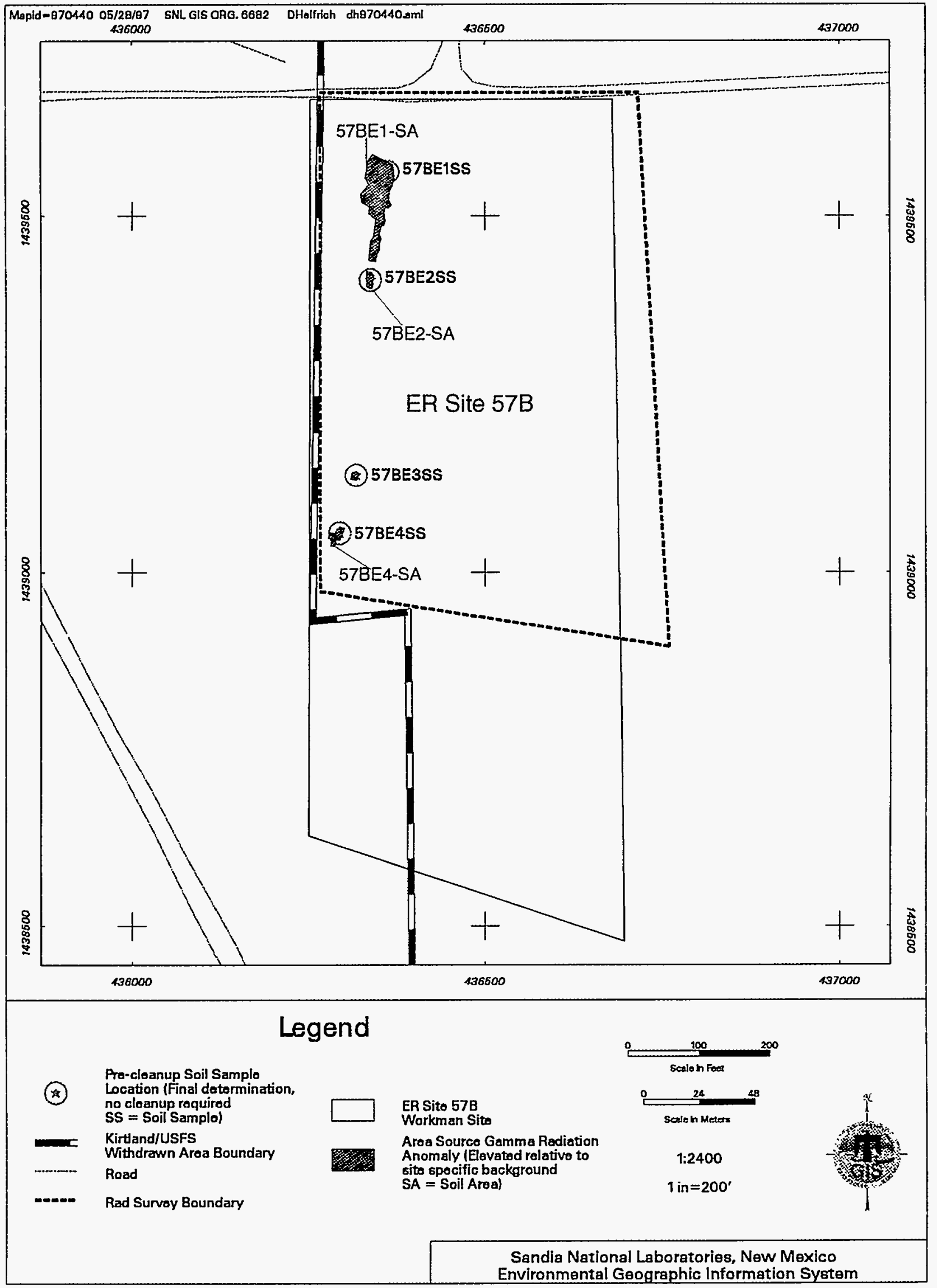

Figure 5.7.2 Phase I Survey Radiation Anomalies and VCM Surface Soil Sampling Locations at ER Site 57B 
Cleanup activities included radiation scanning to verify anomaly location, removal of fragment and/or soil until readings were less than 1.3 times site-specific background levels, and post-cleanup (verification) soil sampling for gamma spectroscopy analysis (see Section 3.1).

Table 5.7.1 summarizes field activities during the VCM

Table 5.7.1 Summary of Field Activities at ER Sites 57A and 57B

Removal Action Procedures

\begin{tabular}{|c|c|c|c|c|c|c|}
\hline $\begin{array}{c}\text { Actual } \\
\text { Acreage } \\
\text { Surveyed }\end{array}$ & $\begin{array}{c}\text { Duration of } \\
\text { Cleanup } \\
\text { (days) }\end{array}$ & $\begin{array}{c}\text { Verify } \\
\text { Anomaly } \\
\text { Location }\end{array}$ & $\begin{array}{c}\text { Rad } \\
\text { Removal }\end{array}$ & $\begin{array}{c}\text { Post- } \\
\text { Cleanup } \\
\text { Sampling }\end{array}$ & $\begin{array}{c}\text { Pre-Cleanup } \\
\text { Sampling } \\
\text { (area sources) }\end{array}$ & Comments \\
\hline 15.60 & 0.25 & $\mathbf{X}$ & $\mathbf{X}$ & $\mathbf{X}$ & $\mathbf{X}$ & $\begin{array}{l}\text { Pre-cleanup } \\
\text { sampling of natural } \\
\text { outcrops. }\end{array}$ \\
\hline
\end{tabular}

${ }^{a}$ Removal of fragment and/or soil until readings are less than 1.3 times site-specific background

\section{Findings and Observations}

\section{Point and Area Source Status}

During the initial cleanup, the one point source (57AE2) at ER Site 57A was removed. The results of gamma spectroscopy analysis on pre-cleanup samples from the six area sources (57AE1, 57AE3, 57BE1, 57BE2, 57BE3, and 57BE4) indicated the elevated radiation was related to the underlying, naturally-occurring geologic material and remediation was not required. No additional point or area sources were identified during VCM activities. Table 5.7.2 shows the pre-cleanup samples collected from six area sources.

Table 5.7.2 Pre-Cleanup (Final Determination) Samples Collected at ER Sites 57A and 57B

\begin{tabular}{|ccc|}
\hline \multicolumn{3}{|c|}{$\begin{array}{c}\text { Area Source } \\
\text { Sample Number }\end{array}$} \\
\hline \hline 57AE1SS & 57AE3SS & 57BE1SS \\
57BE2SS & 57BE3SS & 57BE4SS \\
\hline
\end{tabular}

\section{Post-Cleanup (Verification) Sample Results}

No post-cleanup (verification) samples were required at ER Site 57B. After source removal at ER Site 57A, two post-cleanup (verification) samples were collected from areas exhibiting the highest residual gamma radiation readings. Gamma spectroscopy analysis was performed on the samples to verify that the residual radionuclide concentrations met risk-based action levels. The radiological COC was DU (U-238, U-235, and U-234). Table 5.7.3 shows the post-cleanup (verification) samples collected at the sites, and the maximum levels of residual radionuclides in soils are presented in Table 5.7.4. 
Table 5.7.3 Post-Cleanup (Verification) Samples Collected at ER Sites 57A and 57B

\begin{tabular}{|c|c|}
\hline \multicolumn{2}{|c|}{$\begin{array}{c}\text { Point Source } \\
\text { Sample Number }\end{array}$} \\
\hline 57AE2SS & 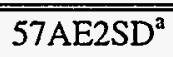 \\
\hline
\end{tabular}

${ }^{\mathrm{a}}$ Sample duplicate

Table 5.7.4 Maximum Residual Radionuclide Levels in ER Site 57A Soils

\begin{tabular}{|c|c|c|}
\hline Radionuclide & Maximum Activity (pCi/g) & Background Activity (pCi/g) \\
\hline U-238 & 0.49 & 1.4 \\
\hline U-235 & ND & 0.18 \\
\hline U-234 & ND & 1.6 \\
\hline
\end{tabular}

\section{Risk Assessment Results}

The surface at ER Site 57A was cleaned up to background levels. Therefore, ER Site 57A has no further radioactive contamination in the soil, and a radiological risk assessment was not necessary. No risk assessment was required at ER Site 57B.

\section{Waste Management}

The cleanup activities produced soil and metal fragment wastes. One 30 -gallon soil drum was generated during cleanup activities. Waste consolidation was performed to minimize the number of drums produced for each waste stream. A small metal fragment collected during the removal action was consolidated with soil waste. Table 5.7.5 shows the number of waste drums after waste minimization/consolidation was performed, and Appendix $J$ summarizes the waste minimization/consolidation effort.

Table 5.7.5 Summary of Waste Drums for ER Sites 57A and 57B (Post Minimization/ Consolidation Effort)

\begin{tabular}{|c|c|c|c|c|c|c|c|}
\hline \multicolumn{2}{|c|}{ Soil Waste } & \multicolumn{2}{|c|}{$\begin{array}{l}\text { Metal Fragment } \\
\text { Waste }\end{array}$} & \multicolumn{2}{|c|}{ PPE Waste } & \multirow[b]{2}{*}{$\begin{array}{c}\text { TCLPI } \\
\text { Gamma } \\
\text { Spec } \\
\text { Samples }\end{array}$} & \multirow[b]{2}{*}{ Comments } \\
\hline $\begin{array}{c}30 \text { Gallon } \\
\text { Drums }\end{array}$ & $\begin{array}{c}55 \text { Gallon } \\
\text { Drums }\end{array}$ & $\begin{array}{c}30 \text { Gallon } \\
\text { Drums }\end{array}$ & $\begin{array}{c}55 \text { Gallon } \\
\text { Drums }\end{array}$ & $\begin{array}{l}\text { 30 Gallon } \\
\text { Drums }\end{array}$ & $\begin{array}{l}55 \text { Gallon } \\
\text { Druins }\end{array}$ & & \\
\hline 0 & 0 & 0 & 0 & 0 & 0 & 1 Soil & $\begin{array}{l}\text { Waste } \\
\text { Minimization/Consolidation } \\
\text { was performed. }\end{array}$ \\
\hline
\end{tabular}

${ }^{a}$ See Appendix J 
One composite soil sample was collected from the waste drum and analyzed for gamma emitters using standard laboratory gamma spectroscopy methods and for leachable RCRA metals using TCLP analytical procedures. Mercury was not identified as a COC and was not included in the TCLP analysis. All samples passed the TCLP tests, and all waste was characterized as "Radioactive-Low Level Only." A summary of radiological activity for the waste is presented in Appendix G.

Disposal of regulated VCM waste was handled by SNL/NM Department 7577 (Waste Operations), which packaged and secured waste drums for transfer to Envirocare of Utah. Nonregulated waste was disposed of using standard SNL/NM-approved waste disposal methods.

\section{Conclusions}

One point source of gamma activity 30 percent or greater than the natural background was removed at ER Site 57A and maximum residual radionuclide concentrations were less than background levels. Six area sources of gamma activity 30 percent or greater than the natural background were not remediated at ER Sites 57A and 57B since the elevated radiation readings are related to underlying, naturally-occurring geologic material. A radiological risk assessment was not performed since the sites have no additional anthropogenic (man-made) radioactive contamination in the soil. No further radiological characterization is planned at the site.

Source removal is summarized in Table 5.7.6 and sources remaining after completion of the VCM are shown in Figures 5.7.3 and 5.7.4.

Table 5.7.6 Summary of Point and Area Source Removal at ER Sites 57A and 57B

\begin{tabular}{|c|c|c|l|}
\hline Anomaly Type & Total Identified & Total Removed & \multicolumn{1}{|c|}{ Comments } \\
\hline Point Sources & 1 & 1 & $\begin{array}{l}\text { Cleanup complete and no further } \\
\text { action is required. }\end{array}$ \\
\hline Area Sources & 6 & 0 & $\begin{array}{l}\text { Sources are related to underlying, } \\
\text { naturally-occurring geologic } \\
\text { material. }\end{array}$ \\
\hline
\end{tabular}

No additional cleanup activities were performed during this VCM. The status of other possible COCs is not addressed in this report.

All waste was characterized as "Radioactive-Low Level Only" and managed in accordance with SNL/NM Department 7572 (Waste Management) procedures. 


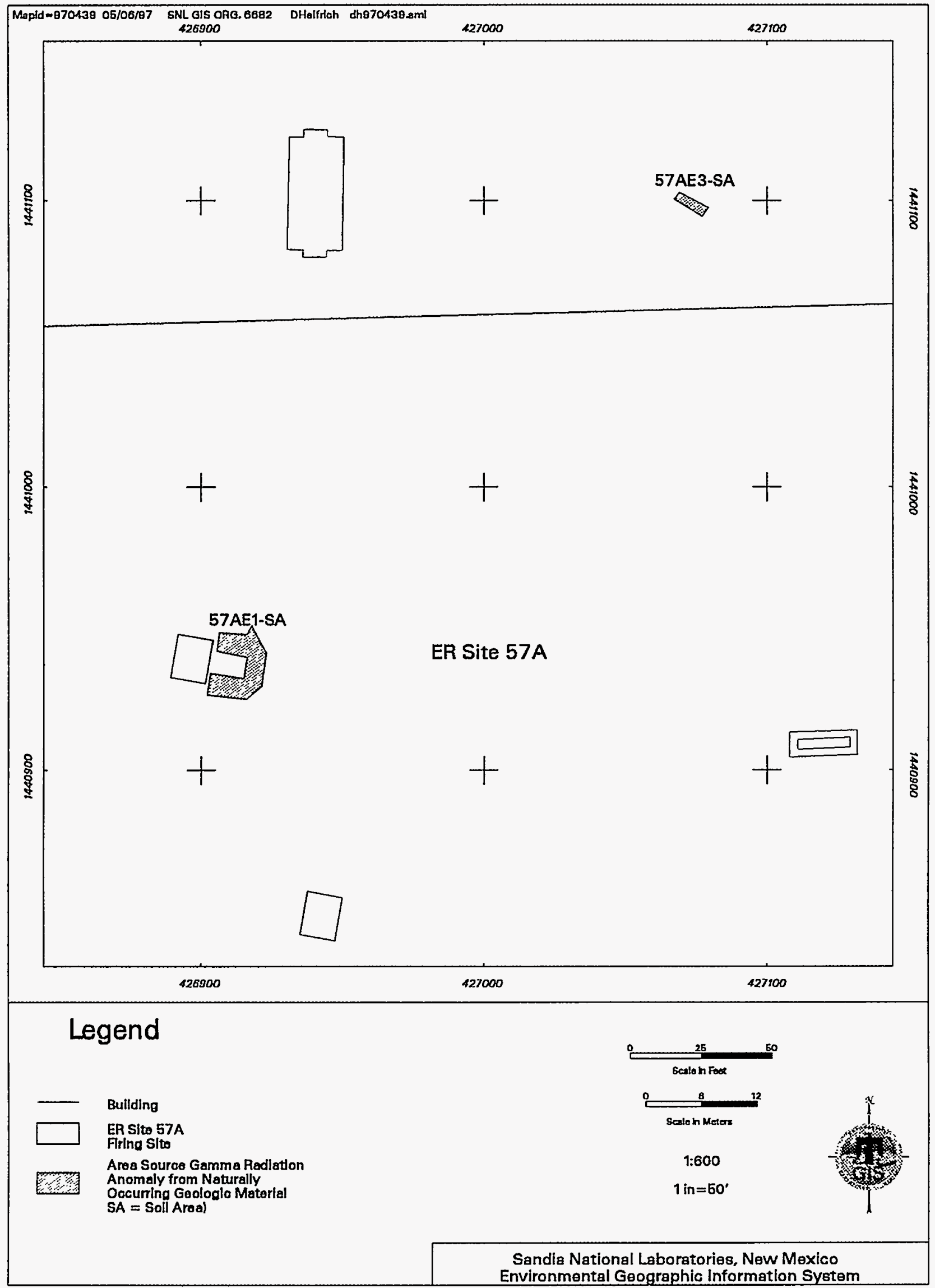

Figure 5.7.3 Radiation Anomalies Remaining After Completion of the VCM at ER Site 57A 


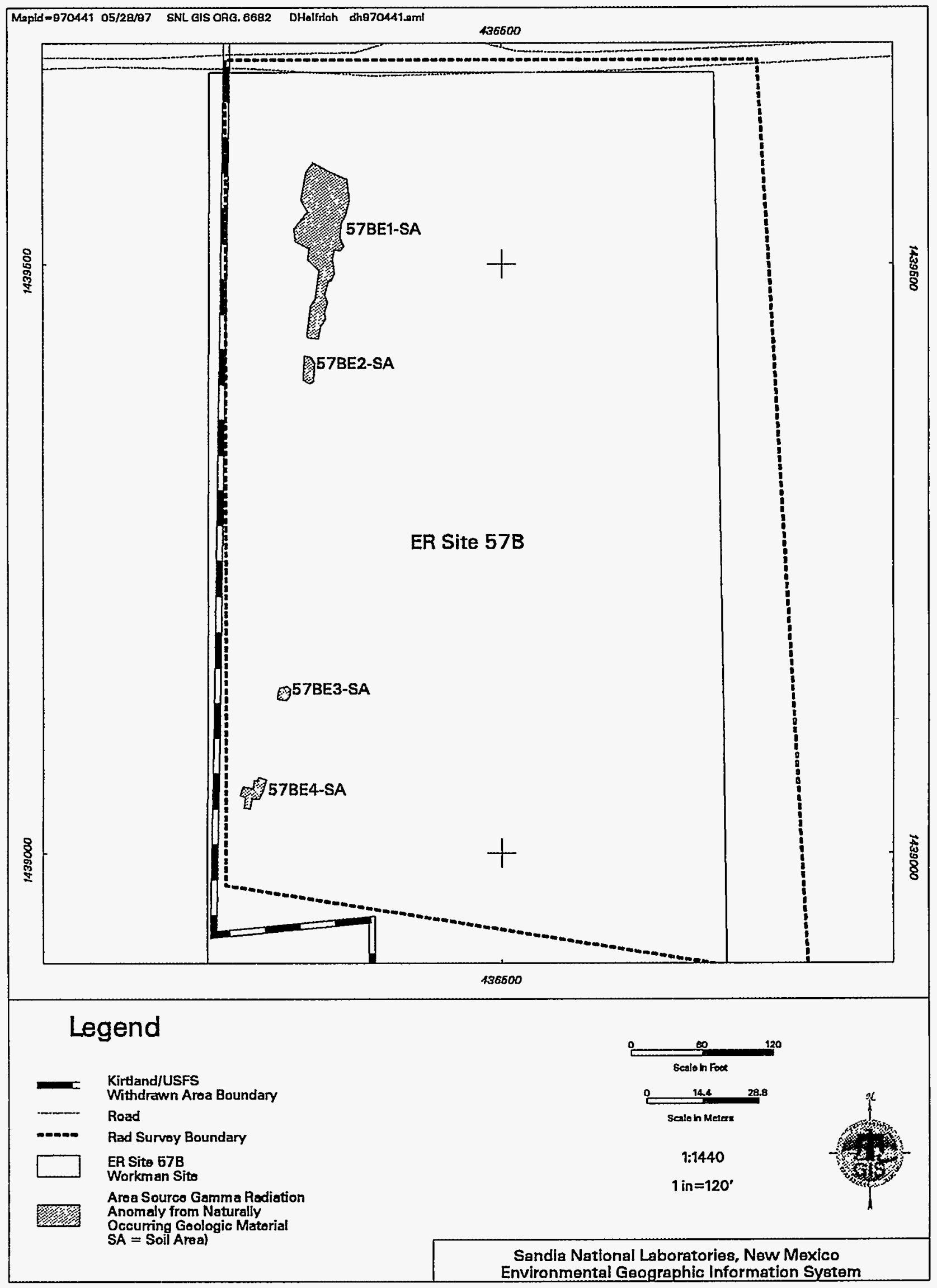

Figure 5.7.4 Radiation Anomalies Remaining

After Completion of the VCM at ER Site 57B 


\subsubsection{Schoolhouse Mesa Test Sites (ER Sites 61A and 9)}

\section{Overview}

The Phase I surveys at ER Sites 61A and 9 were conducted with surveys at ER Sites $61 \mathrm{C}$ and 20 during February and April 1994. These surveys covered a total of 39.5 acres of uneven sloped terrain. No point or area sources of gamma activity 30 percent or greater than the natural background were identified during the surveys at ER Sites $61 \mathrm{C}$ and 20 (see Section 6). ER Site 61A encompasses ER Site 9, and all relevant data are considered to be that of ER Site 61A. A gamma scan survey was performed at 6-foot centers (100 percent coverage) over the surface of ER Site 9 and at 10 -foot centers ( 70 percent coverage) over the surface of ER Site 61A. During this survey, 63 point sources and 11 area sources of gamma activity 30 percent or greater than the natural background were identified at ER Sites $61 \mathrm{~A}$ and 9 . A detailed summary of the surface radiological survey and anomalies found at the site is presented in Section 5.7.1 of the Surface Gamma Radiation Surveys Final Report (Geotech 1994b).

Figure 5.7.5 shows the site, surface radiological survey boundaries, and anomalies found during the Phase I survey.

VCM activities were conducted at ER Sites 61A and 9 during March 1995 and February, March, May, July, and October 1996. Point sources were removed in March 1995. In February 1996, resurveying (scanning) of ER Site 61A was performed on 6-foot centers (100 percent coverage), and pre-cleanup soil sampling for gamma spectroscopy analysis was conducted on one area source to assess the need for remediation. New point sources identified during the resurveying and original area sources identified during the Phase I survey were remediated in February, March, May, and July 1996. Heavy equipment (backhoe) was used to excavate two large area sources at ER 61A since the lateral and vertical extent of elevated radiation exceeded the capabilities of manual cleanup procedures. Gamma scan survey of the debris mound/buried bunker at ER Site 9 was conducted during October 1996. Heavy equipment (backhoe) was used to excavate the debris mound/buried bunker at ER Site 9 since the lateral and vertical extent of elevated radiation exceeded the capabilities of manual cleanup procedures.

Cleanup activities included radiation scanning to verify anomaly location, removal of fragment and/or soil until readings were less than 1.3 times site-specific background levels, and postcleanup (verification) soil sampling for gamma spectroscopy analysis (see Section 3.1). Table 5.7.7 summarizes field activities during the VCM. 


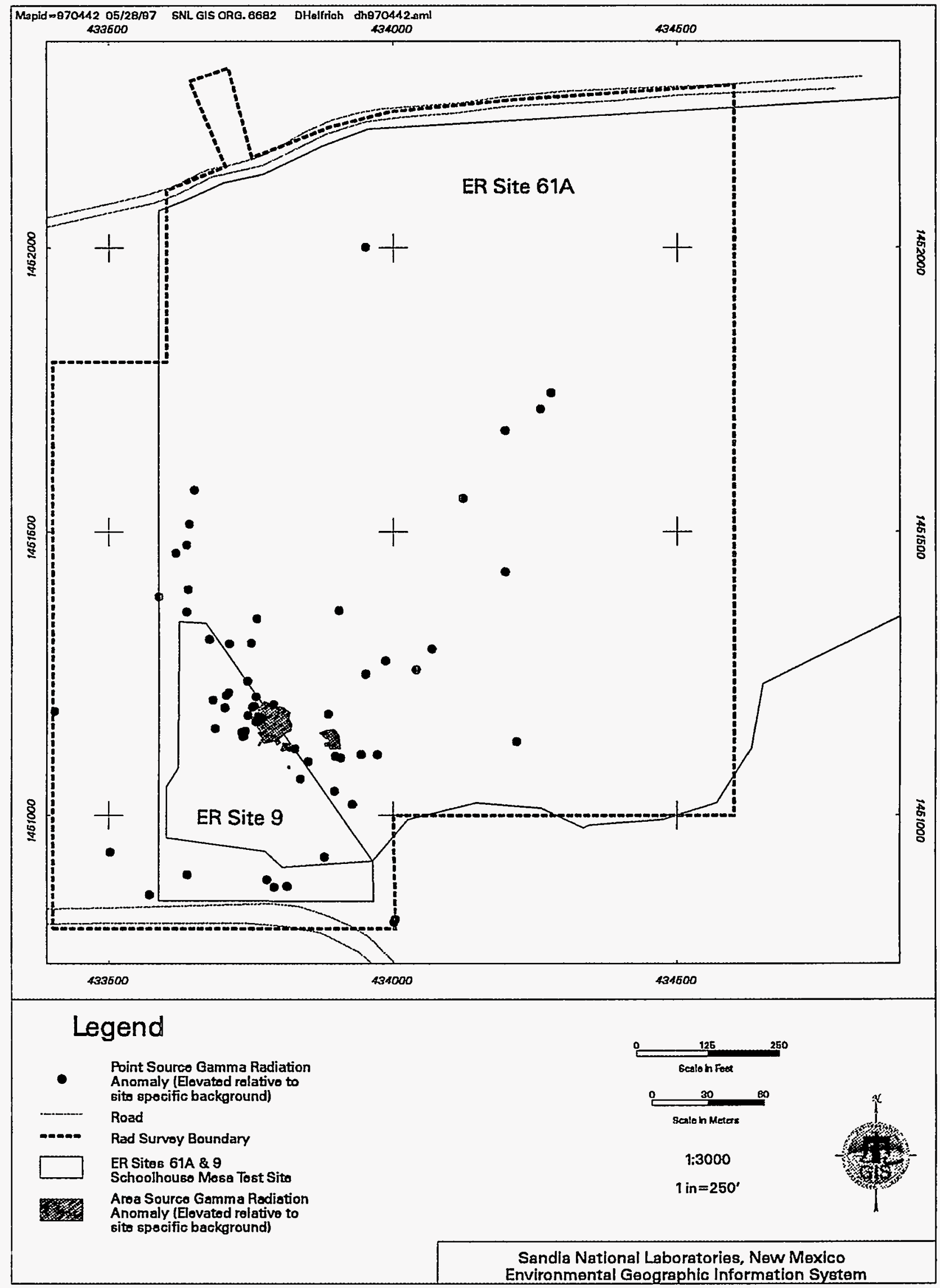

Figure 5.7.5 Phase I Survey Radiation Anomalies at ER Sites 61A \& 9 
Table 5.7.7 Summary of Field Activities at ER Sites 61A and 9

Removal Action Procedures

\begin{tabular}{|c|c|c|c|c|c|c|c|c|}
\hline $\begin{array}{c}\text { Actual } \\
\text { Acreage } \\
\text { Surveyed }\end{array}$ & $\begin{array}{c}\text { Duration of } \\
\text { Cleanup } \\
\text { (days) }\end{array}$ & $\begin{array}{c}\text { Verify } \\
\text { Anomaly } \\
\text { Location }\end{array}$ & $\begin{array}{c}\text { Rad } \\
\text { Removal }\end{array}$ & $\begin{array}{c}\text { Post- } \\
\text { Cleanup } \\
\text { Sampling }\end{array}$ & $\begin{array}{c}\text { New Area/ } \\
\text { Resurveyed } \\
(\mathbf{1 0 0 \% )}\end{array}$ & $\begin{array}{c}\text { Pre-Cleanup } \\
\text { Sampling } \\
\text { (area sources) }\end{array}$ & $\begin{array}{c}\text { Heavy } \\
\text { Equipment } \\
\text { Support }\end{array}$ & Comments \\
\hline 39.50 & 29.25 & $\mathbf{X}$ & $\mathbf{X}$ & $\mathbf{X}$ & $\mathbf{X}$ & $\mathbf{X}$ & $\mathbf{X}$ & $\begin{array}{l}\text { Resurveyed original } \\
\text { area on 6-ft centers } \\
(100 \%) \text {. Pre-cleanup } \\
\text { sampling of natural } \\
\text { outcrops. Backhoe } \\
\text { used on large area } \\
\text { sources. }\end{array}$ \\
\hline
\end{tabular}

${ }^{a}$ Removal of fragment and/or soil until readings are less than 1.3 times site-specific background

\section{Findings and Observations}

\section{Point and Area Source Status}

Of the sources identified during the Phase I survey, 62 point sources were remediated during the initial cleanup. At one point source location (61AE60), no fragment or visible contamination was observed, and no cleanup was conducted. This location was excavated to bedrock, and the elevated gamma readings were related to the underlying, naturally-occurring geologic material. During subsequent cleanup activity, 11 area sources were remediated. Two of theses area sources (61AE47 and 61AE22) were discovered to be of such extent that they required the use of a backhoe for excavation and remediation.

During resurveying (scanning) of ER Site 61A, 21 new point sources and 1 new area source were identified. Gamma spectroscopy results on the pre-cleanup sample from the new area source (61AE76) indicate the elevated radiation is related to the underlying, naturally-occurring geologic material and remediation was not required. The new point sources were remediated, along with the 11 original area sources, during subsequent cleanup activity. The new sources identified during the VCM are summarized in Table 5.7.8, and Table 5.7.9 shows the pre-cleanup sample collected from the new area source. Figure 5.7.6 shows VCM radiation anomalies and verification sampling locations (pre-cleanup and post-cleanup).

Table 5.7.8 Radiation Anomalies 30 Percent or Greater Than Natural Background Identified During the VCM at ER Sites 61A and 9

\begin{tabular}{|c|c|l|}
\hline Anomaly Type & Total & \multicolumn{1}{c|}{ Comments } \\
\hline Point Sources & 21 & $\begin{array}{l}\text { Gray, black fragments with yellow } \\
\text { uranium oxide (DU) in soil }\end{array}$ \\
\hline Area Source & 1 & $\begin{array}{l}\text { Appears to be related to } \\
\text { underlying, naturally-occurring } \\
\text { geologic material. }\end{array}$ \\
\hline
\end{tabular}




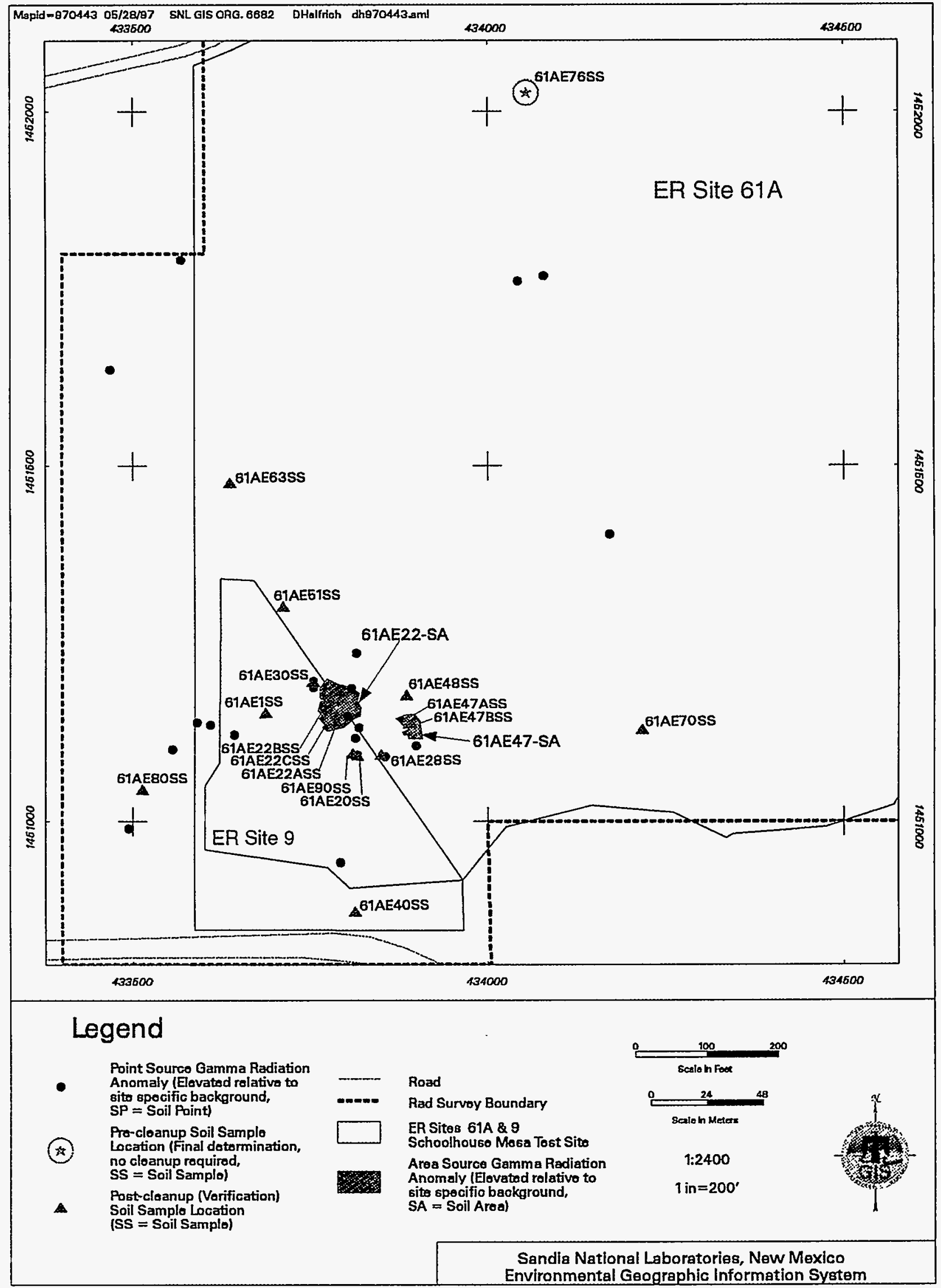

Figure 5.7.6 VCM Radiation Anomalies and

Surface Soil Sampling Locations at Sites 61A \& 9 
Table 5.7.9 Pre-Cleanup (Final Determination) Samples Collected at ER Sites 61A and 9

Area Source

Sample Number

61AE76SS

At ER Site 9, elevated gamma readings were detected during soil segregation and gamma scan survey of the debris mound/buried bunker. Remediation was completed on the debris mound; however, cleanup was not completed on the buried bunker due to UXO concerns.

\section{Post-Cleanup (Verification) Sample Results}

After the removal of radiologically contaminated soils, 18 post-cleanup (verification) samples were collected from areas exhibiting the highest residual gamma radiation readings. Gamma spectroscopy analysis was performed on these samples to characterize the residual radioactivity remaining in the soil. The radiological COCs were DU (U-238, U-235, and U-234) and thorium (Th-232).

Table 5.7.10 summarizes the post-cleanup (verification) samples collected at the sites, and the maximum level of residual radiological COCs in soils is presented in Table 5.7.11.

Table 5.7.10 Post-Cleanup (Verification) Samples Collected at ER Sites 61A and 9

\begin{tabular}{|lll|lll|}
\hline \multicolumn{3}{c|}{$\begin{array}{c}\text { Point Source } \\
\text { Sample Number }\end{array}$} & \multicolumn{3}{c|}{$\begin{array}{c}\text { Area Source } \\
\text { Sample Number }\end{array}$} \\
\hline \hline 61AE1SS & 61AE28SS & 61AE28SD & 61AE20SS & 61AE22ASS & 61AE22BSS \\
61AE40SS & $61 \mathrm{AE} 48 S S$ & $61 \mathrm{AE} 51 \mathrm{AS}$ & $61 \mathrm{AE} 22 \mathrm{CSS}$ & 61AE30SS & 61AE47ASS \\
61AE63SS & $61 \mathrm{AE} 70 S S$ & $61 \mathrm{AE} 80 S S$ & $61 \mathrm{AE} 47 \mathrm{BSS}$ & & \\
61AE90SS & & & & & \\
\hline
\end{tabular}

${ }^{a}$ Sample duplicate

Table 5.7.11 Maximum Residual Radionuclide Levels in ER Sites 61A and 9 Soils

\begin{tabular}{|c|c|c|}
\hline Radionuclide & Maximum Activity (pCi/g) & Background Activity (pCi/g) \\
\hline U-238 & 32.0 & 1.4 \\
\hline U-235 & 0.85 & 0.16 \\
\hline U-234 & 2.8 & 1.6 \\
\hline Th-232 & 6.56 & 1.01 \\
\hline Ra-228 & 6.84 & 1.01 \\
\hline
\end{tabular}




\section{Risk Assessment Results}

Further work is planned at ER Sites 61A and 9 and, therefore, risk assessment has been postponed pending additional characterization and remediation. After cleanup is complete, it is anticipated that the potential effects on human health due to exposure to radionuclides at the site will be within proposed standards. This is based on preliminary review of site-specific input parameters and land-use scenarios for the risk assessment to be performed using the RESRAD code.

\section{Waste Management}

The cleanup activities produced soil, metal fragment, and PPE wastes. All waste was containerized in either 30-gallon or 55-gallon drums. A total of 337 waste drums were generated during cleanup activities: 331 soil drums, 2 metal fragment drums, and 4 PPE drums. Waste consolidation was performed to minimize the number of drums produced for each waste stream. One metal fragment drum was consolidated, and one PPE drum was consolidated. Table 5.7.12 shows the number of waste drums after waste minimization/consolidation was performed, and Appendix J summarizes the waste minimization/consolidation effort.

Table 5.7.12 Summary of Waste Drums for ER Sites 61A and 9 (Post Minimization/ Consolidation Effort)

\begin{tabular}{|c|c|c|c|c|c|c|c|}
\hline \multicolumn{2}{|c|}{ Soil Waste } & \multicolumn{2}{|c|}{$\begin{array}{l}\text { Metal Fragment } \\
\text { Waste }\end{array}$} & \multicolumn{2}{|c|}{ PPE Waste } & \multirow[b]{2}{*}{$\begin{array}{c}\text { TCLP/ } \\
\text { Gamma } \\
\text { Spec } \\
\text { Samples }\end{array}$} & \multirow[b]{2}{*}{ Comments } \\
\hline $\begin{array}{l}30 \text { Gallon } \\
\text { Drums }\end{array}$ & $\begin{array}{l}55 \text { Gallon } \\
\text { Drums }\end{array}$ & $\begin{array}{l}30 \text { Gallon } \\
\text { Drums }\end{array}$ & $\begin{array}{l}55 \text { Gallon } \\
\text { Drums }\end{array}$ & $\begin{array}{l}30 \text { Gallon } \\
\text { Drums }\end{array}$ & $\begin{array}{c}55 \text { Gallon } \\
\text { Drums }\end{array}$ & & \\
\hline$\overline{1} 1$ & 330 & 1 & $\overline{0}$ & 0 & $\overline{3}$ & $\begin{array}{l}8 \text { Soil } \\
1 \text { Frag }\end{array}$ & $\begin{array}{l}\text { Waste } \\
\text { Minimization/Consolidation } \\
\text { was performed. }\end{array}$ \\
\hline
\end{tabular}

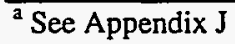

Eight composite soil samples and one metal fragment sample were collected from the waste drums and analyzed for gamma emitters using standard laboratory gamma spectroscopy methods and for leachable RCRA metals using TCLP analytical procedures. Mercury was not identified as a COC and was not included in the TCLP analysis. All samples passed the TCLP tests, and all waste was characterized as "Radioactive-Low Level Only." A summary of radiological activity for the waste is presented in Appendix G.

Disposal of regulated VCM waste was handled by SNL/NM Department 7577 (Waste Operations), which packaged and secured waste drums for transfer to Envirocare of Utah. Nonregulated waste was disposed of using standard SNL/NM-approved waste disposal methods. 


\section{Conclusions}

Remediation at ER Site 61A was completed on all point and area sources of gamma activity 30 percent or greater than the natural background with the exception of two sources related to underlying, naturally-occurring geologic material. At ER Site 9, cleanup was not completed on the buried bunker due to UXO concerns. Further radiological characterization is planned, and source removal may be required for the remaining area of the buried bunker. A radiological risk assessment will be conducted after completion of radiological characterization and source removal.

Source removal is summarized in Table 5.7.13, and sources remaining after completion of the VCM are shown in Figure 5.7.7.

Table 5.7.13 Summary of Point and Area Source Removal at ER Site 61A

\begin{tabular}{|c|c|c|l|}
\hline Anomaly Type & Total Identified & Total Removed & \multicolumn{1}{|c|}{ Comments } \\
\hline Point Sources & 84 & 83 & $\begin{array}{l}\text { One source is related to underlying, } \\
\text { naturally-occurring geologic } \\
\text { material. }\end{array}$ \\
\hline Area Sources & 12 & 11 & $\begin{array}{l}\text { One source is related to underlying, } \\
\text { naturally-occurring geologic } \\
\text { material. }\end{array}$ \\
\hline
\end{tabular}

No additional cleanup activities were performed during this VCM. The status of other possible COCs is not addressed in this report.

All waste was characterized as "Radioactive-Low Level Only" and managed in accordance with SNL/NM Department 7572 (Waste Management) procedures.

\subsubsection{Old Burnsite and Moonlight Shot Areas (ER Sites 68 and 71)}

\section{Overview}

The Phase I survey at ER Sites 68 and 71 was conducted during December 1993 and January 1994 and covered a total of 78.9 acres of flat alluvial terrain. A gamma scan survey was performed at 6 -foot centers (100 percent coverage) over 14.7 acres of the central portion of the area, and at 10-foot centers ( 70 percent coverage) over 64.2 acres of the remaining site surface area. During this survey, 242 point sources and 16 area sources of gamma activity 30 percent or greater than the natural background were identified. A detailed summary of the surface radiological survey and anomalies found at the site is presented in Section 5.7.7 of the Surface Gamma Radiation Surveys Final Report (Geotech 1994b).

Figure 5.7.8 shows the site, surface radiological survey boundaries, and anomalies found during the Phase I survey. 


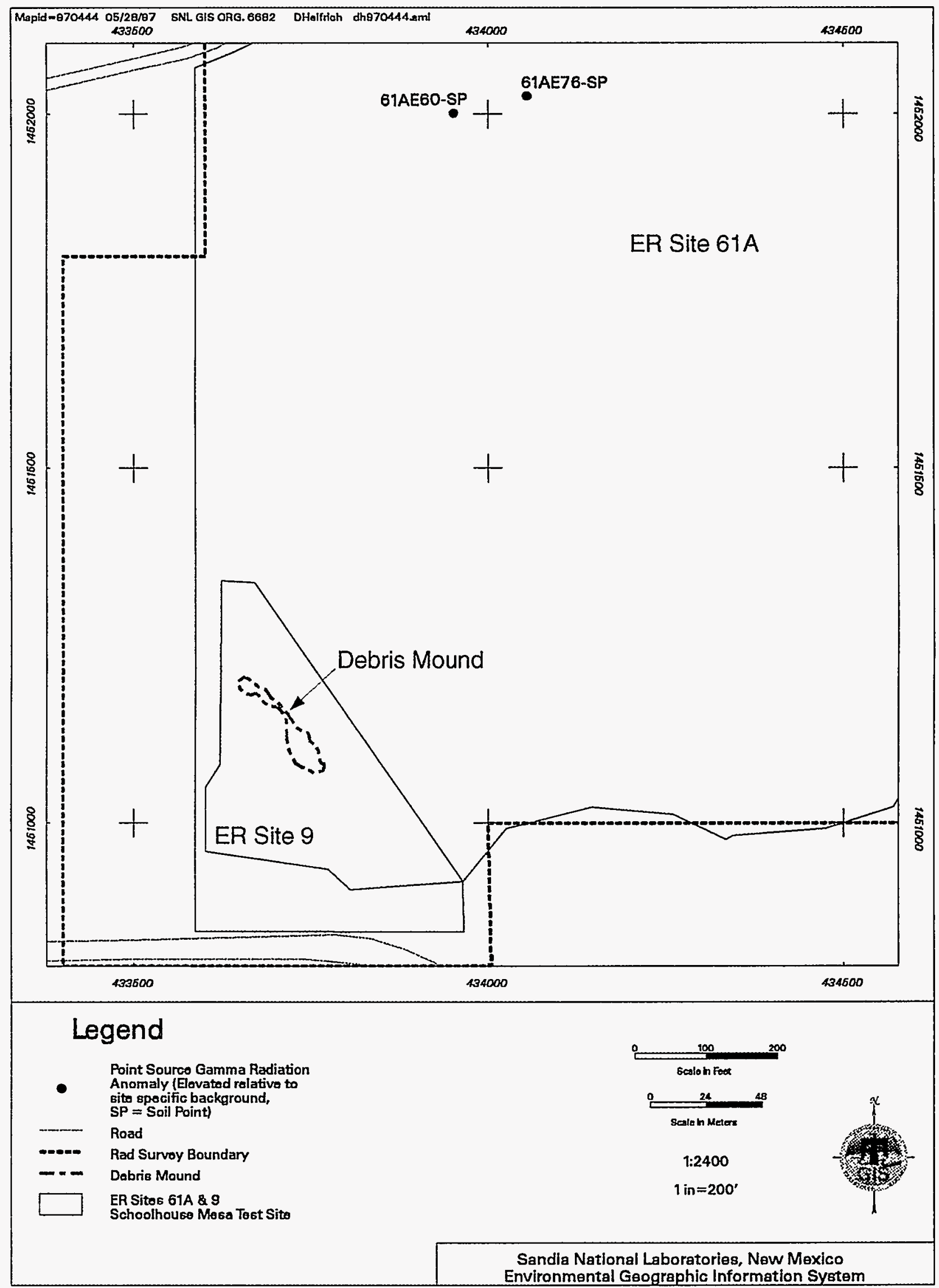

Figure 5.7.7 Radiation Anomalies Remaining After Completion of the VCM at ER Sites 61A \& 9 


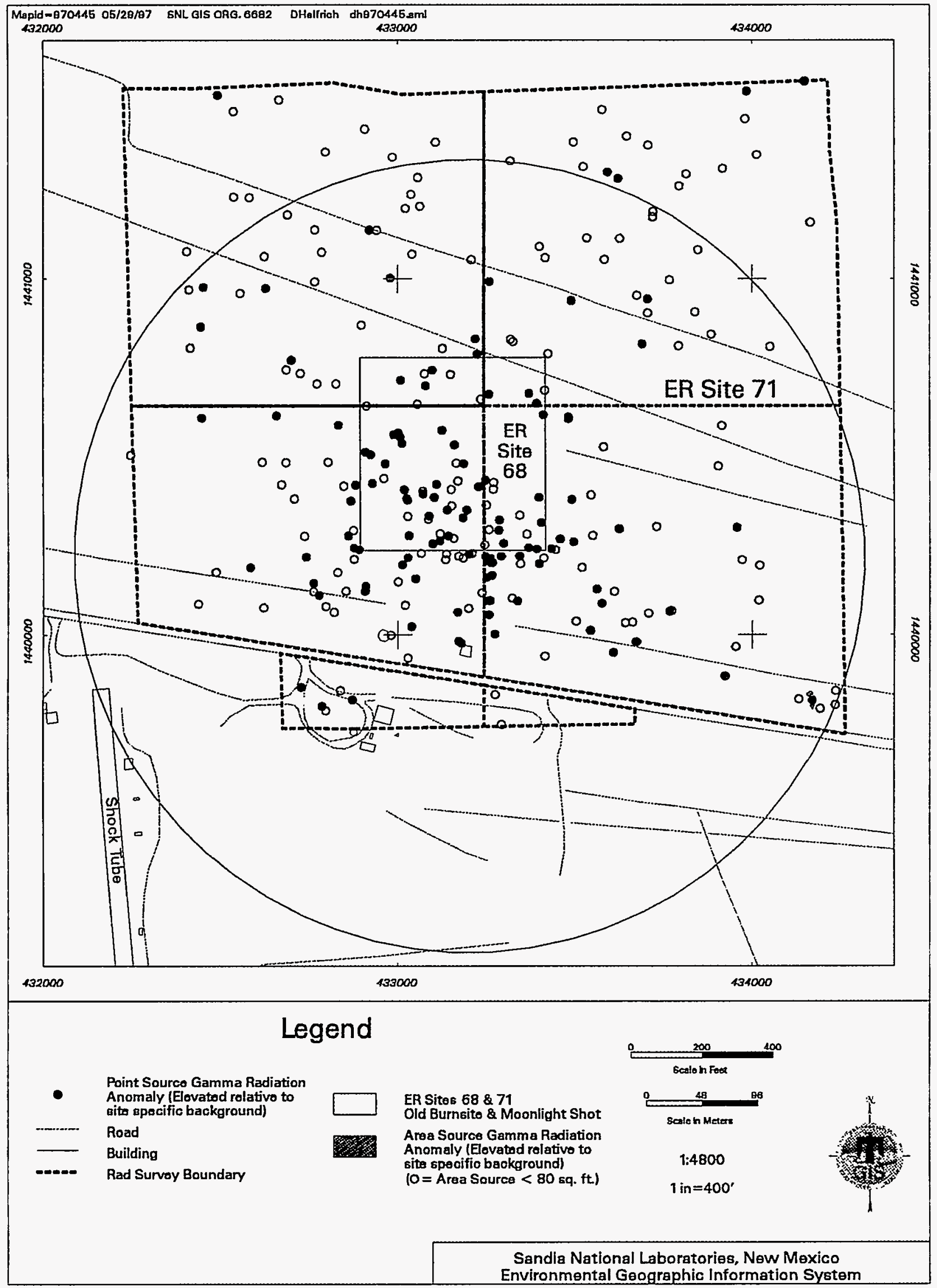

Figure 5.7.8 Phase I Survey Radiation Anomalies at ER Sites 68 \& 71 
VCM activities were conducted during January to March 1995 and January to March 1996. Point sources and small area sources identified during the original Phase I survey were removed in January to March 1995. In February 1995, pre-cleanup soil sampling for gamma spectroscopy analysis was conducted to assess the need for remediation on one of five area sources suspected of being naturally-occurring geologic material. These area sources contain light-gray granular material, similar in appearance to bentonite absorbent material. In January to March 1996, resurveying (scanning) of the site was performed. Survey boundaries were expanded to the south of Isleta Road, and an additional 59 acres were surveyed on 6-foot centers (100 percent coverage). Point sources and area sources identified during resurveying were remediated in January to March 1996. During April 1996, in-situ gamma spectroscopy measurements were obtained by RPO personnel at eight new area sources to assess the need for remediation. The area sources are suspected of being related to the underlying, naturally-occurring geologic material.

Cleanup activities included radiation scanning to verify anomaly location, removal of fragment and/or soil until readings were less than 1.3 times site-specific background levels, and postcleanup (verification) soil sampling for gamma spectroscopy analysis (see Section 3.1). Table 5.7.14 summarizes field activities during the VCM.

\section{Table 5.7.14 Summary of Field Activities at ER Sites 68 and 71}

Removal Action Procedures

\begin{tabular}{|c|c|c|c|c|c|c|c|}
\hline $\begin{array}{c}\text { Actual } \\
\text { Acreage } \\
\text { Surveyed }\end{array}$ & $\begin{array}{c}\text { Duration of } \\
\text { Cleanup } \\
\text { (days) }\end{array}$ & $\begin{array}{c}\text { Verify } \\
\text { Anomaly } \\
\text { Location }\end{array}$ & $\begin{array}{c}\text { Rad } \\
\text { Removal }\end{array}$ & $\begin{array}{c}\text { Post- } \\
\text { Cleanup } \\
\text { Sampling }\end{array}$ & $\begin{array}{c}\text { New Area/ } \\
\text { Resurveyed } \\
(\mathbf{1 0 0 \%})\end{array}$ & $\begin{array}{c}\text { Pre-Cleanup } \\
\text { Sampling } \\
\text { (area sources) }\end{array}$ & (nemments \\
\hline 137.90 & 31.00 & $\mathbf{X}$ & $\mathbf{X}$ & $\mathbf{X}$ & $\mathbf{X}$ & $\mathbf{X}$ & $\begin{array}{l}\text { Resurveyed original } \\
\text { area expanded } \\
\text { area (59 acres) on 6- } \\
\text { ft centers (100\%). } \\
\text { Pre-cleanup } \\
\text { sampling and in-situ } \\
\text { gamma spec. of } \\
\text { natural outcrops. }\end{array}$ \\
\hline
\end{tabular}

a Removal of fragment and/or soil until readings are less than 1.3 times site-specific background

\section{Findings and Observations}

\section{Point and Area Source Status}

Of the sources identified during the Phase I survey, 240 point sources and 8 small area sources were remediated during the initial cleanup. Two point sources (71E103 and 71E123) could not be relocated. Field screening of these two locations indicated no elevated gamma radiation levels. Remediation on three of the original area sources (71E15, 71E23, and 71E29) was not completed due to elevated thorium concentrations. The results of gamma spectroscopy analysis on the pre-cleanup sample collected from one of five original area sources (71E147) indicated the 
elevated radiation is related to the underlying, naturally-occurring geologic material. Therefore, remediation of the five area sources $(71 \mathrm{E} 146,71 \mathrm{E} 147,71 \mathrm{E} 148,71 \mathrm{E} 149$, and 71E150) was not required. Table 5.7.15 shows the pre-cleanup sample collected from the area source.

Table 5.7.15 Pre-Cleanup (Final Determination) Samples Collected at ER Sites 68 and 71

\begin{tabular}{|c|}
\hline $\begin{array}{c}\text { Area Source } \\
\text { Sample Number }\end{array}$ \\
\hline $71 \mathrm{E} 147 \mathrm{SS}$ \\
\hline
\end{tabular}

During resurveying on 6-foot centers (100 percent coverage) over 64.2 acres of the remaining site surface area and 59 additional acres to the south of Isleta Road, 275 new point sources and 9 new area sources were identified. Cleanup was completed on 260 of these new point sources. Excavation of 15 new point sources showed them to be linked to the new area sources located just east of the 20-foot diameter shock tube. In-situ gamma spectroscopy measurements collected by RPO personnel at these nine area sources showed that the elevated radiation is related to the underlying, naturally-occurring geologic material, and remediation was not required. Table 5.7.16 summarizes the new sources identified during the VCM, and Table 5.7.17 summarizes the in-situ gamma spectroscopy locations. Figure 5.7.9 shows VCM radiation anomalies and verification sampling locations (pre-cleanup and post-cleanup).

Table 5.7.16 Radiation Anomalies 30 Percent or Greater Than Natural Background Identified During the VCM at ER Sites 68 and 71

\begin{tabular}{|c|c|l|}
\hline Anomaly Type & Total & \multicolumn{1}{c|}{ Comments } \\
\hline Point Sources & 275 & $\begin{array}{l}\text { Gray, black fragments with yellow } \\
\text { uranium oxide (DU) in soil }\end{array}$ \\
\hline Area Sources & 9 & $\begin{array}{l}\text { Yellow rock and soil appears to be } \\
\text { natural formation }\end{array}$ \\
\hline
\end{tabular}

Table 5.7.17 In-situ Gamma Spectroscopy Locations at ER Sites 68 and 71

\begin{tabular}{|c|c|c|}
\hline \multicolumn{3}{|c|}{ Location Number } \\
\hline $\begin{array}{l}71 E 452 \\
71 E 470\end{array}$ & $71 \mathrm{E} 456$ & $71 \mathrm{E} 457$ \\
\hline
\end{tabular}

\section{Post-Cleanup (Verification) Sample Results}

After the removal of radiologically contaminated soils, 72 post-cleanup (verification) samples were collected from point and area sources. Samples from point sources were collected in the immediate vicinity of the point source (fragment) and at one in every ten locations to provide 


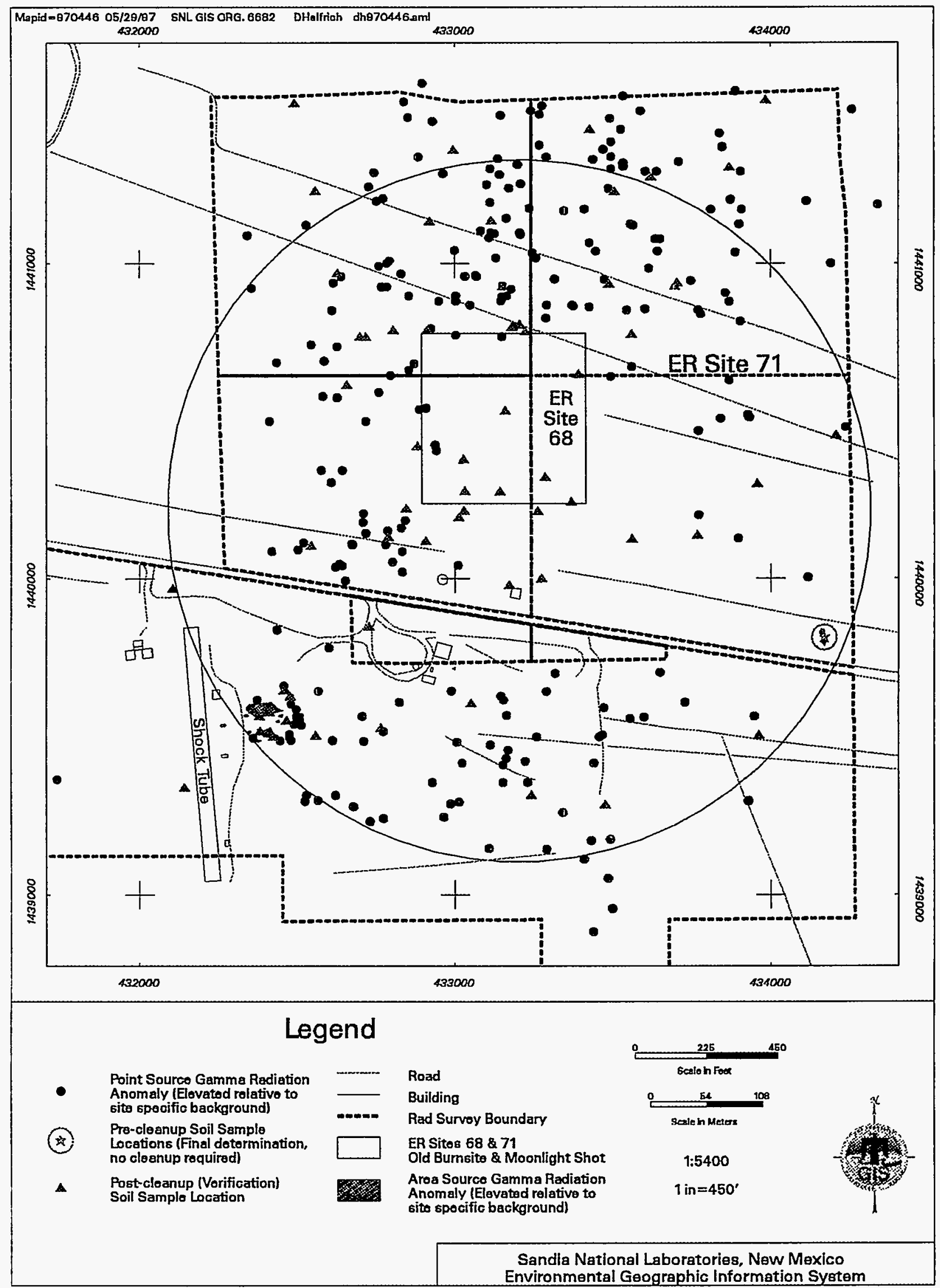

Figure 5.7.9 VCM Radiation Anomalies and

Surface Soil Sampling Locations at ER Sites 68 \& 71 
verification that cleanup was achieved. At area sources, samples were collected from areas exhibiting the highest residual gamma radiation readings. Gamma spectroscopy analysis was performed on these samples to characterize the residual radioactivity remaining in the soil. The radiological COCs were DU (U-238, U-235, and U-234) and thorium series radionuclides. Table 5.7.18 summarizes the post-cleanup (verification) samples collected at the sites, and the maximum level of residual radiological COCs in soils is presented in Table 5.7.19.

Table 5.7.18 Summary of Post-Cleanup (Verification) Samples Collected at ER Sites 68 and 71

\begin{tabular}{|c|c|}
\hline $\begin{array}{c}\text { Point Source } \\
\text { Totals }\end{array}$ & $\begin{array}{c}\text { Area Source } \\
\text { Totals }\end{array}$ \\
\hline 57 & 17 \\
\hline
\end{tabular}

Table 5.7.19 Maximum Residual Radionuclide Levels in ER Sites 68 and 71 Soils

\begin{tabular}{|c|c|c|}
\hline Radionuclide & Maximum Activity (pCi/g) & Background Activity (pCi/g) \\
\hline U-238 & 51.6 & 1.4 \\
\hline U-235 & 0.73 & 0.16 \\
\hline U-234 & 4.5 & 1.6 \\
\hline Th-232 & 3.5 & 1.01 \\
\hline Ra-228 & 3.2 & 1.01 \\
\hline
\end{tabular}

\section{Risk Assessment Results}

Further work is planned at ER Sites 68 and 71 and, therefore, risk assessment has been postponed pending additional characterization. It is anticipated that the potential effects on human health due to exposure to radionuclides at the sites will be within proposed standards. This is based on preliminary review of site-specific input parameters and land-use scenarios for the risk assessments to be performed using the RESRAD code.

\section{Waste Management}

The cleanup activities produced soil, metal fragment, and PPE wastes. All waste was containerized in either 30 -gallon or 55-gallon drums. A total of 20 waste drums were generated during cleanup activities: 15 soil drums, 2 metal fragment drums, and 3 PPE drums. Waste consolidation was performed to minimize the number of drums produced for each waste stream. One metal fragment drum was consolidated, and two PPE drum were consolidated. Table 5.7.20 shows the number of waste drums after waste minimization/consolidation was performed, and Appendix $\mathrm{J}$ summarizes the waste minimization/consolidation effort. 
Table 5.7.20 Summary of Waste Drums for ER Sites 68 and 71 (Post Minimization/ Consolidation Effort)

\begin{tabular}{|c|c|c|c|c|c|c|c|}
\hline \multicolumn{2}{|c|}{ Soil Waste } & \multicolumn{2}{|c|}{$\begin{array}{l}\text { Metal Fragment } \\
\text { Waste }\end{array}$} & \multicolumn{2}{|c|}{ PPE Waste } & \multirow[b]{2}{*}{\begin{tabular}{|l} 
TCLP/ \\
Gamma \\
Spec \\
Samples
\end{tabular}} & \multirow[b]{2}{*}{ Comments } \\
\hline \begin{tabular}{|c}
30 Gallor \\
Drums
\end{tabular} & \begin{tabular}{|c|}
55 Gallon \\
Drums
\end{tabular} & $\begin{array}{l}\text { 30 Gallon } \\
\text { Drums }\end{array}$ & $\begin{array}{c}55 \text { Gallon } \\
\text { Drums }\end{array}$ & $\begin{array}{c}0 \text { Gallon } \\
\text { Drums }\end{array}$ & $\begin{array}{l}55 \text { Gallon } \\
\text { Drums }\end{array}$ & & \\
\hline 1 & 14 & 1 & 0 & 0 & 1 & $\begin{array}{l}3 \text { Soil } \\
1 \text { Frag }\end{array}$ & $\begin{array}{l}\text { Waste } \\
\text { Minimization/Consolidation } \\
\text { was performed. }\end{array}$ \\
\hline
\end{tabular}

${ }^{\text {a }}$ See Appendix J

Three composite soil samples and one metal fragment were collected from the waste drums and analyzed for gamma emitters using standard laboratory gamma spectroscopy methods and for leachable RCRA metals using TCLP analytical procedures. Mercury was not identified as a COC and was not included in the TCLP analysis. All samples passed the TCLP tests, and all waste was characterized as "Radioactive-Low Level Only." A summary of radiological activity for the waste is presented in Appendix G.

Disposal of regulated VCM waste was handled by SNL/NM Department 7577 (Waste Operations), which packaged and secured waste drums for transfer to Envirocare of Utah. Nonregulated waste was disposed of using standard SNL/NM-approved waste disposal methods.

\section{Conclusions}

Remediation was completed on all point and area sources of gamma activity 30 percent or greater than the natural background with exception of three area sources (71E15, 71E23, and 71E29), naturally-occurring geologic outcrops, and those two point sources that could not be re-located. Further radiological characterization and source removal will be required for the three area sources associated with elevated thorium readings where remediation was not completed. A radiological risk assessment will be conducted upon completion of radiological characterization and source removal.

Source removal is summarized in Table 5.7.21, and sources remaining after completion of the VCM are shown in Figure 5.7.10.

No additional cleanup activities were performed during this VCM. The status of other possible COCs is not addressed in this report.

All waste was characterized as "Radioactive-Low Level Only" and managed in accordance with SNL/NM Department 7572 (Waste Management) procedures. 


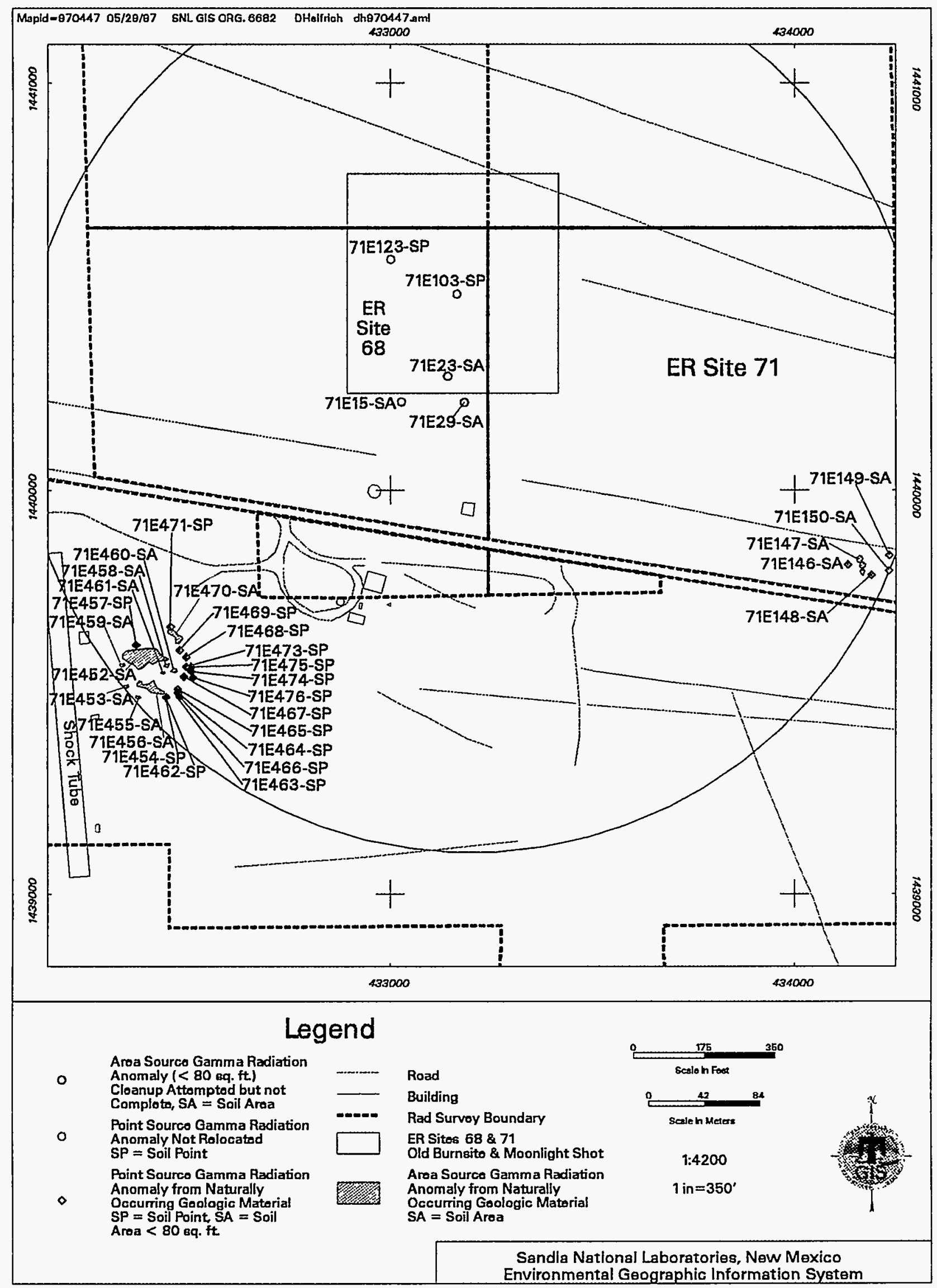

Figure 5.7.10 Radiation Anomalies Remaining After Completion of the VCM at ER Sites 68 \& 71 
Table 5.7.21 Summary of Point and Area Source Removal at ER Sites 68 and 71

\begin{tabular}{|c|c|c|l|}
\hline Anomaly Type & Total Identified & Total Removed & \multicolumn{1}{|c|}{ Comments } \\
\hline Point Sources & 517 & 500 & $\begin{array}{l}\text { Two sources could not be relocated. } \\
\text { Fifteen sources are related to } \\
\text { underlying, naturally-occurring } \\
\text { geologic material. }\end{array}$ \\
\hline Area Sources & 25 & 8 & $\begin{array}{l}\text { Three sources have high thorium } \\
\text { and will require further cleanup. } \\
\text { Fourteen sources are related to } \\
\text { underlying, naturally-occurring } \\
\text { geologic material. }\end{array}$ \\
\hline
\end{tabular}

\subsubsection{Firing Site and Instrumentation Pole (ER Site 88)}

\section{Overview}

The Phase I survey at ER Site 88 was conducted during January 1994 and covered a total of 16.6 acres of flat alluvial terrain. A gamma scan survey was performed at 10 -foot centers (70 percent coverage) over the surface of the site. One area source of gamma activity 30 percent or greater than the natural background was identified during this survey. The one small area source was attributed to two pieces of orange, ceramic "Fiesta" dinner ware. The elevated readings were most likely caused by uranium oxide used in the ceramic glaze. A detailed summary of the surface radiological survey and anomaly found at the site is presented in Section 5.7.6 of the Surface Gamma Radiation Surveys Final Report (Geotech 1994b).

Figure 5.7.11 shows the site, surface radiological survey boundaries, and anomaly found during the Phase I survey.

VCM activities were conducted during March 1995. Resurveying (scanning) of the site was not performed.

Cleanup activities included radiation scanning to verify anomaly location and removal of the dinner ware until readings were less than 1.3 times site-specific background levels (see Section 3.1). Table 5.7.22 summarizes field activities during the VCM.

Table 5.7.22 Summary of Field Activities at ER Site 88

\begin{tabular}{|c|c|c|c|c|}
\hline $\begin{array}{c}\text { Actual Acreage } \\
\text { Surveyed }\end{array}$ & $\begin{array}{c}\text { Duration of } \\
\text { Cleanup (days) }\end{array}$ & $\begin{array}{c}\text { Verify } \\
\text { Anomaly } \\
\text { Location }\end{array}$ & Rad Removal $^{\mathrm{a}}$ & Comments \\
\hline 16.60 & 0.25 & $\mathbf{X}$ & $\mathbf{X}$ & $\begin{array}{l}\text { One point source (fiesta ware) } \\
\text { removed during Phase I } \\
\text { survey. No post-cleanup } \\
\text { sampling performed. }\end{array}$ \\
\hline
\end{tabular}

${ }^{a}$ Removal of fragment and/or soil until readings are less than 1.3 times site-specific background 


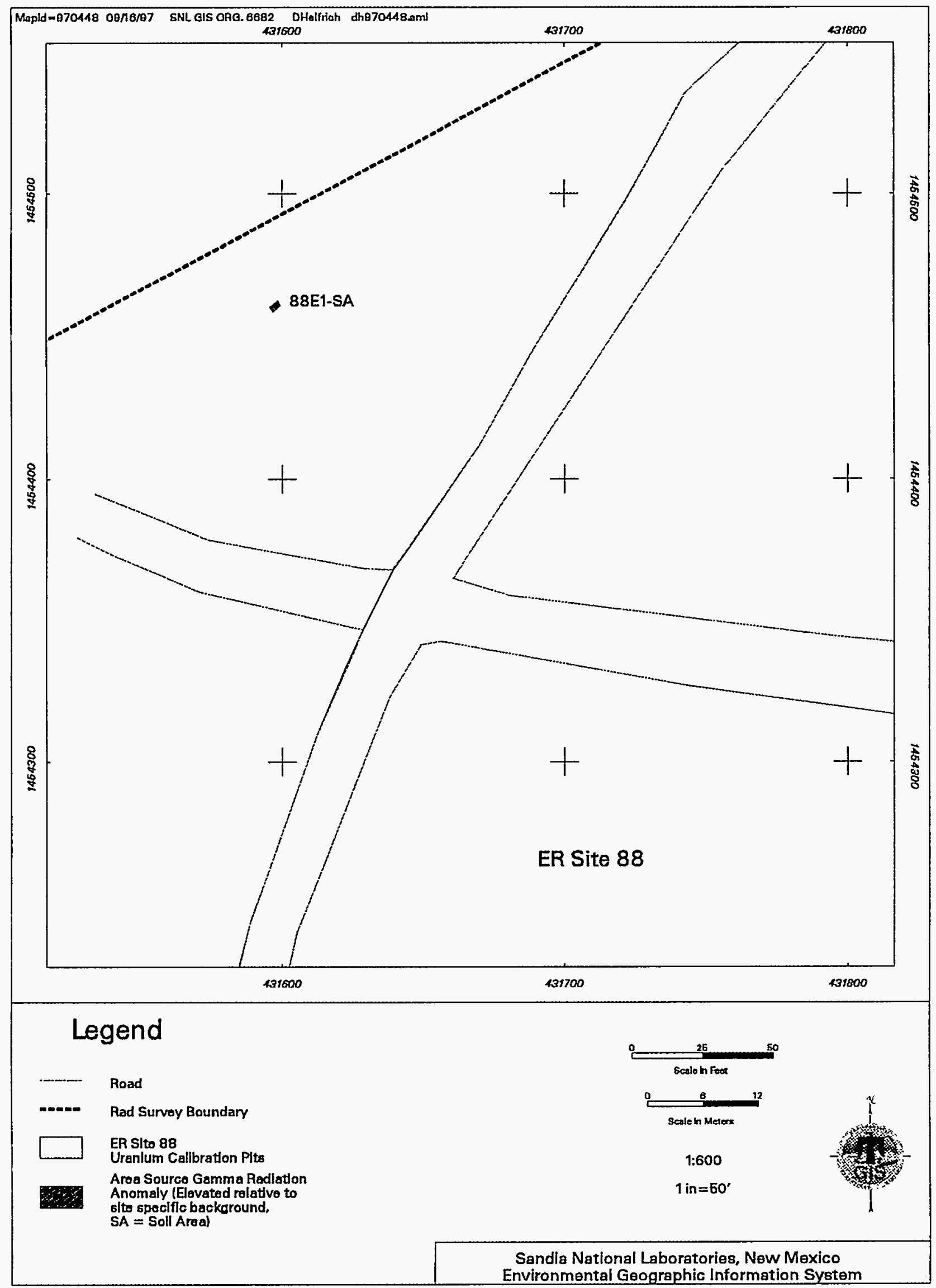

Figure 5.7.11 Phase I Survey Radiation Anomalies at ER Site 88 


\section{Findings and Observations}

\section{Point and Area Source Status}

The one area source was remediated. The two pieces of ceramic dinner ware were removed, and no radioactive contaminated soil was identified at the site. No additional point or area sources were identified.

\section{Post-Cleanup (Verification) Sample Results}

No soil samples were taken since no radioactive contaminated soil was identified or remediated at the site.

\section{Risk Assessment Results}

Since anomalies were limited to ceramic dinner ware pieces, no risk assessment was performed.

\section{Waste Management}

Cleanup activities produced ceramic pieces of dinner ware. Waste consolidation was performed to minimize the number of drums produced. The ceramic dinner ware pieces were consolidated with metal fragment waste from 10 other sites into one fragment drum. No TCLP sample was collected on the dinner ware due to the small volume remediated. The metal fragments from the other sites had been characterized as radioactive waste. The waste characterization results for the consolidated metal fragment waste drum are statistically valid, even with the addition of a minor volume of dinner ware fragments that have not been sampled and analyzed.

Disposal of regulated VCM waste was handled by SNL/NM Department 7577 (Waste Operations), which packaged and secured waste drums for disposal. Nonregulated waste was disposed of using standard SNL/NM-approved waste disposal methods.

\section{Conclusions}

One area source (dinner ware) of gamma activity 30 percent or greater than the natural background was removed from the site. No further radiological characterization is planned at the site. A radiological risk assessment will not be performed since no radioactive contaminated soil was identified at the site. Source removal is summarized in Table 5.7.23.

Table 5.7.23 Summary of Point and Area Source Removal at ER Site 88

\begin{tabular}{|c|c|c|l|}
\hline Anomaly Type & Total Identified & Total Removed & \multicolumn{1}{c|}{ Comments } \\
\hline Area Source & 1 & 1 & $\begin{array}{l}\text { One source (fiesta ware) removed } \\
\text { during Phase I survey. }\end{array}$ \\
\hline
\end{tabular}


No additional cleanup activities were performed during this VCM. The status of other possible COCs is not addressed in this report.

All waste was characterized as "Radioactive-Low Level Only" and managed in accordance with SNL/NM Department 7572 (Waste Management) procedures.

\subsection{Southwest Test Area Operable Unit Sites (ADS 1335)}

\subsubsection{Building 9920 - Burial Site and Firing Site (ER Sites 14 and 85 ) \\ Overview}

The Phase I survey at ER Sites 14 and 85 was conducted during March 1994 and covered a total of 1.4 acres of flat graded terrain. A gamma scan survey was performed at 6-foot centers (100 percent coverage) over the surface of these sites. Only one area source of gamma activity 30 percent or greater than the natural background was identified during this survey at ER Site 14. A detailed summary of the surface radiological survey and anomaly found at the site is presented in Section 5.8.1 of the Surface Gamma Radiation Surveys Final Report (Geotech 1994b).

Figure 5.8.1 shows the site, surface radiological survey boundaries, and anomalies found during the Phase I survey.

VCM activities were conducted during July and September 1995, and March to June 1996. In July 1995 at ER Site 14, pre-cleanup soil sampling for gamma spectroscopy analysis was conducted on the area source to assess the need for remediation. This area source was remediated in September 1995. From March to June 1996, an additional 19.6 acres were surveyed on 6-foot centers (100 percent coverage) at the ER Site 85 , Cable Suspension Facility. Two new point sources were remediated in June 1996.

Cleanup activities included radiation scanning to verify anomaly location, removal of fragment and/or soil until readings were less than 1.3 times site-specific background levels, and postcleanup (verification) soil sampling for gamma spectroscopy analysis (see Section 3.1). Table 5.8.1 summarizes field activities during the VCM.

\section{Table 5.8.1 Summary of Field Activities at ER Sites 14 and 85}

Removal Action Procedures

\begin{tabular}{|c|c|c|c|c|c|c|c|}
\hline $\begin{array}{c}\text { Actual } \\
\text { Acreage } \\
\text { Surveyed }\end{array}$ & $\begin{array}{c}\text { Duration of } \\
\text { Cleanup } \\
\text { (days) }\end{array}$ & $\begin{array}{c}\text { Verify } \\
\text { Anomaly } \\
\text { Location }\end{array}$ & $\begin{array}{c}\text { Rad } \\
\text { Removal }\end{array}$ & $\begin{array}{c}\text { Post- } \\
\text { Cleanup }\end{array}$ & $\begin{array}{c}\text { New Area/ } \\
\text { Resurveyed } \\
\text { Sampling }\end{array}$ & $\begin{array}{c}\text { Pre-Cleanup } \\
\text { Sampling } \\
\text { (100\%) }\end{array}$ & Comrces) \\
\hline 21.00 & 6.00 & $\mathbf{X}$ & $\mathbf{X}$ & $\mathbf{X}$ & $\mathbf{X}$ & $\mathbf{X}$ & $\begin{array}{l}\text { At ER Site 85 } \\
\text { surveyed new area } \\
(19.6 \text { acres) on 6-ft } \\
\text { centers (100\%). }\end{array}$ \\
\hline
\end{tabular}

Removal of fragment and/or soil until readings are less than 1.3 times site-specific background 


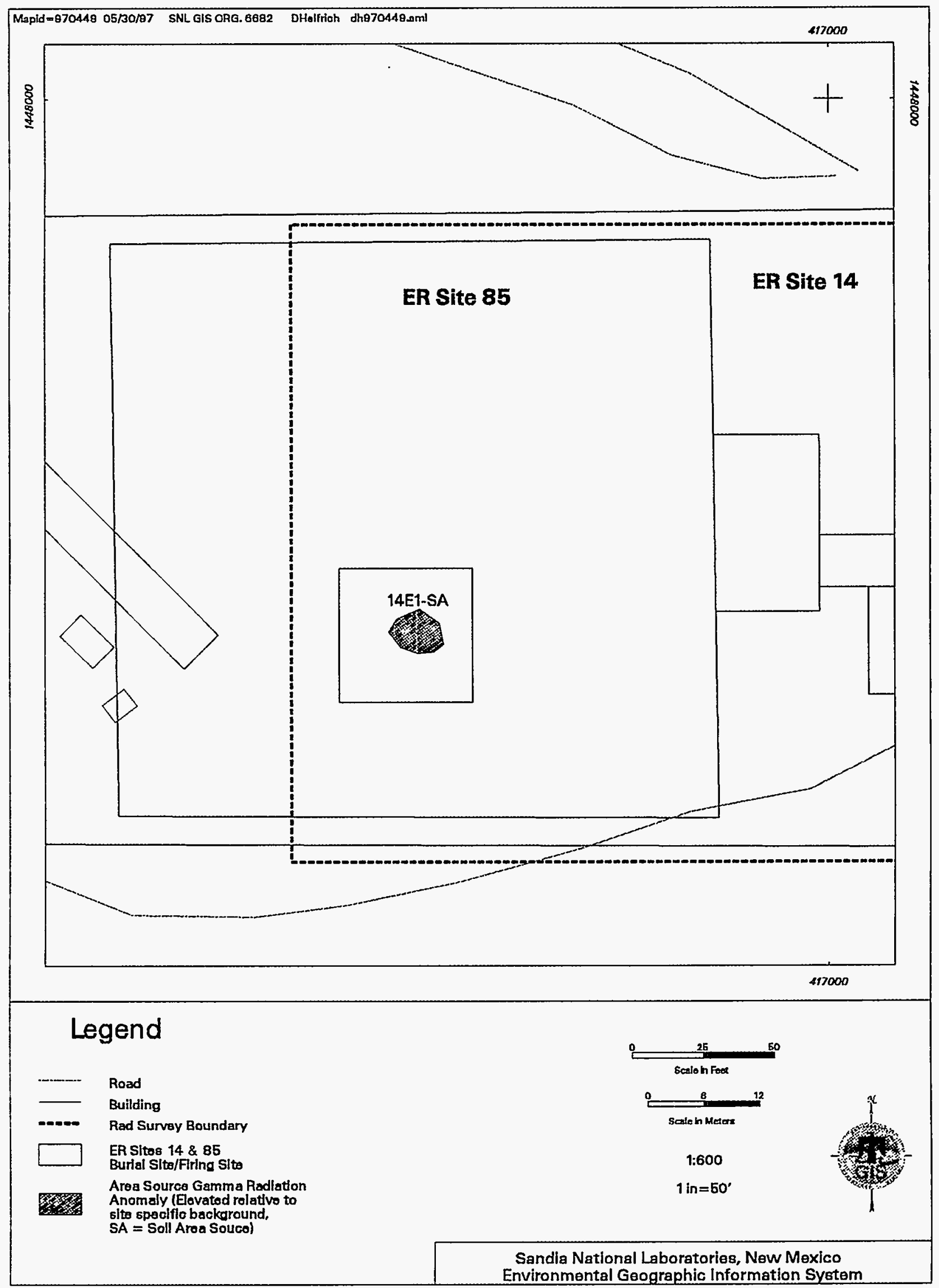

Figure 5.8.1 Phase I Survey Radiation Anomalies at ER Sites 14 \& 85 


\section{Findings and Observations}

\section{Point and Area Source Status}

The one area source at ER Site 14 was remediated based on gamma spectroscopy results from pre-cleanup samples that showed the elevated radiation was related to anthropogenic (man-made) material. Cleanup was completed on the source, and no additional point or area sources were identified at this site.

During the gamma scan survey of the additional acres at the ER Site 85 Cable Suspension Facility, two new point sources were identified. The new point sources were remediated, and no additional point or area sources were identified during this VCM. The new sources identified during the VCM are summarized in Table 5.8.2, and Figure 5.8.2 shows VCM radiation anomalies and verification sampling locations (post-cleanup).

Table 5.8.2 Radiation Anomalies 30 Percent or Greater Than Natural Background Identified During the VCM at ER Site 85

\begin{tabular}{|c|c|l|}
\hline Anomaly Type & Total & \multicolumn{1}{c|}{ Comments } \\
\hline Point Sources & 2 & $\begin{array}{l}\text { Gray, black fragments with yellow } \\
\text { uranium oxide (DU) in soil }\end{array}$ \\
\hline
\end{tabular}

\section{Post-Cleanup (Verification) Sample Results}

After the removal of radiologically contaminated soils, two post-cleanup (verification) samples were collected from ER Site 14. The samples were collected from areas exhibiting the highest residual gamma radiation readings. At ER Site 85 , one post-cleanup (verification) sample was collected after the removal of radiologically contaminated soils. The sample was collected in the immediate vicinity of the point source (fragment) where the highest residual gamma radiation readings were exhibited. Gamma spectroscopy analysis was performed on the sample to characterize the residual radioactivity remaining in the soil. The radiological COC was DU (U-238, U-235, and U-234). Table 5.8.3 summarizes the post-cleanup (verification) samples collected at the sites, and the maximum level of residual radiological $\mathrm{COC}$ in soils are presented in Table 5.8.4 and Table 5.8.5.

Table 5.8.3 Post-Cleanup (Verification) Samples Collected at ER Sites 14 and 85

\begin{tabular}{|c|c|}
\hline $\begin{array}{c}\text { Point Source } \\
\text { Sample Number }\end{array}$ & $\begin{array}{c}\text { Area Source } \\
\text { Sample Number }\end{array}$ \\
\hline \hline $85 E 1 S S$ & 14E1CSS 14E1DSS \\
\hline
\end{tabular}




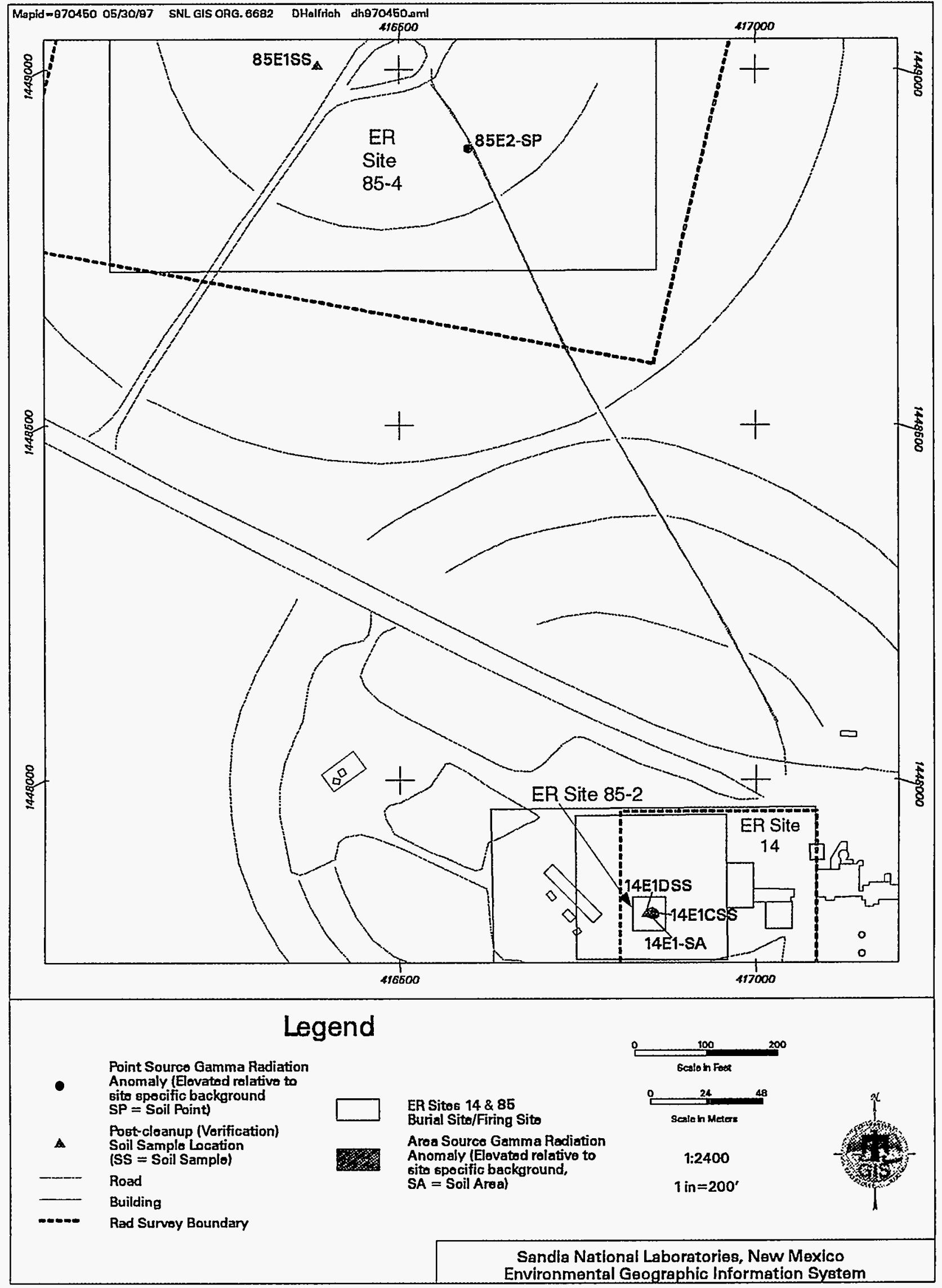

Figure 5.8.2 VCM Radiation Anomalies and Surface Soil Sampling Locations at ER Sites 14 \& 85 
Table 5.8.4 Maximum Residual Radionuclide Levels in ER Site 14 Soils

\begin{tabular}{|c|c|c|}
\hline Radionuclide & Maximum Activity (pCi/g) & Background Activity (pCi/g) \\
\hline U-238 & 10.9 & 1.4 \\
\hline U-235 & 0.15 & 0.16 \\
\hline U-234 & 1.4 & 1.6 \\
\hline
\end{tabular}

Table 5.8.5 Maximum Residual Radionuclide Levels in ER Site 85 Soils

\begin{tabular}{|c|c|c|}
\hline Radionuclide & Maximum Activity (pCi/g) & Background Activity (pCi/g) \\
\hline U-238 & 2.43 & 1.4 \\
\hline U-235 & ND & 0.16 \\
\hline U-234 & ND & 1.6 \\
\hline
\end{tabular}

\section{Risk Assessment Results}

Further work is planned at ER Sites 14 and 85 and, therefore, risk assessments have been postponed pending additional characterization and remediation. After cleanup is complete, it is anticipated that the potential effects on human health due to exposure to radionuclides at the sites will be within proposed standards. This is based on preliminary review of site-specific input parameters and land-use scenarios for the risk assessments to be performed using the RESRAD code.

\section{Waste Management}

The cleanup activities produced soil waste. No metal fragment waste was generated. All waste was containerized in 55-gallon drums. A total of 22 soil drums were generated during cleanup activities. Waste consolidation was performed to minimize the number of drums produced. Table 5.8.6 shows the number of waste drums after waste minimization/consolidation was performed, and Appendix J summarizes the waste minimization/consolidation effort.

One composite soil sample was collected from the waste drums and analyzed for gamma emitters using standard laboratory gamma spectroscopy methods and for leachable RCRA metals using TCLP analytical procedures. All samples passed the TCLP tests, and all waste was characterized as "Radioactive-Low Level Only." A summary of radiological activity for the waste is presented in Appendix G. 
Table 5.8.6 Summary of Waste Drums for ER Sites 14 and 85

\begin{tabular}{|c|c|c|c|c|c|c|c|}
\hline \multicolumn{2}{|c|}{ Soil Waste } & \multicolumn{2}{|c|}{$\begin{array}{l}\text { Metal Fragment } \\
\text { Waste }\end{array}$} & \multicolumn{2}{|c|}{ PPE Waste } & \multirow[b]{2}{*}{$\begin{array}{l}\text { TCLP/ } \\
\text { Gamma } \\
\text { Spec } \\
\text { Samples }\end{array}$} & \multirow[b]{2}{*}{ Comments } \\
\hline $\begin{array}{c}\text { 30 Gallon } \\
\text { Drums }\end{array}$ & $\begin{array}{c}55 \text { Gallon } \\
\text { Drums }\end{array}$ & $\begin{array}{l}30 \text { Gallon } \\
\text { Drums }\end{array}$ & $\begin{array}{c}55 \text { Gallon } \\
\text { Drums }\end{array}$ & $\begin{array}{c}30 \text { Gallon } \\
\text { Drums }\end{array}$ & $\begin{array}{l}55 \text { Gallon } \\
\text { Drums }\end{array}$ & & \\
\hline 0 & 22 & 0 & 0 & 0 & 0 & 1 Soil & $\begin{array}{l}\text { Only one bag of PPE was } \\
\text { generated at this site, so it } \\
\text { was placed in a PPE drum } \\
\text { from ER Site } 108 \text { to } \\
\text { minimize waste. }\end{array}$ \\
\hline
\end{tabular}

${ }^{\mathrm{a}}$ See Appendix J

Disposal of regulated VCM waste was handled by SNL/NM Department 7577 (Waste Operations), which packaged and secured waste drums for transfer to Envirocare of Utah.

Nonregulated waste was disposed of using standard SNL/NM-approved waste disposal methods.

\section{Conclusions}

All point and area sources of gamma activity 30 percent or greater than the natural background were removed from the sites. Further nonradiological characterization is planned, and risk assessments will be conducted after characterization and remediation is performed. Source removal is summarized in Table 5.8.7.

Table 5.8.7 Summary of Point and Area Source Removal at ER Sites 14 and 85

\begin{tabular}{|c|c|c|l|}
\hline Anomaly Type & Total Identified & Total Removed & \multicolumn{1}{|c|}{ Comments } \\
\hline Point Sources & 2 & 2 & $\begin{array}{l}\text { Sources identified during gamma } \\
\text { survey of additional acres at Cable } \\
\text { Suspension Facility. }\end{array}$ \\
\hline Area Source & 1 & 1 & $\begin{array}{l}\text { Cleanup complete and no further } \\
\text { action is required. }\end{array}$ \\
\hline
\end{tabular}

No additional cleanup activities were performed during this VCM. The status of other possible COCs is not addressed in this report.

All waste was characterized as "Radioactive-Low Level Only" and managed in accordance with SNL/NM Department 7572 (Waste Management) procedures. 


\subsubsection{Scrap Yards/Open Dump (ER Sites 17A, 17B, and 17D)}

\section{Overview}

The Phase I survey at ER Site 17B was conducted with surveys at ER Sites 17A and 17D during January 1994. These surveys covered a total of 2.8 acres of flat alluvial terrain. A gamma scan survey was performed at 10 -foot centers ( 70 percent coverage) over the surface of the sites. Five point sources and two area sources of gamma activity 30 percent or greater than the natural background were identified at ER Site 17B. No gamma activity 30 percent or greater than the natural background was detected at ER Sites 17A and 17D. A detailed summary of the surface radiological survey and anomalies found at the site is presented in Section 5.8.2 of the Surface Gamma Radiation Surveys Final Report (Geotech 1994b).

Figure 5.8.3 shows the site, surface radiological survey boundaries, and anomalies found during the Phase I survey.

VCM activities were conducted at ER Site 17B during February and August 1995. Point sources identified during the Phase I survey were removed in February 1995. In July 1995, pre-cleanup sampling for gamma spectroscopy analysis was conducted on two area sources to assess the need for remediation. Resurveying (scanning) of the sites was performed during August 1995. The original survey boundaries ( 2.8 acres) were surveyed on 6 -foot centers (100 percent coverage). Previously identified area sources and new point sources identified during resurveying were remediated in August 1995.

Cleanup activities included radiation scanning to verify anomaly location, removal of fragment and/or soil until readings were less than 1.3 times site-specific background levels, and postcleanup (verification) soil sampling for gamma spectroscopy analysis (see Section 3.1). Table 5.8.8 summarizes field activities during the VCM.

Table 5.8.8 Summary of Field Activities at ER Sites 17A, 17B, and 17D Removal Action Procedures

\begin{tabular}{|c|c|c|c|c|c|c|c|}
\hline $\begin{array}{c}\text { Actual } \\
\text { Acreage } \\
\text { Surveyed }\end{array}$ & $\begin{array}{c}\text { Duration of } \\
\text { Cleanup } \\
\text { (days) }\end{array}$ & \begin{tabular}{|c|} 
Verify \\
Anomaly \\
Location
\end{tabular} & $\begin{array}{c}\operatorname{Rad} \\
\operatorname{Removal}^{a}\end{array}$ & \begin{tabular}{|c|} 
Post- \\
Cleanup \\
Sampling
\end{tabular} & \begin{tabular}{|c|} 
New Area/ \\
Resurveyed \\
$(100 \%)$
\end{tabular} & $\begin{array}{l}\text { Pre-Cleanup } \\
\text { Sampling } \\
\text { (area sources) }\end{array}$ & Comments \\
\hline 2.80 & 3.50 & $\mathbf{X}$ & $\mathbf{x}$ & $\mathbf{X}$ & $\mathbf{X}$ & $\mathbf{X}$ & $\begin{array}{l}\text { Resurveyed original } \\
\text { area on 6-ft centers } \\
(100 \%) \text {. }\end{array}$ \\
\hline
\end{tabular}

\footnotetext{
Removal of fragment and/or soil until readings are less than 1.3 times site-specific background
} 


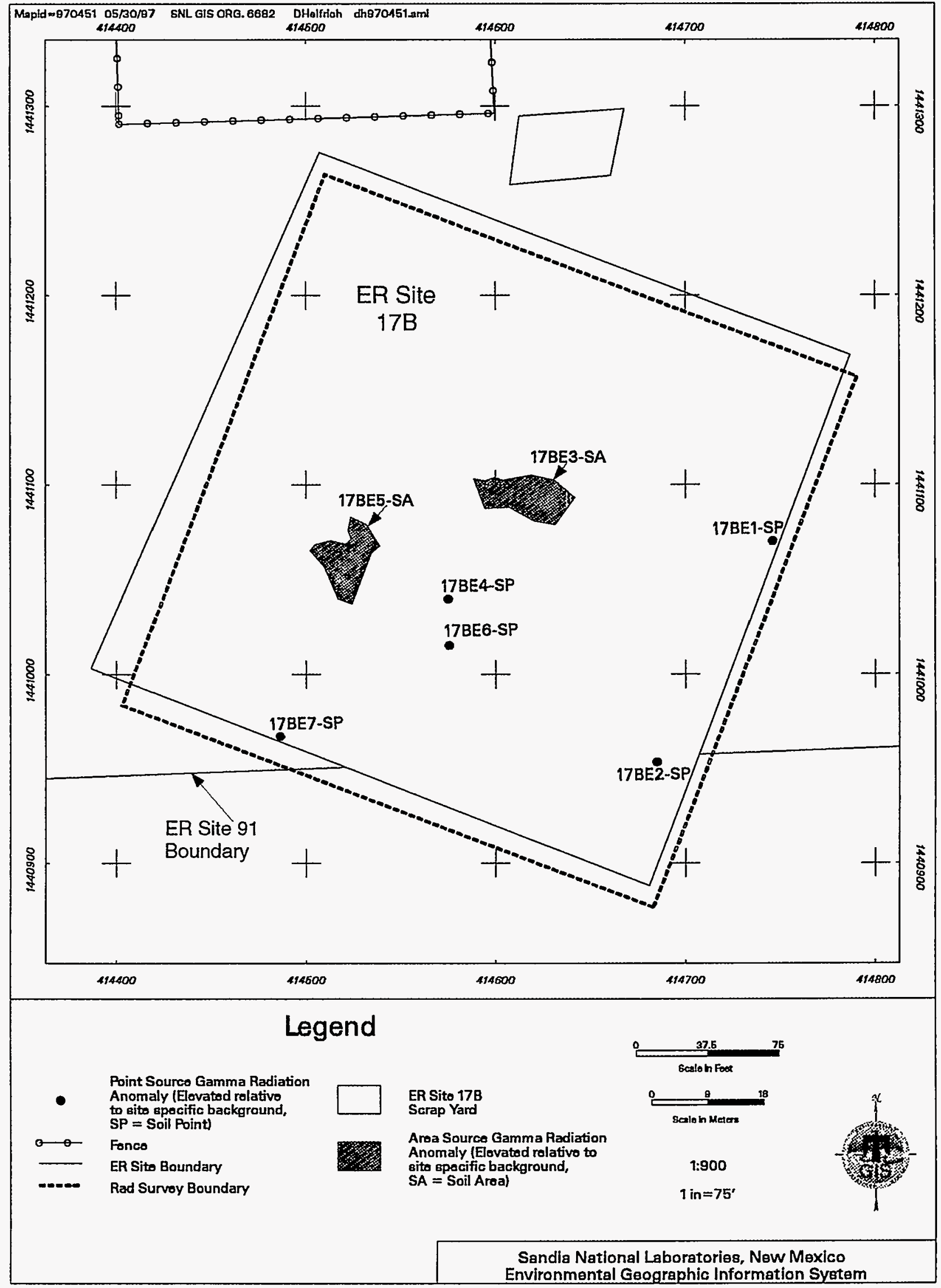

Figure 5.8.3 Phase I Survey Radiation Anomalies at ER Site 17B 


\section{Findings and Observations}

\section{Point and Area Source Status}

Of the sources identified during the Phase I survey, five point sources were removed during the initial cleanup. The two area sources (17BE3 and 17BE5) were remediated based on the results of gamma spectroscopy analysis from pre-cleanup samples that showed the elevated radiation was related to anthropogenic (man-made) material.

During resurveying (scanning) of the original sites, six new point sources were identified at ER Site 17B. No additional elevated gamma readings were identified at ER Sites 17A and 17D. Cleanup was completed on these new point sources along with the previously identified large area sources. The new sources identified during the VCM are summarized in Table 5.8.9, and Figure 5.8.4 shows VCM radiation anomalies and verification sampling locations (post-cleanup).

\section{Table 5.8.9 Radiation Anomalies 30 Percent or Greater Than Natural Background} Identified During the VCM at ER Site 17B

\begin{tabular}{|c|c|l|}
\hline Anomaly Type & Total & \multicolumn{1}{c|}{ Comments } \\
\hline Point Sources & 6 & $\begin{array}{l}\text { Gray, black fragments with yellow } \\
\text { uranium oxide (DU) in soil }\end{array}$ \\
\hline
\end{tabular}

\section{Post-Cleanup (Verification) Sample Results}

After the removal of radiologically contaminated soils at ER Site 17B, six post-cleanup (verification) samples were collected from point and area sources. Samples from point sources were collected in the immediate vicinity of the point source (fragment). At area sources, samples were collected from areas exhibiting the highest residual gamma radiation readings. Gamma spectroscopy analysis was performed on the samples to verify that the residual radionuclide concentrations met risk-based action levels. The radiological COC was DU (U-238, U-235, and U-234). Table 5.8.10 summarizes the post-cleanup (verification) samples collected at the sites, and the maximum level of residual radiological COCs in soils is presented in Table 5.8.11.

Table 5.8.10 Post-Cleanup (Verification) Samples Collected at ER Site 17B

\begin{tabular}{|l|lc|}
\hline \multicolumn{1}{|c|}{$\begin{array}{c}\text { Point Source } \\
\text { Sample Number }\end{array}$} & \multicolumn{1}{c|}{$\begin{array}{c}\text { Area Source } \\
\text { Sample Number }\end{array}$} \\
\hline \hline 17BE1SS 17BE1SD ${ }^{\mathrm{a}}$ 17BE2SS & $17 \mathrm{BE} 3 \mathrm{SS}$ & $17 \mathrm{BE} 5 \mathrm{SS}$ \\
$17 \mathrm{BE} 10 \mathrm{SS}$ & & \\
\hline
\end{tabular}

${ }^{a}$ Sample duplicate 


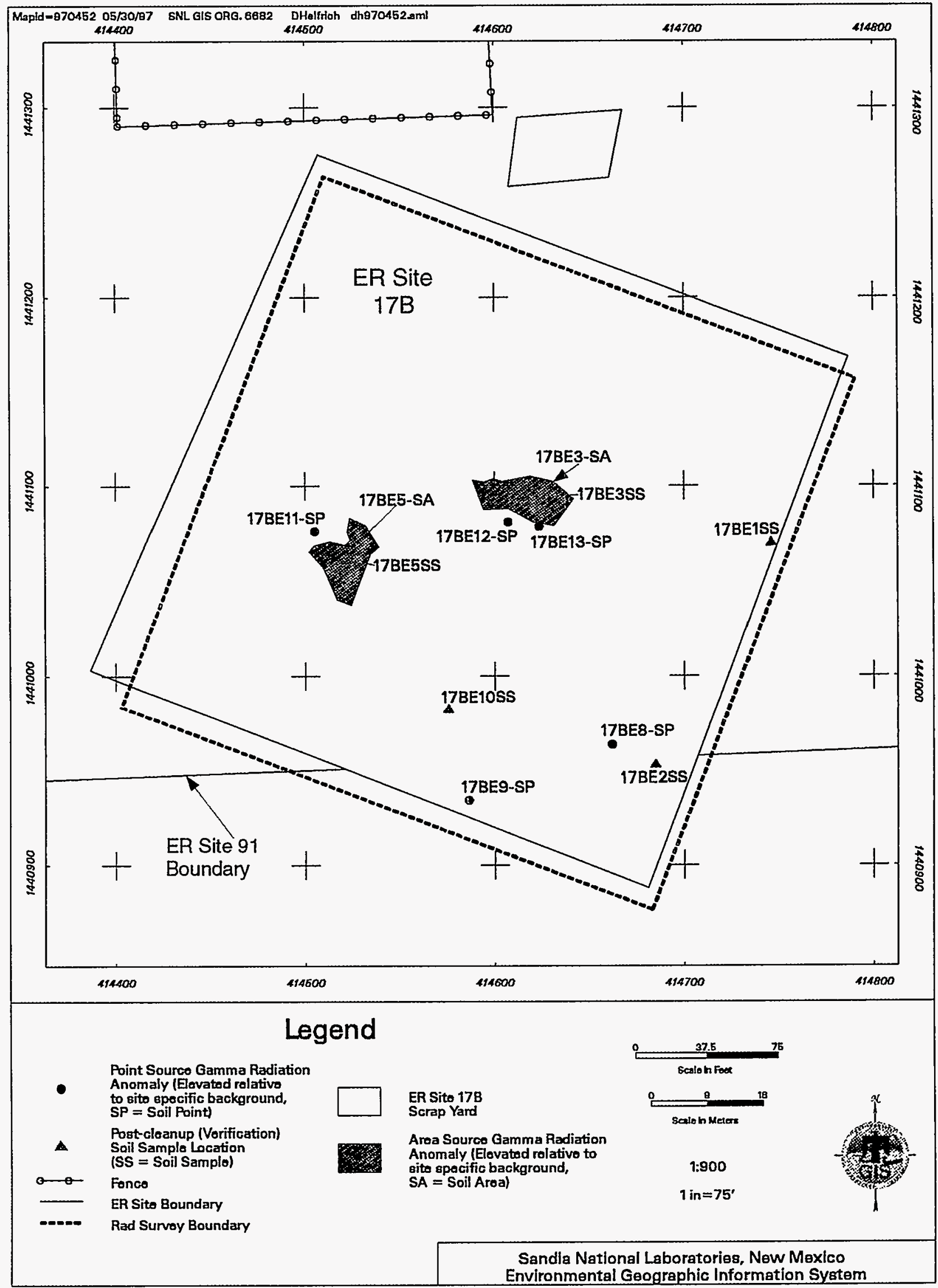

Figure 5.8.4 VCM Radiation Anomalies and Surface Soil Sampling Locations at ER Site 17B 
Table 5.8.11 Maximum Residual Radionuclide Levels in ER Site 17B Soils

\begin{tabular}{|c|c|c|}
\hline Radionuclide & Maximum Activity (pCi/g) & Background Activity (pCi/g) \\
\hline U-238 & 19.1 & 1.4 \\
\hline U-235 & 0.26 & 0.16 \\
\hline U-234 & 2.4 & 1.6 \\
\hline
\end{tabular}

\section{Risk Assessment Results}

A risk assessment, using the DOE computer code RESRAD, was performed on ER Site 17B assuming both an industrial and a residential (loss of active control measures) land-use scenario, consistent with Section 3.3.2. The RESRAD input parameters that were not site specific are provided for both land-use scenarios in Section 3.3.2. Site-specific input parameters were developed based on information provided by the Task Leader responsible for the site and were as follows:

- Area of Contaminated Zone: $8,500 \mathrm{~m}^{2}$

- Thickness of contaminated zone: $0.15 \mathrm{~m}$

- Length Parallel to Aquifer Flow: $100 \mathrm{~m}$

- Density of Contaminated Zone: $1.85 \mathrm{~g} / \mathrm{cm}^{3}$

- Contaminated Zone Total Porosity: 0.4

- Contaminated Zone Effective Porosity: 0.35

- Contaminated Zone Hydraulic Conductivity: 3,650 m/yr

- Contaminated Zone b Parameter: 4.9 (Silty Sand)

- Runoff Coefficient: 0.4

Site-specific risk assessment resulted in the following TEDEs to the RME individual:

- Industrial Land-Use: $0.63 \mathrm{mrem} / \mathrm{yr}$

- Residential Land-Use: $1.7 \mathrm{mrem} / \mathrm{yr}$

The calculated TEDEs for both scenarios are well below the proposed EPA guidance discussed in Section 2.2 .2 of $15 \mathrm{mrem} / \mathrm{yr}$ maximum TEDE for industrial land-use and $75 \mathrm{mrem} / \mathrm{yr}$ for residential land-use. The average radiation exposure due to natural sources (radon, internal radiation, cosmic radiation, and terrestrial radiation) in the U.S. is approximately $295 \mathrm{mrem} / \mathrm{yr}$ TEDE (NCRP 1987). Given the above, the potential effects on human health due to exposure to radionuclides at the site are well within proposed standards when considering both an industrial land-use scenario and a residential land-use scenario.

The uncertainties associated with this assessment are considered small because of the location and history of the site. There is low uncertainty in the future land-use and the potentially affected populations considered in making the risk assessment analysis. An RME approach was used to calculate the risk assessment values. As a result, the parameter values used in the calculations were conservative, and the calculated intakes are likely overestimates. Maximum measured concentrations of the COCs were used to provide conservative results. Because the COCs were 
found in the surface soils and because of the location and physical characteristics of the site, there is little uncertainty in the exposure pathways relevant to the analysis.

\section{Waste Management}

The cleanup activities produced soil, metal fragment, and PPE wastes. All waste was containerized in either 30-gallon or 55-gallon drums. A total of 24 waste drums were generated during cleanup activities: 23 soil drums and 1 metal fragment drum. Waste consolidation was performed to minimize the number of drums produced for each waste stream. A metal fragment drum was consolidated. PPE waste was generated and was consolidated with PPE waste from Site 55 where cleanup activities were ongoing. Table 5.8.12 shows the number of waste drums after waste minimization/consolidation was performed, and Appendix $\mathrm{J}$ summarizes the waste minimization/consolidation effort.

Table 5.8.12 Summary of Waste Drums for ER Site 17B (Post Minimization/ Consolidation Effort)

\begin{tabular}{|c|c|c|c|c|c|c|c|}
\hline \multicolumn{2}{|c|}{ Soil Waste } & \multicolumn{2}{|c|}{$\begin{array}{l}\text { Metal Fragment } \\
\text { Waste } \\
\end{array}$} & \multicolumn{2}{|c|}{ PPE Waste } & \multirow[b]{2}{*}{$\begin{array}{c}\text { TCLP/ } \\
\text { Gamma } \\
\text { Spec } \\
\text { Samples }\end{array}$} & \multirow[b]{2}{*}{ Comments } \\
\hline $\begin{array}{c}30 \text { Gallon } \\
\text { Drums }\end{array}$ & $\begin{array}{c}55 \text { Gallon } \\
\text { Drums }\end{array}$ & $\begin{array}{c}30 \text { Gallon } \\
\text { Drums }\end{array}$ & $\begin{array}{c}55 \text { Gallon } \\
\text { Drums }\end{array}$ & $\begin{array}{c}30 \text { Gallon } \\
\text { Drums }\end{array}$ & $\begin{array}{c}55 \text { Gallon } \\
\text { Drums }\end{array}$ & & \\
\hline 1 & 22 & 0 & 0 & 0 & 0 & 2 Soil & $\begin{array}{l}\text { Waste } \\
\text { Minimization/Consolidati } \\
\text { on was performed. }\end{array}$ \\
\hline
\end{tabular}

${ }^{\mathrm{a}}$ See Appendix J

Two composite soil samples were collected from the waste drums and analyzed for gamma emitters using standard laboratory gamma spectroscopy methods and for leachable RCRA metals using TCLP analytical procedures. Initially, mercury was not identified as a COC and was not included in the TCLP analysis in June 1995. In August 1995, mercury was identified as a COC and was included in the TCLP analysis. All samples passed the TCLP tests, and all waste was characterized as "Radioactive-Low Level Only." A summary of radiological activity for the waste is presented in Appendix G.

No TCLP metal fragment sample was collected due to the small volume of metal fragment waste generated (less than $120 \mathrm{~g}$ ). This fragment waste was consolidated with other metal fragment waste that had been analyzed using TCLP analytical procedures. This other fragment waste passed the TCLP tests and was characterized as "Non Regulated/Radioactive." The TCLP results are statistically valid, even with the addition of a minor volume of metal fragment waste that has not been sampled and analyzed. 
Disposal of regulated VCM waste was handled by SNL/NM Department 7577 (Waste Operations), which packaged and secured waste drums for transfer to Envirocare of Utah. Nonregulated waste was disposed of using standard SNL/NM-approved waste disposal methods.

\section{Conclusions}

All point and area sources of gamma activity 30 percent or greater than the natural background were removed from ER Site 17B. A radiological risk assessment was performed assuming both an industrial and a residential (loss of active control measures) land-use scenario, and using sitespecific input parameters. The risk assessment shows the potential effects on human health due to exposure to radionuclides at the site are within proposed standards when considering both land-use scenarios. Source removal is summarized in Table 5.8.13.

Table 5.8.13 Summary of Point and Area Source Removal at ER Site 17B

\begin{tabular}{|c|c|c|l|}
\hline Anomaly Type & Total Identified & Total Removed & \multicolumn{1}{|c|}{ Comments } \\
\hline Point Sources & 11 & 11 & $\begin{array}{l}\text { Six sources identified during } \\
\text { resurvey of original area on 6-ft. } \\
\text { centers (100\%). }\end{array}$ \\
\hline Area Sources & 2 & 2 & $\begin{array}{l}\text { Sources remediated based on results } \\
\text { from pre-cleanup samples. }\end{array}$ \\
\hline
\end{tabular}

No additional cleanup activities were performed during this VCM. The status of other possible COCs is not addressed in this report.

All waste was characterized as "Radioactive-Low Level Only" and managed in accordance with SNL/NM Department 7572 (Waste Management) procedures.

\subsubsection{Red Tower Site (ER Site 55)}

\section{Overview}

The Phase I survey at ER Site 55 was conducted during January 1994 and covered a total of 14.6 acres of flat alluvial terrain. A gamma scan survey was performed at 6-foot centers (100 percent coverage) over the surface of the site. One hundred and twenty-three point sources and one area source of gamma activity 30 percent or greater than the natural background were identified during this survey. A detailed summary of the surface radiological survey and anomalies found at the site is presented in Section 5.8.3 of the Surface Gamma Radiation Surveys Final Report (Geotech 1994b).

Figure 5.8.5 shows the site, surface radiological survey boundaries, and anomalies found during the Phase I survey.

VCM activities were conducted during February and August 1995, and October to November 1996. Point sources were removed in February 1995. In July 1995, pre-cleanup sampling for 


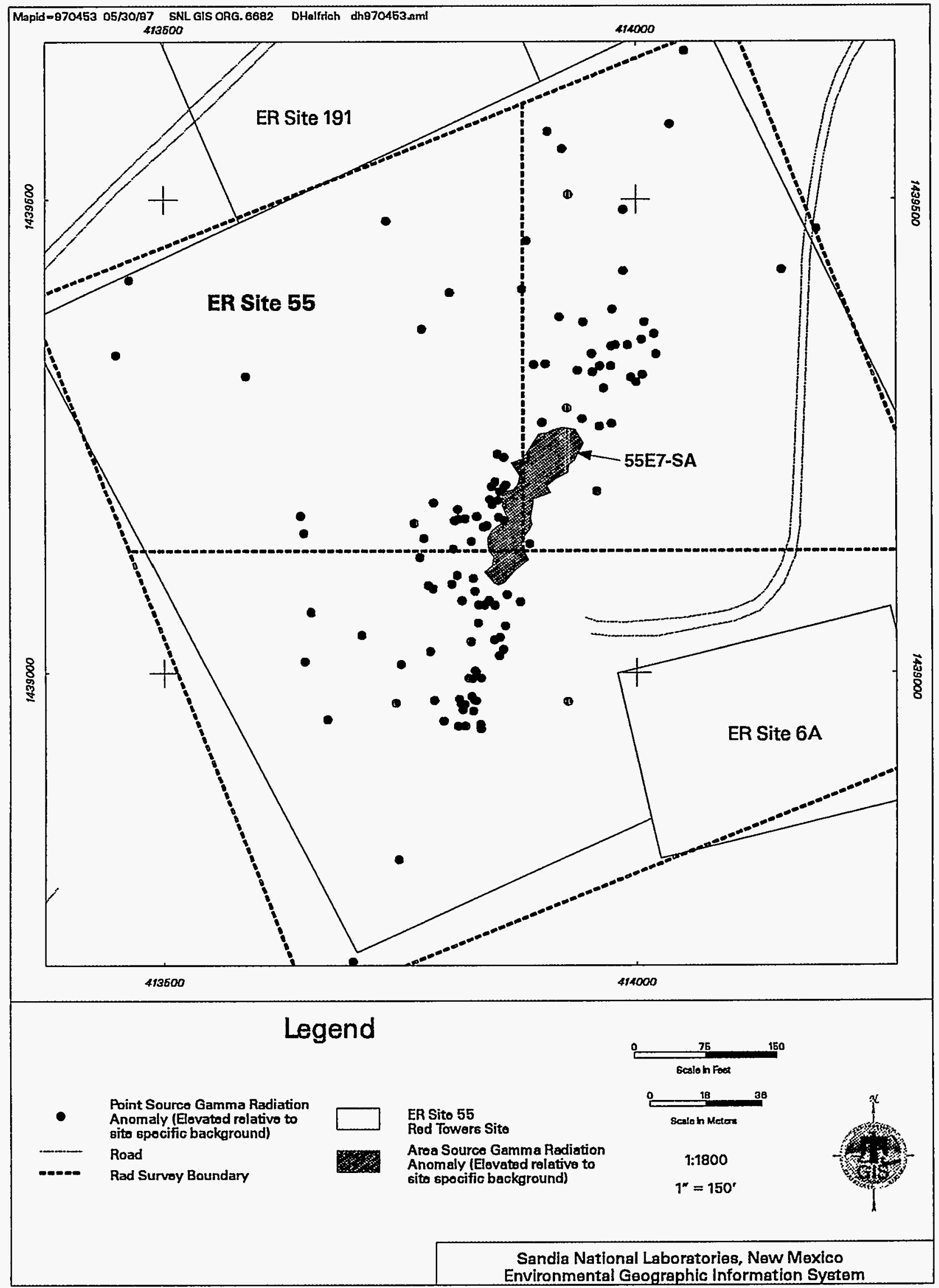

Figure 5.8.5 Phase I Survey Radiation Anomalies at ER Site 55 
gamma spectroscopy analysis was conducted on the large area source to assess the need for remediation. In August 1995, heavy equipment (skidloader) was utilized to remediate the large area source since the lateral and vertical extent of elevated radiation exceeded the capabilities of manual cleanup procedures. SNL/NM personnel removed the red tower in October 1996. Resurveying (scanning) of the area previously covered by the tower and the 1.8 acres south and west of this tower was surveyed on 6-foot centers (100 percent coverage) during October to November 1996. Point and area sources identified during the resurveying were remediated in November 1996.

Cleanup activities included radiation scanning to verify anomaly location, removal of fragment and/or soil until readings were less than 1.3 times site-specific background levels, and postcleanup (verification) soil sampling for gamma spectroscopy analysis (see Section 3.1). Table 5.8.14 summarizes field activities during the VCM.

Table 5.8.14 Summary of Field Activities at ER Site 55

Removal Action Procedures

\begin{tabular}{|c|c|c|c|c|c|c|c|}
\hline $\begin{array}{c}\text { Actual } \\
\text { Acreage } \\
\text { Surveyed }\end{array}$ & $\begin{array}{c}\text { Duration of } \\
\text { Cleanup } \\
\text { (days) }\end{array}$ & $\begin{array}{c}\text { Verify } \\
\text { Anomaly } \\
\text { Location }\end{array}$ & $\begin{array}{c}\text { Rad } \\
\text { Removal }\end{array}$ & $\begin{array}{c}\text { Post- } \\
\text { Cleanup } \\
\text { Sampling }\end{array}$ & $\begin{array}{c}\text { New Area/ } \\
\text { Resurveyed } \\
(\mathbf{1 0 0 \% )}\end{array}$ & $\begin{array}{c}\text { Pre-Cleanup } \\
\text { Sampling } \\
\text { (area sources) }\end{array}$ & \multicolumn{1}{c|}{ Comments } \\
\hline 14.60 & 18.75 & $\mathrm{X}$ & $\mathrm{X}$ & $\mathrm{X}$ & $\mathrm{X}$ & $\mathrm{X}$ & $\begin{array}{l}\text { Resurveyed large } \\
\text { area source (1.8 } \\
\text { acres) on 6-ft centers } \\
\text { (100\%). }\end{array}$ \\
\hline
\end{tabular}

${ }^{a}$ Removal of fragment and/or soil until readings are less than 1.3 times site-specific background

\section{Findings and Observations}

\section{Point and Area Source Status}

Of the sources identified during the Phase I survey, 123 point sources were remediated during the initial cleanup. The one large area source (55E7) was remediated based on the results of gamma spectroscopy analysis from pre-cleanup samples that show the elevated radiation was related to anthropogenic (man-made) material. The lateral and vertical extent of elevated radiation within the area source resulted in heavy equipment (skidloader) being utilized in the cleanup. However, it became apparent the volume of waste being generated was significant and would completely exceed the project's waste management capabilities. Consequently, manual cleanup procedures were used within the area source boundary to cleanup the "hot spots" exhibiting the highest gamma radiation readings. Cleanup was completed on these "hot spots," and no additional areas exhibiting elevated gamma radiation were identified within the area source boundary.

During resurveying (scanning) of the area previously covered by the red tower and southwest of the former tower location, 296 new point sources were identified. The majority of these elevated gamma readings coincide with the original large area source (55E7) that was previously remediated. These gamma anomalies were at a depth beyond the detection capabilities of the 
gamma scintillometers during the initial cleanup and have become exposed over time by weathering events. No locations were surveyed for these new point sources since the majority are within the original large area source boundary. The new sources identified during the VCM are summarized in Table 5.8.15, and Figure 5.8.6 shows VCM radiation anomalies and verification sampling locations (post-cleanup).

\section{Table 5.8.15 Radiation Anomalies 30 Percent or Greater Than Natural Background} Identified During the VCM at ER Site 55

\begin{tabular}{|c|c|l|}
\hline Anomaly Type & \multicolumn{1}{|c|}{ Total } & \multicolumn{1}{c|}{ Comments } \\
\hline Point Sources & 296 & $\begin{array}{l}\text { Yellow uranium oxide (DU) in soil } \\
\text { associated with the original large } \\
\text { area source (55E7) }\end{array}$ \\
\hline
\end{tabular}

To assess remediation requirements for these new point sources, pre-cleanup soil sampling for gamma spectroscopy analysis was conducted on 30 of these new sources. The gamma spectroscopy results on these pre-cleanup soil samples indicate the elevated gamma readings are related to anthropogenic (man-made) material and require remediation. Cleanup was completed on only these 30 new sources. No additional surface radiation cleanup was performed during this VCM.

\section{Post-Cleanup (Verification) Sample Results}

After the removal of radiologically contaminated soils, 29 post-cleanup (verification) samples were collected from areas exhibiting the highest residual gamma radiation readings. Gamma spectroscopy analysis was performed on the samples to verify that the residual radionuclide concentrations met risk-based action levels. The radiological COC was DU (U-238, U-235, and U-234). Table 5.8.16 summarizes the post-cleanup (verification) samples collected at the sites, and the maximum level of residual radiological COCs in soils is presented in Table 5.8.17.

\section{Risk Assessment Results}

Further work is planned at this site and, therefore, risk assessment has been postponed pending additional characterization and remediation. After cleanup is complete, it is anticipated that the potential effects on human health due to exposure to radionuclides at the site will be within proposed standards. This is based on preliminary review of site-specific input parameters and land-use scenarios for the risk assessment to be performed using the RESRAD code.

\section{Waste Management}

The cleanup activities produced soil, metal fragment, and PPE wastes. All waste was containerized in either 30-gallon or 55-gallon drums. A total of 116 waste drums were generated during cleanup activities: 113 soil drums, 1 metal fragment drums, and 2 PPE drums. Waste consolidation was performed to minimize the number of drums produced for each waste stream. 


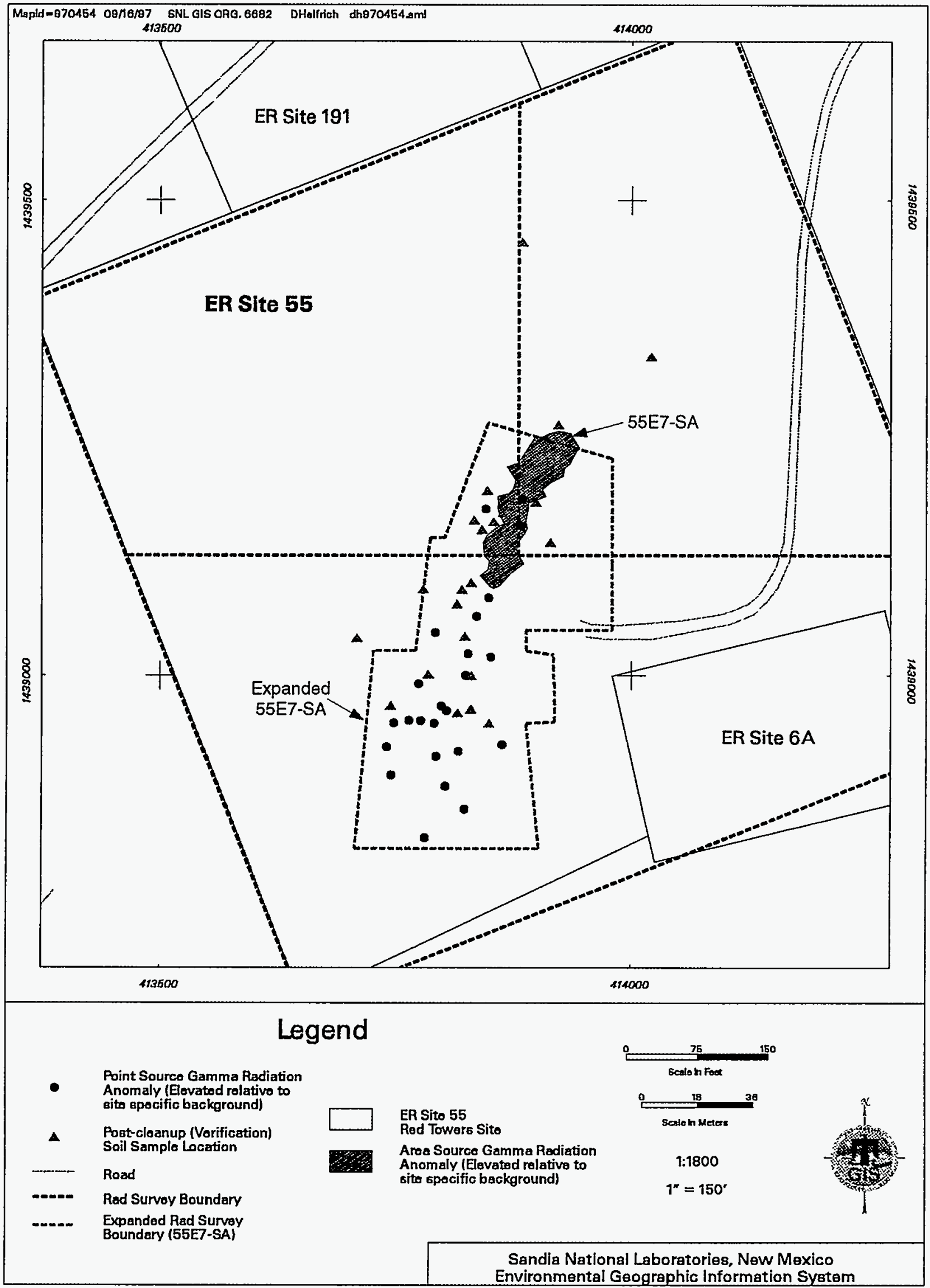

Figure 5.8.6 VCM Radiation Anomalies and Surface Soil Sampling Locations at ER Site 55 
Table 5.8.16 Post-Cleanup (Verification) Samples Collected at ER Site 55

\begin{tabular}{|lll|}
\hline & $\begin{array}{c}\text { Point Source } \\
\text { Sample Number }\end{array}$ \\
\hline $55 \mathrm{E} 6 \mathrm{SS}$ & $55 \mathrm{E} 7 \mathrm{DSS}$ & $55 \mathrm{E} 7 \mathrm{ESS}$ \\
$55 \mathrm{E} 7 \mathrm{FSS}$ & $55 \mathrm{E} 7 \mathrm{GSS}$ & $55 \mathrm{E} 16 \mathrm{SS}$ \\
$55 \mathrm{E} 16 \mathrm{SD}$ & $55 \mathrm{E} 20 \mathrm{SS}$ & $55 \mathrm{E} 3 \mathrm{SS}$ \\
$55 \mathrm{E} 62 \mathrm{SS}$ & $55 \mathrm{E} 78 \mathrm{ES}$ & $55 \mathrm{E} 112 \mathrm{SS}$ \\
$55 \mathrm{E} 83 \mathrm{SS}$ & $55 \mathrm{E} 101 \mathrm{SS}$ & $55 \mathrm{E} 124 \mathrm{SS}$ \\
$55 \mathrm{E} 121 \mathrm{SS}$ & $55 \mathrm{E} 121 \mathrm{SD}^{\mathrm{a}}$ & $55 \mathrm{E} 182 \mathrm{SS}$ \\
$55 \mathrm{E} 127 \mathrm{SS}$ & $55 \mathrm{E} 152 \mathrm{SS}$ & $55 \mathrm{E} 307 \mathrm{SS}$ \\
$55 \mathrm{E} 277 \mathrm{SS}$ & $55 \mathrm{E} 287 \mathrm{SS}$ & $55 \mathrm{E} 362 \mathrm{SS}$ \\
$55 \mathrm{E} 318 S \mathrm{SS}$ & $55 \mathrm{E} 318 \mathrm{SD}^{\mathrm{a}}$ & \\
$55 \mathrm{E} 376 \mathrm{SS}$ & $55 \mathrm{E} 376 \mathrm{SD}^{\mathrm{a}}$ & \\
\hline
\end{tabular}

${ }^{a}$ Sample duplicate

Table 5.8.17 Maximum Residual Radionuclide Levels in ER Site 55 Soils

\begin{tabular}{|c|c|c|}
\hline Radionuclide & Maximum Activity (pCi/g) & Background Activity (pCi/g) \\
\hline U-238 & 13.1 & 1.4 \\
\hline U-235 & 0.18 & 0.16 \\
\hline U-234 & 1.6 & 1.6 \\
\hline
\end{tabular}

One metal fragment drum was consolidated. Table 5.8.18 shows the number of waste drums after waste minimization/consolidation was performed, and Appendix J summarizes the waste minimization/consolidation effort.

Table 5.8.18 Summary of Waste Drums for ER Site 55 (Post Minimization/Consolidation Effort)

\begin{tabular}{|c|c|c|c|c|c|c|c|}
\hline \multicolumn{2}{|c|}{ Soil Waste } & \multicolumn{2}{|c|}{$\begin{array}{l}\text { Metal Fragment } \\
\text { Waste }\end{array}$} & \multicolumn{2}{|c|}{ PPE Waste } & \multirow[b]{2}{*}{$\begin{array}{c}\text { TCLP/ } \\
\text { Gamma } \\
\text { Spec } \\
\text { Samples }\end{array}$} & \multirow[b]{2}{*}{ Comments } \\
\hline $\begin{array}{l}30 \text { Gallon } \\
\text { Drums }\end{array}$ & $\begin{array}{c}55 \text { Gallon } \\
\text { Drums }\end{array}$ & $\begin{array}{c}30 \text { Gallon } \\
\text { Drums }\end{array}$ & $\begin{array}{c}55 \text { Gallon } \\
\text { Drums }\end{array}$ & \begin{tabular}{|c|}
30 Gallon \\
Drums
\end{tabular} & $\begin{array}{c}55 \text { Gallon } \\
\text { Drums }\end{array}$ & & \\
\hline 2 & 111 & 0 & 0 & 0 & 2 & $\begin{array}{l}5 \text { Soil } \\
1 \text { Frag }\end{array}$ & $\begin{array}{l}\text { Waste } \\
\text { Minimization/Consolidati } \\
\text { on was performed. }\end{array}$ \\
\hline
\end{tabular}

${ }^{\mathrm{a}}$ See Appendix J

Five composite soil samples and one metal fragment sample were collected from the waste drums and analyzed for gamma emitters using standard laboratory gamma spectroscopy methods and for leachable RCRA metals using TCLP analytical procedures. Mercury was not identified 
as a COC and was not included in the TCLP analysis. All samples passed the TCLP tests, and all waste was characterized as "Radioactive-Low Level Only." A summary of radiological activity for the waste is presented in Appendix G.

Disposal of regulated VCM waste was handled by SNL/NM Department 7577 (Waste Operations), which packaged and secured waste drums for transfer to Envirocare of Utah. Nonregulated waste was be disposed of using standard SNL/NM-approved waste disposal methods.

\section{Conclusions}

Remediation was completed on all original point and area sources of gamma activity 30 percent of greater than natural background. Further radiological characterization will be required on the remaining 266 new point sources associated with the original area source (55E7). Source removal of these new point sources will be addressed under future cleanup activities. A risk assessment will be conducted after additional characterization and source removal is performed.

Source removal is summarized in Table 5.8.19, and sources remaining after completion of the VCM are shown in Figure 5.8.7.

Table 5.8.19 Summary of Point and Area Source Removal at ER Site 55

\begin{tabular}{|c|c|c|l|}
\hline Anomaly Type & Total Identified & Total Removed & \multicolumn{1}{|c|}{ Comments } \\
\hline Point Sources & 419 & 153 & $\begin{array}{l}\text { Sources remaining are those } \\
\text { identified during resurvey of } \\
\text { original large area source on 6-ft. } \\
\text { centers (100\%). }\end{array}$ \\
\hline Area Source & 1 & 1 & $\begin{array}{l}\text { Source remediated based on results } \\
\text { from pre-cleanup samples. }\end{array}$ \\
\hline
\end{tabular}

No additional cleanup activities were performed during this VCM. The status of other possible COCs is not addressed in this report.

All waste was characterized as "Radioactive-Low Level Only" and managed in accordance with SNL/NM Department 7572 (Waste Management) procedures.

\subsubsection{Lead Firing Site (ER Site 91)}

\section{Overview}

ER Site 91 is a new site identified during the VCM and was not included in the Phase I survey. A surface radiological survey was conducted during July 1996 and covered a total of 21.2 acres of flat alluvial terrain. The survey was performed on 6 -foot centers (100 percent coverage) over the surface of the site. Ten point sources of gamma activity 30 percent or greater than the natural 


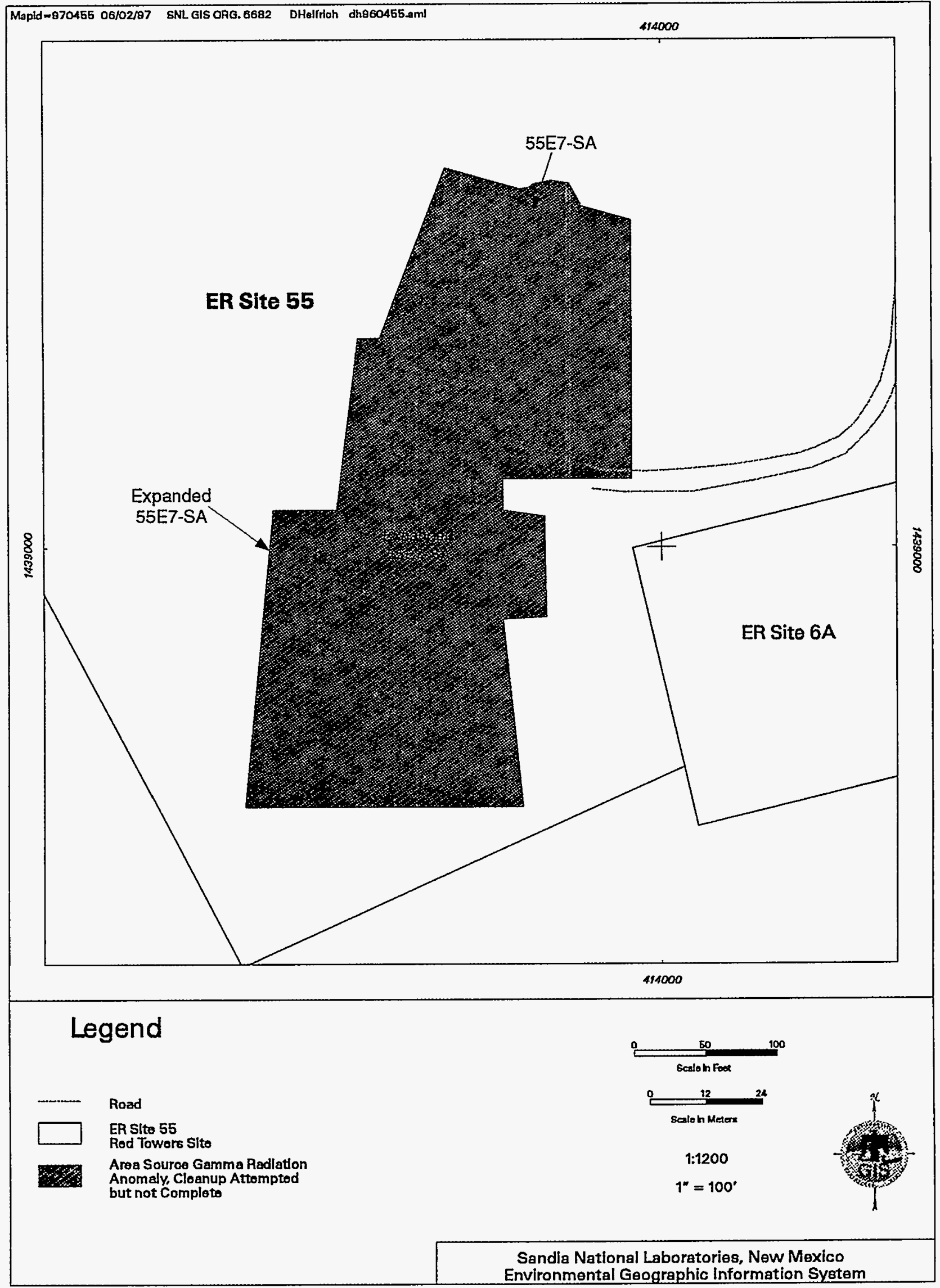

Figure 5.8.7 Radiation Anomalies Remaining After Completion of the VCM at ER Site $\mathbf{5 5}$ 
background were identified during this survey. These point sources were remediated during VCM activities in July 1996.

Figure 5.8.8 shows the site, surface radiological survey boundaries, and anomalies found during the Phase I survey, and VCM verification sampling locations (post-cleanup).

Characterization activities included a gamma scan survey (100 percent coverage) within the site boundaries. Cleanup activities included radiation scanning to verify anomaly location, removal of fragment and/or soil until readings were less than 1.3 times site-specific background levels, and post-cleanup (verification) soil sampling for gamma spectroscopy analysis (see Section 3.1). Table 5.8.20 summarizes field activities during the VCM.

Table 5.8.20 Summary of Field Activities at ER Site 91

Removal Action Procedures

\begin{tabular}{|c|c|c|c|c|c|c|}
\hline $\begin{array}{c}\text { Actual } \\
\text { Acreage } \\
\text { Surveyed }\end{array}$ & $\begin{array}{c}\text { Duration of } \\
\text { Cleanup } \\
\text { (days) }\end{array}$ & $\begin{array}{c}\text { Verify } \\
\text { Anomaly } \\
\text { Location }\end{array}$ & $\begin{array}{c}\text { Rad } \\
\text { Removal }\end{array}$ & $\begin{array}{c}\text { Post- } \\
\text { Cleanup } \\
\text { Sampling }\end{array}$ & $\begin{array}{c}\text { New Area/ } \\
\text { Resurveyed } \\
(\mathbf{1 0 0 \%})\end{array}$ & Comments \\
\hline 21.20 & 3.00 & $\mathbf{X}$ & $\mathbf{X}$ & $\mathbf{X}$ & $\mathbf{X}$ & $\begin{array}{l}\text { Surveyed new area } \\
(21.2 \text { acres) on 6-ft } \\
\text { centers (100\%). }\end{array}$ \\
\hline
\end{tabular}

a Removal of fragment and/or soil until readings are less than 1.3 times site-specific background

\section{Findings and Observations}

\section{Point and Area Source Status}

Of the sources identified during the gamma scan survey, 10 point sources were remediated. Cleanup was completed on these sources and no additional surface radiation cleanup was performed during this VCM.

\section{Post-Cleanup (Verification) Sample Results}

After the removal of radiologically contaminated metal fragments and soils, three post-cleanup (verification) samples were collected from areas exhibiting the highest residual gamma radiation readings. Gamma spectroscopy analysis was performed on the samples to verify that the residual radionuclide concentrations met risk-based action levels. The radiological COC was DU (U-238, U-235, and U-234). Table 5.8.21 summarizes the post-cleanup (verification) samples collected at the site, and the maximum level of residual radiological COCs in soils is presented in Table 5.8.22. 


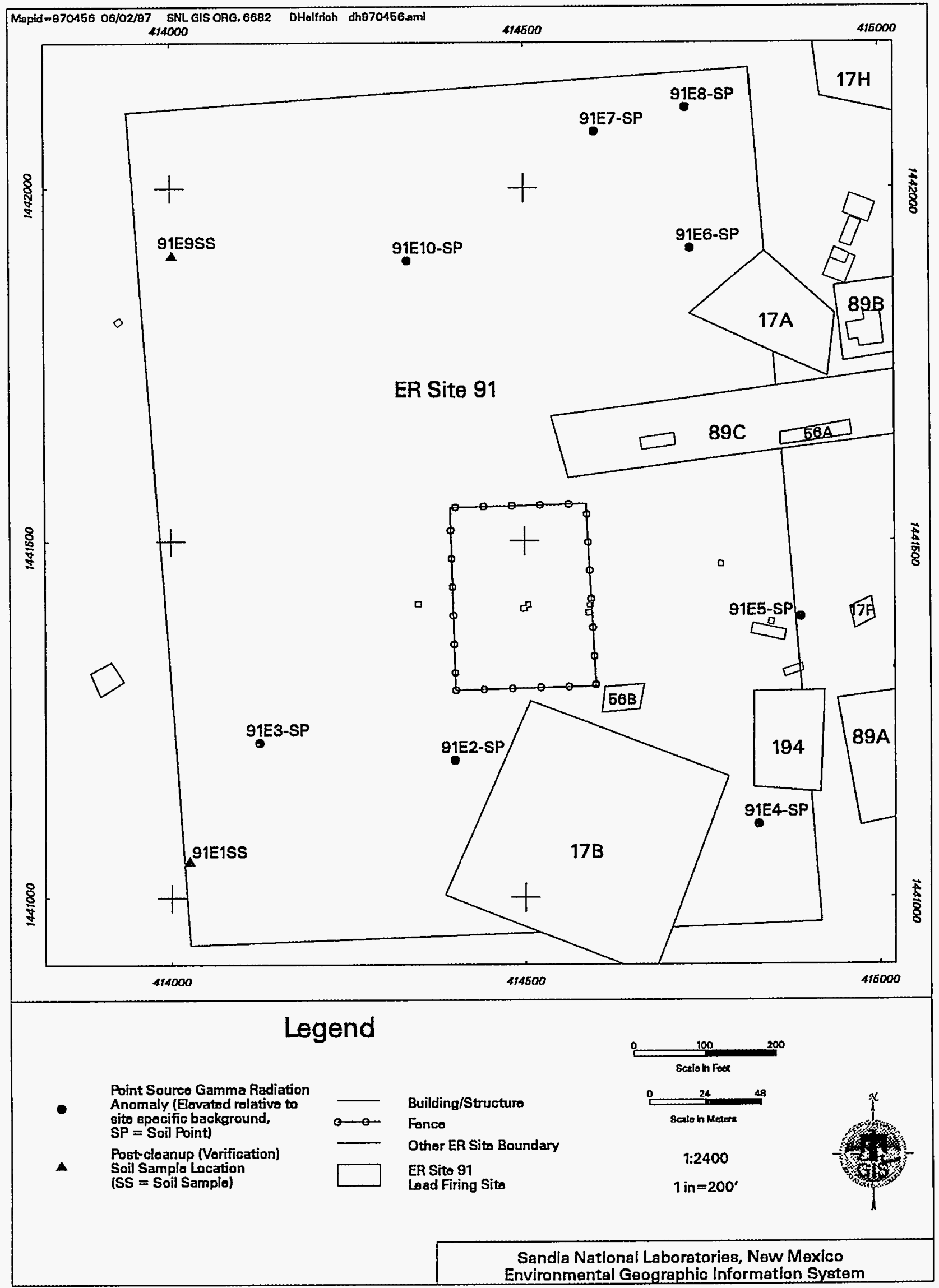

Figure 5.8.8 VCM Radiation Anomalies and

Surface Soil Sampling Locations at ER Site 91 
Table 5.8.21 Post-Cleanup (Verification) Samples Collected at ER Site 91

\begin{tabular}{|c|c|c|}
\hline & $\begin{array}{c}\text { Point Source } \\
\text { Sample Number }\end{array}$ & \\
\hline 91E1SS & $91 \mathrm{E} 1 \mathrm{SD}^{\mathrm{a}}$ & $\overline{91 E 9 S S}$ \\
\hline
\end{tabular}

a Sample duplicate

Table 5.8.22 Maximum Residual Radionuclide Levels in ER Site 91 Soils

\begin{tabular}{|c|c|c|}
\hline Radionuclide & Maximum Activity (pCi/g) & Background Activity (pCi/g) \\
\hline U-238 & 8.3 & 1.4 \\
\hline U-235 & 0.11 & 0.16 \\
\hline U-234 & 1.0 & 1.6 \\
\hline
\end{tabular}

Although U-235 and U-234 values for the DU were below background concentrations, for conservatism they were included in the risk assessment by their association with the elevated levels of U-238 and the known DU contamination on site.

\section{Risk Assessment Results}

A risk assessment, using the DOE computer code RESRAD, was performed on ER Site 91 assuming both an industrial and a residential (loss of active control measures) land-use scenario, consistent with Section 3.3.2. The RESRAD input parameters that were not site specific are provided for both land-use scenarios in Section 3.3.2. Site-specific input parameters were developed based on information provided by the Task Leader responsible for the site and were as follows:

- Area of Contaminated Zone: $36,500 \mathrm{~m}^{2}$

- Thickness of contaminated zone: $0.15 \mathrm{~m}$

- Length Parallel to Aquifer Flow: $30 \mathrm{~m}$

- Density of Contaminated Zone: $1.85 \mathrm{~g} / \mathrm{cm}^{3}$

- Contaminated Zone Total Porosity: 0.4

- Contaminated Zone Effective Porosity: 0.35

- Contaminated Zone Hydraulic Conductivity: $3650 \mathrm{~m} / \mathrm{yr}$

- Contaminated Zone b Parameter: 4.9 (Silty Sand)

- Runoff Coefficient: 0.4

Site-specific risk assessment resulted in the following TEDEs to the RME individual:

- Industrial Land-Use: $0.33 \mathrm{mrem} / \mathrm{yr}$

- Residential Land-Use: $0.91 \mathrm{mrem} / \mathrm{yr}$

The calculated TEDEs for both scenarios are well below the proposed EPA guidance discussed in Section 2.2.2 of $15 \mathrm{mrem} / \mathrm{yr}$ maximum TEDE for industrial land-use and $75 \mathrm{mrem} / \mathrm{yr}$ for residential land-use. The average radiation exposure due to natural sources (radon, internal 
radiation, cosmic radiation, and terrestrial radiation) in the U.S. is approximately $295 \mathrm{mrem} / \mathrm{yr}$ TEDE (NCRP 1987). Given the above, the potential effects on human health due to exposure to radionuclides at the site are well within proposed standards when considering both an industrial land-use scenario and a residential land-use scenario.

The uncertainties associated with this assessment are considered small because of the location and history of the site. There is low uncertainty in the future land-use and the potentially affected populations considered in making the risk assessment analysis. An RME approach was used to calculate the risk assessment values. As a result, the parameter values used in the calculations were conservative, and the calculated intakes are likely overestimates. Maximum measured concentrations of the COCs were used to provide conservative results. Because the COCs were found in the surface soils and because of the location and physical characteristics of the site, there is little uncertainty in the exposure pathways relevant to the analysis.

\section{Waste Management}

The cleanup activities produced soil and PPE wastes. No metal fragment waste was generated. All waste was containerized in 55-gallon drums. A total of two waste drums were generated during cleanup activities: one soil drum and one PPE drum. Table 5.8.23 shows the number of waste drums generated during the VCM.

Table 5.8.23 Summary of Waste Drums for ER Site 91

\begin{tabular}{|c|c|c|c|c|c|c|c|}
\hline \multicolumn{2}{|c|}{ Soil Waste } & \multicolumn{2}{|c|}{$\begin{array}{l}\text { Metal Fragment } \\
\text { Waste }\end{array}$} & \multicolumn{2}{|c|}{ PPE Waste } & \multirow[b]{2}{*}{$\begin{array}{c}\text { TCLP/ } \\
\text { Gamma } \\
\text { Spec } \\
\text { Samples }\end{array}$} & \multirow[b]{2}{*}{ Comments } \\
\hline $\begin{array}{c}30 \text { Gallon } \\
\text { Drums }\end{array}$ & $\begin{array}{l}55 \text { Gallon } \\
\text { Drums }\end{array}$ & $\begin{array}{l}30 \text { Gallon } \\
\text { Drums }\end{array}$ & $\begin{array}{l}55 \text { Gallon } \\
\text { Drums }\end{array}$ & $\begin{array}{l}30 \text { Gallon } \\
\text { Drums }\end{array}$ & $\begin{array}{l}55 \text { Gallon } \\
\text { Drums }\end{array}$ & & \\
\hline 0 & 1 & 0 & 0 & 0 & 1 & 1 Soil & \\
\hline
\end{tabular}

One composite soil sample was collected from the waste drum and analyzed for gamma emitters using standard laboratory gamma spectroscopy methods and for leachable RCRA metals using TCLP analytical procedures. Mercury was identified as a COC and was included in the TCLP analysis. All samples passed the TCLP tests, and all waste was characterized as "RadioactiveLow Level Only." A summary of radiological activity for the waste is presented in Appendix G.

Disposal of regulated VCM waste was handled by SNL/NM Department 7577 (Waste Operations), which packaged and secured waste drums for transfer to Envirocare of Utah. Nonregulated waste was disposed of using standard SNL/NM-approved waste disposal methods. 


\section{Conclusions}

All point and area sources of gamma activity 30 percent or greater than the natural background were removed from the site. A radiological risk assessment was performed assuming both an industrial and a residential (loss of active control measures) land-use scenario, and using sitespecific input parameters. The risk assessment shows the potential effects on human health due to exposure to radionuclides at the site are within proposed standards when considering both land-use scenarios. Source removal is summarized in Table 5.8.24.

Table 5.8.24 Summary of Point and Area Source Removal at ER Site 91

\begin{tabular}{|c|c|c|l|}
\hline Anomaly Type & Total Identified & Total Removed & \multicolumn{1}{c|}{ Comments } \\
\hline Point Sources & 10 & 10 & $\begin{array}{l}\text { Sources identified during survey of } \\
\text { new area. }\end{array}$ \\
\hline
\end{tabular}

No additional cleanup activities were performed during this VCM. The status of other possible COCs is not addressed in this report.

All waste was characterized as "Radioactive-Low Level Only" and managed in accordance with SNL/NM Department 7572 (Waste Management) procedures.

\subsubsection{Building 9939 - Scrap Yard and Trenches (ER Sites 103 and 117)}

\section{Overview}

The Phase I survey at ER Sites 103 and 117 was conducted during March 1994 and covered a total of 6.3 acres of flat alluvial terrain. A gamma scan survey was performed at 6 -foot centers (100 percent coverage) over the surface of the site. Eight point sources and thirteen area sources of gamma activity 30 percent or greater than the natural background were identified during this survey. A detailed summary of the surface radiological survey and anomalies found at the site is presented in Section 5.8.6 of the Surface Gamma Radiation Surveys Final Report (Geotech 1994b).

Figure 5.8.9 shows the site, surface radiological survey boundaries, and anomalies found during the Phase I survey.

VCM activities were conducted during March and July to September 1995 and June 1996. Resurveying (scanning) was not performed at this site. Point sources and small area sources were removed in March 1995. In July 1995, pre-cleanup soil sampling for gamma spectroscopy analysis was conducted on large area sources to assess the need for remediation. Large area sources were remediated in August to September 1995 and June 1996. Heavy equipment (skidloader) was used on an area source (103E12) since the lateral and vertical extent of elevated radiation exceeded the capabilities of manual cleanup procedures. 


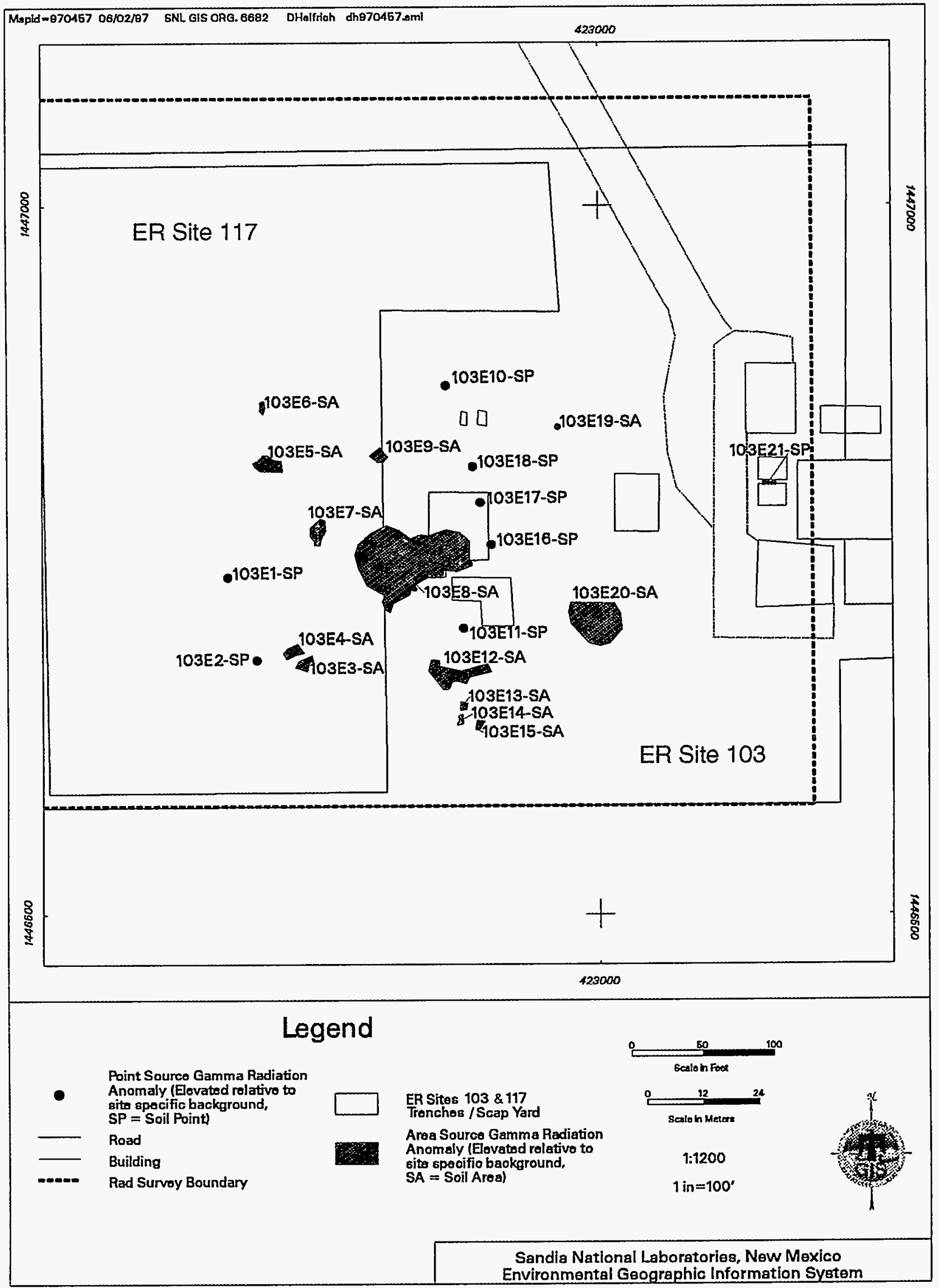

Figure 5.8.9 Phase I Survey Radiation Anomalies at ER Sites 103 \& 117 
Cleanup activities included radiation scanning to verify anomaly location, removal of fragment and/or soil until readings were less than 1.3 times site-specific background levels, and postcleanup (verification) soil sampling for gamma spectroscopy analysis (see Section 3.1).

Table 5.8.25 summarizes field activities during the VCM.

Table 5.8.25 Summary of Field Activities at ER Sites 103 and 117

Removal Action Procedures

\begin{tabular}{|c|c|c|c|c|c|c|c|}
\hline $\begin{array}{c}\text { Actual } \\
\text { Acreage } \\
\text { Surveyed }\end{array}$ & $\begin{array}{c}\text { Duration of } \\
\text { Cleanup } \\
\text { (days) }\end{array}$ & $\begin{array}{c}\text { Verify } \\
\text { Anomaly } \\
\text { Location }\end{array}$ & $\begin{array}{c}\text { Rad } \\
\text { Removal }^{\mathrm{a}}\end{array}$ & $\begin{array}{c}\text { Post- } \\
\text { Cleanup } \\
\text { Sampling }\end{array}$ & $\begin{array}{c}\text { Pre-Cleanup } \\
\text { Sampling } \\
\text { (area sources) }\end{array}$ & $\begin{array}{c}\text { Heavy } \\
\text { Equipment } \\
\text { Support }\end{array}$ & Comments \\
\hline 6.30 & 7.50 & $\mathrm{X}$ & $\mathrm{X}$ & $\mathrm{X}$ & $\mathrm{X}$ & $\mathrm{X}$ & $\begin{array}{l}\text { Skidloader used on } \\
\text { one area source. }\end{array}$ \\
\hline
\end{tabular}

${ }^{2}$ Removal of fragment and/or soil until readings are less than 1.3 times site-specific background

\section{Findings and Observations}

\section{Point and Area Source Status}

Of the sources identified during the Phase I survey, five point sources (103E10, 103E11, 103E16, $103 \mathrm{E} 17$, and 103E18) and one area source (103E3) were remediated during the initial cleanup. One point source (103E2) was associated with a concrete cylinder and was not remediated. Remediation was started at one point source (103E1) and five area sources $(103 \mathrm{E} 4,103 \mathrm{E} 12$, $103 \mathrm{E} 13,103 \mathrm{E} 14$, and 103E15). To determine if further remediation was required of these sources, soil samples for gamma spectroscopy analysis were collected on the top 6 inches of soil. Results of the gamma spectroscopy analysis for these sources indicated the elevated radiation was related to anthropogenic (man-made) material. During subsequent cleanup activities, remediation was completed on these six sources.

Pre-cleanup soil samples were collected for gamma spectroscopy analysis from one point source (103E21) and seven area sources (103E5, 103E6, 103E7, 103E8, 103E9, 103E19, and 103E20) to determine if remediation was required. Results of the gamma spectroscopy analysis for five of these sources indicated the elevated radiation was related to anthropogenic (man-made) material. Remediation was completed on these five sources during subsequent cleanup activities. Gamma spectroscopy results on samples collected at one point source (103E21) and two area sources (103E8 and 103E20) indicated the elevated gamma readings were related to "shine" (gamma interference) from material stored within adjacent buildings. Remediation was not conducted at these sources. Table 5.8.26 shows the pre-cleanup samples collected from these sources.

Table 5.8.26 Pre-Cleanup (Final Determination) Samples Collected at ER Sites 103 and 117

\begin{tabular}{|c|c|c|}
\hline \multicolumn{3}{|c|}{$\begin{array}{c}\text { Area Source } \\
\text { Sample Number }\end{array}$} \\
\hline 103E8ASS & 103E8BSS & 103E8CSS \\
\hline 103E20ASS & 103E20BSS & 103E21SS \\
\hline
\end{tabular}


During the initial cleanup, one new area source (103E22) was identified within an area roped-off by RPO personnel and was remediated during subsequent cleanup activities. Table 5.8.27 summarize the new source identified during the VCM, and Figure 5.8.10 shows VCM radiation anomalies and verification sampling locations (pre-cleanup and post-cleanup).

Table 5.8.27 Radiation Anomalies 30 Percent or Greater Than Natural Background Identified During the VCM at ER Sites 103 and 117

\begin{tabular}{|c|c|l|}
\hline Anomaly Type & Total & \multicolumn{1}{c|}{ Comments } \\
\hline Area Source & 1 & $\begin{array}{l}\text { Multiple fragments with yellow } \\
\text { uranium oxide (DU) in soil }\end{array}$ \\
\hline
\end{tabular}

\section{Post-Cleanup (Verification) Sample Results}

After the removal of radiologically contaminated soils, 13 post-cleanup (verification) samples were collected from point and area sources. Samples from point sources were collected in the immediate vicinity of the point source (fragment), and at area sources samples were collected from areas exhibiting the highest residual gamma radiation readings. Gamma spectroscopy analysis was performed on these samples to characterize the residual radioactivity remaining in the soil. The radiological COC was DU (U-238, U-235, and U-234). Table 5.8.28 summarizes the post-cleanup (verification) samples collected at the sites, and the maximum level of residual radiological COCs in soils is presented in Table 5.8.29.

Table 5.8.28 Post-Cleanup (Verification) Samples Collected at ER Sites 103 and 117

\begin{tabular}{|ll|lll|}
\hline \multicolumn{2}{|c|}{$\begin{array}{c}\text { Point Source } \\
\text { Sample Number }\end{array}$} & \multicolumn{3}{c|}{$\begin{array}{c}\text { Area Source } \\
\text { Sample Number }\end{array}$} \\
\hline \hline 103E1SS 103E18SS 103E22ASS & $103 E 4 A S S$ & $103 E 5 A S S$ & $103 E 6 A S S$ \\
103E22BSS & & $103 E 7 A S S$ & $103 E 7 B S S$ & $103 E 9 A S S$ \\
& & $103 E 12 A S S$ & $103 E 13 A S S$ & $103 E 14 A S S$ \\
\hline
\end{tabular}

Table 5.8.29 Maximum Residual Radionuclide Levels in ER Sites 103 and 117 Soils

\begin{tabular}{|c|c|c|}
\hline Radionuclide & Maximum Activity (pCi/g) & Background Activity (pCi/g) \\
\hline U-238 & 18.2 & 1.4 \\
\hline U-235 & 0.25 & 0.16 \\
\hline U-234 & 2.3 & 1.6 \\
\hline
\end{tabular}

\section{Risk Assessment Results}

Further work is planned at ER Sites 103 and 117 and, therefore, risk assessment has been postponed pending additional characterization and remediation. After cleanup is complete, it is anticipated that the potential effects on human health due to exposure to radionuclides at the sites 


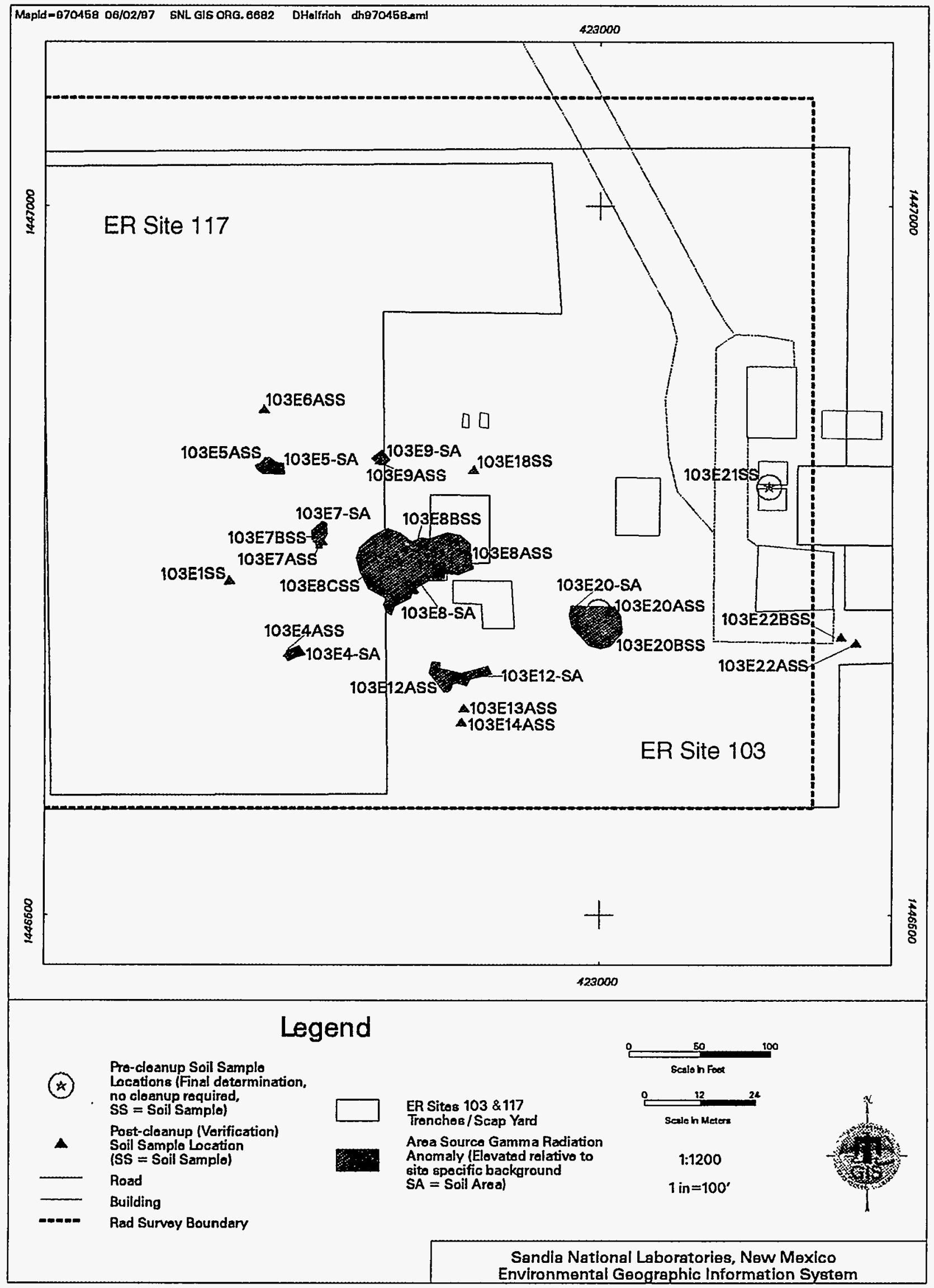

Figure 5.8.10 VCM Radiation Anomalies and

Surface Soil Sampling Locations at ER Sites 103 \& 117 
will be within proposed standards. This is based on preliminary review of site-specific input parameters and land-use scenarios for the risk assessments to be performed using the RESRAD code.

\section{Waste Management}

The cleanup activities produced soil, metal fragment, and PPE wastes. All waste was containerized in either 30-gallon or 55-gallon drums. A total of 50 waste drums were generated during cleanup activities: 46 soil drums, 1 metal fragment drums, and 3 PPE drums. Waste consolidation was performed to minimize the number of drums produced for each waste stream. One soil drum was consolidated, one metal fragment drum was consolidated, and one PPE drum was consolidated. Table 5.8.30 shows the number of waste drums after waste minimization/consolidation was performed, and Appendix J summarizes the waste minimization/consolidation effort.

Table 5.8.30 Summary of Waste Drums for ER Sites 103 and 117 (Post Minimization/ Consolidation Effort)

\begin{tabular}{|c|c|c|c|c|c|c|c|}
\hline \multicolumn{2}{|c|}{ Soil Waste } & \multicolumn{2}{|c|}{$\begin{array}{l}\text { Metal Fragment } \\
\text { Waste }\end{array}$} & \multicolumn{2}{|c|}{ PPE Waste } & \multirow[b]{2}{*}{$\begin{array}{c}\text { TCLP/ } \\
\text { Gamma } \\
\text { Spec } \\
\text { Samples }\end{array}$} & \multirow[b]{2}{*}{ Comments } \\
\hline $\begin{array}{c}30 \text { Gallon } \\
\text { Drums }\end{array}$ & $\begin{array}{c}55 \text { Gallon } \\
\text { Drums }\end{array}$ & $\begin{array}{l}30 \text { Gallon } \\
\text { Drums }\end{array}$ & $\begin{array}{c}55 \text { Gallon } \\
\text { Drums }\end{array}$ & $\begin{array}{l}30 \text { Gallon } \\
\text { Drums }\end{array}$ & $\begin{array}{c}55 \text { Gallon } \\
\text { Drums }\end{array}$ & & \\
\hline$\overline{0}$ & $\overline{45}$ & $\overline{0}$ & 0 & 1 & 1 & $\begin{array}{l}\text { S Soil } \\
1 \text { Frag }\end{array}$ & $\begin{array}{l}\text { Waste } \\
\text { Minimization/Consolidation } \\
\text { was performed. }^{\mathrm{a}}\end{array}$ \\
\hline
\end{tabular}

${ }^{a}$ See Appendix J

Two composite soil samples and one metal fragment sample were collected from the waste drums and analyzed for gamma emitters using standard laboratory gamma spectroscopy methods and for leachable RCRA metals using TCLP analytical procedures. Mercury was not identified as a COC and was not included in the TCLP analysis. All samples passed the TCLP tests, and all waste was characterized as "Radioactive-Low Level Only." A summary of radiological activity for the waste is presented in Appendix G.

Disposal of regulated VCM waste was handled by SNL/NM Department 7577 (Waste Operations), which packaged and secured waste drums for transfer to Envirocare of Utah. Nonregulated waste was be disposed of using standard SNL/NM-approved waste disposal methods.

\section{Conclusions}

All point and area sources of gamma activity 30 percent or greater than the natural background were removed from the sites with the exception of four area sources. The elevated radiation at 
three of these sources are related to "shine" (gamma interference) from material stored within adjacent buildings underlying, and the other source is related to a concrete cylinder. Further nonradiological characterization is planned at the sites, and risk assessments will be conducted after characterization and remediation is performed.

Source removal is summarized in Table 5.8.31, and sources remaining after completion of the VCM are shown in Figure 5.8.11.

Table 5.8.31 Summary of Point and Area Source Removal at ER Sites 103 and 117

\begin{tabular}{|c|c|c|l|}
\hline Anomaly Type & Total Identified & Total Removed & \multicolumn{1}{|c|}{ Comments } \\
\hline Point Sources & 8 & 6 & $\begin{array}{l}\text { One source is associated with a } \\
\text { concrete cylinder. One source is } \\
\text { related to "shine" (gamma } \\
\text { interference from material stored } \\
\text { within adjacent building. }\end{array}$ \\
\hline Area Sources & 14 & 12 & $\begin{array}{l}\text { Two sources are related to "shine" } \\
\text { (gamma interference) from material } \\
\text { stored within adjacent building. }\end{array}$ \\
\hline
\end{tabular}

No additional cleanup activities were performed during this VCM. The status of other possible COCs is not addressed in this report.

All waste was characterized as "Radioactive-Low Level Only" and managed in accordance with SNL/NM Department 7572 (Waste Management) procedures.

\subsubsection{Building 9940 - Firing Site (ER Site 108)}

\section{Overview}

The Phase I survey at ER Site 108 was conducted during October 1993 and covered a total of 2.2 acres of flat alluvial terrain encompassing Building 9940. A gamma scan survey was performed at 6-foot centers (100 percent coverage) over the surface of the site. Four point sources and eleven area sources of gamma activity 30 percent or greater than the natural background were identified during this survey. A detailed summary of the surface radiological survey and anomalies found at the site is presented in Section 5.8.7 of the Surface Gamma Radiation Surveys Final Report (Geotech 1994b).

Figure 5.8.12 shows the site, surface radiological survey boundaries, and anomalies found during the Phase I survey.

In July 1995, pre-cleanup soil sampling for gamma spectroscopy analysis was conducted on 10 area sources to assess the need for remediation. VCM activities were conducted during September to October 1995 and required a total of 18.5 days. Point sources and small area sources were removed in September 1995. Large area sources were remediated in October 1995. Cleanup activities included radiation scanning to verify anomaly location, removal of fragment 


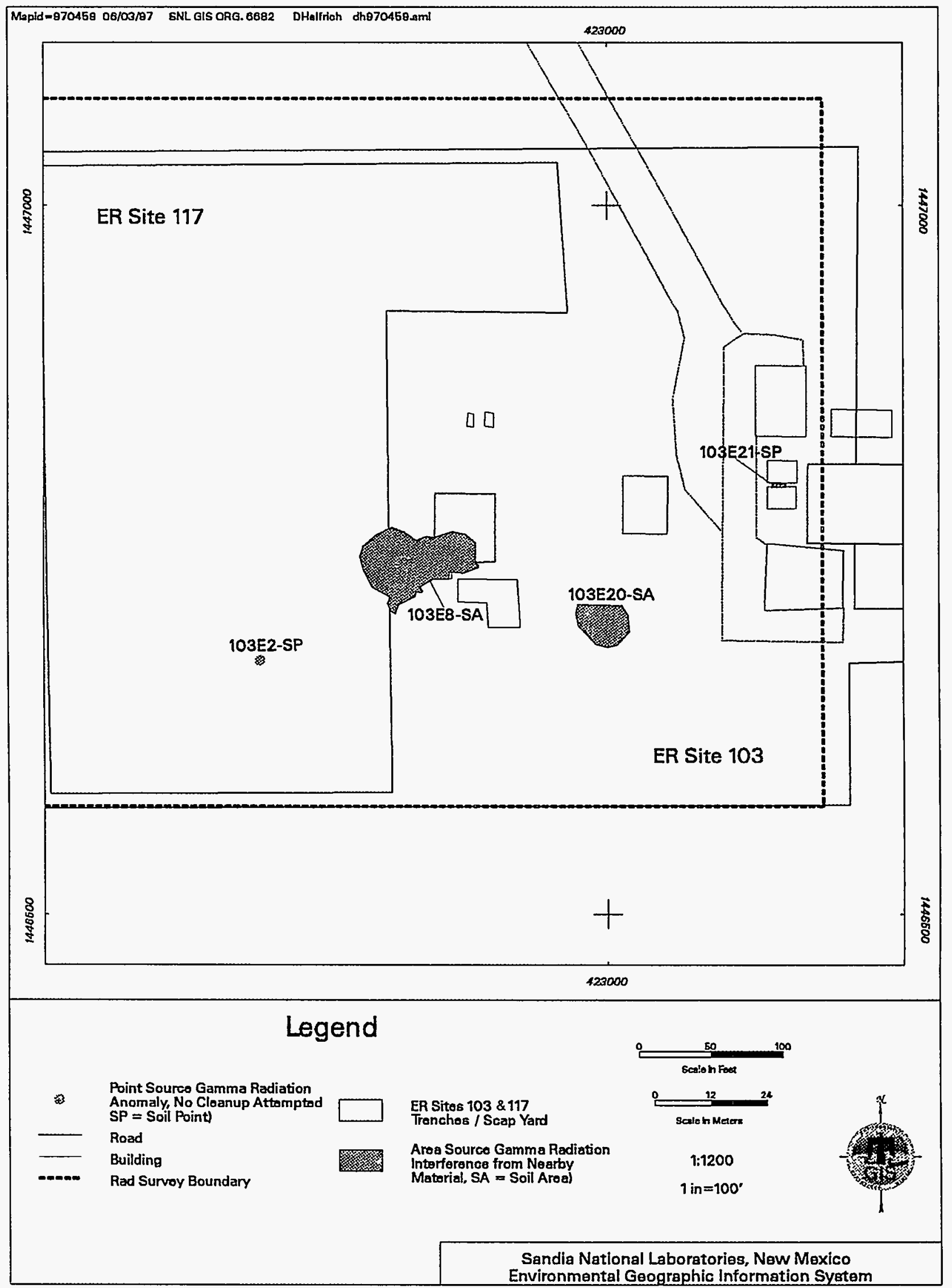

Figure 5.8.11 Radiation Anomalies Remaining After Completion of the VCM at ER Sites 103 \& 117 


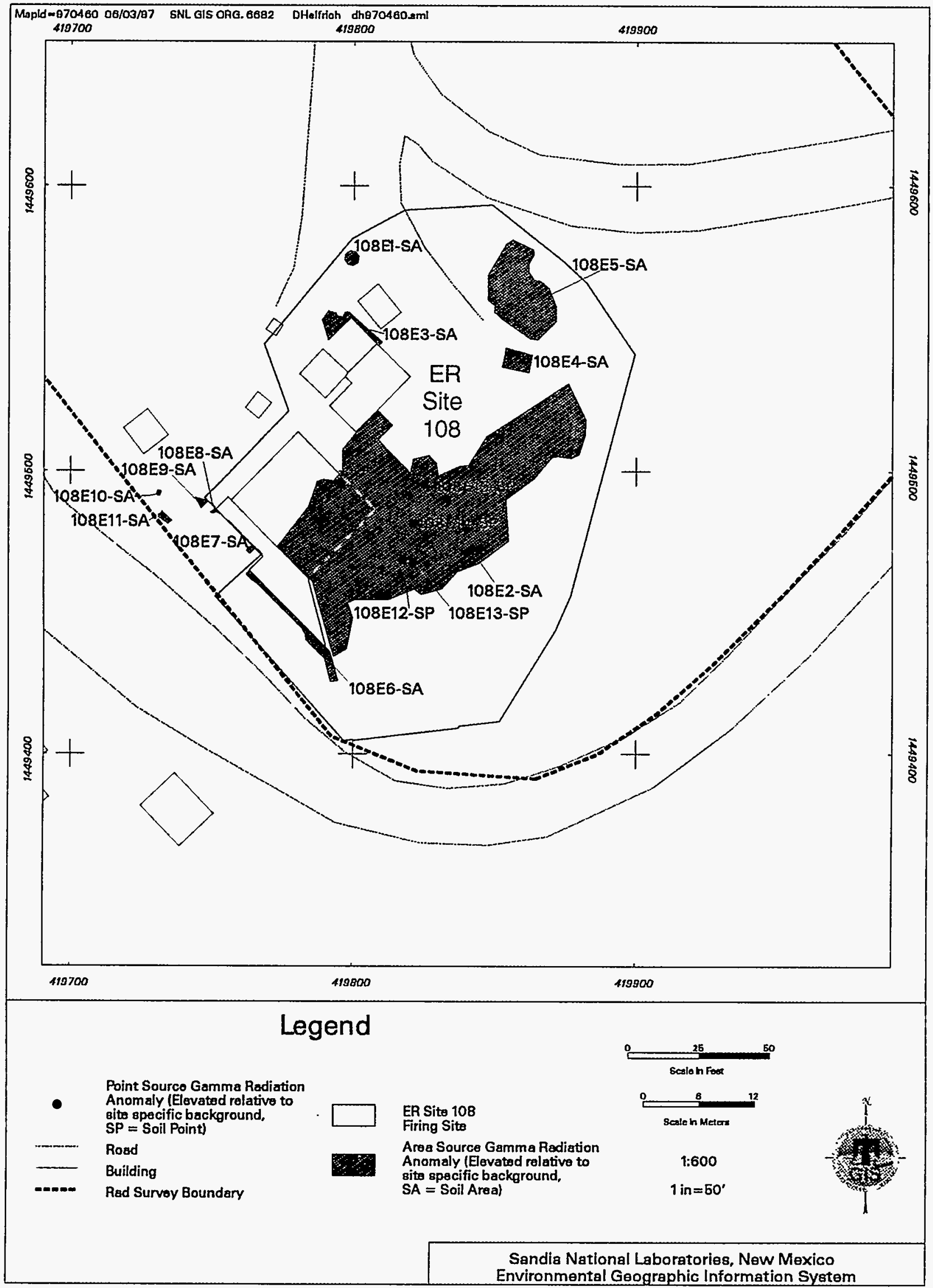

Figure 5.8.12 Phase I Survey Radiation Anomalies at ER Site 108 
and/or soil until readings were less than 1.3 times site-specific background levels, and postcleanup (verification) soil sampling for gamma spectroscopy analysis (see Section 3.1).

Table 5.8.32 summarizes field activities during the VCM.

Table 5.8.32 Summary of Field Activities at ER Site 108

Removal Action Procedures

\begin{tabular}{|c|c|c|c|c|c|c|}
\hline $\begin{array}{c}\text { Actual } \\
\text { Acreage } \\
\text { Surveyed }\end{array}$ & $\begin{array}{c}\text { Duration of } \\
\text { Cleanup } \\
\text { (days) }\end{array}$ & $\begin{array}{c}\text { Verify } \\
\text { Anomaly } \\
\text { Location }\end{array}$ & $\begin{array}{c}\text { Rad } \\
\text { Removal }\end{array}$ & $\begin{array}{c}\text { Post- } \\
\text { Cleanup } \\
\text { Sampling }\end{array}$ & $\begin{array}{c}\text { Pre-Cleanup } \\
\text { Sampling } \\
\text { (area sources) }\end{array}$ & Comments \\
\hline 2.20 & 18.50 & $\mathbf{X}$ & $\mathbf{X}$ & $\mathbf{X}$ & $\mathbf{X}$ & $\begin{array}{l}\text { Pre-cleanup sampling of } \\
\text { original area sources } \\
\text { adjacent to concrete and } \\
\text { asphalt areas }\end{array}$ \\
\hline
\end{tabular}

${ }^{a}$ Removal of fragment and/or soil until readings are less than 1.3 times site-specific background

\section{Findings and Observations}

\section{Point and Area Source Status}

Before cleanup was initiated on the sources identified during the Phase I survey, pre-cleanup soil sampling for gamma spectroscopy analysis was performed on ten area sources to assess if remediation is required. Due to the close proximity and similar appearance of two area sources (108E10 and 108E11), only one area source (108E10) was sampled.

For six small area sources (108E1, 108E2, 108E3, 108E4, 108E5, and 108E10), results of the gamma spectroscopy analysis from pre-cleanup samples indicated the elevated radiation was related to anthropogenic (man-made) material. During the initial cleanup, remediation was completed on four of these area sources and the four point sources identified during the Phase I survey. Remediation of two of these area sources (108E4 and 108E5) showed them to be linked to one large area source. Cleanup was not completed on one area source (108E2) and will require additional remediation because radioactive contaminated soil extended under the concrete pad and exceeded the capabilities of manual cleanup procedures. The remediation of two area sources (108E10 and 108E11) was completed during subsequent cleanup activities.

The gamma spectroscopy results from pre-cleanup samples on four area sources (108E6, 108E7, $108 \mathrm{E} 8$, and 108E9) showed the elevated radiation was related to "shine" (gamma interference) from adjacent buildings, and no remediation is required. No additional point or area sources were identified during this VCM. Table 5.8 .33 shows the pre-cleanup samples collected from these sources, and Figure 5.8.13 shows VCM verification sampling locations (pre-cleanup and post-cleanup). 


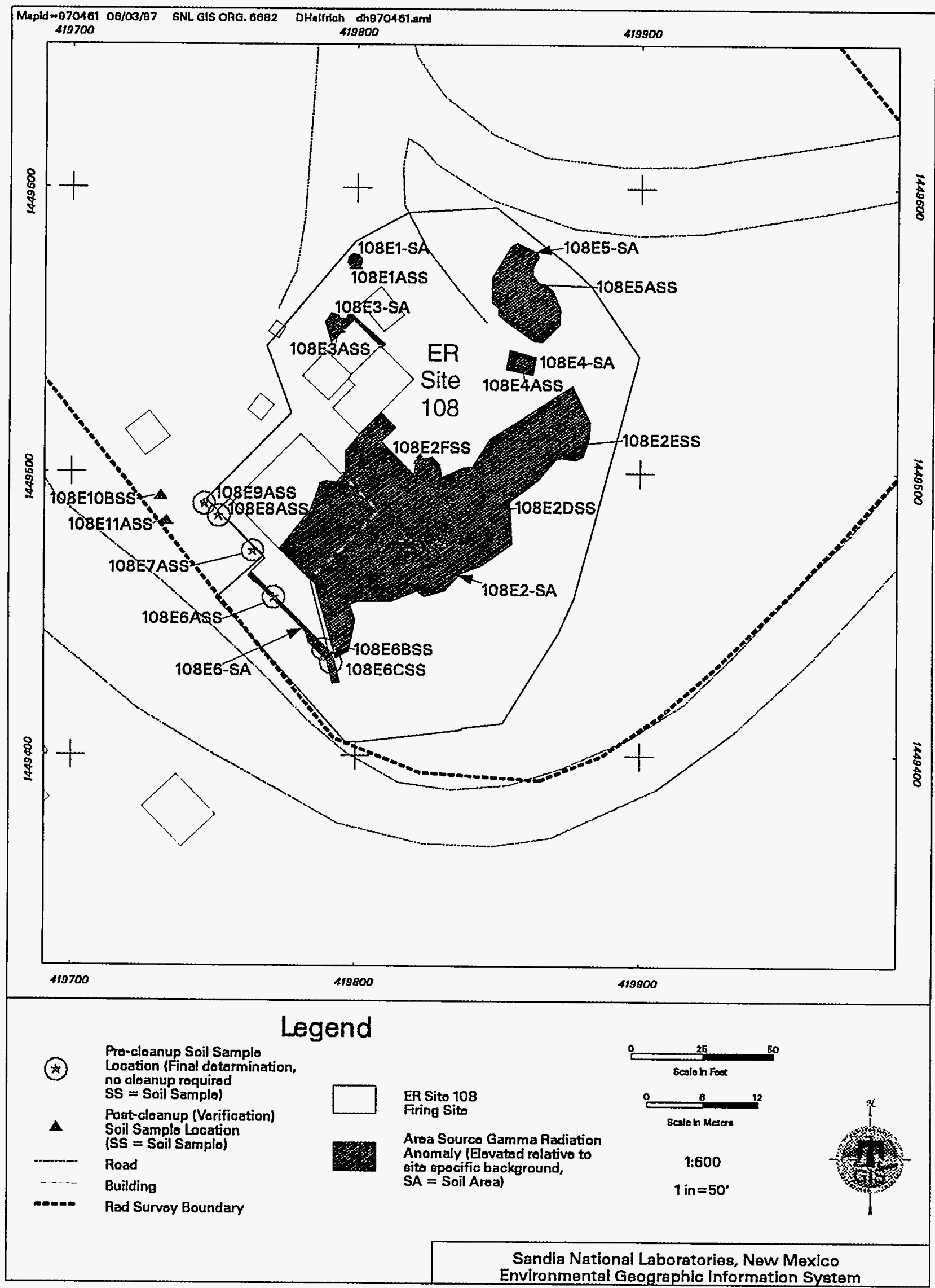

Figure 5.8.13 VCM Surface Soil Sampling Locations at Site 108 
Table 5.8.33 Pre-Cleanup (Final Determination) Samples Collected at ER Site 108

\begin{tabular}{|lll|}
\hline & $\begin{array}{c}\text { Area Source } \\
\text { Sample Number }\end{array}$ \\
\hline \hline 108E6ASS & 108E6BSS & 108E6CSS \\
108E7ASS & 108E8ASS & 108E9ASS \\
\hline
\end{tabular}

\section{Post-Cleanup (Verification) Sample Results}

After the removal of radiologically contaminated soils, ten post-cleanup (verification) samples were collected from areas exhibiting the highest residual gamma radiation readings. Gamma spectroscopy analysis was performed on the samples to verify that the residual radionuclide concentrations met risk-based action levels. The radiological COC was DU (U-238, U-235, and U-234). Table 5.8.34 summarizes the post-cleanup (verification) samples collected at the site, and the maximum level of residual radiological COC in soils is presented in Table 5.8.35.

Table 5.8.34 Post-Cleanup (Verification) Samples Collected at ER Site 108

\begin{tabular}{|lll|}
\hline \multicolumn{3}{|c|}{$\begin{array}{c}\text { Area Source } \\
\text { Sample Number }\end{array}$} \\
\hline \hline $108 E 1 A S S$ & $108 E 2 C S S$ & $108 E 2 D S S$ \\
$108 E 2 E S S$ & $108 E 2 F S S$ & $108 E 3 A S S$ \\
$108 E 4 A S S$ & $108 E 5 A S S$ & $108 E 10 B S S$ \\
$108 E 11$ ASS & & \\
\hline
\end{tabular}

Table 5.8.35 Maximum Residual Radionuclide Levels in ER Site 108 Soils

\begin{tabular}{|c|c|c|}
\hline Radionuclide & Maximum Activity (pCi/g) & Background Activity (pCi/g) \\
\hline U-238 & 54.0 & 1.4 \\
\hline U-235 & 0.84 & 0.16 \\
\hline U-234 & 6.75 & 1.6 \\
\hline
\end{tabular}

\section{Risk Assessment Results}

A risk assessment, using the DOE computer code RESRAD, was performed on ER Site 108 assuming both an industrial and a residential (loss of active control measures) land-use scenario, consistent with Section 3.3.2. The RESRAD input parameters that were not site specific are provided for both land-use scenarios in Section 3.3.2. Site-specific input parameters were developed based on information provided by the Task Leader responsible for the site and were as follows: 
- Area of Contaminated Zone: $1,600 \mathrm{~m}^{2}$

- Thickness of contaminated zone: $0.15 \mathrm{~m}$

- Length Parallel to Aquifer Flow: $60 \mathrm{~m}$

- Density of Contaminated Zone: $1.85 \mathrm{~g} / \mathrm{cm}^{3}$

- Contaminated Zone Total Porosity: 0.4

- Contaminated Zone Effective Porosity: 0.35

- Contaminated Zone Hydraulic Conductivity: 3,650 m/yr

- Contaminated Zone b Parameter: 4.9 (Silty Sand)

- Runoff Coefficient: 0.4

Site-specific risk assessment resulted in the following TEDEs to the RME individual:

- Industrial Land-Use: $2.1 \mathrm{mrem} / \mathrm{yr}$

- Residential Land-Use: $5.8 \mathrm{mrem} / \mathrm{yr}$

The calculated TEDEs for both scenarios are well below the proposed EPA guidance discussed in Section 2.2 .2 of $15 \mathrm{mrem} / \mathrm{yr}$ maximum TEDE for industrial land-use and $75 \mathrm{mrem} / \mathrm{yr}$ for residential land-use. The average radiation exposure due to natural sources (radon, internal radiation, cosmic radiation, and terrestrial radiation) in the U.S. is approximately $295 \mathrm{mrem} / \mathrm{yr}$ TEDE (NCRP 1987). Given the above, the potential effects on human health due to exposure to radionuclides at the site are well within proposed standards when considering both an industrial land-use scenario and a residential land-use scenario.

The uncertainties associated with this assessment are considered small because of the location and history of the site. There is low uncertainty in the future land-use and the potentially affected populations considered in making the risk assessment analysis. An RME approach was used to calculate the risk assessment values. As a result, the parameter values used in the calculations were conservative, and the calculated intakes are likely overestimates. Maximum measured concentrations of the COCs were used to provide conservative results. Because the COCs were found in the surface soils and because of the location and physical characteristics of the site, there is little uncertainty in the exposure pathways relevant to the analysis.

\section{Waste Management}

The cleanup activities produced soil and PPE wastes. No metal fragment waste was generated. All waste was containerized in 55-gallon drums. A total of 273 waste drums were generated during cleanup activities: 272 soil drums and 1 PPE drum. The number of waste drums produced at the site is shown in Table 5.8.36.

Five composite soil samples were collected from the waste drums and analyzed for gamma emitters using standard laboratory gamma spectroscopy methods and for leachable RCRA metals using TCLP analytical procedures. Mercury was not identified as a COC and was not included in 
Table 5.5.36 Summary of Waste Drums for ER Site 108

\begin{tabular}{|c|c|c|c|c|c|c|c|}
\hline \multicolumn{2}{|c|}{ Soil Waste } & & $\begin{array}{c}\text { Metal Fragment } \\
\text { Waste }\end{array}$ & \multicolumn{2}{c|}{ PPE Waste } & & Comments \\
$\begin{array}{c}\text { 30 Gallon } \\
\text { Drums }\end{array}$ & $\begin{array}{c}\text { 55 Gallon } \\
\text { Drums }\end{array}$ & $\begin{array}{c}\text { 30 Gallon } \\
\text { Drums }\end{array}$ & $\begin{array}{c}\text { 55 Gallon } \\
\text { Drums }\end{array}$ & $\begin{array}{c}\text { 30 Gallon } \\
\text { Drums Gallon }\end{array}$ & $\begin{array}{c}\text { TCLP/ } \\
\text { Drums }\end{array}$ & $\begin{array}{c}\text { Gamma } \\
\text { Spec } \\
\text { Samples }\end{array}$ & \\
\hline \hline 0 & 272 & 0 & 0 & 0 & 1 & 6 Soil & \\
\hline
\end{tabular}

the TCLP analysis. All samples passed the TCLP tests, and all waste was characterized as "Radioactive-Low Level Only." A summary of radiological activity for the waste is presented in Appendix G.

Disposal of regulated VCM waste was handled by SNL/NM Department 7577 (Waste Operations), which packaged and secured waste drums for transfer to Envirocare of Utah. Nonregulated waste was disposed of using standard SNL/NM-approved waste disposal methods.

\section{Conclusions}

All point and area sources of gamma activity 30 percent or greater than the natural background were removed from the site with the exceptions of five area sources. Four area sources were related to "shine" (gamma interference) from adjacent buildings, and one area source exceeded the capabilities of manual cleanup procedures (beneath concrete pad). A radiological risk assessment was performed assuming both an industrial and a residential (loss of active control measures) land-use scenario, and using site-specific input parameters. The risk assessment shows the potential effects on human health due to exposure to radionuclides at the site are within proposed standards when considering both land-use scenarios.

Source removal is summarized in Table 5.8.37, and sources remaining after completion of the VCM are shown in Figure 5.8.14.

Table 5.8.37 Summary of Point and Area Source Removal at ER Site 108

\begin{tabular}{|c|c|c|l|}
\hline Anomaly Type & Total Identified & Total Removed & \multicolumn{1}{|c|}{ Comments } \\
\hline Point Sources & 4 & 4 & $\begin{array}{l}\text { Cleanup complete and no further } \\
\text { action is required. }\end{array}$ \\
\hline Area Sources & 11 & 6 & $\begin{array}{l}\text { One source extends beneath } \\
\text { concrete pad. Four sources are } \\
\text { related to "shine " (gamma } \\
\text { interference) from adjacent } \\
\text { buildings. }\end{array}$ \\
\hline
\end{tabular}




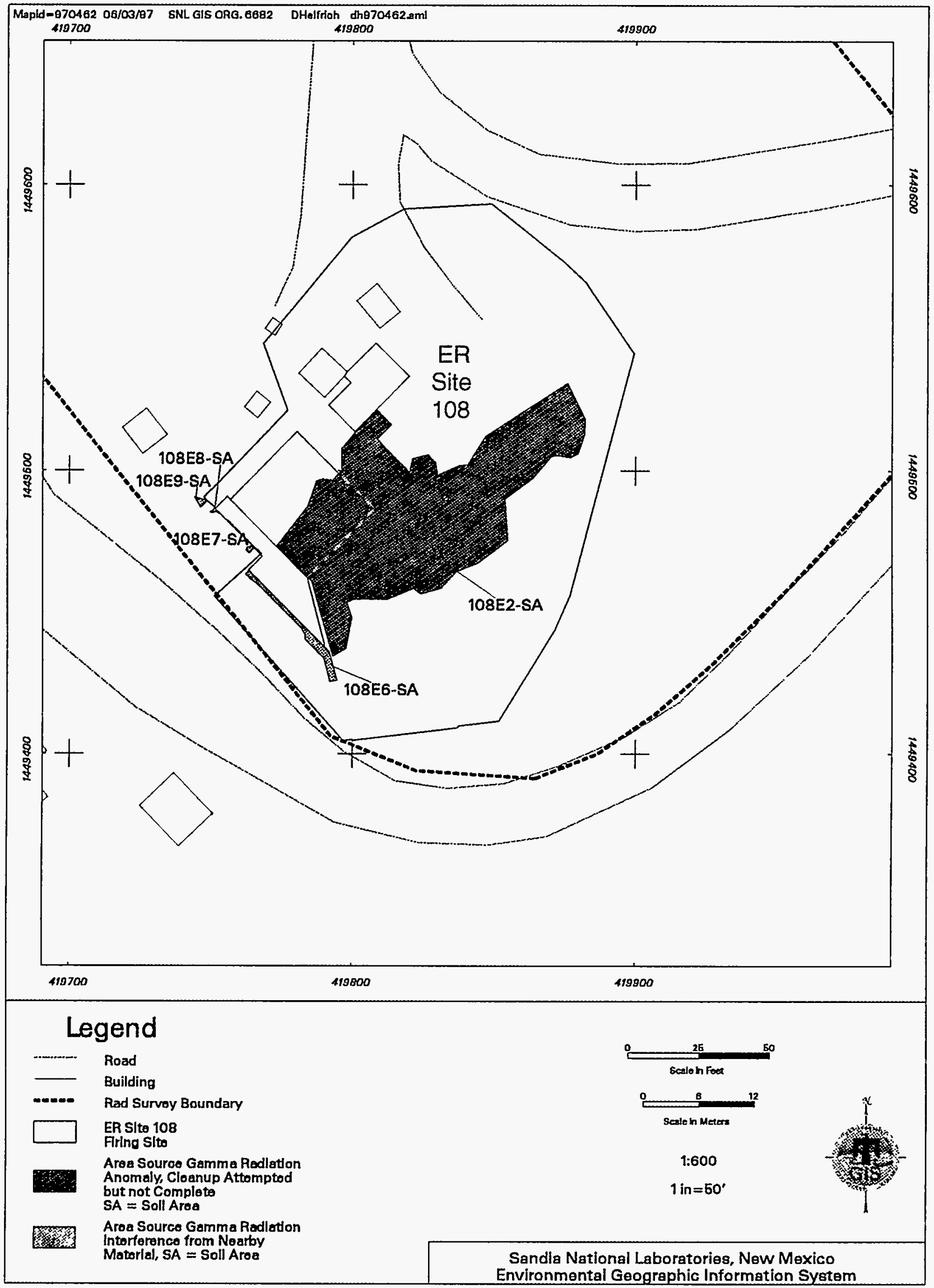

Figure 5.8.14 Radiation Anomalies Remaining After Completion of the VCM at ER Site 108 
No additional cleanup activities were performed during this VCM. The status of other possible COCs is not addressed in this report.

All waste was characterized as "Radioactive-Low Level Only" and managed in accordance with SNL/NM Department 7572 (Waste Management) procedures.

\subsubsection{Building 9930 - Firing Site (ER Site 115)}

\section{Overview}

The Phase I survey at ER Site 115 was conducted during March 1994 and covered a total of 1.0 acre of uneven terrain encompassing the experimental test site. A gamma scan survey was performed at 6 -foot centers (100 percent coverage) over the surface of the site. One area of gamma activity 30 percent or greater than the natural background was identified during the survey. The elevated radiation is suspected of being related to the underlying, naturallyoccurring geological material. A detailed summary of the surface radiological survey and anomalies found at the site is presented in Section 5.8.9 of the Surface Gamma Radiation Surveys Final Report (Geotech 1994b).

Figure 5.8.15 shows the site, surface radiological survey boundaries, and anomaly found during the Phase I survey, and VCM verification sampling locations (pre-cleanup).

In October 1996, pre-cleanup soil sampling for gamma spectroscopy analysis was conducted on the one area source to assess the need for remediation. Table 5.8.38 summarizes field activities during the VCM.

Table 5.8.38 Summary of Field Activities at ER Site 115

\begin{tabular}{|c|c|c|c|c|}
\hline $\begin{array}{c}\text { Actual Acreage } \\
\text { Surveyed }\end{array}$ & $\begin{array}{c}\text { Duration of } \\
\text { Cleanup (days) }\end{array}$ & $\begin{array}{c}\text { Verify } \\
\text { Anomaly } \\
\text { Location }\end{array}$ & $\begin{array}{c}\text { Pre-Cleanup } \\
\text { Sampling } \\
\text { (area sources) }\end{array}$ & Comments \\
\hline 1.00 & $<0.25$ & $\mathbf{X}$ & $\mathbf{X}$ & $\begin{array}{l}\text { Pre-cleanup sampling of } \\
\text { natural outcrops. }\end{array}$ \\
\hline
\end{tabular}

\section{Findings and Observations}

\section{Point and Area Source Status}

The one area sources (115E1) was not remediated. The results of gamma spectroscopy analysis on pre-cleanup samples collected from this location indicate the elevated radiation is related to the underlying, naturally-occurring geologic material. No additional point or area sources were identified during this VCM. 


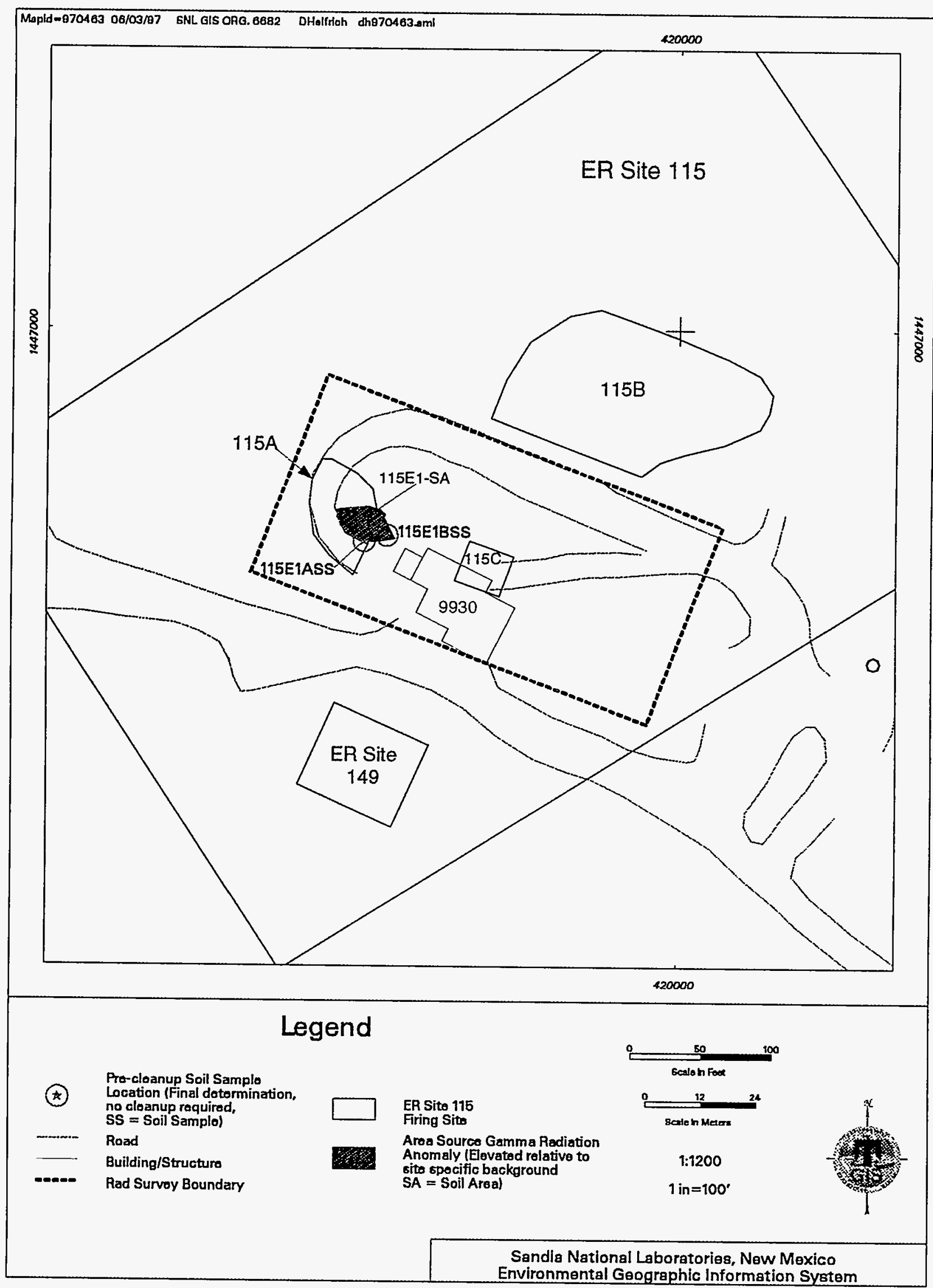

Figure 5.8.15 Phase I Survey Radiation Anomalies and VCM Surface Soil Sampling Locations at ER Site 115 


\section{Pre-Cleanup (Confirmatory) Sample Results}

The area source consisted of one yellowish natural rock outcrop containing elevated thorium and uranium series radionuclides. Two pre-cleanup (confirmatory) samples were collected from areas exhibiting the highest residual gamma radiation readings. Gamma spectroscopy analysis was performed on the samples to characterize, if present, the residual radioactivity in the soil. Review of these analyses showed that, although the results were in excess of regional background values, the samples were representative of background distributions. The combination of this analysis and the fact that the elevated gamma readings were from rock outcrops led to the conclusion that elevated levels were due to naturally-occurring radionuclides. Table 5.8.39 shows the pre-cleanup samples collected at the site, and the maximum level of residual radiological COCs in soil is presented in Table 5.8.40.

Table 5.8.39 Pre-Cleanup (Final Determination) Samples Collected at ER Site 115

\begin{tabular}{|c|c|}
\hline \multicolumn{2}{|c|}{$\begin{array}{c}\text { Area Source } \\
\text { Sample Number }\end{array}$} \\
\hline $115 \mathrm{E} 1 \mathrm{ASS}$ & 115E1BSS \\
\hline
\end{tabular}

Table 5.8.40 Maximum Residual Radionuclide Levels in ER Site 115 Soils

\begin{tabular}{|c|c|c|}
\hline Radionuclide & Maximum Activity (pCi/g) & Background Activity (pCi/g) \\
\hline U-238 & 1.4 & 1.4 \\
\hline U-235 & ND & 0.16 \\
\hline U-234 & ND & 1.6 \\
\hline Th-232 & 1.32 & 1.01 \\
\hline Ra-228 & 1.56 & 1.01 \\
\hline
\end{tabular}

\section{Risk Assessment Results}

No risk assessment was performed since the anomaly was characterized as being only elevated background.

\section{Waste Management}

No VCM was conducted and, therefore, no waste was generated.

\section{Conclusions}

No surface radiation cleanup activities were performed, and no waste was generated. The one area source of gamma activity 30 percent or greater than the natural background was not remediated since the elevated radiation is naturally-occurring. No radiological risk assessment is planned. Source removal is summarized in Table 5.3.41. 
Table 5.8.41 Summary of Area Source Removal at ER Site 115

\begin{tabular}{|c|c|c|l|}
\hline Anomaly Type & Total Identified & Total Removed & \multicolumn{1}{c|}{ Comments } \\
\hline Area Source & 1 & 0 & $\begin{array}{l}\text { Source is related to underlying, } \\
\text { naturally-occurring geologic } \\
\text { material. }\end{array}$ \\
\hline
\end{tabular}

No additional cleanup activities were performed during this VCM. The status of other possible COCs is not addressed in this report.

\subsubsection{Equus Red (ER Site 191)}

\section{Overview}

The Phase I survey at ER Site 191 was conducted during January 1994 and covered a total of 4.2 acres of flat alluvial terrain. A gamma scan survey was performed at 6 -foot centers (100 percent coverage) over the surface of the site. Five point sources of gamma activity 30 percent or greater than the natural background were identified during this survey. A detailed summary of the surface radiological survey and anomalies found at the site is presented in Section 5.8.10 of the Surface Gamma Radiation Surveys Final Report (Geotech 1994b).

Figure 5.8.16 shows the site, surface radiological survey boundaries, and anomaly found during the Phase I survey, and VCM verification sampling locations (post-cleanup).

VCM activities were conducted during February 1995 when five point sources were removed. Resurveying (scanning) was not performed at this site.

Cleanup activities included radiation scanning to verify anomaly location, removal of fragment and/or soil until readings were less than 1.3 times site-specific background levels, and postcleanup (verification) soil sampling for gamma spectroscopy analysis (see Section 3.1). Table 5.8.42 summarizes field activities during the VCM.

Table 5.8.42 Summary of Field Activities at ER Site 191

Removal Action Procedures

\begin{tabular}{|c|c|c|c|c|}
\hline $\begin{array}{c}\text { Actual Acreage } \\
\text { Surveyed }\end{array}$ & $\begin{array}{c}\text { Duration of } \\
\text { Cleanup (days) }\end{array}$ & $\begin{array}{c}\text { Verify Anomaly } \\
\text { Location }\end{array}$ & Rad Removal $^{\mathrm{a}}$ & Post-Cleanup Sampling $^{\text {Poch }}$ \\
\hline 4.20 & 0.25 & $\mathbf{X}$ & $\mathbf{X}$ & $\mathbf{X}$ \\
\hline
\end{tabular}

${ }^{a}$ Removal of fragment and/or soil until readings are less than 1.3 times site-specific background 


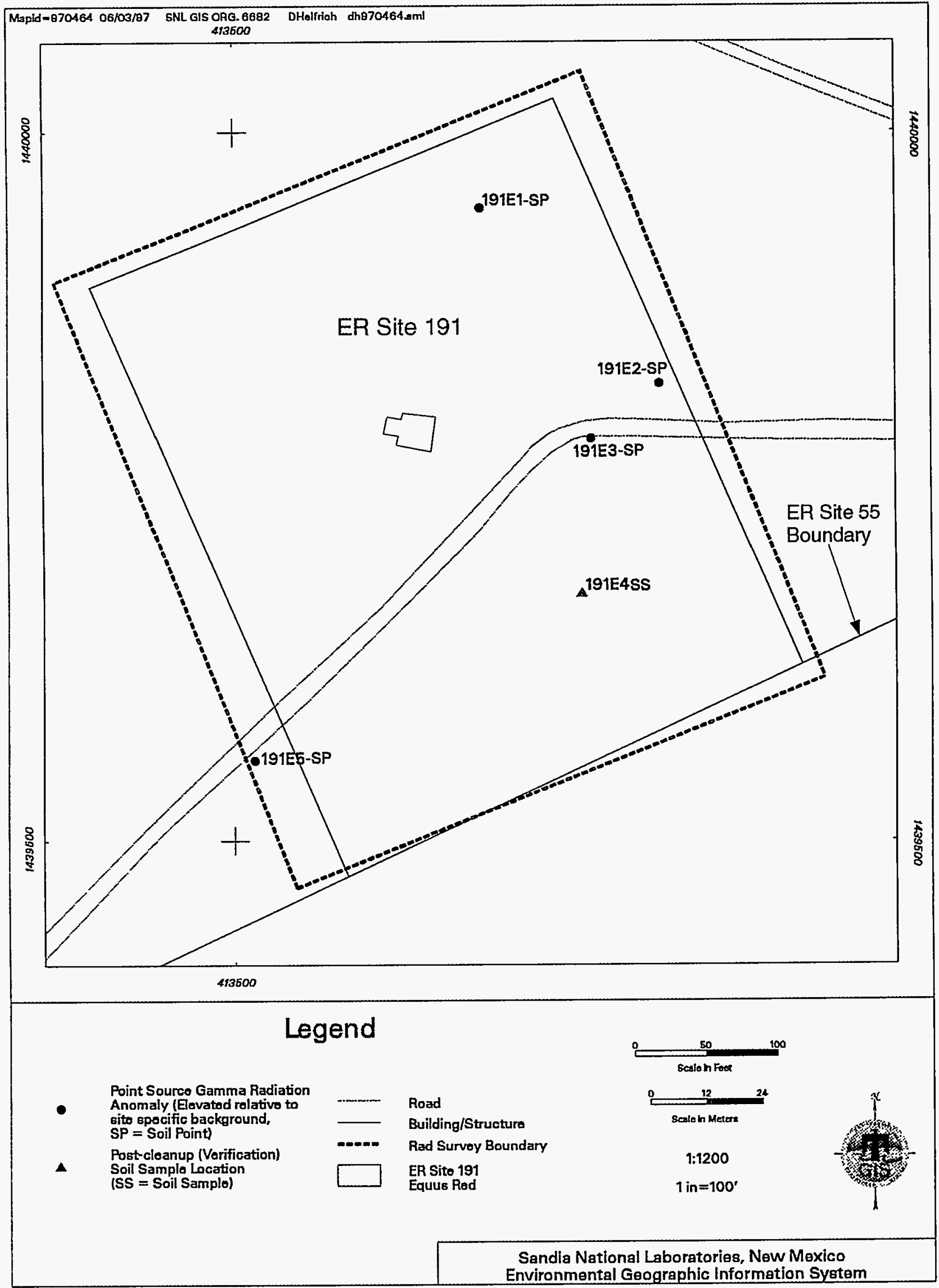

Figure 5.8.16 Phase I Survey Radiation Anomalies and VCM Surface Soil Sampling Locations at ER Site 191 


\section{Findings and Observations}

\section{Point and Area Source Status}

Of the sources identified during the Phase I survey, five point sources were remediated during the initial cleanup. Cleanup was completed on these point sources and no additional point or area sources were identified during this VCM.

\section{Post-Cleanup (Verification) Sample Results}

After the removal of radiologically contaminated soils, two post-cleanup (verification) samples were collected from areas exhibiting the highest residual gamma radiation readings. Gamma spectroscopy analysis was performed on the samples to verify that the residual radionuclide concentrations met risk-based action levels. The radiological COC was DU (U-238, U-235, and U-234). Table 5.8.43 shows the post-cleanup (verification) samples collected, and the maximum level of residual radiological COCs in soils is presented in Table 5.8.44.

Table 5.8.43 Post-Cleanup (Verification) Samples Collected at ER Site 191

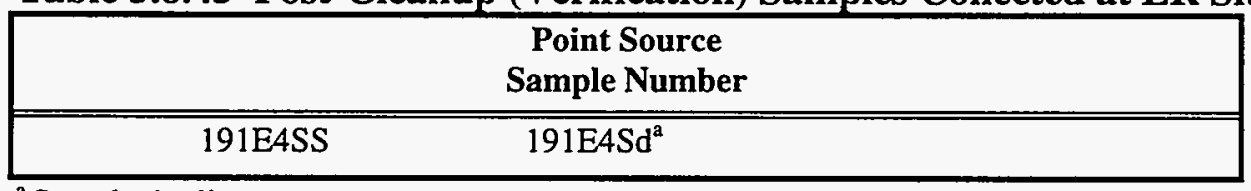

${ }^{\text {a }}$ Sample duplicate

Table 5.8.44 Maximum Residual Radionuclide Levels in ER Site 191 Soils

\begin{tabular}{|c|c|c|}
\hline Radionuclide & Maximum Activity (pCi/g) & Background Activity (pCi/g) \\
\hline U-238 & 2.01 & 1.4 \\
\hline U-235 & 0.03 & 0.16 \\
\hline U-234 & 0.25 & 1.6 \\
\hline
\end{tabular}

Although U-235 and U-234 values for the DU were below background concentrations, for conservatism they were included in the risk assessment by their association with the elevated levels of U-238 and the known DU contamination on site.

\section{Risk Assessment Results}

A risk assessment, using the DOE computer code RESRAD, was performed on ER Site 191 assuming both an industrial and a residential (loss of active control measures) land-use scenario, consistent with Section 3.3.2. The RESRAD input parameters that were not site specific are provided for both land-use scenarios in Section 3.3.2. Site-specific input parameters were developed based on information provided by the Task Leader responsible for the site and were as follows: 
- Area of Contaminated Zone: $14,500 \mathrm{~m}^{2}$

- Thickness of contaminated zone: $0.15 \mathrm{~m}$

- Length Parallel to Aquifer Flow: $80 \mathrm{~m}$

- Density of Contaminated Zone: $1.85 \mathrm{~g} / \mathrm{cm}^{3}$

- Contaminated Zone Total Porosity: 0.4

- Contaminated Zone Effective Porosity: 0.35

- Contaminated Zone Hydraulic Conductivity: $3,650 \mathrm{~m} / \mathrm{yr}$

- Contaminated Zone b Parameter: 4.9 (Silty Sand)

- Runoff Coefficient: 0.4

Site-specific risk assessment resulted in the following TEDEs to the RME individual:

- Industrial Land-Use: $0.08 \mathrm{mrem} / \mathrm{yr}$

- Residential Land-Use: $0.02 \mathrm{mrem} / \mathrm{yr}$

The calculated TEDEs for both scenarios are well below the proposed EPA guidance discussed in Section 2.2 .2 of $15 \mathrm{mrem} / \mathrm{yr}$ maximum TEDE for industrial land-use and $75 \mathrm{mrem} / \mathrm{yr}$ for residential land-use. The average radiation exposure due to natural sources (radon, internal radiation, cosmic radiation, and terrestrial radiation) in the U.S. is approximately $295 \mathrm{mrem} / \mathrm{yr}$ TEDE (NCRP 1987). Given the above, the potential effects on human health due to exposure to radionuclides at the site are well within proposed standards when considering both an industrial land-use scenario and a residential land-use scenario.

The uncertainties associated with this assessment are considered small because of the location and history of the site. There is low uncertainty in the future land-use and the potentially affected populations considered in making the risk assessment analysis. An RME approach was used to calculate the risk assessment values. As a result, the parameter values used in the calculations were conservative, and the calculated intakes are likely overestimates. Maximum measured concentrations of the COCs were used to provide conservative results. Because the COCs were found in the surface soils and because of the location and physical characteristics of the site, there is little uncertainty in the exposure pathways relevant to the analysis.

\section{Waste Management}

The cleanup activities produced soil and metal fragment wastes. All waste was containerized in 30-gallon drums. A total of two waste drums were generated during cleanup activities: one soil drum and one metal fragment drum. Waste consolidation was performed to minimize the number of drums produced for each waste stream. One soil drum was consolidated, and one metal fragment drum was consolidated. Table 5.8.45 shows the number of waste drums after waste minimization/consolidation was performed, and Appendix J summarizes the waste minimization/consolidation effort. 
Table 5.8.45 Summary of Waste Drums for ER Site 191 (Post Minimization/ Consolidation Effort)

\begin{tabular}{|c|c|c|c|c|c|c|c|}
\hline \multicolumn{2}{|c|}{ Soil Waste } & \multicolumn{2}{|c|}{$\begin{array}{l}\text { Metal Fragment } \\
\text { Waste }\end{array}$} & \multicolumn{2}{|c|}{ PPE Waste } & \multirow[b]{2}{*}{$\begin{array}{c}\text { TCLP/ } \\
\text { Gamma } \\
\text { Spec } \\
\text { Samples }\end{array}$} & \multirow[b]{2}{*}{ Comments } \\
\hline $\begin{array}{c}30 \text { Gallon } \\
\text { Drums }\end{array}$ & \begin{tabular}{|c|}
55 Gallon \\
Drums
\end{tabular} & \begin{tabular}{|c|}
30 Gallon \\
Drums
\end{tabular} & \begin{tabular}{|c}
55 Gallon \\
Drums
\end{tabular} & $\begin{array}{c}30 \text { Gallon } \\
\text { Drums }\end{array}$ & $\begin{array}{c}55 \text { Gallon } \\
\text { Drums }\end{array}$ & & \\
\hline 0 & $\overline{0}$ & 0 & 0 & 0 & 0 & 1 Soil & $\begin{array}{l}\text { Waste } \\
\text { Minimization/Consolidati } \\
\text { on was performed. }{ }^{2}\end{array}$ \\
\hline
\end{tabular}

${ }^{a}$ See Appendix J

One composite soil samples was collected from the waste drums and analyzed for gamma emitters using standard laboratory gamma spectroscopy methods and for leachable RCRA metals using TCLP analytical procedures. Mercury was not identified as a COC and was not included in the TCLP analysis. All samples passed the TCLP tests, and all waste was characterized as "Radioactive-Low Level Only." A summary of radiological activity for the waste is presented in Appendix G.

No TCLP metal fragment sample was collected due to the large dimension of the metal fragment (approximately 18 inches by 0.25 by 0.5 inch ). The fragment appeared to be a ferrous metal. This fragment waste was consolidated with other metal fragment waste that had been analyzed using TCLP analytical procedures. This other fragment waste passed the TCLP tests and was characterized as "Radioactive-Low Level Only." The TCLP results are statistically valid, even with the addition of a minor volume of metal fragment waste that has not been sampled and analyzed.

Disposal of regulated VCM waste was handled by SNL/NM Department 7577 (Waste Operations), which packaged and secured waste drums for transfer to Envirocare of Utah. Nonregulated waste was disposed of using standard SNL/NM-approved waste disposal methods.

\section{Conclusions}

All point sources of gamma activity 30 percent or greater than the natural background were removed from the site. A radiological risk assessment was performed assuming both an industrial and a residential (loss of active control measures) land-use scenario, and using sitespecific input parameters. The risk assessment shows the potential effects on human health due to exposure to radionuclides at the site are within proposed standards when considering both land-use scenarios. Source removal is summarized in Table 5.8.46. 
Table 5.8.46 Summary of Point Source Removal at ER Site 191

\begin{tabular}{|c|c|c|l|}
\hline Anomaly Type & Total Identified & Total Removed & \multicolumn{1}{c|}{ Comments } \\
\hline Point Sources & 5 & 5 & $\begin{array}{l}\text { Cleanup complete and no further } \\
\text { action is required. }\end{array}$ \\
\hline
\end{tabular}

No additional cleanup activities were performed during this VCM. The status of other possible COCs is not addressed in this report.

All waste was characterized as "Radioactive-Low Level Only" and managed in accordance with SNL/NM Department 7572 (Waste Management) procedures.

\subsubsection{Sabotage Test Area (ER Site 193)}

\section{Overview}

The Phase I survey at ER Site 193 was conducted during January 1994 and covered a total of 0.5 acre of flat alluvial terrain with several concrete structures. A gamma scan survey was performed at 6 -foot centers (100 percent coverage) over the surface of the site. Seven point sources and three area sources of gamma activity 30 percent or greater than the natural background were identified during this survey. A detailed summary of the surface radiological survey and anomalies found at the site is presented in Section 5.8.11 of the Surface Gamma Radiation Surveys Final Report (Geotech 1994b).

Figure 5.8.17 shows the site, surface radiological survey boundaries, and anomalies found during the Phase I survey.

VCM activities were conducted during February and March 1995 and June 1996. Resurveying (scanning) was not performed at this site. Point sources and small area sources were removed in February and March 1995. One large area source was remediated in June 1996. Heavy equipment (backhoe) was used to removed a concrete block that covered a portion of one area source (193E8).

Cleanup activities included radiation scanning to verify anomaly location, removal of fragment and/or soil until readings were less than 1.3 times site-specific background levels, and postcleanup (verification) soil sampling for gamma spectroscopy analysis (see Section 3.1). Table 5.8.47 summarizes field activities during the VCM.

Table 5.8.47 Summary of Field Activities at ER Site 193

Removal Action Procedures

\begin{tabular}{|c|c|c|c|c|}
\hline $\begin{array}{c}\text { Actual Acreage } \\
\text { Surveyed }\end{array}$ & $\begin{array}{c}\text { Duration of } \\
\text { Cleanup (days) }\end{array}$ & $\begin{array}{c}\text { Verify Anomaly } \\
\text { Location }\end{array}$ & Rad Removal $^{\mathrm{a}}$ & Post-Cleanup Sampling $^{\text {Pean }}$ \\
\hline 0.50 & 1.75 & $\mathrm{X}$ & $\mathrm{X}$ & $\mathrm{X}$ \\
\hline
\end{tabular}

${ }^{a}$ Removal of fragment and/or soil until readings are less than 1.3 times site-specific background 


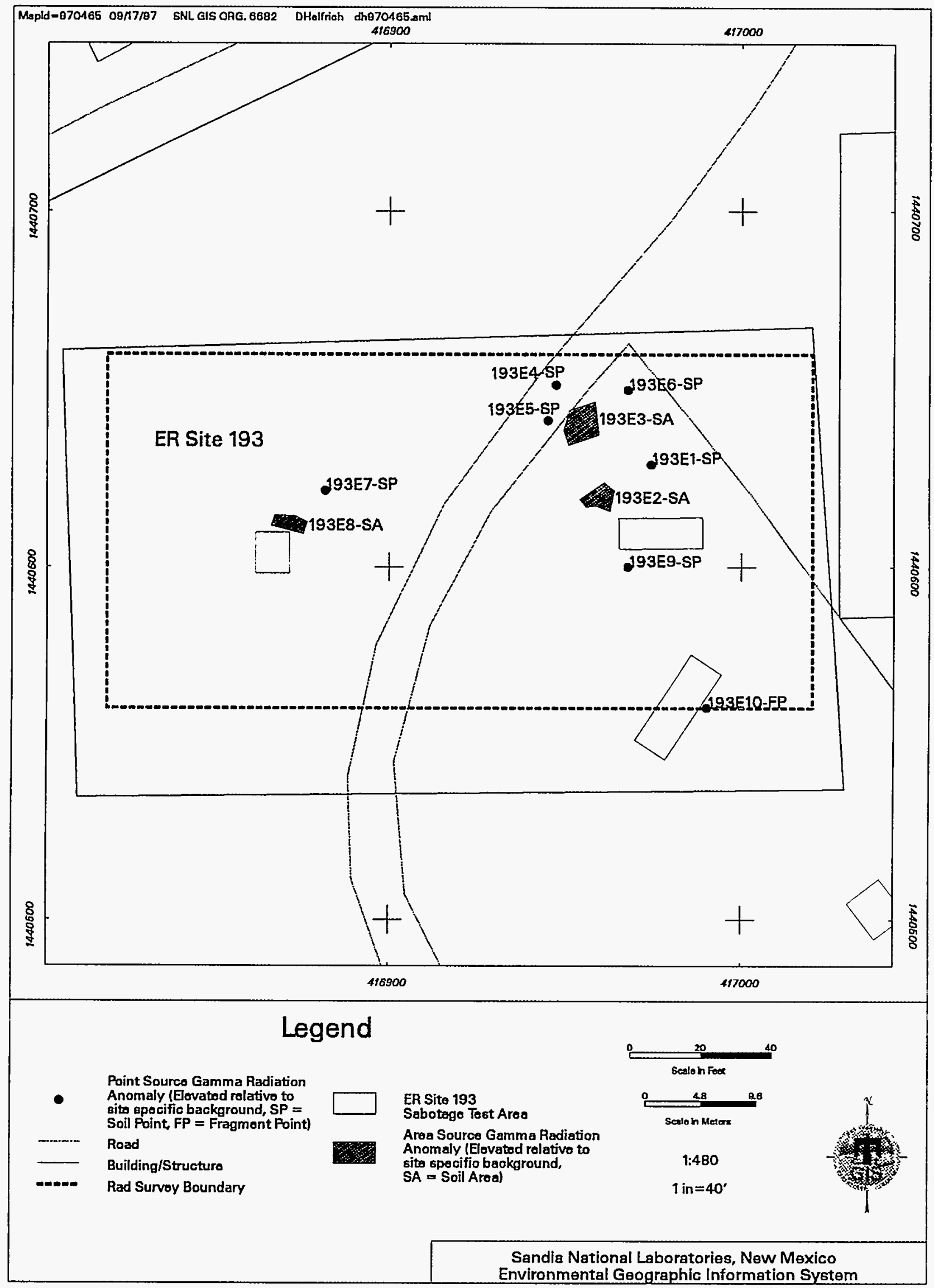

Figure 5.8.17 Phase I Survey Radiation Anomalies at ER Site 193 


\section{Findings and Observations}

\section{Point and Area Source Status}

Of the sources identified during the Phase I survey, seven point sources and two small area sources were remediated during the initial cleanup. One area source (193E8) was remediated after SNL/NM personnel removed a large concrete block that covered a portion of the anomaly. During remediation of this area source, a purple crystalline material was discovered that was determined by SNL/NM Health and Safety personnel to be nonhazardous. No additional anomalies were detected during this VCM. Cleanup was completed on all point sources, and no additional surface radiation cleanup is required. Figure 5.8.18 shows VCM verification sampling locations (post-cleanup).

\section{Post-Cleanup (Verification) Sample Results}

After the removal of radiologically contaminated soils, seven post-cleanup (verification) samples were collected from point and area sources. Samples from point sources were collected in the immediate vicinity of the point source (fragment). At area sources, samples were collected from areas exhibiting the highest residual gamma radiation readings. Gamma spectroscopy analysis was performed on the samples to verify that the residual radionuclide concentrations met riskbased action levels. The radiological COCs were DU (U-238, U-235, and U-234) and Cs-137. Table 5.8.48 summarizes the post-cleanup (verification) samples collected at the sites, and the maximum level of residual radiological COCs in soils is presented in Table 5.8.49.

Table 5.8.48 Post-Cleanup (Verification) Samples Collected at ER Site 193

\begin{tabular}{|c|c|c|c|c|c|}
\hline \multicolumn{3}{|c|}{$\begin{array}{c}\text { Point Source } \\
\text { Sample Number }\end{array}$} & \multicolumn{3}{|c|}{$\begin{array}{c}\text { Area Source } \\
\text { Sample Number }\end{array}$} \\
\hline 193E7SS & 193E10SS & 193E10SD ${ }^{\mathrm{a}}$ & $\begin{array}{l}193 \mathrm{E} 2 \mathrm{SS} \\
193 \mathrm{E} 8 \mathrm{SS} \mathrm{b}^{\mathrm{b}}\end{array}$ & 193E3SS & \\
\hline
\end{tabular}

${ }^{a}$ Sample duplicate

${ }^{\mathrm{b}}$ Anomaly location sampled on two separate dates (see Appendix E for dates).

Table 5.8.49. Maximum Residual Radionuclide Levels in ER Site 193 Soils

\begin{tabular}{|c|c|c|}
\hline Radionuclide & Maximum Activity (pCi/g) & Background Activity (pCi/g) \\
\hline U-238 & 30.4 & 1.4 \\
\hline U-235 & 0.45 & 0.16 \\
\hline U-234 & 3.8 & 1.6 \\
\hline Cs-137 & 1.68 & 0.66 \\
\hline
\end{tabular}




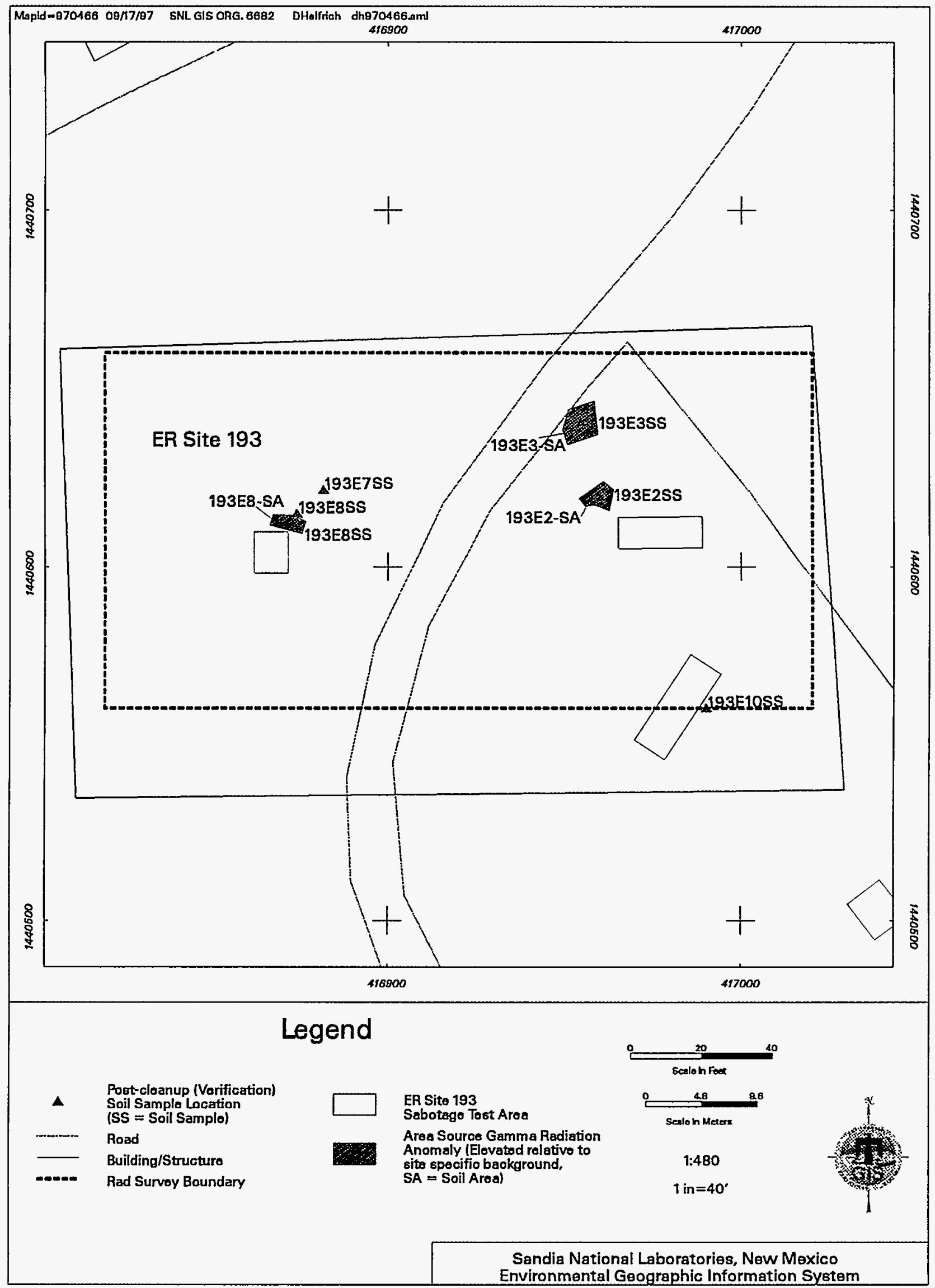

Figure 5.8.18 VCM Surface Soil Sampling Locations at ER Site 193 


\section{Risk Assessment Results}

A risk assessment, using the DOE computer code RESRAD, was performed on ER Site 193 assuming both an industrial and a residential (loss of active control measures) land-use scenario, consistent with Section 3.3.2. The RESRAD input parameters that were not site specific are provided for both land-use scenarios in Section 3.3.2. Site-specific input parameters were developed based on information provided by the Task Leader responsible for the site and were as follows:

- Area of Contaminated Zone: $2,600 \mathrm{~m}^{2}$

- Thickness of contaminated zone: $0.15 \mathrm{~m}$

- Length Parallel to Aquifer Flow: $80 \mathrm{~m}$

- Density of Contaminated Zone: $1.85 \mathrm{~g} / \mathrm{cm}^{3}$

- Contaminated Zone Total Porosity: 0.4

- Contaminated Zone Effective Porosity: 0.35

- Contaminated Zone Hydraulic Conductivity: $3,650 \mathrm{~m} / \mathrm{yr}$

- Contaminated Zone b Parameter: 4.9 (Silty Sand)

- Runoff Coefficient: 0.4

Site-specific risk assessment resulted in the following TEDEs to the RME individual:

- Industrial Land-Use: $2.2 \mathrm{mrem} / \mathrm{yr}$

- Residential Land-Use: $6.1 \mathrm{mrem} / \mathrm{yr}$

The calculated TEDEs for both scenarios are well below the proposed EPA guidance discussed in Section 2.2 .2 of $15 \mathrm{mrem} / \mathrm{yr}$ maximum TEDE for industrial land-use and $75 \mathrm{mrem} / \mathrm{yr}$ for residential land-use. The average radiation exposure due to natural sources (radon, internal radiation, cosmic radiation, and terrestrial radiation) in the U.S. is approximately $295 \mathrm{mrem} / \mathrm{yr}$ TEDE (NCRP 1987). Given the above, the potential effects on human health due to exposure to radionuclides at the site are well within proposed standards when considering both an industrial land-use scenario and a residential land-use scenario.

The uncertainties associated with this assessment are considered small because of the location and history of the site. There is low uncertainty in the future land-use and the potentially affected populations considered in making the risk assessment analysis. An RME approach was used to calculate the risk assessment values. As a result, the parameter values used in the calculations were conservative, and the calculated intakes are likely overestimates. Maximum measured concentrations of the COCs were used to provide conservative results. Because the COCs were found in the surface soils and because of the location and physical characteristics of the site, there is little uncertainty in the exposure pathways relevant to the analysis.

\section{Waste Management}

The cleanup activities produced soil, metal fragment, and PPE wastes. All waste was containerized in 55-gallon drums. A total of nine waste drums were generated during cleanup activities: eight soil drums and one PPE drum. Waste consolidation was performed to minimize 
the number of drums produced for each waste stream. One metal fragment (approximately 18 inches by 2 inches by 0.25 inch) was removed during remediation and consolidated with soil waste, and one PPE drum waste consolidated. Table 5.8.50 shows the number of waste drums after waste minimization/consolidation was performed, and Appendix $\mathrm{J}$ summarizes the waste minimization/consolidation effort.

Table 5.8.50 Summary of Waste Drums for ER Site 193 (Post Minimization/Consolidation Effort)

\begin{tabular}{|c|c|c|c|c|c|c|c|}
\hline \multicolumn{2}{|c|}{ Soil Waste } & \multicolumn{2}{|c|}{$\begin{array}{l}\text { Metal Fragment } \\
\text { Waste }\end{array}$} & \multicolumn{2}{|c|}{ PPE Waste } & \multirow[b]{2}{*}{$\begin{array}{c}\text { TCLP/ } \\
\text { Gamma } \\
\text { Spec } \\
\text { Samples } \\
\end{array}$} & \multirow[b]{2}{*}{ Comments } \\
\hline $\begin{array}{l}30 \text { Gallon } \\
\text { Drums }\end{array}$ & $\begin{array}{l}\text { 55 Gallon } \\
\text { Drums }\end{array}$ & $\begin{array}{l}\text { 30 Gallon } \\
\text { Drums }\end{array}$ & $\begin{array}{l}55 \text { Gallon } \\
\text { Drums }\end{array}$ & $\begin{array}{c}30 \text { Gallon } \\
\text { Drums }\end{array}$ & $\begin{array}{l}55 \text { Gallon } \\
\text { Drums }\end{array}$ & & \\
\hline 0 & 8 & 0 & 0 & 0 & 0 & 2 Soil & $\begin{array}{l}\text { Waste } \\
\text { Minimization/Consolidation } \\
\text { was performed. }\end{array}$ \\
\hline
\end{tabular}

${ }^{a}$ See Appendix J

Two composite soil samples were collected from the waste drums and analyzed for gamma emitters using standard laboratory gamma spectroscopy methods and for leachable RCRA metals using TCLP analytical procedures. Mercury was not identified as a COC and was not included in the TCLP analysis. All samples passed the TCLP tests, and all waste was characterized as "Radioactive-Low Level Only." A summary of radiological activity for the waste is presented in Appendix G.

Disposal of regulated VCM waste was handled by SNL/NM Department 7577 (Waste Operations), which packaged and secured waste drums for transfer to Envirocare of Utah. Nonregulated waste was disposed of using standard SNL/NM-approved waste disposal methods.

\section{Conclusions}

All point and area sources of gamma activity 30 percent or greater than the natural background were removed from the site. A radiological risk assessment was performed assuming both an industrial and a residential (loss of active control measures) land-use scenario, and using sitespecific input parameters. The risk assessment shows the potential effects on human health due to exposure to radionuclides at the site are within proposed standards when considering both land-use scenarios. Source removal is summarized in Table 5.8.51.

No additional cleanup activities were performed during this VCM. The status of other possible COCs is not addressed in this report.

All waste was characterized as "Radioactive-Low Level Only" and managed in accordance with SNL/NM Department 7572 (Waste Management) procedures. 
Table 5.8.51 Summary of Point and Area Source Removal at ER Site 193

\begin{tabular}{|c|c|c|l|}
\hline Anomaly Type & Total Identified & Total Removed & \multicolumn{1}{c|}{ Comments } \\
\hline Point Sources & 7 & 7 & $\begin{array}{l}\text { Cleanup complete and no further } \\
\text { action is required. }\end{array}$ \\
\hline Area Sources & 3 & 3 & $\begin{array}{l}\text { Cleanup complete and no further } \\
\text { action is required. }\end{array}$ \\
\hline
\end{tabular}




\section{GAMMA SURVEYINO RADIOACTIVE SURFACE CONTAMINATION}

During the initial Phase I survey at 27 ER sites, no point or area sources of gamma activity 30 percent or greater than the natural background were identified. Consequently, no surface radiation cleanup was performed, and no further action was proposed. A detailed summary of the gamma survey at these sites is presented in the Surface Gamma Radiation Surveys Final Report (Geotech 1994b). Table 6.1 summarizes the Phase I surface radiological surveys for the 27 ER sites. 
Table 6.1 ER Project Sites Where Gamma Survey Was Conducted And No Radioactive Surface Contamination Was Identified

\begin{tabular}{|c|c|c|c|c|c|c|c|}
\hline ADS \# & ER Site \# & ER Site Name & $\begin{array}{c}\text { No Anomalies, } \\
\text { No Rad VCM } \\
\text { Required }\end{array}$ & $\begin{array}{c}\text { Date } \\
\text { Surveyed }\end{array}$ & $\begin{array}{c}\text { Actual } \\
\text { Acreage } \\
\text { Surveyed }\end{array}$ & $\begin{array}{c}\text { Survey } \\
\text { Coverage }\end{array}$ & Comments \\
\hline
\end{tabular}

Technical Area II Operable Unit Sites (ADS 1303)

\begin{tabular}{|l|c|c|c|c|c|c|}
\hline 1303 & 113 & Area II Firing Sites & $\mathbf{X}$ & Mar-94 & 0.30 & $100 \%$ \\
\hline
\end{tabular}

Technical Area III/V Operable Unit Sites (ADS1306)

\begin{tabular}{|l|l|l|l|l|l|l|l|}
\hline 1306 & 102 & Radioactive Disposal & $\mathbf{X}$ & Apr-94 & 4.40 & $70 \%$ & \\
\hline
\end{tabular}

Tijeras Arroyo Operable Unit Sites (ADS1309)

\begin{tabular}{|c|c|c|c|c|c|c|c|}
\hline 1309 & 7 & $\begin{array}{l}\text { Gas Cylinder } \\
\text { Disposal }\end{array}$ & $\mathbf{X}$ & $|\mathrm{Jan} / \mathrm{Feb}-94|$ & 7.30 & $100 \%$ & \\
\hline 1309 & $\begin{array}{c}23 \mathrm{~A}, 23 \mathrm{~B} \\
23 \mathrm{C}\end{array}$ & Disposal Trenches & $\mathbf{X}$ & Nov-93 & 0.70 & $100 \%$ & \\
\hline 1309 & 45 & Liquid Discharge & $\mathbf{X}$ & Mar-94 & 1.20 & $70 \%$ & \\
\hline 1309 & 46 & $\begin{array}{c}\text { Old Acid Waste Line } \\
\text { Outfall }\end{array}$ & $\mathbf{X}$ & Mar-94 & 0.90 & $100 \%$ & \\
\hline 1309 & 235 & $\begin{array}{c}\text { Storm Drain Systems } \\
\text { Outfall }\end{array}$ & $\mathbf{X}$ & Mar-94 & 1.50 & $100 \%$ & \\
\hline
\end{tabular}

Foothills Test Area Operable Unit Sites (ADS 1332)

\begin{tabular}{|c|c|c|c|c|c|c|c|}
\hline 1332 & 15 & $\begin{array}{c}\text { Trash Pits } \\
\text { (Frustration Site) }\end{array}$ & $\mathbf{X}$ & Oct-94 & 0.60 & $100 \%$ & Original survey conducted on 6-ft centers \\
\hline
\end{tabular}


Table 6.1 ER Project Sites Where Gamma Survey Was Conducted And No Radioactive Surface Contamination Was Identified

\begin{tabular}{|c|c|c|c|c|c|c|c|}
\hline ADS \# & ER Site \# & ER Site Name & $\begin{array}{c}\text { No Anomalies, } \\
\text { No Rad VCM } \\
\text { Required }\end{array}$ & $\begin{array}{c}\text { Date } \\
\text { Surveyed } \\
\text { Acreage } \\
\text { Surveyed }\end{array}$ & $\begin{array}{c}\text { Survey } \\
\text { Coverage }\end{array}$ & Comments \\
\hline 1332 & 67 & Frustration Site & $\mathrm{X}$ & & & & $\begin{array}{c}\text { (100\%) at start of Rad VCM. No } \\
\text { anomalies were identified. }\end{array}$ \\
\hline 1295 & 49 & Drains (9820) & $\mathrm{X}$ & Nov-93 & 1.40 & $100 \%$ & Co-located with Site 27 \\
\hline 1332 & $\begin{array}{c}66,66 \mathrm{~A}, \\
66 \mathrm{~B}\end{array}$ & Boxcar Site & $\mathrm{X}$ & $\begin{array}{c}\text { Jan-94 } \\
\text { Apr-94 }\end{array}$ & 4.70 & $\begin{array}{c}1.8 \mathrm{ac}-100 \% ; \\
2.9 \mathrm{ac}-70 \%\end{array}$ \\
\hline
\end{tabular}

Canyons Test Area Operable Unit Sites (ADS 1333)

\begin{tabular}{|c|c|c|c|c|c|c|c|}
\hline 1333 & 59 & Pendulum Site & $\mathrm{X}$ & Oct-94 & 30.50 & $100 \%$ & Co-located with Sites 10 and 60 \\
\hline 1333 & 63 & Balloon Test Area & $\mathrm{X}$ & $\begin{array}{c}\text { Dec-93 } \\
\text { Oct-94 }\end{array}$ & 19.80 & $100 \%$ & \\
\hline 1333 & 92 & $\begin{array}{c}\text { Pressure Vessel Test } \\
\text { Site }\end{array}$ & $\mathrm{X}$ & $\begin{array}{c}\text { Oct/Nov- } \\
93\end{array}$ & 2.10 & $100 \%$ & \\
\hline 1333 & $236^{\mathrm{c}}$ & $\begin{array}{c}\text { Pit East of Balloon } \\
\text { Site }\end{array}$ & $\mathrm{X}$ & Apr-94 & 6.70 & $\begin{array}{c}3.0 \mathrm{ac}-100 \% ; \\
3.7 \mathrm{ac}-70 \%\end{array}$ & \\
\hline 1333 & $\begin{array}{c}239 \mathrm{~A}, \\
239 \mathrm{~B}^{\mathrm{c}}\end{array}$ & $\begin{array}{c}\text { Impact Area 155mm } \\
\text { and Rockets }\end{array}$ & $\mathrm{X}$ & Jan-94 & 1.20 & $100 \%$ & \\
\hline
\end{tabular}

Central Coyote Test Area Operable Unit Sites (ADS1334)

\begin{tabular}{|c|c|c|c|c|c|c|c|}
\hline 1334 & 21 & $\begin{array}{c}\text { Metal Scrap (Coyote } \\
\text { Springs) }\end{array}$ & $\mathrm{X}$ & $\begin{array}{c}\text { Feb-94 } \\
\text { Apr-94 }\end{array}$ & 1.40 & $100 \%$ & \\
\hline
\end{tabular}


Table 6.1 ER Project Sites Where Gamma Survey Was Conducted And No Radioactive Surface Contamination Was Identified

\begin{tabular}{|c|c|c|c|c|c|c|c|}
\hline ADS \# & ER Site \# & ER Site Name & $\begin{array}{c}\text { No Anomalies, } \\
\text { No Rad VCM } \\
\text { Required }\end{array}$ & $\begin{array}{c}\text { Date } \\
\text { Surveyed } \\
\text { Acreage } \\
\text { Surveyed }\end{array}$ & $\begin{array}{c}\text { Survey } \\
\text { Coverage }\end{array}$ & Comments \\
\hline 1334 & 62 & Greystone Manor Site & $\mathbf{X}$ & Feb-94 & & & \\
\hline 1334 & 22 & Storage/Burn & $\mathbf{X}$ & Feb-94 & 0.10 & $100 \%$ & \\
\hline 1334 & 47 & Doomed Bunker & $\mathbf{X}$ & Jan-94 & 1.10 & $100 \%$ & \\
\hline 1334 & 20 & $\begin{array}{c}\text { Schoolhouse Mesa } \\
\text { Test Site (Burn Site) }\end{array}$ & $\mathbf{X}$ & $\begin{array}{c}\text { Feb-94 } \\
\text { Apr-94 }\end{array}$ & 39.50 & $\begin{array}{l}1.8 \mathrm{ac}-100 \% ; \\
37.7 \mathrm{ac}-70 \%\end{array}$ & Co-located with Sites 9, 61A and 61C \\
\hline 1334 & 69 & Firing Pits & $\mathrm{X}$ & Jan-94 & 1.00 & $100 \%$ & \\
\hline 1334 & $\begin{array}{c}70 \mathrm{~A}, 70 \mathrm{~B}, \\
70 \mathrm{C}\end{array}$ & Explosives Test Pit & $\mathrm{X}$ & Jan-94 & 0.50 & $100 \%$ & \\
\hline
\end{tabular}

Southwest Test Area Operable Unit Sites (ADS 1335)

\begin{tabular}{|c|c|c|c|c|c|c|c|}
\hline 1335 & 86 & Firing Site (9927) & $\mathbf{X}$ & Mar-94 & 2.80 & $100 \%$ & \\
\hline 1335 & 90 & Beryllium Firing Site & $\mathbf{X}$ & Jan-94 & 0.20 & $100 \%$ & \\
\hline 1335 & $109 \mathrm{~A}, 109 \mathrm{~B}$ & Firing Site (9956) & $\mathbf{X}$ & Mar-94 & 0.50 & $100 \%$ & \\
\hline 1335 & 194 & $\begin{array}{c}\text { Heat Source Test } \\
\text { Area }\end{array}$ & $\mathbf{X}$ & Jan-94 & 0.20 & $100 \%$ & \\
\hline & & TOTAL & 27 & & 131 & & \\
\hline
\end{tabular}

a Includes anomalies that appear to be natural geologic outcrops. b One area source includes approximately 175 point sources.

c This site is a potential SWMU.

d A new site identified during VCM.

e Preliminary review indicates that the Rad Risk Assesment will be meet for each site. 


\section{REFERENCES}

Adams, A. S., and W. M. Lowder, editors, 1964. The Natural Radiation Environment. University of Chicago Press.

Culp, T., et al, 1993. "1992 Environmental Monitoring Report," Sandia National Laboratories, Albuquerque, New Mexico.

DOE, see U.S. Department of Energy.

EPA, see U.S. Environmental Protection Agency.

Geotech, see RUST Geotech Inc.

IT Corporation, 1996. Background Concentrations of Constituents of Concern to the Sandia National Laboratories/New Mexico Environmental Restoration Project and the Kirtland Air Force Base Installation Restoration Program. IT Corporation, Albuquerque, New Mexico, March 1996.

Munk, L., 1995. Preliminary Risk Analysis for Depleted Uranium in Outdoor Environments. Environmental Monitoring Program, Sandia National Laboratory, New Mexico.

National Council for Radiation Protection and Measurements (NCRP), 1987. "Exposure of the Population in the U.S. and Canada from Natural Background Radiation." NCR Report No. 97, National Council for Radiation Protection and Measurements, Bethesda, Maryland.

NRC, see U.S. Nuclear Regulatory Commission.

RUST Geotech Inc., 1993a. Project Work Plan for Phase I. P-GJPO-1352, U.S. Department of Energy Grand Junction Projects Office, Grand Junction, Colorado, May 1993.

RUST Geotech Inc., 1993b. Health and Safety Plan for Phase I. P-GJPO-1351, U.S. Department of Energy Grand Junction Projects Office, Grand Junction, Colorado, June 1993.

RUST Geotech Inc., 1994a. Health and Safety Plan for Phase I and II. P-GJPO-1351, U.S. Department of Energy Grand Junction Projects Office, Grand Junction, Colorado, August 1994.

RUST Geotech Inc., 1994b. Final Report, Surface Gamma Radiation Surveys for SNLNM Environmental Restoration Project. GJPO-ESO-15, U.S. Department of Energy Grand Junction Projects Office, Grand Junction, Colorado, December 1994. 
Sandia National Laboratories/New Mexico (SNL/NM), 1994a. Voluntary Corrective Measure Plan, Removal of Radioactive Surface Contamination at Environmental Restoration Sites. July 1994.

Sandia National Laboratories/New Mexico (SNL/NM), 1994b. Trail Removal Action Waste Management Plan, Surface Radiation Voluntary Corrective Measures. August 1994.

Sandia National Laboratories/New Mexico (SNL/NM), 1994c. Unexploded Ördnance/High Explosives (UXO/HE) Visual Survey of ER Sites, Final Report. September 1994.

Sandia National Laboratories/New Mexico (SNL/NM), 1994d. Waste Management Plan, Removal of Surface Radiation Voluntary Corrective Measure. October 1994.

Sandia National Laboratories/New Mexico (SNL/NM), 1995a. Voluntary Corrective Measure Plan, Surveying and Removal of Radioactive Surface Contamination at Environmental Restoration Sites. May 1995.

Sandia National Laboratories/New Mexico (SNL/NM), 1995b. Task-Specific Health and Safety Plan, Use of Bobcat to Address Radiation Area Sources, Surface Radiation Voluntary Correction Action Plan. August 1995.

Sandia National Laboratories/New Mexico (SNL/NM), 1996. Task-Specific Health and Safety Plan, Use of Backhoe, Bobcat, and Forklift to Address Radiation Area Sources, Surface Radiation Voluntary Measures Plan. March 1996, revised September 1996.

Sandia National Laboratories/New Mexico (SNL/NM), 1997. The SNL Radiological Protection Procedures Manual. (RPPM), 1997.

SNL/NM, see Sandia National Laboratories/New Mexico.

U.S. Department of Energy (DOE), 1983. Radiological Guidelines for Application to DOE's Formerly Utilized Sites Remedial Action Program. Oak Ridge Operation, ORO-831, March 1983.

U.S. Department of Energy (DOE), 1990. Radiation Protection of the Public and the Environment. DOE Order 5400.5, Assistant Secretary for Environment, Safety, and Health, Washington, DC, February 1990, revised January 1993.

U.S. Department of Energy (DOE), 1993. Radiation Protection of the Public and the Environment, Draft. Title 10, Code of Federal Regulations (CFR), Part 834, U.S. Department of Energy, March 1993.

U.S. Department of Energy (DOE), 1994. Draft Environmental Implementation Guide for Radiological Survey Procedures. Assistant Secretary for Environment, Safety, and Health, Washington, DC 20585, November 1994. 
U.S. Department of Energy (DOE), 1995. Occupational Radiation Protection. Title 10, Code of Federal Regulations (CFR), Part 835, U.S. Department of Energy, 1995.

U.S. Environmental Protection Agency (EPA), 1980. Samplers and Sampling Procedures for Hazardous Waste Streams. EPA-600/2-80-018, Office of Emergency and Remedial Response, Washington, DC, January 1980.

U.S. Environmental Protection Agency (EPA), 1981. "Disposal or Onsite Storage of Thorium or Uranium Waste from Past Operations." Title 46 Federal Register (FR) 205, October 23, 1981.

U.S. Environmental Protection Agency (EPA), November 1986. "Test Methods for Evaluating Solid Waste," Third Edition, Update 1, SW-846, U.S. Environmental Protection Agency, Office of Solid Waste and Emergency Response, Washington, D.C.

U.S. Environmental Protection Agency (EPA), 1990. Corrective Action for Solid Waste Management Units (SWMU) at Hazardous Waste Management Facilities, Proposed Rule. Federal Register, Vol. 55, Title 40, Parts 264, 265, 270, and 271, July 1990.

U.S. Environmental Protection Agency (EPA) Office of Emergency and Remedial Response, 1991. "Risk Assessment Guidance for Superfund: Volume I - Human Health Evaluation Manual (Part B, Development of Risk-based Preliminary Remediation Goals)," U.S. Environmental Protection Agency, Washington, DC.

U.S. Environmental Protection Agency (EPA), 1994a. Hazardous Waste Management Facility Permit No. NM5890110518. EPA Region 6, issued to Sandia National Laboratories, Albuquerque, New Mexico.

U.S. Environmental Protection Agency (EPA), 1994b. Radiation Site Cleanup Regulation, preliminary draft. Title 40, Code of Federal Regulations (CFR), Part 196, U.S. Environmental Protection Agency, June 1994.

U.S. Nuclear Regulatory Commission (NRC), 1992. Manual for Conducting Radiological Surveys in Support of License Termination, Draft Report for Comment. NUREG/CR-5849, June 1992.

U.S. Nuclear Regulatory Commission (NRC), 1995. Measurement Methods for Radiological Surveys in Support of New Decommissioning Criteria, Draft Report for Comment. NUREG-1506, July 1995.

Wolford, R., et al, 1996. "1995 Site-Wide Hydrogeologic Characterization Project," Sandia National Laboratories, Albuquerque, New Mexico. 
Yu, C., A. J. Zielen, J. -J. Cheng, Y. C. Yuan, L. G. Jones, D. J. LePoire, Y. Y. Wang, C. O. Loureiro, E. Gnanapragasam, E. Faillace, A. Wallo III, W. A. Williams, and H. Peterson, 1993a. Manual for Implementing Residual Radioactive Material Guidelines Using RESRAD, Version 5.0. ANL/EAD/LD-2, U.S. Department of Energy, Argonne National Laboratory, Environmental Assessment Division, Argonne, Illinois, Colorado, September 1993.

Yu, C., C. Loureiro, J. -J. Cheng, L. G. Jones, Y. Y. Wang, Y. P. Chia, and E. Faillace, $1993 \mathrm{~b}$. Data Collection Handbook to Support Modeling the Impacts of Radioactive Material in Soil, Argonne National Laboratory, Argonne, Illinois. 


\section{DISTRIBUTION:}

\begin{tabular}{|c|c|c|}
\hline 1 & MS 9018 & Central Technical Files, $8940-2$ \\
\hline 5 & MS 0899 & Technical Library, 4916 \\
\hline 2 & MS 0619 & $\begin{array}{l}\text { Review \& Approval Desk, } 12690 \\
\text { for DOE/OSTI }\end{array}$ \\
\hline 11 & MS 0184 & John Gould, DOE-KAO \\
\hline 1 & MS 1147 & Warren Cox, 6681 \\
\hline 1 & MS 1148 & Dick Fate, 6685 \\
\hline 1 & MS 1148 & Caroline Byrd, 6685 \\
\hline 1 & MS 1148 & Kevin Lambert, 6685 \\
\hline 1 & MS 1132 & Craig Brown, 7714 \\
\hline 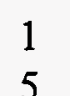 & MS 1309 & $\begin{array}{l}\text { Environmental Operations Records Center, } 7512 \\
\text { extra }\end{array}$ \\
\hline
\end{tabular}

